\title{
Los Tribunales del Trabajo como escenario del conflicto entre el capital y el trabajo. 1948-1960
}

\author{
Andrés Stagnaro \\ Tesis para optar por el grado de Doctor en Historia \\ Director Osvaldo Barreneche, UNLP
}

La Plata, 21 de Diciembre de 2012 
_Toc343797374

\section{INDICE}

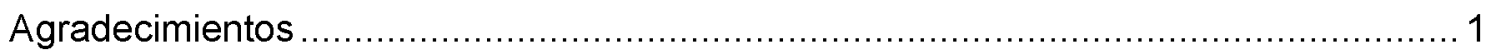

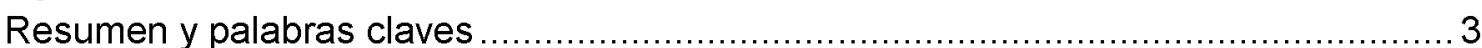

\section{INTRODUCCIÓN}

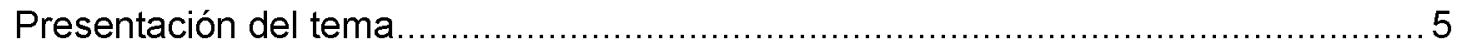

Estado de la cuestión y marco teórico: ¿un tema huérfano? .................................. 9

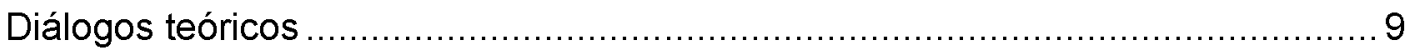

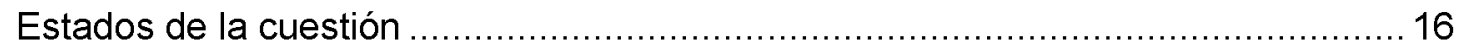

a) La Nueva Historia de la Justicia................................................................ 16

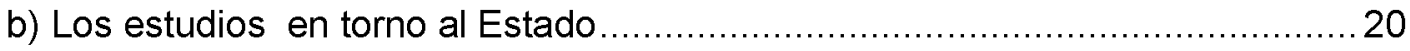

c) Aportes para un diálogo regional: la Justicia del Trabajo en la historiografía

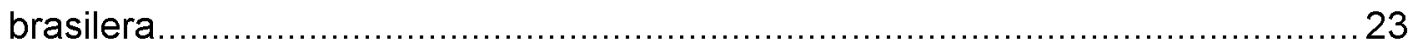

d) Aportes desde la normalización de los estudios sobre el peronismo................26

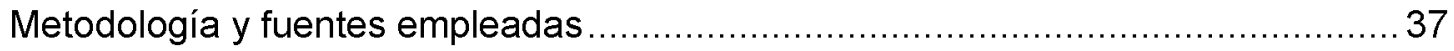

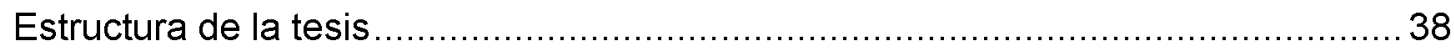

\section{PRIMERA PARTE: \\ LA INSTITUCIONALIZACIÓN DE LA JUSTICIA DEL TRABAJO \\ CAPÍTULO I \\ Una nueva rama del Derecho}

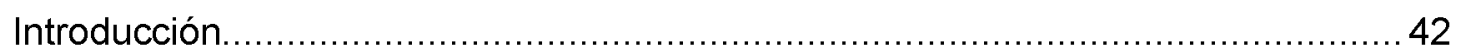

I.1 Modernización, la cuestión social y la ciudad de La Plata................................ 45

I.1.1 Cambios en la región pampeana: modernización económica y el mundo del

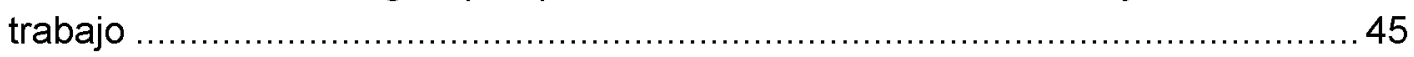

I.1.2 Libertad de trabajo y cuestión social ............................................... 47

I.1.3 La Ciudad de La Plata: hija de la modernización y respuesta a la cuestión

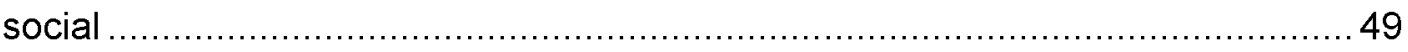

I.2 La Primera Guerra Mundial y el avance de la legislación laboral .......................55

I.3 Un espacio de innovación: el Departamento Nacional del Trabajo ....................60 60

I.4 La constitución del Nuevo Derecho en el sistema universitario: cambios en la

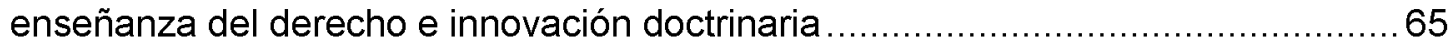

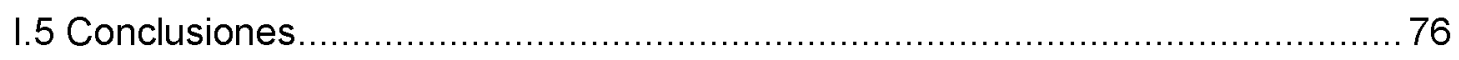

\section{CAPÍTULO II}

La legislación laboral Argentina y el rumbo del Nuevo Derecho

Introducción. 
II.1 Las leyes laborales y los límites de la tradición civil

II.1.1 El Código Civil y la mercantilización del trabajo

II.1.2 El contrato de trabajo y los límites de la tradición civil................................ 84

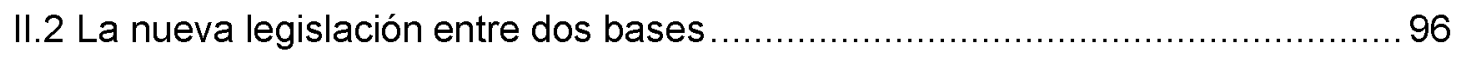

II.2.1 La Ley 4.661 de Descanso Dominical y la cuestión de la Jurisdicción ........96

II.2.2 El proyecto de Código del Trabajo de Joaquín V. González ................... 100

II.2.3 El Congreso: ambiente hostil a las leyes laborales .............................. 106

II.2.4 La Ley de Accidentes de Trabajo, el Derecho del Trabajo elige su bando 112

II.2.5 El proyecto de Código de Trabajo de 1921. La sintetización del Nuevo

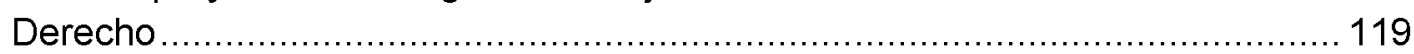

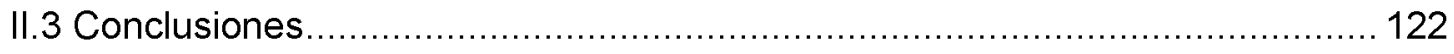

\section{CAPÍTULO III \\ El capital y el trabajo cara a cara}

Introducción. 125

III. 1 Algunas respuestas estatales ante las problemáticas de la relación laboral ... 126

III.2 La hora del fuero laboral se hace esperar. Proyectos y antecedentes de la constitución de la Justicia del Trabajo ......................................................... 144

III.3 El peronismo llegó en buena hora. Impulso político al fuero laboral ............... 154

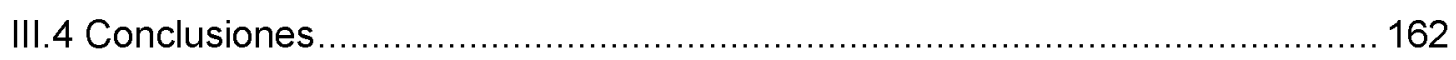

\section{CAPÍTULO IV}

Los Tribunales del Trabajo en la provincia de Buenos Aires

Introducción. 166

IV.1 El debate del fuero del trabajo en la provincia de Buenos Aires. Las ventajas platenses.

IV.2 El gobierno de Domingo Mercante en la provincia de Buenos Aires y el debate legislativo sobre los Tribunales del Trabajo ...................................................... 177

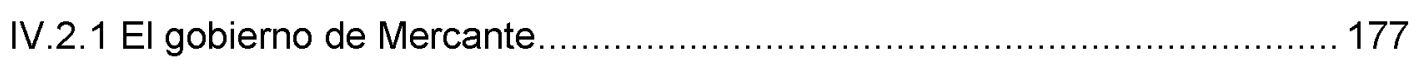

IV.2.2 Una Legislatura activa ............................................................. 182

IV.2.3 El proyecto del Poder Ejecutivo para la conformación de los Tribunales del

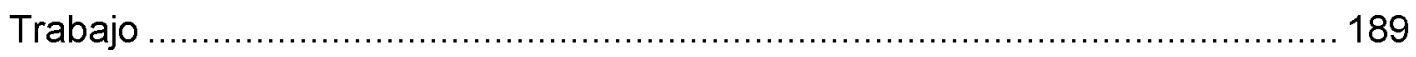

IV.3 La Ley N`5.178 de los Tribunales del Trabajo.......................................... 197

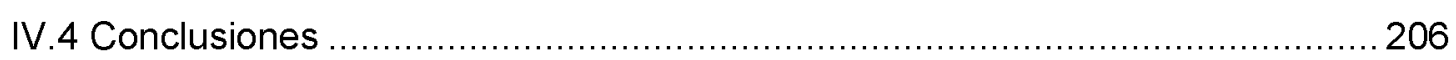




\section{SEGUNDA PARTE: \\ ACTORES Y CONFLICTOS EN LA JUSTICIA LABORAL PLATENSE DURANTE EL PERONISMO}

\section{CAPÍTULO V}

Los profesionales

Introducción. 210

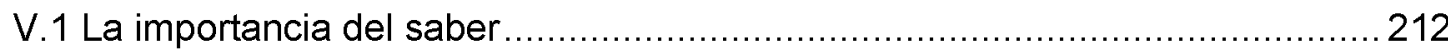

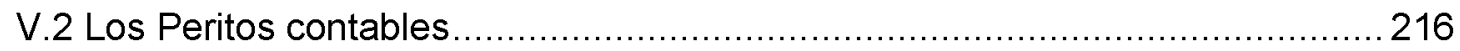

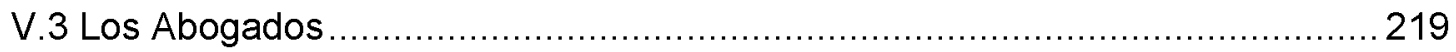

V.3.1 Los abogados de la Delegación Regional de la Secretaría de Trabajo y

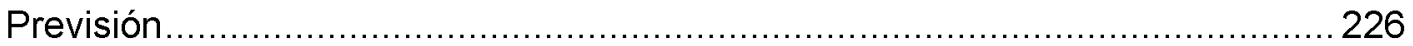

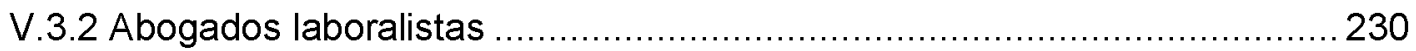

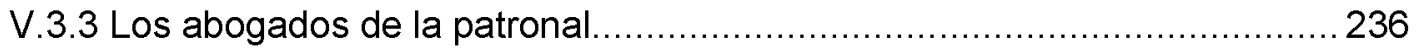

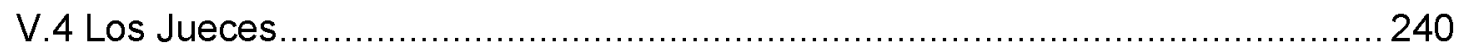

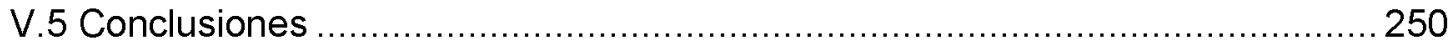

CAPÍTULO VI

Trabajadores y patrones en la justicia del trabajo

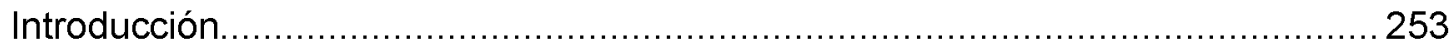

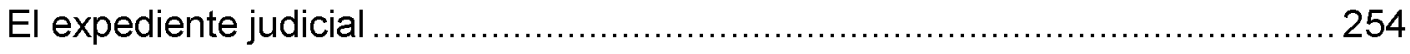

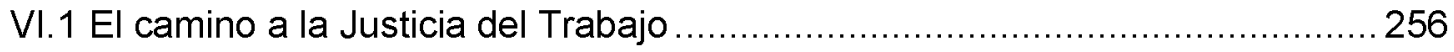

VI.1.1 Los sindicatos en la promoción de derechos ....................................... 258

VI.2 Obrero o empleado, representación de los trabajadores frente a la justicia

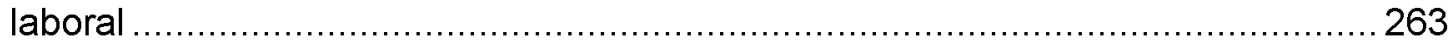

VI.3 Los patrones ante la impugnación de los Tribunales del Trabajo .................. 284

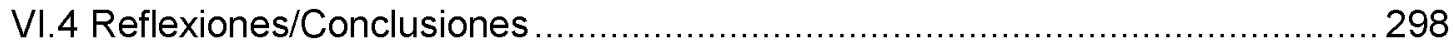

TERCERA PARTE:

\section{LA JUSTICIA DEL TRABAJO ANTE EL ORDEN POST-PERONISTA}

\section{CAPÍTULO VII}

\section{La justicia laboral postperonista. Reorganización y revancha}

Introducción

VII.1 La Desperonización del Poder Judicial bonaerense .................................. 309

VII.1.1 Panorama de la Justicia a la caída de Perón ...................................... 309

VII.1.2 Desperonización del Poder Judicial ................................................. 312

VII.2 Continuidades y cambios en la administración de la justicia laboral ............. 319

VII.2.1 Los tiempos procesales cortos, garantía de justicia ............................ 323

VII.2.3 Continuidad doctrinaria, ¿ruptura política? ..................................... 327 
VII.3 La revancha de los patrones y sus límites. 337

VII.3.1 Las revanchas de los patrones ¿antiperonistas? ............................. 343

VII.3.2 El Peronismo y el Antiperonismo en las causas judiciales .................... 346

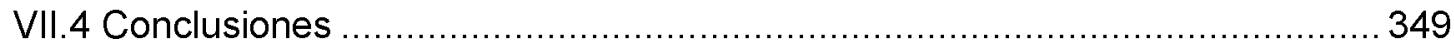

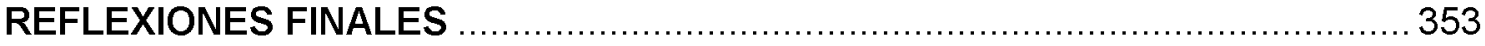

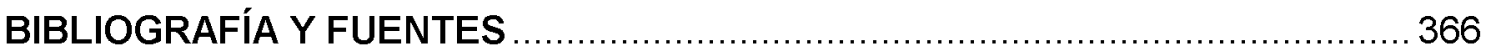

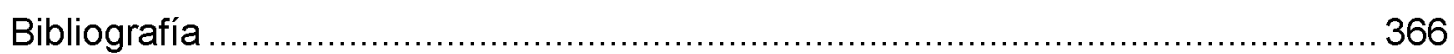

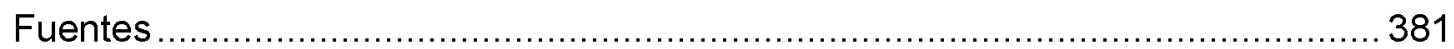




\section{Agradecimientos}

Fiel a la idea de las trayectorias no puedo menos que recorrer la mía para dar cuenta de aquellos que de una manera u otra hicieron posible esta tesis con riesgo de olvidarme de alguno, vaya para ellos mis disculpas.

A Osvaldo Barreneche que asumió el riesgo de dirigir una tesis sobre un tema poco explorado y supo orientarme con dedicación, brindándome su tiempo, sus ideas y su conocimiento, y, cuando no, su afecto.

A los compañeros del proyecto de investigación les estoy en deuda por venir hasta un sábado a la mañana a escucharme y brindarme sus consejos.

A los que compartieron mi camino en el ámbito académico y supieron guiarme con sus comentarios, críticas y sugerencias. En los cursos de posgrado y las jornadas académicas tuve el gusto de cruzarme con colegas que como profesores, comentaristas o compañeros ampliaron los horizontes de la pesquisa.

Le agradezco al director del $\mathrm{CISH}$, Anibal Viguera, por haberme brindado la oportunidad de radicar allí mi proyecto para optar por la beca del Conicet que hizo posible financiar la investigación y por haberme brindado el apoyo necesario para concluirlo. A mis compañeros del centro que hicieron más agradable la estadía en el octavo piso vaya para ustedes también mi agradecimiento. Colegas de la FaHCE también compartieron mis idas y venidas por los pasillos, algún mate y más de un comentario. A mis compañeros en las cátedras de Historia Americana II de la carrera de Historia y de Historia Socioeconomica de la Facultad de Trabajo Social vaya también un reconocimiento.

La tesis fue posible por la calidez que en el departamento Histórico de la Suprema Corte de la provincia de Buenos Aires tuvieron para conmigo. Alicia, María Angélica, Carlitos Sorá, María y, especialmente Susana se brindaron para orientarme en las pesquisas de expedientes y con ellos comenté cada sorpresa y cada detalle de los expedientes judiciales. Bibliotecarias del fondo Perón de la Biblioteca del Congreso de la Nación, bibliotecarios de la biblioteca de la Legislatura bonaerense, personal de la biblioteca Obiols de Humanidades y de la Hemeroteca de la UNLP y de la Facultad de Ciencias Jurídicas y Sociales también me brindaron su apoyo cuando tuve que acudir a ellos. 
Este recorrido hubiese sido imposible sin los afectos. Especialmente mis abuelos -Joaquín y Azucena, la granny y el abuelo Victorio que vivía en sus palabras y su corazón- y mi tía chichi fueron fundamentales en mi vida. No sólo me llenaron de amor y cariño, escuchándolos a ellos me enamoré de la historia: viajes ultramarinos, cigarrillos tapados con bosta de vaca, huelgas al amanecer, sueños de prosperidad, barcos que explotaban en el puerto y aviones que pasaban temblando la casa nutrieron mis tardes. Espero algún dia mirar hacia atrás y darme cuenta que hice lo que me enseñaron.

Muchos son los colegas que me escucharon hasta el hartazgo hablar de esta tesis y al día de hoy nunca me negaron un oído ni me retacearon una palabra, con ustedes me une la más profunda amistad. Julián Carrera, Agustín Casagrande, Sole Lemmi, Natalia Cabanillas, Diego Citterio, Martín Serra, Pablo Ardenghi, Fabián Viegas, Delicia Zurita, Fernanda Barcos, Emanuel Pfoh y Julieta González: espero algún día poder tener la misma paciencia.

Y muchos son también los que no me prestaron un oído, pero fueron mi cable a tierra en la esquina, en el fútbol o en la vida: Diego, Gastón, Juani, Luciano, Manuel, Martín, Maxi, Nico, Pablo y Santi.

Mis viejos me bancaron hasta donde pudieron, y siempre un poquito más. Mi hermano no tiene la paciencia para estirar los límites, pero de él también aprendo.

Para Sabrina no tengo palabras de agradecimiento porque agradecerle sería serle injusto, no hay GRACIAS ni gracias que puedan devolverle todo lo que me da. Para Isabella más que un agradecimiento un perdón, porque esta tesis me quitó el tiempo que tendría que haber estado con ella. 


\section{Resumen y palabras claves}

\section{Palabras clave: CONFLICTO JUSTICIA TRABAJO}

La tesis propone indagar en el desarrollo de la justicia laboral platense y aborda los conflictos que en ella se ventilaron durante los años 1948 y 1960. Busca dar cuenta de los antecedentes que impactaron en la forma en que se constituyeron los Tribunales del Trabajo en la ciudad de La Plata. Estos fueron parte de una serie de procesos de búsqueda de respuestas legales a la cuestión social que fueron dando forma al surgimiento de un Nuevo Derecho, tanto desde la construcción de un corpus legislativo como mediante la constitución de una base doctrinaria propia. Recorre la tesis los antecedentes de la legislación laboral y el debate en torno a las posibilidades de legislar sobre una materia nueva, para eso ahonda en los debates parlamentarios y académicos desde principios del siglo XX hasta la década de 1930 Esta conformación de una rama del derecho especializada en la relación entre el trabajo y el capital no podía ser contemplada en las instituciones judiciales existentes, pero sin embargo fueron objeto de los intentos de mediación y arbitraje por otros poderes del Estado -principalmente el Poder Ejecutivo- Por eso se busca describir los antecedentes de esta propuesta en la medida en que fueron fundamentales en los debates sobre la necesidad de conformar un fuero específico para tratar los conflictos de la relación laboral. Especialmente importante en la tesis es rescatar la forma en la que se debatió la creación de Tribunales de Trabajo para la provincia de Buenos Aires. Al realizarse este debate en el gobierno de Domingo Mercante -el corazón de Perón- la tesis dialoga con los estudios del peronismo y ahonda en las características particulares del gobierno de Mercante.

En tanto que a la justicia del trabajo se presentaban actores sociales identificados como uno de los dos polos de la relación laboral -trabajadores y patrones-, se aborda la forma en que estos actores interactuaron entre si y con los actores propios de la vida judicial -peritos, abogados, jueces-. En un intento de presentar a los actores cuyas interrelaciones construían el cotidiano de los tribunales del trabajo. Siempre bajo la premisa de la construcción relacional de las identidades es histórica se pretende dar cuenta de cómo estas relaciones constituía a los sujetos hacia el interior de una institución como los Tribunales 
del Trabajo. En tanto que la resolución del conflicto que los vinculaba era el objetivo de la justicia laboral, el recorrido que ambos extremos de la relación de explotación es fundamental para comprender las estrategias que ambas partes adoptaron hacia el interior del fuero.

En tanto institución creada bajo el peronismo, la justicia laboral sufrió los avatares posteriores a 1955. Por eso se le dedica también un espacio a describir los cambios y las continuidades de la justicia del trabajo en el postperonismo. La hipótesis es que en un contexto distinto al de su nacimiento estas le otorgarán un rol más destacado dentro del esquema de la conflictividad obrera. 


\section{INTRODUCCIÓN}

No podemos tener amor sin amantes

E. P. Thompson ${ }^{1}$

\section{Presentación del tema}

Esta tesis es el intento de organizar una serie de cuestionamientos que me asaltaron en torno a la institución Tribunales Laborales bonaerenses, y principalmente los actores colectivos e individuales que en ella interactuaban. Institución judicial de central trascendencia para los trabajadores, y escenario de conflictos entre el capital y el trabajo, que sin embargo no fue abordada por la historiografía argentina. Esta ausencia es consecuencia del desinterés de los distintos campos sobre los que se constituye el objeto de estudios: las obras sobre las instituciones judiciales y la ley, la construcción del Estado Social y sus burocracias, los que refieren a la clase obrera y los trabajadores, aquellos que abordan el peronismo sólo por mencionar algunos. En este sentido no es objetivo de la tesis dar respuestas acabadas a los diferentes ejes del debate académico que cruzan el objeto de estudio, aunque si delinear algunos de estos a fin de recalcar la importancia que para estos campos puede tener la indagación en torno a dicha institución.

A lo largo de este proyecto de investigación las preguntas iniciales fueron adquiriendo la fisonomía que será aquí expuesta, quedando muchas de ellas sin respuesta aparente, aunque buscando en su formulación la apertura a nuevas posibilidades de investigación. El recorrido de la tesis apunta a indagar sobre las posibilidades ideológicas y materiales que permitieron el surgimiento de una institución encargada de administrar justicia en torno a los casos que se desprendían de la relación laboral entablada entre patrones y trabajadores. Además la misma acción de administrar justicia -fundamental para los Estados modernos- será abordada por medio del análisis de las causas de uno de estos tribunales -el Tribunal del Trabajo $N^{\circ} 1$ de la ciudad de La Plata-. El Tribunal $\mathrm{N}^{\circ} 2$, aunque presente por medio de la cita de fallos en las causas del Tribunal

\footnotetext{
${ }^{1}$ THOMPSON Edward Palmer, "Prefacio", La Formación de la clase obrera en Inglaterra, Ed. Capitan Swing, Madrid, 2012. Pp. 27.
} 
$\mathrm{N}^{\circ} 1$ o por la jurisprudencia establecida por los jueces, no pudo ser analizado al no contar con causas de dicho tribunal.

La elección del recorte espacial responde no solamente al lugar sobre el que el Tribunal del Trabajo $N^{\circ} 1$ ejercía su jurisdicción, sino también a la importancia que el espacio platense adquirió en el entramado de la consolidación de la institución analizada. La ciudad de La Plata es la capital de la provincia más grande de la Argentina y por lo tanto cabecera administrativa de un estado. Esta importancia política y administrativa de la ciudad permitía ubicar espacialmente los proyectos y los actores que estuvieron detrás del surgimiento de los Tribunales del Trabajo bonaerenses en una interrelación directa. La cercanía de las autoridades administrativas, legislativas y judiciales de la provincia con el centro académico más importante de la provincia facilitaba el intercambio de ideas y pareceres sobre varios temas, incluidos las propuestas renovadoras del espacio judicial.

Sumado a esta preeminencia política, administrativa y académica de la ciudad, el hecho de ser también una ciudad con múltiples formas de empleo y relaciones laborales permitió acceder a diferentes formas de conflictos laborales ligados a las diferentes posibilidades de empleo. Al igual que otras ciudades de la zona pampeana, sufrió cambios importantes a partir del desarrollo de la industrialización por sustitución de importaciones, que vino a profundizar un proceso de industrialización comenzado en las postrimerías del siglo XIX. El empleo industrial constituía una de las opciones laborales para los trabajadores de la región. Industria de vieja data como los frigoríficos berissenses, distantes a solo $10 \mathrm{~km}$ del centro de la ciudad, el crecimiento del polo petroquímico en la también vecina Ensenada, ambas poblaciones dependientes administrativa y judicialmente de la ciudad de La Plata, constituían algunas de las posibilidades de empleo industrial. Además en la ciudad florecieron establecimientos pequeños y medianos ligados al sector de los servicios, y la industria de la construcción, empujada por la obra pública, pero principalmente por el proceso similar de crecimiento al experimentado por otras ciudades argentinas como Rosario, o la misma Buenos Aires. También debemos sumarle un generoso hinterland rural, con poblaciones ligadas a la producción agrícola como Brandsen, Bavio, Navarro, Lobos, Roque Pérez y 
magdalena, General Belgrano, Ranchos y Saladillo que pertenecían estaban incluidos en la jurisdicción del Tribunal del Trabajo $\mathrm{N}^{\circ} 1$.

El casco urbano, con sus edificios públicos característicos de la administración provincial, alojaba oficinas ocupadas por los trabajadores del empleo público². A esto debemos sumarle la actividad comercial que creció como consecuencia de la recuperación económica posterior a la crisis de los primeros años de la década del treinta ${ }^{3}$.

Pero por otra parte el tamaño relativamente pequeño de la ciudad facilita la contextualización de los casos que se presentaran como fuentes. En términos metodológicos las investigaciones pormenorizadas sobre el contexto local y regional permiten diferenciar la realidad social de manera de escapar a las fórmulas de interpretación que dominan las historias "nacionales".

La reducción de la escala de la investigación histórica nos permite observar, o mejor, reinterpretar la experiencia de hombres y mujeres insertos en redes de relaciones sociales. Nos permite ver las tensiones y el equilibrio del funcionamiento de las redes. ${ }^{4}$

La elección de una unidad de análisis más pequeña tendría, así, la posibilidad de profundizar el estudio de las interrelaciones de los actores en una situación espacio temporal precisa donde la agencia de estos actores adquieren significación. Además permite una reconstrucción de lo social pasible de ser contrastado con diferentes experiencias que se perciben al variar la escala de observación ${ }^{5}$. Esta focalización en la ciudad de La Plata no implica desatender el hecho de que no es un caso aislado. Será objetivo entonces también descentrar el estudio de los Tribunales del Trabajo de la ciudad de La

\footnotetext{
${ }^{2}$ La expansión del empleo en la administración pública fue paralela a la mayor intervención estatal en diferentes aspectos de la vida social y económica. En la provincia de Buenos Aires el crecimiento del empleo público comenzó en la administración del gobernador conservador Manuel Fresco, para sufrir un aumento vertiginoso con la llegada de Domingo Mercante a la casa de gobierno. REITANO Emir. Manuel Fresco. Entre la renovación y el fraude. Archivo Histórico de la Provincia de Buenos Aires, La Plata, 2005.

${ }^{3}$ Algunos datos del clima de progreso que se vivía en la ciudad se pueden inferir de la publicación celebratoria del cincuentenario de la ciudad, La Plata a su fundador, Edición de la Municipalidad, La Plata, 1939.

4 "A redução da escala da pesquisa histórica nos permite enxergar, ou melhor, reinterpretar a experiência de homens e mulheres inseridos em redes de relacionamento social. Nos permite ver as tensões e o equilibrio do funcionamento das redes" NEGRO Antonio Luigi, "O que a Justica do Trabalho não queimou: novas fontes para o estudo do trabalho no século XX", en Politeia. Historia e Sociedade, Vitória da Conquista, Vol. 6, No. 1, 2006. Pp. 197 y sig. Traducción Propia.

${ }^{5}$ REVEL Jacques, "Microanálise e construçao do social", en REVEL, Jacques (org.), Jogos de escala. A experiencia da microanálise. Fundaçao. Getulio Vargas Editora, Rio de Janeiro, 1998. Pags. 15-38.
} 
Plata como un caso aislado y carente de vinculaciones con un marco conceptual y político más amplio que incluye debates y discusiones que se daban en otras instancias. Asumiendo el abordaje como histórico se presupone la necesidad de ubicar los conceptos teóricos y las relaciones sociales abordadas en un contexto espacio temporal preciso, y como tal contingente e irrepetible. Los análisis (de las grandes estructuras y los amplios procesos) sostiene Tilly

deberían ser concretos a la hora de referirse a tiempos, lugares y personas reales. Deberían ser históricos para así limitar su alcance a una época definida por el acaecimiento de ciertos procesos claramente definidos, y reconocer desde el comienzo la importancia del tiempo -el cuándo pasan las cosas dentro de una secuencia afecta al cómo ocurren, que toda estructura o proceso constituye una serie de posibilidades de elección. ${ }^{6}$

Esta ubicación del caso empírico en un marco mayor permite una comprensión mayor ya sea matizando las hipótesis en tanto no constituye necesariamente un procesos de extrema originalidad, como facilitando probables análisis a ser aplicado al proceso concreto.

La cita de Charles Tilly es también un buen disparador para desarrollar el cuándo. Si la ciudad de La Plata es el escenario descentrado de la tesis, la fijación de los límites temporales es tanto o más arbitraria. Los antecedentes de la conformación de la institución judicial analizada son contemporáneos a los primeros intentos del Estado por dar cuenta de la emergente Cuestión Social y por tanto se puede ubicar el comienzo del marco temporal de esta tesis en los primeros años del siglo XX. En tanto que la cuestión obrera es el eje de la cuestión social los límites de este estudio no podían ser llevados hacia atrás más allá de la existencia de un mercado de trabajo urbano moderno. La ciudad de La Plata es, en este sentido, también atractiva como estructura espacial de la tesis porque su fundación y desarrollo está enmarcada en el mismo proceso al tratarse de una ciudad de fines del siglo XIX y con estrechas vinculaciones con la Cuestión Social.

Fuerte impacto tiene -de manera lógica- el peronismo como referencia contextual de la tesis siendo que es durante la gobernación de Domingo Mercante que se crean los Tribunales del Trabajo de la provincia de Buenos

\footnotetext{
${ }^{6}$ TILLY Charles, Grandes estructuras, procesos amplios, comparaciones enormes, Alianza, Madrid, 1984. Pp. 29.
} 
Aires (1948). El desarrollo de la institución posterior a esa fecha implica el ejercicio de -una vez más- de la arbitrariedad del investigador. He decidido dar por finalizado el marco temporal circa 1960. Razones históricas pueden y serán utilizadas para fundamentar el corte (derrota o recomposición de la clase obrera, pleno funcionamiento del plan de estabilización económica, ejecución del plan CONINTES), pero las características de la institución y los conflictos analizados resisten obstinadamente la posibilidad de trazar un corte definitivo. En el período analizado, Septiembre de 1955 otorgaba la posibilidad de brindar ese corte, sin embargo la voluntad de indagar en las razones de la permanencia de los Tribunales del Trabajo más allá de la fuerza política que la había creado y observar los cambios o continuidades en la administración de justicia sobre nuevas realidades políticas.

\section{Estado de la cuestión y marco teórico: ¿un tema huérfano?}

Diálogos teóricos

Múltiples son los aportes teóricos que se utilizan en esta tesis. La mayoría de ellos son discutidos en el cuerpo mismo al entrar en contacto con el objeto de estudio. Sin embargo algunas categorías por su relevancia para interpretar los resultados de la pesquisa se exponen aquí brevemente.

Al hacer referencia al conflicto en el caso de esta tesis se abre los cuestionamientos sobre el tipo de conflicto al que refiere. El análisis de causas judiciales tiende a presentar a la sociedad como inminentemente conflictiva ${ }^{7}$ ya que la misma fuente de lo que da cuenta es de un conflicto. Teniendo en cuenta esta cuestión es necesario pensar al conflicto judicial en el marco de la sociedad en la que se desarrollan.

El conflicto entre el capital y el trabajo recibió gran parte de la atención por parte de las ciencias sociales. Tanto las teorías marxistas como no marxistas han constituido a este conflicto en el eje de las disputas teóricas de la teoría social, al asumir que su comprensión otorga la clave para entender el cambio o la estabilidad social. Dentro de los análisis históricos del conflicto entre los dos polos de la relación laboral se ha hecho foco fundamentalmente

\footnotetext{
7 MAYO Carlos, "En torno al valor de la fuente judicial" en AAW La Fuente judicial en la Construcción de la Memoria. Jornadas, Suprema Corte de Justicia provincia de Buenos Aires, La Plata, 1999.
} 
en las huelgas como momentos privilegiados para la observación empírica. Esta preeminencia de la huelga como objeto de la teoría social llevó las más de las veces a trazar un paralelismo entre actividad huelguística y conflictividad laboral, descartando otras formas de conflicto. Si bien no puede negarse la importancia de la huelga como expresión colectiva $-y$ como formadora de ese colectivo- de la clase obrera, centrarse exclusivamente en la huelga conlleva el doble riesgo advertido por Hobsbawm ${ }^{8}$, en primer lugar trazar una distinción demasiado tajante entre el conflicto abierto y otros tipos de conflicto, y en segundo lugar, se corre el riesgo de reproducir en parte el esquema de la clase alta de prestar atención exclusivamente a los conflictos violentos.

Esta preeminencia tiene impactos sobre la forma en que se aborda la historia de la los trabajadores. En primer lugar la elección de la huelga como momento fundamental del conflicto tiende a delimitar los momentos conflictivos según la un esquema basado en la cantidad de huelgas/trabajadores y huelga/horas perdidas de cada período. Por lo general esta línea interpretativa va vinculada a diferentes debates sobre el grado de conciencia de la clase obrera -su conformación en tanto clase para sí- y observan en el conflicto mismo la conformación de la clase y la estrategia desplegada en tanto clase ${ }^{9}$.

La "renovación" historiográfica de mediados de los ochenta propuso indagar no ya en las instituciones formales $-y$ por lo tanto dejó de lado preguntas sobre la conciencia- sino en la vida cotidiana y en las condiciones de vida y consumo de los trabajadores. El puntapié inicial fue la hipótesis de Gutiérrez y Romero ${ }^{10}$ que sostenía que las pautas de vivienda, consumo, y la alta movilidad social en las ciudades desdibujaba la identidad obrera en sectores populares en donde convivían trabajadores manuales, pequeños comerciantes y burócratas de los escalafones más bajos del servicio estatal. Sin clase obrera a la vista, la huelga como eje del conflicto -y la conflictividad misma- fue reemplazado en la historia de entreguerras por la imagen de una sociedad armoniosa.

\footnotetext{
${ }^{8}$ HOBSBAWM Eric, El mundo del trabajo. Estudios históricos sobre la formación y evolución de la clase obrera, Crítica, Barcelona, 1987.

${ }^{9}$ IÑIGO CARRERA Nicolás, La estrategia de la clase obrera. 1936. Ediciones Madres de Plaza de Mayo, Buenos Aires, 2004.

${ }_{10}$ GUTIERREZ Leandro y ROMERO Luis Alberto, Sectores populares, cultura y política. Buenos Aires en entreguerra, Sudamericana, Buenos Aires, 1995.
} 
De todas maneras algunas de las críticas del trabajo de Gutiérrez y Romero a las propuestas estructuralistas llevaron a otros caminos historiográficos. Desde el estudio de la vida dentro y fuera de la fábrica de los trabajadores se ha buscado no ya la imagen de una sociedad igualitaria y sin conflictos, sino la existencia de las distinciones de clase, la presencia de la cultura obrera en ámbitos fuera del lugar del trabajo y de las instituciones gremiales y políticas de la clase. La huelga, en esta perspectiva, es un elemento importante en el estudio de la clase obrera, pero no tiene ya el lugar preponderante en el análisis de la clase obrera ${ }^{11}$.

La huelga entonces, si bien ha perdido cierta relevancia a la hora de investigar sobre la historia de los trabajadores, sigue siendo el presentado como el momento de conflicto entre el capital y el trabajo. Tanto para justificar el conflicto como la ausencia del mismo las investigaciones sobre los trabajadores (o los "sectores populares" en el caso de la armonía) hacen referencia a los ciclos de huelga. Sin ir en desmedro de dicha interpretación el conflicto judicial implica otro tipo de conflictividad que adquiere un carácter permanente. Esta conflictividad está además institucionalizada, pero expresa el enfrentamiento entre el capital y el trabajo de manera directa con eje en el valor de la mano de obra -principalmente- pero sobretodo es una pelea por la obtención y ampliación de derechos y control patronal de los establecimientos. Esta institucionalización desde ya evita que este tipo de conflicto tenga como objetivo las transformaciones profundas de la sociedad, pero aun así refiere a enfrentamientos que implicaban transformaciones en las relaciones entre el capital y el trabajo.

La primacía de la actividad huelguística como eje de los análisis historiográficos y su correlación en el estudio de las organizaciones sindicales fueron determinantes a la hora de abordar el conflicto obrero en relación con los otros actores en la disputa, el capital y el estado. La creciente presencia

\footnotetext{
${ }^{11}$ LOBATO Mirta Zaida, La vida en las fábricas. Trabajo, protesta y política en una comunidad obrera, Berisso (1904-1970), Prometeo, Buenos Aires, 2004. De la misma autora "Los trabajadores en la era del progreso", en El progreso, la modernización y sus límites t. V de la Nueva Historia Argentina, Buenos Aires, Sudamericana, 2000 pp. 467-505. Véase también SURIANO Juan, "Los dilemas actuales de la historia de los trabajadores" en GELMAN Juan (comp.), La Historia económica argentina en la encrucijada. Balances y perspectivas, Prometeo Libros, Buenos Aires, 2006.
} 
mediadora estatal en el conflicto desde principios del siglo $\mathrm{XX}$, con una mayor especialización en las instituciones puestas al servicio de atender el conflicto obrero, posicionaron a los trabajadores frente a un actor cuyos objetivos en el enfrentamiento no era ya sólo el sometimiento de los trabajadores sino también del capital.

La intervención del Poder Ejecutivo en el conflicto entre el trabajo y el capital promovió la interpelación en términos colectivos. El Poder ejecutivo se presenta como el mediador en los aspectos conflictivos de la esfera pública ofreciendo su papel de árbitro en las disputas entre actores antagónicos. A fin de desarrollar este rol fue construyendo un entramado institucional cada vez más complejo por medio de las negociaciones con los actores envueltos (sindicales, patronales, profesionales, burocráticos). El Poder Ejecutivo, como mediador, cumplió su función en torno a lo que consideraba cuestiones de índole pública. Distintos factores intervenían en la elección de los actores habilitados para intervenir. La aceptación por parte de los funcionarios estatales de los interlocutores obreros era fundamental para poder sentarse en la mesa de negociación. Al reconocerlos los dotaba de sentido para otros actores, pero al mismo tiempo lo clasificaba por medio de sus propios mecanismos. Estos mecanismos no estaban exentos de pretensiones de control, pero lo más importante es remarcar el carácter clasificador que ejercía el Estado por medio del Poder Ejecutivo. Las instituciones dispuestas en el Poder Ejecutivo para lidiar con la cuestión social, a pesar de sus contradicciones y tensiones inherentes a la entidad estatal, funcionaron siempre en un orden en donde lo importante era la representación de corte corporativo. Incluso durante etapas de predominancia del liberalismo, la representación corporativa estaba presente.

Sin embargo la conflictividad entre el trabajo y el capital no se limita a los conflictos que se expresan en las irrupciones al espacio público como lo son las huelgas y las manifestaciones, o a los conflictos fabriles de gran escala. La relación misma entre capital y trabajo implica la existencia de conflicto en la medida en que sus actores cargan con intereses antagónicos. El enfrentamiento no se reduce a aquellos que tienen a los sindicatos y las asociaciones patronales como actores sino que se reproduce en cada relación entre patrón y trabajador. 
Así, mientras el Poder Ejecutivo piensa en la resolución de los conflictos en términos colectivos, ya sea mediante instituciones corporativistas 0 mediante la apelación a actores colectivos -básicamente a los sindicatos y las asociaciones patronales-, dentro del Poder Judicial se concretó la creación de una institución destinada a individualizar a los actores. Tanto en la forma que adquirió en la Capital Federal como en la provincia de Buenos Aires los Juzgados y Tribunales del Trabajo individualizaban a los actores en pugna ${ }^{12}$. Si en el ámbito del Poder Ejecutivo se pensaba en torno a colectivos identificables como clases antagónicas que debían ser armonizadas en pos de solucionar un conflicto inherente a la relación laboral, en el poder judicial solucionaba un conflicto determinado entre el actor tal y el demandado cual.

Esta presencia de trabajadores individuales ante el estrado obliga a pensar el porqué de su presencia allí. Los límites expuestos Ilaman la atención sobre basar la explicación en la acción racional del individuo. Buscar las causas sociales la razón implica concebir actos de este tipo como expresión de un fenómeno colectivo. El tipo de conflicto analizado también plantea la dificultad de no tratarse de un conflicto tendiente al cambio social, entendiendo este como el reemplazo de una sociedad por otra, sino a la dotación de derechos -individuales y colectivos- en una relación social.

El concepto clave para vincular la individuo, el conflicto, la relación entre capital y trabajo y las razones sociales detrás del motivo de los trabajadores de acudir a los estrados judiciales es el de agencia histórica definida, en los términos de Alex Callinicos, como la capacidad estructural de los individuos en un momento determinado ${ }^{13}$.

Al romper con la dicotomía explicativa, ya no basada en la exclusivamente en la estructura, pero tampoco centrada en el individuo como si este existiese por fuera de la sociedad, la agencia histórica permite dar cuenta de las interacciones que hacen al entramado social que construyen -y restringen- los individuos. La agencia histórica permite además relacionar los conceptos de

\footnotetext{
${ }^{12}$ NIETO Agustín, "Conflictividad obrera en el terreno de la justicia laboral. La experiencia de las obreras/os del pescado, 1950-1955", en Segundo Congreso de Estudios sobre el Peronismo (1943-1976), Caseros, 2010.

${ }^{13}$ CALLINICOS Alex, Making History. Agency, Structure and Change in Social History, Brill, London-Leiden, 2004. Especialmente capítulos 1 y 2 donde describe la relación entre el sujeto y la estructura proponiendo una resolución intermedia al debate Thompson-Althusser.
} 
individuo y estructura en el marco propuesto por Norbert Elías en La Sociedad de los individuos ${ }^{14}$.

Definida la agencia como el ejercicio de la capacidad estructural de los individuos se puede sostener que la voluntad (individual) de presentarse como parte de un conflicto implica el análisis de la situación y la elección del medio para logar el fin deseado. El conflicto judicial habilita las preguntas en torno a la agencia de los actores -en este caso los trabajadores-. La fuente judicial puede ser útil a la hora de dotar de voz a aquellos que habían permanecido silenciados durante tanto tiempo. La historia de los subalternos aparece, entonces, como un objeto más accesible, capaz de ser aprehendido a partir de indagar en las señales que dejaron en fuentes antes ignoradas. Tal vez sea en la fuente judicial donde se pueda rastrear parte del discurso oculto ${ }^{15}$ que de otras maneras la presión del poder de clase mantendría en las sombras.

Retomando Thompson es interesante rastrear como a partir del estudio de las revueltas en la campiña inglesa del Siglo XVIII advirtió al mundo académico sobre la racionalidad que se escondía detrás de los levantamientos de los campesinos, que hasta ese momento eran catalogados de "motines de subsistencia" y acciones "espasmódicas"16. Utilizando fuentes judiciales que daban cuenta de los motivos legitimantes que utilizaban los pobladores de las aldeas a la hora de atacar un molino o a acaparadores de granos, E. P. Thompson politizó los movimientos que subyacían detrás de estos enfrentamientos e impulsó los cuestionamientos a las clasificaciones economicistas de las clases sociales, profundizando un camino iniciado en $L a$ formación de la clase obrera en Inglaterra ${ }^{17}$. Centrándose en la disputa en torno a lo justo y lo injusto, ayudó a comprender mejor la concepción de la ley como instrumento de las clases dominantes para mantener la dominación sobre los subalternos.

Pero al mismo tiempo dejó entrever lo que la ley significaba para estos actores. En la medida en que se sostiene sobre pretensiones universalizantes

\footnotetext{
${ }^{14}$ ELÍAS Norbert, La Sociedad de los individuos, Península, Barcelona, 1990.

${ }^{15}$ SCOTT, James C., Los dominados y el arte de la resistencia. Discursos ocultos. Ediciones Era, México D.F. 2000.

${ }_{16}$ THOMPSON Edward Palmer, Costumbres en común, Ed. Crítica, Barcelona, 1995. Especialmente el capítulo III "La economía "Moral" de la multitud en la Inglaterra del siglo XVIII".

${ }^{17}$ THOMPSON Edward Palmer, La formación... Op. Cit.
} 
la ley -incluso como mecanismo de dominación- muchas veces es realmente justa, de otra manera no cumpliría con su función ideológica. $Y$ detrás de los preceptos legales se esconde muchas veces la construcción de lo justo. El tiempo también es importante al dar cuenta de la idea de los justo y de los propios preceptos legales. No pueden ser reducidas muchas veces a la costumbre $o$ al habitus. Los preceptos legales -expresados o no en el derecho"no solamente regulan la conducta, sino que la construyen"18. Es un poder enraizado en los recursos colectivos de la cultura más que en las capacidades independientes de los individuos.

La categoría de la agencia implica la relación, entonces, del individuo con la estructura en tanto se conforman de manera mutua -aunque con incidencias desiguales-. Si la definición del sujeto es ya de por si conflictiva la estructura ha estado vinculada a debates aun más densos. Aunque en parte sin referirse a ellos como una estructura Pierre Bourdieu propone analizar los campos como los espacios en donde los sujetos desarrollan su propia acción. Aunque sin la rigidez que el estructuralismo -valga la redundancia- otorga a la estructura, los campos, en el caso de Bourdieu, cumple con algunas características de la estructura. Sus reglas internas propias y las limitaciones a la acción que imprime a los individuos -a pesar de la dinámica propia del campo- se asemejan a lo que se describe para las estructuras sociales ${ }^{19}$. Para el caso del campo jurídico establece Bourdieu jerarquías hacia el interior como hacia el exterior del campo. Hacia afuera limita la participación de aquellos que no poseen saber capaz de disputar en el interior del campo, o sea, los profanos. Hacia el interior cada campo establece reglas para la acumulación del capital simbólico capaz de garantizar el ascenso dentro del campo, en este caso el manejo de la ley. Así, quienes poseen el poder simbólico en el mismo campo poseen el monopolio de decir qué es la ley ${ }^{20}$. Sin descartar la existencia de fuerzas externas cada campo goza de autonomía en la definición de sus reglas.

\footnotetext{
${ }^{18}$ GEERTZ Clifford, Conocimiento local. Ensayos sobre la interpretación de las culturas. Paidos, Barcelona, 1994. Pp. 241.

${ }^{19}$ BOURDIEU Pierre, Razones prácticas. Sobre la teoría de la acción. Barcelona, Anagrama, 1997. Especialmente capítulo 4.

${ }^{20}$ BOURDIEU Pierre, "La forcé du Droit" en Actes de la Recherche en Sciences Sociales, Volume 64, Numéro 1, 1986.Pags. 3-19.
} 


\section{Estados de la cuestión}

a) La Nueva Historia de la Justicia

Los diálogos establecidos entre las distintas disciplinas que buscan dar cuenta de la historia de las instituciones judiciales, la ley y la justicia se ha incrementado en los últimos veinte años. La Nueva Historia de la Justicia como se ha denominado al campo que cruza la historia de estas instituciones con las preguntas y el aparato metodológico de la Historia Social se construyó como campo en oposición a la Historia del Derecho. Sin embargo en los últimos años auspiciosamente la barrera que los separaba ha empezado a desmoronarse.

Pero incluso cuando las distancias entre ambas concepciones eran remarcadas con mayor ímpetu las unían los mismos objetos de estudio y el período que abordaban. Efectivamente tanto si concebian y escribian la historia legal como una sucesión de códigos y centraban su interés en las instituciones con especial atención en el entramado jurídico o ya si se centraban en los condicionamientos estructurales y el contexto del surgimiento de las normas y las razones sociales de su promulgación, ambas perspectivas se centraron fundamentalmente en el surgimiento de los estados nacionales en América Latina y su relación con el pasado hispánico.

En el caso de la Historia del Derecho esto se debió -según Salvatore y Aguirre $^{21}$ - a que los encargados de escribir esta historia no eran historiadores, sino que provenían del campo mismo del derecho y en su mayoría eran abogados. Amparados y reconocidos sus intereses corporativos por el Estado tenían interés en desarrollar instituciones legales sólidas como parte de los mismos esfuerzos estatales. La voluntad de establecer una sola ley y un sistema único y universal de aplicación del derecho para el territorio del Estado Nación guiaba sus preocupaciones por establecer la forma en la que estas instituciones se habían consolidado. Dentro de este mismo campo se siguió una especialización en las cuestiones criminales -también de la mano con las necesidades estatales y amparadas por el crecimiento de la criminología positivista desde principios del siglo XX.

\footnotetext{
${ }^{21}$ AGUIRRE Carlos y SALVATORE Ricardo, "Writing the History of Law, Crime and Punishment in Latin America" en en R. SALVATORE, C. AGUIRRE, G.M JOSEPH, Crime and punishment in Latin America. Duke University Press. London, 2001.
} 
La Nueva Historia de la Justicia renovó el arsenal metodológico, pero siguió aplicándolo, por distintos motivos a los de la Historia del Derecho, a los mismos objetos de estudios pero nutridos de diferentes preocupaciones y cuestionamientos. Nuevas perspectivas teóricas y metodológicas permitieron revitalizar la importancia de las fuentes judiciales, hasta no hace tanto ignoradas a la hora de escribir la historia de los sectores subalternos. Las nuevas preguntas alrededor de estos sujetos planteaban la necesidad de

una toma de posición frente a la necesidad e importancia de la recuperación de la "memoria colectiva" en un sentido mucho más amplio, por ejemplo incorporando fuentes que se refirieran a sujetos anónimos, populares y marginales. ${ }^{22}$

En este sentido las fuentes judiciales abrieron una otra posibilidad para la indagación y en parte la historia de los códigos y las leyes fue dejadas de lado, construyéndose dos campos disciplinares sin diálogo.

La revalorización de los registros documentales producidos por diferentes organismos relacionados a la justicia y el derecho fue consecuencia de la influencia que ejerce sobre el campo historiográfico los escritos de Focault, Thompson y Geertz. La obra de estos tres intelectuales, provenientes de distintas disciplinas de las ciencias sociales, "han movilizado con sus trabajos las bases conceptuales mismas desde las que se pensaba el funcionamiento de la sociedad, la ley y la justicia" ${ }^{23}$, en la medida en que, siguiendo a Palacio y Candioti, sus investigaciones fundaron nuevos enfoques. Sus indagaciones en torno a las instituciones productoras de sujetos -en el caso de Michel Foucault, la utilización de la ley y el derecho por los subalternos -tal como hace Edward Thompson-, y las indagaciones en torno a un concepto tan caro a la antropología como es la cultura -preocupación central de Clifford Geertz-, han despertado el interés de sus colegas e inspirado nuevas investigaciones. Por otro lado los caminos previos de estos tres pensadores confluyen en la justicia, pero provienen de distintos campos académicos y dan cuenta de la variedad de disciplinas que han tomado a la justicia y a la ley como su objeto de estudio

\footnotetext{
${ }^{22}$ DIEZ, María Angélica: "Las fuentes judiciales en los estudios socio-históricos: problemas, enfoques y métodos desde la experiencia en historia regional" en La fuente judicial en la construcción de la memoria, Talleres Gráficos del Poder judicial de la Provincia de Buenos Aires, La Plata, 1999.

${ }^{23}$ PALACIO, Juan Manuel y CANDIOTI, Magdalena, "Justicia, política y derechos en América Latina. Apuntes para un debate interdisciplinario" en Juan Manuel Palacio, Magdalena Candioti (comp.), Justicia, politica y derechos en América Latina, Prometeo, Buenos Aires, 2007. pp. 13.
} 
Esta crítica a la unidirecionalidad de la ley, tal como era comprendida por los estudios anteriores también puso en duda la capacidad estatal para generar normas generales de aplicación universal. Los estudios en torno a los sectores subalternos han posado su mirada en las instituciones estatales encargadas de aplicar estas normas $y$, al hacerlo, han contribuido a desestructurar el homogéneo bloque estatal y presentarlo como una suma de voluntades no siempre dispuestas a seguir la misma dirección. En esta tarea las pautas fijadas en los trabajos de Michel Focault en cuanto a las prisiones y los hospicios marcaron el camino a seguir.

Los estudios del filósofo francés dieron origen a toda una serie de investigaciones en torno a la constitución y función de diferentes instituciones estatales que no siempre actuaban guiadas por las mismas pautas para las que habian sido creadas en los papeles, pero aun así capaces de construir los sentidos de lo normal y lo desviado. Esta divergencia entre la teoría y la práctica dejó una rica brecha en donde los historiadores pudieron buscar la interacción de los sujetos subalternos con la institución estatal. Las investigaciones en torno a los manicomios, presidios y la policía ${ }^{24}$ han sido los más beneficiados por la influencia de teoría de la fragmentación del poder propuesta por Foucault.

La conceptualización de la cultura como una "trama pública de significaciones, compartida por una comunidad, que otorga inteligibilidad a su vida social (en donde) el derecho es uno de los componentes de ese conjunto de ideas y valores, hábitos y prácticas que, entrelazados entre si, organizan el modo en que se piensa cómo las cosas son y deben ser en una determinada sociedad" $^{\prime 25}$, permitió a su vez romper con esta unidireccionalidad y manifiesta intencionalidad del derecho, al darle una definición más amplia que permitiese concebirlo como un lugar de disputas por su significado e interpretación. En este sentido las disputas en torno a las instituciones jurídicas dejaron de ser invisibilizadas y la construcción del Estado y sus instituciones es observada en toda su dimensión conflictiva en tanto su existencia y desarrollo no es ya

\footnotetext{
24 DI LISCIA Maria Silvia y BOHOSLAVSKY Ernesto (editores), Instituciones y formas de control social en América Latina, 1840-1940. Prometeo, Buenos Aires, 2005. GAYOL Sandra y KESSLER Gabriel (compiladores), Violencias, justicias y delitos en la Argentina. Ediciones Manantial y Universidad Nacional de General Sarmiento, Buenos Aires, 2002.

${ }^{25}$ Palacio y Candioti, Op. Cit. Pp. 14 cursiva mía.
} 
concebido desde la situación resultante, sino que es colocado en el contexto de su construcción, con todas sus ambigüedades y contradicciones ${ }^{26}$.

Estas disputas en torno al significado de la letra de la ley, que le permitió a Thompson historizar en torno a las resistencias que se generaban desde la construcción de realidades propias mediante el discurso en torno a lo justo ${ }^{27}$, les otorgó a los historiadores sociales una poderosa herramienta a la hora de comprender las acciones individuales y colectivas de los sujetos en su contexto histórico. Por otro lado la construcción de realidades sociales a partir del pensamiento legal inspiraron trabajos sobre la constitución de los estereotipos sociales, ya sea para incluirlos dentro de la "normalidad" como para excluirlos de la misma y otorgarles, de ese modo, una marca estigmatizante que permitiera su sometimiento ${ }^{28}$.

Se desprende de estas líneas que la renovación de la historia social propuesta desde los estudios en torno a la justicia, la ley y el derecho ha dado al campo un nuevo brío, pero estos estudios están generalmente concentrados en los siglos XVII, XVIII, principalmente el XIX, principios y por su incidencia en los recientes procesos de redemocratización, finales del siglo $\mathrm{XX}$, pero no dan cuenta de procesos ligados a la creación de una fuerza de trabajo industrial e urbana. Los estudios en torno a la creación, por medio de normas legales, de una fuerza de trabajo se centran en la importancia que tuvo la persecución de la población rural por medio de la generación de categorías tales como vagancia, y su relación con la construcción del orden estatal tal cual se desprende, por ejemplo, del trabajo de Ricardo Salvatore ${ }^{29}$ o, para un período anterior, Agustín Casagrande ${ }^{30}$.

El proceso de constitución de los Tribunales del Trabajo aun no se vio beneficiado por la renovación en la medida en que el objeto de estudio de

\footnotetext{
${ }^{26}$ BARRENECHE Osvaldo, Dentro de la ley, TODO. La justicia criminal de Buenos Aires en la etapa formativa del sistema penal moderno de la Argentina. Ediciones Al Margen, La Plata, 2001.

27 THOMPSON Edward Palmer, Costumbres en común... Op. Cit. También THOMPSON Edward Palmer, Los origenes de la ley negra. Un episodio de la historia criminal inglesa, Siglo XXI, Buenos Aires, 2010.

${ }^{28}$ CAIMARI Lila, Apenas un delincuente. Crimen, castigo y cultura en la Argentina, 1880-1955, Siglo XXI Editores, Buenos Aires, 2004.

29 SALVATORE Ricardo, Wandering Paysanos. State Order and Subaltern Experience in Buenos Aires during the Rosas Era. Duke University Press, Durham and London, 2003.

${ }^{30}$ CASAGRANDE Agustín, Los vagabundos y la justicia de Buenos Aires durante el período tardo colonial (1785-1810), INHIDE, Buenos Aires, 2012.
} 
ambas perspectivas sigue siendo o las formas en las que las instituciones impactaron en el desarrollo institucional mismo, o la forma en la que fueron apropiadas y resignificadas por actores sociales excluidos de su diagramación. Esto se debe también a las fuentes teóricas sobre las que se basó la renovación. Los trabajos de Thompson citados refieren a actores rurales y se percibe cierta deficiencia a la hora de aplicar su teoría a otros actores sociales. Al mismo tiempo también se presume ciertos límites en los procesos de conformación de instituciones legales universales. La historia política y la historia del derecho marcan aun la agenda en este sentido ya que aunque con otras preguntas la historia social de la justicia sigue aún pendiente de la cronología de la historia del derecho.

De todas maneras las nuevas indagaciones de ambas perspectivas están avanzando hacia mediados del siglo XX, y mientras desde la Historia del Derecho se organizaron recientemente jornadas especializadas sobre el derecho privado y la modernización ${ }^{31}$-forma eufemística de hacer mención a la crisis del Derecho Civil- desde la Nueva Historia de la Justicia se comenzó a indagar tímidamente en lo que implicó el peronismo en el ámbito del derecho y los cambios que produjo ${ }^{32}$.

\section{b) Los estudios en torno al Estado}

Las investigaciones que tiene como objeto de estudio las burocracias y los sujetos abocados a la aplicación e interpretación de la ley también se vieron beneficiados con el auge de los estudios en torno a la justicia. La intervención de estos sujetos en la difusión y aplicación de la ley permite otorgarles agencia histórica a personajes que habían quedado olvidados en las narraciones históricas convencionales, ligadas a la importancia de los grandes hombres y acontecimientos, que les concebía claramente un papel determinante en la construcción de las instituciones actuales. La relectura de las fuentes y la

\footnotetext{
31 "Derecho Privado y Modernización en América Latina y Europa en la primera mitad del siglo XX." Seminario a realizado del 4 al 6 de julio de 2012 en la sede dellnstituto de Investigaciones de Historia del Derecho

${ }^{32}$ PALACIO Juan Manuel, "De la paz a la discordia: El peronismo y la experiencia del Estado en la provincia de Buenos Aires (1943-1955)". Desarrollo Económico. Revista de Ciencias Sociales. Vol. 49 No 194. Buenos Aires. IDES. 2009. Pp. 221-246. REGOLO Santiago, "La Constitución Social de 1949. Hacia una democracia de masas", ponencia presentada en el Primer Congreso de estudios sobre el Peronismo: la primera década, Mar del Plata, Noviembre de 2008. Disponible en la web: http://redesperonismo.com.ar/archivos/CD1/SC/regolo.pdf
} 
valorización de otras tantas fuentes otrora ignoradas permitió rescatar del olvido la importancia que los funcionarios de segunda y tercera línea, abogados, legos y tinterillos tuvieron en la construcción de la soberanía estatal y en la difusión de la letra e interpretaciones de la ley ${ }^{33}$.

Esto fue posible en la medida en que los estudios sobre el estado también atravesaron un proceso de renovación que implicó prestar atención a las zonas grises y a los actores grises de la institución estatal. Después de haber traído al estado de nuevo al centro de la escena y puesto el ojo en la demanda de saberes y conocimientos que esta institución genera de forma relativamente autónoma $^{34}$, se hizo necesario dotar de materialidad las ideas y los proyectos que se le achacaban al estado. Así desde una matriz en parte weberiana con un fuerte énfasis en la dominación legal que planteaba Sckocpol se buscó superar la propuesta mediante el análisis empírico de las agencias e instituciones estatales. De alguna manera, sin llegar al extremo propuesto por Harold Perkin de considerar al Estado como una sucesión de espacios colonizados por distintos saberes de lo social que reclaman según su competencia profesional ${ }^{35}$.

En la historiografía Argentina la renovación en los estudios del Estado vino asociado fuertemente a una reconsideración de estrategias de investigación colectivas que buscan describir las agencias estatales como espacios de disputa de los sentidos mismos del Estado, pero que además establecen formas de intervención hacia el interior y exterior de la institución estatal que no puede ser soslayada. Las necesidades de contar con instituciones estatales capaces de cambiar y adaptarse ya había sido el centro de preocupaciones de académicos. Un programa ya prefigurado en parte en un

\footnotetext{
33 PALACIO Juan Manuel, La Paz del trigo, Edhasa, Buenos Aires, 2004. Del mismo autor, "Judges, lawyers and the circulation of the law" en SALVATORE, R; AGUIRRE, C; JOSEPH, G.M.: Crime and punishment in Latin America. Duke University Press. London 2001. AZEVEDO Elciene: "En las trincheras de la justicia. Abogados y esclavos en el movimiento abolicionista en San Pablo" en LARA, Silva H. e NUNES DE MENDOCA (orgs), Direitos e Justicas no Brasil. Ensaios de História Social. Editora da Unicamp, Campinas, 2005.

${ }^{34}$ SKOCPOL Theda "Bringing the state back in: strategies of analysis in current research," in $\mathrm{P}$. EVANS, D. RUESCHEMEYER and T. SKOCPOL (eds.), Bringing the State Back In, Cambridge University Press, London, 1985.

${ }^{35}$ PERKIN Harold, The rise of professional society. England since 1880. London \& New York. Routledge, 2002.
} 
trabajo de Oscar Ozslak ${ }^{36}$, que el discurso público sobre la necesidad de reformas sobre el Estado y su reorientación desde mediados de la década del ochenta del siglo pasado trajeron al centro de la escena. Las contribuciones académicas, orientadas con las mismas preocupaciones pero buscando distinto rumbo para el Estado han facilitado la construcción de un imagen distinta de este actor central que presta especial atención a las interrelaciones de los individuos y las configuraciones sociales que $\operatorname{trazan}^{37}$. Al dotar de sustento empírico a los actores sociales que constituyen el Estado se dota a este de un rostro humano y permite contemplar las contradicciones los proyectos, lógicas y aspiraciones de quienes dotan al Estado de consistencia.

Este camino cuenta ya con varias obras colectivas que profundizan los estudios empíricos sobre las agencias estatales. Un Estado con rostro humano ${ }^{38}$ de Germán Soprano y Ernesto Bohoslavsky, El Estado argentino y las profesiones liberales, académicas y armadas ${ }^{39}$ de Sabina Frederic, Osvaldo Graciano y Germán Soprano, con énfasis en la relación entre la formación académica y profesional con las agencias estatales. Recientemente dos volúmenes sobre los estudios del estado han sido publicados con la intención de profundizar en este camino. Compilados por Mariano Plotkin y Eduardo Zimmerman, Los saberes de Estado y Las prácticas del Estado ${ }^{40}$ de alguna manera dan cuenta de la necesidad de indagar en las distancias entre los proyectos de elites académicas e intelectuales y las posibilidades de acción concreta de las instituciones estatales.

En el ámbito de los estudios de las instituciones estatales predominan las investigaciones sobre las instancias del Poder Ejecutivo, mientras que el Poder Judicial y el Legislativo no encuentran la misma repercusión. En el caso de las

${ }^{36}$ OSZLAK Oscar, "Notas críticas para una teoría de la burocracia estatal", en Desarrollo Económico, Num. 74, Vol. 19. IDES, Buenos Aires 1979.

${ }^{37}$ SOPRANO Germán, "Del Estado en singular al Estado en plural. Contribución para una historia social de las agencias estatales en la Argentina". En: Cuestiones de Sociología $N^{\circ} 4$, Departamento de Sociología, Facultad de Humanidades y Ciencias de la Educación, Universidad Nacional de La Plata. La Plata, 2007. Pags. 19-48.

${ }_{38}$ BOHOSLAVSKY Ernesto y SOPRANO Germán (eds.), Un Estado con rostro humano. Funcionarios e instituciones estatales en la Argentina (1880 a la actualidad). Universidad Nacional de General Sarmiento, 2009.

${ }^{39}$ FREDERIC Sabina, GRACIANO Osvaldo y SOPRANO Germán (coords.), El Estado y las profesiones liberales, académicas y armadas, Prohistoria, Rosario, 2010.

${ }^{40}$ PLOTKIN Mariano Ben y ZIMMERMANN Eduardo (comp.), Los Saberes del Estado, Edhasa, Buenos Aires, 2012. De los mismos compiladores, Las prácticas del Estado. Política, sociedad y elites estatales en la Argentina del siglo XX, Edhasa, Buenos Aires, 2012. 
relaciones laborales esto redundó en una mayor atención sobre el DNT y la Secretaría de Trabajo y Previsión mientras que los Tribunales o Juzgados del Trabajo aun no recibieron la atención de estos estudios.

c) Aportes para un diálogo regional: la Justicia del Trabajo en la historiografía brasilera

El surgimiento en Brasil de una fuerza sindical por fuera de la estructura fundada en los años treinta bajo la dirección de Getulio Vargas que devino en uno de los actores centrales de la clase obrera, dio origen a una revisión profunda del lugar del viejo sindicalismo de los pelegos ${ }^{41}$. Los rasgos anómalos de la inclusión de los trabajadores en la ciudadanía fueron resaltados por la bibliografía clásica ${ }^{42}$ y las características autoritarias de las leyes trabalhistas fueron comparadas a los atos institucionais de los gobiernos militares que dominaron el espacio político desde $1964^{43}$. Efectivamente el desarrollo de una fuerza política de alcance nacional y de carácter obrero como el Partido dos Trabalhadores dejo en evidencia las posibilidades del ejercicio de la autonomía de la clase obrera con respecto a la estructura estatal. Por comparación, los sindicatos tradicionales fueron percibidos como simples elementos de control del estado y alejados de las necesidades de la clase obrera. En este avance sobre la posición de los sindicatos, las críticas llegaron hasta el sistema legal

\footnotetext{
${ }^{41}$ Nombre con el que se tildaba a los líderes de los sindicatos oficiales y que asignaba a su portador un carácter poco combativo con respecto a la patronal.

${ }^{42}$ Murilo de Carvalho propone una inversión en la incorporación de la ciudadanía para el caso de Brasil, inversión en la cual los derechos sociales fueron incorporados con anterioridad a los derechos políticos. Esta incorporación fue, además, por medio de la voluntad dl estado y no como producto de la lucha desde los actores sociales. Por lo tanto se enmarca en una general aceptación de la ideología da outorga que propone los derechos, en el caso brasilero, como concedidos siempre desde arriba hacia abajo, visión que es compartida por diferentes analistas para distintos casos históricos. MURILO DE CARVALHO, José, Desenvolvimiento de la ciudadanía en Brasil, Colegio de México/FCE, México, 1995.

43 Kazumi Munakata liga el surgimiento de la legislación trabalhista a los intentos de corporativizar la sociedad brasilera mediante la implantación del Estado Novo, anulando de esta manera los impulsos individuales y anárquicos que implicaba una sociedad diferenciada en clases irreconciliables. El corporativismo de Getulio Vargas, según este autor, reconocía la lucha de clases, pero la eliminaba mediante la sanción de leyes que otorgaban ciertos derechos al tiempo que constreñían el accionar de la clase obrera. En su conclusión, el autor concuerda con el entonces dirigente sindical metalúrgico Luis Inácio Da Silva que coloca en un plano de similitud las leyes del período del trabalhismo con las actas institucionales principalmente la $\mathrm{N}^{\circ} 5$ que marcó el giro autoritario de la dictadura brasilera en 1968- en lo que respecta a los trabajadores ("A CLT é o Al-5 dos trabalhadores"). MUNAKATA Kazumi, $A$ legislação Trabalhista no Brasil, Ed. Brasiliense, Saõ Paulo 1982.
} 
que les dio origen y se estableció muy fuertemente la idea de que la legislación social tenía objetivos corporativos, cuando no netamente fascistas ${ }^{44}$.

A conclusiones diferentes en cuanto al lugar del estado y de las leyes sociales, aunque no a las objeciones desde el punto de vista de la autonomía de los trabajadores, Ilegó Angela de Castro Gomes. En Burguesia e Trabalho la autora sostuvo que la batería de medidas favorables a los trabajadores que se sucedieron desde 1930, si bien tuvieron un impacto positivo en los trabajadores, otorgó a la burguesía mayor predictibilidad a los conflictos a darles un marco institucional y disciplinar el mercado de trabajo. A pesar de algunas pérdidas a corto plazo por parte de la clase burguesa, esta terminó triunfando en el plano político ya que la acción tutelar del Estado era para con las organizaciones de trabajadores y no con las organizaciones de su propia clase. A esto le suma que siendo leyes de difícil cumplimiento las pérdidas económicas quedaron matizadas ${ }^{45}$.

De todas maneras hay que resaltar que esta autora construye su obra desde una perspectiva que busca superar la idea de la "ideologia da outorga" 46 , es decir, la imagen que el Estado Novo había construido sobre sí mismo en relación a los derechos sociales. Si bien no abandona totalmente la idea de un Estado que otorga los derechos, en $A$ Invenção do Trabalhismo coloca la sesión en un marco teórico distinto, en donde dota no sólo a la burguesía o el Estado con racionalidad de sus decisiones sino también a los trabajadores. Estos deciden aceptar la legislación social y apoyan políticamente a los representantes del estado que le otorgan estos derechos en un acto de

\footnotetext{
${ }^{44}$ SAYÂO ROMITA Arion, "A Justiçã do Trabalho: produto do Estado Novo" en PANDOLFI Dulce (org.), Repensando o Estado Novo, Ed. Fundação Getulio Vargas, Rio de Janeiro, 1999. ${ }^{45}$ GOMES Angela de Castro, Burguesia e trabalho. Politica e Legislação social no Brasil 19171937. Campus, Río de Janeiro, 1979.

${ }^{46}$ La ideologia da outorga para este caso refiere a la imagen construida desde el Estado Novo que sostenía que la inclusión social fue producto de una sesión por parte del Estado, y principalmente su líder Getulio Vargas, a los trabajadores. El término ideología da otorga fue concebido por Luis Werneck Vianna para denominar las interpretaciones que establecían una supresión de la memoria de las clases y por lo tanto "impotentes e incapaces de reivindicar sus derechos elementales por sí sólos". WERNECK VIANNA, Luis, Liberalismo e sindicato no Brasil. Paz e Terra, Rio de Janeiro, 1978. Pp 31. De esta manera se negaba la tradición previa de los trabajadores en su lucha por conquistar derechos. La perspectiva de la autora, si bien sostiene que hubo una sesión por parte del Estado, enmarca esa sesión en las disputas entre capital y trabajo y en los reclamos hechos desde las organizaciones obreras a los diferentes gobiernos republicanos en la consecución de sus derechos.
} 
reciprosidad, y no ya simplemente sumisión ${ }^{47}$. En Cidadanía e Direitos do Trabalho, la misma autora suma a la dimensión material de esta política, la dimensión simbólica, en el que el lenguaje de derechos pasó a constituir un parte importante del repertorio de los trabajadores a la hora de fortalecer sus demandas y exigir la aplicación de leyes ${ }^{48}$.

A pesar de sostener un lugar diferente para los trabajadores y no ya un simple lugar de sujeto de cooptación y disciplinamiento, esta autora logró matizar la idea de la ideología da outorga, pero aun así no avanzó en como los sujetos de esas políticas interiorizaban, aceptaban, reproducían y reclamaban esos derechos. Tal es la perspectiva que asumieron varios investigadores de la historia de los trabajadores en Brasil y que forman el corpus principal que estimulo esta tesis. La edición de Na luta por direitos, obra que concentra estudio de alguno de estos autores, marcó el puntapié inicial de esta tesis ${ }^{49}$. En los estudios contenidos en dicho libro se apunta al lugar activo que los trabajadores tuvieron en la reclamación de derechos, y como el no cumplimiento de estos derechos -considerados de cumplimiento poco efectivo según Gomes a pesar de su importancia- era considerado como una falta y por lo tanto reclamados. La perspectiva en la que se enmarcan estos estudios es la que orientó en sus inicios esta tesis: los trabajadores como sujetos conscientes de su rol y con capacidad de agencia histórica.

El lenguaje de derechos permitió a los trabajadores construir un marco de resistencias que escapaban de la más tradicional imagen de leyes que los oprimían o los ahogaban, pero que no necesariamente los protegía ${ }^{50}$. Además la posibilidad de acudir a una institución especializada en conflictos laborales, la Justiça do Trabalho, es pensado no ya como una herramienta de disciplinamiento de la mano de obra, sino entendida como uno más de los caminos que podían recorrer los trabajadores en su afán por lograr sus derechos. En A carga e a culpa, Fernando Teixera Da Silva justamente recorre esta tesis al acentuar sobre la Justiça do Trabalho como opción racionalmente

${ }^{47}$ GOMES Angela de Castro, $A$ invenção do Trabalhismo, IUPERJ/VERTICE, Río de Janeiro, 1988.

${ }^{48}$ GOMES Angela de Castro, Cidadania e Direitos do Trabalho, Jorge Zahar Editor, Rio de Janeiro, 2002.

${ }_{49}$ FORTES Alexandre et al. Na luta por direitos. Estudos recentes em história social do trabalho., Editora da Unicamp, Campinas, 1999.

${ }^{50}$ FRENCH John, Afogados em leis. A CLT e a cultura juridica dos trabalhadores. Editora Fundação Perseu Abramo, Saõ Paulo, 2001. 
escogida en términos políticos que moldeaba nuevos significados para la ley laboral del período. Al centrarse en los sujetos como activos participantes de su propia historia e históricamente situados este autor también rompe con algunas lecturas que trazaban una dicotomía entre trabajadores de base y cúpulas sindicales con respecto al apoyo que el sindicalismo reformista recibió de trabajadores de otras vertientes ideológicas del movimiento obrero ${ }^{51}$.

En lo que respecta exclusivamente a la Justiçã do Trabalho, algunos trabajos presentan conclusiones en torno al rol jugado por el poder judicial que pueden ser interesantes a la hora de cruzar el interés por la historia de la justicia y la historia de los trabajadores. Uno de estos autores es Rinaldo Varussa, que lleva adelante un análisis de la legislación laboral, pero también de algunos juicios que tuvieron lugar en la ciudad de França en el estado de San Pablo. Entre sus conclusiones destaco en particular aquella que hace referencia al sentido que el poder judicial adquiría para los trabajadores. Según Varussa, los procesos de la Justiçã do Trabalho parecen afirmarse como opciones prácticas y políticas asumidas por los trabajadores, en forma conjunta o al margen de otras, tales como la constitución de organizaciones que buscaban el enfrentamiento directo frente al gobierno, otros grupos o situaciones adversas. De manera general los procesos de la Justiçã do Trabalho se presentaban como un conjunto de situaciones vividas por los trabajadores que en determinados momentos y más allá de las perspectivas que orientaron la formulación de dicha institución judicial, acreditaban, concebían e hacían de las vías judiciales una posibilidad de enfrentar diferentes situaciones de conflicto vividas en las y a partir de las relaciones de trabajo $^{52}$.

d) Aportes desde la normalización de los estudios sobre el peronismo

Al centrarse la institución a abordar en un período tan significativo para la historiografía y la política argentina -el peronismo- inevitablemente surgieron

\footnotetext{
${ }^{51}$ Apunta el autor a la declinación del comunismo y, principalmente, el anarquismo, como opción ideológica durante fines de la década del veinte y principios del treinta en la "Barcelona brasilera" -la ciudad-puerto de Santos donde el autor construye su objeto de estudio-.

${ }^{2}$ VARUSSA, Rinaldo J., Trabalho e legislação: experiências de trabalhadores na Justiça do Trabalho (Jundiaí - SP, décadas de 40 a 60). Tese (Doutorado), Pontifícia Universidade Católica/SP, 2002.
} 
las necesidades de cruzar los interrogantes con aquellos que hicieron del peronismo su objeto principal.

Teniendo en cuenta el rol central que en el peronismo alcanzaron los trabajadores, la justificación del porqué del apoyo que estos brindaron a Perón fue un eje central en los debates sobre el surgimiento de dicha fuerza política. Las múltiples temáticas desde las que se aborda el peronismo han logrado matizar las posturas dicotómicas, tal como recuerdan Omar Acha y Nicolás Quiroga $^{53}$, pero subyace siempre la idea del peronismo como parteaguas de la historia. A este lugar central en la historia se le suma el rol preponderante en lo que respecta a las capacidades de modificar los marcos explicativos de las ciencias sociales que el abordaje de los orígenes del peronismo ha producido ${ }^{54}$.

Al retomar estas líneas interpretativas desde una perspectiva de la historia social de la justicia se busca enriquecer el debate en torno al surgimiento del peronismo y los apoyos de los trabajadores, pero, fundamentalmente, a las interrelaciones que hicieron posible que un cambio tan importante en la estructura judicial se completase en dicho período. Al adoptar como objetivo una formulación empírica de algunos de los sentidos que la Justicia Social -como elemento constitutivo de la fuerza discursiva del peronismo- adoptó para los trabajadores y otros actores del período, pretendo reconstruir los sentidos de las nociones de derecho y justicia prevalecientes en ese momento.

\footnotetext{
${ }^{53}$ ACHA, Omar y QUIROGA, Nicolás, "Presentación" en Prohistoria $N^{\circ} 9$, Número Monográfico La Trayectoria de la cultura política peronista, 1943-2003, Rosario, 2005 y de los mismos autores "Pliegues de la normalización de los estudios sobre el primer peronismo: complementos y aclaraciones" en REIN Raanan, BARRY Carolina, ACHA Omar, QUIROGA Nicolás, Los Estudios sobre el primer peronismo. Aproximaciones desde el siglo XXI, Instituto Cultural de la Provincia de Buenos Aires, La Plata, 2009.

${ }^{54}$ Emilio de Ipola traza un recorrido entre las interpretaciones sobre el peronismo, retomando solo aquellas que él considera más influyentes, en base a dos variables. Por un lado su ubicación en el debate de si el peronismo significó una ruptura o una continuidad con respecto al desenvolvimiento histórico previo. Por otro cataloga a las interpretaciones en tanto si significan continuidades o rupturas de los marcos explicativos de dicho fenómeno en términos de interpretación sociológica. Terminará afirmando que existe una "discontinuidad teórica" en los enfoques y una "continuidad histórica" del proceso investigado. DE IPOLA, Emilio, "Ruptura y continuidad. Claves parciales para un balance de las interpretaciones del peronismo" en Desarrollo Económico, Vol. 29, No. 115 (Oct-Dic, 1989), pp. 331-359. Ver también las críticas de Jorge Jorrat a este artículo y la respuesta de de Ipola: JORRAT, Jorge Raúl, "Reflexiones sobre un balance de las interpretaciones del peronismo" en Desarrollo Económico, Vol. 30, No. 118. (Jul-Sep 1990), pp. 277-283; y DE IPOLA, Emilio, "Respuesta a comentario: "reflexiones sobre un balance de las interpretaciones del peronismo"', en Desarrollo Económico, Vol 30 No. 118 , pp. 284-288.
} 
Tal tarea, uno de los objetivos del "campo" de la nueva historia de la justicia, se revela como un punto interesante a discutir en la medida en que permitiría historizar un concepto que desde la historiografía del peronismo siempre estuvo más vinculado a las acciones específicas del Poder Ejecutivo en cuanto resolución de ciertas problemáticas de la cuestión social -tales como las referidas a la vivienda, salarios, salud y educación-. Al volcar la mirada a la justicia social desde esta perspectiva se abren las posibilidades para pensar la configuración de sentidos que este concepto otorgó a los trabajadores en cuanto constitutivo de de la realidad social. Por más que la institucionalización de los conflictos propuestas desde el peronismo -con un fuerte acento en la conciliación de los intereses en pugna- o incluso desde períodos previos pueda ser interpretado como una forma de manipulación de los trabajadores, el peso de la idea de justicia social sin duda debe ser atendido en su complejidad.

Asumiendo que la justicia, la ley y el derecho no necesariamente significan lo mismo para los actores del entramado social, buscaré rastrear en cuestiones como la Justicia Social las expresiones volcadas por dichos actores en torno a la concepción misma de la sociedad. Otra de las preocupaciones en torno a la idea de justicia es la referente al acceso de los diversos sectores sociales a la justicia -entendida en este contexto como la posibilidad de acceso formal a la institución judicial- como medio para resolver sus disputas (en este caso las disputas en el marco de la relación laboral). Al ser referido el acceso a la institución como uno de los derechos que sostiene la ciudadanía, es interesante contrastar algunas de las sugerencias de esta investigación con la forma que adquiere la ciudadanía para los trabajadores. Dentro de las coordenadas trazadas por Daniel James en cuanto a la constitución de la ciudadanía en un "molde nuevo, de carácter social" ${ }^{15}$, es interesante ubicar no solo a la legislación social y laboral del período, sino también a la instrumentación institucional de los mismos por medio de un fuero específico, como partes fundantes de ese nuevo molde de ciudadanía.

\footnotetext{
55 JAMES Daniel, Resistencia e Integración. El Peronismo y la clase trabajadora argentina,
} 1946-1976. Siglo XXI, Buenos Aires, 2005. Pp. 29 
La historia del mundo del trabajo, entendido este en su sentido más amplio ${ }^{56}$, estaría hoy en una encrucijada debido a la crisis del trabajo industrial, esta crisis llevó a la marginalización de la historia de los trabajadores que plantea como desafío, hoy, la reconceptualización de la clase obrera, que debido a esta crisis del trabajo, y por lo tanto la crisis del paradigma de las clases sociales, derivó en un predominio de los análisis del nivel político en desmedro de la historia social y económica. Los trabajadores "quedan excluidos de sus análisis (de la historia política) al diluirse en la más amplia categoría de ciudadanía política" ${ }^{25}$ y pierde así su especificidad obrera. El reemplazo del concepto de clase obrera por el más amplio e indefinido "sectores populares" es parte de esta crisis de los estudios en torno a los trabajadores que no ha permitido una renovación más amplia del campo.

A pesar de estudios más profundos sobre el mundo del trabajo, que refieren a la constitución de la clase obrera en sus aspectos económicos, sociales, culturales, etc. La historiografía aun está marcada por la importancia otorgada a las organizaciones obreras en la constitución de la clase. Esto se debe a que las primeras historias obreras tendieron a identificar las clases trabajadoras con el movimiento obrero organizado. La producción de los primeros escritos en torno al mundo del trabajo estuvo marcada por la militancia de sus autores y no siguieron las pautas de producción científica ya que provenían por fuera del mundo académico. La historia que escribieron militantes como Marota, Abad de Santillán, Oddone o Casaretto, buscaba justificar las decisiones que las corrientes más significativas de la vanguardia obrera habían tomado ante determinadas circunstancias y contextos.

\footnotetext{
${ }^{56}$ Nicolás Iñigo Carrera pone en duda la posibilidad de delimitar como objeto de studio el "mundo del trabajo" porque al hacerlo se desplazaría el centro de observación al mundo de los "factores de producción", reduciendo a los trabajadores a su actividad y dejando de lado la multiplicidad de relaciones sociales que los constituyen. En este sentido el "trabajo" se realiza en un "mundo (el lugar de trabajo)" en el que los seres humanos han sido ya despojados de toda condición que no sea la de atributo de capital, engranaje de un mecanismo. Por otro lado Mirta Lobato parece apoyar la utilización del campo "mundo del trabajo" de una manera más amplia, ya que el trabajador extrae de su condición de trabajador características con las cuáles conforma su propia identificación, y realiza, a partir de la investigación en torno a la fábrica, una profunda indagación sobre las múltiples relaciones sociales que constituyen a los trabajadores en su lugar de trabajo y logra relacionar la vida en la fábrica con la vida en la comunidad circundante. IÑIGO CARRERA Nicolás, "La historia de los trabajadores" en GELMAN Jorge (comp.), La Historia económica argentina en la encrucijada. Balances y perspectivas, Prometeo Libros, Buenos Aires, 2006. LOBATO Mirta Z., "Una visión del mundo del trabajo. Obreros inmigrantes en la industria frigorífica, 1900-1930" en DEVOTO Fernando y MIGUEZ Eduardo (comp.), Asociacionismo, trabajo e identidad étnica, CEMLA-CSER-IEHS, Buenos Aires, 1992.

${ }^{57}$ SURIANO Juan, Los dilemas actuales... Op. Cit. Pp. 289.
} 
A pesar de no provenir del mundo académico, estas historias, como sostiene Iñigo Carrera, deberían ser consideradas como productos académicos, y no simples fuentes para la investigación ${ }^{58}$. Su posición no difiere demasiado de lo que sostiene Hobsbawm, en la medida que el historiador inglés también reconoce a estas historias desde "dentro del movimiento" como producto académico. A pesar de que le otorgan poca atención a las masas y privilegian el papel de los líderes, y es una historia ortodoxa en cuanto a su técnica y su metodología al ser narrativa e institucional, hay que rescatarla, ya que no se debe desechar la ortodoxia en la medida que fueron estas historias las que se preocuparon por "darle al movimiento obrero la importancia que nadie más parecía estar dispuesto darle" ${ }^{59}$ en un contexto en que la historia estaba reducida a la investigación en torno a las ideas fuerza y sus "portadores en este mundo" (políticos, militares, curas y diplomáticos) ${ }^{60}$.

La historiografía de los trabajadores, entonces, estaba reducida hasta la década del sesenta a la historia del movimiento obrero y, principalmente, la lucha de sus líderes. Pero los estudios en torno a los orígenes y a la naturaleza del peronismo dieron comienzo a otro tipo de investigaciones, más vinculadas al área de la sociología, que dejarían ricos debates. A partir de las investigaciones de Gino Germani, que destacaban como fundamental para entender la pérdida de autonomía de la clase obrera frente al líder el rol jugado por la "nueva clase obrera", migrantes del interior que se instalaron en la Capital Federal y alrededores a partir de la década del treinta ${ }^{61}$, se dio un debate en torno a lo que significaba el peronismo y al papel jugado por los trabajadores en su surgimiento. Generalmente en los enfoques sociológicos los trabajadores encarnan "polos de la serie de dicotomías globales en torno ha girado el debate sobre el populismo: tradicional/moderno, cooptación/autonomía, conciencia de clase/falsa conciencia, resistencia/integración"62

\footnotetext{
${ }^{58}$ IÑIGO CARRERA Nicolás, La historia...Op. Cit.

${ }^{59}$ HOBSBAWM Eric, El mundo del trabajo... Op. Cit. Pp. 12.

${ }^{60}$ IÑIGO CARRERA Nicolás, La historia... Op. Cit.

${ }^{61}$ GERMANI G.; S.S. de YUJNOVSKY, "El surgimiento del peronismo: el rol de los obreros y de los migrantes internos", en Desarrollo Económico, N 51, IDES, Buenos Aires,1973.

62 TORRE Juan Carlos, "Acerca de los estudios sobre la historia de los trabajadores en Argentina", Anuario IEHS, No V, Tandil, 1990.
} 
La cuestión fundamental de los trabajos que le siguieron al de Germani giraba en torno a explicar qué condiciones llevaron a la mayoría de la clase obrera a sostener -por medio del ejercicio del derecho al voto o su presencia en los masivos actos oficiales- a Perón en el poder. La idea, proveniente de un sentido común socialista, de una "traición" de los trabajadores para con su vanguardia explicaba la despolitización que habían sufrido las masas obreras y las habría dejado a merced del "populismo". Para este sentido común, la propuesta de Germani de masas de trabajadores recientes, sin desarrollo autónomo de una tradición política y carentes de una perspectiva ideológica, por lo tanto "disponibles" ${ }^{63}$ para ser cooptadas por un líder carismático, era atractiva para explicar esta traición y su propio fracaso. Pero posteriores investigaciones empíricas pusieron en duda el carácter "reciente" de los trabajadores que apoyaron a Perón desde su ascenso a la Secretaría de Trabajo y Previsión.

Las relaciones privilegiadas que tenían los líderes de los sindicatos con Perón fue uno de los pilares desde los cuáles se intentó demoler la imagen de los trabajadores apolitizados que habrían apoyado al ex-presidente argentino. Doyon analiza la alianza que se estableció entre Perón y los sindicatos, como estrategia que este utilizó para lograr el apoyo de los trabajadores. En esta alianza adquirió un lugar central la atención y las respuestas a reivindicaciones largamente postergadas y que incluso habian sufrido un retroceso en la década del treinta con las políticas hacia el sindicalismo llevadas adelante por los gobiernos de la restauración conservadora. Por otro lado los sindicalistas utilizaron su estructura para movilizar a los trabajadores en apoyo al teniente coronel en algunos momentos críticos, como por ejemplo el 17 de Octubre o en la conformación del Partido Laborista ${ }^{64}$.

Hugo del Campo también fue uno de los estudiosos de los vínculos que unían a Perón con los trabajadores por medio de los sindicatos. A partir de la experiencia sindicalista -la más pragmática y de ideología más flexible de las vanguardias obreras-, los vínculos entre Perón y esta vertiente del movimiento obrero permitieron a estos últimos proponer la forma de organización de la

\footnotetext{
${ }^{63}$ GERMANI Y YUJNOVSKY, Op. Cit.

${ }^{64}$ DOYON Louise M., Perón y los trabajadores. los orígenes del sindicalismo peronista, 19431955, Siglo Veintiuno Editora Iberoamericana, Buenos Aires, 2006.
} 
clase obrera bajo el peronismo y de la definición de los términos del conflicto entre el capital y el trabajo, además de facilitar, a pesar de que en sus orígenes a principios del siglo $X X$ se oponían a cualquier injerencia estatal ${ }^{65}$, la intervención del estado como garante de la resolución del conflicto ${ }^{66}$.

A pesar de generar un rico e interesante debate sobre los orígenes del peronismo, estas investigaciones siguieron abordando la historia de los trabajadores a partir de la historia de su movimiento, y, a pesar de no responder a líneas ideológicas de dicho movimiento y provenir del ámbito académico, continuaron colocando a los trabajadores en su carácter de masa uniforme. Otras líneas historiográficas, vinculadas con la historia cultural, llevaron adelante investigaciones en torno a la vida material de los trabajadores en su búsqueda de definir quienes conformaban y como vivía la clase obrera argentina. Desde la pionera investigación de Panettieri ${ }^{67}$, se han desarrollado en el campo historiográfico varios trabajos en torno a las condiciones de existencia material de los trabajadores, centrados fundamentalmente en el período agro-exportador, que buscaban atacar a los historiadores económicos - principalmente Cortez Conde- que veían en el aumento del salario real y en la diferencia entre el país receptor y los expulsores de mano de obra como posibilidad de ascenso social.

Las investigaciones del mencionado Panettieri, y de Leandro Gutiérrez demostraron que las condiciones materiales de los trabajadores distaban de encontrarse dentro del avance general que los historiadores económicos veían como indicadores de progreso. De todas maneras estos estudios en torno al consumo y la vivienda de los trabajadores no ahondaron en el proceso de constitución de la clase obrera argentina, aunque sí dieron impulso a un conocimiento más detallado de la vida fuera de los lugares de trabajo y que permitirían pensar las relaciones sociales que establecían por fuera de su lugar como engranaje, en las palabras de Iñigo Carrera, de la maquinaria de producción capitalista.

\footnotetext{
${ }^{65}$ BERTOLO Maricel, Una propuesta alternativa: el sindicalismo revolucionario (1904-1916), CEAL, Buenos Aires, 1993.

${ }^{66}$ DEL CAMPO Hugo, Sindicalismo y peronismo. Los comienzos de un vínculo perdurable, FLACSO, Buenos Aires, 1983.

${ }^{67}$ PANETTIERI José, Los trabajadores, Jorge Álvarez, Buenos Aires, 1967.
} 
La conformación de la clase obrera siguió estando ajena como problemática de la historia social hasta la lectura, nuevamente, de la obra de $\mathrm{E}$. P. Thompson así como de otros historiadores provenientes del marxismo británico. En la obra de Edward Thompson La formación de la clase obrera en Inglaterra ${ }^{68}$, el concepto de clase es entendido como resultado de un proceso histórico, y no como existente a partir de las relaciones económicas (clase en si), en donde confluyen las nuevas experiencias con las tradiciones previas y donde la vivencia social adquiere importantes significados en la constitución de la clase obrera como sujeto social. En estas vivencias el conflicto adquiría un lugar central, pero no era el único que "formaba" a la clase obrera, y variables como su origen, concepciones en torno a lo justo, vida material, consumo, y las percepciones del mundo en el que vivían eran igual de importantes.

De todas maneras el conflicto seguía estando en el centro de las reflexiones en torno a la clase obrera, pero en su interpretación criolla las primeras lecturas de los marxistas ingleses dejaron de lado el conflicto y se concentraron en las cuestiones culturales que proponían Thompson y sus discípulos. A partir de esta lectura se llevaron adelante investigaciones sobre las condiciones de vida y la identidad política de los trabajadores, pero las conclusiones a las que se arribaron llevaron a diluir la categoría de clase social en un término mucho más vago e impreciso, pero que ha logrado mucho éxito en el medio académico, de "sectores populares" 69 . En esta categoría no solo se incluía a los trabajadores, sino a toda una amplia gama de pequeña y mediana burguesía (comerciantes, profesionales liberales, etc.) que compartían ciertas pautas culturales construidas alrededor de su pertenencia a lugares geográficos -el barrio-, que se transformaba en la base de su identidad.

El problema del concepto de "sectores populares" es que diluye en su interior a la clase obrera y excluye el conflicto como factor determinante en la construcción de la misma. Los sostenedores de este término argumentaban que la derrota del movimiento obrero después de la conflictiva coyuntura que significaron los años 1917-1922, y la superación de dicho contexto por medio de políticas represivas y una nueva actitud del estado bajo los gobiernos

\footnotetext{
${ }^{68}$ THOMPSON Edward Palmer, La formación de la clase... Op. Cit.

${ }^{69}$ ROMERO Luis Alberto, "Los sectores populares en las ciudades latinoamericanas del siglo XIX: la cuestión de la identidad" en GUTIERREZ Leandro y ROMERO Luis Alberto, Sectores populares, cultura y politica. Buenos Aires en entreguerra, Sudamericana, Buenos Aires, 1995.
} 
radicales, formó una sociedad marcada por la desaparición del conflicto laboral que perduraría hasta fines de la década del treinta. Esta argumentación es rebatida por el estudio de Nicolás Iñigo Carrera que demuestra que el conflicto no solo permaneció activo durante todo el período de entreguerras, sino que, a pesar de una disminución relativa con respecto al período posterior a la Primera Guerra Mundial, llegó incluso a los límites de una huelga general, de carácter masivo y con tintes violentos ${ }^{70}$.

La formación de la clase obrera, para este autor y para los historiadores vinculados al grupo Razón y Revolución, se vincula con la conformación de bloques políticos que se expresa especialmente en los momentos de enfrentamientos de clase. De esto se desprende que la conformación de la clase obrera no es, simplemente, consecuencia de su ubicación en el proceso productivo, sino que en el enfrentamiento y su relación con las otras clases está el centro de atención que permite delimitar los límites de la clase obrera en cada coyuntura específica.

El problema principal de esta corriente es que limita el conflicto a los momentos de enfrentamiento abierto entre las clases y dependen de los relatos de la prensa diaria y partidaria para resolver sus interrogantes en torno a la existencia de la clase obrera en cada momento histórico y deja a un lado las propias concepciones que sobre el mundo tenían los trabajadores. La clase obrera sería un dato objetivable, más allá de la propia percepción como tal. Esta investigación, en cambio, hará hincapié principalmente en otra percepción de la realidad que no necesariamente se expresa como conflicto abierto y que permita comprender los datos con todas sus complejidades y ambigüedades. Al adoptar como relevantes solo los eventos que generan desorden y violencia se puede correr el riesgo de aceptar dos supuestos del que ya nos advirtió Eric Hobsbawm en El mundo de/ trabajo: en primer lugar corremos el riesgo de aceptar entre los actos violentos y los no violentos una distinción más marcada que la que existe dentro de cada una de las categorías; y por otro lado aceptar que las clases altas "eligen" cierto tipo de violencia para prestarles una

\footnotetext{
${ }^{70}$ IÑIGO CARRERA Nicolás, "La huelga general de masas de 1936: un hecho borrado de la historia de la clase obrera argentina", Anuario IEHS, N 9, Tandil, UNCPBA, pp. 289-315.
} 
atención especial $^{71}$ y que esta elección se traslada a nuestra práctica académica.

Pero a pesar de esta primera lectura de los marxistas británicos que generó una categoría tan imprecisa como "sectores populares" y que parecía borrar la especificidad de la clase obrera y sus conflictos particulares, desde la década de los noventa dio lugar a una nueva perspectiva para abordar la formación de la clase obrera argentina. Esta perspectiva también se vio beneficiada por la explosión de estudios de casos que ayudaron a deconstuir la imagen de una historia nacional homogénea ${ }^{72}$, pero que estaba, en realidad, atada a la realidad de la ciudad puerto y las zonas adyacentes. La construcción de la clase obrera pasó a estar vinculada socialmente a su territorio y no solo a los grandes eventos nacionales. Las opciones políticas e ideológicas disponibles a los trabajadores estaban ligadas al lugar donde los trabajadores vivían y trabajaban, y su elección dependía de estos factores locales además de los eventos nacionales.

Para lograr comprender las elecciones que los trabajadores realizaban diariamente es necesario conocer cuál era el contexto en el que se encontraban. Las investigaciones pormenorizadas sobre el contexto local, regional y provincial que actualmente se están llevando a cabo ${ }^{73}$ permiten diferenciar la realidad social de los bonaerenses, y entre ellos los habitantes del departamento judicial de La Plata, de las descriptas en las historias "nacionales". Algunas de estas investigaciones ya fueron publicadas en los volúmenes compilados por Claudio Panella que se enmarcan en la gobernación de Domingo Mercante ${ }^{74}$.

Los estudios sobre el peronismo bonaerense rescatan justamente las particularidades de la conformación de esta fuerza política en la provincia de Buenos Aires. Objeto de disputas por parte de las elites políticas por su

\footnotetext{
${ }_{71}^{71}$ HOBSBAWM Eric, El mundo del trabajo... Op. Cit.

${ }^{72}$ MACOR Darío y TCACH César (comp.), La invención del peronismo en el interior del país, Ediciones Universidad Nacional del Litoral, Santa Fe, 2003.

${ }^{73}$ REIN Raanan, "De los grandes relatos a los estudios de "pequeña escala": algunas notas acerca de la hisotriografía del primer peronismo" en REIN Raanan, BARRY Carolina, ACHA Omar, QUIROGA Nicolás, Los Estudios sobre el primer peronismo. Aproximaciones desde el siglo XXI, Instituto Cultural de la Provincia de Buenos Aires, La Plata, 2009.

${ }^{74}$ PANELLA Claudio (Comp.), El gobierno de Domingo A. Mercante en Buenos Aires (19461952). Un caso de peronismo provincial, Instituto Cultural de la provincia de Buenos Aires, La Plata, 2005, 5 volúmenes.
} 
importancia en el entramado político nacional, el territorio bonaerense cuenta con características que lo diferencian de la política nacional, pero que al mismo tiempo, su relación con el centro nacional -en cierto modo más accesible del poder ubican a esta provincia en una situación distinta a la del resto de las provincias. La reducción a la escala bonaerense busca

Ordenar el espacio imaginario de la totalidad, considerando la expansión el poder celular, de donde lo pequeño reverbera en análisis de otra escala pero también pretende o puede mutar radicalmente, abandonar el territorio de la provincianía, traspasar la frontera del pago, universalizarse. $Y$ ese deslizamiento paradójico es lo que hace de lo local relacional: no relacional con tesis finalistas, con aporias sobre la organización societal o la representación política, sino con la sustancia y forma del conflicto. ${ }^{75}$

La provincialización de los estudios del peronismo, concordantes con los estudios micro que refiere Rein, implica una elección metodológica interesante en la medida en que rompe con la homogeneización de las historias nacionales, pero al mismo tiempo implica reconocer que en el territorio provincial -o local o regional- no se encuentran todas las explicaciones. Estos espacios no son autosuficientes ${ }^{76}$-cabria preguntarse si los espacios nacionales lo son- pero reconocer la escala implica poder trazar las relaciones entre el espacio local, el provincial y el nacional, así como también con el internacional. El estudio los tribunales del trabajo permiten, con los recaudos necesarios, establecer un diálogo por medio de la variación de las escalas.

El problema en el que caen muchas veces los estudios de caso es su desvinculación con las corrientes ideológicas nacionales y la atomización de una realidad que debe ser aprehendida de manera global. La focalización en un contexto reducido puede llevar al empirismo a la hora de analizar la realidad de los trabajadores, y muchas veces dejan de lado el establecimiento de un marco metodológico e ideológico que permita articular los interrogantes, y sus posibles respuestas, con corrientes historiográficas más generales. Se corre el riego, como sostiene Hobsbawm, de acumular datos y fuentes sobre la vida de la clase obrera que se constituya un fin en sí mismo, olvidando el importante paso de realizar las preguntas pertinentes.

\footnotetext{
${ }^{75}$ MELON PIRRO Julio César y QUIROGA Nicolás, "introducción" en MELON PIRRO Julio César y QUIROGA Nicolás (comp.), El peronismo bonaerense. Partido y prácticas políticas, 1946-1955, Edición Suárez, Mar del Plata, 2006.

${ }^{76}$ AELO Oscar H., El peronismo en la provincia de Buenos Aires.1946-1955, Eduntref, Caseros, 2012.
} 
El trabajo de Mirta Lobato sobre los trabajadores berisenses de los frigoríficos logra el equilibrio entre las cuestiones coyunturales propias del territorio en las que se insertan las relaciones sociales de su objeto de estudio y su vínculo con las cuestiones políticas ideológicas más amplias que se desarrollan a nivel nacional e internacional. Es a partir de la vinculación de los trabajadores entre sí y con los otros participantes de la realidad social -con las otras clases sociales- en el ámbito propio donde desarrollan sus actividades (la fábrica), pero en estrecha relación con la comunidad que los rodea que le permite a la autora visualizar la construcción de la clase obrera ${ }^{77}$ en los términos que plantean los marxistas ingleses. Esto le permite colocar el conflicto en un lugar central, pero sin caer en la fetichización del momento de enfrentamiento como única fuente constitutiva de la identidad de clase.

Estudios de los trabajadores, estudios del peronismo y estudios de la justicia coinciden, en sintonía con los cambios en la historiografía, en rehusar las historias nacionales y centrarse en las experiencias locales y regionales.

\section{Metodología y fuentes empleadas}

En la pesquisa se indagaron distintos tipos de fuentes. Las leyes, decretos, reglamentaciones y debates parlamentarios fueron centrales en la reconstrucción del establecimiento institucional del Nuevo Derecho. En el mismo camino se indagaron en torno a los proyectos presentados para la constitución de un Código del Trabajo, consultado aquellos que fueron publicados en diversas publicaciones o incluso -como en el caso del Código de 1904- en los tomos de las obras completas de Joaquín v. González.

La indagación sobre las fuentes editadas fue posterior a los primeros acercamientos a los juicios laborales del Tribunal del Trabajo $\mathrm{N}^{\circ} 1$ de la ciudad de La Plata. Estas causas se resguardan en el Departamento Histórico de la Suprema Corte de Justicia de la provincia de Buenos Aires (en adelante DH). La cantidad de causas que sobrevivieron al paso del tiempo imponen análisis de tipo cualitativo ya que para el período 1948-1955 sólo existen 42 causas, mientras que para el período 1955-1960 si bien se resguardaron mayor cantidad de causas estas aun implican un número restringido, siendo sólo 54 .

\footnotetext{
${ }^{77}$ LOBATO Mirta Zaida, La vida en las fábricas... Op. Cit.
} 
El pequeño número de causas resguardadas equivale aproximadamente al $2 \%$ de las causas del período si consideramos que para el bienio 1949-1950 se inician en el Tribunal del Trabajo $N^{\circ} 1827$ causas $^{78}$. Si bien en la ciudad de La Plata se establecieron dos tribunales para el período, los juicios del Tribunal del Trabajo $\mathrm{N}^{\circ} 2$ aun no han pasado por el proceso de destrucción ${ }^{79}$, por lo que aún permanece inaccesibles para los historiadores. Algo similar ocurre con los libros de sentencia y los libros de entrada de cada tribunal cuyo resguardo también corresponde a cada tribunal, por lo que su acceso es restringido y depende de la buena voluntad de los jueces.

Para el caso del período 1948-1960 las causas consultadas no pasaron por un proceso de selección sino que son simplemente las que sobrevivieron al paso del tiempo. Esto implicó abandonar pretensiones de análisis cuantitativo ya que la muestra de ninguna manera puede ser considerada representativa del universo de causas, aunque su representatividad -como la de otras fuentes judiciales- debe ser puesta en contexto en referencia a las categorías con las que se analice.

Otras fuentes nutrieron también distintas etapas de la investigación: programas de Legislación laboral e industrial, Planes de estudio, designaciones docentes, libros de egresados y nóminas del Poder Judicial de la provincia de Buenos Aires fueron fundamentales para reconstruir las trayectorias de los actores -principalmente jueces y abogados- que actuaron en la justicia del trabajo.

\section{Estructura de la tesis}

La tesis se divide en tres partes que intentan ordenar en forma cronológica el desarrollo de la justicia laboral platense. Pero además responde a cuestiones referidas a las temáticas allí abordadas. La primera parte, La institucionalización de la Justicia del Trabajo, busca dar cuenta de los antecedentes que impactaron en la forma en que se constituyeron los Tribunales del Trabajo en la ciudad de La Plata. Dividida en cuatro capítulos el

\footnotetext{
${ }^{78}$ Boletín Judicial de la provincia de Buenos Aires. Diario de Jurisprudencia, Edición del Martes 7 de Agosto de 1951, Dirección del Boletín Oficial, La Plata, Pp. 564

${ }^{79}$ Así se denomina el proceso por el cual el DH toma posesión del corpus documental. El proceso implica -cuando la cantidad lo amerita- la selección y catalogación de causas para su posterior resguardo y la destrucción (quema) del resto. La destrucción es solicitada por las autoridades del tribunal correspondiente.
} 
objetivo principal es develar la forma en que las respuestas legales a la cuestión social fueron dando forma al surgimiento de un Nuevo Derecho objetivo explícito del capítulo I, "Una nueva rama del Derecho"-, tanto desde la construcción de un corpus legislativo como mediante la constitución de una base doctrinaria propia. La legislación laboral y el debate en torno a las posibilidades de legislar sobre una materia nueva es el objeto del Capítulo II, "La Legislación laboral Argentina y el rumbo del Nuevo Derecho" Esta conformación de una rama del derecho especializada en la relación entre el trabajo y el capital no podía ser contemplada en las instituciones judiciales existentes. Por eso los capítulos III -"El Capital y el Trabajo cara a cara" - y IV "Los Tribunales del Trabajo en la provincia de Buenos Aires"- buscan dejar expuestas los vaivenes del Estado en la conformación de los Tribunales del Trabajo dentro de la órbita judicial, con especial énfasis, en el capítulo $\mathrm{N}^{\circ} 4$, en el desarrollo del debate legislativo de la Ley 5178 que creó la justicia laboral para el ámbito bonaerense.

La segunda parte, Actores y conflictos en la justicia laboral platense durante el peronismo, es un intento de presentar a los actores cuyas interrelaciones construían el cotidiano de los tribunales del trabajo. Siempre bajo la premisa de la construcción relacional de las identidades es histórica se pretende dar cuenta de cómo estas relaciones constituía a los sujetos hacia el interior de una institución como los Tribunales del Trabajo. Consta de dos capítulos. El Capítulo V "Los profesionales" da cuenta de la construcción y la importancia del saber dentro de un espacio jerarquizado como lo son los tribunales. Además intenta describir las disputas y la propia jerarquización interna del campo jurídico laboral. El capítulo VI, titulado "Trabajadores y patrones en la justicia del trabajo", indaga sobre la forma en que las dos partes de la relación laboral constituían su propio lugar y se identificaban de acuerdo al propio vinculo relacional. En tanto que la resolución del conflicto que los vinculaba era el objetivo de la justicia laboral, el recorrido que ambos extremos de la relación de explotación es fundamental para comprender las estrategias que ambas partes adoptaron hacia el interior del fuero.

La tercera parte consta de un solo capítulo - el N VII, "La justicia laboral postperonista. Reorganización y revancha"- responde a los cambios institucionales acaecidos en la justicia laboral platense a partir del 
desplazamiento de los miembros de los Tribunales del Trabajo. Centrado en los conflictos posteriores a 1955, La Justicia del Trabajo ante el orden postperonista, busca dar cuenta de las transformaciones de la institución, pero fundamentalmente sus continuidades, ya que en un contexto distinto al de su nacimiento estas le otorgarán un rol más destacado dentro del esquema de la conflictividad obrera.

Por último se presentan una serie de reflexiones en torno al objeto de estudios que intenta retomar en clave analítica las conclusiones de cada capítulo así como aventurar hipótesis en torno al lugar de la justicia laboral en el entramado institucional dedicados a lidiar con la cuestión obrera y la forma en la que esta institución modificó o no el conflicto. 


\section{PRIMERA PARTE: \\ LA INSTITUCIONALIZACIÓN \\ DE LA JUSTICIA DEL \\ TRABAJO}




\title{
CAPÍTULO I \\ UNA NUEVA RAMA DEL DERECHO
}

\begin{abstract}
Al derecho arcaico, cristalizado en criterios vetustos, debe reemplazar el derecho que trae savia fuerte y que presenta serias garantías para una clase que protesta y afirma
\end{abstract} Alfredo Palacios ${ }^{1}$

\section{Introducción}

El Derecho del Trabajo, más allá de las diferentes denominaciones como se lo conoció, no fue solamente un agregado de leyes referidas al trabajo. Si bien las primeras leyes en torno a la cuestión obrera -tales como la ley de trabajo femenino e infantil y la de accidentes de trabajo- marcaron un profundo hito en el campo, el desarrollo del Derecho del Trabajo implico un cambio profundo en la concepción de las bases del Derecho. El camino recorrido por este campo jurídico modificó la relación entre las esferas antinómicas definitorias del derecho (público o privado) y sus debates formaron parte del clima de época de principios del siglo $\mathrm{XX}$ en el que la tradición privada fue puesta en crisis y no era suficiente para regular las relaciones entre los individuos. Si el contractualismo ya había sido criticado para pensar en el surgimiento del Estado, en la medida en que el vínculo con este es permanente e inderogable, su capacidad de aplicación a la realidad de los vínculos entre individuos también estaba puesta en duda en la medida en que estos aparecían cada vez más desiguales.

Para principios del siglo XX, la crisis en la que estaba sumergiéndose el liberalismo como corriente dominante del pensamiento, tanto en Argentina como así también en América Latina, puso en duda la capacidad no sólo de la economía para lograr sus objetivos, sino que ésta arrastró tras de sí otras bases del liberalismo vernáculo. Los códigos legales, entre los que se encontraba el Código Civil, estaban ya puestos en duda desde la exégesis

\footnotetext{
${ }^{1}$ Palabras del diputado Alfredo Palacios sobre la necesidad de fundar un nuevo derecho al presentar su proyecto de ley de accidentes de trabajo. Cámara de Diputados. Diario de Sesiones, 1908, Tomo I, Pp. 110
} 
legal, sobre todo por la influencia del positivismo ${ }^{2}$ y de una escuela influyente del mismo, el formalismo francés ${ }^{3}$.

El Derecho Civil y la sociedad que representaba ya no eran compatibles con algunos de los desafíos del nuevo siglo entre los que la cuestión social era tal vez el problema central. Ante los problemas que aquejaban a la creciente clase obrera urbana en ciudades como, Buenos Aires, Rosario o mismo -aunque con unos años de retraso- La Plata, algunos pensadores y políticos comenzaron a criticar los límites que el derecho civil tenía para dar cuenta de las nuevas problemáticas. Desde fines del siglo XIX la ciudad de Buenos Aires, y en menor medida otras ciudades pampeanas, habían comenzado un proceso de diversificación económica. Si bien aun el centro de las actividades productivas eran las actividades agrarias, las demandas de productos de la industria había dado nacimiento a pequeños establecimientos en manos de trabajadores cuentapropistas o pequeños empresarios. Esta situación llevó a la complejización del mercado de trabajo, hasta entonces dominado particularmente por trabajadores de escasa calificación y alta movilidad, típico de la producción agropecuaria. ${ }^{4}$ Las ciudades pampeanas, receptoras del flujo migratorio, vieron alterarse su composición y reflejaron los cambios en las relaciones sociales y de producción. El surgimiento y ampliación de los primeros talleres modificaron el paisaje urbano y otorgaron a los obreros

\footnotetext{
2 TAU ANZOÁTEGUI, Víctor, "Pensamiento Jurídico y acción legislativa" en Nueva Historia de la Nación Argentina. Academia Nacional de la Historia, Planeta, Buenos Aires, 2001.

${ }^{3}$ ZIMMERMAN, Eduardo, "La enseñanza jurídica y la conformación del derecho administrativo como "saber de estado" en la Argentina 1900-1930", Mimeo (2009) disponible para su consulta en http://www.saberesdeestado.com.ar/wp-content/uploads/2009/11/eduardo_zimmermann.pdf ${ }^{4}$ Varios trabajos que analizan la conformación del mercado de trabajo dan cuenta de esta movilidad y baja calificación. Con la complejización del trabajo urbano si bien se produjeron importantes cambios en la mano de obra, gran parte de esta siguió ligada al trabajo agrícola y alternaron entre la campaña agrícola y la ciudad. Sobre el mercado de trabajo y su homogeneidad inicial ver SABATO Hilda, "La formación del mercado de trabajo en Buenos Aires, 1850-1880" en Desarrollo Económico, Vol. 24, Nㅜ 96, enero-marzo, Buenos Aires, 1985. SABATO Hilda y ROMERO Luis Alberto, "Artesanos, oficiales, operarios, trabajo calificado en Buenos Aires (1854-1887)" en Anuario Escuela de Historia, No 12 1986-1987, Publicaciones UNR, Rosario, 1987. Con otros objetivos ligados a la posibilidades de organización de los trabajadores rurales, tanto los trabajos de Ascolani como los de Sartelli dan cuenta de la vinculación directa entre la temporalidad laboral del campo y de la ciudad. ASCOLANI Adrián. El sindicalismo rural en la Argentina. De la resistencia clasista a la comunidad organizada (1928 - 1952). Universidad Nacional de Quilmes. Bernal, 2009. SARTELLI Eduardo. "Mecanización y conflicto social en la llanura pampeana: Santa Fe y la huelga de braceros de 1928". SARTELLI, Eduardo. "Rehacer todo lo destruido. Los conflictos obrero-rurales en la década 1927-1937" en ANSALDI Waldo (comp.) Conflictos obrero-rurales pampeanos/3 (1900 - 1937), CEAL, Buenos Aires, 1993.
} 
industriales y los trabajadores del área de servicios mayor proporción demográfica y visibilidad.

Ante la evidencia del cambio, fue presentado en 1904 el proyecto de Código del Trabajo de Joaquín V. González, en ese momento ministro del interior de Julio Roca. El proyecto de González de 1904 se incluía en una corriente más amplia de pensamiento que buscaba superar mediante la legislación ${ }^{5}$, y evitando el agravamiento de los conflictos violentos que se sucedían en torno a la cuestión social, los síntomas no deseados de la modernidad. En la realidad argentina el Código Civil, que había sido sancionado en 1869, respondía a una materialidad en donde el impacto de la moderna vida industrial era aun nulo y el liberalismo era la corriente de pensamiento dominante.

Ochenta años después, en la reforma constitucional de 1949, se agregaría el principio de Justicia Social, que sobrevivió a las reformas impuestas por la convención reformadora de Octubre de 1957 y que se mantiene en la Constitución actual de 1994. Este principio, incorporado en el artículo 14 bis de la Carta Magna, equivale a igualar las condiciones de lucha en que se halla el económicamente más débil respecto de la patronal o parte más acaudalada, poniendo en consideración el interés social sobre el exceso del derecho individual. El objetivo de este capítulo es revisar la trayectoria que llevo desde el predominio del Código Civil como institución fundamental que reglamenta la relación de la esfera privada a la crisis posterior de esa tradición y el surgimiento de una nueva tradición que hizo posible legislar sobre la relación laboral bajo nuevos conceptos. Si bien el desarrollo del Nuevo Derecho no fue lineal sus albores se pueden ubicar en los últimos años del siglo XIX y los primeros años del siglo $X X$ llegando a su cenit -en correspondencia con los intentos de resolución corporativa de la crisis del derecho y del Estado- en los años treinta del siglo pasado.

\footnotetext{
${ }^{5}$ La legislación de carácter social que buscaba superar estos conflictos era un intento diferente, pero en ningún modo ajeno, a los intentos más represivos como la ley de residencia que buscaba expulsar del país a los extranjeros "indeseables" entre los que se incluía a los militantes obreros, sobre todo anarquistas. Vease: ASPELL de YANZI FERREIRA Marcela, "Expulsión de extranjeros. La ley 4144 "de Residencia" y la jurisprudencia de la Suprema Corte de Justicia de la Nación "en Revista de Historia del Derecho, N 15, IIIHD, Buenos Aires, 1987. También SURIANO Juan, Anarquistas. Cultura y politica Libertarias en Buenos Aires. 18901910, Manantial, Buenos Aires, 2001.
} 


\section{I.1 Modernización, la cuestión social y la ciudad de La Plata}

Las condiciones históricas sobre las que se delineó los orígenes de la cuestión social como problemática pública plausible de ser atendida por los diferentes actores resulta por demás importante para comprender el desarrollo que se intentó brindar desde las instituciones estatales. Los impactos de la modernización económica, el proceso de urbanización, el aporte inmigratorio y la conformación de los primeros desafíos disruptivos de una sociedad que se pensaba hasta ese momento como armónica y homogénea son fundamentales para comprender el surgimiento de las respuestas a la problemática de la cuestión social de las cuales los Tribunales del Trabajo fueron parte.

En tanto problemas que podrían llevar a la disolución de la cohesión de la sociedad, o que eran percibidos -en este contexto dotados de sentido- como tales, la cuestión social puede ser abordada en los términos que plantea Robert Castel como "la aporía fundamental en la cual una sociedad experimenta el enigma de su cohesión y trata de conjurar el riesgo de su fractura"6. Fue la respuesta a esta cuestión a principios del siglo XX la que habilitó el surgimiento de todo un entramado de dispositivos institucionales dedicados a promover la integración social.

I.1.1 Cambios en la región pampeana: modernización económica y el mundo del trabajo

Los finales del siglo XIX encontraron una región pampeana plétora de cambios sociales y económicos. Consolidada como región agroexportadora, la bonanza de la macroeconomía fue de la mano con el crecimiento urbano y la diversificación -aun bajo la égida hegemónica del capital agrario- de su economía. Las condiciones del mercado laboral -fuertemente homogéneo, descalificado y móvil $^{7}$ - comenzaron a cambiar a fines del siglo XIX y para principios de siglo encontramos un mosaico de situaciones en donde aun predomina la movilidad, pero en el que se encuentran situaciones heterogéneas producto de una diversificación de las actividades económicas

\footnotetext{
${ }^{6}$ CASTEL Robert, Las Metamorfosis de la cuestión social. Una crónica del salariado, Paidós, Buenos Aires, 2009. Pp. 20

${ }^{7}$ SABATO Hilda y ROMERO Luis Alberto, Op. Cit.
} 
propias de la modernización y la llegada de inmigrantes de ultramar que cambiaron la fisonomía de las ciudades y el mundo del trabajo urbano.

La implantación de un orden político permanente en la década del ochenta del siglo $\mathrm{XIX} \mathrm{X}^{8}$ favoreció el establecimiento de un clima favorable para la actividad económica ${ }^{9}$. La superación de ciertos condicionantes tanto internos como externos fueron fundamentales en el establecimiento de las bases de la era del progreso agroexportador. Estos procesos fueron acompañados por la llegada de mano de obra inmigrante que le otorgó al mercado laboral características propias, con altos grados de movilidad territorial que incluía el movimiento de contingentes de trabajadores estacionales atraídos por los altos precios pagados en la campaña pampeana pero con pocas posibilidades de acceder a la propiedad de la tierra en el corto plazo. Gran parte de esta población inmigrante se estableció en las pujantes ciudades y pueblos de la región pampeana -fundamentalmente en Buenos Aires y Rosario, pero el crecimiento urbano es observable en todos los asentamientos de la regiónestableciendo las bases de un proceso urbanizador que, aun con sus dificultades, sería ya irreversible. El asentamiento de estos inmigrantes en las ciudades encontró dificultades en la poca oferta de habitaciones en condiciones y creó serios problemas en torno al acceso a la vivienda y las condiciones higiénicas que reforzaron muchas veces la imagen negativa que pesaba sobre algunas nacionalidades. La visibilidad de la pobreza y los problemas de salubridad que iban ligados a ella llamó la atención sobre lo que ocurría en los márgenes de las grandes ciudades, donde el problema era más evidente.

La presencia en estos lugares de la representación de la miseria llamó la atención sobre la problemática. La marginalidad fue rápidamente asociada a las prácticas reñidas con la moral, el surgimiento de malos hábitos, lugar de la delincuencia y el centro de los focos infecciosos ${ }^{10}$. Este panorama justificaba

\footnotetext{
${ }^{8}$ Se toma aquí la periodización ya clásica sobre el estado argentino de OZLAK Oscar, La formación del Estado Argentino. Orden y progreso y organización nacional, Buenos Aires, Ariel, 1997.

${ }^{9}$ El impacto del ordenamiento institucional en la economía en FERRER, Aldo, "Factores condicionantes y expansión agropecuaria", en La economía argentina. Desde sus orígenes hasta principios del siglo XXI, FCE, Buenos Aires, 2004.

${ }^{10}$ La cuestión de la salud pública fue importante en la búsqueda de soluciones a la problemática habitacional, sobre todo en la ciudad de Buenos Aires ante sucesivas epidemias que afectaban también a barrios tradicionales de la ciudad. La búsqueda de soluciones fue de la mano con el proceso de profesionalización médica y una mayor presencia de los médicos en el debate público. Ver ARMUS Diego, "Consenso, conflicto y liderazgo en la lucha contra la
} 
las ideas de desintegración social y el temor de las clases dominantes sobre la situación producida por la pauperización de las condiciones de vida.

Pero no todos los impactos de la modernización iniciada circa 1860 fueron negativos. El aumento de la población urbana favoreció los cambios a nivel de consumo que proporcionaron los primeros impulsos a la industrialización, generando cambios en los tamaños y la organización interna de los establecimientos, pasando de los talleres artesanales de explotación familiar a establecimientos más grandes con uso de tecnología y división interna del trabajo $^{11}$. Los avances en términos del transporte favorecieron el crecimiento horizontal de los asentamientos urbanos y las mejoras en las técnicas de construcción permitieron su crecimiento vertical, dando al menos algunas respuestas al crecimiento poblacional. La extensión del sistema de educación pública, sobre todo en el nivel primario, propendió a la integración social mediante la socialización de los niños y la inclusión de los cada vez más numerosos inmigrantes.

\section{I.1.2 Libertad de trabajo y cuestión social}

Todos estos cambios en la Argentina del progreso redundó y fue producto del asentamiento de las ideas liberales que gran parte de la elite política venía sosteniendo desde mediados del siglo XIX y sobre el que se fundó el edificio institucional de la nación. El establecimiento de este orden liberal no encontró la resistencia de gremios artesanales o con actores vinculados a la organización del trabajo. La libertad de trabajo en este contexto no estaba amenazada por la existencia de estatutos reguladores y regían para las relaciones laborales las normas liberales. La existencia de un mercado de trabajo libre, en el que se asumía que concurrian, también libremente, el capital y el trabajo es la pauta que marca el predominio de la existencia plena de las relaciones capitalistas de producción ${ }^{12}$. El trabajo era una mercancía que como

tuberculosis. Buenos Aires 1870-1950" y GONZÁLEZ LEANDRI Ricardo, "Notas acerca de la profesionalización médica en Bueno Aires durante la segunda mitad del siglo XIX" ambos en SURIANO Juan (comp), La Cuestión Social en Argentina, 1870-1943, La Colmena, Buenos Aires, 2000.

${ }^{11}$ SCHVARZER Jorge, La industria que supimos conseguir. Una historia politico-social de la industria argentina, Planeta, Buenos Aires, 1996.

${ }^{12}$ LOBATO Mirta Zaida, Los trabajadores en... Op. Cit. 
el resto de las mercancías debía garantizarse su libre circulación a fin de generar riqueza. En ese contexto,

el Estado nada más debía fomentar esa capacidad laboral de la población. De allí que la idea dominante en este período fue la del libre acceso al trabajo y con ello se vinculaba la respuesta a la cuestión social durante el predominio de la visión liberal (al menos en sus comienzos) ${ }^{13}$

Este ideal en el cual el trabajador es portador de una riqueza potencial su fuerza de trabajo- lleva implícito la idea de que aquél que no desarrolla su potencialidad es porque no quiere. La figura del vago y mal entretenido, nacida al calor de la necesidad de empleo estacional en las actividades agrícolas ya a principios del siglo XIX, se reajustó a la realidad urbana y adquirió nuevos bríos. El trabajo se presentó así como un regenerador moral de los hombres y fue el centro de la conformación de nuevos modelos penitenciarios ${ }^{14}$. El estado debía intervenir, pero para garantizar que ese trabajo disponible fuese ofrecido en el mercado de trabajo, es decir, que se garantizara la provisión de trabajo libre a fin de explorar las potencialidades de la riqueza nacional. A pesar de la llegada masiva de inmigrantes, aun después de la crisis de 1890, que proveía el mercado laboral con nuevas manos de manera constante el pedido de mano de obra libre se mantuvo presente por parte de las asociaciones patronales.

Este modelo encontraría sus límites rápidamente en la organización y la ideología proveniente justamente de los actores implicados desde los últimos años del siglo XIX y los primeros y convulsionados años del siglo $X X$. La libertad del trabajo no era percibida por los mismos trabajadores como la garantía del acceso a la riqueza prometida, sino como producto de la injusticia fundante de la relación -la explotación- y desprotección a la que estaban sometidos. Los pedidos de intervención sobre el mercado de trabajo para garantizar su libertad, entonces, durante los años previos a la primera guerra mundial, no pasaba tanto por las asociaciones obreras, sino por los patrones. De hecho el conflicto por el control del reclutamiento de la mano de obra fue uno de los principales puntos de disputa entre las asociaciones de patrones y

\footnotetext{
${ }^{13}$ SURIANO Juan, "Introducción: Una aproximación a la definición de la cuestión social en Argentina" en SURIANO Juan (comp.), La Cuestión Social en Argentina, 1870-1943, La Colmena, Buenos Aires, 2000, Pp.7

${ }^{14}$ SALVATORE Ricardo, "Criminología positivista, reforma de prisiones y lla cuestión social/obrera en Argentina" en SURIANO Juan (comp.), La Cuestión Social en Argentina, 1870-1943, La Colmena, Buenos Aires, 2000.
} 
las asociaciones de trabajadores que actuaron esos años. Lo central de esta disputa derivaba en gran parte del

hecho de que estaba vinculada con la cuestión del reconocimiento del derecho de los sindicatos por parte de los patrones y en consecuencia con el eventual establecimiento de relaciones cotidianas de negociación entre las dos partes ${ }^{15}$

Entablar esas negociaciones era reconocer de hecho la potestad de los sindicatos en la organización del trabajo. Los conflictos que el no reconocimiento de los sindicatos -y por lo tanto la negación de su capacidad de determinar el origen de la mano de obra- generaba entre patrones y asociaciones obreras tuvo dos posibles salidas: la aceptación tácita de la presencia sindical cuando la correlación de fuerzas le era favorable, o su negación mediante la capacidad de la patronal de lograr o el apoyo de otro de los actores enemigos de la intervención sindical en la contratación de la mano de obra, las agencias privadas de colocación, o de lograr el apoyo de algún funcionario estatal dispuesto a inclinar la balanza a favor del patrón.

I.1.3 La Ciudad de La Plata: hija de la modernización y respuesta a la cuestión social

Estas condiciones descriptas de pauperismo y desintegración social no eran aplicables a todos los centros urbanos de la zona pampeana, sino que respondían sobre todo a la realidad cotidiana de Buenos Aires y Rosario. De ninguna manera eran estas condiciones las imperantes en la ciudad de La Plata a principios del siglo XX. Si bien existían barriadas obreras, estas estaban confinadas a barrios por fuera del casco urbano. El barrio de las mil casas primer barrio obrero de argentina- se ubicaba en las proximidades de la estación ferroviaria de Tolosa ${ }^{16}$; Berisso crecía al ritmo de los saladeros desde 1871 y de los frigoríficos a partir de 1904 a casi 9 Km del centro de la ciudad; Ensenada vivía un proceso similar ligado al puerto a la misma distancia. La problemática de la pauperización no era aun tan visible ni siquiera en los

\footnotetext{
${ }^{15}$ FALCÓN Ricardo, El mundo del trabajo urbano (1890-1914), CEAL, Buenos Aires, 1986. Pp. 68

${ }^{16}$ El barrio de las mil casas era habitado predominantemente por trabajadores ligados al ferrocarril, tanto del servicio de línea como en los talleres que se instalaron en la localidad. Aun se mantienen parte de las fachadas en las manzanas comprendidas entre las calles 3, 4, 522 a 524
} 
márgenes de la ciudad o en la zona de los mataderos y frigoríficos. En el caso platense la cuestión social no daba muestras aun de su carácter disruptivo del orden, pero algunas condiciones de esta novel ciudad justificaban el interés sobre el problema.

Su propio nacimiento como entramado urbano estuvo vinculado a la necesidad de crear una ciudad donde lo imperante fuese el orden y en el que la ciencia debía jugar un rol preponderante a fin de garantizar el progreso.

La Plata surgió por un artificio de la razón, por una necesidad de la inteligencia. Hubo en su origen, es cierto, un motivo político ocasional: la urgencia de darle una nueva capital a la provincia de Buenos Aires. Pero el motivo político no hubiese bastado por sí mismo para determinar y justificar la creación desde la nada de una ciudad en grande, si no se hubiese aliado a él la necesidad utópica y el afán de novedades absolutas que como hombres modernos empezaron a sentir los argentinos después de Caseros. ${ }^{17}$

Su fundación como expresión de la resolución de un problema irresuelto con el triunfo de las fuerzas del Estado nacional por sobre la provincia de Buenos Aires - la acefalia del estado más importante de la federación- buscaba más que dar a la provincia una capital. Era la demostración de la etapa de modernización en la que se encontraba la argentina y que era así percibida por su elite, era la idea de imponer el arte y la ciencia por sobre la naturaleza. Tanto era el afán de racionalización que perseguían sus creadores que ni siquiera se contempló el terreno donde debía emplazarse la nueva ciudad siendo, según Gustavo Vallejos, una verdadera paradoja que terminaran a escasos kilómetros de los saladeros y mataderos de Berisso ${ }^{18}$. Esto así porque el desplazamiento de esas actividades a $60 \mathrm{~km}$ de la ciudad de Buenos Aires respondió a la necesidad de apartar lo que era considerado como un foco infeccioso por los médicos higienistas ${ }^{19}$, cada vez más preponderantes en política. Y justamente la ciudad de La Plata, fue establecida en las Lomas de la Ensenada de Barragán, en las cercanías donde antes habían sido desplazadas las actividades infecciosas. En definitiva los primeros impactos de la cuestión social en su vertiente higienista fue causa directa de la traza misma de la

\footnotetext{
${ }^{17}$ SANCHEZ REULET Aníbal, "Historia y presentación de la ciudad" en La Plata a su fundador, Ediciones de la Municipalidad, La Plata, 1939. Pp. 26.

${ }_{18}$ VALLEJO Gustavo, Escenarios de la cultura científica argentina. Ciudad y Universidad (1882-1955), Consejo Superior de Investigaciones Científicas, Madrid, 2007.

19 En 1887, Emilio Coni presenta en la ciudad de París a la ciudad de La Plata como una ciudad Higiénica en un congreso internacional. VALLEJO Gustavo, Ibídem. Sobre la preponderancia de los médicos higienistas ver los trabajos de Salvatore y Armus ya citados.
} 
ciudad, tal como se puede observar en la imagen $\mathrm{N}^{\circ} 1$, poniendo en evidencia un rasgo, una marca de origen de la ciudad: su carácter previsor.

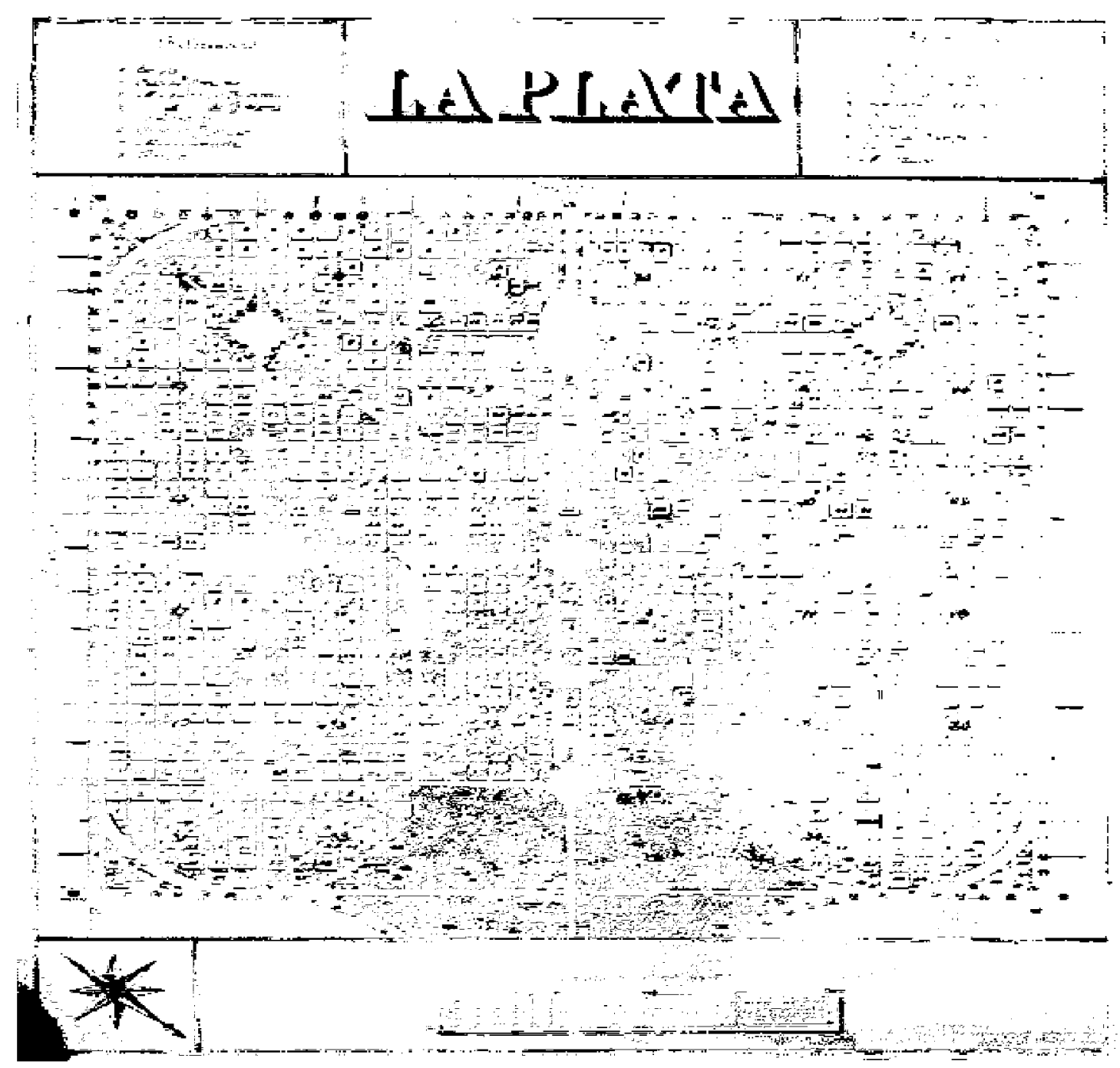

Imagen $\mathbf{N}^{*} \mathbf{1}$. Plano de la ciudad entregado a los asistentes al acto de colocación de la piedra fundamental el 19 de Noviembre de 1882. Fuente: MOROSI, Julio et. Al, La Plata, ciudad nueva, ciudad antigua. Historia, Forma y Estructura de un espacio urbano singular IEAL-UNLP, Madrid-La Plata, 1983.

Estas características de la ciudad de La Plata parecen acercarse a otra interpretación de la Cuestión Social en donde el eje no está puesto tanto en la visibilización del problema por parte de los actores implicados, sino como problema discursivo $o$ al menos como problemática de características intelectuales plausible de ser solucionado mediante medidas previsoras. La ciudad y su existencia parecen vehiculizar el argumento de Eduardo Zimmermann ya que su fundación fue consecuencia de la voluntad de parte de 
la elite de crear una ciudad que ejemplificara el avance modernizador en la Argentina y que estuviese exceptuada de los problemas que el crecimiento urbano presentaba en otras ciudades pampeanas. Además los actores implicados en su fundación y proyección pertenecían muchos de ellos a esa fracción de la elite que Zimmermann conceptualiza como liberales reformistas se debe tener en cuenta que la "refundación" de la ciudad fue de la mano del proyecto universitario de Joaquín González-. ${ }^{20}$

Lo mismo puede decirse del trazado en términos de posibles levantamientos insurrecionales. Si bien en este punto las previsiones iniciales buscaban impedir el levantamiento de una facción de la elite que aun sostenía la autonomía de Buenos Aires -recordemos que el último levantamiento bajo esta bandera en la que fue derrotado Tejedor fue el punta pie inicial de la voluntad de crear la ciudad de La Plata en la medida en que la inversión de la balanza de poder en la ciudad de Buenos Aires había constituido a las autoridades provinciales como huéspedes de las autoridades nacionales ${ }^{21}$ - su trazado con anchas y rectas calles respondían también a las experiencias europeas de levantamientos de republicanos radicales y obreros. Si las respuestas de parte de la elite porteña a la naciente cuestión social respondía más a la realidad europea que al estudio de las condiciones reales ${ }^{22}$ de las ciudades pampeanas, la ciudad de La Plata puede ser considerada el epitome en la medida en que su proyección fue producto de los temores ante futuros inconvenientes que planteaba la cuestión social más que resultado o consecuencia de esos mismos problemas.

De todas maneras algunas de estas condiciones serían evidentes a partir de los últimos años de la década del diez del siglo $X X$, cuando la ciudad fue adquiriendo un paisaje que distaba de aquella sucesión de edificios públicos dispersos en el damero dibujado en la llanura. La presencia de trabajadores en la ciudad de La Plata fue condición sine qua non para su propia construcción que requirió de grandes contingentes de mano de obra para levantar los fastuosos edificios públicos y las primeras casas de la ciudad. Sin embargo

\footnotetext{
20 ZIMMERMANN Eduardo, Los liberales reformistas. La cuestión social en la Argentina, Buenos Aires, Sudamericana-Universidad de San Andrés, 1995.

${ }^{21}$ BARBA Fernando Enrique, La Plata origenes y fundación: La cuestión capital de la República y la fundación de la capital de la provincia de Buenos Aires, La Plata, 1995.

${ }^{2}$ SALVATORE Ricardo, Criminología positivista... Op. Cit. Pp. 155 y sig.
} 
estos no aparecen en las crónicas de la ciudad sino como buscadores de oportunidades en una ciudad que se vanagloriaba de atraer a mil habitantes nuevos cada mes y la construcción del doble de casas por año. La ciudad era así presentada como una meca para el trabajo como rezaba una copla popular rescatada en ocasión del cincuentenario de la fundación de la ciudad:

$$
\begin{gathered}
\text { Me voy para La Plata, } \\
\text { la nueva capital, } \\
\text { donde se gana mucho } \\
\text { con poco trabajar. }{ }^{23}
\end{gathered}
$$

En los tres primeros años la ciudad ya contaba con 40.000 habitantes y aunque la crisis de 1890 impactó de lleno en el crecimiento, este se volvió a producir a partir de la nacionalización de la Universidad y la idea de crear en la ciudad de La Plata un espacio privilegiado para los estudiantes universitarios en donde se pudiese formar la elite argentina aislada de los problemas que la atracción de la gran ciudad generaba entre los jóvenes. Este plan fue concebido por Joaquín González en lo que se conoció como la segunda fundación de la ciudad. Junto con la administración pública dieron a la ciudad su fisonomía hasta al menos fines de la década del diez del siglo pasado cuando pequeñas industrias y el comercio dieron muestras de mayor activación. Las grandes industrias siguieron estando a los márgenes, y si bien La Plata no era una ciudad industrial, su economía se nutría del movimiento de los frigoríficos berissenses, el puerto, la destilería y los talleres navales de Ensenada y los talleres ferroviarios de Tolosa con su barrio obrero contiguo: las mil casas inauguradas en 1882 y que albergó a los obreros de la construcción de la ciudad y de la fábrica de ladrillos Ctibor (ver imagen $\left.\mathrm{N}^{\circ} 2\right)^{24}$.

En los años de la fundación los establecimientos industriales eran cercanos a 180, para 1939 eran ya 624 y ocupaban, según el intendente de ese entonces Luis María Berro, 18.638 obreros $^{25}$. Este crecimiento de la ciudad se expresaba también en la cantidad de habitantes, llegando a 230.000 habitantes a fines de la década del treinta. Producto no solo de la expansión de

\footnotetext{
${ }^{23}$ Copla popular citada en SANCHEZ REULET Anibal, Op. Cit. Pp38

${ }^{24}$ La celeridad con que se levantó el barrio, la llegada de sus primeros habitantes y su vaciamiento temporario con el traslado de los talleres del ferrocarril en 1905 llevó a que en torno a las mil casas se contaran múltiples historias. TARRUELA Ramón, Mitos y Leyendas de La Plata, La Comuna, La Plata, 2006.

${ }^{25}$ BERRO Luis María, "Prólogo" en La Plata a su fundador, Ediciones de la Municipalidad, La Plata, 1939.
} 
las industrias sino también la expansión del empleo público -principalmente provincial, pero también municipal- y el atractivo de la Universidad.

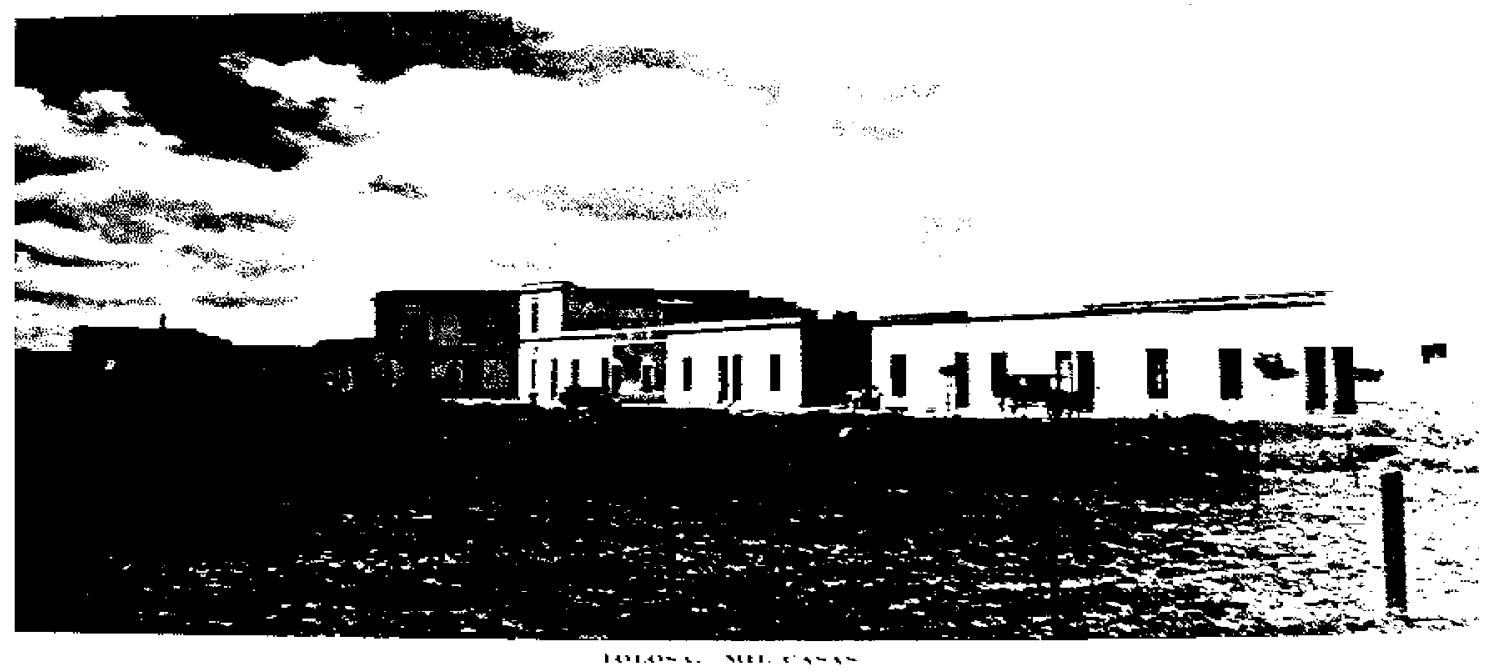

Imagen N²: Barrio de las mil casas circo 1935. Conjunto de 216 viviendas ocupadas por obreros de la construcción y ferroviarios. Actualmente ocupa las manzanas comprendidas entre las calles 3, 4, 522 y 524. Debido al trazado previo de este barrio al de la ciudad de La Plata sus cuadras son más pequeñas y cuentan con varias calles bis.

Fuente: La Plata a su fundador, Ediciones de la Municipalidad, La Plata, 1939.

En definitiva la ciudad de La Plata fue un reflejo directo de la modernización de la economía y la sociedad argentina de fines del siglo XIX y su trazado y concepción estuvo fuertemente ligado a la naciente cuestión social. Aunque la problemática obrera no estaba aun en el centro de dicho entramado de ideas y prácticas que configuraron la cuestión social en Argentina, las ideas del higienismo como respuesta a la epidemia de fiebre amarilla de 1871 dieron lugar a la disposición física de la ciudad higiénica. En tanto también producto de la imposición del orden y la razón por sobre la naturaleza, su decadencia ligada a la crisis de 1890 fue resuelta mediante el asentamiento de la Universidad Nacional de La Plata en 1905 de la mano del proyecto de Joaquín González. El proyecto de Universidad propuesto responde al mismo lineamiento ideológico que el proyecto de Código de Trabajo presentado el año anterior en el Congreso de la Nación por el mismo González. Se trata de una conjunción de medidas preventivas en torno a una problemática que aun no es parte de la realidad cotidiana de la ciudad de La Plata, pero que se prevé en tanto y en cuanto la realidad a la que responde es la realidad industrializada europea a la que se apunta llegar. La ciudad buscaba en su entramado físico el bienestar y el disfrute en sus anchas alamedas y sus 
amplios espacios públicos, al tiempo que su disposición facilitaba el trabajo de las fuerzas del orden en caso de tumultos.

\section{I.2 La Primera Guerra Mundial y el avance de la legislación laboral}

En el ámbito internacional, las diversas crisis $^{26}$ que derivaron en la Primera Guerra Mundial (1914/1918) continuaban aun latentes. Esto llevo a que al momento de fijar las condiciones de la paz después de la Primera Guerra Mundial se diese forma a la primera institución internacional que buscaba conciliar los intereses de los trabajadores y los empresarios y mejorar el trato de estos últimos a sus obreros. La creación de la Organización Internacional del Trabajo (OIT) junto con la Sociedad de las Naciones al finalizar dicha guerra, fue la cristalización de la preocupación en torno a la solución de las contradicciones que la producción industrial capitalista generaba en los más diversos países. La firma de adhesión a las convenciones de la OIT por parte de las autoridades nacionales fue otro de los factores que impulsó el desarrollo del Derecho del Trabajo como rama autónoma. Argentina adhirió a la OIT el 28 de Junio de 1919 y, a pesar de no haber estado entre los primeros, se lo considera aun hasta hoy miembro fundador ${ }^{27}$.

Sin lugar a dudas la Revolución Rusa en 1917 y el creciente poder de la clase obrera organizada sindical y políticamente fundamentaron la necesidad de incluir un título correspondiente al Trabajo en los tratados de paz que pusieron fin a la Primera Guerra Mundial ${ }^{28}$. Los objetivos declarados de la OIT fueron los de lograr mejoras en "las condiciones de trabajo que implican para un gran número de personas la injusticia, la miseria y las privaciones, lo cual engendra tal descontento que la paz y la armonía universales están en peligro" 29 . Con eje en la Justicia Social la OIT se propuso que los estados miembros llevasen adelante una serie de medidas tendientes a institucionalizar

\footnotetext{
${ }^{26}$ Según Hobsbawn, a diferencia de lo que ocurriría con la Segunda Guerra Mundial, en el caso de la Primera es difícil priorizar solo una de las variables que se han expuesto como causantes. HOBSBAWM, Eric, Historia del Siglo XX, Crítica, Buenos Aires, 1998.

${ }^{27}$ Véase una breve reseña de la OIT en su página. En la misma también pueden consultarse algunos documentos claves de su historia. http://www.ilo.org/ilolex/spanish/mstatess.htm

${ }^{28}$ El fin de la Primera Guerra Mundial produjo una serie de tratados de paz conocidos globalmente como Tratado de Versalles. Las cuestiones referidas al trabajo y a la organización de la OIT se encuentran bajo la Parte XIII del Tratado de Versalles, Parte XIII del Tratado de Saint-Germain, Parte XIII del Tratado de Trianón, y parte XII del Tratado de Neuilly.

${ }_{29}$ Organización Internacional del Trabajo, Claúsulas de los Tratados de Paz relativas al Trabajo, Oficina Internacional del Trabajo, Ginebra, 1929. Pp. 3.
} 
el reclamo obrero e impedir de algún modo que la pauperización de sus condiciones de trabajo y la organización de los trabajadores se tradujese en situaciones revolucionarias.

Las reuniones anuales que celebraba la OIT eran el momento óptimo para realizar análisis sobre la legislación argentina en una perspectiva comparada y habilitaba, además la potencialización de los sectores políticos que tendían al reformismo dentro de la escena nacional. Siendo la organización misma promotora de proyectos legislativos, también servían las Conferencias como una usina de ideas donde se discutía no sólo proyectos para los países centrales con una mayor tradición industrial sino que se contemplaban las condiciones específicas de cada miembro ${ }^{30}$.

Las Conferencias eran también espacio de disputas entre los actores participantes, como fue la II Conferencia, realizada en la ciudad de Génova en 1920 , y que se abocó al estudio de la cuestión del trabajo marítimo ${ }^{31}$. En un contexto de conflicto en el país por la huelga parcial de marítimos a la compañía naviera Mihanovich, la participación en la Conferencia de delegados de la patronal, del sindicato y del gobierno transformó el espacio en un lugar de disputa y negociación ${ }^{32}$

La realización de la Conferencia Internacional del Trabajo impulsada por la OIT en Washington en 1919 fue también significativa por los delegados que asistieron a ella como representantes argentinos. Implicó su realización un impulso significativo para el grupo de académicos que seguían con atención el desarrollo de la legislación laboral. Argentina envió una delegación a la capital norteamericana donde participarían dos de las figuras más representativas del Nuevo Derecho, Leónidas Anastasi -jefe de la delegación y reconocido abogado del ámbito porteño, fundador de varias revistas especializadas- y Alejandro Unsain -miembro del Departamento Nacional del Trabajo y autor de varios artículos referidos a la legislación laboral del que ya he dado cuenta-. La

\footnotetext{
${ }^{30}$ Es interesante resaltar que todos los países latinoamericanos formaron parte de la OIT desde sus comienzos, aunque la participación en sus conferencias marca algunas diferencias entre ellos. Argentina, por caso, participó de casi todas las conferencias (principalmente las dos primeras, en Washington en 1919 y en Ginebra en 1920). www.ilo.org

${ }^{31}$ El trabajo marítimo había sido explícitamente excluido de la I Conferencia por la oposición sobre todo de Gran Bretaña, país que poseía al momento una de las mayores flotas del mundo.

32 CARUSO Laura, "Estado, armadores y clase obrera en la Argentina de entreguerras: la Segunda Conferencia de la OIT sobre trabajo marítimo (1920)", Anuario IEHS, №26, Tandil, en prensa.
} 
participación de la delegación argentina, además de atraer a Anastasi a las filas de los impulsadores del derecho laboral, pondría en contacto con dirigentes obreros y especialistas de derecho laboral de otros países con diferentes grados de avance de la legislación del trabajo, impulsándolos a pensar en renovar la legislación argentina desde su exégesis misma.

La figura de Alejandro Unsain destaca en este caso ya que no sólo fue el encargado de redactar el informe sobre la reunión que fue publicado por el DNT, sino que lo convirtió en un nexo permanente entre la OIT y el gobierno argentino.

La conferencia tuvo lugar entre el 29 de octubre y el 29 de noviembre del año 1919 y asistieron por Argentina, además de los ya mencionados Dres. Anastasi y Unsain, el Dr. Felipe Espil, Hermenegildo Pini -representante patronal-, Américo J. Baliño -representante obrero, secretario gerente del gremio La Fraternidad-, y Alejandro Joseph Hayes quien acompaño la delegación con el mismo propósito que Unsain siendo un asesor técnico. El objetivo de la Conferencia era el de dotar de una legislación inspirada en los mismos principios a todos los trabajadores del mundo. Aunque su acción no hubiese alcanzado tal objetivo, su realización implicó un fuerte impulso ya que doto de legitimidad a los actores locales que propugnaban por el desarrollo del derecho del trabajo en la Argentina, así como en otros países con menor tradición industrial que los países europeos o Estados Unidos.

La realización de conferencias internacionales del trabajo o la existencia de instituciones internacionales -e internacionalistas- en torno a los trabajadores y al trabajo no eran un fenómeno exclusivo de la primera post guerra, sino que ya habían logrado cierto desarrollo desde fines del siglo XIX, sobre todo en los países europeos. Lo novedoso era que esta conferencia se daba en el marco del surgimiento de una nueva organización internacional que buscaba la resolución de los conflictos entre las naciones por medios pacíficos, como lo era la Sociedad de Naciones y que otorgaba a países no europeos con la excepción de Estados Unidos y Japón- cierto lugar en el concierto de naciones.

La agenda de la conferencia no fue radical, y según Unsain, encargado de realizar el informe, esto garantizó el éxito de la misma. Los temas abordados permitieron vincular a países con mayor desarrollo industrial con aquellos que 
aun contaban con una industria incipiente. Temas como la duración de la jornada de trabajo -eje de la conferencia y al que se le dedicaron los mayores esfuerzos-, el trabajo nocturno de niños y mujeres, protección de la maternidad obrera y los trabajos insalubres, fueron tratados por comisiones de trabajo que redactaron las convenciones que serían propuestas por la OIT.

La delegación argentina tuvo un rol importante ya que fue el único país latinoamericano en ser incluido dentro del Consejo de Administración de la $\mathrm{OIT}^{33}$. Su elección se debió a varios motivos. La presencia de la comitiva íntegra le garantizó cierto respaldo entre los latinoamericanos, sobre todo porque la mayoría de los países presentaron delegaciones incompletas. Su elevado desarrollo industrial al momento de la realización de la conferencia fue otro de los motivos.

La actuación de la delegación, según se desprende del informe redactado por el Dr. Unsain fue importante en la comisión dedicada al estudio de soluciones al paro obrero, flagelo que ya estaba azotando a países europeos por las interrupciones de la guerra y que era estacional en varios países dedicados a la actividad agropecuaria. La delegación argentina fue la que elevó el escrito que terminaría siendo la base de la resolución de la conferencia con respecto a este tema y esta participación supo generar simpatías entre los participantes de la misma.

Interesa aquí rescatar la propuesta que la delegación argentina tuvo para la organización de la próxima conferencia -propuestas que finalmente quedaron descartadas al abocarse la conferencia del año siguiente realizada en Génova al trabajo marítimo-. En sintonía con el contexto nacional argentino -que discutiría en los años posteriores propuestas como la presentada en Washington- la delegación argentina presento una carta de deseos en donde proponía que la conferencia siguiente tratara:

$1^{\circ}$ un sistema legal que permita:

a)Prevenir las huelgas; $y$

b) Solucionarlas por medio del arbitraje cuando los esfuerzos de prevención no hayan dado el resultado esperado.

\footnotetext{
${ }^{33}$ El Consejo de Administración quedo conformado por las siguientes naciones además de Argentina: Bélgica, Francia, Gran Bretaña, Italia, Japón, Alemania, Suiza, España, Canadá, Polonia y EEUU (lugar que fue ocupado interinamente por Dinamarca hasta que el congreso norteamericano aprobase su ingreso en la sociedad de naciones). "Argentina en el governing body", BDNT N45 Febrero de 1920, Imprenta F. Roig e hijo, Buenos Aires, 1920.
} 
$2^{\circ}$ un sistema que tienda a crear tribunales industriales con jurisdicción exclusiva:

a) En todos los juicios y cuestiones relativas al contrato de trabajo; y

b) en la aplicación de las multas y penalidades que las leyes de cada país señalan para los infractores de las leyes obreras.

Estos tribunales deberán obrar:

a) gratuitamente para los obreros; y

b) con procedimiento rápido y sumario.

$3^{\circ}$ Un sistema legal que proteja el salario de los obreros declarando:

a) Su inembargabilidad;

b) La prohibición de abonarlo en otra forma que en moneda legal; y

c) La fijación de que su pago se hará en períodos no mayores que una quincena

$4^{\circ}$ Un sistema legal que reglamente el trabajo a domicilio sin distinción de sexo y en base a fijación de un salario mínimo legal por comisiones mixtas de patrones y obreros.

$5^{\circ}$ Un sistema legal de interrupción de la jornada de trabajo en base del descanso hebdomadario y en cuanto ello sea posible.

a) el descanso sea en domingo; y

b) Sea absoluto y comprenda 24 horas consecutivas.

$6^{\circ}$ Un sistema legal de indemnización de accidentes del trabajo que reconozca:

a) Que su costo legal recaiga sobre los patrones;

b) Que las enfermedades profesionales queden equiparadas a los accidentes de trabajo; y

c) Que los obreros queden garantidos en los casos de insolvencia patronal.

$7^{\circ}$ un sistema legal que reglamente las condiciones del trabajo en las fábricas, talleres y otros lugares con el propósito:

a) De proteger la seguridad de los obreros, previniendo los accidentes de trabajo; $y$

b) De proteger la salud de los mismos evitando los peligros de los venenos industriales y en conformidad con las conclusiones de la higiene industrial ${ }^{34}$

Esta propuesta implicaba la promoción de medidas en el seno de la OIT que aun no habían sido puestas en práctica en la Argentina. De hecho muchas de las propuestas, si bien ya habían formado parte de algunos proyectos legislativos tempranamente abandonados, marcarían la agenda de los años posteriores a la Conferencia de Washington y algunos, como el caso de los Tribunales del Trabajo, necesitarían aun de más de veinte años para poder ser llevados a la práctica. Esta pretensión de la delegación argentina se puede explicar por el impulso que actores como Unsain sabían daría la aprobación de cuestiones como la propuesta en una institución internacional al desarrollo domestico de las disputas. En sus enfrentamientos con otros actores de la realidad argentina la posibilidad de citar resoluciones extranjeras -sobre todo provenientes de una institución que empezaba a acumular prestigio como la

\footnotetext{
34 "Actuación de la delegación argentina", BDNT N 45 Febrero de 1920, Imprenta F. Roig e hijo, Buenos Aires, 1920. Pp. 207 y sig.
} 
OIT- podía ser de gran utilidad a la hora de disputar a los pioneros del derecho laboral argentino. Así lo hacía saber el mismo Unsain cuando en las conclusiones generales de su informe aseguraba que "para la república Argentina, el primer resultado práctico de la Conferencia significará un aumento en su legislación obrera vigente, bastante importante, por cierto"35.

Así la realización de encuentros internacionales abocados a la legislación laboral dieron un fuerte impulso al derecho laboral argentino. Ya sea mediante la presencia de los especialistas más destacados de nuestro país, como por medio de la influencia que las determinaciones de una entidad extranjera podía tener sobre la disputa local en torno a estas cuestiones. Otro impacto significativo que estas reuniones tenían en el ámbito local era por medio de la influencia en los medios académicos. La innovación producida por la incorporación del estudio del derecho comparado fue muy importante en el caso del derecho del trabajo. Ya quedó expuesto como la reacción a la cuestión social fue en parte una ante hechos que en realidad acontecian en Europa -sobre todo en las primeras manifestaciones del temor por parte de las elites-. La planificación de la ciudad de La Plata respondía a este modelo de la preeminencia de los estudios de la realidad europea. El derecho comparado que será analizado al momento de abordar los cambios en la enseñanza del derecho en la Universidad Nacional de La Plata y el sistema universitariocontaba también con un espacio dentro de la publicación del DNT y los antecedentes de otros países formaban parte de los proyectos legislativos que esta institución estatal enviaba al Poder ejecutivo para su aprobación y envio al Congreso de la Nación.

\section{I.3 Un espacio de innovación: el Departamento Nacional del Trabajo}

El Departamento Nacional del Trabajo (DNT) nació de la mano del debate del presupuesto del año 1907. Su inclusión en la agenda legislativa fue de manera poco ortodoxa y no siguió los canales institucionales preestablecidos en la medida en que no fue parte de un proyecto particular, sino que se lo propuso a partir de una modificación a la ley de presupuesto.

\footnotetext{
35 "Conclusiones generales", BDNT N45 Febrero de 1920, Imprenta F. Roig e hijo, Buenos
} Aires, 1920. Pp. 269 
El accidentado debate dejaba claro que el diputado Roca (se trata del diputado por la provincia de Córdoba que incluyó el debate en la Cámara), en acuerdo con el Poder Ejecutivo, había recurrido a un procedimiento tangencial, legítimo pero escasamente frecuente, para obtener la creación que quizás, de haber recurrido al modo regular de presentar el proyecto como una iniciativa formalmente elaborada, no hubiera logrado la sanción del parlamento ${ }^{36}$

Las trabas político-institucionales que estaban en manos de los legisladores eran capaces de detener los impulsos legislativos incluso cuando el proponente de los proyectos era el Poder Ejecutivo nacional. La estrategia elegida en este caso permitió que fuese votada una partida presupuestaria -a pesar del rechazo del Senado- para la creación del DNT, aunque debería esperar cinco años para contar con una ley orgánica que regulase sus funciones y plantease sus objetivos. Según Auza la sanción de esta modificación en el presupuesto de 1907 fue posible porque ya se percibía en las Cámaras cierta tendencia favorable, o al menos un ánimo más dispuesto, a la legislación laboral.

El argumento no parece demasiado sólido si se lo compara con las dificultades que tuvieron otras leyes laborales para lograr su sanción y la soledad del diputado Palacios en la promoción de la legislación obrera y las oposiciones que los proyectos reseñados en el apartado anterior encontraron en el camino a su sanción definitiva. De hecho los vaivenes de las posibilidades de sancionar una ley orgánica para el DNT dan cuenta de esta falta de interés ocasionado por diversos motivos (falta de interés en la cuestión obrera, adscripción ideológica contraria a la intervención estatal, cuestiones referidas al intervencionismo del poder central sobre las provincias en caso de aceptar un DNT de jurisdicción nacional, etc.). finalmente recién en 1912 tendrá el DNT su ley orgánica aunque sus tareas ya estaba en parte establecidas por su funcionamiento cotidiano.

En términos legislativos el DNT puede ser pensado como un verdadero espacio de innovación en materia de derecho del trabajo. Su acción legislativa concreta, es decir las posibilidades de lograr la sanción por parte del Congreso de la Nación de sus proyectos, fue más bien escasa en relación a la actividad

\footnotetext{
${ }^{36}$ AUZA Tomás, "La política del Estado en la cuestión obrera al comenzar el siglo XX. El Departamento Nacional del Trabajo, 1907-1912" en Revista de Historia del Derecho, $\mathrm{N}^{\circ} 15$, Instituto de Investigaciones de Historia del Derecho, Buenos Aires, 1987. Pp. 106, cursiva agregado mío.
} 
que en este sentido desarrolló durante su existencia como DNT y antes de constituirse en una verdadera usina legal durante los primeros años del peronismo. Más allá de las propias imágenes negativas que el peronismo construyó sobre la acción del DNT durante los años previos a la llegada de Perón al organismo ${ }^{37}$ y su constitución como trampolín para el acercamiento de este con las organizaciones obreras, es importante resaltar que las capacidades concretas de acción del DNT en el campo legislativo estaban limitadas a proponer proyectos a través del Ministro del Interior al Congreso Nacional.

Durante los años de gobierno de facto transcurridos entre 1943 y 1946 el organismo, ya como Secretaria de Trabajo y Previsión, podrá plasmar su febril trabajo en reglamentaciones y decretos de impacto directo. El hecho de que la instancia legislativa estuviese cerrada habilitó a este y otros organismos a legislar de facto mediante los decretos. La mayoría de estos decretos y reglamentaciones serían avalados por le reabierto Congreso de la Nación en el año 1946 mediante la ley 12.921 de dicho año. Sin embargo sus acciones durante sus primeros años apuntaban a promover el debate sobre la necesidad de la construcción de un corpus jurídico en torno al trabajo que respondiese a la realidad industrial argentina. En la redacción del Plan de Trabajos propuesto por el primer director del DNT -Nicolás Matienzo- quedaron estipuladas cuales eran las funciones que sobre la legislación debía cumplir el organismo.

La legislación del trabajo, que este Departamento tiene por misión principal preparar, no puede prescindir del conocimiento exacto de los hechos que ha de regir, y ese conocimiento sólo puede adquirirse por estadísticas fieles y continuadas y por investigaciones metódicas e imparciales

Por valiosas que sean las indagaciones extranjeras, y por más que ellas recaigan sobre temas análogos a los que a nosotros nos preocupan, es decir, sobre formas y estipulaciones del contrato de trabajo y del de aprendizaje, sobre cuantía, límites y garantías del salario, sobre horas y épocas del trabajo, sobre descansos, sobre higiene, seguridad y moralidad de los talleres, sobre responsabilidad por accidentes, sobre asociaciones y sindicatos, sobre seguros contra la enfermedad, la vejez y la invalidez, sobre arbitrajes entre obreros y patronos, sobre costos de producción de los artículos sobre provechos obtenidos por los fabricantes y productores, sobre costo de la vida, etc., etc., por indispensable que sea tener en cuenta los resultados de esas investigaciones en los Estados Unidos, Inglaterra, Francia, Alemania, Bélgica, Australia, Nueva

${ }^{37}$ SOPRANO Germán, "El Departamento Nacional del Trabajo y su proyecto de regulación estatal de las relaciones Capital-Trabajo en Argentina. 1907-1943". En: José Panettieri (comp.) Argentina: Trabajadores entre dos guerras, Eudeba, Buenos Aires, 2000. 
Zelandia y demás países que las han hecho muy completas, más indispensable es penetrar en el seno de nuestro propio pueblo y fijar con la precisión posible las modalidades que en él toman las múltiples relaciones de la vida del trabajo.

Solo así podrá asegurarse que las soluciones a las que se arribe se ajustarán a las condiciones reales del problema social argentino. ${ }^{38}$

El estudio de la legislación extranjera -que tendría un apartado en todos los números del Boletín- era fundamental, pero el objetivo es que sirviese de base para realizar estudios sobre la realidad y las necesidades legislativas argentinas en torno al trabajo. Sin dudas el ascenso de los estudios de derecho comparado eran importantes a la hora de pensar un organismo que puedises dar cuenta de los cambios a los que estaba sometida la sociedad argentina. En este sentido la recurrencia de la legislación extranjera en los antecedentes legislativos de las propuestas del DNT eran contemporáneas a los estudios universitarios sobre el derecho, y especialmente el derecho laboral, que incorporaron como práctica la comparación legislativa. Sin embargo es importante volver a insistir en las características locales que debían tener presenten los proyectos propiciados por el DNT.

Esto así porque el DNT fue pensado como un organismo científico y por tanto enfocado en la promoción de respuestas racionalizadas para la cuestión obrera. La utilización de herramientas metodológicas de las ciencias sociales fundamentalmente la estadística- en la construcción de los problemas a ser resueltos es una constante del organismo. La legislación sobre accidentes de trabajo, en esta perspectiva, no se sostiene en el dolor que un evento de este tipo ocasiona a la familia obrera, sino en la alta tasa de accidentes que la estadísticas sobre la ciudad de Buenos Aires -y eventualmente otras provincias y territorios- tiene. Esta misma lógica cientificista es la que prima en los diferentes proyectos que lleva adelante el DNT durante estos años.

Las posibilidades concretas de crecer en funciones a partir de la ley orgánica de 1912 sumó a estas funciones la fiscalización de condiciones de trabajo y la chance de recabar información de primera mano en los establecimientos industriales ${ }^{39}$. La inspección no hizo más que ahondar la

\footnotetext{
38 MATIENZO José Nicolás, "Plan de Trabajo" en Boletín del Departamento Nacional del Trabajo, N ${ }^{\circ} 1$ Junio 30 de 1907, Departamento Nacional del Trabajo, Buenos Aires, 1907, Pp. 23 y sig.

${ }^{39}$ SOPRANO Germán, "Haciendo inspección. Un análisis del diseño y aplicación de la inspección laboral por los funcionarios del Departamento Nacional del Trabajo entre 1907 y
} 
consideración científica del organismo proyectando así una imagen que era conscientemente propuesta desde la institución que ligaba su capacidad técnico científica con su neutralidad en el caso de conflictos. De esta manera buscaba construirse como árbitro en la medida en que sus resoluciones no estarían animadas por preconceptos a ninguna de las dos partes. Sin embargo habría que preguntarse si esta postura neutral no está detrás de las imposibilidades de acción en los conflictos y esta sólo fue posible al asumir -en concordancia con el derecho laboral- la protección del más débil como horizonte de acción.

En su función como institución innovadora el DNT reproducía, con características académicas, los debates políticos que se daban, por ejemplo, en las cámaras legislativas. Tal es el caso de la jurisdicción de la ley en la que el director Nicolás Matienzo fija una clara posición a favor de la legislación de carácter nacional. Dice Matienzo:
A este respecto, considero oportuno anunciar a V.E. que he de preocuparme muy especialmente de proponer medidas de alcance general para toda la república, ya que los beneficios de la nueva institución deben ser nacionales, sin perjuicio de la disposiciones separadas y especiales que el Gobierno Federal puede dictar en los lugares donde ejerce jurisdicción inmediata y exclusiva. ${ }^{40}$

La pretención nacional de la institución iba a tono con su concepción cientificista: en la medida en que sus respuestas eran de carácter científico no se podía negar a la nación el beneficio que la ciencia tenía para dar.

En algún punto la circulación de sus funcionarios más destacados entre la función pública y las aulas del sistema universitario argentino le otorgó a este organismo características propias. A diferencia de lo que se puede observar en otras funciones administrativas, el DNT vinculaba estrechamente innovación científica y aplicación de la norma. El hecho de actuar sobre un campo aun poco explorado y con ausencia de tradición -incluso a nivel mundial- pero de alto impacto político, sumado al impacto que la concepción científica tenía dentro del paradigma del progreso, dieron al DNT la posibilidad de presentarse como un organismo atípico -en algún punto también modélico- sobre la forma de intervención estatal en la problemática social. Al mismo tiempo su función

1914". En: BOHOSLAVSKY Ernesto y SOPRANO Germán (eds.). Un Estado con rostro humano. Funcionarios e instituciones estatales en la Argentina (1880 a la actualidad). Prometeo, Buenos Aires, 2010.

${ }^{40}$ MATIENZO Nicolás, Op. Clt. Pp. 24 
con impacto concreto en la realidad social se enmarcaba en la añorada intervención pública de un sector profesional -los abogados- que venían propiciando reformas en los métodos de enseñanza y en los planes de estudio a fin de readecuar su tradicional inserción en las estructuras estatales ${ }^{41}$.

\section{I.4 La constitución del Nuevo Derecho en el sistema universitario:}

\section{cambios en la enseñanza del derecho e innovación doctrinaria}

El temprano intento de Joaquín V. González de promulgar un Código del Trabajo no sólo fue criticado desde los ámbitos legislativos y, por diferentes razones, desde las organizaciones obreras y empresarias. Desde los claustros universitarios se sostenía que el derecho del trabajo aun no estaba lo suficientemente definido como para poder ser codificado. El debate en la universidad pasaba por el lugar del Derecho del Trabajo con respecto al Código Civil, por lo tanto la cuestión pasaba por la capacidad de determinar si el trabajo podía ser regulado por las mismas normas que mediaban entre dos particulares, o si por el contrario el trabajo debía ser objeto de legislación específica.

Antes de entrar en el detalle de la disputa doctrinaria es necesario dar cuenta de los cambios en la enseñanza del derecho que impactaron en el debate y que hicieron posible la autonomización del derecho del trabajo en el campo académico y científico que sería determinante en las posibilidades concretas, años más tarde, de la creación del fuero.

El sistema universitario argentino no permaneció ajeno a los desafíos que la cuestión social le impuso. En las carreras de derecho el impacto se hizo sentir fuertemente en la medida en que los abogados, como profesión y grupo social, consideraban como propia la misión de otorgar al estado y a la sociedad una organización racional hija del progreso. A los cambios en la enseñanza del derecho mediante la inclusión del estudio de las ciencias sociales, fundamentalmente la sociología, se sumó la preocupación por el estudio de las cuestiones laborales. En 1906 se creaba bajo la dirección de Juan Bialet Massé

\footnotetext{
${ }^{41}$ ZIMMERMANN Eduardo, Los liberales reformistas... Op. Cit. Sobre las pretenciones de sectores ligados al derecho de modificar la formación para adecuarse a los tiempos que corrían y aportar una diferente inserción en la estructura estatal ver STAGNARO Andrés, "Vocación de poder. Los abogados porteños a través de las colaciones de grado. 1884-1919", Revista Temas de Historia Argentina y Americana, UCALP, en prensa.
} 
la cátedra de "Legislación Industrial y Agrícola" en la Facultad de Derecho de Córdoba $^{42}$, aunque la muerte de Bialet Massé en 1907 y su reemplazo por Juan Guadalberto García volcaron a la cátedra a una enseñanza de corte profesionalista como el que imperaba en esos años en la casa de estudios cordobesa. Los cambios producidos por la Reforma Universitaria y el reemplazo de García por Telasco Castellanos y la incorporación en 1926 de Dardo Rietti dieron nuevo impulso a la materia y se incorporaron nuevos métodos de enseñanza como un mayor énfasis en la práctica. Esta Universidad también fue pionera en la constitución, en 1929, del instituto del Trabajo que llevaría el nombre de su primer titular. La Universidad de Buenos Aires también sería parte de un proceso de renovación con la inclusión del estudio de la sociología o la economía política, al que se sumarían los cursos libres de legislación del trabajo, que aunque sin lugar en el la currícula obligatoria de la carrera sería importantes espacios de promoción de estudiosos del Derecho Laboral. En la Facultad de Ciencias Económicas e creo una cátedra de Legislación Industrial y con el mismo nombre se instituiría después en la Facultad de Derecho, con titulares como Alejandro Unsain, y Leónidas Anastasi -que lo serían también en la Universidad de La Plata- y Carlos Saavedra Lamas $^{43}$.

La Universidad de La Plata fue concebida desde sus inicios como una casa de estudios con particularidades propias. El proyecto fue acuñado justamente por quien solo dos años antes había presentado el proyecto del Código del Trabajo, Joaquín V. González. Según relata Pablo Buchbinder, el "proyecto se nutrió de los debates, discusiones y de las enseñanzas que habían dejado los conflictos en la Universidad de Buenos Aires de 1903 y $1904^{\prime 44}$. Mediante la huelga estudiantil se habian paralizado la Facultad de Derecho y Ciencias Sociales y la Facultad de Medicina. Los pedidos de los

\footnotetext{
${ }^{42}$ Un desarrollo pormenorizado del surgimiento del Derecho Laboral en la Universidad de Córdoba en PORTELLI María Belén, "Saberes modernos para políticas eficaces. El Derecho Laboral y el estudio del mundo del trabajo. Córdoba, 1906-1930", Población \& Sociedad [en línea], Vol. 18, № 2, 2011, pp. 145-185. Puesto en línea en diciembre de 2011. URL: http://www. poblacionysociedad.org.ar/archivos/18/P\&S V18-N2-Portelli.pdf

${ }^{43}$ SARDEGNA, Miguel Ángel, "Historia de la cátedra de Derecho del Trabajo y de la Seguridad Social en la Facultad de Derecho y Ciencias Sociales de la Universidad de Buenos Aires", Revista de Historia del Derecho "Ricardo Levene", № 33, Buenos Aires, 1997.

44 BUCHBINDER, Pablo, Historia de las Universidades Argentinas. Sudamericana, Buenos Aires, 2005. Pp. 81
} 
estudiantes se basaban en reformas en el plan de estudios y un nuevo gobierno universitario. En el caso de la enseñanza de derecho, las reformas propuestas apuntaban a un mayor cientificismo y la enseñanza de derecho comparado, pero principalmente a la inclusión de las ciencias sociales en el plan de estudios de la carrera. También se apuntaba al establecimiento de un profesorado profesional que diese a la enseñanza un nuevo ímpetu mediante la asignación de dedicaciones exclusivas.

González se nutrió de estos debates, pero también de la opinión de los docentes que se alinearon detrás de un nuevo proyecto de enseñanza para la creación de la nueva universidad. En su proyecto la enseñanza del derecho tenía un rol central, por eso sostenía la necesidad "de asegurar un sitio de primera importancia a aquellas disciplinas científicas orientadas al estudio empírico de la realidad social y política. En este contexto señalaba que la Facultad no asumiría solamente el papel de la formación de abogados sino que comprendería también los estudios científicos en materia social, moral y política"45. La Universidad mantuvo siempre estos rasgos de origen, a pesar de que atravesó por períodos de crisis al final de la década del Centenario, como sostiene Buchbinder.

Fue justamente en el ciclo de conferencias dominicales de los cursos de extensión ${ }^{46}$ de la Universidad de La Plata en el que el juez Ernesto Quesada profesor e impulsor de la sociología jurídica en las universidades de La Plata y Buenos Aires, e impulsor en sus fallos de la doctrina del riesgo profesiona ${ }^{47}{ }_{-}$ expuso "La Cuestión Obrera y su Estudio Universitario" 48 que fuese publicado en el primer número del Boletín del Departamento Nacional del Trabajo. Las razones de su promocionada conferencia descansaban en la falta de interés sobre el tema que tendía a dificultar su resolución por medio de la prevención. Sostuvo Quesada:

Universitarios y políticos han hecho gala, entre nosotros, de rehuir hasta ahora ese estudio, como si de esa manera se quitara importancia a la cuestión, sin percatarse de que, con tan cándido temperamento, se magnificaba el problema y se le entregaba por completo a la propaganda

\footnotetext{
45 Ibidem. Pp. 83

${ }^{46}$ La extensión universitaria fue uno de los pilares en los que la Universidad Nacional de La Plata constituía su originalidad y trazaba su proyecto político pedagógico

${ }^{47}$ La doctrina del riesgo profesional será abordado en el capítulo siguiente.

48 QUESADA Ernesto, "La cuestión obrera y su estudio universitario", Boletín del Departamento Nacional del Trabajo, N¹ Junio 30 de 1907, DNT, Buenos Aires, 1907.
} 
de los agitadores profesionales (...) De ahí que gobiernos y opinión pública, apenas estallaba un conflicto del trabajo, no concibiera otra solución que la de la ley marcial. ${ }^{49}$

Su reclamo por la resolución científica de la cuestión obrera fue puesto en relación con los avances que los estudios científicos y los elementos de estudio que se tenían a disposición para lograrlo. Y si el objetivo no se lograba sólo se podía culpar a la "inercia criolla". En el caso de la Unversidad Nacional de La Plata no fue la inercia criolla la que detuvo el estudio de la cuestión obrera, sino una serie de crisis en las que se sumergió la casa de estudios platenses durante la década del diez del siglo pasado. Pero el proceso reformista dio nuevo empuje a la conformación de un espacio académico de estudios de Derecho del Trabajo.

El decanato de Alfredo Palacios de la Facultad de Ciencias Jurídicas y Sociales entre los años 1922 y 1925 revitalizaría la enseñanza del derecho y marcaría definitivamente el comienzo de la consideración del Derecho del Trabajo como una rama autónoma. La importancia que otorgara desde su gestión como decano Alfredo Palacios a la enseñanza, con nuevos métodos (que incluían el dictado de seminarios y la novedosa experiencia del "Laboratorio de Psicofisiología" que buscaba legislar en base a experimentaciones científicas), de la legislación social y laboral ${ }^{50}$, fueron el puntapié inicial de un camino que ya no tendrá retorno.

Desde 1920 había sido designado Leónidas Anastasi como docente provisorio en la cátedra de Legislación Industrial y Obrera, una de las asignaturas en las que se dictaba algunas de las propuestas legislativas del Derecho del Trabajo. La llegada de Palacios al decanato de la Facultad profundizaría estos cambios que se venían sucediendo desde la 1920, en medio del clima generado por la reforma universitaria, con una amplia aceptación de la Federación Universitaria de La Plata. Ya en el plan de estudios aprobado el 20 de Octubre de 1921 la cátedra asignada a Leónidas Anastasi era reconocida como "Legislación del Trabajo" y se le daba una nueva entidad al estudio de la materia. La creación de esta cátedra colocó a La Plata

\footnotetext{
49 Ibídem, Pp. 112

50 GRACIANO, Osvaldo, Entre la torre de marfil y el compromiso político. Intelectuales de izquierda en la Argentina, 1918-1955. Editorial de la Universidad Nacional de Quilmes, Bernal, 2008.
} 
entre las pioneras, al ser la primera en reconocer el "nuevo derecho" con entidad autónoma. Si bien los cursos libres de legislación del trabajo se dictaban en Buenos Aires con docentes como Carlos Saavedra Lamas, Unsain, Anastasi, o el mismo Palacios, y que se dictaba en otras carreras bajo la denominación de legislación industrial ${ }^{51}$, era la primera vez que era reconocido como materia obligatoria en un plan de estudios. Desde su creación la cátedra se dictó en el tercer año de la carrera.

La cátedra comenzó a funcionar en el año lectivo de 1922 con el nombre de "Legislación del Trabajo", de acuerdo al programa que presentara Leónidas Anastasi, al momento titular de la cátedra y su adjunto, Alejandro Unsain. Pero las modificaciones en la enseñanza del derecho no quedarían limitadas a la concreción de la cátedra. El nuevo decano respetó la designación provisoria de Anastasi y la creación de la cátedra, y propondría cambios en la metodología de la enseñanza. Entre las propuestas se encontraba la creación de seminarios que

permitirían lograr la sustitución de la enseñanza tradicional del derecho, fundada en el magisterio verbal del profesor, por la investigación y la experimentación, desarrolladas por los alumnos (...) a través de los métodos provenientes de las ciencias sociales ${ }^{52}$.

La experiencia del Seminario de Investigación y Adaptación Profesional colocaba a los estudiantes en un rol central en la solución de diversas situaciones, en donde debían abandonar la exégesis legal para poder abocarse al estudio de problemáticas concretas. Osvaldo Graciano sostiene que estos seminarios se dictaron entre 1922 y 1923 por Unsain y Anastasi, siendo este último el encargado de dictar el que correspondía a la condición social y económica de los trabajadores del campo. La experiencia de los seminarios perduró al paso de Palacios por el decanato de la Facultad, y en 1934 Benito Pérez -quien se convertiría en el profesor titular de la cátedra de Derecho del Trabajo y de la Previsión Social en $1948^{53}$ - escribía, como trabajo final del

51 Osvaldo Graciano refiere la docencia de Alfredo Palacios en la Facultad de Ciencias Económicas de una materia con esa denominación. Ibídem. Pp. 93.

${ }^{52}$ Ibidem. pp. 102

${ }^{53}$ Benito Pérez fue designado en el cargo el 28 de Marzo de 1947, por lo que probablemente asumió en la cátedra ese mismo año, pero el primer programa que está registrado bajo su nombre es el de 1948. Anales de la Facultad de Ciencias Jurídicas y Sociales de la Universidad Nacional de La Plata. Sección Noticias. La Plata, 1948. 
seminario de Legislación laboral dictado por Alejandro Unsain, "Los Fueros del Trabajo" ${ }^{\prime 5}$.

Al director de los seminarios se le aseguró, además, un puesto en el consejo de redacción de la revista Anales de la Facultad de Ciencias Jurídicas y Sociales de la Universidad Nacional de La Plata, siendo ese puesto ocupado por Armando Spinelli desde 1926 hasta, al menos, 1948, superando a todos sus colegas en cuanto a la duración de sus cargos en el consejo editorial de la revista. La presencia de Spinelli es también una muestra del crecimiento institucional del derecho del trabajo en la Facultad de Ciencias Jurídicas y Sociales. Hombre dedicado al Derecho Laboral, ocupó la dirección del Departamento Provincial del Trabajo bajo el gobierno de Manuel Fresco en la provincia de Buenos Aires y dicto algunos fallos ejemplares con respecto a la materia ${ }^{55}$.

A las propuestas de los seminarios como formadoras de un tipo de profesional predispuesto a utilizar herramientas de las ciencias sociales y a huir de la exégesis legal, debe sumarse lo que parece haber sido el método de enseñanza de la cátedra misma desde su creación. En un relato de la vida de Anastasi, Carlos R. Desmarás -quien al momento del fallecimiento de Anastasi el 17 de Enero de 1940 ya participaba en la cátedra y llegaría a ser profesor suplente- sostiene que Anastasi "impartía la enseñanza teórico-práctica, por cuanto deseaba que los estudiantes egresaran con los conocimientos indispensables para actuar directamente en la profesión, y en especial en el procedimiento de las leyes 9688 y $11.729 " 56$. La figura de Anastasi, como líder académico, regirá sobre los docentes que le sucederán.

\footnotetext{
${ }^{54}$ PÉREZ Benito, "Los Fueros del Trabajo", Anales de la Facultad de Ciencias Jurídicas y Sociales de la Universidad de La Plata, $1^{\circ}$ Parte, Talleres Gráficos Olivieri \& Domínguez, La Plata, 1941

${ }^{55}$ El director del Departamento Provincial del Trabajo oficiaba como juez en disputa laborales, claro que siempre dentro de los límites de su autoridad administrativa. Sus fallos no eran vinculantes para las partes y no tenían el peso legal de un fallo de la justicia ordinaria. Alguno de los fallos de Spinelli están citados en FRESCO Manuel, Cómo encaré la cuestión obrera durante mi gobierno. La Plata 1940.

${ }^{56}$ DESMARÁS Carlos R., "Noticia Biográfica. Leónidas Anastasi", Anales de la Facultad de Ciencias Jurídicas y Sociales de la Universidad Nacional de La Plata, Tomo XII, $2^{\circ}$ Parte, Talleres Gráficos Olivieri \& Domínguez La Plata, 1941. Pp. 909. Las leyes a las que hace referencia Desmarás son las de accidente de trabajo (9688) y la que modificó los artículos 154 a 160 del Código de Comercio que regulaba el contrato de trabajo para los empleados comerciales.
} 
Anastasi fue el profesor titular de la materia desde su creación como cátedra autónoma en 1922 hasta su fallecimiento en 1940. Desde 1926 lo acompañaría como profesor suplente Manuel Pinto (h), quien a la muerte de Anastasi lo sucedería en el cargo de docente titular de la materia, y hasta el 14 de Junio de 1938 ambos estarían acompañados por Alejandro Unsain, quien ocupó el cargo de Docente Extraordinario. Al asumir Manuel Pinto (h) como docente titular, será designado como suplente Carlos Raúl Desmarás. En 1943 se suma como docente adscripto Juan Damián Ramírez Gronda, que llegaría ser ministro de la Corte Suprema de la Provincia de Buenos Aires durante el gobierno de Domingo Mercante y dictará algunos fallos laborales citados en esta tesis. Con la intervención de la Universidad se efectivizaría un recambio docente, y se designa como profesor titular a Benito Pérez el 28 de Marzo de 1947, aunque continuando en su función de adscripto Juan D. Ramírez Gronda $^{57}$.

La continuidad reflejada en el plantel docente (seis docentes ocuparon los distintos cargos en la cátedra entre 1922 y 1948) se percibe también en los programas de la materia. Hasta 1932 el programa no sufre modificaciones radicales de aquél presentado en 1926 por Anastasi. Del programa de 1926 a $1932^{58}$ lo que cambia es particularmente el orden de los temas, dando lugar en las primeras bolillas a la definición académica de la Legislación del Trabajo y a la historia de los derechos laborales, incluyendo regulación sobre el trabajo de los esclavos en Grecia y Roma y referencias a la historia de la legislación del trabajo.

Otro cambio importante es la inclusión de los nuevos avances de la Legislación del Trabajo en Europa, siempre teniendo como ejes la legislación italiana y francesa, aunque remarcando otros casos similares a los que se promovía en la sección de legislación laboral del Boletín del Departamento Nacional del Trabajo. De todas maneras, ya desde 1926 el programa mantendrá como eje la legislación comparada, difundiendo leyes e instituciones principalmente del Viejo Mundo -sobre todo francesas, por la gran cantidad de

\footnotetext{
${ }^{57}$ Los datos sobre los cargos docentes se extraen de la sección Noticias Universitarias de la revista de carácter anual de la Facultad de Ciencias Jurídicas y Sociales. Anales de la Facultad de Ciencias Jurídicas y Sociales de la Universidad Nacional de La Plata. Sección Noticias. La Plata, varios años.

${ }^{58}$ El Programa de 1932 es aprobado por el Consejo Académico de la Facultad de Ciencias Jurídicas y Sociales el 9 de Septiembre de 1932.
} 
bibliografía que contenía en el programa- pero también de Estados Unidos y Nueva Zelanda ${ }^{59}$. A los avances en términos legislativos que se daban en otros países, el programa de 1932 agrega también los cambios en la legislación en nuestro país, y también los cambios en la jurisprudencia particularmente importantes para la autonomía del Nuevo Derecho: la ley de accidentes laborales y las interpretaciones en torno al contrato de empleo.

La muerte de Anastasi no modifico el panorama y su sucesor continuo utilizando el mismo programa. Fallecido el fundador de La Ley, Manuel Pinto se hace cargo de la cátedra. Ese año es aprobado en la sesión del 3 de Noviembre de 1942 del Consejo Académico ${ }^{60}$ un programa con las mismas características que aquél que fuese presentado en 1932. Recién con la llegada de Benito Pérez a la titularidad de la materia el programa sería radicalmente cambiado, dando cuenta también del cambio en la denominación de la asignatura que será rebautizada con el nombre de Derecho del Trabajo y de la Previsión Social. El cambio se reflejó en las páginas del diario El Día, en donde se daba cuenta del suceso. Este cambio fue por medio del decreto presidencial ${ }^{61}$ en cuyos considerandos se sostenía

que, como lo manifiesta la referida Universidad, la actual denominación de dicha cátedra no responde ya al contenido de esa disciplina jurídica, pues la misma ha evolucionado en tal forma que actualmente posee verdadera autonomía científica y por lo mismo, estando informada y sustentada sobre

\footnotetext{
${ }^{59}$ La inclusión de Nueva Zelanda se da por la instauración, en dicho país, de Tribunales de Conciliación y Arbitraje para asuntos laborales de carácter obligatorio, pertenecientes jurisdiccionalmente al poder judicial. El caso neocelandés refleja cómo la intervención estatal sobre las cuestiones laborales no respondieron sólo a modelos societales de corte corporativo, y se erigió en un ejemplo a seguir ya que dejaba en manos de jueces letrados la resolución de Ios conflictos individuales y colectivos entre el capital y el trabajo. TEIXERA DA SILVA, Fernando, "Justiça do Trabalho e Magistratura del Lavoro: apontamientos comparativos", Mimeo.

${ }^{60}$ Cuento con la serie de programas que aun se conservan en el archivo de la Facultad de Ciencias Jurídicas y Sociales de la UNLP. Desde 1926 el programa presentado para la consulta de los estudiantes, que sería compilado por las autoridades de manera anual junto con el resto de los programas de la carrera se mantiene igual hasta el año 1931. En 1932 se modifica levemente el programa con la inclusión de una nueva sección de bibliografía, que incluye publicaciones periódicas en la parte de bibliografía general. El programa de 1932 aparece en las compilaciones hasta el año 1940, en el que se publica un nuevo programa, pero aclarando que se trata de una reedición de aquél presentado en 1932. Para 1942 se presenta, ahora sí, un nuevo programa, con cambios en las bolillas y en la organización de los temas a tratar. Este programa se mantendrá en vigencia hasta la designación de Benito Pérez como docente titular, quien cambiará el dictado de la materia. Facultad de Ciencias Jurídicas y Sociales de la Universidad Nacional de La Plata, Programas, La Plata, 1926 a 1952

${ }^{61}$ Según el artículo 22 de la Ley Convenio 4699, los cambios en las currículas universitarias debían pasar por la aprobación del Poder Ejecutivo Nacional, por eso el cambio de denominación responde a un decreto firmado por el presidente y por el ministro de Justicia e Instrucción Pública.
} 
principios doctrinarios que le son estrictamente propios y que tiene, además, un profundo significado político-social en todas sus manifestaciones. ${ }^{62}$

Se decretaba el cambio de denominación de la cátedra "Legislación del Trabajo" por la de "Derecho del Trabajo y de la Previsión Social"³.

El cambio de denominación acontecido en 1947 pretendía intencionalmente marcar la autonomía del Derecho del Trabajo. Si bien hay que ser cuidadosos a la hora de interpretar este cambio como uno radical -ya que por la época eran comunes las expresiones de cambio con respecto al pasado inmediato-, es cierto que ya para 1948 la autonomía científica del Nuevo Derecho no era discutida seriamente y la continuación de su enseñanza no se ponía en duda. Es decir, había ya conquistado una porción del campo de las ciencias jurídicas y estaba en pie de igualdad, al menos académicamente, con otras ramas del derecho.

El logro por parte del Nuevo Derecho de espacios institucionales relevantes marcó también la enseñanza de la materia en la Facultad de Ciencias Jurídicas y Sociales y le otorgó características científicas a su estudio que colocaría a La Plata, junto con la Universidad del Litoral, como escuelas de relevancia nacional en la materia.

El más importante de sus espacios fue el Instituto de Derecho del Trabajo en creado en 1937. La creación del Instituto fue consecuencia del avance de los estudios en torno a la legislación obrera que se impulsaba desde la cátedra. El recorrido de esta institución comienza con la designación de Anastasi como director del Instituto de Altos Estudios Jurídicos de la Facultad de Ciencias Jurídicas y Sociales. El Instituto de Altos Estudios Jurídicos fue creado por medio de la ordenanza del 12 de Noviembre de 1928 bajo el decanato de David Lascano. Su fin, según reza el artículo $1^{\circ}$ de dicha ordenanza, era el de "contribuir al estudio y solución práctica de los problemas jurídicos y sociales de interés para el país" ${ }^{\prime 64}$. El artículo $3^{\circ}$ designaba a los miembros del Instituto y habilitaba a formar parte de este a "profesores de la Facultad, los abogados y

\footnotetext{
${ }^{62}$ Publicado sin numeración en Diario El Día, edición del 8/10/1947, pp. 4

${ }^{63}$ Ibídem.

${ }^{64}$ Universidad Nacional de La Plata, "Instituto de Altos Estudios Jurídicos y Sociales; Seminario de Investigación y adaptación profesional; Museo Vucetich y Laboratorio de Identificación", La Plata, 1929. pp. 3. Esta gacetilla era vendida a los estudiantes que la solicitaran y contenía los reglamentos de dichas instituciones. Se encuentra en las compilaciones de sus publicaciones que realizaba la facultad de manera anual.
} 
doctores egresados de la misma que se inscribiesen en la rama en ejercicio y los estudiantes que reuniesen las condiciones exigidas por el artículo $5^{\circ}$ de la ordenanza sobre trabajos prácticos; estos últimos al sólo efecto de realizar los trabajos que les encargase el director" ${ }^{\prime 65}$. Para los estudiantes, la posibilidad de participar en proyectos de investigación de este tipo significaba un contacto directo con las problemáticas del momento, pero además un vínculo directo con docentes especializados y con inserción institucional que el día de mañana pudiese servir de nexo con el mercado laboral.

Este Instituto de Altos Estudios Jurídicos tenía direcciones bianuales en los que se encargaba de avanzar en un tema específico y en el que las tareas se abocaban a la resolución de una problemática determinada. En la sesión del Consejo Académico del 28 de Diciembre de 1934 el decano, Eduardo F. Giuffra, puso a consideración de los presentes las opciones para decidir a quien correspondería la dirección bianual del Instituto y por lo tanto a qué tema se dirigirían las investigaciones. Comentó que se limitaba la elección a dos temas diferentes: Derecho Comercial y Legislación del Trabajo, y que por lo tanto la elección del director podía recaer en Francisco Orione o Leónidas Anastasi. A la hora de decidir Giuffra argumentó que "por razones de actualidad y urgencia, dada la precariedad e imperfección de nuestra legislación obrera, se inclinaba por esta última materia"66. Por lo tanto se designaba al vicedecano ${ }^{67}$, Leónidas Anastasi, como director del Instituto de Altos Estudios Jurídicos para el bienio 1935-1937.

Esta experiencia en la dirección de un instituto de investigación impulsó a la cátedra a sostener una institución con estas características pero que funcionase de manera permanente. Es por eso que terminado el proceso de dirección del Instituto de Altos Estudios Jurídicos y Sociales, se propone la

\footnotetext{
${ }^{65}$ Universidad Nacional de La Plata (1929). Op. Cit. pp. 4.

${ }^{66}$ Anales de la Facultad de Ciencias Jurídicas y Sociales de la Universidad Nacional de La Plata, Tomo VII, Imprenta de la Universidad, Buenos Aires, 1935, pp. 660

${ }^{67}$ El cargo de vicedecano fue el más alto al que llegó Leónidas Anastasi dentro de la estructura política de la Facultad, justamente al momento de ser elegido para hacerse cargo de la dirección del Instituto de Altos Estudios Jurídicos. Tanto antes como después del cargo de vicedecano ocupó un lugar en el consejo académico de la Facultad. Otros miembros de la cátedra ocuparían un lugar en el Consejo Académico: Manuel Pinto (h) en varias oportunidades durante el período, Benito Pérez y Juan Damián Ramírez Gronda. Tal vez esta pertenencia de los docentes de Derecho del Trabajo en la gestión política de la Facultad de cuenta también de otro tipo de crecimiento profesional del área, vinculado a la capacidad de obtener recursos y prestigio no sólo mediante el ejercicio de la cátedra sino por la pertenencia de sus docentes al ámbito de toma de decisiones.
} 
creación del Instituto de Derecho del Trabajo, nuevamente bajo la dirección del titular de la materia, Leónidas Anastasi, en una continuación directa de esta experiencia en investigación y difusión. La propuesta es aceptada en la sesión del Consejo Académico del 14 de Junio de 1937. El artículo $2^{\circ}$ de la ordenanza de creación establecía que serían miembros del instituto
a) Los profesores de Legislación del Trabajo; b) los profesores de materias afines; c) los especialistas en legislación del trabajo o en materias afines; d) los egresados de la facultad; e) los alumnos que hubieran aprobado la asignatura $^{68}$.

Al igual que en el Instituto de Altos Estudios Jurídicos y Sociales, los estudiantes eran admitidos entre sus filas y esto permitía un contacto directo con la problemática y podía tejer redes de reclutamiento para una posible vida laboral tanto dentro como fuera de la Universidad.

El artículo $4^{\circ}$ de la ordenanza establecía las funciones del Instituto:

a) hacer conocer periódicamente la bibliografía de las cuestiones obreras y sociales; b) difundir la jurisprudencia nacional y extranjera sobre cuestiones obreras y sociales; c) remitir a los cuerpos legislativos los antecedentes que se conceptúen de interés sobre los proyectos de legislación del trabajo; d) establecer un intercambio con la oficina Internacional del Trabajo, con los Departamentos de Trabajo o instituciones análogas de los países extranjeros y de las provincias argentinas; c) estudiar el derecho internacional del trabajo y la legislación comparada; f) realizar encuestas sobre los asuntos que consideren las conferencias internacionales del trabajo, haciendo llegar al gobierno nacional el resultado de dichas encuestas; g) organizar cursos libres para alumnos de la Facultad, previa aprobación del C.A.; h) propiciar cursos de extensión universitaria, que se dictarán, preferentemente, fuera de la Facultad; i) recopilar antecedentes para el derecho obrero del país; j) publicar monografías de los miembros del Instituto; k) editar publicaciones sobre temas sociales; I) establecer intercambio universitario en institutos similares del país y del extranjero. ${ }^{69}$

La larga cita del artículo permite observar algunas de las pautas que se creía el Instituto podía potenciar. Los puntos a) y b) le otorgaban al instituto una clara función de promoción y divulgación de la legislación sobre el trabajo. Siguiendo esta línea, en su sesión del 14 de Junio de 1938, y por pedido del director del Instituto, el Consejo Académico "autoriza a los miembros del Instituto doctores Carlos R. Desmarás, Benito Pérez y Juan D. Ramírez Gronda

\footnotetext{
${ }^{68}$ Anales de la Facultad de Ciencias Jurídicas y Sociales de la Universidad Nacional de La Plata, Tomo VIII, Talleres Gráficos Olivieri \& Domínguez, La Plata, 1937, pp. 1012.

${ }^{69}$ Ibídem pp. 1012 y sig.
} 
a dictar un ciclo de conferencias a los alumnos de Legislación del Trabajo"70. Otras funciones eran la divulgación de la legislación para los estudiantes de la facultad, así como la divulgación para la sociedad y el intercambio con otros miembros del sistema universitario argentino. Estos objetivos se llevarían adelante no sólo con la publicación de sus investigaciones y los vínculos con organismos internacionales dedicados a los asuntos laborales -por ejemplo con la Organización Internacional del Trabajo-, sino también mediante los cursos de extensión.

El Instituto de Derecho del Trabajo estableció, efectivamente, intercambio con otros organismos dedicados al estudio de las cuestiones laborales, manteniendo el intercambio de publicaciones con la Organización Internacional del Trabajo ${ }^{71}$. Por otro lado la presencia de autoridades del Instituto de Trabajo de la Universidad Nacional del Litoral -el Dr. Tissembaum- y el director del Instituto del Trabajo de la Facultad de Derecho de la Universidad Nacional de Córdoba -el Dr. Rietti- en el homenaje al ex profesor Leónidas Anastasi el 24 de Junio de 1941, indica que el Instituto de Derecho del Trabajo ocupaba un lugar destacado en la red de instituciones universitarias ligadas al tema.

Tenía también el Instituto relevancia en la actividad legislativa, no sólo por lo que se expresa en el punto c) de la ordenanza de su creación, sino sobre todo teniendo en cuenta el rol como parlamentarios tanto de Leónidas Anastasi como de Manuel Pinto (h), que ejercieron como diputados a lo largo de este período, llegando Anastasi a ser presidente de la Comisión de Legislación del Trabajo de la Cámara de Diputados del Congreso de la Nación.

\section{I.5 Conclusiones}

El surgimiento de la Cuestión Social, tanto como problema de estudio para sectores de la elite como en las vivencias concretas de la clase obrera, fue producto del proceso de modernización en el que se vio envuelta la zona pampeana desde finales del siglo XIX. Las características de la región con

\footnotetext{
${ }^{70}$ Anales de la Facultad de Ciencias Jurídicas y Sociales de la Universidad Nacional de La Plata, Tomo XII, $2^{\circ}$ Parte, La Plata, 1941, pp. 917.

${ }^{71}$ En las notas bibliográficas de los Anales dedicadas a la Legislación del Trabajo aparecen continuas menciones a la Reveu International du Travail publicada en Paris hasta 1940 y su sucesora, la Revista Internacional del Trabajo publicada en Montreal desde 1941, órganos oficiales de la OIT. Algunos ejemplares aun se conservan, a pesar de la inundación sufrida, en la sede del Instituto de Derecho Social -sucesor del Instituto de Derecho del Trabajo-.
} 
bajas tasas de ocupación del territorio y posibilidades de inserción en el mercado internacional brindaron el contexto para dicho proceso que vino a cambiar la estructura productiva principalmente en las ciudades y asentamientos urbanos de la región. Diversificación de la economía, urbanización y crecimiento de la producción artesanal e industrial trazaron las pautas de fines del siglo XIX y principios del siglo $X X$.

De manera contemporánea se constituyó definitivamente el edificio institucional del Estado, que reguló las relaciones entre los sujetos por medio del Código Civil. El establecimiento de reglas claras fue un proceso que retroalimento el proceso de modernización, creando una atmósfera de bienestar en torno al progreso. Sin embargo las consecuencias visibles de la Cuestión Social tendieron a ensanchar las rajaduras del edificio del progreso y la razón.

Significativamente la ciudad de La Plata se presenta como eje de estas cuestiones. Su concepción fue consecuencia directa del ordenamiento institucional del país, que había dejado al mayor estado de la fedración sin capital y como huéspedes de las autoridades nacionales con la federalización de la ciudad de Buenos Aires. Su planeamiento respondía a la creencia en la razón y la modernización como respuesta a la naciente Cuestión Social. Su traza urbana y la disposición del espacio estaban directamente ligados con las posibilidades de evitar las consecuencias violentas de la misma. El devenir de la ciudad, con su crisis de la década final del siglo XIX, demostró nuevamente su ligazón con la construcción de la Cuestión Social en la medida en que fue volcando su desarrollo al estudio universitario. En última instancia se trataba de buscar la resolución de la razón a las problemáticas devenidas de la modernización.

La Cuestión Social y principalmente su núcleo, la Cuestión Obrera no fue un problema exclusivamente local. Los tratados de paz posteriores que dieron fin a la Primera Guerra Mundial dieron nacimiento a una institución que con su devenir será central en el desarrollo del Derecho Laboral: la Organización Internacional del Trabajo. Sus conferencias fueron durante estos años el centro de los debates sobre las características que debía tener la legislación obrera, pero principalmente otorgaron el aval necesario a un campo que localmente era 
débil y no contaba con la capacidad suficiente para poder desarrollarse sin tener que brindar continuas disputas con las ramas tradicionales del derecho.

Dos instituciones locales fueron las mayores promotoras del Nuevo Derecho. Ante la lentitud del poder estatal que naturalmente debería haber entendido en la promoción de la legislación laboral -el Poder Legislativo- las banderas de la necesidad de dar respuesta legislativa a la Cuestión Social fueron levantadas por dos instituciones de distinto corte. El Poder Ejecutivo, siempre atento al sostenimiento del orden, albergó en su seno al departamento Nacional del Trabajo. Esta institución, a pesar de sus dificultades iniciales y su falta de poder de policía en torno a las violaciones de las mismas disposiciones que promulgaba se convirtió en una referencia sobre las cuestiones laborales, principalmente debido a su voluntad de intervención basada sobre lineamientos científicos y por medio del estudio empírico.

Similares características en cuanto a la importancia del estudio empírico y la importancia de las razones científicas compartía con la otra institución que, producto de un cambio en la concepción de su función, dio cuenta de la Cuestión Social: el sistema universitario. Para que las distintas universidades pudiesen dar cuenta de este problema fue necesario que cambiasen su forma de producción de conocimiento y enseñanza. La Universidad Nacional de La Plata fue una de las pioneras en la innovación educativa lo que permitió albergar en su casa de estudios a importantes referentes del Nuevo Derecho, incluyendo entre ellos a su promotor más reconocido, Alfredo Palacios. 


\title{
CAPÍTULO II \\ LA LEGISLACIÓN LABORAL ARGENTINA Y EL RUMBO DEL NUEVO DERECHO
}

\author{
El derecho ha evolucionado, los cánones tradicionales \\ parecen hoy fórmulas muertas y anquilosadas \\ Manuel Pinto ${ }^{1}$
}

\section{Introducción}

A pesar del atraso del Poder Legislativo en dar respuesta a la Cuestión Social, el Congreso de la Nación buscó con sus limitaciones dar cuenta de la problemática por medio de generar un corpus legislativo dedicado a regular las relaciones laborales. Aunque las iniciativas represivas fueron más rápidamente adoptadas ante los desafíos que imponía la movilización y organización obrera, la insistencia de ciertos actores sociales y el desarrollo mismo del Nuevo Derecho descrito en el capítulo anterior hicieron posible contar hacia 1943 ya con importantes leyes relativas al trabajo.

El capitulo busca presentar de qué manera la evolución del Derecho Laboral impactó en la actividad legislativa al tiempo que la propia sanción por parte del Congreso Nacional impulsaba la maduración del Nuevo Derecho. Debates intelectuales y académicos fueron parte de los antecedentes que tuvieron en cuenta los legisladores a la hora de discutir sobre las posibles leyes a sancionar, pero también fueron fundamentales las posiciones que adoptaron las organizaciones obreras y patronales. En la medida en que la legislación laboral creció -en cantidad si, pero principalmente en la definición de su base doctrinaria- se fue haciendo patente la necesidad de contar con un fuero propio.

Algunas limitaciones institucionales se sumaron a las herramientas políticas con la que los legisladores lidiaban en la cotidianeidad del parlamento. La posibilidad de no dar quórum, o la negativa a desarrollar el trabajo en las comisiones -donde se produce el verdadero trabajo legislativo- alargando así los tiempos de sanción o evitando directamente la sanción de los proyectos

\footnotetext{
${ }^{1}$ PINTO Manuel, "El Contrato de Trabajo", Anales de Ciencias Jurídicas y Sociales, Tomo 2, Oliveri y Domínguez Editores, la Plata, 1927. Pp. 287
} 
legislativos sobre el trabajo atentaron contra la sanción de una legislación acorde con el desarrollo productivo del país $y$, especialmente, su zona pampeana. Tal fue el destino de los sucesivos proyectos de Código del Trabajo presentados entre 1904 y 1933. Se busca, entonces, explicar las causas de los fracasos de los proyectos haciendo hincapié en dos de ellos que fueron emblemáticos: el proyecto de Joaquín González de 1904 y el presentado en 1921 durante la administración radical en la medida en que se percibe en dicho proyecto la madurez doctrinaria del derecho Laboral.

Este proceso implicó determinar el origen del derecho laboral. La definición sobre si era posible avanzar dentro o no de la tradición civil impactó sobre las posibilidades de dotar de legislación a la relación laboral. Este debate brindado en términos académicos tanto como legislativos estaba cruzado por la cuestión del régimen federal de organización de la república. En la medida en que se trataba de materias legislativas que por la Constitución no había sido delegado en el Poder Legislativo Nacional, las provincias buscaron detener el avance sobre lo consideraban su autonomía. Los recelos contra el poder central llevaron a disputar con la Nación las potestades legislativas sobre el trabajo.

Al mismo tiempo el desarrollo del Nuevo Derecho obligó a repensar el objeto mismo de la legislación. Ya no era posible sostener dentro de la tradición civil a las nuevas leyes en la medida en que responder a esos postulados doctrinarios implicaba asumir la igualdad e las partes contratantes. Se propone mediante la legislación representar el tránsito de conversión del Derecho laboral en un derecho autónomo, escindido de la tradición civil y nutrido, entonces, por nuevas fuentes y doctrinas, en las que se destaca la doctrina del riesgo profesional, verdadero eje de la renovación legislativa. El proceso legislativo fue paralelo a los debates académicos y compartieron el mismo horizonte temporal. El recorrido propuesto entonces es el de la autonomización del Derecho Laboral. En esta trayectoria, la propuesta es detenerse en 1921 ya que ese es el año en el que se presenta el proyecto de Código del Trabajo redactado por Alejandro Unsain y avalado por el DNT y el presidente Hipólito Yrigoyen. Dicho proyecto sintetizó la legislación vigente hasta ese momento, pero fundamentalmente implicó reconocer en el Derecho Laboral a una materia autónoma 


\section{II.1 Las leyes laborales y los límites de la tradición civil}

\section{II.1.1 El Código Civil y la mercantilización del trabajo}

El Derecho Laboral argentino tiene sus orígenes a partir de los últimos años del siglo XIX y principios del siglo $X X$, y siempre estuvo vinculado su desarrollo con una idea más amplia que lo contenía, definida a grandes rasgos como el "Derecho Social". Resultado del proceso iniciado con la Revolución Industrial, el Derecho Laboral o del Trabajo fue surgiendo como oposición a la doctrina del derecho privado que predominaba en las relaciones entre los sujetos pero sin recaer en la antinomia de adscribirse al derecho público. Su desarrollo se puede seguir mediante dos vías, en primer lugar en términos legislativos mediante el rastreo de las leyes que buscaban amparar al trabajador frente a las condiciones adversas, dotándolo de cierto marco de estabilidad que lo protegía ante la vejez, accidentes, desempleo, etc. En segundo lugar el derecho del trabajo significó un cambio en términos doctrinales, dando lugar a interpretaciones de la norma que ya no se ajustaban a la idea de sociedad de iguales.

El Código Civil argentino -inspirado en el Código Napoleónico- como armazón jurídico de la nación reconoció y moldeó lo que Marx llama la forma exterior $^{2}$ y le otorgó carácter jurídico. Esta separación del trabajo y del trabajador asentada en el derecho, autorizó a obrar como si el trabajo fuese una mercancía, organizando un estatuto salarial que limitaba la mercantilización e impidió tratar al trabajador como una cosa. Si bien la libertad de los hombres estaba garantizada desde el proceso independentista de principios del siglo XIX, la libre oferta y demanda del trabajo en tanto mercancía fue un proceso que concluyó recién hacia fines del siglo XIX. Esta "formación de un mercado de trabajo (oferta y demanda de mano de obra) libre y unificado es el rasgo más distintivo de la constitución del capitalismo"3. Proceso concluido en general para fines del siglo XIX -con anterioridad en la región pampeana, aunque con mayor demora en zonas del interior-, la libre

\footnotetext{
${ }^{2}$ MARX Karl, El Capital. El Proceso de producción del capital, Tomo I, Siglo XXI Editores, Buenos Aires,2002. Especialmente los capítulos I "La mercancía" y XVII "Transformación del valor (o, en su caso del precio) de la fuerza de trabajo en salario".

${ }^{3}$ LOBATO Mirta Zaida, Los trabajadores en la era... Op. Cit. Pp.468.
} 
disposición de la mercancía trabajo estaría regida en adelante por las leyes del mercado.

Este intercambio mercantil no sólo se funda en las leyes de la oferta y la demanda, sino que implica un tercero garante de estas leyes y que al mismo tiempo regula la acción, ese tercero en la tradición occidental lo encarna el Estado $^{4}$ al construir un edificio jurídico que hace este intercambio posible. La forma que encontró el estado de garantizar el intercambio fue por medio, como queda dicho, del Código Civil, que funda su razón en el libre consentimiento de los envueltos en la relación contractual. La figura del contrato, en la tradición civil, marca claramente su pertenencia al ámbito de lo privado, en donde cada hombre es capaz, mediante el verbo, de poseer poder legislador. La preeminencia del contractualismo, es decir la idea de que el vínculo contractual sería la forma más evolucionada del compromiso social, concibe a la sociedad como un conjunto de individuos movidos en virtud del cálculo de intereses particulares. Además reafirma la idea de la igualdad de los individuos en la medida en que presupone que cuentan con la posibilidad de no aceptar el acuerdo o contrato.

Sin los imperativos unilaterales de la Ley, el contrato vincula bilateralmente a los individuos y se transforma así en la palabra suprema. Esta ficción es la que hace al contractualismo tan interesante para mediar en las relaciones laborales. Al admitir que el trabajo es una mercancía se permite su venta sin erosionar la sacralidad del cuerpo. Entonces habilita a pensar que esa venta se realiza por medio de un contrato entre dos individuos. Se construye así otra ficción en la que se asume que ambos están actuando según su propia conveniencia. En términos de una economía de mercado esta ficción permitía el desarrollo de la actividad económica bajo la idea de que los bienes intercambiados eran similares ya que su valor era fijado por las mismas leyes del mercado. El sostenimiento de estas ficciones tuvo profundas repercusiones en el desarrollo del derecho laboral.

\footnotetext{
${ }^{4}$ SUPIOT Alain, Homo Juridicus. La Función antropológica del Derecho. Buenos Aires, Siglo XXI, 2007.
} 
El vínculo laboral reconoció en el contrato de locación de servicios su forma jurídica en la tradición civil argentina. Al establecer mediante el artículo 1623 que

la locación de servicios es un contrato consensual [...] Tiene lugar cuando una de las partes se obligare a prestar un servicio y la otra pagarle por ese servicio un precio en dinero. ${ }^{5}$

El trabajo fue legalmente cosificado y pudo ser vendido como cualquier otra mercancía en tanto que su valor era fijado bajo el manto del mercado que brindaba el marco para pensar este intercambio en tanto intercambio de mercancías y no como una relación social.

Esta mercancía, en lo que respecta al Código Civil argentino sancionado en 1869, era vendida entre partes en pie de igualdad, ya que

respondía a la concepción liberal clásica por la cual dicho Código supone que la libertad de las partes contratantes (patrón-obrero) se cumplían en realidad, es decir, se encontraban en un perfecto pie de igualdad para manifestar su consentimiento ${ }^{6}$

Esta ficción, que en la forma consagrada del contrato vincula a dos partes iguales que han suscrito libremente obligaciones recíprocas, raramente se cumple en la realidad, y el contrato pasa a ser un acuerdo generador de obligaciones. Por lo tanto

esas diferentes alteraciones dejan ver el surgimiento de contratos de una nueva indole ${ }^{7}$. Su objeto primario no es intercambiar bienes determinados ni sellar una alianza entre iguales, sino legitimar el ejercicio de un poder $[\ldots]$ y se convierte en instrumento de dominación de las personas ${ }^{8}$

Al colocar la venta del trabajo, en cuanto mercancía, bajo la protección de la figura de la locación de servicios, el Código Civil Argentino inscribía la posible legislación del trabajo bajo las formas doctrinarias de la tradición civil. Esto significaba que se fundamentaba la relación laboral en términos privados, anteponiendo el contrato como legalización de la relación entre los individuos y

5 SASOT BETES Miguel Angel, Código Civil Argentino. Concordado y anotado con la jurisprudencia, Ed Economía Argentina, Buenos Aires, 1932. Capítulo VII "De la Locación de servicios", Artículo 1657 (1623) pp. 807 y sig.

"GARCÍA BOSSIO Horacio, "La Fuente Judicial y el mundo del trabajo", en Actas de las Jornadas La Fuente judicial en la construcción de la memoria, Talleres Gráficos del Poder Judicial de la Provincia de Buenos Aires, La Plata, 1999, pp. 347.

${ }^{7}$ Se refiere a los contratos instituidos bajo la doctrina liberal.

${ }^{8}$ SUPIOT Alain, op. cit. pp. 161. 
no sujetos, por lo tanto, a la ley como expresión de una voluntad general emanada del Estado'.

En este contexto, las primeras leyes obreras buscaban regular el contrato que vinculaba a las partes con las herramientas disponibles en el Código Civil o el Código Comercial $^{10}$, los dos corpus más importantes de la época que hacían referencia a la venta del trabajo. El devenir del derecho del trabajo se encargará de ir rompiendo con la tradición civil en la medida en que el tercero garante, que en la tradición civil es ocultado detrás de la ficción de las voluntades individuales que asumen los derechos y obligaciones del contrato, se hace cada vez más visible. El Estado irá asumiendo un lugar cada vez más importante como regulador de las relaciones laborales y en términos legislativos esto implicó la intervención sobre la relación contractual que liga a trabajadores y patrones.

\section{II.1.2 El contrato de trabajo y los límites de la tradición civil}

El contrato de trabajo como construcción legal siguió el molde de la tradición contractualista en el sentido de ligar a dos partes, pero se fue alejando de su contenido en lo que se refiere a sus bases doctrinarias. Este devenir lento no estuvo ajeno a las tensiones de responder a la tradición civil o intentar romper con ella y los sucesivos intentos de formalizar mediante la ley la figura del contrato de trabajo dieron cuenta de esta dialéctica. Resulta interesante señalar que el contrato de trabajo no contó con una ley específica hasta la década del setenta del siglo XX a pesar de ser un tópico abordado con insistencia en revistas especializadas. El hecho de que no haya sido formalmente promulgada una ley de contrato de trabajo durante el espacio

\footnotetext{
${ }^{9}$ Las distinciones del contrato como expresión de un derecho natural y fundante de la relación entre individuos en la sociedad civil, y la ley como emanada del estado y por lo tanto derecho positivo, pueden seguirse en el breve análisis de Norberto Bobbio. Allí el autor realiza la historización de lo que denomina la "gran dicotomía" entre público/privado, y derivado de esta, ley/contrato. BOBBIO Norberto, Estado, gobierno y sociedad. Por una teoría general de la política, FCE, México D.F., 1994.

${ }^{10}$ El Código de Comercio se enmarcaba dentro del la misma tradición legal que el Derecho Civil, por lo tanto no se trataba de una rama diferente del derecho en la medida en que sus bases son las mismas. El Código de Comercio contemplaba la cuestión de los empleados en los artículos 154 a 160 . Las modificatorias a dichos artículos constituyeron un momento importante de los debates sobre las posibilidades de conformar un Código del Trabajo. Por otro lado la fiscalización de la aplicación de esos artículos pasó a constituir una de las funciones de los Tribunales del Trabajo cuando estos fueron conformados.
} 
temporal que abarca esta tesis hace difícil sostener la idea de la existencia de antecedentes, pero aun así se pueden encontrar proyectos de ley o intentos de reforma del código civil que dan cuenta de esta problemática ${ }^{11}$.

De esta manera el contrato de trabajo se mantuvo -claro que con excepciones- ajeno a las regulaciones jurídicas concretas. Las condiciones específicas pactadas entre los patrones y los trabajadores no tenía una forma instrumental ni siquiera cuando se asumiese la locación de servicios como su marco general.

El contrato de trabajo se elaboraba, en realidad, en forma tácita, teniendo en cuenta las costumbres vigentes y las prescripciones del Código Civil. $Y$ eran precisamente "las comunmente vigentes" lo que estaba constantemente en litigio, sometidas a las presiones que intentaban modificarse en uno $u$ otro sentido ${ }^{12}$.

La ausencia de regulaciones generales establecidas por ley dejó la posibilidad de la existencia de contratos de trabajo escritos ligado a la correlación de fuerzas entre los patrones y sus trabajadores o a la buena voluntad de los patrones mismos, es decir establecido de forma, en este último caso, unilateral. Este modelo de relación individual era coherente tanto con las ideologías predominantes en el mundo del trabajo que veían en la negociación directa con el patrón la mejor herramienta para la obtención de beneficios, como con el modelo de intervención planteado por los patrones industriales que respondía a los lineamientos del paternalismo.

\footnotetext{
${ }^{11}$ El intento de reforma del Código Civil fue tratado largamente en tres tomos consecutivos de los Anales de la Facultad de Ciencias Jurídicas y Sociales entre los años 1939 y 1940 . Sólo un artículo hacía referencia a la legislación laboral y en su contenido se puede vislumbrar el rechazo que los especialistas en derecho del trabajo tenían de ser incorporados a la tradición civil. El autor del mencionado trabajo, el Dr. Benito Pérez, sostenía que "al pretenderse incluir el contrato de trabajo en el proyecto de reformas al código civil, consideramos necesario hacer algunas objeciones a la ubicación de esa figura jurídica en el cuerpo de leyes que se trata de reformar.///El código civil de Napoleón fue en el dominio de la vida jurídica la expresión perfectamente adatada de un estado social, que pronto dejará de serlo, pero que terminaba de triunfar, el de la preponderancia de las clases medias y del individualismo burgués y capitalista". En su análisis diferenciaba claramente al contrato de trabajo de el resto de las figuras contractuales del Código Civil. PÉREZ Benito, "El derecho del trabajo y la reforma del código civil", Anales de la Facultad de Ciencias Jurídicas y Sociales, Tomo XI, Talleres Gráficos Olivieri \& Domínguez, La Plata, 1940, Pp. 542 y sig. La Ley de Contrato de Trabajo se hizo esperar y recién fue sancionada 20 de Septiembre de 1974 como la Ley 20.744 impulsada por el Dr. Norberto Oscar Centeno, abogado recibido en la Universidad de La Plata, militante peronista y de fuertes vínculos con las asociaciones gremiales, trabajó incluso antes de recibirse en la Secretaría de Trabajo y Previsión durante el primer peronismo. Fue secuestrado junto con varios abogados -la mayoría laboralistas- por las Fuerzas Armadas en la Noche de las Corbatas en Mar del Plata, el 7 de Julio de 1976 y llevado a un campo de concentración de la Fuerza Aérea conocido como La Cueva. Apareció muerto días después.

${ }^{12}$ FALCON Ricardo, Op. Cit. Pp 66.
} 
Era un vacío legal que se buscaba subsanar mediante la costumbre, pero en momentos de rápidos cambios ya no era posible dejar en manos de las relaciones entre particulares la definición de una herramienta jurídica de tanta importancia para el mundo de la producción. La rigidez del Código Civil en tanto corpus canonizado del saber jurídico, era una traba a las posibilidades de sancionar una ley de contrato de trabajo que viniese a dar cuenta de estos cambios. Esta situación era percibida por diferentes actores de la vida política e institucional argentina. Expresaba en 1912 Alfredo Palacios que "el obrero, cuyo único capital es su trabajo, aparece equiparado como contratante al patrón a quien entrega su sudor" ${ }^{13}$. Si bien aceptaba la mercantilización del trabajo en tanto único capital disponible del obrero, señalaba la injusticia de creer que el intercambio con su patrón se daba en términos de igualdad. El Código Civil como marco referencial para el contrato de trabajo bajo la forma de contrato de locación de servicio era un anacronismo.

Esta situación no era exclusiva de la Argentina y los límites de la tradición civil encontraba expresión en otras realidades semejantes como la que se percibía en otra naciente polis industrial. En Brasil, por caso, ya en $1903^{14}$, Evaristo de Moraes, padre del Derecho Laboral en Brasil, reflexionaba en las páginas de un matutino paulista sobre la necesidad de superar el Derecho Civil a fin de dar respuesta a los problemas sociales. En Apontamentos de Direito Operario se preguntaba cómo podrían ser los problemas sociales productos de la modernización de la economía resueltos por "leis de outrora, que refletiam outras instituções, outras aspirações, outras situações económicas" ${ }^{15}$. Este reclamo se fundaba en la necesidad de incluir en los debates de la sanción del Código Civil ${ }^{16}$ de nuevos fundamentos legales que fuesen acordes con la problemática contemporánea. Ante quienes defendían los fundamentos

\footnotetext{
${ }^{13}$ Congreso Nacional, Diario de Sesiones de la Cámara de Diputados, Buenos Aires, 1912, Tomo I, pág.727. Citado en SURIANO Juan, Op. Cit, pp. 16

${ }^{14}$ Las líneas que se citarán a continuación del libro Apontamentos de direito operario, del abogado y jurisconsulto Evaristo de Moraes, fueron publicadas desde la fecha señalada por el periódico Correio da Manhã en forma de artículos. En 1905 la obra sería editada en forma de libro por la editorial Imprensa Nacional.

15 "Leyes de antes, que reflejaban otras instituciones, otras aspiraciones y otras situaciones económicas". Traducción propia. DE MORAES Evaristo, Apontamentos de Direito Operário, Ltr Editôra, San Pablo, 1971 (1905). Pp. 25.

${ }^{16}$ En Brasil el Código Civil recién fue sancionado en 1916, tardanza producto de la tardía proclamación de la República en relación con sus vecinos, y el mantenimiento de la esclavitud hasta 1888 que hacían imposible la materialización de sus supuestos.
} 
clásicos del mercado de trabajo -esto es, la libertad de cada individuo de vender su fuerza de trabajo por el precio y las condiciones que quisiere a quién quisiese- sostenía De Moraes "na vida industrial moderna, essa liberdade de trabalho só tem gerado a opressão e a miséria, a expoloração da operadiado e seu rebaixamento progressivo"17.

El Derecho Civil y la sociedad que representaba ya no eran compatibles con algunos de los desafíos del nuevo siglo. La problemática sobre los límites de la tradición civil no era exclusiva de la Argentina y respondía a una realidad en la que se estaban sumergiendo los países de la región a través del proceso de industrialización creciente ${ }^{18}$.

Hubo que esperar hasta 1915 para que un proyecto destinado a superar el vacío legal existente fuese presentado en el Congreso Nacional. A instancias de Departamento Nacional del Trabajo, el Poder Ejecutivo envió al Congreso de la Nación un proyecto de ley sobre contratos de trabajo. El proyecto, presentado en las páginas del Boletín del Departamento Nacional del Trabajo $(B D N T)$, se presentaba como un proyecto de complementariedad del título VI sección II del libro II del Código Civil donde se reglamentaban los contratos. Esta opción enmarcaba el proyecto de ley bajo la égida de la tradición civil, y por tanto como una ley de carácter nacional, pero en su redacción ponía ciertos reparos y dejaba en evidencia la carencia de la tradición civil para dar cuenta de la relación laboral. En su artículo cuarto el proyecto intenta dar cuenta de la precariedad que envolvía la relación entre patrones y trabajadores al sugerir que la inexistencia del contrato escrito no anulaba la relación y que el contrato podía ser probado por otras vías, incluyendo usos y costumbres de la localidad. Es decir que el proyecto reconoce la existencia del contrato de trabajo como realidad no escrita con su base en la relación existente y no en su promulgación jurídica. Esto implicaba reconocer explícitamente el atraso legislativo o la incapacidad de los legisladores de dar respuesta a los cambios percibidos no ya solamente por los actores implicados en la relación laboral

17 "en la vida industrial moderna, esa libertad de trabajo solo ha generado la opresión y la miseria, la explotación de los trabajadores y su rebajamiento progresivo". Traducción propia. DE MORAES, Op. Cit. pp 9.

${ }_{18}$ Sobre las comparaciones entre Brasil y Argentina ver STAGNARO Andrés, "Un Nuevo Derecho. Notas sobre la materialización del derecho laboral en Argentina y Brasil durante la primera mitad del siglo XX" en BARRENECHE Osvaldo y BISSO Andrés, Ayer, hoy y mañana son contemporáneos. Tradiciones, leyes y proyectos en América Latina. EDULP, La Plata, 2010. 
sino también por el staff profesional del estado vinculado a los problemas laborales.

El frustrado proyecto incluía también uno de los tópicos que acompañaría el desarrollo del Derecho del Trabajo como rama autónoma del derecho: la protección de la parte más débil. Su artículo sexto proponía como

ilícita toda clausula del contrato por la cual una de las partes abuse de la necesidad, ligereza o inexperiencia de la otra para imponerle condiciones que están en flagrante desacuerdo con las habituales de la profesión o con el valor o importancia de los servicios prestados. ${ }^{19}$

Este reconocimiento de la desigualdad, explícito en las posibilidades de incluir clausulas ilícitas, sin dudas buscaba romper con la tradición civil aun permaneciendo formalmente dentro de esta. Pero también buscaba limitar las tradiciones en pugna en las relaciones entre patrones y trabajadores. Se reconocía la existencia de contratos no escritos fundados en la desigualdad que respondía a la correlación de fuerzas que tendían a variar en el tiempo o fundados en la voluntad y capacidad del patrón de imponer las condiciones del contrato. En última instancia implicaba reconocer la precariedad del trabajador y proponer un rol para el Estado, en tanto garante del cumplimiento del contrato, como protector de una de las partes. Este tipo de intervención propuesta sin dudas se corría del eje de garante ausente que concebía la tradición contractualista.

El problema que encontraban aquí los legisladores es que en lo que atañe a las relaciones laborales no se trataba sólo de una cuestión técnica. Eran conscientes que los debates presentados en los recintos del congreso tenían amplia repercusión en las organizaciones gremiales obreras y patronales. Las quejas de los trabajadores y sus organizaciones en torno a la incapacidad del marco legal vigente para dar cuenta de su problemática eran continuas, aun cuando sostuvieran las banderas revolucionarias. La reacción de algunos diputados, como la ya citada de Palacios -entre otros miembros de un grupo mayor de la elite política argentina- era un síntoma de esta disconformidad ante los vacios legales. El atraso del derecho enmarcado en la tradición civil los llevaba a empujar en otras direcciones a fin de conformar a los cada vez más importantes obreros e incorporarlos como ciudadanos plenos.

19 "Contrato de Trabajo", en Boletín del Departamento Nacional del Trabajo № 31 Junio 31 de 1915, Talleres Gráficos A. de Martino, Buenos Aires, 1915, Pp. 190 
Los acontecimientos internacionales también darían un empuje a los cambios doctrinales del derecho. El triunfo de la Revolución Rusa y los cambios promovidos por la Revolución Mexicana -ambas experiencias profusamente estudiadas por sus contemporáneos- reformularon algunas bases del derecho y pusieron en cuestión su carácter individualista. En un estudio sobre las posibilidades de legislar sobre el contrato de trabajo de 1927 , el Dr. Manuel Pinto afirmaba que en la génesis jurídica -que definía como la lucha constante contra la injusticia- aparecen nuevos principios: citando a Menger ${ }^{20}$ coloca como un nuevo principio al socialismo jurídico, que sostiene que la organización jurídica actual ha sido impuesta por una minoría tendiente a favorecer sus intereses, y por otro lado haciendo uso de las tesis de Leon Bourgeois ${ }^{21}$ coloca como fuente de nuevos principios el solidarismo que "pone en evidencia el hecho de la solidaridad de los diferentes individuos en una sociedad, no hay acto individual que no tenga consecuencias sociales" ${ }^{22}$. Estos nuevos principios hicieron que el derecho evolucionara, haciendo de los cánones tradicionales fórmulas "muertas y anquilosadas". Por ese motivo las obligaciones y contratos, con la clásica teoría de la declaración de la voluntad y del consentimiento, no pueden servir, como normas jurídicas para regir las relaciones entre capital y trabajo.

En un sentido similar se expresaba Alfredo Palacio desde las paginas de la misma revista. En la publicación de su disertación sobre la democratización de la enseñanza -por entonces Palacio se desempeñaba como presidente de la Universidad Nacional de La Plata- hacía hincapié en el estudio de las nuevas condiciones sociales aplicadas al derecho y decía

si estudiamos el Código Civil y nos detenemos en el artículo 1197 donde se establece que las convenciones hechas en los contratos forman para las partes una regla a la cual deben someterse como a la ley misma, nos encontramos con I principio de autonomía de la voluntad consagrado por el régimen del liberalismo económico. La moderna legislación del trabajo combate esa disposición legal sosteniendo que en el contrato privado de un obrero y un capitalista, el primero no es un agente libre, y que el tiempo por el cual puede libremente vender su fuerza de trabajo, es el tiempo por

\footnotetext{
${ }^{20}$ Se refiere a MENGER Anton: El estado socialista y el derecho civil y el proletariado, 1905. Menger fue un importante jurisconsulto austríaco. Su teoría del derecho rechaza las bases naturales del derecho positivo y sostiene en cambio que el derecho es consecuencia de relaciones de poder de la sociedad.

${ }^{21}$ Ministro de sucesivos gobiernos franceses, fue delegado en las conferencias de Paris posteriores a la Primera Guerra Mundial, obteniendo el Premio Nobel de la paz en 1920.

${ }^{22}$ PINTO Manuel, El contrato... Pp. 286
} 
el cual está obligad a venderla (...) Podríamos entonces decir, aun dentro del Código, que ese contrato "libre", por el cual el obrero ha enajenado su propia libertad, es nulo porque el consentimiento otorgado en condiciones de violencia moral vicia de nulidad el contrato ${ }^{23}$

En la argumentación de Palacios se encuentran las críticas más importantes que señalan los límites de la tradición civil y aquellas que con más esmero trataban de responder los civilistas: la libertad de los trabajadores para dar su consentimiento y la desigualdad fundante de la relación trabajadorpatrón. La libertad de los individuos, centro de la ideología liberal, no podía ser cuestionada sin erosionar las bases mismas del edifico liberal.

Los cambios propuestos desde ámbitos legislativos y académicos no quedaron sólo en la crítica de los límites de la figura del contrato individual, sino que promovieron el estudio de una figura central en las relaciones laborales y que definiría en gran parte el futuro de dichas relaciones. Me refiero a la propuesta de instaurar en la Argentina los contratos colectivos de trabajo. Se trataba de un contrato inédito hasta el momento en nuestro país -aunque ya era conocido y utilizado en otros países con una más larga tradición industrialporque no se asistía ya a individuos libres dando su libre consentimiento. Era un contrato establecido entre dos figuras colectivas que representaban las partes en pugna de la relación laboral pero que además rubricaban su contrato ante la presencia explícita del tercero garante: el Estado.

En su número 39 de Octubre de 1919 el BDNT lo dedicó en su totalidad a la indagación sobre esta forma contractual. Impulsado su estudio por quien fuese su presidente interino, y promotor del Derecho del Trabajo en base al derecho comparado, el Dr. Alejandro Unsain, el contrato Colectivo del Trabajo aparecía ante la mirada de los especialistas como la herramienta que garantizaria estabilidad en las relaciones entre trabajo y capital. Entre sus beneficios se cuenta que determina en ausencia de leyes,

una norma permanente o transitoria para la realización del trabajo, y la solución de las múltiples cuestiones que trae consigo tomando el lugar de la ley misma y llevando a formulas obligatorias, que luego son

\footnotetext{
${ }^{23}$ PALACIO Alfredo, "La democratización de la enseñanza", Anales de la Facultad de Ciencias Jurídicas y Sociales de la Universidad de La Plata, Tomo V. Imprenta de la universidad de Buenos Aires, La Plata, 1930. Pp. 376.
} 
jurisprudencia, los arreglos que las circunstancias o los hechos de la industria han impuesto. ${ }^{24}$

En un contexto de extrema violencia en la represión de los movimientos obreros era meritorio el énfasis que el DNT colocaba en los Contratos Colectivos de Trabajo ya que surge de dicho proyecto como indispensable la conveniencia de dictar una ley sobre asociaciones obreras, en la medida en que contrato colectivo y sindicato eran en el mismo dos términos inseparables. El proyecto, que rompía totalmente con la tradición civil, buscaba llenar un vació legal que hiciese posible, en la concepción de los funcionarios del DNT y principalmente de Alejandro Unsain la resolución legal de los conflictos sociales ligados al mundo laboral. A pesar de que se buscó el apoyo a esta medida por parte de los empresarios, la misma no pudo ser llevada a cabo -con la excepción de la industria gráfica ${ }^{25}$ - hasta mediados de la década del treinta y establecerse como norma a partir del ascenso del peronismo. Las razones esgrimidas por la UIA, la gremial patronal consultada, para su negativa al apoyo de esta medida se basaba en dos motivos: falta de responsabilidad en las organizaciones obreras y carencia de una legislación sobre la materia. Evidentemente no compartían los empresarios el mismo entusiasmo que los funcionarios sobre las posibilidades de las leyes para solucionar o al menos menguar el conflicto.

La problemática del atraso legislativo en una sociedad que se percibia a sí misma en constante cambio modernizador y pujante llevó a la redacción y presentación de diferentes proyectos legislativos que si bien no encontraron una cálida recepción por parte de las legislaturas -tanto la nacional como las provinciales- dan cuenta de esta preocupación por renovar las bases del derecho y romper los límites de la tradición civil. En un temprano intento por sancionar una ley de accidentes de trabajo, el diputado Adrian Escobar, quien impulsó y presentó el proyecto ante la cámara de diputados, sostenía en referencia a la ciudadanía que

\footnotetext{
24 "Contrato Colectivo de Trabajo", Boletín del departamento Nacional del Trabajo N³9 Octubre de 1919, Talleres Gráficos Argentinos de J.L.Rosso, Buenos Aires, 1919. Pp.8.

${ }^{25}$ Fue en la industria gráfica donde el DNT parece haber tenido mayor llegada tanto entre las organizaciones obreras como ante la patronal. Tanto el convenio colectivo como las mediaciones en dicha industria fueron periódicamente publicadas en el Boletín del Departamento Nacional del Trabajo como ejemplo de los beneficios que tenía su intervención.
} 
esos nuevos ocupantes -los trabajadores- tiene conciencia de sus derechos, ellos buscan la protección en el Código Civil y el Código ¿qué les da? Un estado de familia que en realidad no es el de ellos, un contrato de servicios en dos artículos, con una libertad que es nominal y sin textos legales a que recurrir. ${ }^{26}$

Estos derechos de ciudadanía negados a principios del siglo $X X$ fue revertido mediante la lucha. En la teorización ya clásica realizada por Marshall en Ciudadania y Clase Social ${ }^{27}$ en torno a la ampliación de la ciudadanía, se hace hincapié en la concesión por etapas de los derechos. Estas etapas otorgaron a los hombres primero los derechos civiles, luego los políticos y finalmente los sociales. Pero omite Marshall, según Charles Tilly, como la lucha por un tipo de derechos preparó a los demandantes para luchar por los siguientes $^{28}$. La perspectiva de Tilly rompe así no sólo con la idea de cesión de derechos que se desprende de las hipótesis de Marshall, sino que permite pensar además que no se trata de un esquema predeterminado y evolutivo ${ }^{29}$, sino históricamente situado. La lucha obrera del período, no puede, por lo tanto, separarse de la sanción de las leyes referidas al trabajo. Leyes como la de accidentes de trabajo, el descanso dominical, la jornada laboral, o incluso la conformación de tribunales del trabajo eran banderas habituales de las manifestaciones obreras y conformaban parte de la batería de medidas que solicitaban a las autoridades. Esta idea de Derechos conseguidos a través de la lucha es la posición que se adopta en esta tesis, ya que la idea de la concesión impone a los actores un lugar meramente pasivo ${ }^{30}$. Al proponer esta

\footnotetext{
26 "Proyecto de Ley de Accidentes de Trabajo, presentado por el diputado A.C. Escobar (sesión del 16 de Mayo)", BDNT $N^{\circ} 13,30$ de Junio de 1910, Imprenta y casa Editora Juan A Alsina, Buenos Aires, 1910. Pp 353, cursiva mia.

${ }^{27}$ MARSHALL Thomas H, Ciudadanía y Clase social; Alianza, Madrid, 1998. La versión original en inglés data de 1950. Se trata de conferencias dictadas por Marshall en Cambridge en 1949.

28 TILLY, Charles, “¿De dónde vienen los derechos?”, Sociológica, № 55, México, 2004.

${ }^{29}$ De esta manera Tilly lleva adelante su agenda teórica de rechazar los que llama los postulados perniciosos de las ciencias sociales heredadas del siglo XIX. TILLY Charles, Grandes estructuras... Op. Cit.

${ }^{30}$ Los derechos sociales como concesión de un líder carismático ha fundado algunas de las interpretaciones historiográficas en torno al peronismo en la Argentina y el varguismo en Brasil (bajo la denominación de la "ideología da outorga"). Si bien la idea de la cesión de derechos es parte del repertorio común de los análisis de los populismos -sobre todo los populismos "clásicos"- la Revolución Mexicana exceptuó en parte a Cárdenas de este papel, aunque no de manera tajante. Los primeros en remarcar esta cesión de derechos fueron los mismos líderes, ya que esta interpretación garantizaba su propio lugar en el juego político. También aquellos que quisieron ver en los trabajadores a una masa sin conciencia política adhirieron a la tesis de los derechos desde arriba. Tal vez el exponente más importante en términos de ciudadanía que asume la posición de los derechos otorgados -sin participación de los sujetos- sea el brasilero José Murilho de Carvalho quien sostiene incluso que esta cesión de derechos por parte de
} 
perspectiva se asume plenamente la capacidad de los sujetos históricos de convertirse, así, en agentes de su propio devenir.

La lucha, en el caso del derecho del trabajo es por este reconocimiento de una profunda desigualdad fundante de la relación entre capital y trabajo ${ }^{31}$, que de esta forma, desde su génesis, rompía con la lógica liberal de la igualdad de las partes, dotando a los ordenamientos jurídicos de normas de protección informadas por principios propios. El trabajo, cosificado en la tradición civil, vuelve a representar la exteriorización de la persona, cuya dignidad física y espiritual debe ser tutelada por el Estado.

$Y$ es el Estado el que actúa como el que fija tales derechos. Mario Deveali $^{32}$, jurista especialista en derecho laboral y cercano ideológicamente a la idea del otorgamiento, sostenía que es "en aplicación de los principios de justicia social que desde hace tiempo han sido incorporados a la cultura contemporánea, como integración de los principios igualitarios afirmados por la revolución Francesa"33, que el Estado burgués sancionó la legislación laboral. De esta manera Deveali negó que se tratese de un derecho clasista, incorporándose a un debate que se dio en la época sobre la naturaleza del Derecho del Trabajo. Estos debates tuvieron lugar entre principios del siglo y la década del cuarenta, en un período en que aun el derecho laboral no había logrado ni autonomía académica ni legislativa. Uno de los sostenedores del derecho laboral como un derecho clasista en este debate fue Joaquín Coca ${ }^{34}$,

líderes limitó la ciudadanía brasilera e impidió el desarrollo de una verdadera república. MURILO DE CARVALHO José, Desenvolvimiento de la ciudadanía en Brasil, FCE, México, 1993.

${ }_{31}$ "Concepto de Derecho Laboral", material de cátedra correspondiente a la bolilla XI del programa de Derecho Laboral de la cátedra No. 1 de la Facultad de Ciencias Jurídicas y Sociales de la Universidad Nacional de La Plata, 2004.

32 Mario Deveali asumiría como profesor extraordinario en el año 1952 al frente de la Cátedra de Derecho del Trabajo y de la Previsión Social en la Facultad de Ciencias Jurídicas y Sociales de la Universidad Nacional de La Plata, cargo que sostendría incluso con posterioridad al proceso de "desperonización" de la universidad propuesto por la autodenominada "Revolución Libertadora" que expulsó de la presidencia a Juan Domingo Perón en Septiembre de 1955. Su trayectoria académica se desprende del análisis de las designaciones realizadas en la Facultad de Ciencias Jurídicas y Sociales que se publicaban periódicamente en los Anales de la Facultad de Ciencias Jurídicas y Sociales de la Universidad Nacional de La Plata.

${ }^{33}$ DEVEALI Mario, Lineamientos del Derecho del Trabajo, Tipografía Editora Argentina, Buenos Aires, 1953. Pp. 151

${ }^{34}$ El escrito de Joaquín Coca data de 1929. Como militante obrero respondió al socialismo hasta mediados de la década del cuarenta cuando se volcó al peronismo. A pesar de pertenecer a la bancada socialista, en 1937 protagoniza una de las tantas rupturas de dicha tendencia y forma el Partido Socialista Obrero, en desacuerdo con la política del "contubernio" del Partido Socialista con el gobierno conservador, que él mismo denuncia en un panfleto. 
quien veía en la legislación laboral solo un reflejo distorsionado del derecho obrero $^{35}$-como derecho de clase por excelencia-. Para Coca la burguesía como clase era incapaz de seguir funcionando como clase legislativa en la medida en que solo le interesa legislar sobre lo que ya tenía -es decir: la propiedad y su defensa- pero se veía obligada a tomar cuenta de los reclamos de un derecho obrero de clase, y en este camino lo deforma, dejándolo mutilado parcialmente.

El camino que proponía Deveali -quien comenzó su carrera en las postrimerías del debate- era reconocer en la legislación laboral un derecho especial. Por lo tanto

\begin{abstract}
de acuerdo con esta concepción, el derecho del trabajo no es un derecho de excepción que sanciona privilegios conquistados con la fuerza, sino que constituye un derecho especial, que se distingue del derecho común, especialmente porque, mientras el segundo supone la igualdad de las partes, el primero presupone una situación de desigualdad que tiende a corregir mediante otras desigualdades ${ }^{36}$
\end{abstract}

Aun desde ópticas diferentes, ambos autores coincidieron en que, ya sea como reflejo del derecho obrero, o como un derecho otorgado, el derecho del trabajo era un derecho especial, que fundaba su especialidad en la aceptación de la desigualdad que existía detrás de los contratos que regían la compra de la fuerza laboral. Aceptar esta desigualdad significaba alejarse de la ficción de que el trabajo fuese una mercadería como cualquier otra, susceptible de ingresar al mercado en la misma condición que otras mercancías.

Como Derecho especial, el Derecho Laboral se aleja de la tradición civil del contrato consensual. La relación laboral implica una red de compromisos y deja de vincular a las partes sólo por medio del salario. Según sostiene Supiot,

el Derecho Laboral de la era industrial se desarrolló en torno a tres figuras institucionales fundamentales, a las cuales corresponden tres de sus nociones básicas: la figura del Legislador y la noción de Estado providencial; la figura del empresario y la noción de empresa; la figura del asalariado y la noción de empleo. ${ }^{37}$

Obrero zapatero, logró erigir su figura como publicista a base del aprendizaje autodidacta. UNAMUNO, Miguel y CORBIERE, Emilio J., "Joaquín Coca: peronismo y socialismo en la Argentina" en COCA, Joaquín, Derecho burgués y Derecho obrero, CEAL, Buenos Aires, 1985. ${ }^{35}$ COCA, Joaquín, Op. Cit.

${ }^{36}$ DEVEALI, Mario, Op. Cit. Pp. 151.

${ }^{37}$ SUPIOT, Alain, Op. Cit. Pp. 176. 
Estas tres instituciones se relacionan, en el derecho laboral, de un modo nuevo. El Estado deja de ser simplemente el tercero garante ${ }^{38}$ y ocupa un lugar destacado en la forma que adquirirá el contrato de trabajo. A pesar de responder a la tradición contractualista, el contrato de trabajo está mediado por principios diferentes al del voluntarismo de las partes y asume en su forma una relación de interdependencia de las partes que no puede ser soslayada y que escapa a los múltiples tipos que el contrato adquiría en la tradición civil ${ }^{39}$.

En lo que respecta a las fuentes que nutren el Derecho Laboral, el esquema es el mismo que el de las fuentes generales del derecho:

1- la Ley, que comprende a la ley propiamente dicha y los reglamentos del poder ejecutivo.

2- La costumbre, los usos y la equidad: las fuentes normativas no escritas.

3- la jurisprudencia, que en el caso del Derecho Laboral se suma a la jurisprudencia judicial aquella que emana del Ministerio de Trabajo.

4- la Doctrina.

5- Los contratos individuales y los Convenios Colectivos.

La autonomía del Nuevo Derecho también debió recorrer un largo camino antes de confirmarse mediante la sanción de una ley que crease un fuero específico para entender en asuntos propios de esta rama del derecho. A las luchas obreras por lograr una mayor intervención por parte del Estado en las relaciones laborales y a los vaivenes en las salas de los ámbitos legislativos se debe sumar las peleas dadas en los sistemas universitarios por imponer al Nuevo Derecho como disciplina académica. Las figuras que ocupaban lugares de relevancia en la discusión política y académica circulaban entre estos espacios y utilizaron sus influencias para ir creando el clima que hiciese posible esta incorporación a la Carta Magna y que diese como fruto la institucionalización de un nuevo espacio de disputa para los trabajadores.

\footnotetext{
${ }^{38}$ Toda relación contractual contiene la figura de un tercero garante de dicho contrato. A partir de la secularización, ese garante es el Estado, que fija los límites de su garantía en lo que se configura como su territorio soberano.

${ }^{39}$ La definición de la naturaleza del contrato de trabajo fue también motivo de una ardua disputa académica y política. Los impulsores de la autonomía del derecho del trabajo sostenían que el contrato que vinculaba a obrero y patrón no podía ser enmarcado ni dentro de la lógica de la locación de servicios -la forma en la que generalmente legalizaba la relación productivani de ninguno de los otros tipos contractuales -venta, cambio o sociedad-. PINTO Manuel, EI contrato de... Op. Cit.
} 
En definitiva, el Derecho del Trabajo parece haber surgido no sólo de la lucha social que implicaba el avance del proceso de industrialización y complejización de la economía, sino también de las voluntades de juristas y legisladores que buscaban un desarrollo autónomo para esta rama del Derecho. Atado en sus orígenes al Derecho Civil, con el correr del tiempo se fue afianzando como un derecho nuevo, autónomo y basado en principios que le son propios y que se podría reunir en un principio rector: no distinguir entre iguales y no asimilar a los distintos ${ }^{40}$.

Los nuevos criterios que buscaban superar los principios de la legislación civil formarian parte de la mayoría de los proyectos legislativos de la primera mitad del siglo XX. Al considerar el Derecho del Trabajo como autónomo se podía cambiar el estatuto legal del trabajo, abriendo la oportunidad de que este dejase de ser sólo una mercancía. Al colocar en la dignidad humana su punto de partida y acentuar la condición humana del trabajador como tema central de sus fundamentos ${ }^{41}$, el principio que regía estos intentos era definitivamente novedoso para la época. El derecho del trabajo, como rama específica del Derecho, separado de la tradición civil, emergía de las profundidades de la vida social, de sus luchas y tensiones.

\section{II.2 La nueva legislación entre dos bases}

\section{II.2.1 La Ley 4.661 de Descanso Dominical y la cuestión de la Jurisdicción}

En términos concretos, la primera ley que tuvo como objeto al trabajo ${ }^{42}$ fue la dedicada a prohibir y, en algunos casos regular, el trabajo dominical. La ley llevo el número 4661 y fue sancionada el 31 de Agosto de 1905 y promulgada una semana después. Esta ley, largamente añorada por la población obrera, fue propuesta para su tratamiento por el entonces único diputado socialista del Congreso argentino, el Dr. Alfredo Palacios, pero en su tratamiento y posterior sanción puede haber ayudado la concepción católica del

\footnotetext{
${ }^{40}$ DEVEALI, Mario, Op Cit.

${ }^{41}$ DEVEALI, Mario, Op Cit.

${ }^{42}$ Los trabajadores y la cuestión social fueron abordadas por diferentes leyes, ver el apartado sobre Cuestión Social en este mismo capítulo. Algunas modificaciones al Código Comercial con respecto a los empleados de comercio fueron propuestas en 1903 pero sin éxito.
} 
descanso que predominaba en amplios sectores políticos vernáculos ${ }^{43}$. Esto es visible en el nombre que se le dio a la ley, ya que en la propuesta inicial de Palacios se trataba del descanso hebdomadario justamente para alejarse de la concepción católica y promoviendo en cambio que fuese un día de descanso semanal pensado no sólo para el esparcimiento -o en el caso católico reflexión y recogimiento- sino para la formación de los trabajadores ${ }^{44}$.

En el primer artículo de la ley ya se evidencia uno de los grandes problemas que tuvieron que enfrentar los legisladores al sancionar leyes laborales, referente a la jurisdicción de aplicación de esas leyes. Este debate también sería central en la definición del Derecho del Trabajo como un derecho autónomo. Dice el primer artículo de la Ley 4661:

En la Capital de la Republica Argentina queda prohibido en domingo el trabajo material por cuenta ajena y el que se efectúe con publicidad por cuenta propia, en las fabricas, talleres, casas de comercio y demás establecimientos o sitios de trabajo, sin más excepciones que las expresadas en esta ley y en los reglamentos que se dictaren para cumplirla. ${ }^{45}$

La jurisdicción de la ley, es decir, el territorio al que era aplicable, se reducía a la ciudad de Buenos Aires y a los territorios bajo la administración federal. Quedaban fuera de los marcos regulatorios de esta ley ciudades con naciente desarrollo industrial -como Rosario, La Plata, Córdoba, etc.- y gran parte de los territorios donde predominaba la producción agrícola. Estos límites en la jurisdicción de la ley tenían que ver en primer lugar con la forma federal de gobierno asumida en la Constitución de 1853 que limitaba la potestad del Congreso de la Nación para dictar leyes de materias para las que no estuviese habilitado.

La forma de gobierno federal suponía que cualquier área de legislación no explícitamente asignada a la jurisdicción federal era jurisdicción provincial. En el caso de la legislación laboral, el debate era si debía ser complementaria de los códigos civil y comercial, y por lo tanto a cargo del gobierno federal, o si se trataba de un terreno legislativo nuevo, quedando su legislación en manos

\footnotetext{
${ }^{43}$ Para referencias sobre algunos antecedentes del proyecto González ver ASPELL Marcela, "Los precedentes legislativos del primer proyecto de Ley nacional del Trabajo (1880-1904)", Revista de Historia del Derecho, $N^{\circ} 8$, Instituto de investigaciones de Historia del Derecho, Buenos Aires, 1980. La autora da cuenta de la presión de los católicos en la sanción de la ley de descanso dominical y la tradición católica argentina.

${ }^{44}$ FALCÓN Ricardo, Op. Cit.

${ }^{45}$ Anales de Legislación Argentina, Tomo 1889-1919, Buenos Aires, La Ley, s/f, Pp. 651.
} 
de las provincias. Si bien las primeras leyes sobre el trabajo aun respondían a las bases del Derecho Civil, desde sus comienzos se vieron envueltas en debates sobre su autonomización. De todas maneras la cuestión de la jurisdicción no respondía a las perspectivas del debate académico dentro del campo de los juristas, sino con un problema político derivado de de la forma de gobierno, la potestad de la Nación y las autonomías provinciales.

En este caso predominó la idea de que el gobierno federal solo podía promulgar leyes aplicables en donde su jurisdicción era efectiva y actuaba en tanto Legislatura, es decir, en la Capital Federal o en los Territorios Nacionales, ya que los legisladores provinciales se negaban a concebir estas leyes como ampliatorias del Código Civil o del Código Comercial. La posibilidad de pensar la sanción de un corpus de leyes que pudiesen ser aplicadas en todo el territorio nacional estaba atado, entonces, a la superación de estas peleas entre las autoridades nacionales y las provinciales por el control de la aplicación de dichas leyes. Al considerar las leyes laborales como partes de un derecho nuevo, los legisladores no estaban asumiendo una posición en el debate académico aun naciente, sino protegiendo la posición de poder de las provincias frente al avance de la autoridad federal. Habrá que esperar al menos hasta la sanción de la ley sobre salarios en 1923, cuando "se llega a un relativo consenso en cuanto al carácter nacional de la jurisdicción de las leyes laborales" ${ }^{46}$.

La aplicabilidad de la ley era fundamental en este rechazo de las provincias a delegar en el gobierno federal la sanción de leyes laborales de alcance nacional. La fiscalización de la aplicación de las leyes no estaba en manos de los mismos agentes que otras leyes y el poder de policía en el caso de la aplicación de la ley estaba, al menos desde 1907, en el Departamento Nacional del Trabajo. Aprobar leyes de carácter nacional implicaba necesariamente ampliar las potestades de intervención de un organismo nacional en el orden provincial, despertando aun más recelos ${ }^{47}$.

En el debate en general de la ley fue el Diputado Oliver quien sostuvo que el Congreso estaba habilitado a dictar una ley de carácter nacional ya que se

\footnotetext{
${ }^{46}$ AUZA Tomás "La legislación laboral y la complejidad del mundo del trabajo. El Departamento Nacional del Trabajo, 1913-1925" en Revista de Historia del Derecho, $\mathrm{N}^{\circ} 17$, Instituto de Investigaciones de Historia del Derecho, Buenos Aires, 1989. Pp 62 y sig.

${ }^{47}$ AUZA Tomás, La política del Estado.... Op. Cit.
} 
trataba de una modificación del Código $\mathrm{Civil}^{48}$, de una ley que propendía a la prosperidad del país y a la ilustración de la población. Estos tres objetivos, según el mismo diputado, era el que perseguía el proyecto propuesto -que en rigor era parte del Código del Trabajo elevado por el Poder ejecutivo en 1904- y por lo tanto debía ser tratada en general. Por la redacción definitiva del articulado de la ley, queda claro que la postura sostenida por Oliver no prosperó. Los argumentos de Oliver no pudieron torcer la negativa de los diputados provinciales que veían con recelo el crecimiento de las potestades federales.

La promulgación de leyes que regulasen las relaciones entre el capital y el trabajo debió, entonces, enfrentarse con el problema de la jurisdicción, y por lo tanto quedó envuelta en una larga lucha política. Con la pelea por la autonomía política de las provincias perdida en otros campos ${ }^{49}$ los representantes de las provincias en el Senado de la Nación no eran proclives a otorgar al gobierno nacional la posibilidad de legislar en cuestiones para los que la Constitución no lo habilitaba de forma explícita. Por cuestiones de índole temporal obvias, la Constitución de 1853 no habilitaba a la Nación a legislar sobre el trabajo, por lo que este espacio se presentó como un lugar donde podía aun darse la lucha por la autonomía y el federalismo. Este contexto de resentimiento hacia el poder central, puede haber influido en la negativa a promulgar legislación laboral de alcance nacional.

Esta disputa, en términos políticos, fue favorable a las provincias, que guardaron bajo su órbita legislativa la posibilidad de legislar en la materia y eso se expresó en la limitación territorial impuesta a la ley, que sólo habría de aplicarse en la Capital Federal -ni siquiera mencionó en este caso de los territorios nacionales, pero debemos tener en cuenta que la administración de

\footnotetext{
${ }^{48}$ El debate legislativo de la ley fue tratado por José Panettieri consultando los Diarios de Sesiones de la Cámara de Diputados de la Nación. Este autor realiza un interesante despliegue de algunos de los debates que dominaron la sanción de las primeras leyes del trabajo. PANETTIERI José, Las Primeras leyes obreras; CEAL, Buenos Aires, 1985.

${ }^{49} \mathrm{Si}$ bien aun no eran comunes las intervenciones a las provincias por parte del gobierno federal, a partir del gobierno de Hipólito Yrigoyen se tornarían más comunes. Este mecanismo constitucional era percibido como una injerencia en la vida política y administrativa de los estados miembros de la federación. Como herramienta política solía herir las sensibilidades de las elites gobernantes locales. A esto se suma que el entramado político familiar que sostenía el Partido Autonomista Nacional liderado por Julio Argentino Roca y que había dominado la política en el período previo estaba demostrando tener grietas que debilitaban sus bases. Ver BOTANA Natalio, El Orden conservador: la política argentina entre 1880 y 1916, Ed. Hyspamerica, Buenos Aires, 1985.
} 
justicia en dichos territorios distaba mucho de la realidad en la que estaba la ciudad de Buenos Aires ${ }^{50}$-. Definida esta cuestión en el caso de la ley 4161, las posibilidades de una ley de alcance nacional dictada por el gobierno central se vieron reducidas ya que el caso de la primera ley marcó una línea a seguir por parte del cuerpo legislativo.

La ley de descanso dominical fue tratada en forma particular a pesar de que formaba parte de un corpus mucho más abarcativo de las relaciones entre capital y trabajo. Su tratamiento particular se debió a la iniciativa del entonces diputado socialista Alfredo Palacios quien promovió al considerar que su urgencia no podía esperar el tratamiento del proyecto de Ley Nacional del Trabajo, impulsada por el entonces ministro Joaquín V. González.

\section{II.2.2 El proyecto de Código del Trabajo de Joaquín V. González}

El proyecto de González, si bien nunca fue tratado en el Congreso -ni siquiera en comisiones-, fue objeto de un amplio debate público. El rechazo a la ley de González -un verdadero Código del Trabajo- se debió a oposiciones tanto desde el campo patronal -lo consideraban pro obrero- como desde las organizaciones sindicales ${ }^{51}$.

Las oposiciones patronales esgrimían razones vinculadas al aun escaso desarrollo industrial local y las imposibilidades de cumplir con algunas de las obligaciones expuestas en la ley sin que causase perjuicio económico a la actividad industrial. La concepción paternalista que primaba entre los industriales argentinos y la búsqueda de respuestas a los conflictos dentro de ese marco ideológico los llevaba a rechazar la intromisión estatal en las

\footnotetext{
${ }^{50}$ Varios trabajos recientes han puesto en debate la línea cronológica y algunos postulados de la formación estatal argentina -y principalmente la administración de justicia- al abordar casos como los de los territorios patagónicos. RAFART, Gabriel, Tiempo de violencia en la patagonia. Bandidos, policías y jueces, 1890-1940, Buenos Aires, Prometeo, 2008. BOHOSLAVSKY, Ernesto, "Sobre los límites del control social. Estado, historia y política en la periferia argentina, 1890-1930" en DI LISCIA María Silvia y BOHOSLAVSKY Ernesto (editores), Instituciones y formas de control social en América Latina, 1840-1940. Una revisión, Buenos Aires, Prometeo, 2006.

${ }^{51}$ El Código de 1905 contaba con varios artículos referentes a la represión del movimiento huelguístico y ciertos límites a la organización obrera. Artículos represivos: 6, 7, 14, 16, 17, 28 , 46, 52 y todo el Titulo XII que afectaba el funcionamiento de los gremios y establecían límites para otorgarles personería jurídica. Los artículos 408 a 411 y 462 los que habilitaban al Poder Ejecutivo a intervenir en casos de rebelión contra los poderes públicos o las leyes, impresión de panfletos, empleo de la fuerza, atentar contra la libertad de trabajo, alterar la paz y el orden públicos, suspender el tráfico ferroviario o naval por más de diez días, etc.
} 
relaciones del trabajo. De la misma manera que rechazaban cualquier intromisión en el mercado de trabajo -considerando que así se coartaba la libertad de trabajo-, aducían que la intromisión de terceros en la relación laboral sólo podía promover conflictos y problemas. En el contexto de los debates de la ley de Código de Trabajo los terceros en discordia dentro de la familia industrial hacía referencia tanto a los sindicatos y agrupaciones gremiales como $-\mathrm{y}$ cada vez más- al Estado ${ }^{52}$.

En el campo de las organizaciones gremiales y del Partido Socialista, las reacciones fueron encontradas. Miembros prominentes del partido habían participado de diferentes etapas del proyecto, ya sea en la producción de informes, la redacción de algunos artículos o la difusión del mismo. El Partido Socialista, en su sexto congreso, decidió apoyar el despacho que Del Valle Iberlucea y Sesma redactaran como miembros de la comisión especial dedicada al Código González. Si bien se propuso un apoyo general a la ley, se ponía también el acento en los aspectos negativos que para la organización gremial presentaba la ley. Pero en el seno del partido se encontraban ferreas resistencias al proyecto de Código. Adrían Patroni, miembro prominente del ala obrera del partido sostenía que había que rechazar el proyecto ya que este no buscaba más que aplacar el espíritu revolucionario de la clase obrera $\operatorname{argentina}^{53}$.

El articulado represivo del Código que limitaba la asociación obrera fueron, tal vez, el punto más resistido del proyecto. El periódico socialista La Vanguardia reflejó parte de estos debates que se dieron en el seno del socialismo. Luis Bernard -quien después pasaría a las filas del Sindicalismo Revolucionario- rechazaba la idea que pudiese achacarse a elementos extranjeros la agitación. Estas eran una legitima respuesta de los trabajadores a la situación que el capitalismo les imponía y en consecuencia el proyecto tenía un

profundo carácter reaccionario porque al querer eliminar la protesta obrera estaba tratando de eliminar también el desarrollo normal de la

\footnotetext{
52 ROCCHI Fernando, "Un largo camino a casa: empresarios, trabajadores e identidad industrial en Argentina, 1880-1930" en SURIANO Juan (comp), La Cuestión Social en Argentina, 1870-1943, La Colmena, Buenos Aires, 2000.

${ }_{53}$ PANETTIERI José, Las primeras leyes... Op. Cit. Especialmente el capítulo III dedicado al proyecto de González.
} 
evolución industrial que era paralelo al de la emancipación de los trabajadores $^{54}$

Bernard, sostiene Falcón, no cuestionaba solamente los aspectos negativos del proyecto como la represión de los elementos agitadores, sino el hecho mismo de que el Estado legislara sobre las cuestiones del trabajo, aproximándose a las posturas sostenidas por los anarquistas, la otra ideología predominante en el mundo del trabajo en el período del debate sobre el proyecto del ministro del interior.

Pero las posibilidades de mejoramiento de las condiciones materiales y culturales de los trabajadores, preocupación central de los socialistas, impulsaba a fracciones del partido a prestar atención a los intentos legislativos del Estado. Además existía una política concreta del Poder Ejecutivo que buscaba acercarse al Partido Socialista en un intento de debilitar al radicalismo. Política que se expresaba en los discursos presidenciales y de las que el proyecto de González era una pieza fundamental. En este sentido, entonces, miembros del Partido Socialista no escaparon de esta estrategia. Así Juan Schaeffer sostendría el contrapunto con la postura de Luis Bernard. Sostenía Schaeffer que "los trabajadores no podían rechazar la intervención de la legislación en sus asuntos, porque solamente a través de ella podían obtenerse mejoras sustanciales" ${ }^{\prime \prime 5}$. De todas maneras buscaba sostener la autonomía del socialismo ante estas cuestiones aduciendo que tal apoyo no podría ser incondicional, dando lugar al rechazo de las prerrogativas represivas con las que el proyecto de González dotaba al Estado justamente en momentos en que la agitación obrera era percibida como una amenaza al Estado por parte de las elites.

El recibimiento del proyecto por parte de las organizaciones gremiales no fue favorable, con excepción de los Círculos Católicos de Obreros, que saludó el llamado al orden que contenía el proyecto ${ }^{56}$. La Unión Gremial de Trabajadores (UGT), en esos momentos dominada por los gremios de extracción socialista, rechazó la iniciativa. Su pertenencia ideológica, no podía ser de otra manera, reflejó los debates que se dieron en el seno del socialismo.

\footnotetext{
${ }^{54}$ FALCÓN Ricardo, Op Cit. Pp. 77

${ }^{55}$ FALCÓN Ricardo, Ibidém.

${ }^{56}$ ZIMMERMANN Eduardo, Los liberales reformistas... Op. Cit. Sobre el Código de González y su recepción por parte de las organizaciones obreras especialmente capítulo 8.
} 
Su rechazo fue así parcial, respondiendo a la postura de Schaeffer dentro del debate. Aunque resaltando que algunos aspectos del proyecto podían llegar a ser beneficiosos para la clase obrera, su rechazo se baso fundamentalmente en las trabas que a la organización gremial contemplaba el planeado Código.

La Federación Obrera Argentina (FOA), en tránsito a convertirse en la Federación Obrera Regional Argentina (FORA) simpatizante del anarcosindicalismo, no fue tan indulgente con el proyecto de ley y lo rechazó en todos sus planos. Uno de los argumentos esgrimidos por el IV Congreso de la FOA en donde se trató el proyecto, además de repetir en términos más duros los argumentos de la UGT en cuanto a la organización sindical, era que las disposiciones y reglamentaciones establecidas en la ley serían fácilmente eludidas por los capitalistas mientras que los trabajadores tendrían que cumplirlas fielmente $^{57}$. La FOA llegó a proponer una huelga general si era necesario a fin de evitar la sanción de la ley ${ }^{58}$.

El rechazo del anarquismo al proyecto de Código del Trabajo estaba sustentado en sus características ideológicas. Juan Suriano reseña en un artículo las razones que llevaron al anarquismo a rechazar de plano cualquier intento estatal de promover legislación obrera en general y el Código del Trabajo en particular. El liberalismo extremo detrás del Anarquismo acercó los argumentos, paradójicamente, a los que sostenía la Unión Industrial Argentina (UIA) al considerar que la intervención estatal atentaba directamente contra la libertad individual: "la autoridad encarnada por el Estado anulaba al individuo tanto desde la perspectiva jurídica como política, coartando los derechos y las libertades individuales" 59

Los anarquistas

celebraron el fracaso del proyecto como un triunfo propio, tal vez porque intuían que las razones de su relativo arraigo popular se debía a la ausencia estatal en el área socio-laboral y a la consecuente desprotección de las masas trabajadoras. ${ }^{60}$

\footnotetext{
${ }^{57}$ PANETTIERI, Op. Cit. Pp.19

${ }^{58}$ MAROTTA Sebastían, El movimiento sindical argentino, su origen y desarrollo, Buenos Aires, 1960.

${ }^{59}$ SURIANO Juan, "La oposición anarquista a la intervención estatal en las relaciones laborales" en SURIANO Juan (comp), La Cuestión Social en Argentina, 1870-1943, La Colmena, Buenos Aires, 2000. Pp. 94

${ }^{60}$ SURIANO, La oposición, Op. Cit. Pp.90
} 
La Particular visión anarquista sobre el Estado era el principal obstáculo para la aceptación de la legislación laboral:

mediante la legislación, el Estado creaba una normativa legalizadora de su acción, conformando una de las herramientas fundamentales de dominación en tanto todo el funcionamiento de la sociedad se hallaba íntimamente vinculado a la legislación.

Para la cosmovisión libertaria, la ley representaba, entonces, la sanción escrita de la costumbre emergente del orden natural. Pero como las costumbres cambiaban, la ley se convertía en un elemento perjudicial al trabar la evolución de las costumbres (...) la idea subyacente de este pensamiento era que la ley, detrás de su intento por detener las luchas populares, cristalizaba las relaciones sociales y se convertía en un factor de atraso y de freno del progreso, entendiendo en este caso por progreso la liberación de los individuos de todo lazo de explotación. Así, desde una visión absolutamente carente de matices, el proceso de creación legislativo era siempre percibido como un proceso atentatorio de las libertades individuales y, a la vez, como el producto de las elucubraciones maquiavélicas de los grupos dominantes para preservar el poder ${ }^{61 "}$

Herramienta de dominación, retén del progreso y factor de atraso, intento de detener las luchas populares. La ley, en la cosmovisión anarquista, no gozaba de buena prensa. Es interesante resaltar este último punto de intento de detener las luchas sociales que coloca a la legislación -incluso la legislación laboral- como reacción frente a las luchas sociales del período. Esta concepción de la legislación laboral como reacción era compartida con algunos socialistas. En un panfleto escrito por los anarquistas Alberto Castro y C. García Balsas se catalogaba al proyecto de González como una reacción, impulsada por el miedo, y no como una acción meditada por los legisladores. Sus objetivos eran frenar el conflicto social y disciplinar a los trabajadores: era un aspecto de la moral burguesa.

Las leyes protectoras constituyen en realidad, la más sabia y hábil maniobra que haya ideado el capitalismo para hacer que perdure en la mente de sus víctimas la errónea creencia de que conciliables son los intereses del trabajo con los del capital. ${ }^{62}$

Las posturas de ambas sindicales obreras y de las tendencias políticoideológicas más importantes del mundo obrero contemporáneas al proyecto de González concebían en última instancia a las leyes obreras como reacción ante la inevitable caída del capitalismo. La diferencia radicaba en que mientras que en el anarquismo no concebía de ninguna manera la colaboración -o incluso la

\footnotetext{
${ }^{61}$ SURIANO, La oposición...O p. Cit. Pp. 95 y sig.

${ }^{62}$ Pierre Quiroule, Para meditar. Al obrero y obrera huelguística, Buenos Aires, s/f, pags 15 y 16, citado en SURIANO, La Oposición... Op. Cit: Pp 103.
} 
aceptación- con el Estado, el socialismo veía en las leyes laborales la sedimentación de logros para los trabajadores. No quiere decir esto que el anarquismo rechazara las posibilidades de mejoramiento de la clase obrera sino que por su cosmovisión era incapaz de cristalizar sus avances en la lucha en leyes que les permitiera acumular políticamente lo logrado en cada huelga.

El proyecto de González fue producto del trabajo de varias reparticiones del gobierno ${ }^{63}$ y como se mencionó de importantes figuras del socialismo vernáculo. Los criterios que guiaban los artículos de la obra era "el de resaltar la insuficiencia de las normas tradicionales del Código Civil sobre locación de servicios frente a la necesidad de regular los nuevos fenómenos sociales"64. Pero a la ya referida oposición de instituciones gremiales obreras y patronales se sumó la conformación política del Congreso y las leyes que regulaban el funcionamiento de dicha institución -posibilidad de no dar quórum, archivo de los proyectos que pasaban dos períodos sin tratamiento-, que atentaron contra la sanción del Código del Trabajo ${ }^{65}$.

Incluso desde las aulas universitarias se rechazó la posibilidad de sancionar un Código del Trabajo en la medida en que los debates académicos aun no habían resuelto la autonomía del Derecho del Trabajo. Este punto era central para definir la cuestión de la jurisdicción, en la medida en que si se resolvía que se trataba de una rama autónoma, su sanción quedaría en manos de las legislaturas provinciales y no del Poder Legislativo Nacional. Desde las cátedras universitarias, algunos de sus máximos exponentes -como el Dr Leónidas Anastasi- aun consideraba en fecha cercana a su muerte (acontecida en 1936) que la materia no había logrado el desarrollo necesario como para ser codificada aunque parte de su equipo del trabajo no coincidía ${ }^{66}$.

El otro problema grave que se percibía desde los claustros universitarios era si la codificación constituía el mejor mecanismo para dotar de autonomía y

\footnotetext{
${ }^{63}$ Entre las fuentes que se utilizaron para su redacción se promovió el estudio de las condiciones laborales del interior del país que sería dado a conocer como el informe Bialet Massé, en referencia a su autor, el doctor Juan Bialet Massé, médico del Departamento Nacional de Higiene.

${ }^{64}$ ZIMMERMAN, E. Op Cit. pp. 179.

65 SCHJOLDEN, Line, Suing for Justice: Labor and the Courts in Argentina, 1900-1943. Berkeley, Tesis de Doctorado, Universidad de California, 2002.

${ }^{66}$ PINTO Manuel "El Derecho del Trabajo" en Anales de Ciencias Jurídicas y Sociales, Tomo VII año 1934 Imprenta de la Universidad, Buenos Aires, 1935 y PEREZ Benito, Los fueros... Op. Cit.
} 
vida propia a un cuerpo de legislación. De todas maneras, y a pesar de este rechazo a una norma general, los actores universitarios harian un gran aporte a los avances en términos de legislación, ya que muchos de los docentes de las facultades de derecho eran también legisladores u ocupaban espacios de poder dentro de la estructura estatal ${ }^{67}$.

\section{II.2.3 El Congreso: ambiente hostil a las leyes laborales}

A pesar del rechazo generado por el proyecto de Código del Trabajo, la insuficiencia de las leyes basadas en los principios del liberalismo llevaron al Congreso de la Nación a retomar algunas de las propuestas que ya habían sido esbozadas en el proyecto de Joaquín V. González. El Poder Legislativo buscó sancionar leyes que tenían como objetivo beneficiar a sectores de la población obrera o leyes que promocionaban algún tipo de medidas de bienestar social. La llegada del socialista Alfredo Palacios a la Cámara de Diputados en 1902 ya había dado a la cuestión social nuevos bríos como demuestra la sanción del descanso dominical (o hebdomadario como prefirió llamarlo Palacios), y sería él mismo quien impulsaría, aun mientras el proyecto de González se encontraba en comisiones, alguno de sus articulados como leyes particulares debido a la urgencia que percibía. Pero un factor fundamental influía en la sanción de legislación laboral.

Joaquín Coca sostenía que

la legislación del trabajo no es tampoco la manifestación de las funciones tutelares del Estado, y menos la demostración del espíritu de justicia que anima a la clase capitalista dominante, y la prueba está en que esa legislación no aparece más que en donde el proletariado en una fuerza organizada con la cual ha sabido crear e imponer su derecho en los lugares de trabajo. ${ }^{68}$

Destacaba entonces al analizar las causas de la sanción de algunas de las leyes positivas para la población obrera, el mayor beneficio que los trabajadores más organizados y con mayor capacidad de presión habían obtenido del trabajo legislativo del Congreso de la Nación. A pesar de que se trataba de un militante del socialismo, diputado durante varios períodos- y que

${ }^{67}$ Sobre el lugar que ocupaban los abogados en la estructura del poder legislativo y su rol como legisladores ver CANTÓN Dario, El Parlamento Argentino en épocas de cambio, 1890, 1916 y 1946. Ed del Instituto, Buenos Aires, 1966. Este lugar predominante de los abogados como legisladores era correlato de la formación en las aulas de la facultad de Derecho de Buenos Aires, donde se apuntaba a crear una elite política. La preeminencia de los abogados en el DNT en ZIMMERMANN, Op. Cit.

${ }^{68}$ COCA, Joaquín, Op. Cit, pp. 30. 
se debe ser cauto en la interpretación de un escrito con intereses militantes por detrás- no deja de llamar la atención este análisis de la situación de la legislación obrera. Esta percepción de la mayor capacidad de presión en el seno de una economía agroexportadora de ciertos gremios que podían influir en el humor del Congreso y obtener así mayores beneficios fue retomado en análisis posteriores por historiadores del movimiento obrero. La importancia de los gremios ligados a la economía agroexportadora quedó en evidencia con el rol cumplido por la Unión Ferroviaria, La Fraternidad y la Federación de Obreros Marítimos en el movimiento obrero hasta mediados de la década del cuarenta, ya que su posición central en el entramado económico les permitió generar aceitados lazos con los políticos de la época ${ }^{69}$.

Aun cuando Joaquín Coca diferenciaba el Derecho Obrero de la Legislación del Trabajo, a la que consideraba un pálido reflejo, pensaba que valía la pena organizarse para conseguirla y lograr su aplicación en los lugares de trabajo. La acción en el Congreso -que denominaba como una acción indirecta- tenía como finalidad reflejar también las fuerzas reales que se desenvuelven en la lucha de clases, ya que allí donde no existiese movimiento obrero no habría legislación laboral, y menos aun Derecho Obrero. Partía esta premisa de la concepción de que la lucha de clases se expresaba no solo alrededor de la ley, sino también en la ley misma.

Pero si la sanción de leyes pro obreras era consecuencia de la presión del movimiento obrero organizado, no menos cierta era la capacidad de resistencia de las entidades patronales en el campo legislativo. La acción del Congreso en la expedición de normas laborales encontraba la oposición de aquellos que veían en el avance de estas normas un ataque al desenvolvimiento de las leyes de libre mercado. Sin embargo, en el Congreso, además de los socialistas cuyas propias luchas habían dado un gran empuje a los cambios en torno a los principios del derecho-, actuaban miembros de los "liberales reformistas" y

\footnotetext{
${ }^{69}$ El rol central en el proceso organizativo que jugaron estos gremios y su capacidad de presión se desprende de las lecturas de DEL CAMPO Hugo, Sindicalismo y Peronismo. Los comienzos de un vínculo perdurable, Siglo XXI, Buenos Aires, 2005; HOROWITZ, Los sindicatos, el Estado y el surgimiento del peronismo, 1930/1946. Eduntref, Buenos Aires 2004; y TORRE Juan Carlos, La vieja guardia sindical y Perón. Sobre los orígenes del peronismo. Eudeba, Buenos Aires, 1983. Para el caso de la Federación Obrera Marítima ver CARUSO Laura, Op.Cit. Es interesante señalar que el delegado obrero a las Conferencia Internacional del Trabajo celebrada en Washington en 1919 fue el gerente gremial de La Fraternidad, el gremio que nucleaba a los trabajadores de locomotoras.
} 
aquellos que respondían al catolicismo social, que a pesar de no coincidir ni en sus diagnósticos o sus objetivos con los socialistas, buscaban limitar los efectos perniciosos de la libre concurrencia al mercado del capital y el trabajo ${ }^{70}$. La acción legislativa estaba también permeada por el mismo contexto que había puesto en evidencia la insuficiencia de los principios del derecho civil para dar cuenta de los problemas que la agenda social imponía.

De todas maneras Joaquín Coca, en el mismo escrito ya citado, daba cuenta de la desidia y hostilidad del Congreso de la Nación, que permitía "dormir" o "cajonear" los proyectos de ley. Percibía que el Congreso, como poder estatal, era incapaz de mantenerse al tanto con respecto al rápido cambio social y económico que propició la complejización de la vida económica. Este contexto de lentitud legislativa permitía hablar de "lagunas legales" en importantes áreas donde el cambio en las relaciones de producción había generado la necesidad de nuevas regulaciones legales pero que, en la percepción de los legisladores, no eran consideradas urgentes, como las leyes laborales.

Más allá de la desidia y hostilidad que podía percibir Coca, el Congreso, para poder dictar las leyes concernientes a la relación laboral, debía seguir normas institucionales que permitían aplicar mecanismos del juego político para evitar la sanción de algunas leyes. Ya de por si la adopción del modelo norteamericano de gobierno (federal republicano con división de poderes y un ejecutivo fuerte con capacidad de veto) generaba un legislativo débil e ineficaz. Algunas de estas normas institucionales dificultaban el proceso que llevaba a un proyecto a convertirse en ley. Este proceso no era sencillo, ya que al corto período de las sesiones (del $1^{\circ}$ de Mayo al $30^{\circ}$ de Septiembre), se sumaba la frecuente falta de quórum -parte del juego político que desplegaban los legisladores- que impedían el tratamiento legislativo. Esto se traducía en que las leyes que no generaban el interés personal o político de los legisladores o que no fuesen impulsadas de enfáticamente por el Ejecutivo, no lograban ser tratadas en las sesiones ordinarias o eran relegadas en el orden del día ${ }^{71}$.

\footnotetext{
${ }^{70}$ ZIMMERMAN, Eduardo, Los liberales ... Op. Cit.

${ }^{71}$ SCHJOLDEN, Op. Cit. Sobre el parlamento y su función como caja de resonancia de la política argentina a pesar de estas trabas de carácter burocráticas-políticas ver HALPERIN DONGHI Tulio, La república imposible, Ariel, Buenos Aires, 2004.
} 
Por otra parte la ley Olmedo también generaba problemas para la sanción de leyes que no contasen con el interés político necesario. Esta ley mandaba a archivar los proyectos de leyes que no habían sido promulgadas en dos períodos consecutivos del legislativo. El archivo de un proyecto significaba que este debía ser presentado nuevamente para ser propuesto su debate, con lo que el círculo vicioso que llevaba a desestimar los proyectos que no contasen con el aval de la cantidad necesaria de legisladores como para poder ser tratado se cerraba ${ }^{72}$.

De todas maneras hay que tener en cuenta que las negociaciones más importantes del movimiento obrero no buscaban como interlocutor estatal al Poder Legislativo sino el Ejecutivo ${ }^{73}$. No sorprende que los intentos por constituir códigos de la materia hayan sido ignorados por el parlamento incluso cuando fueron parte de proyectos presentados por miembros del mismo partido que dominaba el Poder Ejecutivo, como lo fueron los proyectos presentados durante los gobiernos radicales. De hecho todos los intentos por promulgar un Código de Trabajo encontraron en el Congreso su fin, y los que se presentaron entre 1904 y 1941 nunca fueron considerados por las cámaras ${ }^{74}$. Los artículos que conformaron alguno de estos proyectos fueron aprobados como leyes particulares desde el momento de la discusión del primer proyecto, que correspondió al que presentó el ministro del interior del presidente Julio Argentino Roca en 1904, Joaquín V. González.

Al proyecto presentado por González, y que tuvo amplia difusión y discusión en la prensa y en las organizaciones obreras, le siguió el proyecto del ministro Gómez -redactado por Alejandro Unsain-, enviado a la Cámara de Diputados por el presidente Yrigoyen en Junio de 1921, que estaba estructurado sobre leyes y proyectos de ley elaborados por la administración radical y que contenía significativos avances en las posiciones pro-obreras -

\footnotetext{
${ }^{72}$ Esto produjo que los proyectos de sanción de un Código del Trabajo fuesen presentados varias veces. ASPELL DE YANZI FERREIRA, Marcela, "Los proyectos de Código de Trabajo presentados a las cámaras del Congreso Nacional, 1904-1974" en Cuadernos de Historia №3, Academia Nacional de Derecho y Ciencias Sociales de Córdoba, Córdoba, 1993.

${ }^{73}$ Los vínculos de los líderes sindicales con el Estado eran habituales aunque no necesariamente se daba por medio de los canales institucionales que se planteaban desde la organización administrativa del mismo Estado -por ejemplo mediante el Departamento Nacional del Trabajo-. Ver HOROWITZ Joel, Op. Cit. GAUDIO Ricardo y PILONE Jorge, "Estado y relaciones laborales en el período previo al surgimiento del peronismo, 1935-1943", Desarrollo Económico, Vol. 24, № 94, Buenos Aires, 1984.

${ }^{74}$ ASPELL DE YANZI FERREIRA Marcela, Los proyectos... Op. Cit.
} 
incluía ni más ni menos que el derecho a huelga-. A este proyecto lo sucedió uno más en 1928, basado en su antecesor, presentado por el diputado radical Diego Luís Molinari, que llegó a las instancias de evaluación en la Comisión de Legislación pero tampoco fue tratado. Estos dos proyectos se basaban sin dudas en la presentación del Proyecto de González, pero, a diferencia de aquél, no contaba ya con el articulado represivo que limitaba la acción gremial - la organización de los trabajadores.

En 1933, un proyecto más ambicioso, redactado por el titular de Legislación del Trabajo de la Facultad de Derecho de la Universidad de Buenos Aires, Carlos Saavedra Lamas, fue tomado por el Poder Ejecutivo bajo la presidencia de Justo y enviado al congreso para su tramitación parlamentaria. Este proyecto fue presentado al congreso de manera paralela a la afirmación de la autoridad del Departamento Nacional del Trabajo a mediados de la década del treinta, pero como los proyectos anteriores, no corrió mejor suerte y nunca fue tratado, tal vez por su propia ambición. Por último, en 1941 el diputado Pío Pandolfo intentó darle curso legislativo nuevamente al proyecto de Saavedra Lamas con algunas modificaciones, pero a pesar de ser girado a la Comisión Especial del Código de Trabajo, corrió la misma suerte que el proyecto original.

Esta negativa del Congreso a tratar la sanción de un Código del Trabajo intentó ser suplida con la sanción de partes de estos proyectos o de algunos de sus artículos en forma particular, pero

aun así, el vacío en la legislación específica de la materia es notable y no logra ser solucionado sino hasta la cuarta década de nuestro siglo, pese a la multiplicación de leyes que, sobre aspectos puntuales del trabajo comienzan a sancionar las Cámaras del Congreso Nacional a partir de 1905, año en que se aprueba la primera ley laboral relativa al descanso dominical $^{75}$.

A las razones que podía esgrimir Joaquín Coca sobre la desidia y el desinterés en su crítica contemporánea al Congreso de la Nación, o las que elaboran con posterioridad en su investigación Aspell de Yanzi Ferreira para la negativa a tratar un Código del Trabajo, se puede sumar una cuestión referida a los cambios en la propia cultura jurídica. Es menester recordar que desde principios del siglo XX, los Códigos como el texto por antonomasia de los

${ }^{75}$ ASPELL DE YANZI FERREIRA, Los proyectos... Op. Cit. pp. 77. 
estudios legales estaban en plena crisis y su exégesis legal era atacada principalmente desde las huestes del positivismo reinante en la enseñanza del Derecho en los claustros universitarios.

La cultura del código que predominó desde fines del siglo XIX, hace de éste el objeto preferente o exclusivo de estudio. El Código imponía a los juristas una fuente de conocimientos, un modo de razonar que se trasluce en la enseñanza y en la práctica judicial y por lo tanto hacía carecer de interés una comparación entre el código y la cambiante vida social. Los códigos se convierten así en arquetipo de derecho, en ellos se hallaba la ciencia jurídica ${ }^{76}$. Sin embargo esta visión del derecho positivo estaba inmersa en una profunda crisis en las primeras décadas del siglo $X X$, lo que tal vez impidió que la legislación laboral tomara forma como un Código.

A pesar de todos estos contratiempos el Congreso de la Nación sancionó otras leyes laborales, aunque con las mismas limitaciones que la ley 4661 de Descanso Dominical. La ley reglamentaria del trabajo de las mujeres y los niños fue una de estas leyes. Fue votada el 30 de Septiembre de 1907 y entró en vigencia ese mismo año a pesar de la oposición de los empresarios. El caso de la protección de los trabajadores menores y de las mujeres respondía también a cuestiones ligadas a la universalización de la ciudadanía en la medida en que las medidas protectoras se sostenían sobre la desigualdad y basados en el rol que recluía a las mujeres en el hogar, sin otorgarles derechos políticos $^{77}$. La UIA, sostuvo su posición a esta altura tradicional de oposición a la legislación obrera: el aumento de los coste de producción hacían inviable el proyecto del diputado Palacios ya que obligaría a varios establecimientos a cerrar las puertas. Además aducían que se privaba a los niños de acceder a un trabajo que era vital para las economías familiares obreras. Este rechazo fue escuchado en la reunión que miembros de la UIA tuvieron con diputados de la Comisión de Legislación y que llevó a ciertas modificaciones en el proyecto entre otros disminución de los días de licencia por maternidad ${ }^{78}$. Finalmente el

\footnotetext{
${ }^{76}$ TAU ANZOÁTEGUI Víctor, Op. Cit.

${ }^{77}$ LOBATO Mirta Zaida, "Entre la protección y la exclusión: discurso maternal y protección de la mujer obrera, argentina 1890-1934" en SURIANO Juan (comp), La Cuestión Social en Argentina, 1870-1943, La Colmena, Buenos Aires, 2000.

${ }^{78}$ PANETTIERI José, Las primeras leyes... Op. Cit Capítulo V.
} 
proyecto sería aprobado y constituiría un antecedente importante en la legislación laboral argentina.

II.2.4 La Ley de Accidentes de Trabajo, el Derecho del Trabajo elige su bando

Un avance significativo en la legislación laboral lo constituyó la ley 9688 de Accidentes de Trabajo sancionada en 1915. Ley largamente estudiada ${ }^{79}$ y debatida tanto en ámbitos académicos como en ámbitos legislativos y judiciales, su sanción significó un verdadero triunfo para el polo obrero de la relación laboral. La sanción de esta ley ratificó de forma definitiva la noción de riesgo profesional. Esto implicaba que el patrón debía demostrar legalmente que el accidente había sido causado por la negligencia del obrero y no por deficiencias de las condiciones de trabajo imperantes en su establecimiento o naturales de algunas actividades. Por primera vez al invertir la carga de la prueba, el patrón acusado era considerado culpable en tanto y en cuanto no pudiese probar su inocencia. La ley sancionada en 1915 venía a ratificar fallos judiciales que ya se aplicaban en base a estos principios. Estos fallos -que ya habían sentado jurisprudencia- fueron dictados por primera vez por el juez Ernesto Quesada en 1903, aunque en sus primeros intentos el Dr. Quesada debió ver como sus fallos eran rechazados en las instancias de apelación. Estos fallos sentaron las bases de lo que conoció como la interpretación sociológica del derecho, fenómeno estudiado por Line Schjolden ${ }^{80}$.

La negativa del Congreso, por cuestiones de índole institucional así como política, a tratar proyectos de leyes laborales generó, entonces, un vacio en el campo de la legislación laboral. A pesar de la influencia de los liberales reformistas, los católicos sociales y los socialistas, y a pesar del contexto internacional -marcado por las conferencias internacionales y la adhesión de la Argentina a la OIT- se generó una laguna legal. Fue en esta "laguna legal" que los jueces jugaron un rol importante en la construcción legal e institucional de la Argentina moderna, sobre todo mediante la interpretación de las leyes y el

\footnotetext{
${ }^{79}$ La cuestión de los accidentes del trabajo tuvieron lugar en todos los Boletines del Departamento Nacional del Trabajo desde su creación en 1907 y esta institución llevo adelante un arduo trabajo estadístico sobre los accidentes de trabajo en la Capital Federal que publicaba también de manera períodica. Incluso el $\mathrm{N}^{\circ} 20$ del Boletín estuvo enteramente dedicado a los accidentes del trabajo

${ }^{80}$ SCHJOLDEN Line, Op. Cit. Especialmente el capítulo 2.
} 
asentamiento de jurisprudencia. Respondiendo a una situación cada vez más conflictiva entre capital y trabajo, los jueces buscaron encauzar el conflicto social a través de las estructuras institucionales que representaban los tribunales. La obligación de los jueces de expedirse en todos los casos presentados en su jurado que imponía el artículo 16 del Código Civil, incluso cuando no había legislación sobre el tema, los respaldaba a la hora de realizar interpretaciones análogas de la constitución o de los códigos sin el respaldo de leyes específicas tal como evidencia el caso de los fallos del Juez Quesada.

La voluntad de algunos jueces por dar cuenta del vacío legal no podía suplir la ausencia de una ley que era percibida caca vez más como fundamental. La situación de las familias obreras ante la muerte o invalidez de alguno de sus miembros ponía en jaque toda su estructura de reproducción y dejaba en evidencia las injusticias del proceso de modernización de la región pampeana. Nada impedía que los trabajadores víctimas de un accidente acudieran a las instituciones judiciales a fin de reclamar el pago de indemnizaciones, pero estos procesos solían ser largos y costosos -muy por encima de las posibilidades de una familia obrera- y generaban que los mismos trabajadores no acudiesen a estas instancias, optando por esperar algún resarcimiento voluntario por parte de sus patrones ${ }^{81}$.
Asi era como en los pocos juicios habidos al respecto, el obrero víctima de un accidente, como ser la explosión de una caldera, la rotura de un andamiaje de débil construcción, o cualquier otro, era generalmente condenado en las costas, porque el patrón demandado, además de demostrar que el caso era enteramente ajeno a toda previsión, por mediata que fuera, llegaba también a probar -por medio de testigos fáciles de conseguir- que en el accidente había existido negligencia o culpa del obrero. ${ }^{82}$

Semejante desventaja en el ámbito judicial alejaba a los trabajadores del estrado. En tanto las condiciones establecidas para entablar juicio en caso de accidente permanecieran atadas a la concepción que aquél que iniciaba el juicio debía demostrar la culpabilidad del acusado -en estos casos el patrón-,

\footnotetext{
${ }^{81}$ AUZA Néstor Tomás, "El rostro del dolor en el trabajo industrial. La legislación protectora de accidentes y enfermedades del trabajo" en Revista de Historia del Derecho, №19, Instituto de Investigaciones de Historia del Derecho, Buenos Aires, 1991. La peregrinación de los trabajadores del campo para lograr el resarcimiento en casos de accidentes en BARANDIARAN Luciano, Estado y trabajo. Las políticas públicas y los trabajadores rurales pampeanos en los inicios del estado "interventor" (1925-1950), Tesis doctoral inédita, Universidad Nacional del Centro de la Provincia de Buenos Aires, Tandil, 2008.

${ }^{82}$ PANETTIERI José, Las primeras leyes... Op. Cit. Pp. 54.
} 
la igualdad jurídica entre las dos partes jugaba como una carta desfavorable para el más débil en la relación. La capacidad extrajudicial del patrón de lograr los testimonios necesarios para evadir cualquier cargo y culpa -testimonio incluso de los mismos compañeros de trabajo del obrero accidentado- excluía de facto la posibilidad concreta de los trabajadores de acudir a la justicia en búsqueda de un resarcimiento ante la fatalidad de un accidente.

La inclusión de la doctrina del riesgo profesional fue fundamental para la legislación laboral argentina. Su sanción legislativa indicó un primer paso, mediante la inversión de la carga de la prueba, en la consideración de desigualar judicialmente para igualar sujetos desiguales. Es decir que rompía con la idea de que los participantes en la relación laboral eran iguales. Si bien permanecieron las barreras que los fueros tradicionales (civil, penal y comercial) colocaban a los trabajadores -principalmente los altos costos de llevar adelante un juicio- la inversión de la carga de la prueba que implicaba el riesgo profesional obligaba al patrón a demostrar fehacientemente la negligencia por parte del trabajador. Por otra parte la inclusión de la doctrina del riesgo profesional abrió todo una nueva gama de perspectivas sobre las que el trabajador podía iniciar demandas contra sus empleadores en tanto "amplió el campo de los accidentes indemnizables y posibilitó la reparación de un variado arco de dolencias y enfermedades profesionales con un resarcimiento económico" ${ }^{\prime 83}$.

El $\mathrm{DNT}^{84}$ decidió dedicar un número completo de su publicación a los accidentes de trabajo "elección de tema que se justifica por el crecido número de proyectos de ley que en todo tiempo se han presentado a consideración del Congreso Argentino"85. El número especial puede ser percibido como la voluntad de profundizar monográficamente sobre una temática que el DNT

83 RAMACCIOTTI Karina Inés, "De la culpa al seguro. La Ley de Accidentes del Trabajo, Argentina (1915-1955)" en Mundos do Trabalho, Vol 3, $\mathrm{N}^{\circ} 5$, janeiro-junho de 2011, p266284.Publicación electrónica del GT Mundos do Trabalho, Sp, Brasil. Pp. 270.

${ }^{84}$ Desde enero de 1912 y hasta la sanción de la Ley orgánica de la institución ese mismo año -que llevó por número 8999 y reglamentada en enero de 1913- el DNT por decreto administrativo pasó a denominarse Dirección General del Trabajo. A fines de simplificar el desarrollo de la tesis se continuará mencionando a esta dirección como DNT. No así en el caso de la cita de su publicación periódica que será referido oportunamente cuando se trate del Boletín de la Dirección General del Trabajo, aunque debe tenerse en cuenta que la numeración y periodicidad con respecto al Boletín Del Departamento Nacional del Trabajo no se interrumpe ${ }^{85}$ Boletín de la Dirección General del Trabajo, №20, Julio 31 de 1912, Dirección General del Trabajo, Buenos Aires, 1912. Pp.3 
venía trabajando desde su conformación. Por lo tanto también vino a ordenar lo producido hasta entonces rescatando los aportes que en los números anteriores se había realizado a la materia, destacándose la publicación de las leyes de accidentes de otros países, proyectos legislativos nacionales, las estadísticas sobre accidentes en la Capital Federal, las cuestiones referidas a las contrataciones de seguros obreros y la jurisprudencia argentina sobre los accidentes de trabajo $^{66}$, entre otros temas.

Como quedó mencionado interesa destacar la inclusión legislativa de la doctrina del riesgo profesional en la ley de accidentes de trabajo de 1915. Será Alejandro Ruzzo quien desde las páginas del $\mathrm{N}^{\circ} 20$ del $B D N T$ presente la constitución de esta doctrina fundamental para la autonomización del Derecho del Trabajo de la tradición civil. La Teoría de la culpa predominante en la tradición civil resultaba anacrónica para la realidad industrialista de la Argentina de las primeras décadas del siglo XX. Sostenía Ruzzo sobre la teoría de la culpa:

no tanto como la teoría como un principio, resulta funesta en su aplicación a casos de accidentes del trabajo, sino también en su faz práctica y ante el régimen procesal, al exigir a la víctima la prueba de un hecho, de una negligencia y más aun, de una omisión o mala fe, como causa de su derecho ${ }^{87}$

La teoría de la culpa en caso de accidentes de trabajo era la razón fundamental del poco uso que los trabajadores hacían de los tribunales ordinarios para buscar resarcimiento económico en caso de accidente. Era también, según las amargas referencias que aparecen en los sucesivos números del BDNT referido anteriormente, el motivo por el cual los obreros no denunciaban los accidentes en dicha institución, produciendo deficiencias en las estadísticas que elaboraba. El reemplazo de la teoría de la culpa por el de riesgo profesional finalmente incluida como base de la ley de accidentes de trabajo de 1915 "confirmaba la evolución de la doctrina jurídica sobre el tema" 88 , pero fundamentalmente colocaba una piedra basal sobre la que se constituiría el Derecho del Trabajo. No fue sólo el punto de llegada de la

\footnotetext{
${ }^{86}$ En este último punto se destacan las sentencias del juez Quesada referidas previamente en este capítulo. Ver Boletín del Departamento Nacional del Trabajo, № 16 y 17 del año 1911.

${ }^{87}$ RUZO Alejandro, "Fundamentos jurídicos del riesgo profesional" en Boletín de la Dirección General del Trabajo, №20 Julio 31 de 1912, Dirección General del Trabajo, Buenos Aires, 1912. Pp.12

${ }^{88}$ ZIMMERMANN Eduardo, Los liberales reformistas... Op. Cit. Pp. 194.
} 
evolución, sino un verdadero punto de partida. Ejemplificaba la forma en la que el derecho se nutría de la realidad social para construir el derecho positivo.

Es interesante resaltar este último punto ya que en parte la hipótesis que sostiene Eduardo Zimmmermann con respecto al avance de la legislación social tiende a matizar aquellas sostenidas en otros trabajos fundamentalmente en los de José Panettieri y Juan Suriano ${ }^{89}$ - de que los avances en la legislación social respondían a los temores que en fracciones de la elite dirigente despertaron las posibilidades de organización obrera, para oponer una perspectiva que dé cuenta más de las evoluciones propias del ámbito académico o como conjunto de ideas. Se puede sostener que el trabajo de Alejandro Ruzo, en tanto intento de sintetización da efectivamente cuenta de la evolución de la doctrina de riesgo profesional como consecuencia de un avance del campo. Las pretensiones academicistas de los funcionarios del DNT -proyectado como un organismo técnico- no podía menos que impulsar a Ruzo a dar los antecedentes del caso, pero llama la atención la forma en la que presenta la teoría del riesgo profesional. Dice Ruzo:

acerca de esta teoría, un orador sostenía que "sin verdadera base en el derecho, ha acabado por triunfar en las leyes". Ella procede, en efecto, de un modo más directo de las ciencias económicas y considera principalmente al desarrollo del trabajo en la grande industria. ${ }^{90}$

Esta sentencia es un reconocimiento explícito por parte de Ruzo de la influencia que la vida material externa a la simple evolución de las ideas jurídicas, tuvo en la constitución del riesgo profesional. Sus cuidadas palabras en torno a la pertenencia de la legislación social al ámbito del Código Civil y su tradición que refleja en las primeras páginas de su escrito encuentra en su punto más crítico un fuerte contraste con la realidad en la que se sumerge la teoría del riesgo profesional, haciendo suyas las palabras del anónimo orador de que esta teoría, no proviene del derecho. No hay dudas de que el campo profesional del derecho sintió el impacto desde fines del siglo XIX de las propuestas de las ciencias sociales, pero estas transformaciones fueron consecuencia de la necesidad de aggiornar el derecho a la realidad en la que se desenvolvían sus consecuencias prácticas. En esta declaración de Ruzo se

89 PANETTIERI José, Los Trabajadores... Op. Cit. y SURIANO Juan, "Introduccion" en SURIANO Juan (comp.), La Cuestión Social... Op. Cit.

${ }^{90}$ RUZO Alejandro, Op. Cit. Pp. 16. 
encuentra además uno de los primeros pasos del derecho del Trabajo en su búsqueda de dar respuestas concretas a los trabajadores escapando de la fría letra de la ley y otorgándole a estas una vinculación más estrecha con el contexto histórico.

Por otro lado el surgimiento del riesgo profesional por fuera de las fuentes establecidas del derecho sería una marca de nacimiento con la que debió -y debe- cargar el Derecho del Trabajo. En tanto sus orígenes se encuentran fuera del derecho su conformación como campo autónomo estará supeditado a la posibilidad de vencer el rechazo apriorístico que dentro del campo jurídico encontró en tanto quedó subsumido en la jerarquía interior del campo detrás de otras ramas consideradas tradicionales. Este estigma será importante incluso en el retraso de la conformación de los Tribunales del Trabajo en tanto una medida institucional como esa implica la aceptación del derecho del Trabajo como rama del derecho en pie de igualdad con las tradicionales (civil, penal, comercial).

Retomando el texto de Alejandro Ruzo es importante resaltar la posición que adopta ante las críticas que la naciente legislación social recibía de actores políticos conservadores. Las implicancias que la aplicación procesal del riesgo profesional tenía sobre los fundamentos de la igualdad ante la ley al asumir la existencia de un sujeto a ser resguardado por la ley (uno de los motivos por el cual esta teoría provenía por fuera del derecho tradicional) y la presencia de figuras importantes del socialismo vernáculo detrás de las primeras leyes laborales, llevó a que el derecho del trabajo fuese considerado de matriz socialista.

Esta conceptualización partía de la voluntad explícita de desacreditar los intentos por promulgar leyes laborales mediante la construcción de la imposibilidad de sostener un sistema capitalista ante el imperio de las leyes laborales. Es en este sentido que Ruzo rechazará la posibilidad de concebir a la teoría del riesgo profesional dentro de un derecho socialista ${ }^{91}$.

No recibe inspiración alguna de las doctrinas socialistas y se adapta más, por el contrario, a la concepción capitalista de las industrias. Una empresa implica el ejercicio prolongado e intenso de la producción, bajo una dirección inteligente, representada por el empresario. Este recibe

\footnotetext{
91 Los debates en torno a si el derecho laboral era un derecho obrero o clasista estarán presente durante todo el período que abarca esta tesis.
} 
todas las utilidades de la producción; reúne las fuerzas convergentes de la empresa, sintetizadas por el concurso de la materia prima y de la fuerza individual de cada obrero; asume finalmente, todos los riesgos, siendo uno de ellos el que dimana de los accidentes ${ }^{92}$

Asumirse como patrón exigía, entonces y dentro del marco del capitalismo, deberes y obligaciones, los riesgos tanto como lo beneficios. De esta manera la doctrina del riesgo profesional indicaba como inherente al desarrollo de cualquier actividad económica como patrón la aceptación de la responsabilidad ilimitada por sobre las condiciones en las que el obrero realizaba las tareas y la responsabilidad de velar sobre los derechos de los trabajadores en caso de sufrir estos accidentes y enfermedades.

A pesar de tratarse de la ley que mayor impacto tendría sobre la construcción de la legislación protectora de uno de los dos polos de la relación laboral, la organización patronal industrial no puso demasiados reparos ante la posibilidad de la sanción de esta ley. Los argumentos esgrimidos por la UIA en ocasión de la discusión parlamentaria de los diversos proyectos legislativos apuntan a construir la imagen de la imposibilidad de sostener la producción ante las exigencias exageradas de las leyes laborales (trabajo de mujeres y niños, extensión de las jornadas laborales, descanso semanal, etc.). En el caso concreto de los diversos proyectos de ley de accidentes de trabajo la UIA mostraba una mejor predisposición a parte del articulado de los proyectos, sobre todo porque la contratación de seguros, en el caso de la ciudad de Buenos Aires y parte de la provincia de Buenos Aires, era ya una práctica extendida ${ }^{93}$. De todas maneras propiciaban el pago de los seguros descontados del salario obrero, lo que implicaba en términos reales la desafección del patrón como responsable, a pesar de que era aceptado ilimitada y explícitamente en el texto del proyecto de ley que elevaran al ministro de Agricultura, el Dr. Ramos Mejia.

Además del impacto doctrinario con implicancias reales en los aspectos procedimentales -la inversión de la carga de la prueba- los debates sobre la ley del trabajo iban asociadas generalmente a las necesidad de implementar un fuero específico que atendiese a los objetivos que la sanción de una ley como esta implicaba. En los antecedentes que recogió el DNT durante estos años de

\footnotetext{
${ }^{92}$ RUZO Alejandro, Op. Cit. Pp. 17.

${ }^{93}$ AUZA Néstor Tomás, El rostro del dolor... Op. Cit.
} 
la legislación extranjera -principalmente europea- las referencias a la existencia de tribunales de aplicación especializados saltaba a la vista. Sin embargo aun no eran del todo corrientes estas necesidades en el ámbito legislativo. En el convulsionado año de 1910 el diputado Francisco Guash Leguizamón envió un proyecto para dotar al DNT de una ley orgánica. En los antecedente del proyecto refería los cambios en los que se encontraba transitando la Argentina y hacía especial referencia a los accidentes en el ámbito laboral. Decía Guash Leguizamón: "la producción extraordinaria de accidentes de toda naturaleza, en muchos de los cuales debiera la justicia criminal intervenir con energía" ${ }^{\prime 4}$. Las posibilidades de aplicación de la ley ante accidentes de trabajo debían corresponder al fuero criminal y no había referencia a la chance de constituir un fuero específico. La ley 9688 también cambiaría el rumbo de este debate y, como se verá en el capítulo siguiente, daría nacimiento al fuero del trabajo.

II.2.5 El proyecto de Código de Trabajo de 1921. La sintetización del Nuevo Derecho

El primer gobierno nacido del voto universal de los varones correspondió a una fuerza política que venía a cambiar los paradigmas de construcción política. En este sentido las relaciones establecidas con las organizaciones obreras también sufrirían cambios destinados a profundizar relaciones de corte personalista entre los sindicatos y las autoridades del Poder Ejecutivo. Aun así el gobierno radical del Hipólito Yrigoyen sería el promotor, como ya se mencionó, de un proyecto de Código de Trabajo que comprendía los avances más significativos en materia de legislación laboral y excluía el articulado represivo que había sellado la suerte del proyecto González quince años antes.

Sin embargo la ambigüedad del gobierno radical de Yrigoyen en torno a la cuestión laboral terminó por sellar la suerte de este proyecto, al igual que había sucedido con su sucesor. Si bien el Proyecto de Código del Trabajo fue impulsado por el Poder Ejecutivo Nacional buscando dar una respuesta alejada de la aleatoria intervención estatal en los conflictos, el marco de represión de los años 1920-1921 no fueron de ayuda a la hora de lograr el apoyo de las

${ }^{94}$ Boletín del Departamento Nacional del Trabajo,N¹3, Junio 30 de 1910, Departamento Nacional del Trabajo, Buenos Aires, 1910, Pp.343. 
centrales obreras al proyecto. De hecho ambas centrales se encontraban intervenidas e Yrigoyen había deshecho el estrecho vínculo que lo ligaba a la Federación Obrera Marítima95 ${ }^{95}$ Sin embargo el proyecto fue producto del impulso que los conflictos obrero patronales tuvieron durante esos años, y principalmente por la huelga general declarada en la ciudad de Buenos Aires ese mismo mes de Junio ${ }^{96}$.

El proyecto dio por cerrado algunos debate en torno a la legislación laboral como el referido a la jurisdicción de las leyes laborales. Principalmente sostenía en su artículo tercero que

todas las disposiciones del presente código que alteren, modifiquen, anulen o complementen las disposiciones del Código Civil sobre locación de servicios, serán consideradas como nacionales ${ }^{97}$.

La filiación con el Código Civil permitía la sanción del Código del Trabajo con aplicación nacional sin tener que ahondar en la disputa sobre el federalismo en la medida en que se proponía el corpus legislativo como modificaciones del Código Civil y por tanto potestad legislativa nacional, dejando en manos de las autoridades locales las cuestiones de aplicación. Sin embargo dotaba al DNT de herramientas tendientes a fortalecer su presencia en todo el territorio nacional mediante la ampliación de sus atribuciones. Entre otras el proyecto garantizaba al DNT un presupuesto ampliado por el cobro de las multas, cuyos montos, salvo indicación contraria, se depositarría a cuenta del DNT para su funcionamiento.

El proyecto de 1921 era una verdadera síntesis ${ }^{98}$ de los diferentes proyectos legislativos en torno al trabajo del gobierno radical (jornada de

\footnotetext{
${ }^{95}$ GARGUíN Enrique, "Relaciones entre estado y sindicatos durante los gobiernos radicales, 1916-1930" en PANETTIERI José (comp.), Argentina: trabajadores entre dos guerras, Eudeba, Buenos Aires, 2000.

${ }_{96}$ CARUSO Laura, "La política laboral argentina en la inmediata posguerra: una perspectiva internacional, 1907-1925", Relaciones. Estudios de Historia y Sociedad, Michoacán, en prensa

97 "Proyecto de Código del Trabajo", Boletín del Departamento Nacional del Trabajo, $\mathrm{N}^{\circ} 48$, Noviembre de 1921, DNT, Buenos Aires, 1921. Pp. 14

${ }_{98}$ Los títulos del proyecto pueden otorgar una imagen del amplio abanico de cuestiones sobre los que intentó legislar. Al primer título que contenía las cuestiones de forma le seguían los siguientes: titulo II: DNT, Titulo III: registro nacional de colocaciones, Titulo IV: obreros del estado, Titulo V: trabajo de menores, Titulo VI: trabajo de mujeres, Titulo VII: trabajo de marinos, Titulo VIII: trabajo del personal de empresas ferroviarias, Titulo IX: trabajo de indios, Titulo X: trabajo a domicilio, Titulo XI: descanso dominical y hebdomadario, Título XII: Jornada de trabajo, Titulo XIII: accidentes de trabajo, Titulo XIV: higiene del trabajo, Titulo XV: seguridad en el trabajo, Titulo XVI: del salario, Capitulo III: jueces de salarios, Titulo XVII: Contrato colectivo de trabajo, Titulo XVIII Asociaciones profesionales, Titulo XIX: Conciliación y arbitraje, Titulo XX: Juzgado del trabajo, Titulo XXI: Relaciones internacionales sobre trabajo, Titulo XXII:
} 
trabajo, contratos colectivos, regulación del trabajo en ferrocarriles y marítimo) y daba cuenta de las influencias internacionales sobre todo incluyendo los lineamientos de la Conferencia de Washington en la que Unsain había tenido destacada actuación. En este punto entonces el proyecto también condensaba el devenir del Derecho Laboral, reafirmaba su vocación internacional y su filiación al derecho comparado.

Al mismo tiempo el proyecto de 1921 daba cuenta de los debates en torno a los accidentes del trabajo, sintetizando las propuestas del riesgo profesional pero sumando además la experiencia del DNT en cuanto a los requerimientos de seguridad e higiene de los establecimientos industriales. La incorporación de enfermedades inculpables como la peste bubónica o la insolación (art. 235) con exigencia de indemnización era concebida como una buena forma de impulsar a los patrones a mejorar las condiciones en las que se desarrollaban las actividades. Además ampliaba la categoría de accidente de trabajo a toda relación entre el trabajo y el accidente (art. 232), no siendo necesario que el hecho se produjese en el establecimiento, pudiendo incorporar, así, el trayecto del obrero a la fábrica.

A pesar de abandonar las pretensiones represivas de la actividad gremial, el Código contemplaba la necesidad de regular las asociaciones obreras a fin de obtener interlocutores válidos a la hora de enfrentar los conflictos. La intervención esporádica y aleatoria del Poder ejecutivo en las huelgas más importantes del período se realizó sobre la base de relaciones incluso personales. Pero una intervención más profunda fracaso justamente por la ausencia de una legislación de fondo que contemplar la problemática obrera y trazara los lineamientos de intervención. En última instancia la intervención personalista que primaba en el Poder Ejecutivo Nacional era consecuencia de no dotar a un organismo determinado -el DNT- con las potestades suficientes para lograr una verdadera cotidaneidad de la intervención ${ }^{99}$.

A pesar de haber sufrido en el Congreso el mismo destino que sus sucesores el Proyecto de Código del Trabajo de 1921 marcó la pauta de los

penalidades y procedimientos, Titulo XXIII: jubilación de ferroviarios, Titulo XXIV: jubilaciones de empleados y obreros de empresas particulares de servicios públicos.

${ }^{99}$ SURIANO Juan, "EI Departamento Nacional del Trabajo y la política laboral durante el primer gobierno de Hipólito Yrigoyen" en PLOTKIN Mariano Ben y ZIMMERMAN Eduardo (comp.), Los Saberes del Estado, Edhasa, Buenos Aires, 2012. 
proyectos posteriores e implicó la producción de un corpus novedoso del que se nutrirían los debates sobre la legislación vigente y sobre el que se proyectarían los intentos de modificaciones de la legislación laboral. Al mismo tiempo permite contemplar el avance que durante estos años tuvo el desarrollo del Derecho Laboral en su búsqueda de autonomía como rama del derecho.

\section{II.3 Conclusiones}

La concepción del derecho laboral o del trabajo como un derecho "nuevo", sería una de las razones principales a la hora de proponer y argumentar la necesidad de conformar tribunales del fuero que permitiesen tratar los asuntos que de esta legislación se desprendiese. Sin embargo primero la legislación laboral debió recorrer un largo camino a fin de lograr expresar en leyes los cambios que proponía a nivel doctrinario.

La sanción de leyes laborales estuvo atada a los vaivenes políticos de la Legislatura nacional tanto como a las limitaciones de corte institucionales del mismo Congreso que atentaron contra la posibilidad de la formación de un corpus legislativo amplio sobre la que sustentar la formación de un fuero específico. La conformación conservadora del Congreso, con escasa representación de partidos políticos propensos a la sanción de estas leyes, la escasa representación de las ideologías obreristas en las cámaras y su rechazo -en el caso del anarquismo- a participar en ellas, la representación netamente conservadora de la Cámara Alta -con posibilidades de detener la sanción de las leyes tendientes a mejorar la condición obrera- fueron serios obstáculos a la hora de sancionar leyes laborales.

A esto se sumaron los debates sobre la jurisdicción de las leyes que sí sanciono el Congreso Nacional y que encontró resistencia por parte de las autoridades provinciales en la medida en que se consideraba que este avance legislativo de la Nación se realizaba en desmedro de las autonomías de las provincias. Esto implicó que la mayoría de ellas quedasen circunscriptas a la Capital Federal y los territorios nacionales sobre los que el Congreso de la Nación tenía potestades legislativas locales, generando un desbalance en la producción legislativa en términos territoriales. Además dejó librado a las autoridades provinciales la posibilidad de gestionar y controlar el cumplimiento 
de estas leyes rompiendo con la uniformidad jurídica que pretendían los legisladores nacionales.

Las dificultades que planteaba el tema jurisdiccional, paradójicamente, terminó también potenciando la autonomización del Derecho Laboral. Las resistencias de los legisladores provinciales se sostuvo sobre la idea de que se trataba de un derecho nuevo y no una extensión del Código Civil. En su afán por defender la autonomía legislativa de las provincias y evitar dotar al poder central de mayores potestades abonaron la tesis de que el Derecho Laboral ya no podía ser comprendido dentro de la tradición civil.

Por otro lado la falta de consenso en torno a la necesidad de controlar la relación laboral, la permanencia de las herramientas represivas y la crisis misma de la forma Código, se sumaron a los límites ya descritos para posponer la sanción de un Código del Trabajo. Incluso cuando el Poder Ejecutivo promovió su sanción, el Congreso de la Nación se vio renuente incluso a tratarlo en comisiones. Esta ausencia de un corpus integral sobre el trabajo favoreció la acción aleatoria de las autoridades ante los conflictos laborales y dejó a merced de la voluntad política de turno las posibilidades de atención de la problemática obrera. El Código propuesto por González, primer intento de construcción de un corpus homogéneo y coherente, terminó su camino rechazado tanto por las asociaciones obreras -incluso aquellas que respondían ideológicamente al socialismo a pesar de la participación de prominentes figuras en su redacción-como por las asociaciones patronales. El resto de los intentos no tuvieron mejor suerte a pesar de los distintos apoyos logrados. Este capítulo cierra con el proyecto de 1921 redactado por Alejandro Unsain -a pesar de que en 1933 se volvió a presentar un proyecto, esta vez redactado por Saavedra Lamas- en la medida en que dicho proyecto da cuenta de la voluntad de sintetización del Derecho Laboral y además lo funda sobre nuevas bases doctrinarias.

Aun así, y a pesar de estos obstáculos, se pudo desarrollar una acción legislativa lenta pero continuada que fue delimitando el alcance del Nuevo Derecho. La adopción de la doctrina de riesgo profesional implicó un cambio enorme con respecto a la legislación laboral y permitió fundar el Derecho Laboral sobre nuevas bases. Rompiendo con la tradición civil, la noción de riesgo profesional fue el puntapié inicial en el camino que desembocará en la 
conformación de los Tribunales del Trabajo. La conformación institucional del Derecho Laboral en distintas esferas de la vida social fueron conformando un clima de época que facilitaría incluir el tema en la agenda pública. En una nota editorial del diario El Día de 1947, el redactor encargado argumentaba que en cuanto a la erección del fuero del trabajo, su conveniencia está al margen de toda discusión. Contamos con un vasto cuerpo de normas específicas y las relaciones involucradas dentro del campo de este "nuevo derecho" tienen, a la fecha, por su cualidad y cantidad, jerarquía suficiente como para exigir una subdivisión de la competencia por razón de la materia $^{100}$

Lo novedoso del Derecho Laboral marcaba su separación del ámbito del derecho civil y comercial, y esta novedad justificaba plenamente, por su "jerarquía" según el editor de El Día, la constitución de un fuero especializado. La creciente autonomía del campo permitió sostener con mayor fortaleza los argumentos en torno a la constitución del fuero, debate que se vivió contemporáneamente a la recorrida en este capitulo pero que sin embargo hubo e esperar varios años para poder lograr su conformación institucional.

${ }^{100}$ Diario El Día, edición del 8/10/1947, pp. 3. Nota editorial "Reformas Judiciales Necesarias". 


\section{CAPÍTULO III \\ EL CAPITAL Y EL TRABAJO CARA A CARA}

\section{Introducción}

El surgimiento de una nueva rama del derecho se dio de manera contemporánea a otros eventos que fueron moldeando la forma que finalmente adquirieron los Tribunales del Trabajo en el ámbito bonaerense bajo la sanción de la Ley 5178 promulgada en 1947 por el gobernador Domingo Mercante. El pedido desde las organizaciones obreras por contar con una herramienta en donde los trabajadores pudiesen acudir a reclamar sus derechos estaba contemplada desde principios del siglo XX por algunas de sus asociaciones, aunque tomó mayor ímpetu a partir de los cambios ideológicos de la conducción del movimiento obrero de principios de la década del diez del siglo pasado.

La existencia de instituciones análogas en otras partes del mundo -en un contexto de verdadera internacionalización de la lucha obrera- era un estímulo en este sentido, más aun teniendo en cuenta que el pedido de las organizaciones obreras encontraba eco en el naciente campo del Derecho Laboral también atravesado por un proceso de internacionalización. A esto se sumaba la voluntad del Estado de dar cuenta de la problemática relación entre los trabajadores y sus patrones y la conformación de una burocracia que aun no contaba en el Estado con un espacio propio donde ejercer su poder.

Estos elementos coincidieron en la conformación de instituciones de mediación y arbitraje dedicadas a intervenir en los conflictos obreros, aunque manteniendo siempre un modelo corporativo en el que primaba la representación colectiva. La reconstrucción de la historia de estas instituciones es fundamental para comprender el contexto en las que fueron propuestas las conformaciones de Tribunales del Trabajo. Este recorrido permite dar cuenta del cambio que supuso el paso de las instancias de control de la legislación obrera del Poder Ejecutivo al Poder Judicial y las tensiones que entre los actores suscitó la medida. El recorrido por estos antecedentes busca situar la conformación de los Tribunales del Trabajo en la provincia de Buenos Aires en su contexto tanto histórico como político. En este sentido el arribo al poder de una fuerza política que se presentaba a sí misma como disruptiva del orden 
previo -el peronismo- fue significativo para las posibilidades de vencer las resistencias que la conformación del fuero laboral encontraba en distintos campos. Por medio de este análisis se propone indagar en el lugar que distintos actores -asociaciones obreras, patronales, funcionarios, intelectuales, autoridades políticas, otorgaban al estado en la resolución del conflicto entre trabajadores y patrones. Se recorre, así la trayectoria de Estado en busca de posicionarse como un tercero neutral capaz de regular el conflicto, otorgando el marco de legalidad necesario para la actuación de los actores sociales.

La posibilidad de construcción de una institución dedicada enteramente a resolver las problemáticas devenidas de la relación laboral en la esfera del Poder Judicial fue posible recién con la llegada del Peronismo al poder. Efectivamente las pretensiones de cambio que expresaba esta fuerza política y su construcción discursiva en torno al obrero lograron vencer las resistencias que se oponían a la constitución de un fuero laboral. Aunque no exento de disputas, este finalmente sería establecido por decreto en un enfrentamiento de Perón -líder de la coalición gobernante y figura máxima del peronismo- con la Corte Suprema de Justicia de la Nación. Este antecedente será abordado con especial atención teniendo en cuenta la importancia que tuvo a la hora de promover en la provincia de Buenos Aires una institución análoga.

Los distintos proyectos imponen un marco temporal amplio al capítulo ya que las primeras menciones a la constitución de instituciones mediadoras aparecen ya en el proyecto de Código del Trabajo de Joaquín González en 1904 hasta la promulgación del decreto 32.347 de la Secretaría de Trabajo y Previsión en 1944.

\section{III.1 Algunas respuestas estatales ante las problemáticas de la relación laboral}

La creación de la OIT en el marco del Tratado de Versalles en 1919, dio un fuerte impulso a la consolidación del Derecho del Trabajo como rama autónoma del Derecho. Este impulso también fortaleció, en los casos en los que ya existía, o favoreció el surgimiento de diversas instituciones y mecanismos que se encargaran de actuar en los conflictos colectivos e individuales del trabajo. 
En el caso argentino, desde los comienzos del siglo XX, las respuestas a la "cuestión social" también incluyó un acercamiento a posiciones reformistas del movimiento obrero, encarnado en algunas de las propuestas del Partido Socialista. El objetivo era evitar los síntomas más preocupantes del conflicto. A pesar de mantener la arista represiva funcionando duramente, la elite gobernante buscó atenuar sus políticas mediante la inclusión de algunas de las propuestas obreras dentro de la agenda pública. Esta dualidad en la política estatal con respecto al malestar y movilización obrera tuvo como consecuencia el trazo de los límites del reclamo obrero. A partir de la administración de la represión y la seducción, el Estado buscó acercarse a posiciones del movimiento obrero mientras mantenía a raya a aquellos sectores a los que consideraba irreductibles. Estos límites se fueron definiendo constantemente en un tira y afloje permanente ligado a las condiciones del mercado de trabajo, el impacto de las diversas opciones ideológicas dentro del movimiento obrero, la predisposición de las autoridades estatales, etc.

Fueron, a principio del siglo XX, los liberales reformistas los que se pueden identificar detrás de los proyectos que intentaron de una manera u otra lidiar con los problemas de la "modernización" de la sociedad argentina". Inspirados por nuevas corrientes de pensamiento, en la que destaca el positivismo ${ }^{2}$, estos miembros de la elite buscaron dar algunas respuestas a los cambios y desafíos que se percibían sobre todo en la zona pampeana reseñados en el capítulo anterior.

Las soluciones propuestas abarcaron a los tres poderes del estado e incluyeron el acercamiento a los sectores del movimiento obrero susceptibles de ser seducidos por propuestas legislativas y mediadoras por parte del Estado. En lo que respecta al Poder Ejecutivo la respuesta asumió la forma de una oficina especializada dedicada a las relaciones laborales, el DNT. Este organismo tuvo una profusa actividad en su faceta legislativa promoviendo estudios tendientes a mejorar la legislación obrera -estudios con una fuerte tendencia al derecho comparado- y proponiendo proyectos de leyes y decretos

\footnotetext{
1 ZIMMERMANN Eduardo A., "Los intelectuales, las ciencias sociales y el reformismo liberal: Argentina, 1890-1916", Desarrollo Económico, vol. 31, №124 (Ene-Mar, 1992), Pp. 545-564. Y ZIMMERMANN Eduardo, 1995, op. cit.

${ }^{2}$ Sobre la colonización de las instituciones estatales por parte de actores afines al positivismo SALVATORE Ricardo, Subalternos, derechos y Justicia Penal. Ensayos de Historia Social y Cultural Argentina, 1829-1940. Gedisa, Buenos Aires, 2010.
} 
tanto al Poder Ejecutivo como al Poder Legislativo, contando con una oficina especializada entre sus reparticiones y dedicándole una sección especial en el $B D N T$. De alcance reducido y naturaleza limitada debido a la falta de capacidad de imponer su resolución a las partes en litigio, e incluso al alineamiento ideológico de alguna de sus autoridades ${ }^{3}$, el DNT promovió constantemente la constitución de mecanismos de conciliación y arbitraje. Pero sin poder de policía real, la fiscalización de las condiciones de trabajo dependía de la capacidad de los inspectores del trabajo de imponer las normas mediante la negociación en las locaciones ${ }^{4}$. Esta imposibilidad era objeto de la amarga queja de Joaquín Coca, que reclamaba que, al igual que otras leyes, la fiscalización debería estar a cargo de todas las autoridades y todos los ciudadanos, y no solo de los pocos funcionarios del $\mathrm{DNT}^{5}$. Por otro lado el DNT encontraba escollos en la aplicación de las normas -incluso las que el mismo organismo emitía- cuando estas chocaban con la hostilidad o el llano enfrentamiento de otros sectores u organismos más poderosos del mismo gobierno o la oposición de algunos empresarios lo suficientemente poderosos ${ }^{6}$.

De todas maneras, el DNT parece haber construido desde sus comienzos en 1907 una opción creciente para los trabajadores. Las estadísticas del propio DNT daban cuenta de la poca predisposición de los trabajadores de acudir a la oficina del trabajo lo que dificultaba sus tareas. Según Tomás Auza esto se debía a que

en los primeros cinco años no fue mirado (el DNT) con simpatía por ninguno de los dos sectores básicos de la producción. Los obreros, especialmente los reunidos en torno a las ideas socialistas y anarquistas, no confiaron en la significación que sus trabajos pudieran tener a favor de los sectores que representaban, sobre todo por verlo más como un organismo de estudio que de ejecución de políticas sociales ${ }^{7}$.

Producto de una mirada benévola al organismo estatal, Auza no identifica las razones ideológicas que operaban en los sindicatos obreros que llevaban a la oposición a la intervención estatal, pero de todas maneras es interesante la

\footnotetext{
${ }^{3}$ Según Eduardo Zimmermann el cambio en el Ministerio del Interior en 1910 que colocó como ministro a Indalecio Gómez, significó el alejamiento de los liberales reformistas de la dirección de la DNT, lugar que ocuparían los católicos sociales. Además este ministro habría optado por mediar de manera personal en los conflictos, desautorizando la mediación del Departamento. ZIMMERMAN Eduardo, Los liberales..., Op. Cit.

${ }^{4}$ SOPRANO Germán, Haciendo inspección.... Op. Cit.

${ }^{5}$ COCA Joaquín, Derecho burgués y Derecho obrero, CEAL, Buenos Aires, 1985.

${ }_{7}^{6}$ HOROWITZ Joel, op.cit.

${ }^{7}$ AUZA Néstor Tomás, La legislación laboral... Op. Cit. Pp. 66, cursiva agregado mio.
} 
cuestión de la percepción como organismo técnico y de estudios más que como organismo de mediación y arbitraje en caso de conflicto. En parte da cuenta de los argumentos propios de la institución que justificaba su poca incidencia en la falta de personal y en la ausencia de una ley orgánica que afligió al organismo durante los primeros cinco años de actividad, sin contar los desplazamientos de sus funcionarios y la ausencia de estos del país durante períodos prolongados mientras realizaban tareas para el propio organismo, tales como la investigación de funciones de instituciones similares en otros países. Esta percepción se sostenía también en las figuras que conformaban los escalones más altos del DNT, abogados dedicados en su mayoría a la investigación y reconocidos en los ámbitos académicos ${ }^{8}$. De todas maneras el DNT buscará conformarse como árbitro en las disputas laborales prácticamente desde sus comienzos.

Así, el 27 de Abril de 1907, a poco de haber comenzado a funcionar, el DNT envió una circular a la UIA y a las centrales obreras (UGT y FORA, socialista y anarquista respectivamente) sobre la posibilidad de emplear medios conciliatorios y el establecimiento de convenios colectivos entre las partes a fin de evitar los conflictos violentos entre patrones y empleados. Siguiendo su línea ideológica ${ }^{9}$, la FORA no contestó el mensaje, mientras que sí lo hicieron la UIA y la UGT. La organización patronal, mediante nota enviada por su presidente Alfredo Demarchi del $1^{\circ}$ de Mayo del mismo año, comunicó que no tenían "inconveniente alguno en ensayar el temperamento indicado"10 y que enviaría a sus representantes en caso de ser convocados. Esta postura se contrapone con aquella descripta para el caso de los proyectos de leyes laborales tratados en el Congreso de la Nación, en donde la patronal era abiertamente opositora a la sanción de medidas que pudiesen afectar los intereses materiales de sus asociados. Tal vez aun no percibía la UIA que fuese el DNT una amenaza o, como sostenía Auza, lo percibían como una institución de investigación y estudio más que de intervención concreta. La no concreción de este proyecto de mediación durante los primeros años de la vida

\footnotetext{
${ }^{8}$ Julio Lezama, Alejandro Unsain, Alejandro Ruzzo sólo por mencionar algunos.

9 Para la oposición del anarquismo a la intervención estatal véase SURIANO Juan, La oposición anarquista... Op. Cit.

${ }_{10}$ Boletín del Departamento Nacional del Trabajo, N¹, Junio 30 de 1907, Departamento Nacional del Trabajo, Buenos Aires, 1907. Pp. 41.
} 
institucional del DNT impide, de todas maneras, emitir un juicio firme sobre esta postura contraria a la que la UIA sostenía en relación a otros avances del Estado sobre la relación laboral.

La central obrera UGT fijó su posición en torno al proyecto y en relación al DNT en la nota que enviaran al organismo el 13 de Mayo. Aun tratándose de de una institución de orientación socialista y por lo tanto proclive a adoptar políticas reformistas, y con la consabida política del gobierno de acercamiento a dicha tendencia ideológica a fin de aislar al radicalismo, que podrían haber favorecido un acercamiento, este fue rechazado de plano por la central obrera. La UGT, en las palabras de su secretario general Juan Cuomo, rescató como su lema la lucha de clases reafirmando la ausencia de armonía entre las clases. La misiva marcó fuertemente la postura de la UGT. Se sostenía en la nota que

\begin{abstract}
para que en lo sucesivo no se molesten más, haciéndonos proposiciones semejantes, que están en pugna con la mayoría de los miembros que componen nuestra institución, os manifestamos que no creemos necesario la intervención de esa institución en los asuntos que atañen a nuestra organización por estar convencidos que todo lo que se refiera al bienestar y mejoramiento de nuestra clase, depende única y exclusivamente del esfuerzo que pueda desarrollar la acción obrera por medio de la lucha ejercida contra de los que nos sumen en la más cruel explotación.

Por lo tanto, toda comisión de arbitraje propuesta por instituciones de la clase burguesa (como es ese "Departamento de Trabajo") no puede tener por resultado otra cosa que los intereses capitalistas. ${ }^{11}$
\end{abstract}

El rechazo a la posibilidad de conformar instituciones mediadoras era durante estos años prácticamente imposible ante la oposición que encontraba en las asociaciones obreras. Reafirmando su carácter clasista, la UGT percibía en el DNT no ya un organismo de estudio como la propia institución buscaba proyectarse, sino un organismo de un Estado capitalista, incapaz de sostenerse autónomo en la lucha de clases o al menos en una actitud prescindente. Si se buscaba desde el Estado la intervención de un organismo en las disputas laborales era porque los intereses capitalistas estaban amenazados. Por lo tanto de ninguna manera era posible colaborar con tal empresa. La creencia de las potencialidades de la clase obrera para lograr cambiar el carácter de la sociedad por medio de la lucha de clases era aun el norte estratégico de las organizaciones obreras, incluida en este caso la central socialista.

\footnotetext{
${ }^{11}$ Ibidém, Pp. 42.
} 
A pesar de esta oposición inicial de uno de los dos polos en la relación laboral a la intervención estatal, el DNT seguirá insistiendo con la necesidad de conformar dentro de su égida instancias de conciliación y arbitraje capaz de colocar a los trabajadores y sus patrones cara a cara y buscar así soluciones a los conflictos que surgían de la relación. Tanto en la búsqueda de seducir a los trabajadores proponiéndose como un actor neutral, como en su búsqueda de inserción dentro de la estructura estatal, los funcionarios del DNT trabajaron en pos de lograr la asignación de funciones ligadas a la mediación. En este sentido en 1908 el DNT propone a las autoridades del Poder Ejecutivo la modificación del decreto del 20 de Octubre de 1904 que habilitaba al jefe de la policía de la capital a actuar, mediante ofrecimiento, como mediador entre las partes en caso de conflicto. No era intención de las autoridades del DNT descalificar la acción de los sucesivos jefes de policía de la época en este tipo de conflicto, sino llamar la atención sobre los inconvenientes que otorgar dichas atribuciones al jefe de policía podía tener en los conflictos. Se señalaba en las páginas del BDNT que "esta disposición ha resultado ineficaz, y tiene el inconveniente que en otros países ha sido evitado, de confundir en una sola mano las funciones represivas con las conciliatorias" "12. En última instancia la dualidad estatal frente al conflicto obrero expresado en la misma persona -el jefe de policía- dejaba en evidencia la imposibilidad de constituir al Estado ante la mirada de los actores sociales envueltos como autónomo en la disputa. Al buscar para sí mayores funciones y atribuciones el DNT no sólo constituía su razón de ser dentro de las disputas de captación de recursos estatales, sino que se ajustaba a la idea de arbitraje del Estado ante los conflictos laborales a partir de la construcción de una imagen de neutralidad entre los dos contendientes. La presencia de Ramón Falcón ${ }^{13}$ como jefe de la policía garantizaba la aplicación de las normas represivas y atentaba contra cualquier intento de conciliación. Además debe tenerse en cuenta que el sostenido

\footnotetext{
${ }^{12}$ Boletín del Departamento Nacional del Trabajo, $N^{\circ} 4$ Marzo 31 de 1908, Departamento Nacional del Trabajo, Buenos Aires, 1908. Pp. 6

${ }^{13}$ Ramón Falcón fue designado jefe de la policía de la Capital en 1906, cargo que ostentó hasta su muerte el 14 de noviembre de 1909 a manos del activista Simon Radowitsky. Bajo su mando la policía de la capital reprimió manifestaciones obreras y fue el ideólogo detrás de la semana roja de 1909 dejando tras su mando varios muertos y centenares de heridos. FRYDENBERG Julio y RUFFO Miguel, La semana Roja de 1909, Buenos Aires, Centro Editor de América Latina, 1992.
} 
aumento de la conflictividad durante la primera década del siglo $\mathrm{XX}$, con hitos importantes en la huelga de inquilinos de 1907 y los paros generales de 1907, 1909 y 1910 y la semana roja de 1909, ayudaban a construir una imagen donde la revolución era un horizonte posible.

Fiel a sus características académicas el DNT solicitó el reemplazo del jefe de policía por una junta especial de conciliación que asumiera las funciones delegadas en dicho funcionario policial, fundamentando su proyecto de modificación en el estudio de la legislación comparada. La junta especial de conciliación así propuesta adoptaría la forma de un consejo tripartito conformado por vocales obreros y patronales, y un delegado del DNT. Su actuación -y respondiendo a las limitaciones jurisdiccionales presentadas en el capítulo anterior- sería de oficio en la Capital Federal y por solicitud en el caso de las provincias.

Este tipo de organización contaba con el beneficio de sentar frente a frente a las partes en conflicto pudiendo así evitar que un conflicto puntual en una industria llegase a generar el desarrollo de, por ejemplo, una huelga o que presentase mayores dificultades para las autoridades estatales. Por otro lado al presentar al delegado estatal como un tercero se favorecía la proyección de la autonomía del Estado con respecto al conflicto básico entre el capital y el estado. El jefe de policía, en la materialidad concreta de su posible intervención más allá de la voluntad mediadora es decir la represión- dificultaba la consideración de este actor como neutral por parte de las organizaciones sindicales obreras y patronales participantes en un conflicto. La proyección de la posición neutralista era también fundamental para favorecer la presencia patronal en las instancias que proponía el DNT. Acostumbrado a que la presencia estatal garantizase el orden y fuese prescindente en la mediación de los conflictos, la posición de asumida neutralidad era percibida de forma negativa en la medida en que formulaba un cambio en la actitud hasta ese momento sostenida por las autoridades estatales.

Otro factor que se buscaba fomentar mediante la presentación de esta institución tripartita era la aceptación por parte de las organizaciones obreras y patronales de la autoridad estatal mediante el reconocimiento que la participación llevaba implícito. Para poder ocupar los espacios dentro de la junta especial de conciliación se debía, primero, ser aceptado como parte por el 
árbitro. Es decir que el DNT de esta manera contaría con una herramienta para el reconocimiento de algunas organizaciones obreras por sobre otras. El reconocimiento excluyente en estos casos favorecía, entonces, a aquellas organizaciones sindicales y gremiales que reconociesen la autoridad estatal y les otorgaría la posibilidad de plasmar en medidas concretas lo que tal vez podían lograr en su lucha con los patrones en otras instancias no institucionalizadas. No es de extrañar, entonces, el rechazo de las organizaciones de afiliación anarquista fundada en las mismas razones que las expuestas en el capítulo anterior.

Las medidas del DNT apuntaban a generar la imagen de un Estado neutral en la disputa, con capacidad de imponerse también a los patrones de la misma forma en que lo hacía con los trabajadores y lograr presentarse como un árbitro neutral. Los intentos legislativos -si bien voluntariosos- dejaban en evidencia que a pesar de estas pretensiones y un virtual no rechazo por parte de las asociaciones patronales -como se demostraba en la nota de la UIA oportunamente citada- no todos los legisladores estaban convencidos de que fuese posible sostener la imagen de neutralidad y al mismo tiempo ser atractiva como opción para los patrones. Es en este sentido que para funcionar dentro del Poder Ejecutivo -aunque sin precisar en qué organismo, que la resolución del mismo se elevase al Ministro de Agricultura hace suponer que dependería de dicho organismo, donde funcionaba una oficina de empleo ${ }^{14}$ - el diputado Gerónimo del Barco volvió a presentar un proyecto de ley sobre conciliación y arbitraje $^{15}$. En la sesión 12 de mayo de 1910 llevaba su firma el proyecto que promovía un Consejo de Conciliación y Arbitraje presidido en la Capital Federal por el presidente de la Bolsa de Comercio de Buenos Aires y en los territorios nacionales por el juez letrado, más 6 vocales, tres representantes de cada parte en conflicto. Si bien la figura del presidente que proponía en términos funcionales era la de desempatar en caso de empate entre los votos de los consejeros, esta función de ninguna manera era menor. La presencia, y nada menos que con la función de desempatar en caso de divergencia de opinión,

\footnotetext{
${ }^{14}$ Así lo disponía el Art. 29 del proyecto. BDNT, №13, Junio 30 de 1913, Departamento Nacional del Trabajo, Buenos Aires, 1913. Pags 358-362.

${ }^{15}$ Gerónimo del Barco era diputado de larga trayectoria en el PAN y fundador del Partido Demócrata. "Acción Legislativa", Boletín del Departamento Nacional del Trabajo, N¹3, Junio 30 de 1910, Buenos Aires, 1910. Según la exposición de motivos al sustentar su proyecto, ya lo había presentado en 1903 con motivo de las huelgas de 1902 en Pensilvanía, Estados Unidos
} 
del presidente de la Bolsa de Comercio, no podía presentarse ante la mirada de los dirigentes obreros como una institución neutral.

El contexto de este proyecto, con estado de sitio decretado a fin de reprimir la movilización obrera, proyectos de leyes sobre limitación de la inmigración y el debate de la Ley de Defensa Social, hacía difícil que el Congreso Nacional se aviniera a debatir un proyecto destinado a satisfacer alguna demanda obrera. La forma en la que se pensaba esta institución, a pesar de características que se presentan como loables entendiendo la necesidad de solucionar los conflictos laborales, no dejaba de estar enmarcada en esta situación. El Consejo de Conciliación y Arbitraje se proponía dar respuesta en 15 días (art. 18), obligaba a los patrones a exhibir sus libros aunque a uno solo de los representantes obreros y que no podría divulgarlos(art 24), y establecía que su resolución era de carácter obligatorio, característica que carecía los proyectos del DNT, (art. 22). Pero en definitiva se trataba de encauzar dentro de un orden ya establecido y desfavorable a los trabajadores. Sostenía el diputado Del Barco al exponer su proyecto

Los obreros deben darse cuenta que actúan en una sociedad perfectamente organizada y que como tal en ella existe un núcleo, que es la autoridad, y una intención, que son las leyes, que todos estamos obligados a acatarlas y respetarlas (...) Yo he de dar mi voto y he de patrocinar con mi voz todo aquello que signifique mejorar la condición de la clase obrera; pero he de ser inexorable con aquellos que salen en sedición; en revolución, a la calle, pretendiendo imponerse a los poderes públicos erigiéndose en un poder fuera de la constitución. ${ }^{16}$

La posibilidad de concretar espacios donde trabajadores y patrones pudiesen sentarse cara a cara, proyectada por los funcionarios del DNT, encontraba este tipo de respuestas por parte de las autoridades legislativas. Estos proyectos, a pesar de sus buenas intenciones, estaban supeditados a la sumisión de una de las partes a las reglas del juego establecidas por las clases dominantes. Era indispensable abandonar las pretensiones de cambio social por parte de los gremios obreros para que estos pudiesen incorporarse a la institucionalización propuesta. Este horizonte en el año de la presentación del proyecto, aparecía como lejano, sino imposible.

\footnotetext{
16 "Proyecto de ley sobre conciliación y arbitraje, presentado por el señor Diputado G. del Barco", BDNT, N¹3, Junio 30 de 1913, Departamento Nacional del Trabajo, Buenos Aires, 1913, Рp. 362
} 
Las autoridades del DNT, de todas maneras, lograron establecer en la ley orgánica del organismo -sancionada en 1912- un Consejo del Trabajo, con las características que parecen quedar establecidas para este tipo de instituciones. La Ley orgánica del DNT, en su artículo 7 reza así:

el presidente, cuando lo requieran los conflictos entre capital y trabajo, convocará y presidirá "Consejos de trabajo" compuestos en cada caso con igual número de patronos y obreros. ${ }^{17}$

A pesar de los contratiempos y la falta de obligatoriedad de sus resoluciones -cuestión que impactaba directamente en las posibilidades de proyección del organismo y que sostiene empíricamente las miradas historiográficas que han tendido a desestimar la capacidad del DNT en los conflictos- las páginas del Boletín del Departamento Nacional del Trabajo suele dar cuenta periódicamente de la intervención oficiosa del organismo en los conflictos. Sin dudas el paso del tiempo y la capacidad del DNT para convencer a los actores implicados de su neutralidad, así como los cambios ideológicos de los gremios obreros, terminaron dando lugar al crecimiento de esta función de mediación, conciliación y arbitraje del DNT.

Los cambios políticos a nivel nacional, con la elección de Hipólito Yrigoyen mediante el voto universal para los varones en 1916, produjeron un contexto de mayor relación de algunos gremios con autoridades gubernamentales, aunque siempre de manera discrecional ${ }^{18}$. El DNT se vio reforzado en sus funciones, aunque las negociaciones en caso de conflictos adquirieron durante este período un carácter más personalista, producto de la política de acercamiento que el mismo presidente ejercía con algunos gremios -particularmente la Unión Ferroviaria y la Federación Obrera Marítima. Este acercamiento se vio plasmado en el proyecto de Código del Trabajo de 1921. Entre los títulos del proyecto se destacan varias instancias de institucionalización del conflicto (jueces del salario, Conciliación y Arbitraje y Juzgados del Trabajo). Interesa aquí las Juntas de Conciliación y Arbitraje que poseía las mismas características que las que ya se ejercitaban en el DNT, es

\footnotetext{
${ }_{17}^{17}$ BDNT, Nº27 julio 31 de 1914, Departamento Nacional del Trabajo, Buenos Aires, 1914, pp.4

${ }^{18}$ Los cambios en la relación entre algunos sindicatos y diferentes esferas estatales las analiza Enrique Garguín por medio de la intervención del Poder Ejecutivo Nacional en algunos conflictos huelguísticos. Hace Garguín más hincapié en los cambios acontecidos en los ámbitos estatales que en la transformación ideológica de la conducción del movimiento obrero. GARGUÍN Enrique, Op. Cit.
} 
decir representación tripartita y proceso de conciliación, pero reconocía un derecho fundamental para los trabajadores, el derecho a huelga. Además en su art. 482, proponía ampliar la jurisdicción de estas Juntas de Conciliación y Arbitraje a las provincias, aunque reconociendo la potestad de estas para adoptar la forma institucional que juzgasen más convenientes ${ }^{19}$.

Korzeniewickz sostiene que para mediados de la década del treinta los trabajadores acudían de manera regular al Estado en búsqueda de la resolución al conflicto ${ }^{20}$. Mediante la sanción de convenios y cierta jerarquización del espacio del DNT en la esfera estatal, se brindó una posibilidad de solución administrativa a los conflictos del mundo del trabajo ya que los proyectos reseñados fueron adquiriendo carnadura.

A esta esfera de actuación del Poder Ejecutivo se debe sumar en el análisis otros espacios estatales de resolución de los conflictos del mundo del trabajo. Al pensar el Estado como una entidad heterogénea que desarrolla en su interior diferentes luchas para imponer diversos proyectos los estudios históricos recientes tienen como objetivo descentrar los estudios que se han concentrado mayormente en este organismo. Por lo tanto fue necesario repensar la manera en que se utiliza el Estado ya que en las últimas décadas "se fue deshaciendo la idea de que es posible pensar al Estado como un actor racional, que funciona con una lógica univoca, que diseña y aplica políticas de modo vertical sobre la sociedad civil"21. Por eso se debe incluir al DNT en un entramado institucional más denso que se encargaba de mediar en la cuestión social. Incluso en el caso específico del conflicto obrero (eje central de la cuestión social a decir de Suriano), las maneras en que el Poder Ejecutivo se vinculaba con los actores no estaba ligado a la influencia exclusiva del DNT.

Tal parecen ser los resultados del estudio empírico en el que Horowitz ${ }^{22}$ observa el compuesto de hombres, instituciones, etc. que conforman al Estado en el Buenos Aires de principios del siglo XX. Es analizando las relaciones entre estos hombres del Estado y los hombres del sindicato, que Horowitz logra

\footnotetext{
19 "Proyecto de Código del Trabajo que el P.E remitió a la H Cámara de Diputados con mensaje de 6 de Junio de 1921", Título Decimo Noveno, BDNT, N8, Noviembre, 1921. Departamento Nacional del Trabajo, Buenos Aires, 1921. Pp. 86-89

${ }^{20}$ KORZENIEWICZ Roberto P., "Las vísperas del peronismo. Los conflictos laborales entre 1930 y 1943", Desarrollo Económico, Vol. 33, № 131 (Octubre-Diciembre 1993), IDES, Buenos Aires, 1993.

${ }^{21}$ PALACIO Juan Manuel y CANDIOTI Magdalena, Op. Cit. pp. 17 y sig.

${ }^{22}$ HOROWITZ Joel, Op. Cit. Especialmente el capítulo 7.
} 
desentrañar el recorrido en que el gobierno adquiría cada vez mayor preeminencia en los conflictos entre el capital y el trabajo. No era ésta lograda mediante la aplicación de normas sistemáticas (leyes laborales) o alentando a las organizaciones obreras a que se unan al sistema político, sino que eran las relaciones con diferentes ${ }^{23}$ órganos del Estado, casi de manera personal. Y a pesar de que sostiene que con el correr de los años, y a medida que se avanza en la década del treinta, se comenzó a preferir la firma de "convenios colectivos y a intervenir de manera más activa en los conflictos entre capital y trabajo" 24 , esta forma de vinculación con el estado predominó ya desde el gobierno de Yrigoyen. El Estado -como confluencia de voluntades- y los sindicatos, acostumbraron a tratar el día a día de sus conflictos sin ahondar en soluciones de mayor alcance ${ }^{25}$.

Aun así es importante remarcar que ya en la década infame, a pesar de las restricciones que pesaban sobre las posibilidades de organización del movimiento obrero para reclamar sus derechos, el Departamento Nacional del Trabajo fue saliendo de su inactividad y comenzó a intervenir de manera más profunda en las relaciones laborales. Esta notoriedad estaba vinculada, según Louise Doyon, a la conciencia que el régimen, especialmente desde el ascenso de Justo a la presidencia, había tomado con respecto a "que el inexorable avance del sindicalismo exigía la apertura de un canal institucional para el tratamiento pacífico de sus reclamos" 26 . Además hay que tener en cuenta, como advierte Gemán Soprano, que la imagen de un DNT inoperante fue también parte del discurso mismo del peronismo en el poder que buscó construir su propia imagen mediante el contraste con la década previa ${ }^{27}$.

La provincia de Buenos Aires, como estado de la federación con avanzada producción industrial, dio cuenta también de la necesidad de atender

\footnotetext{
${ }^{23}$ Los contactos de los sindicatos con el estado incluían sin lugar a dudas al DNT, pero también a ministros y funcionarios varios que respondían a otras reparticiones. Por ejemplo la FOET, el gremio de telefónicos dirigida entonces por Luís Gay, tuvo acercamientos y logró la mediación del jefe de policía capitalino Ricardo Hermelo en un conflicto con la empresa telefónica según relata el citado Joel Horowitz.

${ }^{24}$ HOROWITZ Joel, op. cit., pp. 185

25 A una conclusión similar en la manera en que se relacionaban los sindicatos con el Estado arriba Hugo del Campo, aunque este autor hace más hincapié en las relaciones racionales ligadas al predominio de la tendencia sindicalista en las filas del movimiento obrero y la predisposición radical, sobre todo Yrigoyenista, de atender a las demandas obreras. DEL CAMPO Hugo, Op. Cit.

${ }^{26}$ DOYON Louise M., Op. Cit.. pp. 43.

${ }^{27}$ SOPRANO Germán, El Departamento Nacional del Trabajo... Op. Cit
} 
los reclamos obreros. Desde 1916, por iniciativa de los diputados Adolfo Dickman y Jacinto Oddone, contaba con un Departamento Provincial del Trabajo (en adelante DPT) aunque como su par nacional sufrió un serio retraso en su reglamentación. Su actuación quedó principalmente restringida a los accidentes de trabajo, a pesar de que actuó también en huelgas y como organismo conciliador $^{28}$. EI DPT recibió un verdadero impulso con la asunción del gobernador Manuel Fresco en 1936 que impulso una reforma desde el Poder Ejecutivo provincial, el 5 de Mayo de ese mismo año, para dotarlo con atribuciones similares a su par nacional, claro que con jurisdicción en el territorio de la provincia. El impulso vino dado por la sanción definitiva de la ley provincial $N^{\circ} 4548$ el 30 de Abril de 1937 que reordenó su estructura administrativa (ver imagen $\mathrm{N}^{\circ} 3$ ) y lo dotó de nuevas potestades, incluyendo la de resolver conflictos entre los trabajadores y los patrones de forma compulsiva.

El artículo 26 de la ley proveía al organismo de una instancia obligatoria de conciliación y arbitraje colectivo ${ }^{29}$, a las que los patrones y trabajadores estaban obligados a informar cualquier entredicho que no tuviese solución directa de las partes en un plazo de 24 horas (art.27). Esta instancia implicaba la no continuación del conflicto -se prohibían las huelgas y los cierres que implicasen mantener en pie el conflicto mientras durase la actuación del DPTpero además implicaba la aceptación de la autoridad del DPT. Para las asociaciones obreras aceptar la autoridad del DPT implicó un sometimiento ideológico con la expresa renuncia a algunos de sus ideales políticos ya que para poder acceder a la mediación del DPT estas debían ser aceptadas como partes y reconocida su personería. Si el DPT buscaba mediar en el conflicto de dos "fuerzas históricamente antagónicas y contrapuestas" ${ }^{30}$ para que conviviesen en "la paz social y en la tranquilidad de los espíritus" ${ }^{31}$, las asociaciones obreras debían demostrar que

\footnotetext{
${ }^{28}$ BARANDIARAN Luciano, Op. Cit. Pags 196 y sig.

${ }^{29}$ Ley N ${ }^{\circ} 4548$, capítulo VII "Conciliación y Arbitraje" en FRESCO Manuel, Cómo encaré la política obrera durante mi gobierno. 1936-1940, Tomo I, La Plata 1946. Pp. 124.

${ }^{30}$ FRESCO Manuel, "Capital y Trabajo. La palabra del gobernador de la provincia, Dr. Manuel A. Fresco, ante patrones y obreros" en FRESCO Manuel, Op. Cit. Pp. V.

${ }^{31}$ Ibídem.
} 
persiguen una finalidad socialmente útil inspirada en la acción gremial y de acuerdo a las leyes con expresa exclusión de ideologías contrarias al sistema constitucional vigente. ${ }^{32}$

Esta restricción a la actividad gremial supuso la oposición de algunos gremios principalmente socialistas y $\operatorname{comunistas}^{33}$, aunque de todas maneras esta postura no fue representativa de todos los gremios. Incluso José Domenech, secretario general de la Confederación General del Trabajo agradeció al director del DPT en 1939 -el mismo año del congreso de la Federación Socialista Bonaerense- por su ecuanimidad ${ }^{34}$. Pero sin dudas la limitación de las acciones gremiales, el rechazo de las acciones huelguísticas y la forma en la que se pensaba la intervención -por medio de corporaciones avaladas por la misma autoridad administrativa- avalan la interpretación de que la ley orgánica del DPT era de afiliación corporativa y, fundamentalmente, fascista, por su similitud con la Carta del Lavoro de la Italia de Mussolini de $1927^{35}$.

La filiación del proyecto de Fresco con el fascismo italiano sin dudas avala la interpretación de que la ley orgánica trazó una correspondencia con la Carta de/ Lavoro a nivel local. Sin embargo, y sin menospreciar el impacto efectivo de la legislación italiana, hay que tener en cuenta que no sólo la matriz corporativa apuntaba a la construcción de mecanismos de conciliación y arbitrajes basada en la representación colectiva del capital y el trabajo ${ }^{36}$. Incluso al presentar el proyecto ante la legislatura se dio cuenta de la diversidad de propuestas que se tuvieron en cuenta a la hora de redactar el proyecto de Ley Orgánica de

\footnotetext{
${ }^{32}$ Ley N4548, artículo 19 inciso b) en FRESCO Manuel, Op. Cit, Pp. 122.

${ }^{33}$ La declaración del XIV Congreso de de la Federación Socialista Bonaerense de 1939 critico duramente el proyecto de Fresco aduciendo que procuraba el sometimiento gremial a las políticas totalitarias del gobernador. "Declaraciones del XIV Congreso partidario de la Federación Socialista bonaerense" en FRESCO Manuel, Op. Cit. Pp. 21.

${ }^{34}$ Citado en BARBA Fernando Enrique, "Manuel Fresco y el Departamento de Trabajo. Un intento de regular los conflictos sociales" en REITANO Emir (comp.), El gobierno de Manuel Fresco en la provincia de Buenos Aires (1936-1940), Instituto Cultural de la Provincia de Buenos Aires, La Plata, 2010.

${ }^{35}$ REITANO Emir, Manuel A. Fresco... Op.Cit.

${ }^{36}$ La tendencia a equiparar las instituciones pensadas para intervenir en la relación laboral como de inspiración corporativa -e incluso fascista- es común también en Brasil. Ver: SAYÃO ROMITA Arion, OP. Cit.. Sin embargo Fernando Teixera Da Silva a puesto en duda esta interpretación al sostener que distintas instituciones, como las existentes en Nueva Zelanda, fueron inspiración para la legislación laboral en Brasil y sin embargo estos antecedentes de corte liberal son ocultados por la historiografía. TEIXERA DA SILVA Fernando, "Justiça do Trabalho e Magistratura del Lavoro: apontamientos comparativos", Mimeo, 2007.
} 
organismo. Por ejemplo en el caso de la conciliación y arbitraje, punto central en el proyecto, se habian considerado

en esta materia una orientación legislativa, adoptada por los países más adelantados en materia de derecho obrero y legislación social: Italia, creando la Magistratura del Trabajo por la ley de 1936, con facultades para resolver todas las diferencias relativas a la reglamentación de las relaciones colectivas del trabajo, Méjico, con la Ley Federal del Trabajo de 1931, creando las Juntas de Conciliación y Arbitraje; Nueva Zelandia, con la ley de 1936, restableciendo los poderes obligatorios a la Corte de Arbitraje y Francia, con la ley de 1936, implantando el arbitraje obligatorio después de muchas hesitaciones. ${ }^{37}$

De esta manera el autor del proyecto, el director del DPT Dr. Armando Spinelli -abogado de larga trayectoria académica imbuido de las ideas de renovación del Derecho ${ }^{38}$ - daba cuenta de la existencia de distintas instituciones análogas de diversa matriz ideológica. Esto así debido a la internacionalización del derecho laboral y la importancia del derecho comparado para esta rama del derecho. En definitiva las influencias de Spinelli son las mismas que se encuentran en los programas de Legislación Laboral de la Facultad de Ciencias Jurídicas y Sociales de la Universidad de La Plata. Armando Spinelli, especialista en legislación laboral, logró con la sanción de la ley 4548 erigir al DPT como referencia obligada en los conflictos colectivos del trabajo, aunque no así para los conflictos individuales que quedaron aun bajo la órbita privada, con la excepción de los accidentes del trabajo, área tradicional de actuación del DPT, en la que reforzó su autonomía incluso por sobre la justicia civil, ya que estableció jurisdicción exclusiva sobre la materia y para todo el territorio provincial -incluso aquellos bajo dominio nacional como ríos y puertos- ${ }^{39}$. Sin embargo para la defensa de los trabajadores individuales la ley estableció una oficina de asistencia jurídica que en caso de juicio en los tribunales civiles acompañaba al trabajador ${ }^{40}$.

\footnotetext{
${ }^{37}$ FRESCO Manuel, Op. Cit. Pp. 101

${ }^{38}$ Armando Spinelli era el encargado del seminario de investigación establecido en la Facultad de Ciencias Jurídicas y Sociales de la UNLP en donde los estudiantes debían poner en práctica sus conocimientos teóricos. Información recopilada de Anales de la facultad de Ciencias Jurídicas y Sociales de la Universidad de La Plata, Sección Noticias, así como de los programas publicados por la facultad.

39 Ley N ${ }^{\circ} 4548$ Capítulo VIII en FRESCO Manuel, Op. Cit. Pags. 126 y sig.

${ }^{40}$ Ibídem. Capítulo XIV, Pags. 141 y sig.
} 


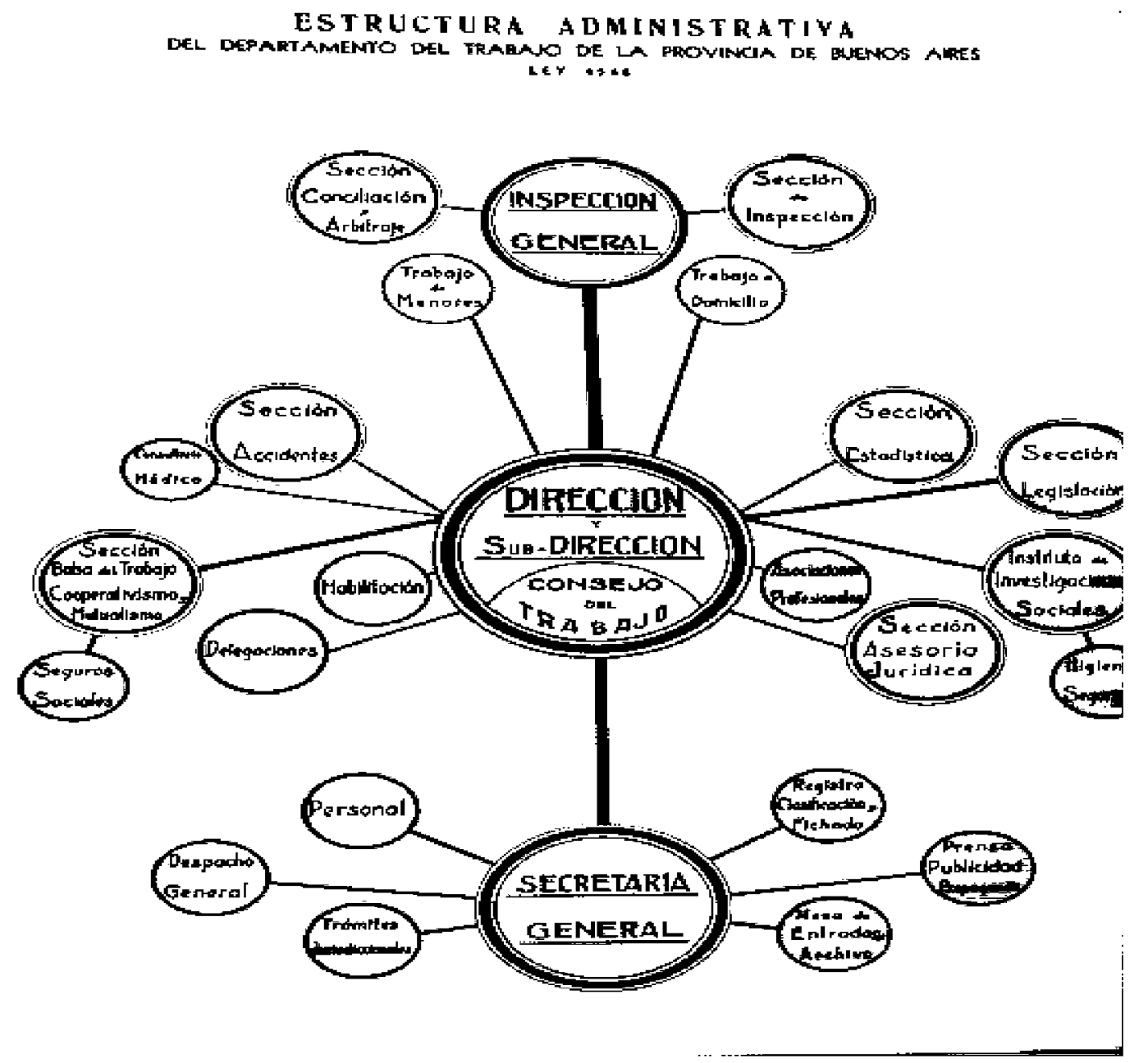

Imagen N*3: Organigrama del Departamento Provincial del Trabajo establecido por la Ley $\mathbf{N}^{\circ} 4548$ bajo el gobierno de Manuel Fresco.

Fuente: FRESCO Manuel, Cómo encaré la politica obrera durante migobierno. 1936-1940, Tomo I, La Plata 1946. Pp. 13.

Armando Spinelli al final de sus gestión se vanagloriaba de haber mantenido buena relación con sindicalistas y patrones, además de haber logrado más de 300 convenios en distintos conflictos dentro del territorio provincial. La acción de Spinelli al frente del Departamento Provincial del Trabajo suele ser uno de los puntos de apoyo de las interpretaciones historiográficas que perciben antecedentes directos del gobierno peronista en el ejercicio de la gobernación de Manuel Fresco ${ }^{41}$. Se suma a esto que el propio Spinelli trabajó bajo las órdenes de Perón en la Secretaría de Trabajo y Previsión Social (en adelante STyP) entre 1943 y 1945.

\footnotetext{
${ }^{41}$ Véase ASCOLANI Adrian, Op. Cit.y REITANO Emir, Op.Cit.
} 
Lo cierto es que a pesar del aumento de presupuesto y personal (llegando a 700 funcionarios en 1939), en lo que refiere a la intervención de arbitraje y a los fallos del Director del DPT la función del organismo nunca pudo llegar a ser lo que se planteaba en su ley orgánica. Sostiene Dolores Béjar en relación al funcionamiento del DPT

A fines de 1939 dicho Consejo (se refiere al Consejo del Trabajo) aún no se había constituido y el Departamento, en la mayor parte de los casos, actuaba sólo como conciliador. La superación del conflicto dependía, centralmente, del acuerdo entre obreros y patrones sin que esto signifique que la presión del Gobierno no fuese reconocida por dichos actores. ${ }^{42}$

La voluntad de resolver los conflictos en el caso del DPT quedó supeditada al buen entendimiento de las partes.

El ejemplo del Departamento Nacional del Trabajo no fue sólo seguido en la provincia de Buenos Aires, jurisdicción que por su grado de desarrollo económico e industrialización sin dudas requería de una institución de este tipo, sino también en otras provincias ${ }^{43}$. Pero la aplicación de una política consensuada en toda la federación estuvo limitada a la voluntad de los gobernadores y los vaivenes del debate jurisdiccional. Es por esta razón que los cambios institucionales propiciados a partir de 1943 tienen relevancia a la hora de abordar el surgimiento de una nueva política social.

Perón, como hombre fuerte del régimen instaurado por el golpe militar del 4 de Junio de 1943, realizó un importante cambio en el DNT al elevarlo al rango de Secretaría. En primer lugar esto implicó que el DNT salió de la órbita del Ministerio del Interior y pasó a ocupar un lugar más destacado dentro del gabinete nacional. Pero el cambio más importante radicó en la nueva estructuración interna. La jerarquización del problema laboral requería según los preceptos de la época, y así se hizo, centralizar toda una serie de organismos dispersos, incluidos aquellos que si bien no estaban vinculados de forma directa a la relación capital/trabajo, sí tenían una función importante en la definición de políticas sociales. Además de una agrupación de organismos

\footnotetext{
${ }^{42}$ BÉJAR María Dolores, "La política laboral del gobierno de Manuel Fresco" en PANETTIERI José (comp.), Argentina: trabajadores entre dos guerras, Eudeba, Buenos Aires, 2000. Pp. 158. ${ }^{43}$ Adrian Ascolani da cuenta de estos organismos en Entre Ríos, Córdoba y Santa Fe. ASCOLANI Adrian, op. cit. Para el caso de la provincia de Santiago del Estero es interesante el recorrido que María Cecilia Erbetta traza de quien fuera el director de la institución, el Dr. Olmos. ERBETTA Cecilia, "La impronta de la justicia social durante el primer peronismo en Santiago del Estero. (1943-1955)." Ponencia presentada al Primer Congreso de Estudios Sobre el Peronismo: la primera década, Mar del Plata, Noviembre de 2008, Mimeo.
} 
dispersos, la novedad residió en la estructura "racionalista" centrada en pocas Direcciones Generales y con alcance nacional ${ }^{44}$. Para lograr alcanzar el conjunto del territorio nacional, el instrumento fue

refundir las oficinas existentes en provincias, en "delegaciones regionales". Estas delegaciones no abarcan sólo aquellas oficinas y organismos que ya eran de carácter nacional, sino que incorporaron también a los provinciales y municipales ${ }^{45}$

Esta reorganización de la STyP significó una centralización de la toma de decisiones por sobre las jurisdicciones provinciales, hiriendo la autonomía de éstas en cuanto a la posibilidad de dar respuesta a la problemática obrera. El DPT, por caso, quedó subsumido a la autoridad nacional y perdió la autonomía administrativa.

La política de la STyP bajo el mando de Perón llevó a una mayor regulación de las relaciones entre el capital y el trabajo, sobre todo mediante una política no formalizada de representación corporativa. Los convenios colectivos, como herramienta de mediación, fueron la norma. La utilización de esta formalidad institucionalizada es objeto de debate entre los historiadores. Es así que aquellos que sostienen la idea del Estado interventor en el período previo al peronismo, y a éste como una continuación de aquel, o incluso aquellos que como Korzeniewick ven el período previo como una época de transición, señalan en la firma de los convenios como el ejemplo fáctico de sus posiciones políticas. Sin embargo, como señala Doyon, no se puede sostener que antes de la llegada de Perón la firma de convenios fuese la norma, "si se tiene en cuenta la gama de actividades que quedaban al margen de esas tratativas $^{\prime \prime 4}$

A pesar de estos comienzos poco favorables, el DNT promovió constantemente la instauración de mecanismos de conciliación y arbitraje para solucionar los diferendos entre el capital y el trabajo y las páginas del Boletín del Departamento Nacional del Trabajo así dan cuenta de manera regular. La insistencia con la que se promovía la conformación de los Consejos del Trabajo debe ser entendida en la disputa que los funcionarios del DNT tenían con otras esferas a la hora de proponerse como el espacio privilegiado para solucionar la

\footnotetext{
44 CAMPIONE Daniel, Orígenes estatales del Peronismo, Miño y Dávila, Buenos Aires, 2007.

45 Ibidem. Pp. 110.

${ }^{46}$ DOYON, Op. Cit. pp. 42.
} 
problemática devenida de la relación laboral - la voluntad de excluir a la policía descripta anteriormente es parte de esta disputa-. Desde los proyectos de ley orgánica de la institución a los proyectos específicos sobre el tema, el DNT buscó que los organismos de conciliación y arbitraje estuviesen bajo su órbita y donde la representación fuese tripartita. De todas maneras esta voluntad de acción no evitaba que se diesen cuenta también de otros proyectos de características similares promovidos en las cámaras legislativas, aun cuando excluyesen al DNT de la resolución del conflicto.

La provincia de Buenos Aires no quedó ajena a la voluntad interventora del Estado en la relación laboral, y así como su par nacional, el DPT fue también objeto de proyecciones sobre su función. Bajo la tutela de su director Armando Spinelli el DPT con sus limitaciones, tanto presupuestarias y organizativas como ideológicas, buscó transformarse en una areferencia para los trabajadores y patrones de la provincia de Buenos Aires.

A las instituciones que por sus objetivos debian lidiar con la cuestión obrera se sumaron diversos organismos que no dependían del Poder Ejecutivo Nacional o Provincial. En lo que respecta a la búsqueda de soluciones de la "cuestión social" el Poder Legislativo y el Poder Judicial reclamaron también su facultad para tomar decisiones. Además, a pesar que el Poder Ejecutivo concentraba el poder de acción (entre otras cosas controlaba el poder de policía), los trabajadores podían acudir, y así lo hicieron, a estos dos poderes en búsqueda de respuestas a sus reclamos. El desarrollo de todas estas instituciones fue contemporáneo entre si y no libre de conflictos. Estos antecedentes de la formación de organismos especializados en el diagnóstico, estadística y resolución de problemas laborales, junto con el avance de los debates en los claustros universitarios y espacios políticos, conformaron una parte importante del clima de época en que se debatió la posibilidad de dotar a la provincia de Buenos Aires de Tribunales del Trabajo.

\section{III.2 La hora del fuero laboral se hace esperar. Proyectos y antecedentes de la constitución de la Justicia del Trabajo}

La importancia de la legislación laboral y las discusiones en torno a la creación de un fuero especial también pueden ser mediadas por el lugar cada vez mayor que ocupan estas cuestiones en las revistas especializadas desde 
mediados de la década del treinta. Publicaciones como Jurisprudencia Argentina y La Ley -ambas fundadas por Leónidas Anastasi-, empezaron a dedicarle espacio en sus páginas, al mismo tiempo en que surgen Derecho del Trabajo y la Gaceta del Trabajo. Pero además, en las páginas de los diarios de tirada nacional y local, la resolución de casos judiciales relacionados a cuestiones laborales comienzan a ser publicados en las secciones que estos periódicos dedicaban a la actividad del foro ${ }^{47}$. La importancia que este tema adquiría en los medios de comunicación masivos y especializados se suma a los cambios en las carreras de abogacía ya expuestos.

La constitución del fuero estuvo íntimamente vinculada con el desarrollo de la legislación laboral presentada en el capítulo II de esta tesis. Ya el proyecto de Joaquín González contemplaba la creación de una justicia laboral. Así decía el artículo 438 del título XIV, de los Tribunales de Conciliación y Arbitraje del reconocido proyecto,

Todos los conflictos, cuestiones o diferencias que se susciten entre obreros y patrones, que no sean en empresas 0 establecimientos directamente regidos por el Estado, sobre la ejecución del contrato de trabajo, ya sea individual, ya colectivamente considerado de una u otra parte, ya se trate de convenios formados entre sociedades de obreros y patrones (...) y que no correspondan por su naturaleza a la justicia ordinaria, o que no tengan en esta ley determinada una autoridad y un procedimiento especiales, se resolverán por árbitros en el modo y forma que se establece en el presente título. ${ }^{48}$

La Justicia del Trabajo aquí concebida era aquella que se desprendía exclusivamente de los preceptos de este proyecto. Aun no era pensada como un fuero autónomo y el primer artículo del título ya marcaba un límite concreto de actuación: aquellos establecidos por la justicia ordinaria. En el proyecto el sistema de Justicia de Trabajo establecía un mecanismo complejo y jerarquizado que incluía conciliación in situ en manos de los inspectores, Consejos de Conciliación tripartitos y una Corte Central de Arbitraje, lo que garantizaba instancias de apelación a los fallos y revisión de las sanciones y condenas.

\footnotetext{
${ }^{47}$ Como ejemplo en su edición del 8 de Agosto de 1948 el diario La Prensa titulaba en su página 14 "Prosperó un juicio iniciado por ex peón de quinta que fue despedido sin previo aviso" Diario "La Prensa" edición del 8/8/1948, pp. 14.

${ }_{48}$ GONZÁLEZ Joaquín V., "Proyecto de Ley Nacional del Trabajo", Obras Completas, Volumen VI, Universidad Nacional de La Plata, Buenos Aires, 1935. Pp. 567.
} 
El mantenimiento de formas ligadas a la tradición de la construcción del Poder Judicial con una estructura como la descripta con instancias de apelación y un vértice en el que las decisiones eran ya inapelables y a la que se llegaba en casos excepcionales ante el fracaso de los escalones previos- la Corte Central de Arbitraje- marca en parte la voluntad de otorgar a la institución a crear un aura de prestigio -aquel que rodea a la independencia del Poder Judicial-. Además se suponía así una institución alejada de los avatares políticos a los que pudiese estar vinculados en caso de tratarse de una dependencia del Poder Ejecutivo. Sin embargo el límite de la justicia ordinaria es también significativo de las resistencias existentes dentro del Poder Judicial a incorporar otro fuero a su institución.

Algunas de las características que presentaban en el proyecto los Tribunales de Conciliación y Arbitraje prefiguraron los lineamientos sobre los que se habría de debatir en los años posteriores la constitución de Tribunales del Trabajo. La búsqueda de múltiples instancias de conciliación -incluso creando Consejos de Conciliación-e incluso la potestad de las autoridades de suspender el proceso en caso de arribar las partes a un acuerdo sea cual fuese el estado del mismo era una pauta que se mantendrá en el debate de los años, no sin críticas y resistencias. La búsqueda de la resolución del conflicto por medio de medidas conciliatorias se proponía desde el primer momento mediante la actuación de los inspectores. Pero si las negociaciones no avanzaban se podía convocar a un Consejo de Conciliación cuya novedad más interesante era la forma de constitución del mismo. El Consejo de Conciliación era tripartito como tantas otras formas de negociación y arbitraje propuestas o en ese momento en funcionamiento tanto aquí en Argentina como en otros países industrializados, lo novedoso era la forma de elección del tercero que desempataría entre los representantes obreros y patronales. A diferencia de otros proyectos de instituciones tripartitas que se presentarían en los años posteriores, el Proyecto de Ley Nacional del Trabajo de 1904 no proponía un funcionario o delegado estatal para ocupar el lugar del tercero.

El artículo 442 del mencionado proyecto, en referencia a los Consejos de Conciliación, sostenía que estos se constituiría en cada caso en particular y "se compondrá de tres personas, una en representación de los obreros, otra del o 
de los patrones, y ambos designaran un tercero, que será el presidente" 49 . E avenimiento de las partes era ya necesario para la designación del presidente del consejo. Pero lo que resulta llamativo es la ausencia de la voluntad de constituir al Estado como el tercero garante de la negociación y como árbitro ecuánime. Contrastado con los proyectos de conciliación y arbitraje que en los años sucesivos presentarían las autoridades del DNT o con la forma que adquirirán finalmente los Tribunales del Trabajo, no deja de llamar este dato la atención. A pesar de que se reservaba a las autoridades de la Junta Nacional del Trabajo ${ }^{50}$ la posibilidad de la asignación del presidente en caso de que las partes no se pusiesen de acuerdo, el lugar del Estado quedaba limitado al refrendamiento de lo decidido por el Consejo de Conciliación. Esta proyección del Estado se acerca más a la idea de un Estado garante pero prescindente en el conflicto. El Estado asumía en esta institución el papel que poseía en relación a las leyes civiles: se entendía el Consejo de Conciliación como una instancia donde las partes asumían un contrato, el Estado, lejos de favorecer a algunas de las partes o buscar mediar en el conflicto funcionaba como escribano de los compromisos asumidos por ambas partes. Diferente era el caso de las Corte Central de Arbitraje en donde la presidencia era asumida por el presidente de la Cámara Nacional de Apelaciones y si bien se sostenía la institucionalización tripartita, los vocales sectoriales eran designados por tres años, mientras que el presidente ocupaba su cargo en tanto y en cuanto fuese también el presidente de la Cámara Nacional de Apelaciones.

La rapidez procesal también era pregonada en el proyecto. Todas las instancias propuestas debian tener como característica su rapidez y sencillez procesal, así como la comunicación clara de los resultados a los que arribaban. Estos objetivos serían constantes en los intentos de constitución de un fueron laboral y ya fueron vivibles en este primer intento. Incluso para el caso de la Corte Central de Arbitraje,

las prácticas sobre el modo de conducir los juicios arbitrales en el fuero ordinario, serán observadas en los de la Corte de Arbitraje, en cuanto sean

\footnotetext{
${ }^{49}$ GONZÁLEZ Joaquín V. Op. Cit. Pp. 569.

${ }^{50}$ La Junta Nacional del Trabajo era la oficina administrativa que creaba el proyecto de ley. En las atribuciones que se le otorgaba se asemejaba a lo que posteriormente fue el DNT.
} 
compatibles con la celeridad de éstos y con el carácter de los asuntos y las partes. $^{51}$

En tanto el personal y el presidente de las Corte Central de Arbitraje eran los mismos que la Cámara Nacional de Apelaciones se suponía que las formas procesales de esta podría impactar en la rapidez de la resolución, por eso se aclaraba que las prácticas se podían mantener, pero que era necesario ser conscientes de la materia que se estaba tratando y, en caso de no ser compatibles con las prácticas habituales, se debía privilegiar la celeridad.

En definitiva el proyecto González preveía una forma de aplicación de la ley que daba cuenta de las dificultades de los tribunales ordinarios para entender en una nueva materia, pero al mismo tiempo marcaba las dificultades para crear una institución con bases nuevas dentro del Poder Judicial. La institucionalización híbrida que presentaba en el proyecto los tribunales, con formas del Poder Judicial, dependencia de las instancias menores con respecto al Poder Ejecutivo y en la instancia máxima del Judicial y presencia de representaciones tripartitas daba cuenta de la falta de madurez aun del campo del Derecho Laboral y la imposibilidades en ese contexto de presentarse como una rama autónoma del derecho.

La necesidad de formar Juzgados o Tribunales del Trabajo se desprendía de las características propias del derecho laboral que implicaba cambios procesales. En definitiva se trataba de dotar de una institución que respondiese a los cambios que el derecho laboral introdujo en referencia al la tradición civil. Los debates de la ley de accidentes del trabajo a mediados de la década del diez del siglo pasado fueron un estímulo importante en la consideración de contar con un fuero capaz de resolver sobre el Nuevo Derecho. Ya en el proyecto sobre una ley de Accidentes de Trabajo, presentada en la sesión del 16 de Mayo de 1910 por el diputado Escobar preveía que las posibilidades de aplicación de la ley de accidentes que proponía encontraría un serio escollo en la institucionalización que tenían los juzgados civiles -entre otras cosas su costo-. Por ese motivo proponía en el cuerpo del proyecto que a los trabajadores que acudiesen a los juzgados civiles en busca de reparación en caso de accidente laboral se les reconociese los "beneficios acordados a los

\footnotetext{
${ }^{51}$ GONZÁLEZ Joaquín V, Op. Cit. Pp. 574.
} 
declarados pobres" ${ }^{\prime 2}$. Pero fundamentalmente fue la inclusión de la noción de riesgo profesional lo que impactó en la formación de un nuevo fuero. La adopción de tal principio implicaba en términos procesales la inversión de la carga de la prueba -que significaba que debía ser el patrón el encargado de demostrar la negligencia del trabajador ${ }^{53}$-. Aun así los jueces civiles se vieron limitados -por la misma tradición del fuero y por una mala predisposición hacia los trabajadores- a la hora de aplicar esta ley, lo que hacía evidente la necesidad de un fuero con características solidarias a los cambios que el derecho laboral imprimió en la tradición civil.

Estas resistencias en el ámbito de la justicia civil a la aplicación de la legislación laboral debe ser tenida en cuenta a la hora de reflexionar sobre el porqué del establecimiento de instituciones que adquirían formalmente rasgos judiciales, pero que ejercían su actuación en el ámbito del Poder Ejecutivo. La construcción del Poder Judicial contemporánea a la construcción estatal del siglo XIX en Argentina, oponía barreras difíciles de franquear para los sostenedores del Nuevo Derecho. Estas resistencias estaban en parte detrás de la constitución o proyectos de constitución de organismos con formato judicial en el ámbito del Poder Ejecutivo.

Ante la ausencia de consenso para erigir un nuevo fuero judicial la opción por incluir a estos organismos dentro del Poder Ejecutivo o buscar formas híbridas como la propuesta por González eran la norma durante este período y el debate sobre si era o no posible constituir un fuero propio separado de la Justicia Civil fue reflejado en las revistas académicas e incluso dividió las aguas dentro de las cátedras de legislación laboral y derecho laboral de las universidades argentinas.

No era este un debate exclusivo de nuestro país, en el caso de Brasil este debate fue cerrado por el gobierno de Getulio Vargas que decidió constituir todo el sistema de la Justiça do Trabalho en el ámbito del Poder Ejecutivo y que marcó profundamente a la institución. La Justicia de Trabajo surgió en el seno del Ministerio de Trabajo y bajo su tutela como parte de un proyecto

\footnotetext{
52 “Legislación Nacional. Proyecto de Ley de Accidentes del Trabajo presentado por el diputado A.C. Escobar", BDNT, №13 Junio 30 de 1910, Departamento Nacional del Trabajo, Buenos Aires, 1910, Pp. 344

${ }^{53}$ Para los impactos de la inversión en la carga de la prueba en términos procesales y su impacto en los juicios civiles sobre accidentes de trabajo ver SCHJOLDEN Line, Op. Cit , BARANDIARAN Luciano, Op. Cit.
} 
político como lo fue el varguismo. Esta marca de origen llevó a que ocupara siempre un lugar de menor valor frente a las otras ramas del Poder Judicial (Civil y Comercial, Penal). Su subordinación frente al Poder Ejecutivo no le permitirá ostentar "los símbolos de prestigio y distinción adecuados a los tradicionales valores honoríficos de la magistratura" ${ }^{15}$ y por ese motivo será denominada comúnmente "justicinha" aun cuando mediante la reforma constitucional de 1946 fue incluida dentro del Poder Judicial.

En este proceso de nominalización como una justicia de menor jerarquía influyeron otros factores, pero que están relacionados con las condiciones de su origen dentro del Poder Ejecutivo y con la idea de que tenía un programa político que cumplir ${ }^{55}$. Este programa político estaba marcado por la concepción de que la Justicia del Trabajo debería superar la concepción de que las relaciones colectivas de trabajo constituían manifestaciones de la lucha de clases y reemplazarla por la cooperación de los grupos opuestos, lo que Sayão Romita denomina "ideología da paz social"56. Por lo tanto el fin de la Justicia del Trabajo era la conciliación de las partes. La conciliación estaba a tono con el "espíritu de la ley" que fundaba la Consolidação das Leis do Trabalho y la Justicia del Trabajo, lo que inclusive llevaba a sus defensores a buscar limitar la presencia de los abogados en la resolución de los juicios. Incluso cuando se daba por fuera de la misma ley -fuera de los tribunales- la conciliación era el objetivo $^{57}$.

La salida brasilera a la cuestión es interesante en tanto resalta la falta de prestigio que afrontaban instituciones de este tipo cuando debían ser incluidas en una institución en el que las marcas del prestigio eran importantes como el Poder Judicial. Si bien no se acuño aquí en Argentina una expresión despectiva como la de justicinha, no hay dudas de la condición subalterna que cualquier proyecto de constitución de Justicia del Trabajo adquiririó dentro del Poder Judicial. Esta cuestión retrasó la hora del fuero laboral y llevó a la presentación de proyectos híbridos o dentro del Poder Ejecutivo.

\footnotetext{
${ }^{54}$ Traducción propia de TEIXEIRA DA SILVA Fernando, "Nem Crematório de Fontes Nem Museu de Curiosidades: por que Preservar os Documentos da Justiça do Trabalho" en BIAVASCHI Magda Barros et al (orgs), Memória e preservação de documentos: direitos do cidadão, San Pablo, LTr, 2007. Pp. 33

${ }^{55}$ CORREA Larissa Rosa, A tessitura dos direitos. Patrões e empregados na Justiçã do Trabalho, 1953-1964, São Paulo, FAPESP-LTr75, 2011.

${ }^{56}$ SAYÃO ROMITA Arion, Op. Cit.

${ }^{57}$ VARUSSA Rinaldo, Op. Cit.
} 
De todas maneras los promotores del Derecho Laboral no cesaron en sus intentos de constituir un fuero propio. En el marco de la primera reunión de la OIT en 1919, Alejandro Unsain planteó las propuestas que debía tratar la conferencia siguiente ${ }^{58}$. Al reseñar para el Boletín del Departamento Nacional del Trabajo la actuación de la Conferencia de Washington y principalmente la acción de la delegación Argentina, comentó la presentación de siete puntos sobre los que, según él, debía versar la conferencia del año siguiente.

En esta serie destacan los dos primeros puntos en relación a la conformación de instituciones de aplicación de la legislación laboral que vale la pena recordar. Proponía Unsain que se debía aplicar los esfuerzos en la conformación de

$1^{\circ}$ un sistema legal que permita:

a)Prevenir las huelgas; $y$

b) Solucionarlas por medio del arbitraje cuando los esfuerzos de prevención no hayan dado el resultado esperado.

$2^{\circ}$ un sistema que tienda a crear tribunales industriales con jurisdicción exclusiva:

a) En todos los juicios y cuestiones relativas al contrato de trabajo; y

b) en la aplicación de las multas y penalidades que las leyes de cada país señalan para los infractores de las leyes obreras.

Estos tribunales deberán obrar:

a) gratuitamente para los obreros; y

b) con procedimiento rápido y sumario. ${ }^{59}$

Se repiten las características de rapidez pregonada en el proyecto González, pero consideraba Unsain que era tiempo de conformar esta institución como fuero propio dentro del Poder Judicial. Como ya quedo dicho en el capítulo II, la presentación de Unsain en Washington de medidas que aun no era posible aplicar en Argentina respondía a la jerarquización que su tratamiento en organismos internacionales tenía. Si el problema para constituir un fuero laboral en Argentina -fuese con la jurisdicción que fuese- debía superar los prejuicios ligados a la falta de prestigio que la materia tenía dentro del campo judicial, la referencia a las instituciones internacionales podía servir de estímulo para jerarquizar el derecho laboral y sus instituciones. Presentar a los Tribunales del Trabajo dentro de una corriente mundial más amplia, y principalmente adoptada por los países considerados ejemplos a seguir por las

${ }^{58}$ Finalmente esta propuesta fue superada por la coyuntura de la problemática del trabajo marítimo y la Conferencia de Génova del año siguiente (1920) trató exclusivamente este problema.

${ }^{59}$ UNSAIN Alejandro, Argentina en el governing... Op. Cit. Pp. 207. 
elites dirigentes argentinas, podía ser una buena manera de evitar la consideración de esta institución como una justicia menor. Sin llegar a romper con las jerarquías dentro del campo permitía al menos dotarla de prestigio por fuera del campo.

El antecedente de la propuesta de la delegación Argentina en la Conferencia de Washington de la OIT es relevante por la presencia de Unsain, quien fue el encargado de la redacción del proyecto de Código de Trabajo de 1921 impulsado por el presidente Hipólito Yrigoyen. En este proyecto el título XX estaba enteramente dedicado a los Juzgados del Trabajo. En términos de antecedentes la propuesta de 1921 fue importante considerando en que era impulsada por un gobierno con pretensiones de modificar las relaciones entre el Estado y las asociaciones obreras. Se puede sostener que la redacción adoptada por Unsain para el proyecto condensaba el punto en el que se encontraban los debates sobre la conformación de la justicia del trabajo. Su lugar en la especialidad y su experiencia como funcionario $-\mathrm{y}$ ocasional presidente- del DNT lo colocaba en permanente contacto con otros especialistas de derecho laboral tanto argentinos como extranjeros -era también el representante de la Argentina en la OIT-.

El proyecto instituía una justicia del trabajo en pie de igualdad con el resto de los fueros del Poder Judicial, superando de este modo los proyectos anteriores que proponían estructuras dentro del Poder ejecutivo o con correspondencia híbrida. El artículo 505 del proyecto de 1921 decía:

Creáse, para la capital federal, un juzgado de trabajo con el mismo personal asignado a los juzgados federales. El juez del trabajo será designado por el Poder Ejecutivo con acuerdo del Senado y su situación será la misma de los restantes magistrados de igual categoría de la justicia federal $^{60}$

Si bien no era el proyecto demasiado ambicioso en cuanto a la creación de tribunales del trabajo -solo creaba uno y para la Capital Federal- suponía un avance con respecto a los proyectos anteriores. La cuestión de la jurisdicción también es interesante remarcar ya que en el artículo tercero del proyecto en el que se enmarcaba este tribunal se sostenía la jurisdicción del Código del Trabajo para todo el territorio de la república. Sin embargo a la hora de crear la

60 "Código del Trabajo" en BDNT, N48, Noviembre de 1921, Departamento Nacional del Trabajo, Buenos Aires, 1921. Pp. 89. 
autoridad judicial de aplicación de las leyes que contenía la jurisdicción quedaba reducida a la ciudad de Buenos Aires, sin contemplar siquiera los territorios nacionales, a pesar de quedar bajo la órbita de la justicia federal.

Otros mecanismos que contemplaba el proyecto que trascendieron al mismo y que fueron reeditados en los proyectos posteriores era el funcionamiento del juzgado del trabajo como instancia de apelación de las resoluciones de las autoridades administrativas, ya fuesen estas los jueces del salario creados por el mismo proyecto, o en los casos de huelgas que no pudiesen ser resueltos por la vía de la conciliación. Este lugar central como instancia de apelación da cuenta de la complejidad del entramado institucional que el Código del Trabajo de 1921 presentaba para la resolución de los conflictos entre el capital y el trabajo. Las múltiples opciones administrativas (Consejos de Conciliación y Arbitraje, Jueces de Salario, Consejo de Tarifas) que convergían sobre el juzgado de trabajo como instancia de apelación plantea la necesidad de pensar el sistema de justicia del trabajo más allá de la mera existencia de juzgados laborales. La interconexión de las instancias administrativas y judiciales adquiere una relevancia en el caso del fuero laboral que no se percibe en la conformación del fuero civil.

Además de las vinculaciones, en tanto instancia de apelación, con las instancias administrativas, el juzgado del trabajo se vinculaba también jerárquicamente con el resto del Poder Judicial. Podían ser instancia de apelación ante el reclamo de sumas menores en la justicia de menor cuantía si bien no aclara se puede suponer que se refiere a la Justicia de Paz-. Además no era una instancia única y ante la apelación de la resolución adoptada por el juez del trabajo la causa seguía los caminos establecidos dentro de la justicia federal. La Cámara de Apelaciones Federal y la Corte Suprema de Justicia de la Nación eran los jueces naturales de las apelaciones. En definitiva, la proyección del juzgado del trabajo no se propuso como un fuero totalmente autónomo en la medida que no contemplaba las instancias de apelación dentro del mismo.

El proyecto contemplaba el establecimiento de mecanismos de justicia laboral en las provincias, pero estas determinarian la forma que se debía adoptar en cada jurisdicción, aunque respetando ciertos parámetros. Entre los límites que el código imponía para la constitución de instancias de mediación y 
arbitraje, destacaba respetar como base "el derecho a huelga por parte de los obreros y empleados" ${ }^{\prime 61}$. El realismo primó en el caso de la redacción del Código del Trabajo de 1921, asumió la voluntad de legislar para toda la nación, pero evidenció los límites y objeciones que podían plantear los poderes provinciales a lo que era considerado intromisiones del Poder Federal sobre las provincias. Dejando en mano de las provincias la legislación concerniente a la construcción del fuero laboral, se permitía, en última instancia, que cada provincia adecuase la institución a sus necesidades productivas, pero también a la correlación de fuerzas no siempre favorable a los cambios.

La presentación y apoyo del Poder Ejecutivo Nacional de este proyecto marca el vaivén que con respecto a la política laboral sufrió el gobierno radical de Yrigoyen. La intervención por parte de las autoridades más altas del Poder Ejecutivo -que en definitiva terminaba por decidir el éxito o fracaso de la protesta- contrastaba con la cotidiana intervención del DNT. Mientras que las autoridades del DNT se quejaban de la falta de un mecanismo normalizado para el tratamiento de los conflictos que tuviese aplicación real y efectiva, el Poder Ejecutivo transitaba distintos caminos que iban desde el arreglo personal de los sindicatos con Yrigoyen o sus representantes, la prescindencia estatal o la represión. En estos vaivenes es que se sostiene la percepción a los límites del obrerismo de los primeros gobiernos radicales ${ }^{62}$.

Sin embargo la presentación de este proyecto puede dar cuenta de la intención de otorgar estabilidad y previsibilidad a la resolución de los conflictos, a la par que favorecería otro tipo de relación entre los trabajadores y el Estado. El fracaso en la sanción de este Código -que siguió el camino de los presentados anterior y posteriormente- puede ser enmarcada en la debilidad legislativa del radicalismo en este período -la imposibilidad de lograr una mayoría simple en ambas cámaras- tanto como a la voluntad integradora personalista del presidente y su elenco de gobierno.

\section{III.3 El peronismo llegó en buena hora. Impulso político al fuero laboral}

Las múltiples temáticas desde las que se aborda el peronismo han logrado matizar las posturas dicotómicas, tal como recuerdan Omar Acha y

\footnotetext{
${ }^{61}$ Ibid, Pp. 86

${ }^{62}$ GARGUÍN Enrique, Op. Cit
} 
Nicolás Quiroga, pero subyace siempre la idea del peronismo como parteaguas de la historia ${ }^{63}$. Para el caso de la Justicia del Trabajo tal aseveración se ve plenamente justificada. La hora de la justicia del trabajo vino a la par con la institucionalización del peronismo en el poder. Los cambios que propuso el peronismo en el DNT, ascendiendo al Departamento al rango de Secretaría, sumada a la reorganización de la misma descripta en las páginas precedentes de la que da cuenta Daniel Campione, se reprodujeron en otros ámbitos del Estado y el Poder Judicial no fue la excepción.

El Decreto 32.347 del 30 de Noviembre de 1944 firmado por Perón como secretario de Trabajo y Previsión creaba los Tribunales del Trabajo para el ámbito de la Capital. La imposibilidad de su aplicación fue la excusa necesaria para que el presidente Perón, ya consagrado en las elecciones de 1946, iniciara juicio político a los miembros de la Corte Suprema de Justicia de la Nación. El estudio previo a la sanción del decreto fue realizado a pedido de Perón por el departamento de Asesoría Jurídica de la Secretaría de Trabajo y Previsión durante los meses de Mayo y Junio de 1944 y elevado al secretario el $1^{\circ}$ de Julio de 1944 por Eduardo Stafforini (a la sazón jefe de la división de asesoría jurídica), César Martínez Vivot y Luis Rufo.

El proyecto contemplaba varios tópicos comunes en los debates sobre este tipo de instituciones en los ámbitos especializados. La presencia en los considerandos de los ejemplos de regímenes existentes en países extranjeros es otra muestra de la importancia que el derecho comparado tenía para el desarrollo de los especialistas de derecho del trabajo y una forma de colocar el proyecto en consonancia con lo que se consideraba el desarrollo internacional de la legislación, fundamentalmente promovida por la OIT. En la resolución de Juan Domingo Perón que solicita el estudio y la redacción del proyecto de decreto para instituir el fuero del trabajo sostenía que

frente a las características específicas de los problemas contemplados por el derecho del trabajo y la legislación social, el Estado debe instituir los organismos y procedimientos que, adaptándose a las exigencias de aquellos, aseguren el adecuado cumplimiento de las prescripciones legales. ${ }^{64}$

\footnotetext{
${ }^{63}$ ACHA, Omar y QUIROGA, Nicolás, Presentación... OP. Cit,

${ }^{64}$ Justicia del Trabajo. Organización, competencia y procedimiento, Imprenta del Congreso Nacional, Buenos Aires, 1944. Pp.3
} 
La construcción de una nueva institución legal no debería, por lo tanto, escapar de las prescripciones y limitaciones que la propia ley le imponía. Esta voluntad de seguir la letra de la ley, si bien no evitaría el posterior conflicto con la Corte Suprema de Justicia, deja entrever la voluntad de constituirse como un verdadero poder constituyente. En definitiva la lógica discursiva del pedido de Perón no escapa de las generales reconocidas en el gobierno peronista que expresaba una manifiesta intención de cambio dotada de un entramado legal entre la tradición y lo novedoso que intenta justificarlo. Este devenir entre la novedad y la tradición marcaría a los redactores del proyecto, quienes sostendrían que

si bien el régimen proyectado importa reformas fundamentales con respecto al procedimiento de la justicia civil, ha respetado, en cuanto fueran compatibles con la finalidad perseguida, los principios de este último así como sus instituciones esenciales. ${ }^{65}$

Se aceptó el cambio con respecto a la tradición civil, pero no se asumió plenamente la ruptura que el mismo derecho del trabajo planteaba justamente con algunas de las instituciones fundamentales del Derecho Civil. El proyecto tenía un carácter híbrido en el que predominaban las innovaciones procesales pero que mantenía formas que lo ligaban a las tradiciones institucionales del poder que se buscaba reformar. Así, la opción de la representación corporativa, presente en instituciones como la Justiça do Trabalho brasilera, o en los proyectos de conciliación y arbitraje del mismo DNT o su par provincial presentados años antes, eran descartadas por los redactores de este nuevo proyecto para las instancias judiciales. La presencia de jueces letrados era requisito fundamental a la hora de presentar a la institución como imparcial ante los problemas para los que se proponía como instancia de resolución. La opción por jueces letrados descansaba en última instancia en la característica de los pleitos a resolver, de carácter individual, que desaconsejaba la presencia corporativa. Sostenían los promotores del proyecto que

si bien la representación patronal y obrera es aconsejable en los organismos destinados a los conflictos colectivos, ha resultado inconveniente para los conflictos individuales.

La experiencia ha demostrado el evidente desequilibrio entre la representación patronal y obrera y, por otra parte, la tendencia de esas

\footnotetext{
${ }^{65} \mathrm{lbid}$. Pp. 7.
} 
representaciones hace que carezcan de la imparcialidad indispensable en la función de administrar justicia. ${ }^{66}$

La administración de la justicia, función sensible del Estado, era preservada para el tercero en la disputa entre capital y trabajo como medida de imparcialidad. $Y$ aunque se reconocía la ascendencia social del problema, los límites de la tradición civil en términos de individuos terminó primando en la constitución institucional del fuero laboral. Esta imparcialidad no escapaba, de todas maneras, del reconocimiento de las razones que habían llevado al desarrollo del derecho del trabajo "cuyo contenido social y humano tiende a proteger la parte débil de esa relación" ${ }^{\prime 67}$. Así en sus proyecciones gráficas significativamente la Justicia aparecía sin su vendaje en los ojos capaz de reconocer la naturaleza del conflicto que tenía que resolver y la desigualdad de los recurrentes, pero aun así se trataba de la Justicia y no ya el Estado representado como un empresario inclinando la balanza a su favor (ver Imagen $\left.N^{\circ} 4\right)$.

La promulgación de este decreto generó un verdadero revuelo en los ámbitos judiciales que alcanzó su punto álgido al enfrentar a Perón con la Corte Suprema de Justicia de la Nación -resuelto mediante la remoción de los jueces por juicio político-. En una larga alocución radial del 9 de Abril de 1945 ante una reunión de dirigentes sindicales-posteriormente publicada por el Ministerio de Trabajo y Previsión Social-, Perón hizo referencia a este conflicto identificando a los opositores al tiempo que sostenía su voluntad de llevar adelante la medida propuesta en el decreto 32.347. Según el entonces Secretario de Trabajo y Previsión el asunto de los Tribunales del Trabajo

ha sido objeto de algunos torpedos. Es natural que lo quieran torpedear los que antes vivían de la explotación de los pobres obreros. Sabemos muy bien que ya se mueven fuerzas hasta en el foro, diciendo que esto es inconstitucional. Sabemos muy bien donde van dirigidos esos dardos y porque se disparan; pero como estamos decididos a defender los intereses de los que tienen menos intereses, hemos de sacrificar cualquier cuestión para que esto se cumpla. Una Justicia del Trabajo rápida, real, sin explotaciones de ninguna naturaleza, es la base de todo el mecanismo de solución de los conflictos del trabajo. Hasta ahora, lo hemos hecho nosotros, aquí en la Secretaría, un poco arbitrariamente si se quiere, pero saben

\footnotetext{
${ }^{66}$ Ibid. Pp. 8

${ }^{67}$ Ibid. Pp. 12
} 
perfectamente ustedes el extraordinario bien que ésa, nuestra justicia, quizá fuera de la ley, ha proporcionado a la masa de trabajadores. ${ }^{68}$

La referencia de Perón a los que vivían de la explotación de los pobres obreros era una representación de lo que la justicia civil ofrecía a los trabajadores. Se entiende del extracto del discurso que hacía Perón referencia a las fuerzas opositoras dentro del foro, donde los abogados civilistas ejercían un alto poder simbólico -en términos bourdieanos- en el campo, y fuerzas exteriores al foro. Sin dudas las medidas adoptadas por un gobierno de facto en momentos en que su propia legitimidad estaba comenzando a ser cuestionada, Ilenaron al debate de un alto contenido político coyuntural. Sin embargo la oposición a medidas como las que adoptaba el decreto tendían también a incidir en disputas hacia el interior del campo judicial que eran de larga data. La preeminencia del Derecho Civil dentro del fuero implicaba la sujeción de las instituciones a sus principios liberales, pero el Derecho del Trabajo venía a poner en debate estos principios.

No debe extrañar, entonces, que ante un cambio en las relaciones de fuerza dentro del campo existieran resistencias dentro del mismo campo. Pero la autonomía del campo judicial no puede sostenerse en términos históricos. La existencia de tensiones exteriores al propio campo capaces de permear fronteras y líneas hacen relativa la autonomía e independencia del campo. Sabida es la relación que establecieron los contemporáneos entre el gobierno militar de facto y los regímenes totalitarios europeos -en esos momentos derrotados o a punto de serlos en la conflagración mundial-. La acusación al gobierno militar de sostener tendencias nazifascistas, y principalmente a la figura de Perón como la personificación del Duce o el mismo Hitler ${ }^{69}$ facilitaron la demonización de las acciones del gobierno. Las continuas arengas de Perón contra el liberalismo y muchas de sus instituciones eran percibidas como un

\footnotetext{
${ }^{68}$ Discursos de Juan Domingo Perón, Carpeta 4. 9 de Abril de 1945 a 31 de Julio de 1946. Biblioteca del Congreso de la Nación. BPD4 (1), Folio 3 y sig.

${ }^{69}$ Ilustrativas de este punto son las imágenes que rescata Marcela Gené sobre Perón. Sostiene Gené: "desde las páginas de La Vanguardia, Tristán fustigó al General desde todos los flancos posibles. Las aspiraciones dictatoriales fueron pronto el blanco predilecto para el ataque en caricaturas que describen escenas complejas, abarrotadas de objetos y personajes", GENÉ Marcela, "Los rostros del General: Perón, del retrato protocolar a la caricatura", Prohistoria $N^{\circ}$ 9, número monográfico. La trayectoria de la cultura política peronista, 1943-2003, Prohistoria Ediciones, Rosario, Primavera de 2005, Pp.92. En una de las imágenes se puede ver a Perón encarnando al César ladeado por una multitud que grita "Heil Perón" mientras sostienen su brazo derecho en alto. Ibídem, Pp. 105.
} 
intento de acabar con las libertades individuales. Sin duda la promoción de una institución como los Tribunales Laborales, efectivamente contraria al liberalismo jurídico y a la neutralidad del tercero garante, fue percibida como un avance autoritario del régimen.

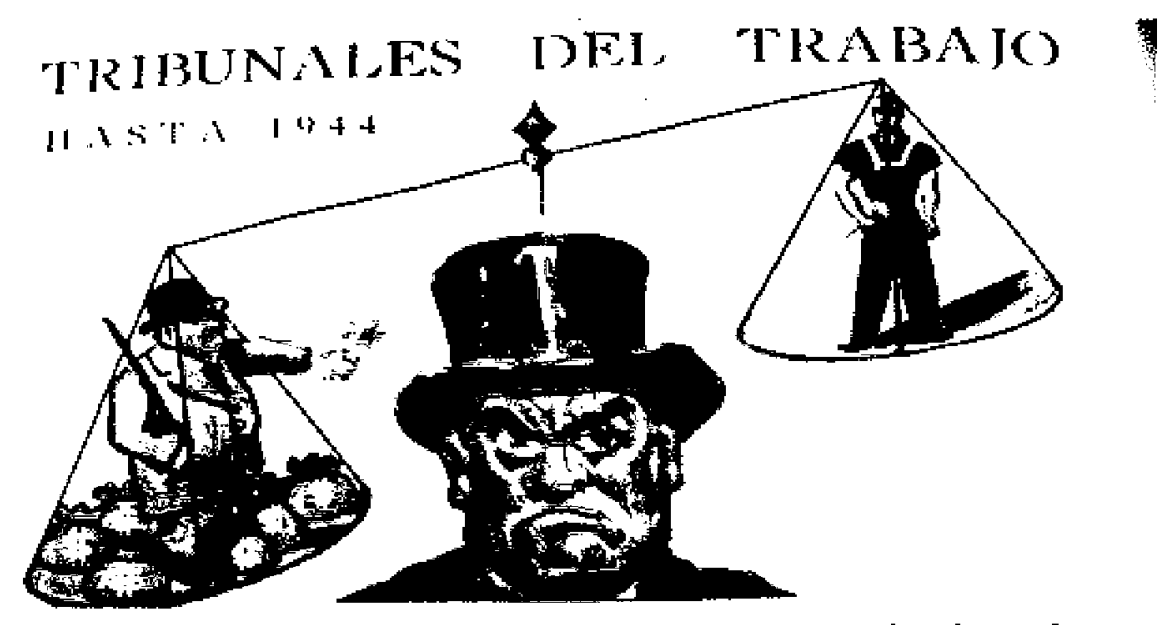

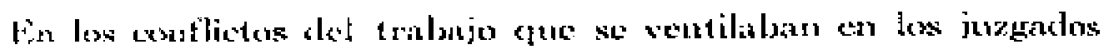

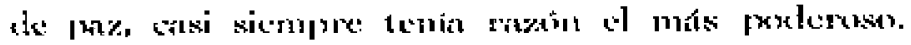

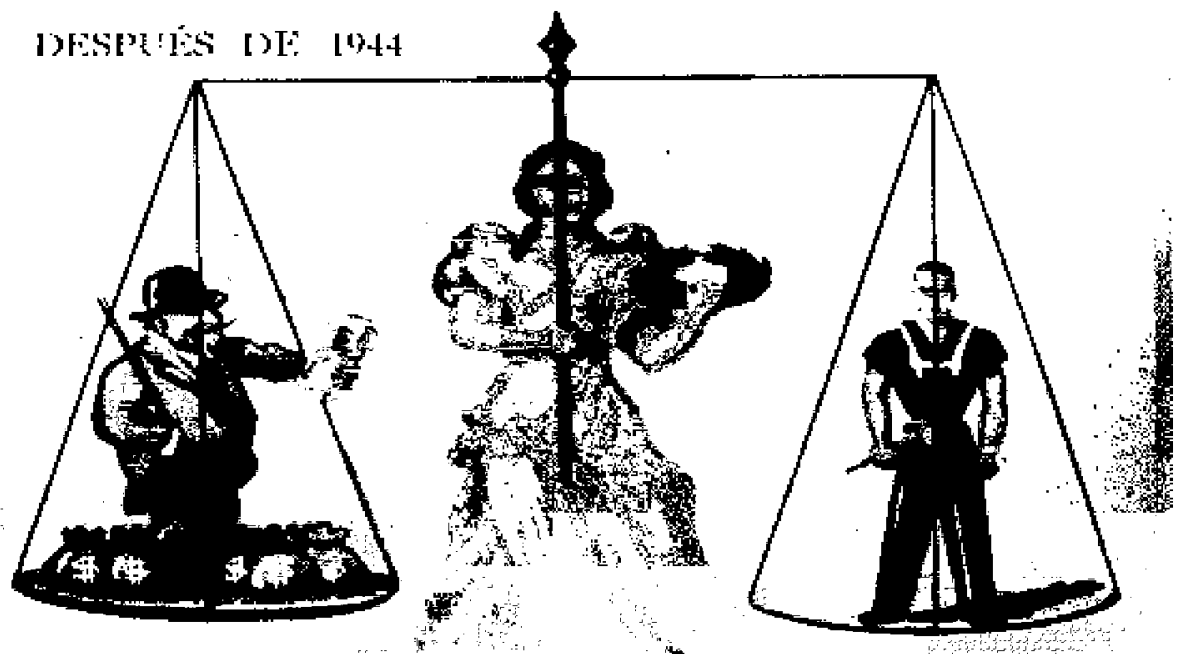

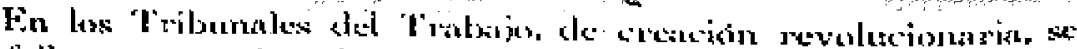

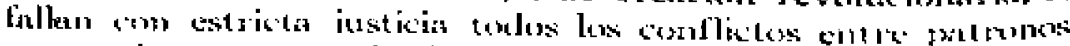

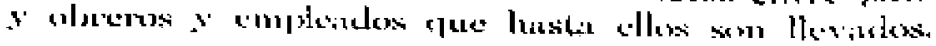

$\ln$

Imagen $\mathbf{N}^{\circ} 4$ : representación de la justicia del trabajo antes y después de la promulgación del Decreto $\mathrm{N}^{\circ} 32.347$.

Fuente: Argentina. Aver, hoy y manana. Subsecretaria de informaciones y prensa, Buenos Aires, 1950. Pp. 170.

La disputa con el Poder Judicial que implicó la creación de los Juzgados del Trabajo con remoción de los ministros de la Corte Suprema incluidos fue objeto del discurso que Perón brindara a la Asamblea Legislativa en su 
segundo mensaje como presidente constitucional después de las elecciones del 24 de Febrero de 1946. La reafirmación de la Justicia Social como eje de las políticas de estado implicaba la promoción de una nueva figura del juez, cuya ecuanimidad dependía de que afirmase dicha justicia social ${ }^{70}$. Ante las críticas recibidas, a pesar de que los jueces fueron elegidos mediante los mecanismos establecidos por la Constitución ${ }^{71}$, Perón contestaría que

sin merma del respeto debido a los jueces, nuestra justicia será deficiente mientras no pierda su estructura de clase y mientras su función no se haga incompatible con toda otra actividad, incluida la docente. Mientras el magistrado judicial alterne en los claustros universitarios con otros profesores que son, a su vez, abogados en ejercicio, no podrá existir una confianza plena. Cuanto más delicado sea un ministerio social, más apartado debe estar de toda sombra de sospecha. ${ }^{72}$

Hay que remarcar la importancia que desde el gobierno peronista se daba a las funciones que debían desempeñar los jueces como funcionarios públicos. El llamado a romper con la estructura de clases a la que pertenecía a fin de colocarse en un lugar más elevado -el ejercicio como funcionario del Estadocoincide con la particular percepción del peronismo en lo que respecta al conflicto entre las clases sociales. La creencia en un estado ecuánime y equidistante capaz de lograr la colaboración de las clases se traducía de este modo en un pedido para la autonomía de los jueces con respecto, incluso, a aquellos que conformaban su propio campo, los abogados y las cátedras universitarias.

Este antecedente nacional era el más poderoso en términos de políticas a seguir por la provincia de Buenos Aires a la hora de pensar una institución dentro del Poder Judicial dedicada a las cuestiones laborales. El discutido decreto finalmente logró ser incorporado al corpus legal de la nación mediante

\footnotetext{
${ }^{70}$ Perón hace referencia a los jueces y camaristas de la Justicia del Trabajo en un discurso previo ante dirigentes obreros con motivo de la inauguración de la Justicia del Trabajo. "Discurso del coronel Perón en la reunión de dirigentes obreros realizada con motivo de la iniciación de los Tribunales del Trabajo", Biblioteca del Congreso de la Nación, Carpeta 4: 9 de Abril de 1945 a 31 de Julio de 1946, BPD4 (25)

${ }^{71}$ Sobre la elección de los jueces para los juzgados y tribunales laborales ver MARCILESE José, "El Poder Judicial bonaerense durante el Primer Peronismo: de la autonomía a la dependencia", EIAL, 2007. Consultado en www1.tau.ac.il/eial. Generado el 14 de Junio de 2008.

72 "Mensaje leído por el General Perón ante la Asamblea Legislativa al declarar inaugurado el período ordinario de sesiones, $1^{\circ}$ de Mayo de 1947", Biblioteca del Congreso de la Nación, BPD9 (11), Folio 269.
} 
la ley $12.921^{73}$ de 1947 que aprobara el congreso poco después de su reapertura. La sanción de la ley ratificó la voluntad del gobierno nacional de constituir una institucionalización nueva para el conflicto laboral, pero al igual que otras leyes sancionadas por el Congreso de la Nación, su jurisdicción era limitada a la Capital Federal y los territorios nacionales. Esto provocó que poco después el diputado Manuel M. Díaz hiciera un pedido de moción solicitando que estas instituciones fuesen creadas en los estados provinciales, a fin de ahondar en la tarea emprendida por el Poder Ejecutivo Nacional. Al sostener su pedido no dudaba en afirmar que

La falta de Tribunales del Trabajo en las provincias ocasionó, y sigue ocasionando, graves perjuicios para los obreros, que se ven en la necesidad de acudir a los tribunales ordinarios, para que se amparen sus derechos, y que obtienen como resultado una justicia dilatoria y cara, lo que equivale, en muchos casos, a la negación misma del derecho, ya que el obrero no puede esperar durante mucho tiempo la solución de sus conflictos económicos, por cernirse sobre él y sobre su familia necesidades apremiantes que requieren rápidas soluciones. ${ }^{74}$

Algunas de las palabras que empujaron al diputado Díaz fueron las que sostuvieron los legisladores bonaerenses a la hora de sancionar la ley 5.178, sobre todo referido a lo dilatorio y caro de los tribunales ordinarios ${ }^{75}$. Esto ocasionó que muchos trabajadores no acudiesen al estrado buscando defender sus derechos. Como sostiene Díaz en su presentación la situación económica de las familias obreras no podía permitirse el lujo de sobrevivir sin el ingreso del salario de sus componentes. Si a esto sumamos la posibilidad de tener que hacerse cargo de los honorarios de los abogados en caso de no prosperar en la demanda, se desprende que los riesgos de iniciar una acción eran muy altos y el pago no siempre resultaba acorde a las expectativas del trabajador o su familia ${ }^{76}$.

\footnotetext{
${ }^{73}$ Dicha ley sancionada por el Congreso de la Nación otorgaba carácter de ley a todos los decretos y resoluciones que concernían al ámbito social dictados por la Secretaría de Trabajo y Previsión desde el 4 de Junio de 1943 hasta 1946, legalizando así la obra legislativa del gobierno provisional en materia laboral.

${ }_{75}$ Diario de Sesiones, Cámara de Diputados de la Nación, Año 1947, Tomo I, pp. 500.

${ }^{75}$ Esta postura parce haber sido compartida por diferentes actores de la época y no eran exclusiva de los miembros del partido en el gobierno. De todas maneras cabe aclarar que en varios de sus discursos Juan Domingo Perón sostenía que la justicia tradicional cuando debía actuar sobre cuestiones laborales era lenta y esto ocasionaba serios perjuicios a las familias obreras.

${ }^{76}$ Schjolden analiza la resolución de algunos casos iniciados en los juzgados civiles de la capital, y llega a la conclusión que incluso cuando salían vencedores del pleito, los demandantes no siempre lograban cobrar lo suficiente como para hacerse cargo de los gastos
} 
De todas maneras el empeño de Díaz por instaurar Tribunales Laborales en las provincias argentinas dio su fruto, convirtiéndose su pedido de moción en el decreto $\mathrm{N}^{\circ} 6717$ del 13 de Agosto de 1947 en el que se

convocaba a las provincias a suscribir con el Gobierno de la Nación un tratado de administración de justicia tendiente a organizar con carácter uniforme la justicia laboral en toda la República ${ }^{77}$.

Los debates en torno a la forma institucional que estos debían adoptar aparecieron en las revistas especializadas o en las cátedras de las diferentes facultades de derecho del país. El llamado de Díaz corresponde al año 1947, mientras que para el año 1949 ya había Tribunales del Trabajo en la Capital Federal y las provincias de Santiago del Estero, Santa Fé, Buenos Aires, Tucumán, Jujuy, Salta y Corrientes, mientras que se encontraba en estudio un proyecto de constitución de dicho fuero para la provincia de San Luís ${ }^{78}$. El debate en torno a las formas que debían tener los tribunales era parte del clima de época. El Nuevo Derecho buscaba las formas de institucionalizarse en todo el mundo y la Argentina no era la excepción.

\section{III.4 Conclusiones}

La constitución de instituciones que colocaban al capital y al trabajo cara a cara estuvo presente desde el desarrollo mismo del Nuevo Derecho. Los debates en torno a la manera en que se debía controlar el cumplimiento de la legislación laboral fue esencial para que prosperen los pedidos de constitución de un fuero específico dentro del Poder Judicial. Sin embargo los primeros intentos de colocar en la misma mesa al capital y al trabajo respondieron a las necesidades del Poder Ejecutivo de contar con herramientas de mediación en

\footnotetext{
o, por la modalidad del pago, poder hacer frente a los largos tiempos procesales. SCHJOLDEN Line, op. cit. Buscando demostrar la contracara, Adrian Ascolani cita varios casos en los que los trabajadores acudieron a los juzgados civiles, sin embargo termina justificando las palabras de Schjolden en la medida en que la mayoría de los casos citados fueron declarados como paralizados. Sobre los accidentes de trabajo en el ámbito agrario también se puede consultar BARANDIARÁN Luciano, "El rol de los tribunales en los accidentes de trabajo rurales fatales, Azul (1930-1945)", XXII Jornadas de Historia Económica, Rio Cuarto, 2010.

77 GENOUD Héctor, "La competencia de los tribunales del trabajo en la legislación provincial", Gaceta del Trabajo, Tomo IX, Abril a Junio de 1949, Editorial Bibliográfica Argentina, Buenos Aires, 1949. pp. 1.

${ }^{78}$ GENOUD, Héctor, "Los órganos de la Justicia del Trabajo en la legislación provincial", Gaceta del Trabajo, Tomo X Julio a Septiembre de 1949, Editorial Bibliográfica Argentina, Buenos Aires, 1949.
} 
el caso de los conflictos -principalmente huelguísticos- que se sucedieron desde fines del siglo XIX en la zona pampeana.

Esta problemática concreta moldeó la forma de intervención del Estado que buscó interlocutores colectivos (corporativos) en la medida en que eran estos los que podían llevar adelante las medidas que se intentaban evitar. El Estado, en tanto instrumento clasificatorio, optó por las formas de representación corporativa tanto del capital como del trabajo. Por ese motivo los distintos intentos y logros de constituir comisiones o juntas de arbitraje y conciliación fueron a la par de la sanción de leyes protectoras del trabajo que muchas $v$ eces hacían referencia a una actividad determinada. Estas instituciones respondían, entonces, a la voluntad de regular y encauzar conflictos que eran percibidos como colectivos. En este sentido las formas institucionales propuestas respondía a esta concepción sobre el conflicto y planteaban, así, la representación corporativa de los actores en pugna. Este tipo de forma institucional favoreció la construcción del diálogo entre el Estado y algunos sectores del movimiento obrero organizado ya que para poder sentarse en la mesa de negociación los sindicatos pasaron a estar avalados por el Estado en tanto actores en el conflicto. Esto es claro para el DPT bajo la gobernación de Manuel Fresco en la provincia de Buenos Aires. Esta institución análoga a su par nacional dejó sentada de forma explícita cuáles eran los sindicatos que podían ser incorporados al sistema de negociaciones que establecía el DPT y excluía, entonces, a las organizaciones socialistas y comunistas en momentos en que estas estaban en auge.

De alguna manera esta elección por parte de las autoridades de la constitución de instituciones de mediación y arbitraje de características colectivas es previo al auge del corporativismo como forma de organización política. Si bien el DPT representa un ejemplo clave de la forma de pensar la política en la década del treinta -sobre todo por la afinidad manifiesta del gobernador y varios de sus funcionarios con el modelo fascista de Mussolini-, la existencia de instituciones con representación corporativa precede el ascenso en la consideración del corporativismo y se puede rastrear en los proyectos legislativos desde comienzos del siglo $\mathrm{XX}$.

Estas instituciones que colocaban a los patrones y los trabajadores en la misma mesa de negociación con la intermediación estatal fueron posibles 
dentro del Poder Ejecutivo. Más allá de las consabidas razones que este poder del Estado poseía para sostener su lugar de preponderancia en el conflicto, las diferentes instancias de conciliación y arbitraje eran insuficientes para dar cuenta de la aplicación de la cada vez más importante legislación laboral. Nuevamente es la ley de accidentes de trabajo la que generó la necesidad concreta de contar con un mecanismo para los casos individuales y de esta manera impulsó el debate sobre la necesidad de contar con un fuero específico que fuese capaz de dar cuenta también de las variantes procesales que dicha ley imponía al proceso judicial -especialmente la inversión de la carga de la prueba y la aplicación de la doctrina de riesgo profesional-. Tal es así que los proyectos de leyes de accidentes de trabajo contemplaban erigir un sistema judicial propio.

Sin embargo el fuero judicial se hizo esperar y a las razones del Poder ejecutivo de retener bajo su dominio las instancias de institucionalización del conflicto se sumaron las resistencias del Poder Judicial a la construcción de un nuevo fuero con características contrarias a las ideas que se encontraban arraigadas en la vida judicial -especialmente la igualdad ante la ley-. La falta de poder dentro del campo judicial del Derecho Laboral, en términos de prestigio, hizo de la constitución del fuero una tarea harto difícil. Fue necesaria la irrupción de la fuerza política del Peronismo para lograr vencer las resistencias que se encontraban ante las posibilidades de erigir un fuero dedicado exclusivamente a la cuestión laboral.

El Peronismo con su fuerza creadora venció estas barreras, no sin encontrar así mismo resistencias de actores políticos e institucionales del primer orden como la Corte Suprema de Justicia de la Nación, y creó, en sintonía con la ampliación del corpus legal sobre el trabajo, un fuero propio para la relación laboral. Dentro de la estructura del Poder Judicial incluyó a los juzgados del trabajo para la Capital Federal con jueces letrados. La representación corporativa -presentes en las instancias del Poder Ejecutivofue descartada a la hora de sancionar el decreto de conformación de los Juzgados Laborales en 1945. Esto llama la atención sobre todo si se atiende a la catalogación que del peronismo se realiza dentro de las formas de gobierno corporativas. La necesidad de individualización del Poder Judicial y su tradición liberal terminaron primando en la forma institucional de la justicia laboral. El 
peronismo en el poder respetó en este caso la conformación federal de la república y dejó en manos de las provincias la constitución del fuero en cada jurisdicción a los poderes locales, en una medida contraria a la que se había tomado con respecto a la STyP. De esta manera el Derecho Laboral se asumía ya como un derecho nuevo, distinto a la rama Civil. 


\title{
CAPÍTULO IV \\ LOS TRIBUNALES DEL TRABAJO EN LA PROVINCIA DE BUENOS AIRES
}

\author{
si bien, las controversias colectivas \\ han reclamado la intervención del Estado \\ por razones de orden y bien público, \\ las controversias individuales -según Balella- \\ la han determinado por los mismos motivos \\ de protección de las clases trabajadoras en que \\ principalmente se informa toda la legislación del trabajo. \\ Y para la aplicación de las normas en la \\ solución de los litigios deberá instituirse \\ un procedimiento especial que imprima al \\ desarrollo del proceso un trámite sumario ${ }^{1}$
}

Benito Pérez

\section{Introducción}

El Surgimiento de los Tribunales del Trabajo estuvo cruzado por el contexto político marcado por la aparición de una nueva fuerza política con características disruptivas como lo fue el peronismo. Sin dudas los debates político académicos anteriores encontraron en el peronismo la oportunidad de llevar adelante el proyecto de constitución de los Tribunales del Trabajo y lograr así el reconocimiento institucional del Derecho del Trabajo.

Se busca recorrer y describir las condiciones que dieron forma a los Tribunales del Trabajo bonaerenses. En el caso de la provincia de Buenos Aires la forma que adquirió la justicia del trabajo fue debido no solo al antecedente fijado en la creación de los juzgados del trabajo para la Capital Federal sino también a los debates propios en el espacio bonaerense y fundamentalmente platense. Esto debido a las características propias de la capital de la provincia, con su ethos universitario, que generaba un espacio de intercambio profundo en el plano de las ideas entre la alta casa de estudios y

\footnotetext{
${ }^{1}$ PEREZ Benito, "Los fueros del trabajo" en Anales de la Facultad de Ciencias Jurídicas y Sociales de la Universidad de La Plata, Tomo XII (1ra Parte), 1941. Pp. 620 y sig
} 
las autoridades provinciales, cuyas jerarquías de los tres poderes residían en la ciudad.

El recorrido por los antecedentes legislativos y académicos que dieron nacimiento a la justicia laboral en la provincia permite da cuenta del contexto histórico de la sanción de la ley 5178 de la provincia de Buenos Aires que estableció los Tribunales del Trabajo para la jurisdicción provincial. También fue particular en la medida en que el gobierno de Domingo Mercante, el gobernador peronista de la provincia, conto con rasgos particulares en cuanto a la cultura y las formas políticas. Trazar esta particularidad no responde simplemente a una voluntad provinciana de dotar de autonomía a los espacios locales de la política, sino proponer como objetivo indagar en algunas razones que impactaron en el desarrollo institucional de la justicia laboral de la provincia. Aunque parte central del proyecto peronista, la gobernación de Mercante se caracterizó por la pervivencia de la organización partidaria de los trabajadores -el Partido Laborista- con cierta autonomía dentro de la alianza gobernante. Además en cuanto a la cultura política el gobernador estuvo siempre dispuesto a sostener formas liberales con respeto a la división de poderes, más allá de los impedimentos concretos que su propia elección impuso a su poder. Es significativo este punto en la medida en que el gobernador Mercante no contó con mayoría parlamentaria en la Legislatura provincial, por lo que muchas de sus medidas fueron sometidas a las negociaciones con la oposición política en el ámbito legislativo.

El análisis de los debates parlamentarios permite abocarse al debate sobre el carácter proactivo de la Legislatura bonaerense y otorga la posibilidad de ahondar en los rasgos políticos del gobernador Mercante. La existencia de distintos proyectos y la forma misma en la que se aprueba la ley 5178 parece confirmar, y así se busca en el capítulo, las diferencias en el estilo político del "Corazón de Perón" y el líder del peronismo.

\section{IV.1 El debate del fuero del trabajo en la provincia de Buenos Aires. Las ventajas platenses}

La presencia en la ciudad de La Plata, sede de la jerarquía de los tres poderes del estado bonaerense, de abogados especialistas en la materia y de 
trabajadores organizados y con capacidad de diálogo y presión sobre los organismos estatales, colocó a la ciudad en un contexto ideal para la discusión de la constitución del fuero especial. Es así que el Centro de Estudios Jurídicos de La Plata volvió a dedicarse en 1946 a cuestiones laborales como lo había hecho en el bienio 1935-1937 cuando fue dirigido por Leónidas Anastasi. Heredero del Instituto de Altos Estudios Jurídicos, este centro asumió como propios los objetivos que habian dado nacimiento al mencionado instituto y conformó una comisión especial para elaborar un proyecto de organización de los Tribunales del Trabajo para la ciudad de Buenos Aires. Este proyecto se convertiría en el antecedente directo de la ley 5178, según reconocieron los integrantes de la comisión bicameral que trató dicha ley antes de su debate parlamentario.

Es interesante que la elaboración del proyecto tuviese como destinatario el gobierno nacional y no el provincial, siendo que su redacción es de 1946, dos años después de creados por decreto para el ámbito federal. A pesar de este desfasaje temporal hay que tener en cuenta que los Juzgados del Trabajo en la ciudad de Buenos Aires empezaron a funcionar después de sancionada la Ley 12.921. El proyecto, entonces, se enmarcaba en el contexto de debate de dicha ley. La elección del centro de estudios de La Plata no sorprende siendo que la facultad de Ciencias Jurídicas y Sociales tenía una, ya para entonces, larga trayectoria en el campo de los derechos laborales. Pero además de esta tradición en la materia seguramente existió una verdadera urgencia por parte de los académicos platenses por dar cuenta de la problemática obrera.

Si La Plata había estado en parte aislada de los conflictos laborales, en la medida en que la vida industrial más importante se ejercía en sus márgenes, el peronismo cambió en parte el ethos de la ciudad. La ciudad letrada, se vio sacudida por las jornadas de octubre de 1945. La movilización obrera fue percibida como una invasión, y no fue casual que uno de los puntos elegidos para dejar en evidencia la debilidad de la ciudad de la razón haya sido la sede de la Universidad Nacional de La Plata y la casa de su rector, al grito de Alpargatas sí, Libros no. Los trabajadores irrumpieron así en los circuitos de 
saber/poder de los que habían estado excluidos como sujetos activos ${ }^{2}$. Esta presencia condicionó de allí en más a la casa de altos estudios platenses.

Con el recuerdo del 17 y 18 de Octubre aun presentes, esta comisión se propuso elaborar un proyecto para la ciudad de Buenos Aires debido al enfrentamiento entre el gobierno y la Corte Suprema "cuyos integrantes se habían manifestado abiertamente contra la administración al anular el decreto que establecía un sistema de tribunales laborales"3. La comisión estaba integrada por los doctores David Lascano, Enrique Rivarola, Emilio Donato del Carril, Juan Ramírez Gronda y Acdeel Ernesto Salas ${ }^{4}$.

El propósito del proyecto era superar el "retardo con relación a los países hispanoamericanos y europeos" ya que "desde el año 1930 se intensifica en América la acción legislativa, creándose por leyes o decretos tribunales del trabajo" . Entre estos países se destacaba Bolivia, Brasil, Colombia, Chile, México, Paraguay y Venezuela entre los americanos y Alemania, Checoslovaquia, Dinamarca, España, Italia, Noruega, Portugal, Suecia, Suiza, la Unión Soviética y Yugoslavia entre los europeos. El argumento principal de la exposición de motivos de este proyecto era que había una necesidad urgente de ajustar los parámetros procesales, mediante un procedimiento especial, que permitiese aplicar los derechos del trabajo. Esto para que

los beneficios acordados por las leyes de fondo no se vean malogrados o disminuidos en un proceso lento o excesivamente formalista, que deje abierta la posibilidad de interponer defensas meramente dilatorias ${ }^{6}$.

\footnotetext{
${ }^{2}$ VALLEJO Gustavo, Op. Cit

${ }^{3}$ Se refiere al decreto $32.347 / 44$ que creaba los Tribunales Laborales para la Capital. DOYON, Louise, Op. Cit. pp. 96

${ }^{4}$ Juan D. Ramírez Gronda se recibió de abogado en 1934 y obtuvo el título de doctor en 1941. Estaba adscrito a la Cátedra de Legislación del Trabajo desde el año 1942 y ocuparía el lugar de adjunto desde el año 1948 y titular desde 1967. A partir de la renovación propuesta por el gobernador de la provincia Domingo A. Mercante en su llegada al poder, ocupó un sillón en la Corte Suprema de la Provincia de Buenos Aires desde 1946 y fue su presidente durante los años 1951 y 1952. Fue removido de este cargo por la intervención del Poder Judicial impulsada por el gobernador Alóe -sucesor de Mercante- en Diciembre del año 1952 y volvió a ser ministro del alto tribunal en el período 1966-1969. Era además miembro del Instituto de Derecho del Trabajo. Acdeel Ernesto Salas se recibió en 1932 y obtuvo su doctorado en 1944. Llegó a la Suprema Corte de Justicia de la provincia de Buenos Aires en 1965, permaneciendo como ministro sol un año hasta 1966.

${ }^{5}$ LASCANO, David; RIVAROLA, Enrique; DONATO DEL CARRIL, Emilio; RAMÍREZ GRONDA, Juan D.; SALAS, Acdeel Ernesto, "Proyecto de la Comisión Especial del Centro de Estudios Jurídicos de La Plata", Jurisprudencia Argentina 1946, Tomo IV, sección Doctrina, La Ley, 1947.pp. 98.

${ }^{6}$ Ibídem., pp. 98
} 
Por ese motivo planteaban la necesidad de una única instancia de carácter oral, con la presentación y evaluación de las pruebas en una única audiencia, y un tribunal colegiado que

asegurara una sentencia meditada y controlada en sus conclusiones (ya que) el interés de los litigantes se encuentra mejor protegido en el procedimiento de instancia única, pues la garantía que presenta su revisión por un Tribunal Superior, es discutible y no compensa la necesaria dilación de los trámites. ${ }^{7}$

La prolongación en el tiempo de los casos que envolvían cuestiones laborales resultaba en suma onerosa para los trabajadores y era una de las preocupaciones centrales de la exposición de motivos de este proyecto.

La imposición de diferentes instancias era una de las causas de la lentitud procesal. Aunque el proceso oral aumentara la velocidad de la resolución en relación a lo descrito por Line Schjolden para la justicia civil, la superposición de instancias desvirtuaba la rapidez de los casos laborales. Esta prolongación temporal era lo que se buscaba evitar en la institución bonaerense, sobretodo en contraposición con lo que ocurría en la justicia civil. El esquema institucional propuesto por el proyecto del Instituto de Altos Estudios Jurídicos hacía necesaria la instancia única ya que

si la apelación se concediera ampliamente y el Tribunal Superior pudiera revisar las conclusiones sobre los hechos, sería necesario dejar constancia documentada de todo lo actuado, con lo cuál volveríamos, como ya lo expresamos, al procedimiento escrito ${ }^{8}$.

Oralidad e instancia única era, entonces las dos mayores innovaciones para evitar la "justicia con descontento", en los términos de French ${ }^{9}$. Se buscaba entonces que la estructura sencilla diese como resultado la protección de la parte más débil de la relación laboral.

\footnotetext{
${ }^{7}$ Ibídem. pp. 99. Cursiva mía.

${ }^{8}$ Ibidem.

${ }^{9}$ Según John French, lo que él denomina el "sistema CLT" imperante en Brasil -es decir leyes laborales detallistas con problemas de implementación y control-, generaba que el trabajador que acudía de buena fe a los tribunales encontraba en estos tribunales abarrotados y una tendencia para la 'conciliación' (que) frecuentemente producían lo que puede denominarse "justicia con descontento". Aun cuando ganaba un caso legal, por ejemplo, un trabajador brasilero era forzado a un acuerdo con su patrones, obteniendo un valor mucho menor de lo que se inscribía en sus derechos legales, en caso contrario tenía que enfrentar atrasos interminables debido a las apelaciones de la empresa -que algunas veces se extendían por hasta 12 años. La tendencia a conciliar se podía deber, según insinúa John French, a las posibilidades institucionales de prolongar el proceso en el tiempo. FRENCH John, Afogados em leis... Op. Cit.
} 
Esta institucionalización de una justicia rápida, con tiempos procesales cortos -erigida en el lugar central que el proyecto le daba a la audiencia única de recolección de pruebas y valoración de los hechos por el juzgador-, favorecería "soluciones equitativas y está más en consonancia con la naturaleza de las gestiones vinculadas al derecho del trabajo" ${ }^{10}$. El juzgador era elevado al rango de juez único en estos asuntos, por eso la necesidad de conformar al juzgador en tribunal, para controlar que la sentencia no respondiese a los impulsos de un solo hombre, como ya se mencionó anteriormente.

Pero el proyecto contemplaba otro mecanismo de contralor que excedía el de la constitución del juzgador en tribunal. Se trataba del control que ejercería el pueblo como garante último de la correcta valoración de las pruebas. Este control por parte del pueblo también estaba vinculado a la oralidad del proceso y la audiencia única. Sostenían que la

publicidad del proceso [...] sólo puede alcanzarse con efectividad cuando el público que presencia la vista de la causa, conoce de inmediato las conclusiones del veredicto. Así se encuentra en condiciones de apreciar el sentido con que los jueces valoran la prueba e indagan la verdad de los hechos $^{11}$.

El pueblo aparecía aquí como contralor por medio de su participación como público en la audiencia.

La justicia laboral debía ser accesible al hombre común, lejos del lenguaje letrado de los tribunales tradicionales, y sobre todo alejados de los mecanismos que hacía de los tribunales un lugar apto sólo para el círculo reducido de los profesionales del derecho ${ }^{12}$. Por eso los profesionales del derecho que recurrían a un lenguaje llano adquirían el aprecio de los trabajadores. Este lenguaje llano se permeaba en las actas de las Audiencias así como en los escritos que constaban en los juicios ${ }^{13}$. Al lenguaje asequible se sumaba la audiencia única, en la cual se reunían y exponían las pruebas y los testimonios, se reconstruían los hechos y se dictaba el veredicto y la sentencia, era la

\footnotetext{
${ }_{11}^{10}$ LASCANO, David, et al., op. cit., pp. 99.

${ }^{11}$ Ibidem.

${ }^{12}$ Se matizaba así la distinción entre expertos y profanos sobre la que constituye Bourdieu el análisis del campo jurídico. BOURDIEU Pierre, La forcé... Op. Cit.

${ }^{13} \mathrm{Si}$ bien los juicios eran de carácter oral, las demandas, las contestación de la demanda y las resoluciones del tribunal- Acuerdo, Veredicto y Sentencia- eran transcriptos a una forma escrita. En el próximo capítulo se ahonda en el contexto de producción de los juicios laborales y la fuente que estos juicios legaron.
} 
herramienta que los juristas del Instituto de Altos Estudios Jurídicos de La Plata habían pensado como el ideal para lograr la comunión entre el tribunal letrado y los legos. La preocupación por el carácter técnico profesional de los tribunales estaba presente desde los primeros años de la experiencia republicana y a lo largo de la historia proyectos que acercasen a ambos mundos fueron presentados en post de incluir al pueblo en la privilegiada tarea de hacer justicia $^{14}$. La oralidad era una de las herramientas que se intuía podía llegar a romper la frontera entre el carácter técnico profesional y el saber cotidiano.

Sin dudas el impacto de las movilizaciones en la ciudad de La Plata en las jornadas de Octubre de 1945 realzó la necesidad de contar al pueblo en los destinatarios del proyecto ya no solo como partícipes en tanto trabajadores lesionados en sus derechos, sino como sujeto fundamental al que se debía dirigir la justicia. Una amplia bibliografía da cuenta de la importancia de constituir el sujeto pueblo dentro de la discursividad política e incluso se lo presenta como la acción política de toda política ${ }^{15}$. Pero para el caso de estos juristas, el pueblo, si antes hubiese podido ser una imagen construida por medios de la ciencia, después del 17 de Octubre había adquirido fisonomía real en la medida en que el impacto de la movilización de ese día y los días subsiguientes en el centro de la ciudad los había dotado de rostros. La ciudad del saber ya no podía obviar al pueblo trabajador que habitaba en sus márgenes.

Superada la cuestión no menor de la formalidad procedimental que debía adquirir la Justicia del Trabajo y la necesidad de reacercamiento al pueblo que el contexto político y social hacían ahora visibles, el proyecto contemplaba medidas reales para facilitar el acceso a la justicia por parte de los trabajadores. El proyecto también proponía que,

los trabajadores o su derechohabientes gozarán del beneficio de pobreza, hallándose exceptuados del pago de todo impuesto o tasa [...] En ningún caso les será exigida caución real o personal para el pago de costas $u$

\footnotetext{
${ }^{14}$ BARRENECHE Osvaldo, "¿Lega o letrada? Discusiones sobre la participación ciudadana en la justicia de la ciudad de Buenos Aires durante las primeras décadas de independencia y experiencia republicana" en PALACIO Juan Manuel y CANDIOTI Magdalena, op. cit.

${ }^{15}$ Sin dudas los trabajos de Ernesto Laclau da cuenta de la importancia que la constitución del pueblo tiene como acción política. Vease especialmente: LACLAU Ernesto, La razón populista, FCE, Buenos Aires, 2008.
} 
honorarios o para la responsabilidad por medidas cautelares, dando sólo caución juratoria de pagar si llegasen a mejorar de fortuna. ${ }^{16}$

El beneficio de pobreza no era algo novedoso en el ámbito judicial bonaerense ya que estaba contemplado en el derecho procedimental civil y podía -y así era- ser reclamado por alguna de las parte para poder litigar sin costos, pero la cesión de dicho derecho de manera universal como se lo planteó para la justicia laboral para una de las partes efectivamente podía ser interpretada como un acercamiento de la justicia a los sectores económicamente menos favorecidos. Esta propuesta adquirió mayor relevancia si se tiene en cuenta que no era una justicia lega y que era obligatorio el patrocinio de un profesional del derecho. La gratuidad del proceso garantizaba al trabajador el acceso también gratuito al asesoramiento letrado, mediante la posibilidad de contar con abogados de la Sección Patrocinio Jurídico de las distintas Delegaciones Regionales de la Secretaría de Trabajo y Previsión. De esta manera se superaba uno de los obstáculos observados por Line Schjolden a la hora de buscar las razones de la poca presencia de los trabajadores en los tribunales civiles y comerciales.

Queda claro que en la ciudad de La Plata se daban las condiciones para una discusión en torno a los tribunales del trabajo que reemplazase en algunas de sus funciones y diese un carácter de mayor institucionalización a las ya existentes instancias dedicadas a la conciliación y arbitraje de las cuestiones laborales dependientes del Poder Ejecutivo ${ }^{17}$. Pero algunas de las propuestas y debates que el clima de época instaló superaron la discusión en torno sólo al fuero del trabajo. Algunos de los postulados y propuestas referían a cambios más profundos de todo el sistema judicial, y se percibía en los debates sobre los Tribunales del Trabajo una pretensión regenerativa del sistema judicial en su conjunto.

Este interés de los juristas platenses sobre la nueva rama del derecho daba la pauta de que se trataba de un tema de mucha actualidad a pesar de que pensaron su proyecto para una jurisdicción distinta ya que lo mismo ocurría

\footnotetext{
${ }^{16}$ LASCANO, David, et al. op. cit., pp. 101.

${ }^{17}$ La Comisión de Conciliación y Arbitraje estaba regulada por la Resolución № 88 de la Secretaría de Trabajo y Previsión. Esta resolución, del 24 de Julio de 1945, también organizaba el ministerio público del trabajo. Su función estaba estrechamente vinculada a la existencia de Tribunales del Trabajo, pero no los reemplazaba, ya que sus veredictos no tenían poder vinculante. Anales de Legislación Argentina Tomo V, 1945, Editorial La Ley, 1946. pp. 806.
} 
con el debate en torno a la creación de los Tribunales Laborales para el ámbito de la provincia de Buenos Aires. El diario El Día reflejaba en sus páginas el interés tanto de los especialistas como de los sindicatos de trabajadores. En su edición del 2 de Octubre de 1947, con el proyecto de creación de los tribunales del trabajo ya girado por el Poder Ejecutivo provincial a la Legislatura, el periódico tituló su editorial "Reformas Judiciales Necesarias". En este se daba cuenta de cuáles eran las áreas en donde el poder judicial se hallaba más atrasado con respecto al momento que se vivía. Remarcaba que eran dos las instituciones que debían ser objeto del rápido trabajo legislativo, por un lado la reforma de la justicia de menor cuantía -la Justicia de Paz- en donde se sostenía la necesidad de que pasase a ser letrada.

En segundo lugar destacaba la necesidad de que la legislatura aprobase el proyecto del ejecutivo sobre los tribunales laborales, ya que

en cuanto a la erección del fuero del trabajo, su conveniencia está al margen de toda discusión. Contamos con un vasto cuerpo de normas específicas y las relaciones involucradas dentro del campo de este "nuevo derecho" tienen, a la fecha, por su cualidad y cantidad, jerarquía suficiente como para exigir una subdivisión de la competencia por razón de la materia. En definitiva, de ello se trata, porque así como tenemos en el orden local una justicia civil y comercial y otra criminal, cabe la presencia de los tribunales del trabajo que entenderán en todos los asuntos vinculados con las leyes obreras y de previsión. ${ }^{18}$

Leyendo entre líneas se percibe que el "progreso" -entendido en términos de complejización de la vida social y económica- en la que se hallaba sumergida la provincia, exigía adecuar las instituciones, en este caso el Poder Judicial, a la nueva realidad. Los conflictos derivados de la relación de empleo ya no podían quedar supeditados a las instituciones judiciales existentes, y la profusión de leyes referidas a los trabajadores que menciona Marcela Aspell de Yanzi Ferrerira ${ }^{19}$, así como la gran cantidad de convenios colectivos firmados para la época, exigía la erección de un fuero especializado.

\footnotetext{
${ }^{18}$ Diario El Día, edición del 2/10/1947, pp. 3

${ }^{19}$ ASPELL DE YANZI FERREIRA, M. op. cit. También se puede dar cuenta de la profusión de leyes y decretos referidos a la materia mediante la consulta de los Anales de Legislación Argentina. Para evitar la dispersión en una maraña de leyes, decretos y regulaciones, la editorial Primicias edito un libro llamado "Todas las leyes obreras de la Revolución". En este ejemplar, que se vendía a dos pesos, se compilaron los "Derechos del Trabajador" que luego serían incorporados a la Constitución Nacional de 1949, los decretos dictados por la Secretaria de Trabajo y Previsión desde el 4 de Junio de 1943 hasta el 6 de Junio de 1946 que serían convertidos en ley mediante la ya mencionada ley $N^{0} 12.921$, y las leyes dictadas por el
} 
A la necesidad de conformar un fuero especial para el "derecho nuevo", sumaba la necesidad de ajustar los parámetros del procedimiento. Seguía el mismo editorial:

la nueva instalación se complementa y al mismo tiempo adquiere mejor justificación aludiendo a otro aspecto del problema: el de dotar a los asuntos de aquél género de un procedimiento que guarde íntima consonancia con su naturaleza. No debe olvidarse, al plantear esta exigencia, cuál es la posición de los que promueven reclamaciones derivadas de contratos de trabajo. Si en algún caso la justicia tiene que ser expeditiva, ninguno ofrece mayores argumentos que en éste. ${ }^{20}$

El nuevo fuero, por lo tanto, no podía quedar atrapado en las reglas procedimentales de los ya existentes, ya que la materia de la que trataban y la "posición de los que promueven reclamaciones" -es decir, los trabajadoresrequería que estos tiempos fuesen más cortos que en otros fueros.

Además del autor del texto, quien cerraba su nota con el optimismo de que "hay derecho a aguardar que el presente período de sesiones no se clausure sin dar a la provincia ese doble instrumento de progreso" ${ }^{21}$, una de las partes interesadas eran los mismos trabajadores. Tanto del Diario de Sesiones de la Cámara de Diputados de la Legislatura bonaerense, como en las mismas páginas del diario "El Día", aparecen menciones a pedidos por parte de sindicatos, sociedades y agrupaciones de obreros requiriendo la rápida sanción del proyecto enviado por el Poder Ejecutivo, o apoyando el proyecto como una manera de presionar a la Legislatura, práctica que para el movimiento obrero organizado no era nueva. Así, en el Diario de Sesiones del período legislativo No 91, que corresponde al de los años 1947/48, en la sección "Peticiones y Asuntos Particulares", suelen aparecer menciones a las misivas recibidas por la Cámara que rezaban textos como "La Unión Obrera Local, de La Plata, apoya al proyecto del Poder Ejecutivo de creación de los Tribunales del Trabajo"22. El Sindicato de Obreros de Frigoríficos y Anexos de Zárate, la Sociedad de Obreros Panaderos de Olavaria, la Agrupación Empleados Anglo y Compañías Afiliadas, La Federación Argentina de Trabajadores de la Imprenta, fueron sólo

Congreso en el período 1946/1947. Todas las leyes obreras de la Revolución, Editorial Primicias, Buenos Aires, c. 1948.

${ }^{20}$ Diario El Día, edición del 2/10/1947, pp. 3

${ }^{21} \mathrm{Ibi}$ dem. Se debe recordar que en la misma nota el autor abogaba por el cambio de la Justicia de Paz de lega a letrada, por eso la mención al doble instrumento de progreso.

${ }^{22}$ Diario de Sesiones. Cámara de Diputados de la Provincia de Buenos Aires. $91^{\circ}$ período, 1947-48. Tomo III, $3^{\circ}$ Sesión de prórroga, 2/10/1947, pp.2335. 
algunos de los que por esta vía presionaron al Poder Legislativo a fin de que se expidiera sobre el proyecto de creación del fuero laboral.

Especialmente importante fue la presión de los trabajadores que se desempeñaban en los frigoríficos. La afirmación de Mirta Lobato de que "los obreros de los frigoríficos sintieron, tal vez como nunca antes, que eran los protagonistas, al menos de esa parte de la historia"23, aparece graficada por las sendas notas que el matutino El Día dedica a los encuentros entre los trabajadores de la industria cárnica y autoridades provinciales. En una primera nota del 4 de Septiembre del año 1947, titulada "El gremio de obreros de la carne aboga por los Tribunales del Trabajo", la noticia daba cuenta de que "la delegación entrevistó al diputado Hipólito Pugliese y llegaron a reunirse con el vicegobernador Machado, pidiendo pronto despacho"24.

En una segunda nota del 28 de Septiembre del mismo año, se notifica que esta vez los

dirigentes de la Federación Gremial del Personal de la industria de la Carne se reunieron con presidentes de las Cámaras de Diputados y Senadores de la provincia y autoridades de los respectivos bloques, a fin de solicitar la pronta sanción de los proyectos de creación de los Tribunales de Trabajo ${ }^{25}$.

La posibilidad de acceso de los trabajadores a las autoridades provinciales -más allá de los vínculos personales del gobernador de la provincia con algunos grupos sindicales ${ }^{26}$ - estaba ligada a la posibilidad que les había abierto la participación en las elecciones bajo un partido propio -el laborismoque había logrado impulsar un candidato propio en las elecciones de 1946 -el gobernador Mercante- en la alianza con el sector de la Junta Renovadora, y que había tenido la suficiente fuerza como para presentarse de manera

\footnotetext{
${ }^{23}$ LOBATO Mirta Zaida, La vida en las fábricas. Trabajo, protesta y política en una comunidad obrera, Berisso (1904-1970), Prometeo Libros, Buenos Aires, 2004, pp. 251

${ }^{24}$ Diario El Día, edición del 4/9/1947, pp. 5

${ }^{25}$ Diario El Día, edición del 28/9/47, pp. 6.

${ }^{26}$ Mario Gasparri sostiene que el vínculo del entonces sindicato más importante, la Unión Ferroviaria (UF), con Juan Domingo Perón (Secretario de Trabajo y Previsión) fueron afianzados mediante la intervención del coronel Mercante en el gremio. La buena predisposición de Domingo Mercante, cuyo padre había sido maquinista, al frente de la UF, le permitió tejer lazos con otras entidades gremiales que serían vitales para el desarrollo de los lazos de cooperación entre las fuerzas sindicales y Perón. GASPARRI Mario R, "Mercante y los ferroviarios. Una relación trascendente y necesaria para la consolidación de la gestión de Perón al frente de la Secretaria de Trabajo y Previsión" en PANELLA, Claudio (compilador), El gobierno de Domingo A. Mercante en Buenos Aires (1946-1952). Un caso de peronismo provincial. Tomo I, Instituto Cultural de la Provincia de Buenos Aires, La Plata, 2005.
} 
independiente en las legislativas ${ }^{27}$. En la conformación del partido laborista tuvieron mucho peso los líderes del Sindicato Independiente de Trabajadores de la Carne, liderados por Cipriano Reyes ${ }^{28}$, y esto tal vez explique en parte estos encuentros, aunque la publicidad que adquirieron -salieron publicados en el diario de mayor tirada de la zona- quizás se deba a que los frigoríficos constituían la industria más grande -en términos de envergadura y mano de obra contratada- de la región.

\section{IV.2 El gobierno de Domingo Mercante en la provincia de Buenos Aires y el debate legislativo sobre los Tribunales del Trabajo}

La llegada a la gobernación de Domingo Mercante estuvo marcada por las internas de la alianza peronista para las elecciones de 1946. De hecho su candidatura, sostenida por los laboristas bonaerenses ante la resistencias de Bramuglia de aceptar ir como candidato de dicha fuerza, fue promovida sin la aceptación inicial del propio Perón quien ya había rechazado la propuesta de los laboristas de que fuese Mercante quien lo acompañase como vicepresidente. Estas negociaciones políticas hicieron "que llegara a la gobernación bonaerense sin ninguna de las ventajas que acompañan normalmente a quien alcanza tan alto cargo"29. Esta debilidad implicó asumir con un Poder Legislativo en mano de la primera minoría opositora -la UCR-.

\section{IV.2.1 El gobierno de Mercante}

El 8 de Noviembre de 1947 el matutino "El Día", diario de mayor tirada y popularidad de la ciudad de La Plata, reflejaba en su página 3 las palabras del gobernador de la provincia de Buenos Aires Domingo Mercante con motivo de la promulgación de tres leyes recientemente sancionadas por la Legislatura. Las tres leyes en cuestión trataban, respectivamente, sobre la reglamentación de las profesiones de abogados, de los procuradores, y la ley que interesa aquí, que creaba los Tribunales del Trabajo en el ámbito provincial.

\footnotetext{
27 AELO Oscar H., "La Legislatura de Buenos Aires y la administración Mercante. ¿Subordinación o cooperación?" en PANELLA Claudio (compilador), El gobierno de Domingo A. Mercante en Buenos Aires (1946-1952). Un caso de peronismo provincial. Tomo II, Instituto Cultural de la Provincia de Buenos Aires, La Plata, 2006.

${ }^{28}$ LOBATO Mirta Zaida, op. cit.

${ }^{29}$ AELO Oscár, El peronismo en ... Op. Cit. Pp. 29.
} 
El discurso fue transmitido en directo por la radio estatal "LS11 Radio Provincia" en cadena con Radio del Estado y las estaciones que integraban la red argentina de radiodifusión, como se desprende del mismo artículo de "El Día". Este hecho marcaba la trascendencia que el acto de promulgación adquirió para "los postulados esenciales de la revolución de nuestros tiempos"30, pero principalmente daba cuenta de la importancia que las autoridades provinciales otorgaban a la divulgación de su obra de gobierno vinculada al trabajo.

En su discurso el coronel Mercante, refiriéndose a la importancia de las leyes promulgadas, destacaba la de los

Tribunales de Trabajo, porque la justicia social que esa revolución (la de nuestro tiempo) ha proclamado no sería más que una lírica expresión de anhelos generosos, si una magistratura competente no le prestara imperio y protección mediante organismos jurisdiccionales con potestad para evitar que la ley se transforme en letra muerta, burlada por los fuertes y encarnecida por los hombres sin escrúpulos. ${ }^{31}$

Es evidente la intención del gobernador de señalar la ruptura de la revolución de nuestros tiempos -en clara referencia al proceso abierto el 4 de Junio de 1943- con respecto a períodos anteriores, donde la letra de la ley aparecía como letra muerta, y de aplicación arbitraria. Pero dejando por ahora de lado los dichos en torno a la aplicación de la ley, es necesario remarcar que la creación del fuero laboral sí significó la concreción de un cambio importante en las relaciones entre patrones y obreros.

El cambio propuesto dentro del marco de la revolución puede ser matizado por otras experiencias regionales e internacionales, que apuntaban a la constitución de tribunales especializados en Derecho Laboral o, como era más conocido, Derecho Social. Aún así sin dudas se trataba de una institución de los tiempos, porque si bien no fue una excepcionalidad bonaerense ni argentina, hay que tener en cuenta que sí fue una marca de la época. En el espacio provincial es evidentemente una novedad que cambió la fisonomía del conflicto, armando nuevos laberintos ${ }^{32}$ : después de la promulgación de la Ley 5.178 los actores envueltos en la relación laboral contaron con un tribunal

\footnotetext{
${ }^{30}$ Diario EL Día, 8/11/1947, pp. 3.

${ }^{31}$ Diario El Día, 8/11/1947 pp. 3, cursiva mía.

${ }^{32}$ PALACIO Juan Manuel, De la paz a la discordia... Op. Clt.
} 
especializado y rápido de solución de conflictos que se daban en las relaciones individuales del trabajo.

El gobierno del Coronel Domingo Mercante presentaba ciertas características que merecen ser analizadas para dar cuenta de la importancia del debate parlamentario y la posterior sanción de la Ley 5.178 que creó los tribunales del trabajo en el ámbito provincial. En primer término es necesario recorrer la manera en que este importante dirigente del peronismo, "el corazón de Perón", llegó a la gobernación. La provincia de Buenos Aires no fue una excepción a las negociaciones y enfrentamientos que se dieron a nivel nacional para el armado de las listas que competirían en las elecciones generales de Febrero de 1946. Y, al igual que en la nación, los partidos que conformarían el Partido Único de la Revolución una vez concluidas las elecciones, coincidieron en los candidatos para el Poder Ejecutivo, pero fueron de manera independiente para la de legisladores. A pesar de este lugar de preeminencia que Mercante logró en la estructura peronista, la candidatura de quien fuera el director de la Dirección de Ayuda Social Directa ${ }^{33}$ no fue la primera opción.

La Unión Cívica Radical (Junta Renovadora), una de las columnas de la coalición, pensó para el cargo a Alejandro Leloir, mientras que el Partido Laborista se inclinó por Juan Bramuglia, quien había sido el interventor federal de la provincia, y poseía aceitados vínculos con los dirigentes sindicales y sería uno de los hombres fuertes del régimen a nivel nacional al ocupar el cargo de ministro del interior ${ }^{34}$. A pesar de que se propuso una fórmula Bramuglia-Leloir, está fue rechazada por los laboristas. Cipriano Reyes, líder sindical de la industria cárnica de Berisso y el mayor referente del laborismo, le propuso la candidatura al Coronel Domingo Mercante, quien -a pesar de su paso por la Dirección de Acción Social Directa y su feliz intervención en la Unión

\footnotetext{
${ }^{33}$ En el proceso de racionalización del Poder Ejecutivo Nacional, uno de los organismos que logró mayor poder fue la Secretaría de Trabajo y Previsión. La Dirección de Acción Social Directa se destacaba entre las cuatro direcciones que conformaban la cúpula de esta secretaría, y le permitía a su director relacionarse de manera directa con los más altos dirigentes sindicales. CAMPIONE, Daniel, op. cit. La llegada de Mercante al cargo de Director de Acción Social Directa estaba vinculada a su importancia en frente de la intervención de la Unión Ferroviaria, uno de los gremios más importantes. GASPARRI, Mario R., op. cit.

${ }^{34}$ Juan Bramuglia, junto con Mercante, constituiría lo que Rannan Rein denomina la "segunda línea" del peronismo. A sus aceitados vínculos con líderes sindicales sumaba una formación en derecho del trabajo. Dictó clases de Legislación del Trabajo en la Facultad de Derecho y Ciencias Sociales de Buenos Aires -su clase inaugural se encuentra impresa en las páginas de la revista Hechos e Ideas, Año VI, Tomo XI, N43, 1947-. REIN Rannan, Peronismo, populismo y politica. Argentina 1943-1955. Editorial de Belgrano, Buenos Aires, 1998.
} 
Ferroviaria- aun no tenía peso propio y que por esa razón no tuvo incidencia alguna en la elección de aquél que lo acompañaría en la lista. El elegido sería un Yrigoyenista, Juan Machado, también a propuesta del laborismo ${ }^{35}$.

Los pormenores de su elección para el cargo colocaban a Mercante en una posición de debilidad frente a la coalición que lo había llevado a ocupar la casa de gobierno, por lo que en la elección de su gabinete también estuvo constreñido por la correlación de fuerzas y las disputas entre las dos fuerzas dominantes. De todas maneras mediante una gestión avalada por los resultados logró construir la imagen de un gobernante eficaz ${ }^{36}$. Al mismo tiempo que su posición inicial frente al Poder Ejecutivo dependía de la coalición que lo había llevado al poder, la unidad de las listas en cuanto a los cargos para la Legislatura no se mantuvo, por lo que cada uno de los partidos de la coalición presentó lista propia, dándose la particularidad de que la primera minoría correspondía en la Legislatura a la Unión Cívica Radical.

El llamado de Perón a disolver las fuerzas que componían la coalición en mayo de 1946, lo que en términos de Mackinnon significó el triunfo del polo organizativo carismático ${ }^{37}$, no resolvió las tensiones hacia el interior de la coalición que tenía la mayoría, ya que cinco legisladores del laborismo, fluctuaron entre acatar la orden o no, resolviéndose cuatro de ellos finalmente por el acatamiento, en un espejo de lo que ocurría a nivel nacional. De esta manera la legislatura quedó conformada con una mayoría peronista en la cámara de Diputados, pero no así en la de Senadores, ya que uno de los

\footnotetext{
${ }^{35}$ Los datos aquí volcados fueron extraídos de AELO Oscar, El peronismo en la provincia... Op. Cit.

${ }^{36}$ La gobernación de Mercante fue uno de los momentos de mayor expansión del aparato estatal bonaerense. Fue muy importante la elección para las segundas y terceras líneas de la burocracia entre técnicos con voluntad de trabajo, aunque tal vez ignotos al momento de su elección. Un ejemplo es el recorrido que siguió Pedro Poggio dentro del Ministerio de Obras Públicas. Entrevista a Pedro Poggio en CLARKE Guillermo A.; GHISIGLIERI Juan A.; SARNO Alicia, "La gobernación Mercante. Construcción Histórica con documentos orales" en PANELLA, Claudio (compilador), El gobierno de Domingo A. Mercante en Buenos Aires (19461952). Un caso de Peronismo provincial., Tomo I, Instituto Cultural de la Provincia de Buenos Aires, La Plata, 2006.

${ }^{37}$ La autora analiza mediante el esquema de Ángel Panebianco la vida interna del Partido Peronista y la sucesión de diferentes coaliciones dominantes hacia el interior del partido. Su análisis tiene la virtud de romper con la idea de un partido subsumido a la voluntad del líder y sin disensos internos. Al remarcar la existencia de dos polos organizativos (el carismático y el democrático) da cuenta de la tensión entre ambos en cuanto contaban con recursos organizativos propios y de la imposibilidad del ejercicio permanente del poder de uno de estos polos por sobre el otro, lo que llevaba a interminables negociaciones. MACKINNON Moira, Los Años formativos del partido peronista, Siglo XXI, Buenos Aires, 2002.
} 
laboristas decidió permanecer independiente, por lo que la mayoría quedó en manos del radicalismo por un voto. Esto llevó a una situación de empate, y esta

situación obligo a los peronistas (independientemente de su voluntad) a mantener abiertos los canales del diálogo y la negociación; en definitiva, el acuerdo con la oposición era inevitable para que las iniciativas políticas recibieran sanción legislativa. ${ }^{38}$

Pero además de una correlación de fuerzas que hacía imposible el predominio de una de las fuerzas por sobre la otra -en un virtual empate- las características propias de la forma de gobernar de Mercante daba a la Legislatura un lugar central en la definición de las políticas públicas. Analizando la trayectoria del diputado socialista Teodoro Bronzini en la Legislatura bonaerense, Liliana Da Orden realiza un repaso de algunos de los debates en los que se sumergió la Cámara de Diputados durante la presencia de este legislador, entre los años 1948 y 1954. A pesar de que la autora fija su estudio meses después de la aprobación de la ley 5178 es interesante retomar algunas de sus propuestas en lo que corresponde a la vida legislativa bajo la gobernación de Mercante. En su análisis Da Orden alega que, contrariando la imagen que el Partido Socialista brindaba del Congreso Nacional, la Legislatura bonaerense daba cuenta de una agitada vida parlamentaria, con debates y deliberaciones que incluía discusiones en torno a la conformación de las comisiones especiales, interpelaciones a ministros, leyes presupuestarias y cuestiones referidas principalmente al control de la gestión. Todo esto a pesar de que por tratarse de una legislatura provincial, cuya menor repercusión pública podría haber afectado negativamente su actividad. La autora se cuestiona entonces si esto no se debía a una mayor predisposición de Mercante, a diferencia de lo que ocurría con Perón, a legitimar su gobierno mediante las vías más tradicionales de la democracia liberal ${ }^{39}$.

La propuesta de Da Orden de que se trataba de una característica del gobierno de Mercante es compartida por Oscar Aelo, en su trabajo sobre la legislatura de la provincia ya citado, donde contrasta su trabajo de campo con las que serían las características usualmente aceptadas del papel del

\footnotetext{
${ }^{38}$ AELO, Oscar H., La Legislatura de Buenos Aires... Op. Cit. Pp. 20.

39 DA ORDEN María Liliana, "Socialismo y Peronismo en la Provincia de Buenos Aires: discurso y práctica legislativa durante el gobierno de Mercante, 1948-1952" en MELON PIRRO Julio César y QUIROGA Nicolás, El Peronismo bonaerense. Partido y prácticas políticas, 19461955, Ediciones Suárez, Mar del Plata, 2006.
} 
parlamento peronista: acatamiento y subordinación a los dictámenes del Poder Ejecutivo. Extensa es la cita pero vale la pena dar cuenta de las conclusiones a las que este autor llega en dicho trabajo. Sostiene Aelo:

El análisis de este conjunto de iniciativas muestra que el cuerpo legislativo asumió un papel bastante más activo en la elaboración de políticas públicas durante el período 1946/1948, cuando iniciativas de amplia relevancia fueron impulsadas desde el interior de la Legislatura. Aunque este perfil, es decir, un carácter "proactivo" como iniciadora de legislación no se perdió posteriormente, parece si haber cambiado el espectro. Las iniciativas de los legisladores parecen dirigidas prioritariamente en el sentido de mantener su "conexión electoral", y menos con el diseño de políticas estatales propiamente dichas. Esta variación puede explicarse en virtud de dos procesos simultáneos. En primer lugar, el creciente fortalecimiento del Gobernador Mercante. La debilidad inicial del ejecutivo posibilitó, o precipitó, que la Legislatura -esto es, los líderes legislativos peronistas- ocuparan un espacio de poder que el gobernador, por los motivos indicados anteriormente, no podía ocupar. Una vez estabilizado, y con un equipo de gobierno más homogéneo, Mercante estuvo en condiciones de diseñar la "agenda" política bonaerense que, en rigor, nunca fue "impuesta" sino siempre negociada: una característica principal del "estilo" político mercantista. ${ }^{40}$

La debilidad inicial de Mercante, su estilo político caracterizado por la tendencia a la negociación, la crisis de la coalición gobernante ante el pedido de disolución de sus fuerzas y su unión en un partido único -que dejó al radicalismo como la primera minoría en la Cámara de Diputados y en la Cámara de Senadores con la mayoría hasta las elecciones de 1948- y el carácter proactivo de la Legislatura, dieron como resultado un escenario que difiere de la aceptada visión general de un parlamento chato con voluntad sólo refrendatoria de las políticas del Poder Ejecutivo. Al contrario, la imagen de la Legislatura bonaerense fue la de un campo de discusión y debate abierto, al cual, como quedó dicho paginas atrás, acudían diferentes actores a fin de presionar por la sanción de legislación que consideraban afín a sus proyectos.

\section{IV.2.2 Una Legislatura activa}

Esta capacidad de presión de ciertos actores, sumados a la variada representación política y el carácter proactivo de la legislatura bonaerense brindó el marco para que sus miembros presentasen proyectos propios de conformación de la justicia del trabajo. En la sesión del 12 de Junio de 1946, a poco de reiniciadas las tareas de la Legislatura, se presentaron dos proyectos

\footnotetext{
${ }^{40}$ AELO Oscar H., La Legislatura de Buenos Aires... Op. Cit. Pp. 30
} 
para constituir los tribunales del trabajo. En primer término fue presentado el proyecto de los diputados Pablo Calabrese y Toribio García para crear la Justicia de Paz letrada y la Justicia del Trabajo. Al ligar la justicia del trabajo a la ya existente justicia de paz lo que se buscaba era tener inserción territorial en toda la provincia aprovechando la inserción local que una institución como los juzgados de paz tenían en la resolución de los conflictos ${ }^{41}$.

El proyecto retomaba la existente estructura de los juzgados de paz hasta ese momento legos para transformarlos en letrados y le sumaba la potestad de actuar en los casos que envolviesen disputas laborales. Por lo demás la estructura propuesta era similar a la de las otras ramas de la justicia, con Cámara de Apelaciones -una novedad para los Juzgados de Paz- que funcionaria en las cabeceras judiciales, aunque se proponían tiempos procesales más cortos en cada una de las instancias, haciéndose eco del reclamo de una justicia rápida. La justificación de esta nueva institución era su propia inexistencia ya que los autores entendían "que es innecesario todo otro argumento para justificar la necesidad urgente de implantar la Justicia de Paz Letrada y del Trabajo, ya que la legislación vigente no contempla las modalidades actuales" ${ }^{42}$. Sin duda la sanción de esta ley hubiese significado un gran regocijo para el encargado de la editorial del diario El Día que año y medio más tarde hacía referencia a la necesidad de los dos instrumentos del progreso. El proyecto también contemplaba los requerimientos de paz social que se proponían desde el gobierno nacional y provincial, y en su artículo 73 habilitaba al juez para que "sin perjuicio del procedimiento fijado el juez o la cámara, en cualquier estado del juicio, tratarán de que las partes pongan fin al mismo" ${ }^{\prime 3}$. La idea de la conciliación entre las partes reflejaba la voluntad de que la conciliación entre las clases fuese el norte que guiase el campo de la producción.

Mayor fundamentación y un articulado más meticuloso presentaba el proyecto presentado en la misma sesión por el diputado laborista Rodoldo Yezid Yanzón, en el que se proponía la creación de la Magistratura del Trabajo. De forma institucional semejante a las otras ramas de la justicia -con juzgados

\footnotetext{
${ }^{41}$ PALACIO Juan Manuel, La Paz del.... Op. Cit.

${ }^{42}$ Diario de Sesiones. Cámara de Diputados de la Legislatura de la Provincia de Buenos Aires. 90 Período, 1946-1947. Tomo I, Taller de Impresiones Oficiales, La Plata, 1947. Pp. 269.

${ }^{43}$ Ibidem. Pp 267.
} 
y Cámaras de Apelaciones- a fin de atacar la demora que estos procedimientos podían tener en la resolución de los juicios, establecía en su artículo 20 que "El procedimiento será sumatorio, oral y público"44 a fin de garantizar la velocidad del pleito y abaratar sus costos, y fijaba como plazo en la sentencia tres días después de realizada la audiencia de vista de causa. De todas maneras para la parte obrera establecía el beneficio de la pobreza, con lo cual quedaban eximidos del pago de cualquier costa o sellado de las causas ${ }^{45}$. Es interesante el encuadre institucional que realiza el diputado Yanzón de la Magistratura del Trabajo con respecto a sus funciones y su relación con otras instituciones ligadas al trabajo ya existentes. Sostiene en el artículo 30,

\begin{abstract}
toda interpretación que la Magistratura del Trabajo realice acerca de las disposiciones legales o reglamentarias sobre trabajo y previsión social, se ceñirá en un todo a la finalidad esencial que debe caracterizar ineludiblemente a la Justicia del Trabajo en su función social. En tal carácter, podrá requerirse la opiniós (sic) de la autoridad administrativa de aplicación sin que ello importe compromiso alguno en la resolución definitiva. Pero los hechos en que se fundamente la demanda ante la jurisdicción del trabajo y que hayan dado lugar a resoluciones condenatorias de esa autoridad administrativa en uso de sus facultades, serán tenidos por ciertos, salvo prueba en contrario. ${ }^{46}$
\end{abstract}

Si bien se mantenía una relación jerárquica entre los dos poderes estatales -la opinión de la autoridad administrativa no implicaba compromisoimporta el lugar que en la reconstrucción de los hechos se le otorgaba a la autoridad administrativa, fundándose en una prueba en el juicio que debe ser refutada, dando lugar a un proceso de inversión de la prueba (por ejemplo el patrón tendría que demostrar su inocencia en caso de haber sido condenado por la autoridad administrativa al pago de indemnización por despido injustificado). Pero además fijaba la finalidad de la Justicia del Trabajo a la función social, y era para determinar dicha función social que se debía recurrir a la autoridad administrativa. En el momento histórico en que este proyecto buscaba ser aprobado esto significaba atar la finalidad de la Magistratura del Trabajo a lo que el gobierno peronista entendía era la función social, con un tinte pro obrero y de reparación histórica.

A los beneficios que se extendían de la gratuidad y rapidez del juicio, y la importancia de la autoridad administrativa, se sumaban dos elementos

\footnotetext{
44 ibidem. Pp. 272.

${ }^{45}$ Artículo 34 del mencionado proyecto.

${ }^{46}$ Diario de Sesiones 1947 Op. Cit. Pp. 272 y sig.
} 
importantes. El primero era la difusión: se establecía que medio millón de ejemplares de la ley fuesen impresos y distribuidos por el gobierno de la provincia entre sindicatos, miembros del poder judicial, etc. a fin de hacer conocer su contenido ${ }^{47}$. En segundo lugar, y de mayor importancia, la fiscalización de las leyes del trabajo era obligación de todas las autoridades, sobre todo aquellas que protegían a los obreros en caso de accidentes laborales. El artículo 59 obligaba a las autoridades policiales o administrativas a denunciar los accidentes laborales, incurriendo en una falta punible en caso de no hacerlo. Se debe recordar uno de los reclamos que realizara Joaquín Coca años antes con respecto a la imposibilidad de dejar la fiscalización de las leyes laborales exclusivamente a los inspectores de los -en esos momentosdepartamentos nacionales o provinciales del trabajo, y la necesidad de que la fiscalización fuese extendida a todos los empleados gubernamentales y a toda la ciudadanía. Este artículo cumplía así con uno de los anhelos de los defensores del Derecho del Trabajo al obligar a las autoridades a igualar las leyes del trabajo a otras leyes.

En su fundamentación el diputado Yanzón hizo gala de una vasta referencia a trabajos previos ${ }^{48}$ y argumentaba, siguiendo a Alejandro Unsain, que siendo la legislación del trabajo una legislación aun en formación "exige puntales. Uno de ellos es el fuero del trabajo, con la garantía de una mayor especialización"49. A la mayor especialización que la creación de un fuero especializado podía tener ${ }^{50}$, se le sumaba la urgencia de la sanción de una ley

\footnotetext{
${ }^{47}$ Artículo 88 del proyecto de creación de la Magistratura del Trabajo. Diario de Sesiones 1947 Op. Cit.

${ }_{48}$ En su fundamentación cita las naciones que cuentan con esta institución, entre ellas Venezuela, Brasil, Alemania e Italia. Entre los tratadistas que han planteado la formación de estos tribunales recata la figura de Cesarino Junior de Brasil, y en el caso de Argentina a Mariano Tissembaum -director del Instituto de Derecho del Trabajo de la Universidad Nacional del Litoral-, Carlos Saavedra Lamas -docente en la Facultad de Derecho de Buenos Aires-, Juan Ramírez Gronda, David Lascano, y el director de la revista "Derecho del Trabajo", Mario Deveali - estos tres últimos vinculados al Instituto de Derecho del Trabajo de la Universidad Nacional de La Plata, autores de proyectos de creación de tribunales y dos de ellos, Deveali y Ramirez Gronda, docentes de la cátedra de Derecho del Trabajo en la misma facultad-. Asi mismo, hace referencia a los legisladores nacionales que impulsaron esta institución: Del Barco, Sanchez Sorondo, Del Valle Iberlucea, Oddone, Coca, Dickman, Bard, Anastasi, Molinari, Ahumada, Palacios, y a los tres proyectos impulsados por el poder ejecutivo.

49 Diario de Sesiones 1947 Op. Cit. Pp. 278.

50 Ver las referencias sobre algunos debates en torno a si el fuero del trabajo debía ser la culminación de la especialización, un corolario de los esfuerzos académicos, o, si por el contrario, la existencia del fuero era necesaria para una mayor especialización en PINTO Manuel "El Derecho del Trabajo" en Anales de Ciencias Jurídicas y Sociales de la universidad de La Plata, Tomo VII año 1934 Imprenta de la Universidad, Buenos Aires, 1935.
} 
con estas características. La importancia "está proclamada desde largo tiempo atrás por la voz impaciente de todo un pueblo que reclama su parte de justicia" ${ }^{n 1}$. La parte que entendía Yanzón le correspondía al pueblo en su parte de justicia no era la de participar como jueces. Después de una breve exposición sobre si era conveniente la inclusión de jueces legos o letrados y si estos debían pertenecer a los sectores en disputa, y sobre las soluciones que se había alcanzado en diferentes casos -incluyendo la de la Capital Federal que definía el diputado bonaerense como fundada en criterios eclécticos-, optaba en su proyecto por los jueces letrados sin representantes ni del capital ni del trabajo. Esta opción buscaba

\begin{abstract}
evitar así, las discusiones de los cuerpos colegiados o comisiones partidarias, muchas veces estériles y siempre demoradoras del procedimiento; el mayor encono de ambos factores de la producción, como consecuencia de la diaria disputa de las respectivas defensas de causas, en ocasiones carentes de razón y de sentido; y de asegurar una absoluta imparcialidad, al margen de sugestiones momentáneas o medidas de emergencia. ${ }^{52}$
\end{abstract}

La imparcialidad del juez era parte fundamental del entramado. Tratándose de dos clases sociales en pugna, el juez representaba la imparcialidad del mismo Estado ajeno a los intereses mundanos de ambos contendientes y por lo tanto dotado de la capacidad de determinar el "bien común" con razones superiores a las de las partes. De todas maneras el juez no era presentado sólo como un representante ajeno a la problemática que debía resolver. Según el autor del proyecto, el derecho a ser aplicado,

requiere del juzgador algo de psicólogo, algo de filósofo y mucho de altruista. Deberá conocer la norma legal, pero es preciso que antes -y siempre- que haya conocido de cerca al dolor, a la angustia, a la desesperanza, y haya sabido ser rebelde ante una injusticia y fuerte ante la adversidad $^{53}$

A diferencia de otros proyectos o instituciones similares presentados tanto en la legislatura bonaerense como en otras provincias, este proyecto no contemplaba la conciliación, porque las leyes de accidente de trabajo $-\mathrm{N}^{\circ}$ 9.688- y la de despido injustificado $-\mathrm{N}^{\circ} 11.729$ - establecen que sus beneficios no pueden transarse, renunciarse, compensarse ni reducirse por ningún concepto y por lo tanto no cabía al juez propiciar un arreglo que atentase contra

\footnotetext{
${ }^{51}$ Diario de Sesiones 1947. Op. Cit. Pp. 279.

52 Ibidem Pp. 280.

${ }^{53}$ Ibidem. Pp. 281.
} 
la voluntad general que guiaba las dos leyes fundamentales de la legislación laboral. Al cerrar su alocución, Rodolfo Yanzón sostenía que

nosotros, que conocemos las mil y una artimañas de que puede echarse mana (sic) para espaciar todavía más, el ya de por sí complicado y lento organismo de los estrados civiles; nosotros no podemos sino estar a favor de la norma nueva, distinta, particular, que procure salvar todos los obstáculos, acortar los plazos, limitar los recursos, rechazar las excepciones dilatorias, proscribir las recusaciones infundadas, y poner, a la mayor brevedad posible, frente al hecho ocurrido, la sentencia firme que lo dilucide [...] llevará a la gran mayoría de los habitantes bonaerenses una mayor sensación de seguridad. Sabrán, por fin, que un tribunal no es algo lírico, inalcanzable, sino una realidad concreta, tangible, palpable... se humanizará entonces, el concepto frígido de justicia, y habrá una esperanza más en la lucha eterna por una humanidad mejor ${ }^{54}$

Rapidez y humanización de la justicia por medio de una interpretación de las leyes por parte de jueces que respondiesen a una sensibilidad nueva, eran los elementos centrales que fundamentaba casi todos los proyectos y los objetivos que se puede leer a veces entre líneas, u otras, como en el caso del proyecto de Yanzón, explicitados en la fundamentación misma de la ley. Estos proyectos fueron importantes en la construcción del consenso para la aprobación posterior del proyecto del Poder ejecutivo. Sus debates, si bien no llegaron a la Cámara de origen, si fueron dados en las comisiones específicas.

El período legislativo siguiente y casi un año después de presentados los proyectos anteriores, los diputados laboristas Fragueiro, Galizia y Fossa volvieron a insistir con la presentación de un nuevo proyecto, dando una muestra más del carácter proactivo de la Legislatura. Este proyecto no contaba con propuestas novedosas ${ }^{55} \mathrm{e}$ incluso se acercaba a las formas institucionales existentes para el resto de las ramas de la justicia, juzgados y Cámaras de Apelaciones constituidas por tres miembros. Como novedades, no tal vez en tanto a proyectos anteriores sino a la institucionalidad vigente, se proponía la instancia de conciliación -artículo 28- y, principalmente, la posibilidad de recurrir para cuestiones colectivas. Como se desprende de los proyectos anteriores y del decreto que estableció la justicia del trabajo para la Capital Federal, la

\footnotetext{
${ }_{55}^{54}$ Diario de Sesiones 1947. Op. Cit. Pp. 282 y Sig.

${ }^{55}$ En su fundamentación sostenían los diputados sostenían: "expresar la necesidad de una Justicia del Trabajo en la provincia de Buenos Aires, equivale a incurrir en redundancia [...] el clamor doctrinario y público, son índices por demás elocuentes para exteriorizar lo imprescindible del proyecto". Diario de Sesiones de la Cámara de Diputados de la Legislatura de la Provincia de Buenos Aires, 91 periodo, 1947-1948, Taller de Impresiones Oficiales, La Plata 1948. Tomo I, $3^{\circ}$ sesión ordinaria del 22 de Mayo de 1947. Pp. 378.
} 
justicia del trabajo sólo estaba pensada para actuar en los casos de conflictos individuales, quedando la resolución de los conflictos colectivos en manos de las autoridades del Poder Ejecutivo.

El proyecto de los diputados laboristas, sin embargo, contemplaba la posibilidad de que el juez pudiese actuar de árbitro entre las partes cuando estos lo soliciten para aumentos de salario etc., de manera colectiva, aunque no por rama, sino por empresa. Funcionaba la intervención como un convenio colectivo $^{56}$. En este punto se asemejaba más al modelo imperante en la Justiça do Trabalho brasilera en la que los tribunales oficiaban tanto para cuestiones individuales como colectivas y eran los árbitros en las disputas por el aumento de salarios. Al dotar al poder judicial de estas atribuciones le otorgaba un peso específico más importante en términos de capacidad política y dejaba abierta la posibilidad de convertir a estos tribunales en un espacio de lucha obrera y sindical como ocurrió con los tribunales del trabajo en el vecino país ${ }^{57}$. La posibilidad de contar con una justicia con capacidad normativa era una verdadera novedad y asemejaba este mecanismo a las resoluciones que las instancias de arbitraje habían tenido en el DNT y el DPT, aunque refrendado esta vez por una verdadera capacidad de aplicación. Además al crear una justicia con estas posibilidades se atentaba contra la tradicional división de poderes, ya que los jueces tendrían en sus manos la posibilidad de construir normas para casos específicos.

A la hora de realizar su fundamentación tampoco escaparon demasiado de los parámetros impuestos en los otros proyectos, en el cierre de su disertación sostenía el diputado Fossa

se establece un sistema sencillo, claro y sin formulismos legales, para contribuir a resolver y disminuir los conflictos entre el capital y el trabajo, que con la paralización de las tareas que trae aparejado, lesionan los pequeños patrimonios obreros, y perjudican el siempre existente interés social, en el mantenimiento de todas las actividades ${ }^{58}$

\footnotetext{
${ }^{56}$ Diario de Sesiones 1948. Op. Cit. Título III: Procedimiento arbitral, art 55 a 61 inclusive del mencionado proyecto.

${ }^{57}$ La Justiça do Trabalho en Brasil contaba con dos canales separados que permitía su utilización tanto por parte de trabajadores individuales que viesen lesionados sus derechos, como instancias colectivas en donde se desarrollaban las negociaciones salariales, entre otras cosas. CORRÉA Larissa Rosa, A tesitura dos direitos... Op. Cit. Ver especialmente el capítulo 2.

${ }_{58}$ Diario de Sesiones 1948. Op. Cit. Pp 583.
} 
En definitiva la frase final del diputado Fossa condensa los objetivos que se buscaba con la sanción de una ley de Tribunales del Trabajo: rapidez, sencillez procesal y acercamiento de la justicia a los trabajadores para solucionar los problemas entre el trabajo y el capital buscando la paz social.

IV.2.3 El proyecto del Poder Ejecutivo para la conformación de los Tribunales del Trabajo

Los debates en comisiones de estos proyectos coincidieron con el análisis de la propuesta del Poder Ejecutivo presentado ante la Legislatura provincial el 6 de Agosto de 1947. El trabajo de comisiones, central en la acción parlamentaria en la medida que es el espacio donde los proyectos se debaten en profundidad para pasar después al debate general de las cámaras, permitió condensar las fuerzas políticas de la alianza gobernante en el proyecto del gobernador. El carácter proactivo de la Legislatura bonaerense creó un clima favorable al tratamiento de un proyecto que ya a esas alturas era considerado indispensable por las fuerzas políticas en pugna al interior de ambas cámaras. La debilidad inicial de Domingo Mercante y la profusión de proyectos en torno a la creación de la Justicia del Trabajo fue un marco ideal para el debate.

Al momento de comenzar la deliberación, el proyecto del Poder Ejecutivo fue presentado en ambas cámaras por los miembros informantes de la Comisión Bicameral que se encargó de evaluarlo y realizarle algunos cambios antes de su tratamiento. En el caso del Senado, la presentación -así como la discusión- fue más acotada, aprobándose el proyecto sin modificaciones ${ }^{59}$. Por eso se retomará la presentación que en la Cámara de Diputados hiciese el miembro informante, el diputado peronista Simini. En su presentación a la Cámara de Diputados sostenía que la Comisión en la que participaba estaba encargada de varios objetivos: proyectar la justicia de menor cuantía, la descentralización judicial y la creación de nuevos juzgados. Pero se había dedicado profundamente a uno de ellos

\footnotetext{
${ }^{59}$ Tal vez sea necesario aclarar que a diferencia del sistema bicameral del Congreso Nacional, en la Legislatura ambas cámaras representaban a la ciudadanía, ya que la Cámara de Senadores no representaban a jurisdicciones.
} 
motivo de una verdadera ansiedad popular, además de una impostergable necesidad: los Tribunales del Trabajo [...] Fue sensible al sentir colectivo, captó la aspiración unánime del pueblo de la Provincia ${ }^{60}$.

A juzgar por la presión de los trabajadores -mediante la entrevista con autoridades y los pedidos a la Legislatura- el diputado Simini no erraba cuando reclamaba la urgencia del tratamiento de dicho proyecto.

Refiriéndose a la importancia de los derechos de los trabajadores, sostenía que "ha entendido el Poder Ejecutivo que no bastan los enunciados de los programas de gobierno, ha comprendido que es menester, en caso como éste, juridializarlos de modo que se estructuren bases sólidas e las cuales se han de afirmar las conquistas sociales y han de tener concreción los enunciados" $"$.

La judicialización del conflicto aparecía como una de las formas de institucionalizarlo, pero principalmente era presentada como una manera de lograr el cumplimiento de la legislación que amparaba al trabajador en la relación laboral. Este proceso de judicialización escapa de la concepción del sentido común que impera sobre el concepto en la actualidad. Por lo general la judicialización es entendida en los procesos contemporáneos como la criminalización de la protesta mediante la imputación de cargos criminales a referentes de las protestas sociales. La judicialización es percibida, entonces, como una herramienta más de la represión. Sin embargo, y también en clave contemporánea, judicialización también implica un proceso de persuasión:

promover desde el poder político los procesos de judicialización de la política puede dar paso a un discurso legitimador de compromiso con el Estado de derecho y el principio de gobierno limitado. ${ }^{62}$

Aunque con avances y retrocesos este es un proceso que puede ser pensado aquí para el caso de los trabajadores. El conflicto judicial laboral debe ser enmarcado en esta línea de judicialización de la política, entendida como mecanismos no de represión sino de persuasión. Además estos procesos

\footnotetext{
${ }^{60}$ Diario de Sesiones. Cámara de Diputados de la Provincia de Buenos Aires. $91^{\circ}$ Período, 1947-1948, Tomo III, Taller de Impresiones Oficiales, La Plata, 1948. pp. 2549.

${ }^{61}$ Ibidem. pp. 2551.

${ }^{62}$ DOMINGO Pilar, "La judicialización de la política: el nuevo perfil de la Suprema Corte en el sistema político de México" en PALACIO Juan Manuel y CANDIOTI Magdalena (comp.), Justicia, política y derechos en América Latina, Prometeo, Buenos Aires, 2007. Pp. 29. La Judicialización de la política y la relación de este proceso con la accountability horizontal, el surgimiento de nuevos actores sociales, mayor politización de los jueces y la reinstauración de las democracias en América Latina son analizadas en la primera parte del libro titulada "Sistemas judiciales: reformas y democracia".
} 
pueden implicar- y así sucedió con los trabajadores- la movilización jurídica desde abajo y la "formulación de demandas en términos jurídicos y judiciales"

Retomando la defensa esgrimida por el diputado Simini en la presentación del proyecto a la Cámara de Diputados, este reconocía la novedad del derecho laboral mediante una pequeña síntesis de su desarrollo y no ocultaba que se trataba de "un cuerpo de leyes y reglamentos dictados a favor de una de las dos fuerzas que colaboran en la producción: el trabajo"64. A pesar de que el derecho del trabajo reconocía la desigualdad entre las partes del contrato, y buscaba, mediante otras desigualdades según Deveali ${ }^{65}$, igualar las partes, en ningún momento proclamaba ser dictado para una de las dos fuerzas, sino que procuraba mantener para ambas partes la justicia. Esta máxima parecería encontrarse detrás de las palabras del diputado radical Calabrese, también parte de la comisión bicameral. Después de señalar el papel que su partido había tenido en las respuestas institucionales a la cuestión obrera, remarcando la obra de Yrigoyen, apuntaba contra algunas de las soluciones que había propuesto el peronismo y rescataba la función que debía cumplir el Poder Judicial: administrar justicia.

En una parte de su larga intervención, Calabrese rescataba la importancia de que fuese el Poder Judicial quien administrase la justicia y lo hacía de la siguiente manera:

ya hemos visto cómo muchas veces, los organismos administrativos encargados de aplicar la norma del trabajo, han utilizado esa misma norma para aplicarla en violación a los verdaderos y auténticos intereses de la justicia, la han utilizado para inclinarse tan solo, hacia una de las que ha creado el problema. $Y$ lo grave es que lo han hecho en base a bastardos intereses políticos. [...] Con esto no quiero que se entienda que defendemos la posición de los poderosos y de los privilegiados. Queremos, si, colocarnos en la verdadera posición de la justicia. Deseamos que los Tribunales del Trabajo no se desjerarquicen con la aplicación del derecho en forma unilateral, con la aplicación de un derecho, atendiendo tan solo las justas reclamaciones de las clase trabajadora y haciendo oídos sordos o cerrando los ojos, al derecho que posee también, el capital ${ }^{66}$.

\footnotetext{
${ }^{63}$ UPRIMNY YEPES Rodrigo, "La judicialización de la política en Colombia: casos, potencialidades y riesgos" en PALACIO Juan Manuel y CANDIOTI Magdalena (comp.), Justicia, política y derechos en América Latina, Prometeo, Buenos Aires, 2007. Pp. 46.

${ }^{64}$ Ibidem. Pp. 2553.

${ }^{65}$ DEVEALI, Mario, Op.Cit.

${ }^{66}$ Diario de Sesiones Diputados de la Provincia de Buenos Aires. Op. Cit., 1948. pp. 2563.
} 
Esta posición era claramente la expuesta en ámbitos académicos por Mario Deveali en Lineamientos del Derecho del Trabajo, cuando argumentaba que el derecho del trabajo no era un derecho clasista, sino un derecho especial, y que por lo tanto mantenía la necesidad de lo que el diputado consideraba la "verdadera" justicia. Pero vale la pena remarcar que esta falta en la administración de la justicia era consecuencia no de la naturaleza del derecho del trabajo sino del organismo encargado de administrarla. En un claro ataque a la Secretaría de Trabajo y Previsión, que contaba con una sección destinada a la conciliación y el arbitraje entre las partes, la acusaba de beneficiar sólo a una de las partes con fines políticos. Por eso el legislador radical apoyaba "firmemente" la creación de los Tribunales del Trabajo, una institución que suponía un mejoramiento con respecto a los Juzgados del Trabajo de la Capital Federal debido, básicamente, a que "el desdoblamiento de la función judicial, en cuanto a lo específico de la conciliación, perturba la marcha de los juicios" ${ }^{\prime \prime T}$. Con el desdoblamiento se refería el diputado a la administración de la justicia por medio de dos poderes del Estado: mientras la parte conciliatoria y de arbitraje se establecía en el Poder Ejecutivo, pasada esa etapa el juicio quedaba en manos del Poder Judicial, según se desprende del texto del decreto $32.347 / 44$ que creaba los tribunales del trabajo para la

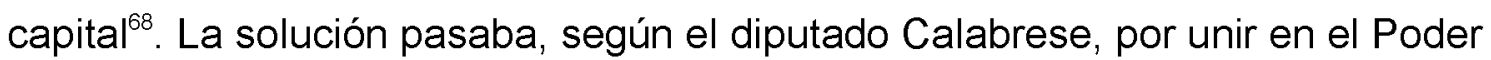
habilitado por la constitución, la administración de la justicia.

Las discusiones en torno a qué poder del estado debía encargarse de administrar justicia no es menor. El clima de época ponía en duda la capacidad de los entramados institucionales heredados del liberalismo, incluida la división de poderes. La mentalidad judicial, con sus formalismos y tecnicismos, era percibida como contraria a los objetivos que se perseguían con la constitución del nuevo fuero. Además la división de tareas que imperaba hasta ese momento había dejado en manos del Poder Ejecutivo la resolución de problemas que eran considerados de coyuntura y de alto riesgo político como lo era la relación entre el capital y el trabajo.

El decreto que creaba la Justicia del Trabajo en la Capital Federal de la Argentina, citado entre los antecedentes de esta ley, desdoblaba esta tarea

\footnotetext{
${ }^{67}$ Ibídem.

${ }^{68}$ Decreto No. 32.347, A.L.A., Tomo V, 1945, Editorial La Ley, Buenos Aires, 1946.
} 
entre dos de los poderes estatales. El diputado radical, al apoyar la creación del fuero laboral bajo la órbita judicial, respondía también a una tradición liberal que prefería mantener la separación estricta de poderes y la administración de la justicia en manos del Poder Judicial. La diferencia radicaba en la elección de los encargados de administrar la justicia. Estos debían ser "jueces probos", especializados y conocedores del derecho que iban a aplicar, y ponía énfasis en que el Poder Ejecutivo no debía defraudar la confianza que los legisladores de la UCR al promover a hombres que no pudiesen cumplir con el deber del cargo.

Además no perdió la oportunidad de golpear al Poder Ejecutivo Nacional por la manera de resolver los casos que violaban -o no- derechos laborales. Se refería puntualmente a lo que consideraba un avasallamiento de los derechos que constituían a Argentina en una república federal. Se debe recordar que la reorganización administrativa que fue objeto la Secretaría de Trabajo y Previsión le otorgó a esa dependencia jurisdicción nacional. Al absorber en su seno a las distintas reparticiones provinciales que se ocupaban de la cuestión laboral -en el caso de la provincia de Buenos Aires el Departamento Provincial del Trabajo-, dejó sin posibilidades concretas de cada provincia de definir su propia política laboral. En contrapartida, a nivel nacional esta operación permitió brindar respuestas homogeneizadas en todo el territorio. Tal vez por ello la posibilidad de conformar un espacio dependiente del Poder Ejecutivo provincial que se encargara de los conflictos laborales era una manera de reafirmar la soberanía del Estado provincial

Retomando el argumento de la separación de poderes es significativa la acusación que con menos diplomacia esgrimió el presidente del Bloque Radical, el diputado Pérez Aznar, quien pidió al diputado Parera, del peronismo, que aclarase sobre sus dichos de que el poder legislativo sería coparticipe si la administración de la justicia laboral fracasaba. Según Pérez Aznar respondía sólo al Poder Ejecutivo dar cuenta del éxito o fracaso de la iniciativa, mientras que le cabía al Legislativo fiscalizar la labor de ambos poderes. De todas maneras no espera mucho el diputado Pérez Aznar, ya que

el Poder Ejecutivo está convirtiendo en un régimen de burocracia parasitaria, que se ha copiado los viejos procedimientos dilatorios de la burocracia judicial, y las aplica a los problemas del trabajo, agravando su intervención con sus propósitos políticos 
y continuaba

esa responsabilidad incumbe al Poder Ejecutivo, en cuanto ha permitido que el Departamento del Trabajo de la Provincia de Buenos Aires fuera absorbido por una organización nacional, violando disposiciones inequívocas de nuestro régimen federal ${ }^{69}$

Acusaba indistintamente al Poder Ejecutivo Nacional, Provincial (actual y anterior), pero se puede leer en estos argumentos la misma tradición política liberal en la que los legisladores radicales encontraban su propia justificación como partido político.

La intervención del Diputado Fossa, no buscaba afirmar una tradición política de su partido que, por los datos volcados por Oscar Aelo ${ }^{70}$, se puede suponer que no tenía. Pero no perdió oportunidad de remarcar la importancia de su proyecto y las distancias que lo separaba del proyecto del poder ejecutivo en cuanto a las posibilidades de su tratamiento. El diputado Fossa admitía abiertamente, dando a entender lo que parecía ser el sentir de la cámara toda, que

ha traído el diputado Simini un gran acopio de citas para predisponer la opinión de la opinión (sic) de la Cámara que posiblemente estaba predispuesta ya unánimemente a darle su apoyo condicionado a este despacho que nos trae la Comisión ${ }^{71}$.

El debate por la separación de poderes y por el carácter federal no deja de llamar la atención, sobre todo porque se desarrolla en un ámbito legislativo que, como se sostuvo páginas atrás, no tenía mayor repercusión pública ${ }^{72}$. Tal vez la seriedad con la que los representantes se dieron la discusión con respecto a estos temas deba ser ligado al cierre de otros espacios de debates $^{73}$. La mención a que se trata de un proyecto que la cámara ya estaba predispuesta a aprobar, y así se desprendía de las intervenciones de los

\footnotetext{
69 Diario de Sesiones. Cámara de Diputados de la Provincia de Buenos Aires. $91^{\circ}$ Período, 1947-1948, Tomo III, Taller de Impresiones Oficiales, La Plata, 1948. pp. 2564.

${ }^{70}$ De los 70 legisladores que ingresaron a la legislatura (en ambas cámaras) provenientes de los dos partidos que conformaron la coalición peronista, solo 2 tenían experiencia previa en los cuerpos colegiados, mientras que el $30 \%$ de los legisladores que ingresaron por la UCR ya habían pertenecido al cuerpo. AELO Oscar, La Legislatura de Buenos Aires..., Op. Cit.

${ }^{71}$ Diario de Sesiones. Cámara de Diputados de la Provincia de Buenos Aires. $91^{\circ}$ Período, 1947-1948, Tomo III, Taller de Impresiones Oficiales, La Plata, 1948. pp. 2565.

${ }^{72}$ Los debates en las Cámaras sobre proyecto de las comisiones probablemente estaban mediados por reuniones previas que garantizaban el tratamiento y la aprobación de los proyectos DA ORDEN, Liliana, Op. Cit.

${ }^{73}$ En el diario El Día se hace referencia a la persecución política de algunos diputados del radicalismo como uno de los motivos que postergaron los debates parlamentarios ese mismo año.
} 
diputados, hace aún más relevante este tipo de debates al fijar el foco en un conflicto que en realidad superaba el espacio legislativo y era expresión de discusiones políticas más amplias.

Más allá de las disputas, es interesante también percibir algunos de los puntos de contacto entre los justificativos para aprobar el proyecto. Cuestiones como el avance de la industrialización, la necesidad de una justicia rápida, gratuita y accesible, la autonomía del derecho laboral y la percepción de los tribunales laborales como una herramienta para conseguir la "paz social" o llegar a la "justicia social" fueron comunes a los discursos de los diputados y senadores de los dos (tres) bloques. Claro que el énfasis puesto en cada uno de los puntos varió, y si el senador peronista Ferrari denominaba a los Tribunales del Trabajo "verdaderos Tribunales Populares, tribunales de auténtico pueblo para el pueblo trabajador"74, el senador radical Sáenz prefería remarcar que se había comprendido "que era más equitativo y pacífico encauzar la solución de esos problemas por el camino del orden jurídico"75.

Se percibía entonces ciertas críticas a la justicia tradicional y el deseo de solucionar estos problemas en las tres fuerzas políticas que nutrieron el debate. La adhesión que había entre los círculos profesionales sobre la creación de un fuero especial dedicado a tratar los problemas del trabajo, expresado en los diarios, las revistas especializadas, los congresos profesionales, etc. ${ }^{76}$, se traducía en una adhesión de los legisladores. A las críticas del diputado Pérez Aznar sobre los vicios burocráticos que la Delegación Regional del Trabajo había copiado de burocracia judicial, se sumaba la voz del senador Carvajal, representante del peronismo y claramente proveniente del catolicismo social, que veía en los Tribunales del Trabajo la ocasión para

restituir a los trabajadores la confianza en la justicia, que largos años de maniobras diversas le han hecho perder, hasta llegar al convencimiento de que los estrados de la justicia la diosa de la balanza no era ajena a la calidad de los concurrentes ${ }^{77}$.

\footnotetext{
${ }^{74}$ Diario de Sesiones. Cámara de Senadores de la Provincia de Buenos Aires. $91^{\circ}$ Período, 1947-1948, Tomo III, Taller de impresiones Oficiales, La Plata, 1948, pp. 2553.

${ }^{75}$ Ibidem, pp. 2555.

${ }^{76}$ Tanto en el debate parlamentario como en el proyecto presentado por la Comisión especial del Centro de Estudios Jurídicos de la ciudad de La Plata se citan congresos nacionales e internacionales que avalan la creación del fuero especial y que dan cuenta del avance del derecho laboral.

${ }^{77}$ Diario de Sesiones Senadores de la Provincia de Buenos Aires Op. Cit., Pp. 2561.
} 
Las críticas a la justicia tradicional a la hora de impartir justicia entre los litigantes era justamente esta sensación de que no se trataba de algo justo, una pérdida de fe en la justicia, en las palabras del senador Carvajal.

Estas palabras reflejar la preocupación de los legisladores por la falta de capacidad de la ley -entendiendo ésta por la ley en sí misma, pero también los tribunales y los hombres encargados de administrarla- para aparecer justa ante los intereses de los trabajadores (y no solo de ellos, ateniéndose a los dichos de los diputados radicales). Tal vez los legisladores no pensaron en los Tribunales del Trabajo en términos de constitución de la hegemonía de clase. Pero sin duda eran conscientes de la importancia de la institución judicial como garante de la "pacificación" de la sociedad en la medida en que garantizaba la creencia de la sociedad en las mismas instituciones, y no su rechazo frontal, que podría haber significado la "aparición de una masa desheredada" que está en "la médula de profundos trastornos políticos y sociales"78.

El lugar que se le otorgaba a la ley en el imaginario de los ciudadanos es fundamental para comprender la preocupación de que se estaba ante la construcción de una institución verdaderamente justa. Sobre la efectividad de la ley como justicia sostiene Thompson que la

mayoría de los seres humanos tienen un fuerte sentido de la justicia, por lo menos en lo que atañe a sus propios intereses. Si la ley es evidentemente parcial e injusta, no podrá enmascarar nada, ni legitimar nada, ni contribuir en nada a ninguna hegemonía de clase. La precondición esencial para la efectividad de la ley es, en su función ideología, es que muestre su independencia frente a la manipulación flagrante y parezca ser justa [...] siendo a veces, de hecho, realmente justa ${ }^{79}$.

Aun cuando la constitución de los Tribunales del Trabajo puedan haber resultado en una manera de evitar la lucha mediante otros medios, es importante remarcar que se trató de dotar de sentido concreto a la idea de justicia. La jurisprudencia en el fuero civil, a pesar de haber constituido un paso adelante importante, aun no podía dar cuenta de los problemas a los que se aplicó la Justicia del Trabajo. Por lo tanto la manera en que los actores envueltos tanto en su constitución, como en el día a día de estos tribunales, resultan importantes a la hora de analizar la constitución del fuero.

\footnotetext{
${ }^{78}$ Intervención del diputado Parera. Diario de Sesiones. Cámara de Diputados de la Provincia de Buenos Aires. $91^{\circ}$ Período, 1947-1948, Tomo III, Taller de impresiones Oficiales, La Plata, 1948 , pp. 2558.

${ }^{79}$ THOMPSON Edward Palmer, Los origenes de la Ley... Op. Cit.
} 


\section{IV.3 La Ley $\mathrm{N}^{\circ} 5.178$ de los Tribunales del Trabajo}

La ley que finalmente se aprobó establecía como parte integrante del Poder Judicial de la Provincia de Buenos Aires a los Tribunales de Trabajo, compuestos de tres jueces letrados ${ }^{80}$. La institucionalización de los tribunales en un molde más cercano a la tradición del Poder Judicial se debió a la inclinación de Mercante por "consensuar" sus obras de gobierno mediante las instituciones liberales, y la tradición liberal-reformista de los que participaron del debate (la UCR como partido político, pero también los abogados que provenían de una facultad con una cátedra de Legislación Laboral con esa tradición ideológica). La desaprobación de un modelo mixto como el existente en la Capital Federal significó abandonar cualquier pretensión de representación clasista en órganos encargados de administrar justicia, ya que las Comisiones de Conciliación y Arbitraje (que si contaba con representantes obreros y patronales) eran incluidas en el aparato institucional como instancias no vinculantes, aun cuando sus decisiones fuesen tenidas en cuenta en los antecedentes de los juicios ${ }^{81}$. La separación de los poderes en las diatribas de los diputados era un eje central a la hora de justificar la conformación de Tribunales del Trabajo como institución autónoma. Las lógicas políticas ya referidas que distanciaban a la conducción política del peronismo en la provincia de Buenos Aires de las de la misma fuerza a nivel nacional -y sobre todo en su disputa parlamentaria en la Capital Federal- se conjugaron para nutrir al debate de tradiciones políticas con mayor arraigo, como la naturaleza republicana de la separación de poderes.

La conformación en Tribunal difería de la tradicional constitución en juzgados (y por lo tanto con un solo juez) que predominaba en las ramas tradicionales -civil y comercial y penal-. En su conformación se aproximaba a las Cámaras de Apelaciones, también conformadas por tres jueces. Esta similitud no es casual, ya que los Tribunales Laborales actuaban en grado de apelación de las sentencias de los jueces de paz sobre la materia ${ }^{82}$, y lo mismo

\footnotetext{
${ }^{80}$ A.L.A, Tomo VII, Año 1947, Editorial La Ley, Buenos Aires, 1948, pp. 1071 y sig.

${ }^{81}$ Artículos 6 y 7 del Decreto $32.347 / 44$ ratificado por Ley 12.948. A.L.A. 1946, Tomo VII, Editorial La Ley, Buenos Aires, 1947.

${ }^{82}$ Los jueces de paz eran competentes para actuar en los casos laborales cuyo monto no superase los mil pesos. Artículo 7, Capítulo I, Ley 5178, A.L.A., Op. Cit.
} 
en lo que respecta a las resoluciones de la autoridad administrativa -que como tal no era una resolución vinculante- ${ }^{83}$. El objetivo de esta conformación era reducir los pasos procesales para la resolución de los conflictos, ya que la instancia de apelación era la Suprema Corte de Justicia de la Provincia de Buenos Aires, órgano máximo de la justicia provincial. El consenso en torno a la rapidez de la justicia laboral expresado en las cámaras se veía expresado en esta determinación de la conformación en tribunal, siguiendo también lo propuesto, e incluso esgrimiendo los justificativos, en el proyecto presentado por el Centro de Estudios Jurídicos de la ciudad de La Plata.

La eliminación de instancias de apelación fue concebida como una manera de agilizar el trámite judicial. A la única instancia se le sumaba la capacidad de los jueces para decidir en el mismo momento de la audiencia sobre la resolución del pleito. Esta potestad de los jueces despertó un duro debate entre el diputado Fossa, y los diputados Parera y Simini -ambos peronistas y el último miembro de la Comisión Bicameral- quienes llegaron a acusar al representante del laborismo, Seisdedos Martín, de no haber asistido a las reuniones de Comisión. Dejando de lado el dato anecdótico, el conflicto surgió por el pedido del diputado Fossa de cambiar el proyecto a fin de poder incluir un Tribunal de Casación como el existente en el fuero federal. La respuesta de Simini fue terminante: hacerlo implicaría destruir la unidad jurídica del proyecto. La instancia única era inseparable de la potestad del juez, ya que este tomaría las decisiones basándose en la aplicación de la ley promulgada por el legislativo. En cambio, la instauración del Tribunal de Casación implicaba erigir a los jueces de dicho tribunal en legisladores, al formular criterios de interpretación de la ley. Para los diputados que actuaron en la comisión bicameral, la separación de poderes debía ser estricta. Ya no existía el vacío legal que requiriese un tribunal de casación, y por otro lado el proyecto, el código de procedimiento y la constitución provincial contemplaban la posibilidad de elevar un recurso de inaplicabilidad de la ley a la Suprema Corte de la Provincia de Buenos Aires. En última instancia, y como también lo sostenía el proyecto del Centro de Estudios Jurídicos, la correcta interpretación descansaba no en uno, sino tres jueces letrados.

\footnotetext{
${ }^{83}$ Artículo 6, inciso b y c de la Ley 5.178, en Anales de la Legislación Argentina, Op. Cit. pp. 1072.
} 
Otro punto en el que la futura Ley 5.178 también marcó un cambio importante con respecto a la usanza establecida en la justicia Civil y Comercial, que actuaba en los casos vinculados al contrato de trabajo antes de la creación del fuero laboral, fue en la gratuidad ${ }^{84}$. Las costas del juicio ya no quedaban supeditadas a la resolución del mismo, sino que se fijaba el Beneficio de Pobreza a los trabajadores de manera automática. La asignación de este beneficio garantizaba la gratuidad del proceso para los trabajadores, ya que los exceptuaba "de todo impuesto o tasa", como se desprende del artículo 27 de la ley en cuestión ${ }^{85}$. La gratuidad se extendió a todos los procesos del juicio, como ser la recolección de pruebas (cuando estas debían generarse fuera del tribunal), mientras que no ocurría lo mismo con la parte patronal, que debía abonar los gastos de traslado y representación ${ }^{86}$. La herramienta de la gratuidad era concebida como una de las más eficaces a la hora de hacer esta justicia accesible. Este recurso no era privativo de este proyecto, ya en el caso de la Capital y proyectos anteriores para el ámbito bonaerense se formulaba la misma pretensión.

Fue también una novedad con respecto a la etapa previa la inversión de la carga de la prueba en lo que respecta a los montos, aunque este punto no fue objeto de observaciones por parte de los legisladores. Este camino procesal era solidario con la doctrina del Derecho Laboral que se fue constituyendo desde la sanción de la ley de accidentes de trabajo en 1915. Al contrario de lo que ocurría en la tradición civil, aquel que llevaba adelante la demanda no tenía que presentar las pruebas sino que "la prueba contraria a la reclamación corresponderá a la parte patronal demandada” ${ }^{27}$. Es necesario aclarar que la inversión de la carga de la prueba ya se aplicaba en los casos de accidentes de trabajo en los tribunales civiles, y esta doctrina continuó ampliada en otros propósitos en los Tribunales Laborales. La novedad residía aquí en que una de las pruebas centrales en los casos de despido, diferencia de sueldos y aguinaldos -es decir, aquellas pruebas que nutrían las pericias

\footnotetext{
${ }^{84}$ Se llama aquí Contrato de Trabajo a fines prácticos. En realidad la forma contractual que unía a trabajadores con sus patrones no podía ser enmarcada en ninguna de las formas contractuales existentes en el marco del Código Civil. PÉREZ Benito, "El derecho del trabajo y la reforma del código civil", Anales de la Facultad de Ciencias Jurídicas y Sociales de la Universidad de La Plata. Tomo XI, 1940, La Plata.

${ }^{85}$ Capítulo II, Artículo 27, Ley 5.178, A.L.A., Op. Cit. pp. 1074.

${ }^{86}$ Capítulo V, artículo 46, Ley 5.178, A.L.A, Op. Cit, pp. 1076.

${ }^{87}$ Capítulo IV, artículo 41, Ley 5.178, A.L.A., Op. Cit, pp. 1076.
} 
contables- deberían ser aportadas por la parte patronal demandada y no por la acusación.

Difiere esta forma con respecto a la inversión de la carga de la prueba en los casos de accidentes de trabajo, en que la inversión en el caso de los montos era fijado por la ley y no por la jurisprudencia. La doctrina establecida por el juez Quesada en los casos de accidentes de trabajo en una fecha tan temprana como 1905, buscó reinterpretar el Código Civil y el Código Comercial para expandir la noción de la "culpa" en los accidentes de trabajo y achacarles ésta a los patrones por medio de la "omisión", es decir: el patrón estaba obligado a garantizar la seguridad de su empleado y no hacerlo constituía a una omisión en sus deberes. De aquí se desprendía que el patrón debía demostrar que había cumplido con las diligencias pertinentes para garantizar la seguridad de sus subordinados a fin de quedar eximido de la culpa ${ }^{88}$. El hecho de que la inversión de la prueba fuese incorporado al texto de la ley, le otorgaba a este principio un status jurídico diferente. Es posible vincular este hecho a la interpretación otorgada para Quesada, pero ha de recordarse que la Justicia del Trabajo se regía bajo un principio nuevo, que era la aceptación de la desigualdad de las partes contratantes. La inversión de la prueba, contraria al principio de la justicia civil donde es la parte que establece la demanda la que debe probar sus dichos, es consecuencia de este principio.

Otra novedad que sí produjo discusiones que rayaban lo cómico -como acusaciones de que tal legislador sólo conocía su partido, acusaciones de beneficio personal por ser el que proponía abogado, chanzas en torno a la exageración con respecto a la importancia de los partidos que representaban- a pesar de que se trataba de un punto central de la ley fue la modificación del mapa jurisdiccional del Poder Judicial Bonaerense. Hay que tener en cuenta que la modificación del mapa jurisdiccional y la inclusión de nuevas cabeceras modificaba también el mapa político. Más aun si se tiene presente que con posterioridad a la sanción de la Ley 5178 muchas ciudades que recibieron Tribunales del Trabajo se constituyeron con el pasar de los años en nuevos departamentos judiciales, siendo el caso más evidente el de la ciudad de Mar

${ }^{88}$ SCHJOLDEN Line, op. cit., pp. 65 y sig. El caso al que hace mención la autora es Olivera c/ Mareyra y Othacché y consta en FEDERICO FIGUEROA, "La Jurisprudencia nacional sobre accidentes del trabajo" en Boletín del Departamento Nacional del Trabajo, No. 20, Julio de 1912. 
del Plata, pero también Quilmes y Avellaneda, sólo a modo de ejemplos (ver imágenes $\mathrm{N}^{\circ} 5, \mathrm{~N}^{\circ} 6$ ).

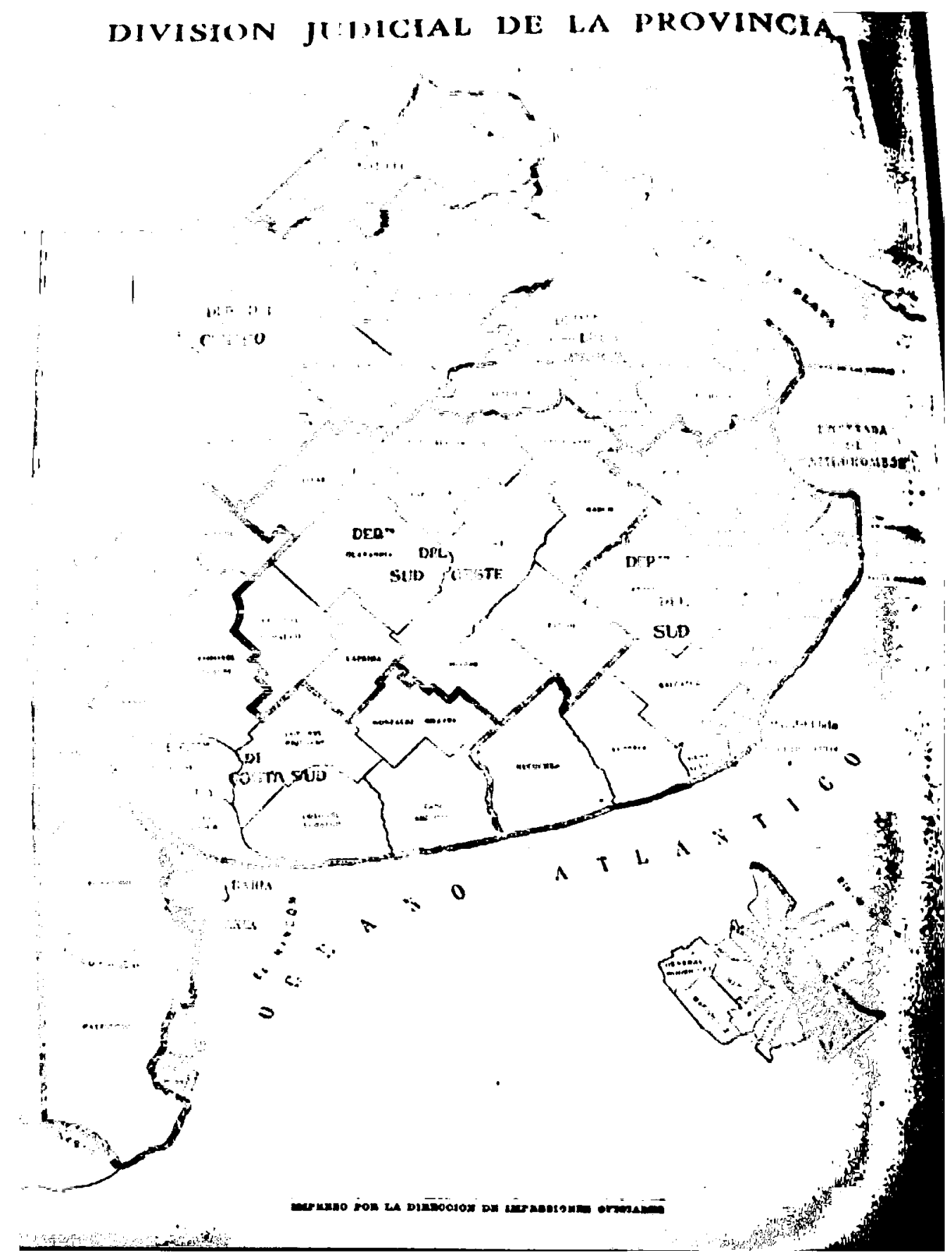

Imagen $N^{\circ} 5$ : Mapa de los departamentos judiciales bonaerenses en 1948 antes de comenzar a funcionar los Tribunales del Trabajo. Fuente: Diario de Jurisprudencia, edición del viernes 13 de Julio de 1948. Pp. 480. 


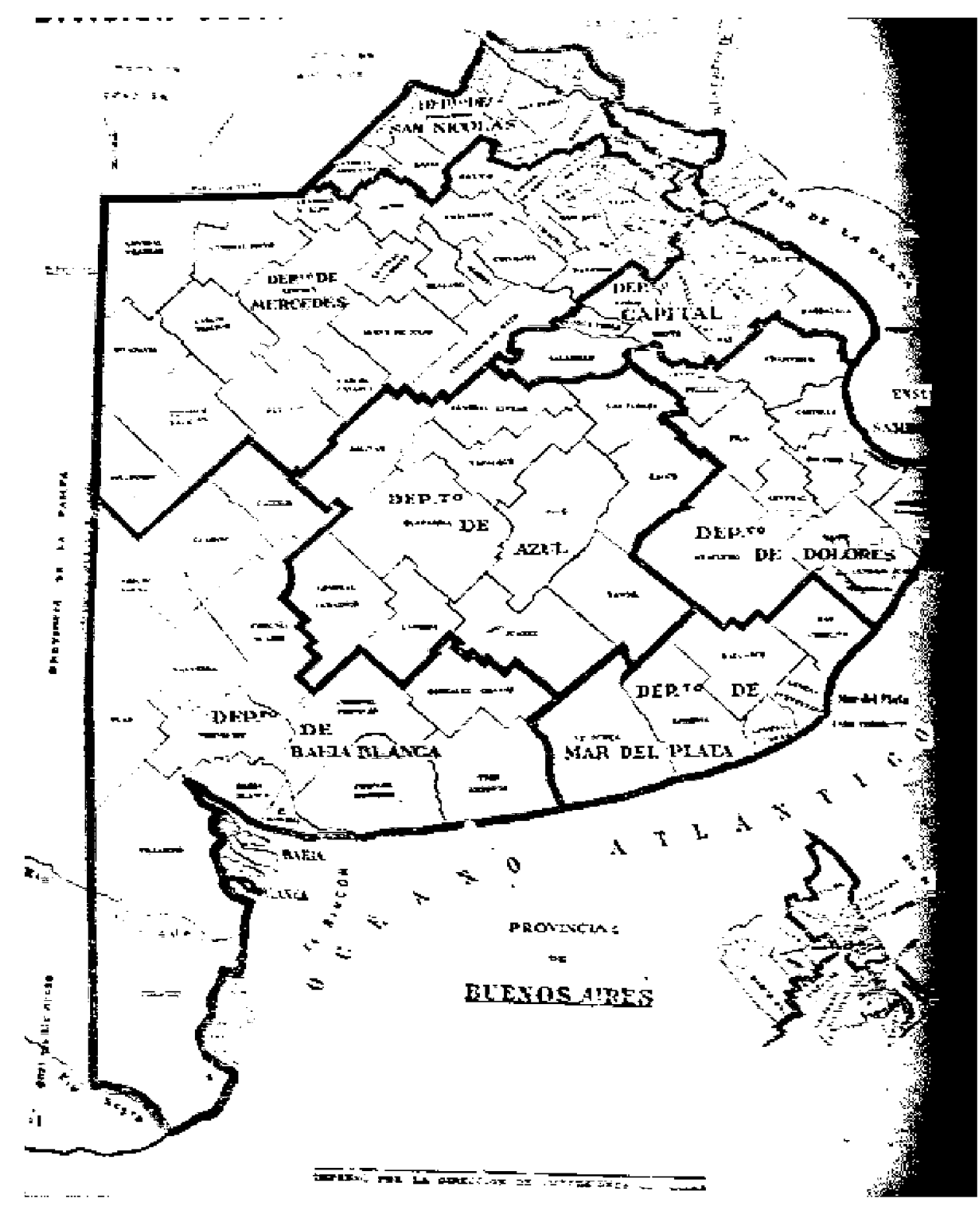

Imagen $N^{\circ}$ 6: Mapa de los departamentos judiciales bonaerenses en 1955. Ese año se creó el Departamento Judicial Mardel Plata al sepáraselo del Departamento de Dolores.

Fuente: Diario de Surisprudencia, edición del 17 de Noviembre de 1955. Pp. 836.

Los seis departamentos judiciales existentes a la sanción de la Ley (Departamento Capital, Departamentos del Norte -San Nicolás-, Departamento del Centro -Mercedes-, Departamento del Sud -Dolores-, Departamento del Sud Oeste -Azul- y Departamento Costa Sud -Bahía Blanca-) recibieron Tribunales del Trabajo que no siempre respetaron la cabecera departamental sino que se establecieron en 18 ciudades consideradas en ese momento con creciente actividad industrial. En el artículo $2^{\circ}$ la ley establecía las sedes de los 
Tribunales del Trabajo. Para el Departamento Capital se crearían dos en la ciudad de La Plata -cabecera departamental-, dos en Avellaneda, uno en San Martín, uno en Morón, uno en Zárate y uno en Quilmes. Al Departamento del Sud se le asignaban dos tribunales, uno en la ciudad de Mar del Plata y otro en la cabecera departamental, Dolores. El Departamento Costa Sud mantendría un Tribunal del Trabajo en su ciudad más importante, el puerto de Bahía Blanca, y sumaría el tribunal establecido en Tres Arroyos. El Departamento del Sud Oeste tendría sus tribunales del trabajo en la ciudad de Azul -sede departamental- y uno en Olavarría. El Departamento del Centro contaría con un Tribunal del Trabajo en Mercedes- sede departamental-, uno en Junín, uno en Chivilcoy, uno en Bragado y uno más en Trenque Lauquen. Por último el Departamento del Norte el Tribunal del Trabajo tendría asiento en la sede departamental, la ciudad de San Nicolás. Incluso en las situaciones en que las ciudades elegidas como cabeceras (ver Imagen $\mathrm{N}^{\circ} 7$ ).

La ciudad de La Plata fue la única que contó con dos Tribunales del Trabajo durante el peronismo. La ley también definió la jurisdicción de cada tribunal, siendo para los dos establecidos en la ciudad de La Plata los distritos de La Plata -incluían Ensenada y Berisso que no eran aun distritos- Coronel Brandsen, Chascomús, General Belgrano, General Paz, Lobos, Magdalena, Monte, Roque Pérez y Saladillo (ver Imagen N8).

Este tipo de disputas por constituir cabeceras en las ciudades que no contaban con sedes del poder judicial sin dudas marcaba el ritmo político -al fin y al cabo los representantes mantenían lazos de carácter local con sus representados- al que estaban sujetos los legisladores a la hora de proponer modificaciones de este estilo.

Producto de considerar la accesibilidad a la justicia también en términos de distancias, el proyecto, según los informantes de la Comisión Bicameral en ambas Cámaras, había modificado sustancialmente el proyecto del Poder Ejecutivo, al incorporar mayor número de Tribunales, y al localizarlos geográficamente según una doble variante: por un lado en las cabeceras de los distritos judiciales existentes, y por el otro debido a la importancia de la actividad fabril de las localidades del interior de la provincia. Esto ocasionó una larga discusión sobre qué ciudades y localidades -que no fuesen ya cabeceras distritales- debían contar con Tribunales del Trabajo. A pesar de que en las 
discusiones se ventilaron cuestiones más referidas a localismos de los mismos legisladores, la inclusión de la doble variante implicó un cambio importante en la distribución del Poder Judicial en el territorio de la provincia. De hecho, significó la posibilidad de acercar a la masa trabajadora el recurso de acceder a la justicia. La constitución de Tribunales Laborales en ciudades con tradición industrial -la localidad de Quilmes por ejemplo- permitía el acceso de millares de trabajadores a la administración de la justicia.

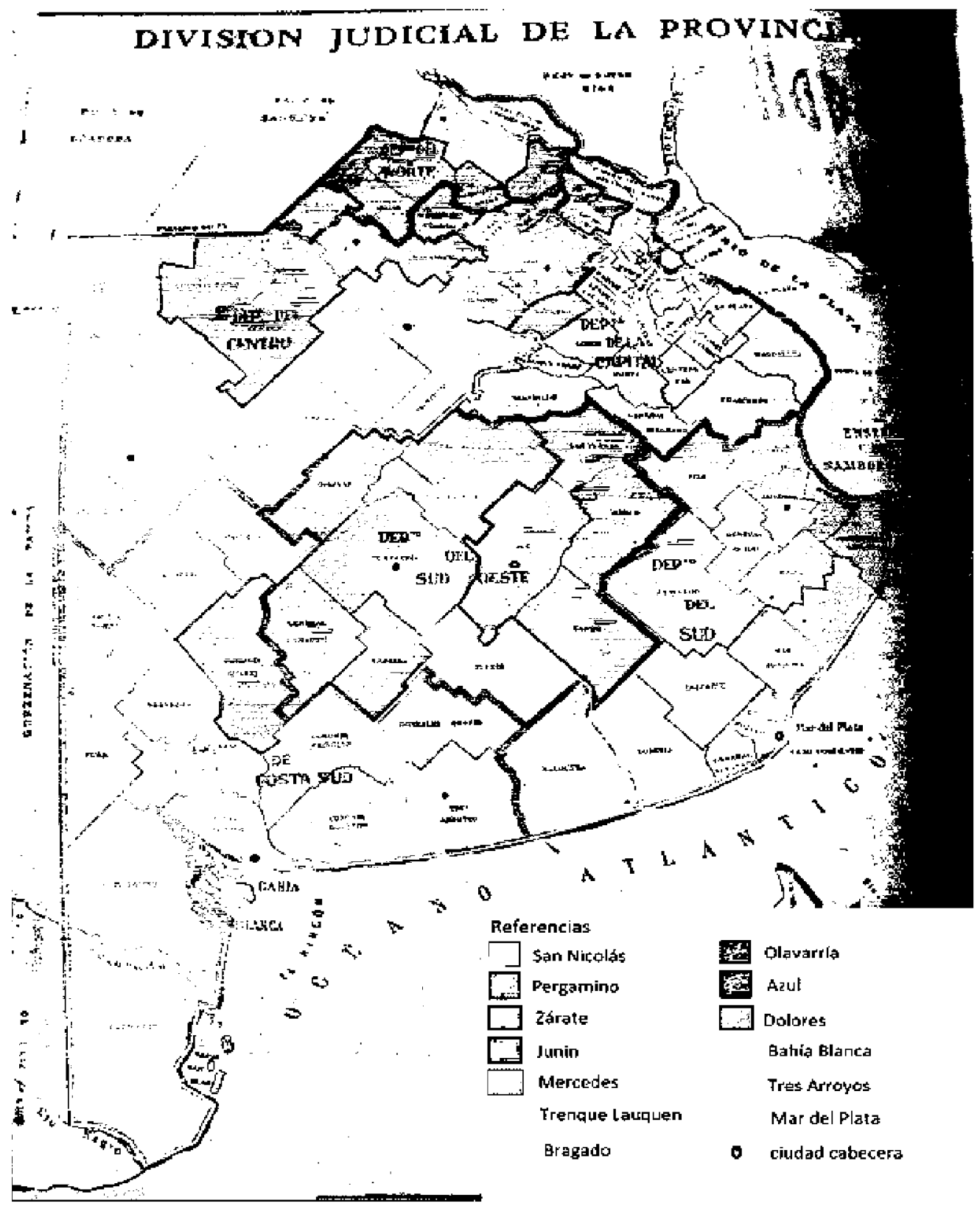

Imagen N 7 : Mapa de las jurisdicciones de los Tribunales del Trabajo Bonaerense. Elaboración propia en base a las jurisdicciones establecidas en la Ley 5178 


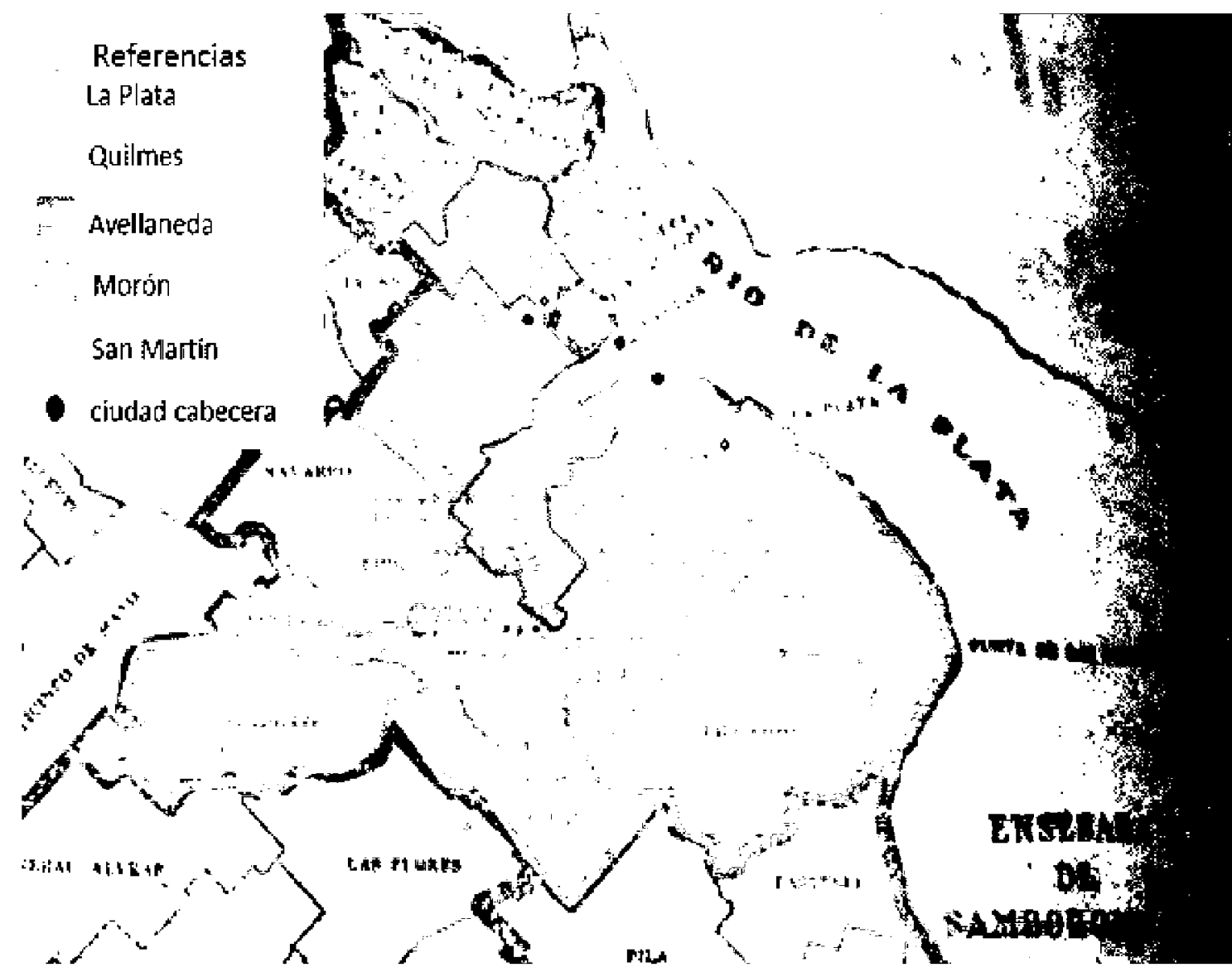

Imagen $N^{\circ} 8$ : Tribunales del Trabajo con cabecera dentro del Departamento Judicial Capital. Los distritos excluidos pasaron a formar parte de otras jurisdicciones en lo que respecta a la justicia del trabajo. Elaboración propia en base a las jurisdicciones establecidas por la Ley 5178.

La cuestión de la cantidad y ubicación de Tribunales del Trabajo fue objeto de una modificación a la ley en 1954. La Ley 5764 promulgada el 2 de Agosto de 1954 modificó la cantidad de Tribunales del Trabajo y otorgó 3 a la ciudad de San Martín y uno más a la ciudad de Bahía Blanca -elevando su número a dos- y sumó tribunales en las ciudades de Lomas de Zamora y Lanús $^{89}$. De todas maneras la puesta en marcha de estos tribunales del Trabajo se retrasó quedando en pie durante el período los designados originalmente.

${ }^{89}$ A.L.A., La Ley, Tomo XIV, Buenos Aires, 1955. 
La ley 5178 fue tratada y pasada a la Cámara de Senadores por los diputados el Martes 15 de Octubre de 1947 y aprobada por la Cámara alta el miércoles de la semana siguiente, el 23 de Octubre de ese año.

La ley sufrió dos modificaciones, la ya referida al establecimiento y cantidad de tribunales del trabajo y, por medio del texto de la ley $\mathrm{N}^{\circ} 5532$, en cuestiones de forma pero que no afectaron el principio que rigió a la sanción de la ley.

\section{IV.4 Conclusiones}

La reconstrucción del camino que hizo posible la promulgación de la ley 5178 de la provincia de Buenos Aires permitió observar algunos de los cambios operados en la época de su sanción que la hicieron posible. Los debates que se habían desarrollado en las décadas previas en torno a la legislación del trabajo, la importancia de contar con un fuero propio, o incluso los límites y posibilidades de la intervención estatal en la esfera del mundo del trabajo encontraron algunas resoluciones bajo la forma de una nueva institución.

La conformación de un consenso en torno a la necesidad de contar con los fueros del trabajo fue posible en parte gracias al impulso que se le dio al debate desde el arribo de Juan Domingo Perón al Departamento Nacional del Trabajo. Es por demás cierto que este organismo ya actuaba en conflictos laborales mediante la intervención en casos específicos así como también a través de la sanción de convenios colectivos. Pero eso no puede opacar el hecho de que la reorganización administrativa y una mayor visibilidad política por parte del organismo, produjeron un fuerte impacto en los diferentes ámbitos donde se discutían proyectos como los del fuero laboral y los trajeron al centro de la escena.

El decreto que creó la justicia laboral en 1944 en el ámbito de la ciudad de Buenos Aires fue el puntapié inicial que se encuentra detrás de la iniciativa de las provincias para conformar sus propios andamiajes institucionales referidos a la solución de conflictos laborales en el ámbito judicial. Este camino no estuvo exento de obstáculos. La posibilidad de constituir un espacio no controlado por el gobierno central fue uno de los ejes del debate y dio lugar a expresiones de federalismo que llevaron a extensas discusiones parlamentarias y académicas. Resuelto el tema de la jurisdicción -que aun así 
permaneció presente a lo largo de los debates legislativos incluso después de haberse establecido la necesidad de que fuesen las provincias quienes constituyeran sus propios fueros- los gobernantes de la provincia de Buenos Aires debieron discutir qué forma adquiriría la nueva institución.

La profusión de proyectos presentados en la legislatura y la conformación de un espacio académico específico dispuesto a elaborar un proyecto propio, dio cuenta de las intersecciones de los actores que se encontraban detrás del objetivo de conseguir un fuero para el mundo laboral. La participación de sindicatos, intelectuales, legisladores, periodistas, etc., en el debate sobre la justicia del trabajo llama la atención sobre el contexto en que esas deliberaciones fueron llevadas a cabo.

A esto debe sumarse el carácter conciliador y atado a las formas democráticas del gobernador Domingo Mercante que fueron un factor determinante en la amplitud de los debates. Su debilidad inicial que marcó su estilo político lo llevaron a adoptar medidas tendientes a favorecer la división de poderes. Con el antecedente reciente del conflicto entre Perón y la Corte Suprema de Justicia de la Nación por el decreto de creación de la justicia del trabajo para la Capital Federal aun en el escenario político, la medida adoptada por Mercante de proponer la creación de los Tribunales del Trabajo a la Legislatura marca las diferencias entre ambos estilos de conducción política. Sin desdeñar la idea de los cambios que eran necesarios y proponer fuertemente una nueva institucionalidad para los conflictos -así se desprende de su discurso al promulgarse la ley de creación de los Tribunales del Trabajosu estilo político lo llevó a proyectar una institución que aun con sus diferencias seguía manteniendo lazos de pertenencia con el Poder Judicial y sus costumbres.

De hecho el proyecto de constitución de Tribunales del Trabajo enviado por el Poder Ejecutivo provincial destacó fuertemente esta pertenencia. El mensaje que acompañaba el proyecto remarcaba que

se destaca en forma especialísima este aspecto, porque en algunos países los ha ubicado en el ala órbita del Poder Administrador o Ejecutivo; siendo ello contrario a los principios de la clásica división tripartita que 
oportunamente adoptara la Constitución de la Republica y también asegura la de esta provincia. ${ }^{90}$

La necesidad de los tribunales del trabajo, la disposición política de Mercante de consensuar sus medidas y el carácter proactivo de la propia Legislatura bonaerense hicieron posible que todo el arco político estuviese de acuerdo con el proyecto del Poder ejecutivo, aun cuando no ahorraron críticas. Pero significativamente las diatribas más importantes fueron dirigidas contra el gobierno nacional -como en el caso de la injerencia en la jurisdicción de la provincia por medio de la Delegación Regional de la Secretaría de Trabajo y Previsión o por su manejo del conflicto obrero- y no contra la administración de Mercante.

La ley sancionada terminó fijando las características institucionales que habrían de tener los Tribunales del Trabajo, además de modificar significativamente el mapa judicial de la provincia mediante su establecimiento en ciudades que no eran sedes de los departamentos judiciales existentes, pero que sin embargo contaban con un avanzado desarrollo industrial. Medidas como el establecimiento en estas ciudades, la gratuidad para los trabajadores y las innovaciones procesales cumplieron un rol importante en el acercamiento de la justicia a los trabajadores.

90 "Mensaje y proyecto de Ley del Poder Ejecutivo por el que se crean los Tribunales del Trabajo", Diario de Sesiones. Cámara de Diputados de la provincia de Buenos Aires, $91^{\circ}$ Período, 1947-1948, Tomo 1, Taller de Impresiones Oficiales, la Plata, 1948Pp. 1095. 


\section{SEGUNDA PARTE: \\ ACTORES Y CONFLICTOS EN LA JUSTICIA LABORAL PLATENSE DURANTE EL PERONISMO}




\section{CAPÍTULO V \\ LOS PROFESIONALES}

\section{Introducción}

Institucionalizados los Tribunales Laborales mediante la ley 5178, comenzaron a funcionar en el año 1948 en la ciudad de La Plata el Tribunal $\mathrm{N}^{\circ} 1$ y $\mathrm{N}^{\circ} 2$. En su labor cotidiana el rol cumplido por los diferentes actores fue llenando de contenido la letra de la ley. El objetivo de este capítulo es presentar a los actores que respondían a una lógica letrada y que intervenían en la vida diaria de los Tribunales Laborales de la ciudad de La Plata, para intentar comprender las tácticas asumidas por ellos en el contexto de profundos cambios políticos, económicos y sociales, en una institución de reciente creación y con el sello del gobierno peronista. Por eso el análisis que sigue tiene como fecha final Octubre de 1955, cuando los jueces que conformaban ambos Tribunales del Trabajo fueron desplazados definitivamente por la autoproclamada Revolución Libertadora.

En el día a día de los tribunales trabajadores, abogados, peritos, patrones, jueces y testigos fueron configurando un campo de relaciones cambiante, en donde cada actor y el grupo que representaban pusieron en juego sus relaciones de poder. Pero este campo tenía ciertas reglas que fijaban límites mediante la ley, que dependían del accionar de los distintos actores para cambiar o reinterpretar su significado. El ejercicio de la autoridad jurídica colocó a los diferentes actores ante una lucha que fue también simbólica hacia el interior de la institución, en donde los saberes "técnicos"1 se midieron y reforzaron mediante la acción de las fuerzas que acompañaron a los actores.

Este capítulo se centrará en la experiencia en estos actores profesionales y cómo su papel era construido y reconstruido mediante la interacción tanto entre sí como con los legos. Por otro lado también será objeto de análisis la comprensión de los significados que la ley y lo justo adquiría para los diferentes actores que intervenían en la cotidaneidad de los tribunales. Teniendo en

\footnotetext{
1 En "La force du droit", Bourdieu analiza la descalificación que se realiza hacia el interior de la ciencia jurídica de aquellos que no poseen el saber técnico, y de esta manera se llega a la "monopolización" del saber en alguno de los actores intervinientes (sobre todo en los jueces y los abogados). BOURDIEU Pierre, La force du... Op. Cit.
} 
cuenta la importancia que la ley tuvo para los actores que encontraron en el manejo de este recurso la razón de ser de su función.

En el caso de los abogados el fuero implicó también asumir la defensa de dos partes en litigio que eran considerados desiguales. Por las trayectorias y por los nombres de los abogados que representaban a una y otra parte se puede sostener la existencia en el foro de cuatro tipos de abogados: 1- los abogados laboralistas exclusivamente orientados a representar a los trabajadores; 2- los abogados de la Delegación Regional que representan a los trabajadores en tanto también responden a un función burocrática; 3- los abogados que toman una causa laboral como cualquier otro encargo judicial; 4los abogados de empresas. En el caso de los patrones quienes asumieron la defensa de sus intereses se enmarcan en el grupo 3 y 4 . Mientras que los abogados del tercer grupo no demuestran demasiado interés por uno u otro bando en conflicto y solían defender indistintamente a unos y otros. Tal es el caso de Héctor Demo ${ }^{2}$ que mientras que en 1954 impulsará una acción judicial contra la intervención del Ex Jockey Club en nombre de la señora María Virginia Mattos de Bordón ${ }^{3}$, será el abogado al año siguiente de la sociedad Formenti José e Hijos ${ }^{4}$ o Ángel Castellanos quien aparece las más de las veces como abogado patrocinante de la parte patronal, aunque también defiende los intereses de cinco trabajadores que le reclaman a la empresa INEGI SRL la indemnización por despido 5 .

Al analizar a estos actores se puede percibir que la elección de una de las dos partes conllevaba una cierta especialización, pero también, y sobre todo en el caso de los representantes de los trabajadores, cierto sentido de misión u obligación para con el más débil de la relación laboral.

Ligados a los abogados por su formación, los jueces eran el engranaje central sobre el que giraban los tribunales del trabajo. La indagación en torno a sus funciones y carreras busca llamar la atención sobre lo que implicaba ser juez en un fuero judicial que no contaba con el prestigio que cubría a las ramas

\footnotetext{
${ }^{2}$ Héctor Demo fue un importante abogado en el fuero platense y tuvo un paso como juez del trabajo en el Tribunal del Trabajo $\mathrm{N}^{\circ} 2$ de la ciudad de la Plata durante los primeros años de su conformación, Ilegó a ser ministro de la Suprema Corte de Justicia de la provincia de Buenos Aires entre los años 1966 y 1969.

${ }^{3}$ DH 104/2 Mattos Maria Virginia de Bordón c/ Jockey Club de la provincia de Buenos Aires s/despido, falta de preaviso, dif. Haberes y vacaciones no gozadas. Año 1954.

${ }^{4} \mathrm{DH}$ 104/7 Formenti e Hijos S.A c/Fernández Juan Francisco s/consignación. Año 1955.

${ }^{5}$ DH 103/15 Tirinato Francisco y otros c/ INEGI S.R.L. s/ despido. Año 1953.
} 
tradicionales del Poder Judicial. Además su formación y su misión era tan o más importante que en el caso de los abogados.

Entre los profesionales que hacían a la causa judicial no se puede obviar a los peritos. La pesquisa se centra sobre los peritos contadores no por un capricho, sino por la importancia que estos tenían en el aspecto procesal y en las resoluciones mismas de los jueces. Su saber profesional era central a la hora de los jueces definir la sentencia de las causas. Contrario al sentido común actual, los Tribunales del Trabajo no hicieron uso de los peritos médicos de manera exhaustiva. Este punto llama la atención porque si para los años que comprende la investigación la causa laboral era "una pericia contable y listo", el devenir del sistema judicial laboral llevó a una mayor jerarquización del saber médico. En la medida en que cada vez más la justicia del trabajo se fue volcando al resarcimiento en casos de accidentes laborales, los peritos médicos debían definir el grado de incapacidad del trabajador sobre la que se calculaba el resarcimiento económico ${ }^{6}$.

Sin embargo para el período en cuestión la figura del perito médico no era aun de relevancia. De hecho en las causas que se conservan de los años 1949 a 1955 los tribunales del trabajo aceptaban como válidos los certificados médicos firmados por cualquier galeno, incluso aquellos que pertenecían a los departamentos de sanidad de las mismas industrias.

\section{V.1 La importancia del saber}

En tanto institución judicial estatal, los Tribunales del Trabajo otorgaron especial importancia a actores sociales capaces de desplegar su saber técnico y otorgar los marcos de referencia a las disputas laborales. No se trata aquí de seguir las trayectorias de los juristas detrás de los proyectos de conformación de los Tribunales del Trabajo. Como hombres de Estado los juristas justificaban su función social en tanto capaces de desempeñar tareas específicas de organización para el despliegue de la clase social a los que estaban vinculados

\footnotetext{
${ }^{66}$ Los meses de Septiembre y Octubre de 2012 encuentran múltiples referencias a la industria del juicio -especialmente en las ediciones de los matutinos del 20 de Septiembre posterior al discurso presidencial sobre las modificaciones a la ley de ART impulsadas por el gobierno nacional- que según los promotores de las modificaciones de la ley 26.773 promovían las acciones ligadas a los accidentes y enfermedades del trabajo en la justicia laboral.
} 
orgánicamente, verdaderos intelectuales orgánicos ${ }^{7}$. Más bien se trata de vislumbrar a aquellos que conformaron un cuerpo casi burocrático, y, aunque desempeñando tareas intelectuales, atados a una lógica institucional que en parte constreñía la acción creadora necesaria para que se considerasen a sí mismos intelectuales. Se trata de sujetos capaces de comprender las reglas del campo jurídico y utilizarlas, pero que dentro del campo no cuentan con las capacidades y el capital necesario para construir los límites propio de ese campo.

El campo jurídico, en una conceptualización bourdieana ${ }^{8}$, implica concebirlos como un espacio social en el que se ejercen relaciones sociales. Los campos poseen una jerarquía interna establecida mediante la posesión del capital propio del campo en cuestión. De alguna manera separa Bourdieu la construcción de la jerarquía de la posesión exclusiva de capital material, aunque reproduce el esquema de dominación. En el caso del campo jurídico la producción y posesión de capital específica -el conocimiento de la ley- excluye a los que no poseen dicho capital en un orden binario entre los profanos y los expertos.

Pero al mismo tiempo establece una jerarquización dentro de los expertos en tanto son los habilitados por disputar el poder simbólico disponible en el campo jurídico. El campo determina, mediante las reglas autónomamente definidas por las relaciones establecidas dentro del campo, la forma en la que se dará la lucha por acceder al capital en disputa, que en el caso del derecho es por el entendimiento del derecho (que se evidencia en la tensión entre la teoría y la práctica del derecho). Esta lucha tiene una repercusión directa en la práctica jurídica. En esta no se trata de lograr la justicia, sino establecer quien tiene el monopolio de decir qué es el derecho.

Al mismo tiempo esta lucha en el campo jurídico -que como tal excede largamente el espacio de los tribunales- se debe dar en el marco de cierta autonomía que permita el establecimiento de reglas para la disputa, se trata de una concurrencia estructuralmente reglada. Es así que

\footnotetext{
${ }^{7}$ GRAMSCI Antonio, Los intelectuales y la organización de la cultura, Ediciones Nueva Visión, Buenos Aires, 1984.

8 BOURDIEU Pierre Respuestas por una antropología reflexiva, México, Grijalbo, 1995, pp. 82.
} 
las divergencias entre las "interpretaciones autorizadas" son necesariamente limitadas y la coexistencia de una pluralidad de normas jurídicas concurrentes está excluida por definición del orden jurídico. ${ }^{9}$

Por la división de trabajo establecido en el campo jurídico, la acción en los tribunales queda a cargo de aquellos capaces de disputar por la interpretación de la ley en un marco regulado con reglas claras que otorga cierta previsibilidad al proceso. Interesa resaltar del marco teórico propuesto por Bourdieu que estas reglas para el campo se sustentan en la existencia de períodos de equilibrio en el que los habitus espontáneos de los intérpretes están mediados por la disciplina de un cuerpo jerarquizado "que pone en práctica procedimientos codificados de resolución reglada de conflictos"10. En el caso de los Tribunales del Trabajo aun estos habitus no estaban encasillados en las reglas de un fuero nuevo donde justamente las posibilidades de tener el derecho a dictar el monopolio del derecho aun no se encontraban tan jerarquizadas.

Lo novel de la institución dentro del campo jurídico permite pensar aun en un habitus no conformado con el peso que se le otorga al mismo en los otros fueros del Poder Judicial. La existencia del fuero con sus reglas y jerarquías (tiempos procesales, potestad del juez de adoptar la interpretación que consideraba ajustadas a derecho) no eran suficientes en la medida en que lo que carecía el fuero del trabajo era un corpus legal que pusiese coto a las divergencias entre las interpretaciones autorizadas. Las referencias a resoluciones, decretos, artículos del Código Civil, artículos del Código de Comercio, leyes y jurisprudencia, situaciones particulares sobre lo justo y lo injusto, etc. convivían tanto en los escritos de demanda como en los escritos de contestación.

En este contexto el saber experto fue puesto entonces en disputa en la medida en que las jerarquías dentro del sub campo de la justicia laboral aun no estaban establecidas y que las herramientas para la disputa sobre el capital simbólico difería de aquellas ya establecidas para los otros fueros. De hecho el lenguaje que se conserva en los expedientes judiciales del Tribunal del Trabajo $\mathrm{N}^{\circ} 1$ de la ciudad de La Plata no seguía los preceptos de las consideraciones

\footnotetext{
${ }^{9}$ BOURDIEU Pierre, La forcé du droit... Op. Cit. Pp.4 Traducción propia.

${ }^{10}$ Ibídem, Pp 5. Traducción propia.
} 
sobre la neutralidad e impersonalidad que deben primar en el lenguaje jurídico. Desgraciadamente las instancias orales previstas por la Ley 5178 me privan de acceder a un momento central en la confrontación como lo eran las Audiencias de vista de causa previas a que el tribunal dictase el veredicto. Sin embargo algunas referencias en los Acuerdos y Veredictos dan cuenta de los argumentos in voce, estos parecerían estar lejos de las formalidades con las que se considera ejerce su dominación el campo jurídico.

Por tanto al considerar a los profesionales (expertos en la propuesta del campo de Bourdieu) en los Tribunales del Trabajo se debe tener presente la informalidad que primaba en el foro. Esta informalidad posicionaba al fuero laboral lejos de aquellos actores que gozaban del prestigio (la acumulación del capital simbólico) en el campo jurídico. Este lugar subordinado dentro del campo tuvo repercusiones en las prácticas jurídicas que se desarrollaban en su interior. Aun respetando internamente el orden jerárquico establecido para otros fueros, su permeabilidad a los discursos no jurídicos y la falta de un corpus legal definido sobre el cual disputar -siempre internamente- el derecho a dictar el derecho, impactó sobre la consideración de los expertos al interior del campo.

Esta informalidad, sin embargo, no desestima la división entre expertos y profanos. Aun con sus características propias el fuero laboral no dejó de ser una institución judicial en la que los actores debian conocer ciertas reglas y compartir el lenguaje para poder llevar adelante la disputa. Tanto los proyectos de constitución de la justicia del trabajo en sus múltiples formas -ya sea como juzgados o tribunales, con presencia de las partes (capital y trabajo) en la conformación de juez o con jueces profesionales- buscaron explícitamente romper con la barrera que las formas judiciales imponian a los profanos. Sin embargo se sostuvo la necesidad de preservar espacios definitorios para los expertos que mantuvieron de ese modo el control de los procesos judiciales

Las disputas dentro del campo también tuvieron que lidiar con algunas lógicas que escapaban estrictamente de las disputas en tanto campo jurídico. La Justicia del Trabajo, como organismo del Estado, estaba atravesado por las lógicas burocráticas que implicaban necesariamente otro tipo de saberes no estrictamente jurídicos. No todos los actores expertos debían conocer y saber disputar el saber burocrático, pero debe ser una referencia a tener en cuenta 
sobre todo al analizar a aquellos que buscaban construir una carrera burocrática (el caso de los jueces y los abogados que dependían de las instancias estatales).

\section{V.2 Los Peritos contables}

En la resolución de los juicios laborales cumplía un rol central la figura del perito contable. Debido a la naturaleza de lo que se reclamaba (pago de haberes, aumentos no otorgados, sueldo anual complementario, indemnizaciones por despido, etc.) era fundamental contar con el saber de un contador que pudiese determinar el monto final de lo reclamado por los trabajadores. El tránsito de los peritos por el juicio seguía los pasos procesales establecidos por la ley 5178, es decir mediante sorteo entre aquellos que estuviesen inscriptos en la matrícula. Pero los peritos no sólo daban cuenta de los números pendientes entre ambas partes -cuando los había-. En la presentación de sus pericias no ahorraban comentarios que muchas veces tenían que ver con la cuestión de fondo y su opinión, como opinión de experto, era utilizada por los abogados para reforzar sus argumentos.

En la causa 102 del paquete $\mathrm{N}^{\circ} 4^{11}$ en la que Alfredo Desio intentaba cobrar de sus patrones la indemnización por accidente inculpable, la información volcada por el perito en la pericia fue retomada por el abogado de la demandada Jorge Romano Yalour. En la Audiencia de vista de causa del 27 de Diciembre de 1949 se hace Ilamar al perito, Carlos Federico Delaplace, quien bajo juramento ratifica la pericia en todas sus partes, sin que las partes hagan observaciones sobre la misma. Habiendo entonces ratificado las partes como verdadero lo actuado en la pericia, el abogado de la parte demandada solicita que "se deje sentado en el acta que según el criterio del perito, considera a los estibadores como changuistas"12.

En este caso el criterio de los peritos juega como un "saber experto" del que se desprenden consecuencias sobre la acción de fondo. En tanto portador de un saber especializado el criterio del perito no expresaba solamente una cuestión de sentido común o un deseo, sino que fundamentaba principalmente la posición que había esgrimido el abogado de la parte demandada al contestar

\footnotetext{
${ }^{11} \mathrm{DH} 102 / 4$ Desio Alfredo c/ Murchinson Estibajes y cargas SRL s/ haberes. Año 1949.

$12 \mathrm{DH} 102 / 4$ foja 103.
} 
el escrito de demanda. En tanto que las causas judiciales otorgaban al perito un lugar central en el proceso su saber era especialmente útil a la hora de disputar las capacidades de interpretar la ley. Los jueces estaban especialmente atentos a los resultados de las pericias contables y sostenían las más de las veces sus resoluciones en lo demostrado o no en las pericias. Como constructores de una prueba vital, el perito ocupaba un lugar determinante dentro de la construcción y la disputa del capital simbólico. Sin embargo en tanto actores con un saber profesional no disputaban por el capital simbólico dentro del campo jurídico. El discurso sobre el que operaban los peritos era determinante para la disputa entre las partes, pero poco impactaba la consideración sobre el saber específico que portaban -rara vez sus pericias eran observadas por los partes-.

Esto implicaba que su posición dentro de la jerarquía del campo estaba establecido de antemano y respondía a la situación de ser portador de un saber de por fuera del campo. A diferencia de lo que ocurría con otros saberes -como el saber jurídico- el saber del perito contador era fundamental en la disputa de los actores judiciales al tiempo que el actor portador de esos saberes no ponía en juego su propio capital simbólico en la disputa.

Por otro lado la importancia de los peritos también radicaba en que la función oficial que cumplían, les permitía tener acceso a los libros y cuentas del empleador. Y siendo la pericia una prueba fundamental a la hora de dictar el veredicto, la palabra del contador sobre los libros era por demás importante. Se debe resaltar que en los casos en los que el perito determinara que los libros no eran llevados según la ley, la prueba se invertía. Esto quiere decir que ya no sería obligación del obrero probar sus dichos (ya sea sobre la relación de dependencia o sobre los montos reclamados), sino que el patrón estaba obligado a demostrar fehacientemente que lo que sostenía el actor no era cierto. Sin la prueba legal necesaria, la inversión de la carga de la prueba como doctrina implicaba adjudicar directamente de la culpabilidad al patrón.

Tal es el caso del pleito sostenido entre Lorenzo Ortega y Francisco Picó ${ }^{13}$ en el año 1950. En esta causa el actor reclama la indemnización por despido debido a que el demandado era dueño del hotel donde oficiaba de mozo. Pero

${ }^{13} \mathrm{DH}$ 102/14 Ortega Lorenzo c/ Pico Francisco s/ cobro de pesos. Año 1950. 
el hotel fue vendido, y nunca se le pagó la indemnización. El demandado sostuvo que el actor siguió trabajando para los nuevos dueños y que además cuando él volvió a hacerse cargo del hotel por problemas con la venta, Ortega se siguió desempeñando bajo sus órdenes, y aun continuaba en el hotel a pesar de haberlo vendido a nuevos dueños. Pero en la pericia, el encargado de llevarla a cabo, Juan Carlos Di Falco, anunció que

[E]l perito ha constatado que la demandada no ha dado cumplimiento a lo exigido por el artículo 44 del Código de Comercio, desde que no ha llevado los libros declarados indispensables (...) Por carecer la demandada de libros, el perito no puede aportar elemento alguno importante para el asunto que se plantea ${ }^{14}$.

A pesar de no aportar elemento alguno para el asunto, la declaración de que Francisco Picó no llevaba los libros fue suficiente para que la estrategia de sus abogados cambiase. A partir de allí debió demostrar que efectivamente el actor había continuado en su puesto, que mientras trabajó para él se había tomado los francos, y que le había abonado los salarios y los sueldos anuales complementarios establecidos por la ley. Desafortunadamente la causa no llega a ser resuelta por el tribunal, ya que se llegó a un acuerdo privado entre las partes. Pero quedó en evidencia que la declaración del perito influyó de manera determinante, ya que una de las pruebas centrales de los juicios laborales era favorable a priori al actor al invertir la necesidad de presentar las pruebas, según lo establecía la misma ley 5178 que creó el fuero. El Perito contador oficiaba en estos casos como un delegado del tribunal en la medida que era el que aportaba la prueba para determinar si el actor o el demandado se encontraba en los límites que establecía la ley.

Es significativo que para el caso de las pericias contables no se permitiese la presentación de los peritos de parte. No hay dudas que el lugar donde el perito realizaba la pericia era fundamental para la concreción de la misma y en esas circunstancias podía entrar en contacto con otros contadores. Sin embargo el perito parece haber gozado de ser indisputado, aun cuando realizaba pericias sobre los libros de grandes empresas que contaban con su propio personal contable, como el caso de los frigoríficos o las empresas medianas que eran auxiliados por contadores. Los peritos generalmente daban cuenta de la buena o mala disposición de la parte patronal para hacer entrega

${ }^{14} \mathrm{DH} 102 / 14$ fojas 46 y 46 volta. 
del material necesario para la pericia, pero al parecer incluso en el caso de las grandes empresas -con lo que implica poder revisar la cuestión contable-, no se les negaba el material a sabiendas que una acción así podría mal predisponer al tribunal.

\section{V.3 Los Abogados}

La lógica jurídica de los Tribunales Laborales no coincidía con la "realidad" que los trabajadores vivían. Para conciliar las lógicas diferentes, la figura de los abogados era central. Los argumentos debían construirse en "moldes de racionalidad" ${ }^{15}$ consecuentes con las formas de la institución y esto requería de un saber específico y especializado. Si los trabajadores expresaban su noción de justicia a través de un lenguaje de derechos, correspondía a los abogados expresar ese lenguaje de derechos en un lenguaje de leyes.

La importancia del rol del abogado al hacer más accesible la lógica de los tribunales a los trabajadores no puede ser menospreciada. Aun así es necesario mantener la perspectiva para evitar creer que es solo el abogado que se expresa en los expedientes judiciales. Las mismas mediaciones que realiza el historiador cuando se acerca a la fuente hacen de esta una voz variopinta. Pero hay también condiciones en la producción de esa fuente que deben ser tenidas en cuenta. En primer lugar, al tratarse de una fuente judicial, está condicionada por la función de su producción. El objetivo de la producción de estos discursos era reclamar derechos y reivindicaciones en "un ámbito del propio Estado, en este caso, en su función específica de administrar justicia"16, con lo cual el grado de "veracidad" debe ser contemplado a la luz de este objetivo. Lo que importa aquí es reflexionar sobre otra mediación que ocurría en la producción misma de la fuente y que conduce, pertinentemente, a preguntar sobre quién es el sujeto que se expresa en esos escuetos escritos.

\footnotetext{
15 El "Molde de Racionalidad", según Rinaldo Varussa, funcionaba en Brasil para desplazar la pelea desde el campo político, económico y social al plano técnico y de esta manera desmotivar la movilización de los trabajadores, y evitar tener que recurrir a la represión directa. El "Molde de Racionalidad" no se refiere solo a las instituciones judiciales, ya que la intervención estatal adquirirá diferentes formas. VARUSSA Rinaldo J., Op. Cit.

16 DURAN Claudia L., "Apuntes sobre la fuente judicial como recurso para la investigación social" Sociohistórica. Cuadernos del CISH, No 6, Segundo Semestre de 1999, Ediciones AI Margen, La Plata, 1999.
} 
La firma que cerraba las presentaciones escritas eran las de los abogados, y podemos suponer detrás de estas al profesional que representa a las partes. Pero la definición del estilo, la narración de los hechos, e incluso hasta en la estrategia procesal, se debe pensar que no era simplemente la voluntad del letrado. A pesar de que tanto los términos procesales como la necesidad de encauzar el reclamo en "moldes de racionalidad" aparecen como velos que obscurecen a los actores detrás de la fuente, es posible pensar en los entramados sociales que se establecían y del que el escrito es solo una expresión. Analizando casos de divorcios en la Inglaterra del siglo XVIII, la historiadora Joanne Bailey dio con unos cuantos expedientes de juicios de divorcio y también con cartas que se enviaban entre los actores del juicio y sus representantes legales en las cortes. La posibilidad de cruzar estas fuentes le permitió establecer que muchas veces eran las propias partes en litigio quienes le daban al proceso legal una dinámica que difería del proceso que establecían sus representantes legales ${ }^{17}$ y obligaban a sus representantes a adoptar diferentes estrategias. Si bien el ejemplo es temporal y territorialmente distante, permite retomar la pregunta que instala en torno a la validez del testimonio de los sujetos más allá de sus representantes legales. Es decir que los testimonios expresados tanto en la demanda como en las contestaciones surgían de la interacción de los promotores (tanto los obreros como los patrones) y sus representantes legales, y no se puede asumir que la forma final del documento fuese solo la expresión de la voluntad, los hechos, y las estrategias que imponen los abogados.

En estos expedientes se puede percibir el "marco normativo que sostiene la trama social. Los actores en el litigio, en el conflicto definen la normalidad perdida, añorada, buscada"18. Más allá de la mediación interpuesta por los que ajustan a las normas del fuero, el hecho de que los actores hayan acudido a los tribunales deja en evidencia la concepción sobre el marco normativo en el que operaban en su vida cotidiana. Aun cuando la imagen que despliegan los expediente es la del conflicto, dan cuenta de los motivos de este conflicto y cuando los actores implicados consideraban que se había superado la barrera

17 BAILEY Joanne, "Voices in Court: lawyers or litigants" Historical Research, Vol. 74, No 186 (November 2001), Blackwell Publishers, Oxford, 2001, pp. 392-408.

${ }^{18}$ MAYO Carlos, Op. Cit. Pp. 583. 
de los normativo. Es en este sentido que estas causas son representativas del tipo de esquema normativo sobre el trabajo que predominaba entre los distintos actores sociales.

Hecha la salvedad con respecto a la necesidad de percibir también la presencia de sus representados en los escritos de los abogados, es necesario reconsiderar el rol de los abogados. A pesar de la novedad que el campo de la justicia laboral representaba como rama jurídica, este campo se regía por reglas no tan distintas a la de las otras ramas del derecho. Aun el expediente tenía que guardar los tiempos procesales propios y normas establecidas. La utilización de la legislación, la jurisprudencia y la doctrina requería del conocimiento y la habilidad del abogado para concatenar los elementos dentro de la lógica procesal. El saber "profesional", en términos de Bourdieu, limita el acceso al "campo jurídico" a aquellos considerados "profanos" por no contar con la especialización necesaria ${ }^{19}$. Pero retomando el texto de Joanne Bailey, e incluso las mismas palabras de Bourdieu cuando sostiene que, a pesar de que el derecho aporta en virtud de su misma forma una contribución en la función de regulación de la vida social por lo cual exige ser aprehendido en toda su especificidad, es necesario alejarse de los intentos por purificar el "derecho" de los condicionamientos contextuales a los que está sometido ${ }^{20}$ a riesgo de sino avalar exclusivamente sus condicionantes internistas. El concepto de campo jurídico pierde así algo de su autonomía. La relación entre los profesionales y los profanos permite pensar al "campo jurídico" como el lugar el que se entrecruzan diferentes discursos en donde, sin lugar a dudas, el profesional tiene una relevancia mayor por la forma en la que son distribuidos los bienes sociales (sobre todo el poder). Pero la importancia de las concepciones "profanas" de lo que significa la justicia, la ley y la transgresión, y que en última instancia hablan del ordenamiento social ${ }^{21}$, no pueden ser dejadas de lado. Es en el campo de la justicia laboral, donde no hubo un Código que marcase fuertemente la distinción entre los dos campos, donde esta relación aparece

\footnotetext{
19 BORDIEU Pierre, La forcé du..., Op. Cit.

${ }^{20}$ lbidem.

21 Retomando las categorías de Bourdieu sobre lo "profano" en contraposición a lo "profesional", Lila Caimari propone un compilación en donde el eje es justamente la manera en que estos sujetos externos al campo jurídico conciben la ley, el delito, y la justicia. CAIMARI, Lila, "Presentación" en CAIMARI, Lila, (comp.) La Ley de los profanos. Delito, justicia y cultura en Buenos Aires (1870-1940), FCE- Universidad de San Andrés, Buenos Aires, 2007.
} 
por momentos de manera más evidente, sobre todo si tenemos en cuenta que las leyes laborales eran objeto de una continua propaganda por parte de sindicatos y del Estado.

Por cuestiones propias a las formas procesales que debía seguir un juicio el trabajador podía ir acompañado por un representante legal habilitado para poder entablar la demanda, tal como lo establecía el artículo 28 de la ley $5178^{22}$. Haciendo uso del derecho que la ley otorgaba a los trabajadores, estos acudian acompañados por los abogados. La Carta Poder que habilitaba a los abogados o procuradores a representar a las partes en el estrado, lo facultaba para

que en nombre de (su mandante), demande a (el demandado) por (los motivos de la demanda).- A tales efectos faculta al mandatario para que se presente ante los Señores Jueces, tribunales y autoridades que correspondan con escritos, escrituras, documentos y todo género de pruebas,,(sic) pudiendo presentar y tachar testigos, prestar juramentos y cauciones juratorias, recusar, declinar y prorrogar de jurisdicción, poner y absolver posiciones, decir de nulidad, interponer todos los recursos legales y desistir de ellos, pedir embargos y la venta de los bienes del deudor, reconocimientos de firmas, cotejos de letras, pericias caligráficas, compulsas, nombrar toda clase de peritos, martilleros, tasadores, y escribanos, transar, comprometer en árbitros, percibir y otorgar recibos y asimismo lo faculta para intentar y oponer cuantoas (sic) acciones y recursos competan al mejor cumplimiento de éste mandato, el que podrá sustituir $^{23}$.

La carta poder da cuenta de las actividades que el abogado podía realizar en el curso de una causa, muchas de las cuáles requerían el conocimiento especializado de los letrados. Este conocimiento no se desprendía tanto de la resolución de grandes cuestiones, sino también del manejo de las pequeñas triquiñuelas que envolvía el ejercicio de la profesión. La formación de estos profesionales, entonces, era importante a la hora de afrontar los juicios laborales. A pesar de que el fuero laboral era pensado como una justicia más accesible y de un lenguaje más cercano a la cotidaneidad del trabajador, seguía siendo una institución que mantenía ciertas reglas que eran comunes a otros fueros.

\footnotetext{
22 "Art. 28.- Los empleados, obreros y aprendices, y sus derechohabientes podrán hacerse representar por mandatario letrado o procurador habilitado para el ejercicio de la procuración, mediante simple carta poder, autenticada la firma por escribano o funcionario judicial del partido en que resida", Ley 5178, Anales de Legislación Argentina, Tomo VII, Buenos Aires, Editorial La Ley, 1947, pp1071-1079.

${ }^{23} \mathrm{DH}$ 102/7 Ruelli, Arnaldo Tomás c/ Fiorovanti Fulvio s/ despido, falta de preaviso y vacaciones, Año 1949, foja 1.
} 
Los tribunales laborales como espacio institucional nuevo eran consecuencia de los debates en torno a las leyes laborales -ligadas antes a la rama civil del derecho- que habían comenzado ya a fines del siglo XIX. En este debate influyó la formación de los abogados en las facultades de derecho, que había incluido, de manera gradual, a las Ciencias Sociales en su currícula ${ }^{24}$. Producto de la influencia del positivismo sobre el ámbito político y académico de principios de siglo, las Ciencias Sociales (y principalmente la sociología) nutrieron al movimiento reformista e inspiraron la incipiente legislación laboral. Varios de los impulsores de las ciencias sociales en la Argentina tenían como objetivo el tratamiento de la "cuestión obrera", y entre ellos los abogados reformistas fueron los más buscados para integrar las filas del Departamento Nacional del Trabajo ${ }^{25}$.

Las instituciones estatales y las aulas de las Facultades de derecho fueron "colonizadas" por una generación de abogados y referentes en derecho que otorgaron a las ciencias sociales un rol determinante en la enseñanza del derecho ${ }^{26}$. El lugar central que Joaquín V. González tuvo en la creación de la Universidad de La Plata, y su rol como docente de la Facultad de Ciencias Jurídicas y Sociales, es solo un hito de esta colonización. La importancia de las ciencias sociales en la enseñanza del derecho afectó la formación de los abogados que actuaron en el foro como representantes de las partes en litigio en los Tribunales Laborales. Su influencia no quedó solo plasmada en la vida política de los grandes personajes (como el mismo Joaquín González o el primer director del Departamento Nacional del Trabajo, Nicolás Matienzo), sino también en la formación de aquellos que en nuestras fuentes se encargan de promover "el desenvolvimiento de las estructuras de poder en el interior de los límites de las propias instituciones" 27.

\footnotetext{
${ }^{24}$ Los cambios en los planes de estudio hacen eco de los cambios en las ciencias del derecho y se orientan a las ciencias sociales. El movimiento estudiantil en las facultades de derecho, principalmente Buenos Aires y La Plata, fue un factor determinante en la presión por la inclusión de principios sociales en el estudio del derecho. AGULLA Juan Carlos, "Crisis en la Facultad de Derecho de la Universidad de Buenos Aires (una huelga estudiantil a principios de siglo)" en Revista del Instituto de Historia del Derecho "Ricardo Levene", № 31, Buenos Aires.

${ }^{25}$ ZIMMERMAN Eduardo, Las ciencias sociales..., Op. Cit.

${ }^{26}$ SALVATORE Ricardo, Op. Cit.

${ }^{27}$ El sociólogo brasilero Sergio Adorno, en su estudio de la vida académica y extraacadémica de la Academia de Direito de Sao Paulo, sostiene que la Academia educaba al gran intelectual, pero, sobre todo, al pequeño y esto se debía a que la creación de las Academias de Derecho
} 
Fue el abogado formado en las décadas previas en estas facultades de derecho marcadas por la influencia de las ciencias sociales los que actuaron en el fuero laboral. Los abogados -y sobre todo los jueces- como elite profesional encontraron en la solución de la problemática obrera la justificación de la importancia de su rol social durante las décadas previas, ya sea actuando en las instituciones como el Departamento Nacional del Trabajo o dando nuevas interpretaciones a las leyes para facilitar el acceso de los trabajadores a la justicia. Además de estos cambios en la formación, debe ahondarse en la figura del abogado militante que veía en este campo de la justicia laboral la posibilidad de aplicar su militancia social ${ }^{28}$. Sin querer negar la novedad que el fuero laboral pudo haber significado como espacio institucional $y$, principalmente, social, los años previos a la creación de los tribunales fueron prolíferos en la preparación de los profesionales que servirian en el foro.

A fines de la década del cincuenta del siglo pasado Díaz Guijarro, abogado y juez de la nación, escribía:

Incumbe al abogado el juzgamiento originario del problema que se le plantea y orientar al consultante hacia el recto ejercicio de sus derechos, si no comparte la causa deberá dar un paso al costado. Este principio es fácil de sentar pero difícil de cumplir, no porque el abogado encuentre veta propicia para pleitear, que si así lo hace obrará como un rábula, sino porque le será difícil desentrañar la verdad. ${ }^{29}$

Siguiendo la afirmación del autor se observa que se presentaba a los abogados como el "primer juez", es decir, aquél que considera si se ha violado algún derecho que requiera la intervención del sistema judicial. El abogado era un intermediario entre el solicitante y el sistema judicial, aquel que, en palabras de Rinaldo Varussa, coloca en "moldes de racionalidad" el pedido de justicia del trabajador.

respondieron a las necesidades del estado. ADORNO Sergio, Os Aprendices do poder. $O$ bacharelismo liberal na politica brasileira. Paz e Terra, Río de Janeiro, 1988.

${ }^{28}$ Virginia Vecchioli da algunas pautas para analizar la importancia de la militancia -así como también las posibilidades que un nuevo campo del derecho (en términos de mercado) daba a los jóvenes- en la especialización de los abogados en tal o cual rama del derecho. VECCHIOLI Virginia, A luta pelo direito: engajamento militante e profissionalizaçao dos adrogados nas caussas pelos direitos humanos na Argentina, Rio de Janeiro, Tesis de Doctorado PPGAS/UFRJ, 2006. Larissa Correa también hace hincapié en el prestigio que adquirían en su profesión aquellos abogados que se demostraban como más audaces a la hora de enfrentar a los patrones en la justicia o aquellos que eran buenos oradores en los actos públicos y eran reconocidos como promotores del derecho laboral entre los trabajadores. CORREA, Larissa Rosa, Op. Cit.

${ }^{29}$ DIAZ DE GUIJARRO Enrique, Abogados y Jueces. Buenos Aires, 1959. 
Pero por otro lado debe estar convencido que la causa es justa o "dar un paso al costado". A pesar de que la afirmación escondía un deseo no del todo reprimido más que una afirmación de la realidad del foro -aún hay lugar para los que sólo quieren pleitear- se puede sostener que era necesario cierto grado de compromiso con la causa de los trabajadores. Los abogados que actuaban en el fuero laboral compartían, al menos, la creencia en la necesidad del foro como una herramienta rápida y eficaz en la resolución de los conflictos. En las palabras del gobernador de la provincia, el justicialista Domingo Mercante, la creación del foro laboral respondía a la necesidad de

una justicia rápida e imparcial, con sentido revolucionario; una justicia que sin prevenciones de clase, descifre ágilmente la letra de los nuevos textos jurídicos y generalice el imperio de los postulados de redención social que propugnamos ${ }^{30}$.

En esta nueva justicia los abogados, en su función de primeros jueces, jugaron un rol central en el descifrado de los nuevos textos jurídicos ${ }^{31}$.

Se buscaba la puesta en marcha de una justicia que se debía despegar de las tradiciones ligadas a las más antiguas ramas civil y penal. Si bien en la ciudad de La Plata no se descartó la participación de los abogados en el nuevo fuero, efectivamente fueron actores nuevos en el foro los que se hicieron cargo de las plazas que ofrecía la instalación de estos tribunales. La designación de jueces y abogados desató la reacción del Colegio de Abogados de la Provincia de Buenos Aires que sostendrá que

algunos magistrados de los tribunales de trabajo de dicha provincia carecerian de la antigüedad en el ejercicio de la profesión exigida por el estatuto supremo... situación que luego había sido aceptada por la Suprema Corte de Justicia ${ }^{32}$.

La designación de "inexperimentados" letrados en altas posiciones jerárquicas de la justicia laboral puede ser colocada dentro del contexto más amplio señalado por Daniel Campione que alerta sobre la posibilidad que el peronismo significó para los funcionarios de segundo y tercer orden de

\footnotetext{
${ }^{30}$ Mensajes de los gobernadores de la Provincia de Buenos Aires. Domingo Alfredo Mercante 1946-1952, La Plata, 2002 (edición digital del Archivo Histórico de la Provincia de Buenos Aires), citado por MARCILESE José, "EI Poder Judicial Bonaerense en el Primer Peronismo: de la autonomía a la dependencia". Estudios Interdisciplinarios de América Latina y el Caribe, 2007.

${ }_{31}$ Véase la constitución de parte en un juicio en el capítulo siguiente.

32 La Prensa, 25.4.1949. Citado por MARCILESE José, El Poder Judicial... Op. Cit.
} 
ascender en su carrera administrativa ${ }^{33}$. La ampliación de las funciones estatales y los cambios en la estructura orgánica del mismo, de los cuáles el establecimiento del fuero laboral es un ejemplo, permitieron la llegada a funciones estatales de cuadros nuevos tal como se ha visto. La renovación también fue intensa en el poder judicial, en donde -siempre siguiendo los pasos constitucionales- el gobierno de Mercante renovó la Corte Suprema de la provincia y propuso un debate en torno a la inamovilidad de los jueces que habían actuado durante la "década infame"34.

V.3.1 Los abogados de la Delegación Regional de la Secretaría de Trabajo y Previsión

En este esquema de ascensos y actores nuevos en el foro, los abogados/funcionarios ${ }^{35}$ de la Delegación Regional de la Secretaría de Trabajo y Previsión, que rápidamente adquirirá el rango ministerial, no se pueden pasar por alto. En ocho de las cuarenta y dos causas para el período 1948-1955, los abogados de la parte actora son funcionarios de la Delegación Regional. La representación de la parte actora en manos de funcionarios de la Secretaría debe ser interpretada como otra señal de la intervención del gobierno a favor de los trabajadores al otorgar asesoría legal gratuita para pleitear en los tribunales. Al mismo tiempo da cuenta de la importancia del Poder Ejecutivo, a través de la Delegación, en la función de acercar la ley a los obreros. El

\footnotetext{
${ }^{33}$ CAMPIONE Daniel, Op. Cit.

34 José Marcilese analiza los cambios en el Poder Judicial durante el período del gobernador Mercante, así como la posterior intervención en el gobierno provincial del también peronista Alóe. El recambio en la Suprema Corte se tradujo en la jubilación o el retiro de los jueces Manuel Argarañaz y Elías Casas Peralta, nombrados durante la década infame, y el reemplazo de tres jueces que habían sido nombrados por la intervención de la provincia consecuencia del golpe militar del 4 de Junio de 1943, estos fueron: Antonio Quijano, Julio Facio y Jorge Echagüe. En su lugar fueron nombrados, por acuerdo de la Legislatura, los jueces Eduardo Illesacas, Julio Escobar Sáenz, Fernando Demaría Massey, Juan Ramirez Gronda y Luis Longhi. Además de los jueces de la Corte, fueron removidos otros jueces de primera instancia, la mayoría de ellos en el Distrito Capital, que correspondía a la ciudad de La Plata. MARCILESE José, "La justicia bonaerense durante la gobernación de Domingo A. Mercante" en PANELLA Claudio (comp.), El gobierno de Domingo A. Mercante en Buenos Aires (19461952). Un caso de peronismo provincial. Tomo III., Instituto Cultural de la Provincia de Buenos Aires, La Plata, 2007.

${ }_{35}$ Carta Poder que consta en las causas en las que actúan los funcionarios de la Delegación Regional de la StyP están firmadas a favor de Roberto Terrasa, Armando Amarilla, Héctor Legáis, Gustavo Melían, Ricardo Bernal, Pedro Lazzola, Rodolfo Barbery, Leandro Gil Ibarra y Julio A. Poblet Villegas. Todos funcionarios de la Delegación Regional del Ministerio de Trabajo y Previsión de la Provincia de Buenos Aires. El poder era especial para esa causa particular y gratuito.
} 
contacto fluido que tenía la Delegación Regional con los trabajadores ${ }^{36} \mathrm{se}$ desprende de las actuaciones que han quedado registradas en los expedientes.

La mayoría de los abogados de la Delegación Regional de la Secretaría de Trabajo y Previsión eran jóvenes si tomamos como referencia el año en que se recibieron de la Facultad de Ciencias Jurídicas y Sociales de la UNLP. Roberto Terrasa se recibió en 1939, Ricardo Bernal lo hizo en 1940, Héctor Legris en 1941, Leandro Gil Ibarra en 1942, en 1944 se recibía Armando Amarilla, lo seguían en 1946 Pedro Cazzola -quien además continuaría con una carrera como docente de la facultad llegando a ser jefe de trabajos prácticos-, y Julio Poblet Villegas y, en 1948, año en que se reglamentó el funcionamiento de los Tribunales del Trabajo en la ciudad, se recibían Jorge Arena, Rodolfo Barbery y Gustavo Melían ${ }^{37}$. Así considerado podemos entonces pensar que Roberto Terrasa, el que contaba con mayor antigüedad de recibido, debería estar promediando en 1948 unos 45 años, con la mitad de ellos menores de treinta años.

Esta juventud marca en algún punto las posibilidades que el derecho laboral abría como perspectivas de trabajo para los jóvenes abogados. Como abogados especialistas formados en Derecho del Trabajo también fueron conformando, en tanto profesionales, un campo de acción. En la relación de estos abogados con el Estado, en virtud de ser ellos mismos empleados estatales, tal vez sea necesario matizar la mirada que propone que fue el Estado -si entendemos este como un ente homogéneo con un objetivo determinado- quien brindó a los actores las directivas en cuanto a su función. No cabe dudas que sectores dirigenciales del Estado buscaban fijar las normas y las directivas con las cuáles se debian mover sus funcionarios. Pero en tanto poseían un saber específico, los abogados de la Sección Patrocinio Jurídico reclamaron para sí una porción en la toma de decisiones -al fin y al cabo eran ellos los que determinaban la estrategia judicial a seguir a la hora del litigio-. Se puede pensar a estos jóvenes abogados como grupos profesionales que

\footnotetext{
${ }^{36}$ La delegación regional formaba parte del "recorrido" que los trabajadores realizaban en su búsqueda de "justicia". Este recorrido será analizado más adelante.

${ }_{37}$ Nómina de Egresados, Facultad de Ciencias Jurídicas y Sociales, 1905-1951. Universidad Nacional ciudad Eva Perón, Ministerio de educación, 1951. (mecanografiado)
} 
exigen cada vez más lugar como recursos humanos altamente calificados en construcción de un espacio de saber ${ }^{38}$.

El recorrido de los abogados laboralistas de la Delegación Regional marca temporalidades bien distintas, en cuanto que sus funciones como abogados litigantes en cuestiones relacionadas al trabajo, en donde pudiesen aplicar los conocimientos de su formación Derecho del Trabajo como disciplina autónoma, vinieron de la mano con la creación de los Tribunales del Trabajo propuesto por un gobierno con una idea determinada de la acción estatal sobre la sociedad. Por lo tanto su formación no estaba determinada por un requerimiento estatal, en la medida en que aun ese espacio estaba en construcción por los mismos actores.

Las funciones que los abogados de la Delegación Regional debían cumplir estaban ligadas a los litigios, en donde los objetivos y acciones estaban marcados no tanto por las líneas rectoras que la dirigencia del Poder Ejecutivo marcaba como pautas, sino por un rol determinado por el espacio en el actuaban. Esta situación es un llamado de atención en tanto en el fuero también existían lógicas que no respondía a la configuración misma del campo jurídico, sino a la instauración de una burocracia con fines determinados al tiempo que portadores de un proyecto de intervención.

En el caso de las dos trabajadoras que deciden denunciar a su empleador el Sr. Labury, estas habían concurrido -junto al demandado y al representante del Sindicato de Trabajadores de la Madera y Afines, Antonio Minicelli- a la División de Conciliación y Arbitraje de la Delegación Regional a fin de firmar un convenio que fijase el jornal y las condiciones de trabajo, así como su lugar en la jerarquía de la empresa. El convenio suscripto entre las partes tiene como fecha 27 de Septiembre del año 1949, pocos días antes del despido ${ }^{39}$.

De todas maneras lo importante es que las actoras ya habían entrado en contacto con los funcionarios estatales de la Delegación previo al inicio de la demanda y este contacto se mantuvo en el lapso que transcurrió entre el

\footnotetext{
${ }^{38}$ PERKIN Harold, Op. Cit. Las conclusiones de Perkin, aplicables a la sociedad inglesa post victoriana, son sugerentes en cuanto permiten matizar la idea del estado marcando las pautas de formación en determinadas disciplinas como parte de su objetivo de obtener técnicos o especialistas.

${ }_{39}$ El despido se produjo, preaviso mediante, el 30/11/49, mientras que el aumento de sueldo suscripto el 27/9/49 entró en vigencia el 6/10/49. DH 102-13 Comini Elba y otra c/Labury Eduardo s/ Indem. despido, Año 1950.
} 
despido efectivo de las dos obreras y el recurso judicial. En el escrito de la demanda el abogado que finalmente firma, el Dr. Roberto J. Terrasa, comenta que

mis mandantes realizaron oportunamente gestiones ante el Ministerio de Trabajo y Previsión, Delegación Regional en La Plata, por expediente $\mathrm{B} / 13546 / 49$, para obtener el cobro de las sumas que les corresponden, con resultado negativo. ${ }^{40}$

El recurso del expediente administrativo colocó a las trabajadoras ante personal calificado para amoldar sus derechos a la ley y así poder reclamar ante los tribunales ${ }^{41}$. Esta instancia administrativa también podía aparecer como una experiencia previa que sirviera de aprendizaje para los trabajadores.

La forma institucional de la instancia administrativa asemejaba mucho a la instancia oral que proponía la justicia del trabajo. Las pocas copias de audiencias de esta instancia conservada en los expedientes de los juicios laborales, dan cuenta de que en ese espacio que proponía la conciliación de las partes, también actuaban abogados, como se desprende del acta de la Audiencia del 18 de Agosto de 1953 de la Secretaria de Conciliación N* 5 de la División Trabajo y Acción Social Directa por un reclamo que Ricardo García le había iniciado a Cohen Semaría y Cía por el cobro de una deuda en concepto de despido. En esta audiencia la empresa fue representada por Raúl Domingo Spinetto que era asistido por el abogado Héctor Pérez Alzuela ${ }^{42}$.

La intervención de los funcionarios en el caso en cuestión le otorgaba a Elba Comini y Alba Baglivo la oportunidad de tener rápido acceso a la asesoría legal de los abogados. Es preciso recordar que el funcionariado del gobierno peronista estaba bajo constante supervisión y se esperaba de él que escapase a la letra de la ley para acercarse a las innovaciones doctrinarias ${ }^{43}$. Para lograr este paso el gobierno creó la Secretaría Técnica, dictó cursos y especializaciones, organizó el Estado mediante precisos organigramas, redactó

\footnotetext{
$40 \mathrm{DH} 102 / 13$, Foja 4.

${ }^{41}$ STAGNARO Andrés, "Los Abogados laboralistas de la Delegación Regional de la Secretaría de Trabajo y Previsión de La Plata, 1948-1955" en en S. FREDERIC, O. GRACIANO y G. SOPRANO (comp.), Profesión, Estado y Política. Prohistoria, Buenos Aires, 2010.

42 DH 104/4 García Ricardo c/ Cohen Semaría y Cía s/ Despido y cobro de pesos, Año 1954. Foja 180.

43 BERROTARRÁN Patricia M., «Educar al funcionario: "de la frialdad de las leyes a las innovaciones doctrinarias" (Argentina 1946-1952). », Nuevo Mundo Mundos Nuevos, Debates, 2008, [En línea], Puesto en línea el 16 juin 2008. URL: http://nuevomundo.revues.org//index36602.html. Consultado el 23 juin 2008.
} 
manuales, y hasta el presidente de la República brindó un discurso para alentar a los funcionarios de la "Nueva Argentina"44. En este contexto la intervención parece haber estado dentro de lo esperado de estos funcionarios. Pero adquiere mayor relevancia si se considera la dificultad que en el período previo encontraban los trabajadores para conseguir representación legal, sobre todo por los costos económicos.

El recurso de acudir a la Delegación Regional es una constante que parece en muchas de las causas analizadas. Incluso en aquellas oportunidades en las que los abogados no terminan siendo los funcionarios del Estado, el paso por las oficinas administrativas era una instancia previa. Claro que la ley de creación de los tribunales laborales establecía que los Tribunales funcionaban como una instancia de apelación en los casos de instancias administrativas o resoluciones de los jueces de paz ${ }^{45}$, pero lo que interesa aquí es resaltar que el paso de los trabajadores por la Delegación era uno de los pasos para amoldar sus derechos a las leyes, y seguramente funcionaría como una manera de entrar en contacto con los abogados, tanto de la misma institución, como con abogados particulares. Esto se veía reforzado en tanto las oficinas de la Delegación Regional de la Secretaría de Trabajo y Previsión funcionaban en el mismo edificio que los Tribunales Laborales ${ }^{46}$.

\section{V.3.2 Abogados laboralistas}

Aun no siendo funcionarios del Estado, los abogados buscaban diferentes maneras de ponerse a disposición de los trabajadores. Con el funcionamiento de los tribunales se afirmó la especialización de abogados en derecho laboral y surgió el abogado laboralista. Como abogado laboralista era especialista en derecho laboral pero fundamentalmente se vinculaba a la defensa de los derechos de los trabajadores. La distinción en tanto laboralistas funcionó hacia el interior de la especialidad de derecho laboral, destacándose un sentido de

\footnotetext{
${ }^{44}$ CAMPIONE Daniel, Op. Cit. BERROTARRÁN Patricia, Op. Cit.

${ }^{45}$ Ley 5178 , artículo 6 , inciso c. A.L.A., Op. Cit

46 Según se desprende de telegramas, exhortos y citaciones, las oficinas de la Delegación Regional de la Secretaría de Trabajo y Previsión, y los Tribunales Laborales, funcionaban en el edificio ubicado en la esquina de las Avenidas 1 y 60 de la ciudad de La Plata. Es significativo que los Tribunales Laborales funcionen en el edificio de las tareas administrativas y no en el Palacio de Tribunales ubicado en la Avenida 13 entre las calles 47 y 48.
} 
misión a desarrollar ${ }^{47}$. La formación que recibieron en su paso por la Universidad puede haber funcionado como catalizador de esta misión en la medida en que los colocó ante la posibilidad de aplicar sus conocimientos al servicio de los más débiles. La misma constitución de los tribunales del trabajo otorgó una oportunidad a los abogados que no encontraba una institución donde poner su conocimiento en acción.

En el plano de las suposiciones se puede pensar que los mismos trabajadores funcionarían como nexo entre un trabajador y su abogado. Un detalle del expediente que lleva el número 464 del año $1950^{48}$ Ilama la atención en este sentido. Al presentar la demanda, el abogado de la parte actora pide como prueba de la relación que unía a su representado, el albañil Alejandro Raymondo, al demandado, el Sr. Hermes Oliveri, se remita desde el Tribunal de Trabajo $\mathrm{N}^{\circ} 2$ de la misma ciudad de La Plata el expediente caratulado "Nogareda Alfredo c/ Oliveri Hermes s/ haberes" que justamente el mismo abogado promueve contra el mismo demandado. ¿Es posible entonces que Alfredo Nogareda haya funcionado como nexo entre el abogado y su compañero de trabajo? Es muy probable, no sería descabellado pensar en un obrero recomendando su abogado a un compañero. La expansión de la noción de los derechos que atañen a los trabajadores estaba sin duda vinculada a la función que el gobierno tenía en la difusión ${ }^{49}$, pero no podemos descartar el rol que en esta cuestión cumplía el boca a boca, la sociabilidad diaria de los mismos actores involucrados.

La recomendación personal puede haber sido en el caso previo la manera que el trabajador tuvo para acceder a los servicios de un abogado que aceptase llevar adelante su causa ante los jueces. Pero en al menos seis causas encontramos a los mismos abogados oficiando de representantes. Así ocurrió en las causas que opone a sendos obreros de panaderías contra sus

\footnotetext{
${ }^{47}$ La distinción se sostiene hasta el día de hoy. Los abogados laboralistas de la actualidad que en el caso de la ciudad de La Plata han conformado una asociación recientementerechazan en su seno a aquellos que se dedican a representar a la patronal en los juicios, refiriéndose a ellos como abogados empresariales o de empresas aunque sean especialistas de Derecho Laboral. La información se desprende de varias charlas informales con el Dr. Fabio Arechabala durante el año 2009. Sobre la asociación que conformaron véase su página web: http://www.laboralistasplatenses.org/

${ }_{48} \mathrm{DH}$ 102/15 Raymondo Alejandro c/ Oliveri Hermes s/ haberes, Año 1950.

49 Una obra como "Todas Las leyes Obreras de la Revolución", que se vendía a solo $\$ 2$, y la utilización de los medios como la radio para promover la obra del gobierno, fueron importantes a la hora de dar a conocer los derechos que regían para los trabajadores.
} 
patrones. Es significativo que todas las carta poder resguardadas en los documentos estén firmadas el mismo día y que los abogados sean los mismos. Todas las cesiones del derecho a litigar están firmadas a nombre de dos abogados laboralistas, Emilio Sigwald y Luís Benito Cerruti Costa ${ }^{50}$, y este derecho es cedido el mismo día por todos los actores, el 20 de Marzo de 1950.

Teniendo en cuenta que los actores terminan por desistir del juicio por

lo sentenciado por el exmo tribunal $\mathrm{N}^{\circ} 1$ y $\mathrm{N}^{\circ} 2$ en casos análogos y atento a la jurisprudencia sentada por la Suprema Corte de la Pcia de Bs As, según fallo publicado en "La Ley" del 11 de Septiembre de $1950^{51}$

Se puede asumir que estos casos resguardados fueron iniciados de manera conjunta. Entonces cabe preguntarse qué fue lo que empujó a estos trabajadores a iniciar la disputa en la instancia judicial de manera simultánea.

¿Quién o qué pudo haber empujado a los trabajadores a iniciar la demanda de manera simultánea? El contexto en el que se llevaron adelante las acciones judiciales, con preeminencia del actor sindical en las disputas entre el capital y el trabajo parece guiar la respuesta a un solo lugar: el sindicato. Esta proposición aquí sostenida se podría argumentar mejor indagando en la trayectoria de los dos abogados patrocinantes y observar si mantenían vínculos con el sindicato de trabajadores. Pero a pesar de no contar con esta información, algunos indicios en los expedientes mismos pueden ayudar a dilucidar esta cuestión. En la contestación de la demanda que les entabló Félix González a los hermanos Alfredo y Delfor Casale ${ }^{52}$, como propietarios de la panadería que ambos poseen en 67 entre 20 y 21, el abogado de la patronal

\footnotetext{
50 Mientas que poco pude indagar sobre Emilio Sigwald, la trayectoria de Cerruti Costa se ha conservado debido a la notoriedad pública que obtuvo en su época. Proveniente de catolicismo social, este abogado comenzó su carrera como laboralista en los comienzos del peronismo y su actuación construyó a su alrededor la imagen de una persona comprometida con los derechos de los trabajadores. Una vez depuesto Perón, su buena predisposición para con el movimiento sindical y su raíz católica lo impulsaron a ocupar la cartera de Trabajo durante el gobierno de Lonardi que siguió al derrocamiento. Su actuación al frente del Ministerio de Trabajo buscó mantener los logros obtenidos por los trabajadores durante el peronismo y resguardar a las cúpulas sindicales de la represión. Desacuerdos con el presidente de facto en torno a la nueva ley sindical llevaron al ministro a presentar su renuncia y posteriormente pasar a denunciar la persecución que el gobierno del general Aramburu sometía a los trabajadores. La trayectoria de este abogado continuó radicalizándose a medida que la represión hacia los trabajadores iba en aumento, y la llegada de Onganía a la presidencia marcó su acercamiento a las tendencias revolucionarias, llegando a ser director del diario "EI Mundo" ligado política y financieramente al PRT-ERP. CAPARRÓS Martín y ANGUITA Eduardo, La Voluntad. Una historia de la militancia revolucionaria en la. Argentina 1973-1976, Tomo II, Norma, Buenos Aires, 1998.

${ }^{51} \mathrm{DH}$ 102/11 Tato Jesús c/ Coidessa Pedro s/ Cobro de Pesos, Año 1950. Foja 17.

${ }^{52}$ DH 102/9 González Félix c/ Casale Alfredo Hnos. s/ Cobro de Pesos, Año 1950.
} 
Antonio Morzone, opone excepción de Litis Pendencia a la demanda que le entablara González por medio de los abogados Sigwald y Cerruti Costa.

Esta treta jurídica ${ }^{53}$ da cuenta de que existe una demanda similar entre ambas partes aun en curso. Morzone sostiene que el actor, bajo el patrocinio del Doctor Leandro C. Gil Ibarra, tiene promovida ante el tribunal del Trabajo $\mathrm{N}^{\circ}$ 2 una demanda que se encuentra en estado de "autos para sentencia" previa una medida de mejor proveer, dictada por él mismo. En esa causa consta que el actor le seguía un juicio por la misma resolución del 11 de marzo de 1949, y que pedía se le otorgue el aumento retroactivo como peón estibador de panadería. Eran, por lo tanto, dos causas promovidas bajo la misma resolución, se puede interrogar, entonces, sobre el motivo que impulsó al actor a tomar la vía judicial por segunda vez.

Por un lado se puede pensar que la causa de este litigio, impulsado en dos juzgados pero sobre el mismo asunto, se debía al desconocimiento del actor de las cuestiones procesales. Buscando el beneficio que le otorgaba la resolución de la Dirección de Acción Social Directa, acudió a los tribunales a fin de hacer cumplir una norma que consideraba estaba siendo ignorada por su patrón, pero sin saber que una vez juzgada en un tribunal el asunto no podía ser atendido en otro tribunal de la misma instancia. Este accionar del obrero de la panadería da fuerza a la distinción entre los profesionales, por un lado, y los profanos, por el otro. Aun así la presentación judicial, por más de ser incluso un impulso del trabajador, contaba con el aval de dos abogados laboralistas. Tal vez en el intercambio entre Sigwald, Cerruti Costa y Félix González, el detalle de que ya había iniciado una causa por el mismo motivo pasó desapercibido. Pero por otro lado también tendría sentido, en este juego de la imaginación, pensar que el actor fue incluido dentro de una estrategia más amplia de confrontación que utilizaba la justicia laboral como arena de disputa. El juicio que promovió Félix González parece haber sido uno de toda una serie de litigios impulsada por una organización, en este caso el sindicato que nuclea a los trabajadores. Esta opción se sustenta en la simultaneidad de las causas y de la cesión de la carta poder que acompañan los abogados patrocinantes, como se recordará todas firmadas el mismo día.

\footnotetext{
53 La acción del abogado es una cuestión de puro derecho procesal: no se puede entablar dos o más demandas sobre el mismo reclamo en diferentes tribunales de una misma instancia.
} 
Pero el apoyo que los trabajadores podían encontrar tanto en sus filas (la experiencia de otros trabajadores) como en la institucionalización misma de los tribunales, debió reforzarse con el papel que cumplían los abogados como representantes de los trabajadores ante el estrado. En su calidad de representantes, eran los que llevan a la justicia la voz de los trabajadores que sentían vulnerados sus derechos en el ámbito laboral. $Y$ en este rol construyeron, junto a sus mandantes, los límites de los justo y lo injusto, y definieron, a través de los litigios que entablaban con sus patrones, los contornos de las leyes y disposiciones que el Estado y sus agentes dictaban.

Los casos de los obreros panaderos que se analizan aquí son un ejemplo de ello. La norma dictada por la Dirección de Acción Social Directa -una de las cuatro direcciones que conformaban la Secretaría de Trabajo y Previsión ${ }^{54}$ - el 11 de Marzo de 1949 otorgaba a los trabajadores del ramo un aumento en sus jornales. En la demanda los abogados sostuvieron que dicha norma fue sólo cumplida de manera parcial por los patrones, ya que ignoraron parte de la misma que establecía la retroactividad de la misma a los meses de Marzo y Febrero del mismo año. Por lo tanto reclamaban el pago del diferencial entre los sueldos realmente abonados y los sueldos establecidos por la resolución. A partir de esta demanda lo que se puso en tela de juicio fue la capacidad de la Dirección de Acción Social Directa para establecer las normas, y la capacidad que tenía para hacerlas cumplir.

Aun así los actores recurrieron convencidos de que la norma expresaba no sólo lo justo, sino el derecho. Hoy llamaría la atención que se reclame como "fundado en derecho" ${ }^{\text {"55 }}$ sobre una norma emanada del Poder Ejecutivo, pero se debe recordar la maraña de instituciones que creó este poder ya desde mediados de la década del treinta. La superposición de funciones y la amplia gama de instituciones estatales creadas en torno al mundo del trabajo, a pesar de la reorganización y "racionalización" que supuso la llegada de Perón al poder, pudo llevar fácilmente a la confusión en torno a la capacidad de dictar normas que cada organismo tenía. Las normas fijadas en leyes, convenios (colectivos e individuales), disposiciones, decretos y resoluciones se

\footnotetext{
${ }^{54}$ CAMPIONE Daniel, Op. Cit.

55 Este latiguillo solía preceder a las normas en las cuales se fundaban la demanda y la contestación de la misma.
} 
superponían y más aún en el caso de disposiciones en torno a los salarios y remuneraciones, que eran reformadas de manera continua por diferentes instituciones. Correspondió a los abogados, como "primeros jueces" en las palabras de Díaz de Guijarro, dilucidar si la justicia y el derecho que sostuvieron los trabajadores estaba dentro del marco de la ley.

La presencia sindical es observable detrás de la representación por parte de los mismos abogados en causas distintas ante el mismo reclamo. Otra forma en que los abogados laboralistas promovieron sus servicios fue cuando el empleado o patrón a demandar era el mismo. Entre 1950 y 1951 los abogados Manuel Santos Lavalle y Arsenio Osvaldo Granillo llevaron adelante una serie de demandas contra la Compañía de Ahorro y Capitalización que estaba siendo liquidada por el Estado ${ }^{56}$. En este caso el actor de la primera acción, Carlos Mengotti, que se desempeñó como vendedor de títulos en la compañía demandada logró el pago de diferencia de sueldos de acuerdo a un aumento de emergencia que no había cobrado cuando se desempeñaba para la empresa. Este antecedente parece haber sido lo que impulsó a los otros trabajadores a reclamar en base al mismo aumento y a los diferenciales de sueldo según convenio colectivo. Así en distintas causas Castaño Carrizo, Rodolfo Gutierrez, Amilcar Piscitelli y Oscar Luis María Bertolini lograron que las demandas iniciadas sirviesen de disparadoras de los arreglos con la compañía.

En este caso la presencia de los mismos abogados permitió presentar un caso como testigo y a partir de allí lograr los mismos derechos para el resto de los trabajadores de la empresa ${ }^{57}$. Incluso las resoluciones favorables obtenidas en casos análogos son presentados como jurisprudencia a la hora de reclamar en el estrado:

Un caso más reciente, el del empleado JOSE BUENO, tramitado por ante el Tribunal No, ofrece un caso similar al de estos autos. En efecto, el citado empleado reclamó diferencias por sueldo mínimo, arribándose finalmente a una conciliación, en la que la accionada admitió la procedencia del reclamo, pese a que el actor había obtenido anteriormente, en otro juicio, la indemnización por cese y las demás

\footnotetext{
${ }^{56} \mathrm{DH}$ 102/12 Mengotti Carlos R. c/Compañía de Ahorro y Capitalización Sociedad Anónima Argentina (en liquidación) s/Dif. Haberes, Año 1950. DH 103/1 Carrizo Castaño c/ Compañía de Ahorro y Capitalización S. A. (en liquidación) s/ Haberes, Año 1951. DH 103/2 Gutierres Rodolfo Isabelino y otros c/ Compañía de Ahorro y Capitalización S.A. (en liquidación) s/ dif. de haberes, Año 1951.

${ }^{57}$ En estos casos el cumplimiento del art. 12 del decreto 12.366/45.
} 
retribuciones a que tenía derecho. Su caso es, pues, idéntico al de los actores y no podría justificarse una solución distinta ${ }^{58}$

Los abogados laboralistas en este caso conociendo las resoluciones previas de los tribunales incluso arriesgaron a solicitar la mediación, que finalmente consiguieron.

La presencia de los abogados se debe pensar, tal vez, incluso previo a la existencia misma de la causa judicial. En el plano de la suposición se puede pensar en el consejo del abogado a los trabajadores. Las causas que se iniciaron en el fuero durante estos años, principalmente las que se referían a despidos, aunque no exclusivamente, suelen contar con instancias previas de negociación entre ambas partes que quedan registradas en los telegramas que se cruzan al momento del conflicto. Es significativo que muchos telegramas tienen fechas anteriores a la firma de la Carta Poder -momento este en el que se puede certificar la relación de los abogados con los trabajadores-. Considerando que muchas veces el telegrama se convirtió en la prueba fundamental para determinara tanto la relación de dependencia existente como los motivos de la cesantía (despido o abandono de trabajo), se podría sostener la existencia de una asesoría legal previa que permitiese después la construcción de una demanda fundamentada en el derecho.

Es clara la importancia de los abogados, como aquellos que ajustan las demandas -en el caso de los trabajadores- a la ley y la jurisprudencia. Sus servicios eran ofrecidos de diversas maneras, pero la experiencia misma de los trabajadores parece haber sido una buena forma de conseguir los servicios de los letrados. Por otro lado no es de extrañar que los mismos letrados estuviesen interesados en ofrecer sus servicios cuando veían que los derechos que reclamaban ante el tribunal les eran concedidos. Claro que en el logro de sus fines debieron enfrentar a otros abogados que representaban a la parte patronal en su búsqueda de tener el derecho de dictar el derecho.

\section{V.3.3 Los abogados de la patronal}

Si los trabajadores contaban con un grupo de abogados, los laboralistas, dispuestos a dar forma al reclamo en un lenguaje jurídico, los patrones no

\footnotetext{
${ }^{58} \mathrm{DH}$ 103/2 Foja 21 vuelta.
} 
contaron con esa opción. En tanto fuero sencillo en términos procesales los abogados no parecían dispuestos a rechazar lo que implicaba un trabajo seguro. A diferencia de lo que ocurre con los abogados laboralistas, la presencia de abogados patronales es más difícil de distinguir si se tiene en cuenta la danza de nombres que se encuentran detrás de las defensas patronales.

La forma en que actuaban los abogados patronales difería de la de los laboralistas y una constante era la utilización en las defensas de argumentos que excedían o que al menos no provenían del derecho Laboral. Si para Emilio Sigwald y Benito Cerruti Costa en las causas reseñadas las normas del ejecutivo tenían peso de ley, para los abogados de los demandados ${ }^{59}$ la cuestión era más bien simple: la Dirección de Acción Social Directa no estaba autorizada a imponer aumentos de salarios, ni condiciones laborales. Si la demanda apuntaba a la aceptación tácita por parte de los empleadores- al haber llevado a cabo alguno de los puntos de la resolución- como fundamento de la capacidad del Poder Ejecutivo de dictar normas, la contestación del traslado apuntaba a negar cualquier derecho de dicha institución de establecer nuevas escalas de trabajo. En la contestación de la demanda que le interpusieron Enrique Lignasse y Enrique López a Carlos Regioso ${ }^{60}$, el abogado de la parte demandada, Luís Morzone, desconoció la validez de la norma emitida por la Dirección de Acción Social Directa, al carecer esta de imperium. Además sostuvo que era ilegal y contraria a los preceptos constitucionales, ya que no estaba autorizada a emitir normas obligatorias, según lo estableció el decreto de su creación. Ante un escenario institucional nuevo, el abogado de la demandada estaba buscando definir los límites, incluso constitucionales, de las medidas adoptadas. En una cuestión de derecho, como la aquí planteada, se jugaba la capacidad del Poder Ejecutivo de imponer las normas que consideraba necesarias para el bien común.

\footnotetext{
59 A pesar de que los demandados son diferentes, y lo mismo los abogados que los representan ante la justicia, las acciones interpuestas son casi coincidentes. La mayoría de los abogados que defienden a los establecimientos panaderos sostiene la inconstitucionalidad de la medida dictada por la Dirección de Acción Social Directa. Entre los abogados de la parte patronal se destacan en varias causas Antonio Morzone y Jorge Romano Yalour, al parecer socios en un estudio de abogados. Yalour es uno de los principales representantes de patrones durante los primeros años de funcionamiento de la justicia laboral.

${ }^{60} \mathrm{DH}$ 102/10 Lignasi Enrique y otro c/ Carlos Regioso s/ Cobro de pesos, Año 1950.
} 
Las palabras de Morzone, volcadas en su escrito, hasta parecen advertir a los funcionarios de la Dirección de Acción Social Directa cuáles eran sus límites. Sostiene que si la medida adoptada era ilegal y anticonstitucional, en cambio el organismo

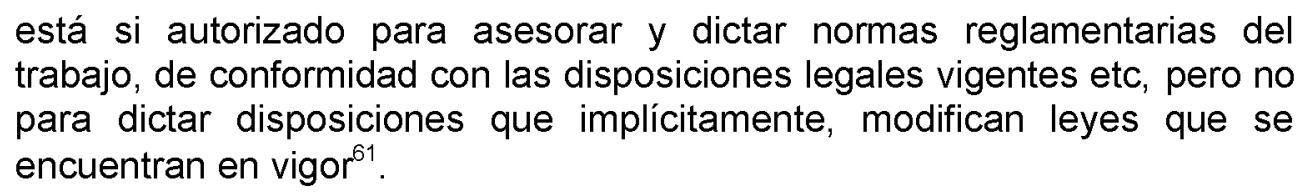
trabajo, de conformidad con las disposiciones legales vigentes etc, pero no para dictar disposiciones que implícitamente, modifican leyes que se encuentran en vigor ${ }^{61}$.

Aceptaba la intervención del Estado en la regulación de las relaciones entre el capital y el trabajo, pero dejó bien en claro cuáles son los limites en los que dicha intervención se podía desenvolver. Los límites de la intervención social, pensada en términos colectivos, son los derechos individuales establecidos en la Constitución, en este caso, los derechos del dueño de la panadería, Carlos Regioso. Desgraciadamente esta causa, como las otras iniciadas por otros obreros panaderos bajo el amparo de la resolución de la Dirección de Acción Social Directa, no llegó a ser resulta por los jueces ya que González desistió del juicio y dejó sin efecto la demanda instaurada.

Como en otras causas, la defensa de los patrones no fue abordada desde los lineamientos del derecho laboral, sino en base a las inconstitucionalidades o excesos que se contenía en la creciente legislación social. Los abogados de las patronales buscaron poner coto a la aplicación de la legislación social del período. Estos excesos, para estos protagonistas, terminaban por desvirtuar la idea de justicia y favorecer los intentos sin sustento de lo que en ocasiones aparecen graficados como aventuras jurídicas por parte de los trabajadores.

Las empresas más importantes de la región contaban con abogados en su planta permanente de empleados. Tal era el caso de los frigoríficos de Berisso. En las causas en las que se ven envueltas estas empresas los abogados patrocinantes de la empresa rechazaban la liquidación que se establecía al finalizar las causas ya que no estaban habilitados para cobrar los honorarios al ser empleados en relación de dependencia de sus defendidos. Fue así que estas empresas contaron con especialistas en legislación laboral y legislación de previsión social capaces de oponer seria resistencia a las pretensiones legales de los trabajadores.

${ }^{61} \mathrm{DH} 102 / 10$, foja 11 vuelta. 
Las armas más habituales de las empresas para logar el desestimiento de la acción era recurrir a la Suprema Corte. Como instancia única, los Tribunales del Trabajo sólo contaban con la apelación en la instancia de Corte. En tres de las cuatro ${ }^{62}$ causas que se conservan que envuelve a alguna de las dos empresas frigoríficas (Armour y Swift) cuentan con al menos un intento de elevación a Corte, siendo la única en la que no se intenta en la que el tribunal falló a favor del Frigorífico Armour ${ }^{63}$. Aunque sólo prosperó en un caso la elevación a la Suprema Corte y esta terminó ratificando la sentencia de la primera instancia favorable al trabajador era significativo que las empresas que contaban con abogados como empleados recurriesen a todas las instancias legales para demorar el proceso.

Incluso antes de llegar a la instancia de sentencia -lo que habilitaba como canal exclusivo de impugnación del fallo a la Corte- durante el proceso, los abogados de estas empresas solicitaban recursos extraordinarios a fin de evitar la demanda o, en el peor de los casos, enlentecer el proceso. De esta manera la práctica judicial de los abogados patronales de las empresas frigoríficas (Jorge Romano Yalour y Manuel Pérez de Vargas) generaba la sensación de imposibilidad de la acción contra el frigorífico. Teniendo en cuenta que la Justicia del Trabajo fue pensada para dotar de un sistema rápido de resolución de los conflictos, la postura que adoptaban los abogados patronales tendió a entorpecer el funcionamiento de la justicia laboral.

En el caso de Jorge Romano Yalour su conocimiento sobre el fuero parece haberlo ayudado en su propia carrera laboral ya que es el abogado que más asiduamente acudió a los Tribunales del Trabajo y siempre como abogado de la parte patronal. Incluso su presencia de alguna manera garantizaba la ralentización del proceso ya que echaba mano de cuanto recurso legal estaba habilitado. Hay que destacar que sus escritos $-y$ por lo general los de los abogados de las patronales- diferían de los escritos de demanda por el nivel jurídico de sus expresiones. Mientras que no era inusual encontrar palabras de

${ }^{62} \mathrm{DH}$ 102/16 Lagorio Beltrán c/Frigorifico Armour de La Plata s/ indemnización por antigüedad, Año 1950; DH 103/3 Lagarde Domingo c/Frigorífico Armour de La Plata s/despido, Año 1951; 103/4 Paita Ángel Anselmo c / Frigorífico Armour de La Plata s/ despido, Año 1951; 103/13 Gambla Teobaldo Oliver c/Cía Swift de la Plata s/despido y preaviso, Año 1953.

${ }^{63} \mathrm{DH}$ 103/4 A pesar de que el motivo que causo la demanda eran idénticos a los de la causa DH 103/3, Ángel Anselmo Paita cometió el error de firmar la renuncia ante informarle la empresa que estaba en condiciones de jubilarse y ese consentimiento anulaba su derecho de reclamar volviendo improcedente la demanda. 
uso coloquial en los escritos de demanda, las contestaciones de Yalour estaban siempre cargadas de formulismos jurídicos y demostraba un amplio conocimiento de la jurisprudencia. Esta situación lleva a reflexionar sobre si los abogados patronales no actuaban también en otros foros, como el civil y comercial, en donde las fórmulas jurídicas eran fundamentales, mientras que los abogados de los trabajadores se dedicaban con cierta exclusividad al fuero laboral.

\section{V.4 Los Jueces}

Le correspondía al tribunal resolver las causas que se le presentaran. El Tribunal Laboral, a diferencia de lo que ocurre en el caso de los juzgados civiles y comerciales o los penales, estaba compuesto por tres jueces que decidían, en una única instancia, la suerte de la demanda. El papel de los jueces era dictar si el reclamo estaba dentro de los marcos de la ley. Pero en los casos en la que los abogados y los jueces discrepaban con respecto a puntos de la causas, siempre estaba la posibilidad de recurrir, mediante apelación, a la Suprema Corte de Justicia de la Provincia de Buenos Aires. En esta instancia los jueces de la Corte solo fallaban con respecto a si el juicio había sido resuelto en el marco de la Constitución Provincial.

La presidencia era rotativa entre los miembros del tribunal, mientras que al momento de emitir los fallos se sorteaba un orden de votación. A pesar de que la conformación en forma de tribunal buscaba evadir el problema de dejar las resoluciones de un conflicto en una sola firma -y por eso se constituían en tribunal tal como las instancias de apelaciones de la justicia civil- en todo el período 1948-1955 no se encuentran grandes disidencias en los Veredictos y los Acuerdos -momentos definitorios de la causa judicial- que precedían a la Sentencia. Esto implicaba que el juez elegido para fundamentar el fallo era secundado por sus compañeros de tribunal que hacían suyas sus razones. Cuando había alguna disidencia esta no era sobre cuestiones de doctrina o jurisprudencia, sino que se refería a las cifras que debían considerarse para el resarcimiento económico.

Desde su constitución a fines de 1948, el Tribunal de Trabajo N¹ de la ciudad de La Plata contará entre sus jueces al Dr. Alberto Montaña, el Dr.Luis Néstor Cabanillas, y el Dr. Miguel Ángel Zorraindo -quien sería reemplazado en 1951 por Víctor Alberto de la Vega, y el Tribunal del Trabajo N² se 
conformó con los Dres. Heberto Amilcar Baños, Jesús Edelmiro Porto y Héctor Rodolfo Demo. El Tribunal $\mathrm{N}^{\circ} 2$ tuvo una alta movilidad de sus jueces y para el final del período (1955) contaba con una conformación totalmente diferente ${ }^{64}$ siendo sus jueces los Dres. Epifanio Carlos Caso, Beatriz Isabel Gómez Roblas y Lisandro Oscar Benavidez. Como ocurriera con los abogados de la Delegación Regional de la Secretaría de Trabajo y Previsión, los jueces parecen haber comenzado su carrera judicial directamente en el fuero laboral. Una revisión de las nóminas del Poder Judicial ${ }^{65}$ de los meses previos a la conformación de los tribunales del trabajo confirma que ninguno de los jueces 0 secretarios designados para ocupar puestos en estos dos tribunales habian ocupado cargos de importancia en el Poder Judicial bonaerense ${ }^{66}$.

Esto parece reforzar la idea de que la justicia del trabajo se abría como un campo de actuación a los "recién llegados" al mundo del derecho. Esto se refuerza si tenemos en cuenta los años en los que se recibieron de la Facultad de Ciencias Jurídicas y Sociales. Luis Néstor Cabanillas se recibió en 1944, sólo 5 años antes de entrar en funciones, Alberto Montaña y Héctor Rodolfo Demo egresaron en 1941, año en el que recibió el título de Doctor Jesús Edelmiro Porto quien había egresado en 1935, 1932 fue el año de egreso de Miguel Ángel Zorraindo, quien contaba con la mayor antigüedad al momento de iniciar la actividad el fuero laboral. Los años de recibidos de Epifanio Carlos Caso y Lisandro Oscar Benavidez son indicativos de la juventud de los jueces laborales y lo meteórico de sus carreras en el Poder Judicial, ya que se recibieron en 1947 y 1948 respectivamente ${ }^{67}$.

La apertura del nuevo fuero brindó, entonces, oportunidades a jóvenes especialistas del derecho que seguramente no habrán encontrado espacios de inserción en los fueros más tradicionales y que requerían, por tanto, una

\footnotetext{
${ }^{64}$ Teniendo en cuenta que el Poder Judicial de la provincia fue intervenido por el Poder ejecutivo nacional en 1952, es necesario aclarar que ninguno de los jueces de ambos tribunales fueron removidos en ese proceso.

${ }^{65}$ La nómina del Poder Judicial, publicada en forma periódica en el Boletín Judicial de la provincia de Buenos Aires. Diario de Jurisprudencia, en adelante Diario de Jurisprudencia permite reconstruir las carreras de los funcionarios judiciales ya que indica quien ocupaba cada cargo jerárquico (jueces, secretarios, fiscales y defensores oficiales) en un determinado momento en cada departamento judicial.

${ }^{66}$ Lo mismo ocurría con los jueces y secretarios designados en los Tribunales del Trabajo de otras jurisdicciones de la provincia de Buenos Aires.

${ }^{67}$ Los datos son extraídos de MINISTERIO DE EDUCACIÓN, Nómina de Egresados... Op. Cit. Los jueces que no se consignan es porque no aparecen en los registros, por lo que se puede asumir que no se recibieron en la Universidad Nacional de La Plata.
} 
carrera más prolongada para acceder al cargo de jueces. La trayectoria del juez Miguel Ángel Zorraindo fue indicativa de las oportunidades que brindaba el nuevo fuero. Inició su carrera judicial en el fuero laboral a casi quince años de haberse recibido y obtuvo a partir de allí varios ascensos ${ }^{86}$ que incluyeron la designación como juez del juzgado Civil $\mathrm{N}^{\circ} 5$ del Departamento de la Capital en 1951 y como vocal de la sala $1^{\circ}$ de la Cámara $2^{\circ}$ de Apelación del mismo departamento para 1952. El paso por el tribunal laboral fue el que abrió las puertas a su ingreso a la carrera judicial. Su ingreso como juez le permitió sortear los escalones previos si hubiese iniciado en el fuero civil y de alguna maner su ingreso como juez laboral le permitió también recuperar los años en los que no tuvo participación en el Poder Judicial. Su carrera -también un dato importante- se vio interrumpida por la autoproclamada Revolución Libertadora que promovió la remoción de los jueces considerados peronistas e implicados con los "males" que aquejaron al Poder Judicial ${ }^{69}$. Las designaciones para ocupar los cargos en el nuevo fuero estuvieron sospechadas por las asociaciones profesionales -como los Colegios de Abogados- a pesar de que fueron realizadas por los mecanismos establecidos por la Constitución ${ }^{70}$. Los jueces fueron promovidos por el acuerdo de las Cámaras -la UCR se abstuvoy la designación de los jueces laborales no difirió de las designaciones de los jueces civiles o penales ${ }^{71}$.

En el caso de los jueces laborales estos fueron puestos en funciones por la Suprema Corte de Justicia de la provincia de Buenos Aires una vez que fue aprobada, por medio del Acuerdo $N^{\circ} 1144$ del 29 de Octubre de 1948, la instalación definitiva de los Tribunales del Trabajo. En el mismo acuerdo consta el acta de designación de los funcionarios de todo el sistema de justicia laboral de la provincia y el juramento de los mismos, que iniciarían sus funciones el $1^{\circ}$ de Diciembre de ese año ${ }^{72}$.

\footnotetext{
${ }^{68}$ Teniendo en cuenta la escala de prestigio que se sostiene en el campo jurídico el paso de una justicia menor como la laboral al fuero civil -el de mayor tradición y prestigio- implica un verdadero ascenso.

${ }^{69}$ Diario de Jurisprudencia, ediciones del 23 de Septiembre de 1951, Pp. 632; del 18 de diciembre de 1952 Pp. 920 y del 17 de noviembre de 1955 Pp. 825.

${ }^{70}$ MARCILESE José, El Poder Judicial bonaerense... Op. Cit. Pp.5 y sig.

${ }^{71}$ El gobernador Mercante inició un proceso de recomposición del Poder Judicial que implicó remoción de jueces designados tanto en la "década infame" como con posterioridad al golpe de Estado del 4 de Junio de 1943. Ibídem, Pp. 4.

${ }^{72}$ El mismo acuerdo estableció las pautas a seguir con los casos iniciados con anterioridad al $1^{\circ}$ de diciembre de 1948 que quedaron en los juzgados donde se iniciaron las causas si es que
} 
Más allá de haber seguido los pasos establecidos por la Constitución provincial, el reclamo de las asociaciones profesionales reflejadas en la prensa se sustentaba en la falta de antigüedad y experiencia de los jueces comprobado por los datos de los años de recibidos-, pero debe tenerse en cuenta la importancia que para el proyecto peronista tenía la administración de justicia.

El lugar que ocuparon los jueces en el proceso político que significó el peronismo es fundamental para comprender la práctica jurídica misma de los Tribunales del Trabajo. En tanto funcionarios de la Nueva Argentina los jueces debían también llevar adelante los preceptos de la doctrina justicialista además de aplicar la ley, o aplicar la ley interpretándola por medio de la doctrina justicialista. Siendo el eje de la doctrina justicialista la Justicia Social, los jueces laborales fueron especialmente sindicados como agentes del cambio. La vinculación de estos con la una de las máximas discursivas del peronismo es incluso previa a la intervención del Poder Judicial de la provincia de Julio de 1952 promovida por el gobernador Carlos Aloe que reemplazó a Mercante al frente de la primer magistratura provincial ese mismo año.

La intervención del Poder Judicial es el eje sobre el que se sostienen las interpretaciones que avalan la idea del sometimiento del judicial a las autoridades del Poder Ejecutivo nacional. La sucesión de intervenciones a los poderes judiciales provinciales fue percibido como una avanzada del peronismo sobre la justicia. Sin desdeñar estas interpretaciones para el caso de la justicia laboral es interesante remarcar que los jueces laborales continuaron en sus funciones a pesar de la intervención y no fueron desplazados. Si se tiene en cuenta que la intervención fue concebida para superar

un supuesto estado de anormalidad que afectaba el desempeño de los magistrados provinciales y asumía el objetivo de alcanzar una "reorganización" luego de la cual se restablecería su normal funcionamiento. ${ }^{73}$

Se puede asumir que la estructura que logró la intervención era la deseada por las autoridades peronistas. Por tanto si los jueces y secretarios de los tribunales del trabajo no fueron desplazadso se puede asumir que fueron

estas ya habían sido aceptadas por el tribunal de origen. "Acuerdo $\mathrm{N}^{\circ} 1144$ ", Acuerdos y Sentencias dictados por la Suprema Corte de Justicia de la provincia de Buenos Aires, Tomo V, Imprenta de la Dirección General de Rentas, La Plata, 1951. Pags. 101 y sig.

${ }^{73}$ MARCILESE José, El Poder Judicial bonaerense... Op. Cit. Pp.7. 
considerados por las autoridades de la intervención -el interventor fue el Dr. Rodríguez De Felipe- como jueces probos para la Argentina peronista.

En Agosto de 1954 por medio de una ley provincial se crearon nuevos departamentos judiciales y Mar del Plata fue elegida para ser sede departamental. La inauguración del Departamento Mar del Plata corrió por cuenta del entonces gobernador de la provincia, Carlos Aloé, quien al dirigirse a la concurrencia el 12 de Febrero de $1955^{74}$ sostuvo sobre los jueces que ocuparían las diferentes magistraturas que

son hombres que viene circunstanciados con los principios de la Doctrina Nacional y que, como todos los que están identificados con su pueblo, que sienten como siente el pueblo y piensan como piensa el pueblo, son leales y fieles intérpretes de la nueva mística, del nuevo sentimiento de la Argentina de Perón. Un juez no puede vivir apartado de la realidad de su pueblo, ni puede vivir apartado de los principios doctrinarios que han inspirado la ley que debe aplicar ${ }^{75}$

Al igual que en el Poder Ejecutivo, los funcionarios del sistema judicial debían adherir a los postulados de la Doctrina Justicialista mediante la afiliación al partido ${ }^{76}$ y los jueces ya no sólo debían contar con las herramientas que por medio del estudio habían adquirido para el desarrollo de su profesión. La Doctrina justicialista y sus pilares debían ser sostenidos por todos los funcionarios estatales, siguiendo el ejemplo de Perón. La identificación de Perón con la Nueva Argentina y de los funcionarios con Perón, exigía de estos que actuasen como el líder, atentos siempre a la consideración de las demandas sociales. Así, para Febrero de 1955, sostenía Aloé: "los jueces de Perón no son los jueces fríos de la toga y el Código, sino jueces humanistas con profundo sentimiento humano, como es el espíritu de la

\footnotetext{
${ }^{74}$ El acto estaba inicialmente programado para el 2 de Febrero, fecha de inicio de la actividad judicial de ese año y primer día de funcionamiento del Departamento Judicial Mar del Plata. Por cuestiones de agenda del gobernador la inauguración se llevó a cabo finalmente el sábado 12.

${ }^{75}$ Alocución del gobernador de la provincia de Buenos Aires, Carlos Aloé, con motivo de la inauguración del Departamento Judicial Mar del Plata. Diario El Día, 13/2/1955, Pp. 3.

${ }^{76}$ Por medio de la resolución del interventor del Poder Judicial bonaerense del 31 de julio de 1952 se dejó sin efecto las acordadas y resoluciones que impedían la libre afiliación política de los magistrados, funcionarios y empleados de todo el Poder Judicial. Si bien no implicaba la afiliación compulsiva al partido gobernante, abría las puertas para dicho proceso. Diario de Jurisprudencia, edición del $1^{\circ}$ de Diciembre de 1952. Pp. 871.
} 
Justicia Social"77. La Nueva Argentina no era lugar para la fría letra de la ley, sino para la innovación doctrinaria ${ }^{78}$.

A fin de lograr esta comunión entre los postulados de la Doctrina Justicialista y la resolución de los jueces en la aplicación de la ley se utilizaron diferentes mecanismos. La adhesión partidaria significó un paso importante en este sentido aunque a fin de lograr jueces que actuasen con el Código en la mano, pero la Doctrina en el alma y el corazón, no fue suficiente. En el caso de la provincia de Buenos Aires la separación entre los jueces y la doctrina promovió que el Poder Ejecutivo Nacional, por pedido del gobernador Aloé, interviniese el Poder Judicial bonaerense en 1952.

Como se mencionó esta intervención promovió fuertes desplazamientos del personal del Poder Judicial. Sin embargo es de destacarse que durante el proceso de intervención los Tribunales del Trabajo de la ciudad de La Plata no se vieron afectados, aunque debieron aplazar la resolución de varias causas. En términos de la Comisión Nacional de Investigaciones "removió a los antiguos magistrados y los reemplazó por otros totalmente adictos" ${ }^{79}$.

Esta intervención implicaba la concreción de su proyecto político hacia el interior de una burocracia estatal reacia al cambio. Las pretensiones, entonces, de jueces en conexión con la realidad social, se sostenían sobre las designaciones realizadas por una intervención federal sobre el Poder Judicial que no afectó profundamente al fuero laboral. Sobre este dato se pude suponer que la adhesión de los jueces laborales a la doctrina peronista o a los

\footnotetext{
${ }^{77}$ Alocución del gobernador de la provincia de Buenos Aires, Carlos Aloé, con motivo de la inauguración del Departamento Judicial Mar del Plata. Diario El Día, 13/2/1955, Pp. 3.

${ }^{78}$ Sobre la importancia de la innovación doctrinaria para construir la Nueva Argentina véase BERROTARÁN, Patricia M., Educar al funcionario... Op. Cit.

${ }_{79}$ Comisión Nacional Investigadora, Libro negro de la Segunda Tiranía, Comisión de la afirmación de la Revolución Libertadora, Buenos Aires, 1987, Pp. 119. El sometimiento de los jueces por parte del Poder Ejecutivo se basaba en las renuncias que sin fecha debieron presentar los jueces nombrados por la intervención al gobernador Carlos Aloé. Muchas de ellas hacían referencia a su adhesión a los postulados de la Doctrina Justicialista, al partido peronista o expresaban su lealtad personal a Perón ${ }^{79}$. Los textos de las renuncias se le solicitaban a prácticamente todos los escalafones del Poder Judicial. Estas renuncias fueron el puntapié para la acusación de peronización de la justicia que hiciese la Comisión Nacional Investigadora. Al romper con la tradición judicial de inamovilidad de los jueces mediante el pedido de renuncia firmado previo a su aceptación al cargo, se suponía que los jueces no tendrían muchas posibilidades de fallar en contra de los intereses del gobierno, ya que hacerlo hubiese significado perder su puesto. Aun así la misma comisión sostuvo que no todos los magistrados fallaron según se les solicitaba, aunque algunos casos resonantes -como la expropiación del grupo Bemberg y la situación del Departamento Judicial San Nicolás ${ }^{79}$ - eran lo suficientemente claros para demostrar las complicidades de los magistrados peronistas en el sostenimiento del aparato totalitario con el que se acusaba al peronismo.
} 
postulados que esta sostenía era previo a la intervención que propiciaba justamente esos objetivos. Tal vez el origen de la justicia laboral en el período peronista se pueda pensar como una marca de nacimiento difícil de borrar.

Los resultados de esta intervención fueron los que permitieron el discurso del gobernador Aloé en la inauguración del Departamento Judicial Mar del Plata, cuyos argumentos pueden ser aplicados al Poder Judicial bonaerense, - los que sostuvo el ministro Ángel Borlenghi -en un tono más liberal- en ocasión de la inauguración del año judicial en 1955. En su discurso y refiriéndose a las capacidades de los señores jueces y su repercusión decía

por sobre todas las jerarquías, los magistrados han de merecer aquella nacida espontáneamente del juicio de sus conciudadanos al saberlos ajenos a las banderias, pero no encerrados en una torre de marfil. Los libros y los expedientes no han de levantarse cual un muro entre el magistrado y la vida. Tenemos confianza en nuestra justicia y en nuestros jueces. Cada vez observamos con mayor satisfacción que estos son patriotas, estudiosos, honestos, justos y que en sus fallos alienta la Doctrina Nacional Peronista ${ }^{80}$

Esto le permitía expresar "la complacencia con que el Poder Ejecutivo observa el desempeño de los señores magistrados y demás integrantes de la administración de justicia." 81 . Percibida la adhesión a la Doctrina Justicialista como un bien necesario para romper la torre de marfil durante el gobierno peronista, esta misma adhesión sería la base para que sus adversarios sostuvieran que el peronismo sólo había sido justo para los suyos mientras que al enemigo ni justicia, sino sólo arbitrariedad ${ }^{82}$

En oportunidad de la inauguración del año judicial de ese año de 1955 la comunión de los magistrados con el peronismo se expresó en el almuerzo que Juan Domingo Perón mantuvo con los magistrados nacionales y algunos provinciales -la nota periodística da cuenta de que los miembros del Poder Judicial se encontraban en gran número-. Perón les agradeció la misión que cumplían los magistrados "al ir enseñando nuestra doctrina en todos los procedimientos" ${ }^{\prime 3}$. El presidente de la Suprema Corte de Justicia, el Dr. Valenzuela aprovechó la ocasión para solicitarle la creación de una escuela Superior de Justicia, en consonancia con otras instituciones que existía en la

\footnotetext{
${ }^{80}$ Discurso de Ángel Borlenghi. "Inauguración del año judicial", El Día, 2/2/1955, Pp. 3.

${ }^{81}$ Ibídem.

${ }^{82}$ Acusaciones vertidas en el ya citado Libro Negro de la Segunda Tiranía.

83 "El primer mandatario recibió la visita de los magistrados de toda la república", El Día, 3/2/1955, Pp3.
} 
época a fin de que "los hombres que abrazan esta carrera puedan ir formándose dentro del espíritu de la doctrina Nacional, que es la ley de la Nación" "84. La conformación de esta institución era una medida acorde con los motivos que habían provocado la intervención del Poder Judicial bonaerense. Esta se había justificado por

falta de interpretación de la Constitución de 1949 y de las leyes de justicia social, corruptelas de diversa índole y, en general, un sentimiento popular de desconfianza que hacía pensar que el poder encargado de hacerlo no tutelaba ni vigilaba los auténticos intereses de la comunidad, trajeron como resultado inevitable, y buscando una solución drástica e inmediata, la necesidad de la intervención. ${ }^{85}$

En definitiva el ajuste de la estructura del Poder Judicial a los pilares ideológicos del Justicialismo se sostuvo fuertemente en la cesantía y designación de nuevos magistrados por medio de la intervención, y la búsqueda de vinculaciones de los magistrados con las ideas justicialistas, expresadas en la caída de la torre de marfil y la vinculación de los magistrados con los problemas sociales. Sin lugar a dudas este proceso puede ser entendido como un proceso de subordinación y pérdida de independencia con respecto a las autoridades del Poder Ejecutivo ${ }^{66}$, tanto nacional como provincial. De todas maneras, la contextualización del proceso, en donde la Doctrina Justicialista había sido homologada como Doctrina Nacional a través de la Constitución de 1949, permite pensar un avance justificado por los cambios que la alianza de fuerzas gobernante quería imponer en todos los órdenes.

El hecho de que los jueces laborales no fuesen cesados en sus funciones por la intervención de 1952 del Poder Judicial bonaerense es un dato fundamental para considerar si la justicia del trabajo no era efectivamente la herramienta de concreción de la Justicia Social. Los jueces del Tribunal del Trabajo $\mathrm{N}^{\circ} 1$ no simplemente permanecieron en sus cargos sino que debieron tomar obligaciones en el fuero civil durante el proceso de intervención. Así de

\footnotetext{
${ }^{84}$ Ibidem.

${ }^{85}$ Información suministrada por el interventor del Poder Judicial de la Provincia de Buenos Aires, Dr. Rodríguez de Felipe al jefe de la Coordinación de Informaciones de la provincia de Buenos Aires, mayor don Alberto Bialade en Noviembre de 1954 al finalizar la intervención. Citado como prueba en Comisión Nacional de Investigaciones, Vicepresidencia de la Nación, Documentación, autores y cómplices de las irregularidades cometidas durante la Segunda Tiranía, Tomo I, Buenos Aires, 1958. Comisión № 15, Román A. Subiza.

${ }^{86}$ MARCILESE José, El Poder Judicial bonaerense... Op. Cit.
} 
manera rotativa los tres jueces fueron reemplazados en ocasiones ya que estaban designados en los juzgados civiles de la ciudad.

La actuación de los jueces suele en parte justificar su decripción como funcionarios de la Nueva Argentina en la medida en que asumieron plenamente sus potestades para buscar aplicar la Justicia Social. En el caso de la causa que involucra a Lagorio Beltrán y el Frigorífico Armour de La Plata $^{87}$ se puede percibir la forma en que los jueces buscaron promover los derechos de los trabajadores o incluso ampliar los sujetos a los que las leyes y disposiciones laborales hacían referencia. En esta causa el actor reclama el pago de indemnización por despido y antigüedad al frigorífico, ya que este lo despidió porque consideró que el obrero estaba en condiciones de recibir la jubilación ordinaria íntegra, al contar con la edad y los años de aporte. Pero los abogados de Beltrán interponen la demanda porque el frigorífico no consultó previamente a la medida de despido si el actor tenía acreditado esos hechos en el Instituto Nacional de Previsión Social. Por lo tanto al despedirlo sin tener la confirmación del Instituto, la empresa no podía adherirse al decreto $31.665 / 44$ que dispone, en su artículo 32 que las personas con 30 años de servicios y 55 de edad pueden obtener su jubilación ordinaria íntegra mientras que el artículo 58 dispone que en el despido de empleados en condiciones de obtener jubilación queda eximido del pago de indemnización por antigüedad.

La sentencia del Tribunal que condena al frigorífico a pagar al actor la indemnización por despido y antigüedad, tomando como central que la empresa no haya esperado la respuesta oficial del Instituto ni haya enviado notificación para enterarse del estado del trabajador. Ante este veredicto el abogado del frigorífico, nuevamente el Dr. Romano Yalour, interpondrá un recurso de inaplicabilidad de la ley y violación de la Constitución Nacional y la Constitución de la Provincia de Buenos Aires. Actúa de este modo porque considera que las razones que sostiene el veredicto son anticonstitucionales, ya que no se puede adoptar como jurisprudencia sentencias de la Corte Suprema de Justicia de la Nación mientras no se reglamente el recurso de

${ }^{87}$ DH 102/16 Beltrán Lagorio c/ Frigorifico Armour S.A. de La Plata s/ indem. Despido. Antigüedad, Año 1950. 
casación $^{88}$, tal como lo establece el artículo 95 de la Carta Magna. Además cita fallo de la Suprema Corte de la Provincia que reza:

contraría principios de economía procesal, la insistencia de los Tribunales inferiores en interpretaciones contraria a la que priva en la Corte de Buenos Aires, cuya jurisprudencia constituye la doctrina legal. Por otra parte la opinión de los magistrados debe aportar argumentos jurídicos nuevos susceptibles de reparar los supuestos errores de la doctrina legal ${ }^{89}$.

La chance de Yalour está en declarar la inaplicabilidad de la ley al proceso y evitar el pago.

Pero lo que interesa en este punto no es la resolución que finalmente terminará adoptando la Suprema Corte ${ }^{90}$, sino el papel que jugaban los jueces. Nótese que al referirse al fallo de la misma Suprema Corte hace alusión a la "economía procesal". Esto es así porque en su veredicto, el Tribunal Laboral N¹ adoptará como suyo un fallo de la Corte Suprema de Justicia Nacional por eso tilda de inconstitucional el proceso al violar el art. 95-. Hay que tener en cuenta que uno de los motivos que llevó a la creación de los Tribunales Laborales como una institución independiente de la justicia civil y comercial era facilitar el acceso de los trabajadores a la justicia, y esto incluía acortar los tiempos procesales ${ }^{91}$. Los jueces del Tribunal, al fallar utilizando un fallo de la Corte Nacional, están yendo más allá de lo que permite la estructura jerárquica y piramidal que fija el organigrama del Poder Judicial.

El juez, en el campo laboral, no se ajustó a lo que sostiene Line Schjolden en las conclusiones de su tesis. Esta autora concluye que con la llegada de Juan Domingo Perón a la presidencia y el establecimiento de los juzgados y tribunales laborales, el rol de las cortes cambió de "hacer"92 la ley ante el vacío existente a aplicarla. Sin embargo en el caso citado se observó que la ley aun no estaba del todo definida como para que los jueces se pudiesen limitar simplemente a aplicarla. Al contrario de lo que sostiene la investigadora

${ }^{88}$ La Casación es el paso previo a la Corte Suprema de Justicia de la Nación.

$89 \mathrm{DH}$ 102/16 foja 53 vuelta, el fallo citado por Romano Yalour es de la causa "Molnar Miguel c/ Inga Fábrica de Aceites", citado en La Ley, el 4 de Junio de 1950.

90 La Suprema Corte terminará negando el recurso de inaplicabilidad de la ley con los votos negativos de los Dres. Brunet, Illescas, Demaría Massey y Escobar Saenz. Mientras que los Dres. Giardulli, Ramirez Gronda y su presidente Moreno Hueyo sí dan lugar al recurso, aunque al encontrarse en minoría este no prospera.

91 Las causas, incluso cuando llega a instancias de Suprema Corte, son resueltas en un lapso no mayor al año.

92 Durante su tesis Schjolden sostiene que al dar interpretaciones novedosas a las leyes y los Códigos, los jueces "crearon" la ley mediante el establecimiento de la jurisprudencia. 
noruega, la masiva promulgación de leyes, decretos, resoluciones y derechos no parece haber acabado con la necesidad de los jueces de tener que dar su propia interpretación sino que la potenció.

Justamente la maraña legal en la que debían resolver hacía difícil construir la jurisprudencia sobre bases sólidas. A pesar del fallo citado por el abogado de la parte demandada, y que tiene fecha de publicado del año 1950, la Suprema Corte se pronunció a favor de la parte actora el 31 de Diciembre de 1951, menos de dos años después del fallo contrario anterior.

En este contexto, las interpretaciones que de la ley pudiesen hacer los tribunales estaban creando jurisprudencia en un campo en donde la mayoría de la legislación era reciente. Por lo tanto el papel que les tocó a los jueces fue importante ya que en su camino iban trazando hasta donde llegaban los derechos de los trabadores, y en última instancia señalaba los límites de la justicia social.

\section{V.5 Conclusiones}

Los actores aquí presentados tenían garantizado su identificación mediante el saber "técnico". A diferencia de lo que ocurría con los abogados, los peritos, y menos aun los jueces, los trabajadores debía demostrar mediante la ley que podían actuar en el foro, según consta en el próximo capítulo.

En este entramado, la figura del abogado resalta por su centralidad, ya que en calidad de "primer juez" era el encargado de adaptar los requerimientos de sus representados, sin duda conscientes del "derecho" que los avalaba, a la letra de la ley. Convencidos de la necesidad de llevar la causa ante el estrado $y$, sobre todo en el caso de aquellos abogados que también eran funcionarios estatales, empujados por la fuerza de un contexto que colocaba la construcción de la justicia social en el centro de su retórica, estos sujetos no escatimaron en recursos para construir una jurisprudencia que permitiera ampliar las leyes para lograr su universalización.

El campo jurídico, con sus reglas y disputas de poder simbólico, estableció para el caso de la justicia laboral, una clasificación a los abogados que actuaban en el fuero. Así a los abogados laboralistas que sólo se dedicaban a defender los intereses de los trabajadores, y a los funcionarios de la Delegación Regional de la Secretaría de Trabajo y Previsión debe 
contraponerse la figura del abogado patronal. Aunque algunos de estos abogados eran empleados de las empresas -tal el caso de los abogados de las industrias frigoríficas- muchos de los abogados de la parte patronal parecen haber defendido a los patrones como cualquier otra causa. Interesó resaltar en estos casos lo que implicaba la creación de un nuevo fuero tanto para los que percibieron en dicha acción la construcción de un espacio donde desarrollar su actividad -su misión en algunos casos- o los que simplemente actuaban en el fuero laboral como en cualquier otro. Las distinciones del campo se percibieron, entre otros signos, por el lenguaje utilizado por los profesionales en la construcción del relato y de la argumentación de los derechos que amparaban a su parte. Los abogados de la patronal demostraron una mayor predisposición a citar jurisprudencia y legislación específica, mientras que los laboralistas acudieron a un lenguaje más llano coincidente con la pretensión de acercar la justicia a los trabajadores.

En una situación similar se encontraban los jueces, conscientes de que su lugar -y su autoridad- en la estructura jerárquica del Poder Judicial se debía a su capacidad para vincular sus sentencias a la letra de la ley, debieron dar cuenta de las innovaciones doctrinarias pero sin negar la importancia de la jurisprudencia previa, ya que allí residía en parte su propio poder. En la tensión entre la innovación y la tradición, debieron abocarse a la resolución de conflictos generados en un ámbito recientemente legislado. La misma novedad les permitió ir adaptando sus soluciones a situaciones nuevas. La falta de una jurisprudencia clara los colocó en un papel importante en lo relativo a las generaciones futuras, ya que fueron sus fallos los que marcaron las interpretaciones que correspondía hacer en la maraña de leyes, decretos y resoluciones recientes -muchas de ellas contradictorias entre sí- producto del gobierno de Juan Domingo Perón.

Pero al mismo tiempo para los jueces la apertura de un nuevo espacio como el que representó la justicia laboral implicó la posibilidad de iniciar una carrera dentro del Poder Judicial. En su mayoría jóvenes, su designación, aun cuando siguió los canales institucionales establecidos, implicó un enfrentamiento entre las autoridades y algunas asociaciones profesionales del fuero -principalmente los Colegios de Abogados-. En el caso de los Tribunales del Trabajo se estableció la vinculación de los jueces allí designados con la 
Justicia Social, el ideal de la época. Su continuidad en el cargo al momento de ser intervenido el Poder Judicial bonaerense en Julio de 1952 por pedido de los legisladores peronistas y del gobernador Alóe, demostró la comunión de estos magistrados con el ideario justicialista. Además la trayectoria significativa del Dr. Miguel Ángel Zorraindo permitió reconstruir el ascenso de segundas líneas o de nuevos actores en el Poder judicial mediante su carrera iniciada en el fuero laboral.

En el caso de los testigos se resaltó la figura del perito contador, ya que su testimonio era central a la hora de determinar el veredicto y la sentencia. La ausencia de los testigos no especializados se debió a cuestiones de elección metodológica. Poco es lo que se puede decir de los testigos debido a que el lugar que ocupan en esa institución que es el expediente ${ }^{93}$ los margina a unas pocas líneas donde consta su nombre, su edad, y su profesión. Aun así eran citados a absolver posiciones, pero su testimonio no tenía la fuerza del testimonio ofrecido por el testigo preferencial, el perito contable.

Las causas laborales envuelven dentro de si toda una serie de relaciones que pone en tensión el lugar que cada actor, en su accionar consciente, ocupa dentro del mundo judicial. El capítulo siguiente dará cuenta de cómo influye en este mundo la experiencia de los actores legos, los trabajadores y patrones, al entrar en contacto y ser interpelados por diferentes instituciones, fundamentalmente la judicial.

93 Para relevar la importancia que tiene el control de la "construcción" del expediente, y el fuerte lugar simbólico que dicho elemento aun tiene en el mundo judicial, ver: MARTINEZ Josefina, "La guerra de las fotocopias. Escritura y poder en las prácticas judiciales" en PALACIO Juan Manuel y CANDIOTI Magdalena (compiladores), Justicia, política y derecho en América Latina, Prometeo, Buenos Aires, 2007. 


\section{CAPÍTULO VI \\ TRABAJADORES Y PATRONES EN LA JUSTICIA DEL \\ TRABAJO}

"... al convertir de ese modo al individuo

En el alfa y el omega del pensamiento Jurídico, se olvida la única certeza que Puede aportar el estudio del derecho: No hay identidad sin límites, y quien no Encuentre sus límites dentro de si Los hallará en el exterior"1

Alain Supliot

\section{Introducción}

Toda la construcción institucional de los Tribunales del Trabajo tenía como objetivo poner frente a frente, en un ambiente regulado, a los trabajadores y sus patrones a fin de evitar que los conflictos no encontrasen cauce y desbordaran el orden establecido. Sin embargo la Justicia del Trabajo, fundada sobre la desigualación legal a fin de igualar, no podía ser percibida de la misma manera por los obreros -el centro sobre el que se construía toda la institución- y los patrones. Estas formas divergentes de concebirse frente a la institución judicial impactó de manera directa en las estrategias utilizadas por los contendientes a fin de lograr que la justicia fallase a su favor.

El presente capítulo busca indagar sobre la forma en que estos actores enfrentados en términos de la relación que comparten hicieron uso de la institución judicial. Esto permite reconstruir el espacio de disputa que significaron los Tribunales del Trabajo pero además reflexionar sobre el conflicto mismo que reflejan los expedientes judiciales laborales. El análisis cualitativo de las causas busca dar cuenta de las problemáticas más importantes que atravesaron a la institución durante los años del peronismo clásico.

La inclusión de los contendientes se propuso, desde la sanción de la ley 5178 , en el marco de la individualización de los actores. A pesar de tratar de resolver los conflictos derivados de la relación laboral que oponía a dos clases sociales diferenciadas, los Tribunales del Trabajo estaban no buscaba resolver el enfrentamiento en tanto colectivo, sino individual. Así, no enfrentaba a los

\footnotetext{
1 "Prólogo", SUPIOT Alain, Op.Ccit.
} 
trabajadores con los patrones, sino que colocaba frente a frente al trabajador $X$ contra el patrón Y. Sin embargo al abordar el análisis de las causas se comprobó que este proceso de individualización encontró límites en la conformación misma de los actores como sujetos de derechos que no pueden ser desestimadas. Y a pesar de la voluntad explícita de excluir instancias colectivas -como ser los sindicatos- estos ejercerían un papel importante en el camino a la concreción de los derechos. La trayectoria de los trabajadores en el camino de concretar sus derechos permite, de esta manera, matizar el proceso de individualización y tal vez pensar la justicia laboral como una instancia donde el conflicto que se tiende a resolver no es entre dos sujetos libres y autónomos como era el caso de la Justicia Civil.

El camino a lograr la satisfacción de sus derechos, los trabajadores tenían que constituirse como parte en el conflicto y esta construcción es un punto central del capítulo. Además también se busca reconocer la utilización de distintas redes de solidaridad y al mismo tiempo el entramado institucional montado por el Estado para satisfacer sus demandas.

El expediente judicial

El expediente judicial, que compone la fuente principal sobre la que se sostiene el capítulo, es una fuente que permite proseguir el conflicto en su temporalidad. Las causas generalmente eran iniciadas por los trabajadores mediante la presentación de un escrito de demanda, en el que se vertían los hechos según su versión y los derechos lesionados que fundamentaban la presentación ante la justicia. Una vez notificada la contraparte ${ }^{2}$ contaba con diez días para presentar la contestación de la demanda o traslado. Algunas veces en esa misma ocasión la parte demandada presentaba recursos de excepciones -falta de jurisdicción o competencia, por ejemplo-. Cumplido el plazo procesal si la demandada no presentaba el escrito de traslado se le declaraba en rebeldía y la causa podía definirse sin otorgar la posibilidad de plantear la defensa. De todas maneras incluso en esos casos algunos recursos

\footnotetext{
${ }^{2}$ Las notificaciones estaban a cargo de la policía. En los casos en que el demandado pertenecía a otra jurisdicción -por ejemplo a la capital Federal- las notificaciones se realizaban mediante exhorto a la justicia del trabajo de la jurisdicción en cuestión que debía llevar adelante los diligenciamientos necesarios para cumplimentar con el proceso.
} 
legales, como alegar deficiencias en la notificación, permitieron presentar fuera de plazo. El paso siguiente era otorgar la oportunidad para que la parte actora -quién inicia la demanda- rectifique o amplie la demanda y conteste a los puntos que el traslado rechazó. Lo mimo permitía dar las razones, en caso de que se hubiesen interpuestos recursos, para presentar su argumentación aceptando o rechazando tales recursos. Si existían recursos el tribunal debía resolver los mismos antes de proseguir con las acciones o siquiera contemplar las razones de fondo de la causa.

A partir de allí los pasos procesales implicaban la recolección de las pruebas, el sorteo del perito a ser designado -si este era necesario- la confección de la pericia, citación de testigos y la presentación de las posiciones a absolver $^{3}$ en las Audiencias. En cualquier instancia del pleito, tal como estableció la ley 5178, las partes podian solicitar al tribunal que convocase a Audiencia para llegar a un arreglo amistoso o conciliación. El Tribunal, de todas maneras, estaba obligado a buscar la conciliación previa al inicio de la vista de la causa. Las audiencias, la declaración de los testigos y el intercambio entre las partes eran in voce y no se resguardan en el expediente transcripciones de esos momentos.

Concluida la Audiencia de vista de causa -última instancia para presentar pruebas, rechazar testigos o impugnar las pericias- los jueces pasaban a deliberar a fin de dictar Veredicto y redactar el Acuerdo. Veredicto y Acuerdo momentos donde se decidía la suerte de la causa- eran dictados el mismo día de la Audiencia de Vistas de causa. Mientras que el Veredicto daba cuenta de los hechos de la causa -por ejemplo si tal o cual trabajador fue despedido o abandono el trabajo-, el Acuerdo exponía los fundamentos jurídicos de la determinación del tribunal. Días después (por lo general menos de una semana) se dictaba la Sentencia y en el mismo acto se decidía a quien correspondía las costas del proceso -al patrón o al orden causado- junto con los honorarios de los profesionales intervinientes..

\footnotetext{
${ }^{3}$ Las posiciones a absolver eran preguntas entregadas por las partes en sobre cerrado que se abrían en el momento de la audiencia -en algunas causas que llegaron a conciliación previo a la audiencia aun se mantienen en la actualidad los sobre cerrados-. Generalmente las preguntas apuntaban a los hechos de la demanda. Estas preguntas eran realizadas por los jueces y el declarante se encontraba en esos momentos bajo juramento.
} 
La mayoría de las veces esa era la resolución definitiva de la causa. Pero existía la posibilidad de impugnar la sentencia o el mismo proceso. En esos casos según la medida solicitada -como por ejemplo inaplicabilidad de la ley, inconstitucionalidad, caso federal- el tribunal decidía si era válido el recurso y se lo elevaba a la Suprema Corte de Justicia de la provincia de Buenos Aires o a la corte Suprema de Justicia de la Nación. En esos casos los abogados de ambas partes debían escribir una presentación en la que constaran los motivos por los que se solicitaba la revisión del caso o los argumentos por los que se pedía su rechazo. La instancia superior resolvía la cuestión y enviaba la resolución al tribunal de origen que según el caso ratificaba o modificaba el Veredicto, Acuerdo y Sentencia.

La materialidad del expediente permite seguir la causa en su desarrollo temporal, ya que las distintas actuaciones y los momentos en que se produce cada prueba queda registrado por el orden en el que son cosidas al expediente. Muchas veces las causas judiciales tenían una instancia previa -la delegación regional de la Secretaría de Trabajo y Previsión- y los expedientes allí producidos se agregaba al cuerpo de la causa a "cuerda floja". Esto implica que el expediente administrativo era cosido por fuera del corpus principal y la mayoría de las veces una vez concluida la causa se devolvía a la institución de origen, por lo que las actuaciones en esas instancias puede ser reconstruida por medio de referencias indirectas en el corpus del expediente-por ejemplo mediante la mención en el Veredicto-.

\section{VI.1 El camino a la Justicia del Trabajo}

La ley 5178 habilitaba a los trabajadores y patrones a acudir a los Tribunales del Trabajo sin mediar acción previa. La simple presentación por ante el tribunal era mérito suficiente para ser tenido como parte en el pleito, y a pesar de que posteriormente el trabajador tuviese que demostrar su condición de tal ante el tribunal, esto significó un acercamiento de la justicia a los trabajadores. A fin de garantizar el acceso a la justicia los Tribunales del Trabajo de la provincia de Buenos Aires fueron distribuidos en el territorio bonaerense siguiendo pautas de concentración obrera y dotando al distrito de un nuevo mapa judicial. De esta manera la justicia se acercó a la población que era objeto de su función. 
Sin negar el impacto que los cambios procesales y el lugar físico del asentamiento de los Tribunales del Trabajo tuvo en el real acercamiento de la justicia a los trabajadores, las trayectorias de estos en procura de sus derechos es una buena oportunidad para reconstruir las interacciones entre distintos actores que ayudaron en la promoción de los derechos. Los Tribunales del Trabajo se constituyeron en la meta de un recorrido a la que los trabajadores llegaron, entre otros motivos, por una verdadera difusión discursiva de sus derechos, en la construcción de una cultura legal. Que un trabajador decidiese reclamar lo que consideraba justo en un lenguaje de derechos y acudiendo a una instancia especializada del Poder Judicial -instancia que no fue siempre percibida como suceptible a los reclamos obreros- daba cuenta de un cambio en la cultura legal de los trabajadores.

El establecimiento por sí solo de los Tribunales del Trabajo no puede dar cuenta de este cambio. Sin embargo la trayectoria de los trabajadores era indicativa del mismo. Como ya quedó dicho el acceso a los tribunales estaba garantizado formalmente por la ley 5178 que constituyó los tribunales, pero la costumbre de acudir a una institución nueva fue fomentada por un discurso de derecho fuertemente instalado por el peronismo y por la promoción efectiva de los derechos por parte de los mismos trabajadores, los sindicatos y las Delegaciones Regionales de la Secretaría de Trabajo y Previsión.

El capítulo anterior hizo referencia a la manera en que estos trabajadores, por medio de los abogados, lograban construir su reclamo del lenguaje de derechos al lenguaje jurídico. La existencia de una sección de Patrocinio Jurídico en la delegación Regional de la Secretaría de Trabajo y Previsión fue importante a la hora de acceder a los expertos capaces de promover las demandas de los trabajadores. La existencia del boca a boca y la misma propensión de los abogados a ofrecer sus servicios pareció haber constituido una cultura legal en los trabajadores que los colocó en una posición expectante ante la posibilidad de recurrir a los Tribunales del Trabajo, o al menos cambió la percepción sobre el sistema judicial logrando que este pareciese más cercano y una herramienta con la cual contar para logar sus objetivos.

En el caso de las delegaciones regionales estas establecieron un mecanismo de conciliación y arbitraje de la cual los Tribunales del Trabajo eran la instancia de apelación. Estas resoluciones solían constar como pruebas 
generalmente por parte de los trabajadores, a la hora de entablar las demandas. Si bien las resoluciones de la delegación no eran vinculantes para el tribunal, muchas veces funcionaban como certificación de los hechos expuestos o probaba algunas cuestiones referidas a la causa.

\section{VI.1.1 Los sindicatos en la promoción de derechos}

La justicia laboral actuaba sobre casos concretos y era por este motivo individualizante. Incluso cuando las causas pudiesen presentar más de un actor las sentencias de los jueces retomaban en sus consideraciones cada caso de forma individual. Además los sindicatos y gremios no podían constituirse como partes actoras ya que sólo podían hacerlo personas físicas. Esto excluía a los sindicatos como promotores de demandas de forma directa. Sin embargo los sindicatos desarrollaron otras funciones que terminaron por matizar el aspecto individualizante de la justicia laboral.

De los 42 expedientes que se conservan para el Tribunal del Trabajo $\mathrm{N}^{\circ} 1$ entre los años 1948 y 1955, 15 presentan la presencia de Sindicatos de manera activa en diferentes papeles. Como curiosidad, y tal vez producto de la casualidad, sólo una causa en donde la presencia del sindicato es visible llegó a una conciliación previa al dictado del veredicto, de un total de 13 causas que lograron un acuerdo. En un fuero donde la finalidad era la conciliación, una correlación como esta habilita la pregunta de si la intervención sindical no atentaba contra el objetivo mismo de la justicia laboral. Rechazados los argumentos a favor de la irrenunciabilidad de ciertos derechos ${ }^{4}$ en su ley fundante los Tribunales del Trabajo debían contemplar la conciliación sin importar la instancia en la que se encontraba la causa.

Resulta interesante pensar que posiblemente el acompañamiento sindical dotase de fuerza al reclamo del trabajador. Que la presencia de la fuerza sindical hiciese posible el sostenimiento de la demanda ante el patrón, mientras que la ausencia del sindicato dejaba al trabajador ante una situación en donde la desigualdad fundante de la relación se le hacía más evidente y el arreglo

\footnotetext{
${ }^{4}$ La cuestión de la irrenunciabilidad de los derechos laborales, y por lo tanto el rechazo a cualquier posibilidad de conciliación, fundamentaron el proyecto del diputado provincial Fossa, revisado en el capítulo IV.
} 
aparecía como una buena opción, aun incluso cuando fuese sabedor de que sus derechos podian prevalecer.

La presencia de los sindicatos, excluidos de la posibilidad de pleitear directamente, tomaba diversas formas. Podía ser el comienzo del recorrido ante la violación de un derecho, ser testigo privilegiado en la causa, ser un apoyo material al trabajador por medio de la dotación de profesionales principalmente abogados- e incluso otorgar las estrategias legales para enfrentar al patrón.

La presencia del sindicato en el caso de los vendedores ambulantes de la empresa Saint Hnos de 1949 es evidente, ya que el reclamo en la instancia administrativa es producto de un logro del Sindicato de Empleados y Obreros de la Alimentación. Además la existencia de reclamos similares en el Tribunal del Trabajo $\mathrm{N}^{\circ} 2^{5}$, e incluso en otras jurisdicciones dan cuenta de la presencia de una estructura organizativa detrás. El reconocimiento fue producto de una acción sindical conjunta de los vendedores ambulantes de la empresa demandada y los vendedores de la empresa Noel \& Cía, que incluyó también demandas en los Juzgados laborales de la Capital Federal e intervención en la Delegación Regional de la Secretaría de Trabajo y Previsión con sede en la ciudad de La Plata.

Ya el motivo por el cual pleiteaban los vendedores ambulantes motivó la acción conjunta de 55 trabajadores contra la misma empresa en la Capital Federal y dado origen a la causa "Amnie Aboul Rahman y otros c/ Saint Hnos. S.A." del Juzgado $N^{\circ} 30$ del Trabajo de la Capital Federal en la que vendedores en cines, calles, etc. demandaron el pago de aguinaldo, vacaciones y aumentos de emergencia del decreto ley 33.302, procurando con ello ser declarados empleados de la empresa ${ }^{6}$. Las razones que habían motivado esta causa eran las mismas. Es interesante observar que se trataba de una causa impulsada simultáneamente a la que se está tratando aquí.

En la instancia administrativa la causa había sido directamente encarada por el sindicato como persona jurídica. El contacto más fluido de los sindicatos

\footnotetext{
${ }^{5} \mathrm{DH}$ 102/1 Raffino Juan y otros c/Saint Hnos S.A. s/ despido, etc, Año 1949. En el Acuerdo sobresale la causa del Tribunal del Trabajo № 2 de La Plata, Secretaría 4, caratulada "López Dalmiro Ulises y otros c/ Noel y Cia Ltda. - Indemnización por despido"

${ }^{6} \mathrm{DH} 102 / 1$, foja 40 y sig. La causa del Juzgado $\mathrm{N}^{\circ} 30$ del Trabajo de la capital Federal fue resuelto de manera negativa para los trabajadores ya que fueron declarados comerciantes y por lo tanto sin relación de dependencia con la empresa.
} 
con las autoridades del Poder Ejecutivo y el carácter marcadamente corporativo permitía que la acción fuera encarada por el sindicato en lugar de por los trabajadores de forma individual. En el marco judicial la función fue otra, básicamente la de dotar de contenido la causa y promoverla mediante otros mecanismos. Sumado a este rol buscado por el mismo sindicato se sumó los requeridos por la misma justicia. En conocimiento de la existencia del convenio colectivo y sabiendo el rol del sindicato como promotor de las acciones en la instancia administrativa, el abogado de la empresa demandada, el Dr. Miramon Pourtales, decide convocar al Secretario General del sindicato, el Sr. José Sucar Tau, como testigo. Esta táctica obligó al Secretario General a reconocer la existencia de contratos comerciales entre la empresa Saint Hnos y dos casas comerciales de la ciudad de La Plata. Así se desarticulaba el pedido de los trabajadores de mantener relación laboral directa con la empresa demandada.

La consecución de los hechos propone pensar el conflicto en términos de simultaneidad de acción de los trabajadores avalados por el Sindicato de Empleados y Obreros de la Alimentación de acciones en distintos planos para logar el mismo fin. Causas judiciales, firma de convenios colectivos, requerimientos a la autoridad administrativa: hacen evidentes la conformación de una estrategia sindical que buscaba aprovechar el contexto político que se mostraba favorable a los trabajadores.

Este contexto ponía a disposición del sindicato otros caminos para hacer oír su descontento con la situación en la que se encontraban algunos de sus asociados. La disponibilidad tanto de la instancia administrativa, como de la instancia judicial, evitaba tener que recurrir exclusivamente a la huelga como medio de protesta. La huelga, como método de lucha, implicaba la movilización de la fuerza social acumulada del sindicato sin garantías de resolución favorable, sin contar que genera la puesta en juego del capital político, tanto hacia los otros actores intervinientes como a sí mismo para los trabajadores. En cambio las opciones puestas a disposición por medio de la instancia administrativa y sobre todo la justicia del trabajo, permitía llevar adelante estrategias más conservadoras en tanto que el capital puesto en juego era menor.

Pero lo más llamativo de esta causa no fue la opción tomada por el sindicato de avalar y, se puede suponer, consensuar la presentación de sus 
afiliados como damnificados ante la justicia, sino la apropiación por parte del sindicato de una herramienta de acción individual y tornarla colectiva. La acción judicial de carácter individual fue trasmutada en una acción sindical de carácter colectivo, parte de una estrategia más amplia del sindicato para hacer valer los derechos de sus afiliados.

La existencia de los tribunales como arena del conflicto puede haber sido, en situaciones como esta, una manera más de reafirmar los derechos de los trabajadores. De haber sido el sindicato quien tomó la decisión de comunicar a sus agremiados la opción judicial para la resolución de un conflicto pequeño como el que suscita la demanda y otorgarles las herramientas necesarias para llevar la disputa buen puerto, más allá del resultado negativo que la intervención obtuvo, significaría la inclusión de un agente más en las disputas entre el trabajador y su patrón, pero asociado a una vía menos explorada por la historiografía. De esta manera la experiencia del paso del trabajador por los tribunales estaría lejos de tratarse de un impulso del individuo en pos de sus derechos, sino que incluye otros actores que, si bien aparecen con mayor o menor intensidad en el expediente, darían un importante "acompañamiento" al trabajador.

Mediante el asesoramiento legal y el apoyo material el sindicato constituyó junto con el trabajador la idea de un colectivo común que le otorgaba al individuo la fuerza social para enfrentarse a su patrón en el estrado. La debilidad de origen que el trabajador tenía frente a su patrón buscaba ser equilibrada mediante la sensación del número. La lógica del enfrentamiento en otras instancias, la calle por ejemplo, entraba, de la mano con el apoyo de los sindicatos a los reclamos de sus asociados, en la arena judicial. La disputa, a diferencia de lo que ocurría en las calles donde la fuerza se medía en la capacidad de presión de ambos bandos, se resolvía mediante un canal institucional con reglas determinadas, donde la ley y las cuestiones de "derecho" son fundamentales.

La irrupción del peronismo en la escena política nacional y las innovaciones institucionales que propuso -como los tribunales laboralesgeneró la percepción de que el Estado se pondría definitivamente del lado de 
los trabajadores. La idea de que los trabajadores ya no estaban solos ${ }^{7}$ cambió la apreciación de la desigualdad en la batalla. La actividad de los abogados buscaba llevar los límites de la acción del Estado hasta puntos que escapan del sentido común de nuestra época pero que encontraban su sentido en el contexto de las políticas favorables a los obreros vigentes durante el peronismo.

La "aceptación tácita de la parte demandada" da cuenta de la creencia compartida por los actores de la parte actora -es decir, por los sindicatos, los abogados y los trabajadores- de la nueva capacidad del ejecutivo para imponer sus normas a las partes en conflicto. El lugar que ocupa el poder ejecutivo como garante del bienestar de los trabajadores, ya estudiado por otros investigadores, se traslada a la rama judicial dando cuenta de la personificación del Estado como peronista en sus tres poderes que hacian los actores. La idea tácita que flotaba en el ambiente era que la justicia, encarnada en los tribunales laborales, fallaría a favor de la parte más débil de la relación contractual. Al fin y al cabo la constitución de los Tribunales Laborales apuntaba justamente a beneficiar a quien se presume la parte más débil de la relación. Las normas fijadas en leyes, convenios (colectivos e individuales), disposiciones, decretos y resoluciones se superponían y más aun en el caso de disposiciones en torno a los salarios y remuneraciones, que eran reformadas de manera continua por diferentes instituciones.

La organización obrera generalmente causó rechazo en el campo patronal. El empoderamiento de los sindicatos durante el peronismo fue percibido como una ruptura del orden tradicional de las cosas. Tal rechazo se evidencia en el ánimo revanchista expresado en algunos de los miembros de la autoproclamada Revolución Libertadora ${ }^{8}$. Los sindicatos, al promover la difusión de los derechos de los trabajadores, parece funcionaron como disparadores de causas judiciales. El recorrido de los trabajadores que se evidencia en varias de las causas conservadas colocaba al sindicato como el

\footnotetext{
${ }^{7}$ Vease el capítulo "En tiempos de Perón Berisso era una hermosura" del libro LOBATO, Mirta Zaida, La vida en... Op. Cit.

${ }^{8}$ El desarme de la estructura sindical heredada del peronismo fue uno de los objetivos de los ejecutores del golpe de estado. A pesar de que no habría "vencedores ni vencidos" la correlación de fuerzas dentro de la heterogénea alianza antiperonista terminaría por determinar el triunfo de las posiciones contrarias al movimiento obrero en su conjunto. MELON PIRRO Julio César, El Peronismo después del Peronismo. Resistencia, sindicalismo y política luego del 55, Siglo XXI, Buenos Aires, 2009. Especialmente el capítulo 3.
} 
primer eslabón en la cadena que llevaba al patrón a tener que comparecer ante el Tribunal del Trabajo.

Si se considera que el paso por los tribunales de justicia como parte demandada no es una experiencia deseada por ningún sujeto, se comprende el resentimiento que en los patrones ocasionaron los sindicatos y los sindicalistas como promotores de demandas de los trabajadores. Los sindicatos aparecieron ante los ojos de los patrones como verdaderos generadores de discordias en una relación que se suponía armónica y jerarquizada hacia el interior del establecimiento. Es claro que el avance del Estado sobre la esfera productiva produjo una pérdida de poder por parte de los patrones, aun en situaciones en los que generalmente se considera que la voluntad del patrón era la ley ${ }^{9}$. Los expedientes judiciales exponen muchas veces el choque entre la lógica de un patrón que aun no es del todo consciente de las limitaciones impuestas a su accionar dentro del establecimiento. Si a esto sumamos el empoderamiento de los sindicatos en la estructura de control de cumplimiento de los derechos laborales y el lugar de los sindicatos en el imaginario de la Justicia Social, estos no podían menos que ser considerados como parte del problema.

La idea del sentido común de que los sindicatos se dedicaron a controlar a la clase obrera destruyendo su potencial conflictivo puede ser revisitada teniendo en cuenta estas nuevas funciones de las organizaciones gremiales tendientes a defender los derechos de sus asociados.

\section{VI.2 Obrero o empleado, representación de los trabajadores frente a la justicia laboral}

La justicia laboral, a pesar de estar pensada como una instancia de mediación a la que podían recurrir ambos intervinientes en la relación capitaltrabajo, asumió un claro perfil que orientaba su función a satisfacer las demandas de los trabajadores. La existencia de los tribunales como arena del conflicto fue, en situaciones de injusticia, una manera más de hacer valer los derechos de los trabajadores. Pero a pesar de no encontrar en el derecho

\footnotetext{
${ }^{9}$ Las instituciones estatales expresaban la voluntad de imponer reglas bajo diferentes lógicas a aquellas sostenidas por los patrones. Las visitas de inspección se escudaban detrás de esta pretensión y se hacía evidente en situaciones como la de los ingenios azucareros. SOPRANO Germán, Haciendo inspección... Op. Cit.
} 
obstáculos que impidan su acceso al recurso judicial, los patrones no recurrían a los tribunales a fin de reclamar por incumplimiento del contrato de trabajo establecido por la ley. Contando con otras herramientas a la hora de resarcirse ante el incumplimiento, como las suspensiones o retención de sueldos para las faltas menores y el despido o el reemplazo por otro trabajador en casos graves, el tribunal laboral no asomaba como una opción tentadora. La preconcepción dictada por el "espíritu" de las leyes laborales- de que se trataba de beneficiar a la parte más débil de la relación, sin duda convirtió al espacio del tribunal en un lugar "hostil" para los empresarios y dueños de industrias y comercios.

A pesar de existir la posibilidad de ambas partes de recurrir al estrado, fueron los trabajadores quienes más utilizaron esta vía a la hora de reclamar sus derechos. En los casos analizados para esta tesis son, efectivamente, los trabajadores quienes mayormente dan comienzo al proceso judicial. Incluso en el caso en que fuere el patrón quien acudió a realizar la denuncia, una vez contestada la demanda el caso fue rápidamente reconvertido ${ }^{10}$. Pero para poder acudir a estos tribunales, en términos legales, las partes tenían que pertenecer a dos categorías a simple vista bien definidas: o se era trabajador, o se era empleador.

Estas dos etiquetas daban por supuesto que quienes acudían a los tribunales conformaban uno de estos dos polos que constituían las relaciones laborales. Pero no siempre la asunción a priori de alguno de estos dos lugares podían ser sostenidos al momento de entablar la demanda. La forma que adquirió la definición de estos polos opuestos en la lógica diaria de los tribunales era de carácter relacional. Demostrar la existencia del vínculo era la principal justificación para constituirse como parte en un juicio, y por lo tanto sujeto de derechos en lo que a leyes laborales se refiere.

\footnotetext{
${ }^{10}$ La reconversión es un mecanismo jurídico mediante el cual la parte que inició la demanda pasa a ser la parte demandada. El caso que ejemplifica esta reconversión es DH 104/7 Formenti José e Hijos Sociedad Anónima c/ Fernández Juan Francisco s/ Consignación de haberes, Año 1955. El demandado es un menor que dependía de la Dirección de Menores del Ministerio de Salud de la Provincia de Buenos Aires. En la causa DH 103/8 Cozimatti Ángel c/ Prenz y Zanette s/ Despido, Año 1953, el abogado de la patronal interpone un recurso de Litis Pendencia (que existe un juicio previo sin sentencia en curso), que daba cuenta que existía una causa previa que al igual que el caso anterior también es por consignación de haberes. Esas dos causas son las únicas referencias en las que hay mención a la parte patronal como iniciadora del juicio.
} 
La justificación de la constitución como parte en un pleito en los Tribunales Laborales era, entonces, fundamental para reclamar los beneficios de la legislación laboral del período. Mientras que en algunos casos este paso era rápidamente zanjado mediante la presentación de recibos de sueldo o la aceptación por parte de la empresa demandada de la existencia del vínculo contractual, algunas formas que adquirió el trabajo en la época hacían difícil la inclusión de una multiplicidad de realidades laborales dentro de los cánones de los tribunales. La normalización de las diferentes realidades laborales no pudo aprehender todas las situaciones. Incluso desde la formación doctrinaria del Derecho del Trabajo, la figura que había recibido mayor atención -junto con aquellas referidas a los accidentes del trabajo y la legislación provisional- fue la del contrato de trabajo. Los debates académicos en torno a esta figura legal y la definición teórica del contrato del trabajo como un contrato de índole especial, y que no estaba contemplada en ninguna de las figuras contractuales de la tradición civil, no lograron definirlo de manera definitiva. Además los vínculos laborales no siempre estaban definidos por la firma de algún tipo de contrato previo, lo que dejó en manos de los jueces la potestad de delimitar el vínculo laboral existente según cada caso. La existencia del vínculo laboral que daba por supuesto la existencia de un contrato de hecho o de derecho era parte constitutiva de la actividad de los tribunales.

A pesar de las pretensiones del gobierno de dictar medidas universales y de constituir al trabajador como ese beneficiario universal de sus políticas -que se tradujeron en una profusa legislación que alcanzó a actores antes excluidos $^{11}$ - la particularización de ese universal se constituyó en una de las actividades de los tribunales. Sin negar el carácter claramente pro obrero que tenías las políticas gubernamentales y los cambios con respecto al período anterior en cuanto a la necesidad de mantener las apariencias hegemónicas de la dominación, que en términos de Scott ${ }^{12}$, tenían estos actores, es necesario

\footnotetext{
11 El autor analiza los cambios en la experiencia del estado y las posibilidades que abrió la instauración de toda una serie de instituciones en el interior pampeano que marcaron un rumbo diferente en la organización del sistema productivo agrícola del sur bonaerense, principalmente para algunos actores que habían quedado relegados en la expansión productiva de la etapa entre fines del siglo XIX y la década peronista. PALACIO Juan Manuel, La experiencia del estado..., Op. Cit.. Para tener un panorama más acabado de la idea de cambio contrastar con el trabajo previo del mismo autor: La Paz del trigo... Op. Cit.

${ }_{12}$ Sostiene Scott que el espectáculo de las afirmaciones discursivas de los de abajo dará la impresión de que la hegemonía ideológica está firmemente asentada. El discurso oficial de las
} 
ahondar en uno de los puntos centrales a la hora de reclamar por vía judicial los beneficios de dichas medidas que fue la constitución como parte en juicio. Si bien era evidente que para el trabajador el Estado apareció más cercano que en otros tiempos, la formación normalista de una institución como los tribunales forzaba a ciertas definiciones que no necesariamente eran el reflejo de la realidad social.

Este problema sobre la definición del sujeto que encarnaba en los tribunales al universal que declamaba la ley no necesariamente recayó sobre todos los trabajadores que acudían a la justicia. Como ya quedó dicho, muchas veces la relación laboral era rápidamente establecida mediante el reconocimiento de la parte patronal -que aun así implica un reconocimiento de orden relacional- o mediante la presentación de pruebas como recibos de sueldo o contratos escritos. La regulación del trabajo no contempló, como en el caso de Brasil, un registro de los trabajadores. En dicho país el Estado Novo, por medio del Ministerio do Trabalho, estableció un registro llamado Carteira Proffisional obligatorio que definía a su poseedor como un trabajador y por lo tanto lo constituía en el eje de la definición de un nuevo tipo de ciudadanía ${ }^{13}$. Esa falta de regulación otorgó a los jueces laborales la posibilidad de delimitar de manera más definida quienes eran los que podían acudir a la justicia.

A esta potestad jurisdiccional quedaron sometidos el grupo de vendedores ambulantes que en el año 1949 le iniciaron juicio a la empresa de golosinas Saint Hnos. por despido, falta de preaviso, cobro de aguinaldos, vacaciones no gozadas y comisiones. El motivo de la demanda ya revisada era obtener de la empresa el pago de los beneficios que la reciente legislación laboral otorgaba a los trabajadores. Los doce actores que inician la demanda ${ }^{14}$

relaciones de poder es una esfera en la cual el poder aparece naturalizado, porque las elites ejercen su influencia para conseguir precisamente eso y porque normalmente es útil a los intereses inmediatos de los subordinados evitar el desenmascaramiento de estas apariencias, el peronismo, desde la construcción discursiva de esa esfera de poder, rompió con la necesidad de mantener las apariencias. SCOTT James C., Op. Cit.

${ }_{13}$ CASTRO GOMES Ângela de, Cidadania e direitos... Op. Cit.

14 Según se desprende las carta poder que los trabajadores firman a favor del abogado Pedro Apaolaza, los trabajadores que inician la causa son: Juan Raffino, argentino, soltero, empleado, 55 años, domiciliado en La Plata. Francisco Niembro, español, soltero, empleado, 56 años, La Plata. Juan Polichella, italiano, casado, empleado, 72 años, La Pata. José Freyre, español, casado, empleado, 76 años, La Plata. Victorio R Freyre, argentino, soltero, empleado, 42 años, La Plata. Joaquín Marambio, argentino, casado, empleado, 47 años, La Plata. Arturo Zaneroni, argentino, soltero, empleado, 65 años, La Plata. José Armando Valdéz, argentino, soltero, empleado, 50 años, La Plata. Mana Aboralech, sirio, empleado, 57 años, La Plata. Julián 
sostienen que trabajaron a las órdenes de la empresa vendiendo los productos de la misma (helados, chocolates y demás golosinas) en la vía pública, canchas de fútbol de Estudiantes y Gimnasia, y el Hipódromo local, obteniendo los productos de dos casas comerciales de la ciudad o bien de la sucursal de la empresa en la localidad. Percibían por las ventas una comisión del veinte por ciento.

A Partir del 20 de Abril de 1949, debido a un reclamo conjunto que los vendedores de estos productos y los de la casa Noel \&Cía. hicieron en la Delegación Regional de Trabajo y Previsión, la casa comercial decidió negar la relación de dependencia de los trabajadores y reclamó que continuaran trabajando bajo nuevas condiciones. Esto produjo que los vendedores se consideraran en situación de despido y reclamen los beneficios la ley les confería $^{15}$. El diferendo con respecto a la situación de estos vendedores los llevó a recurrir a las instancias que estaban disponibles para atender sus reclamos.

El litigio sobre la relación que unía a los trabajadores con la empresa había dado origen al expediente $\mathrm{N}^{\circ} 13.439 / 1948$ Letra A de la Secretaría de Trabajo y Previsión-Delegación Regional La Plata, en el que se discutió el vínculo que ligaba a ambas partes, siendo la resolución de la Secretaria favorable al reclamo obrero. La existencia de esta resolución otorga ciertas pautas para pensar en la multiplicidad de opciones que tenían los trabajadores a la hora de reclamar ante las situaciones cotidianas que se desprendían de la situación de empleo. Lo que importa en este punto es la disputa entablada en torno a las definiciones del "empleado" que se escondía detrás de la asunción de la pertenencia a uno de los dos polos constituyentes de la relación laboral.

Como se mencionó anteriormente la constitución como parte en un litigio otorgaba la posibilidad de reclamar los beneficios de la ley que buscaban estos trabajadores, ser los sujetos de la ciudadanía social. A pesar de que era este el punto central que entra en discusión en la causa - de otra manera los actores no podrían reclamar el cumplimiento de la norma- en el texto de la demanda los

Bermejo, español, casado, empleado, 59 años, La Plata. Bernardo Roque Padilla, mayor de edad, casado, empleado, La Plata. Alejo A. Todoroff, búlgaro, casado, empleado, 58 años, La Plata. DH 102/ fojas 2-12.

${ }_{15}$ La descripción se desprende de los hechos narrados en la demanda que consta en las fojas 20-26 de la causa $\mathrm{DH} 102 / 1$. 
trabajadores aparecían bajo la denominación de "empleados", es decir, se asumió como propia la etiqueta relacional que fue objeto de discusión. Pero al momento de definir su situación el abogado de los trabajadores, el Dr. Pedro Apaolaza, utilizó categorías que no se relacionaban directamente con la figura contractual. Al redactar el escrito que dió origen a la causa el Dr. Apaolaza sostuvo que la relación de dependencia que unió los actores a la demandada se desprendía del hecho de que los

trabajadores que represento ejercían tareas en determinadas condiciones pre-establecidas y bajo el control y vigilancia de la firma productora. Solo podían vender el producto utilizando el uniforme y elementos materiales suministrados por la sociedad fabricante y a los precios por ella establecidos. Por otra parte única y exclusivamente podían vender los productos de Saint Hnos. ${ }^{16}$

De estas pocas líneas se desprende que para el Dr. Apaolaza la relación de dependencia se sostenía mediante dos variables. Por un lado la potestad que otorgaba al contratante de controlar y vigilar a sus "empleados". Por otro lado la "exclusividad" de la relación. La capacidad de la empresa de fijar las condiciones en las que se desarrollaba la actividad marca para el abogado demandante la relación que une a sus representados con la empresa. Era el ejercicio de esta potestad de los patrones -la potestad de obligar a la utilización del uniforme que los identificaba como vendedores de la fábrica, la potestad de definir los precios - lo que marca que la otra parte fuese "empleado" en los términos que exige la ley. Esta relación era, además, exclusiva. Esto quiere decir que ataba a ambas partes a una serie de derechos y obligaciones de los cuales eran únicos responsables.

El lenguaje en estos puntos era fundamental, las diferencias establecidas entre "empleado", "obrero", o "trabajador", fue delimitando el significado de la amplia categoría que englobaba el polo Trabajo en la relación jurídica. Para la empresa Saint Hnos. S.A., no cabe ninguna duda, ante la inexistencia de un contrato tangible que ligase a las partes los actores no podían considerarse "empleados". Sostuvo que

el Juez Titular del Juzgado $\mathrm{N}^{\circ} 30$ del Trabajo de la Capital Federal ha dictado sentencia en los autos: "Amnie Aboul Rahman y otros c/ Saint Hnos. S.A." en el cual cincuenta y cinco actores, vendedores en cines, calles, etc. demandaron el pago de aguinaldo, vacaciones y aumentos de emergencia del decreto ley 33.302, procurando con ello ser declarados

${ }^{16} \mathrm{DH} 102 / 1$ Fojas 20 y sig. 
empleados de mi mandante. Dicha sentencia rechaza la demanda, declarando que los actores son comerciantes y no empleados como alegan. ${ }^{17}$

La sentencia citada por el abogado defensor fue importante ya que marcó la construcción de la jurisprudencia en torno al Trabajo en momentos en que la figura del obrero se erigía ante la sociedad como el actor social al que se dirigían los esfuerzos gubernamentales ${ }^{18}$. La construcción de la jurisprudencia delimitaba el uso que se podía hacer de los tribunales laborales por parte de los trabajadores, al fijar los requisitos que debían reunir para poder litigar. La parte demandada, mediante la pluma del Dr. Néstor Miramon Pourtales, sostuvo, entonces, que la demanda era improcedente, ya que los actores no eran empleados de la firma, sino comerciantes que compraban los productos de la misma para vender por cuenta propia. Para el abogado defensor, la figura del contrato, figura clásica del Derecho Civil, era fundamental en la cuestión de la definición de la categoría a la que pertenecían estos trabajadores.

Pero los esfuerzos de Pedro Apaolaza no se detuvieron y propuso al tribunal

ir al fondo de la cuestión y entonces se podrá apreciar que la subordinación resulta evidente, cuando Saint Hnos. dirige I (sic) actividad de los vendedores con un fin determinado o sea su exclusivo beneficio ${ }^{19}$.

Ya que "no hay duda que la demandada no ha incluido entre su personal a los vendedores ambulantes y en los libros de la ley 11.729 que por otra parte es indiferente" 20 . Es decir, Apaolaza propuso escapar de la figura legal del contrato y buscar la definición del empleado mediante la reconstrucción del lugar que el trabajador ocupaba en el aparato productivo de la empresa.

A pesar de lo extensa de la cita, vale la pena reproducir el núcleo de la argumentación del abogado que representa los intereses de los trabajadores en esta causa. Apaolaza argumentó:

el hecho que la demandada no haya tenido intervención en los contratos de trabajo, no es un motivo que la pueda eximir de las obligaciones emergentes de los mismos, desde el momento que la directamente

\footnotetext{
${ }^{17} \mathrm{DH} 102 / 1$ foja 40 vuelta.

18 El trabajador se había convertido en el centro de las representaciones discursivas del gobierno peronista. A las apelaciones en el discurso político (sobre todo por medio de la figura del "descamisado"), se suma la centralidad del trabajador manual industrial en la gráfica. Veáse GENÉ Marcela, Un mundo feliz. Imágenes de los trabajadores en el primer peronismo, 19461955, FCE-Universidad de San Andrés, Buenos Aires, 2008.

${ }_{19} \mathrm{DH} 102 / 1$ foja 52 vuelta.

20 Ibídem.
} 
beneficiada por la actividad de los vendedores ambulantes, resulta ser la S.A. Saint Hnos., ella pués viene a ser el patrón de esos vendedores utilizados para su fín lucrativo, aun cuando la contratación de los mismos se haya encomendado a otras personas, pués así lo tiene resuelto la Jurisprudencia y la Doctrina, cuando expone el concepto de patrón, diciendo lo que por tal debe entenderse: "todo persona que ejerza-explote industria y empresa, auxiliandose por otras personas".

Dando una ojeada a los tratados de Economía, se llega a la conclusión de que el concepto amplio de Empresa, abarca a toda una organización que persigue un fin de utilidad valiéndose de colaboradores, cuya retribución convencional puede ser muy variada.

Los obreros que represento no son sino colaboradores de esa Empresa llamada Saint Hnos.

Nunca podría negarse con éxito que la demandada utilizaba y dirigía las energías de mis representados para una mejor distribución y circulación de sus productos, para poder así obtener una mayor utilidad en su empresa. ${ }^{21}$

Nuevamente negó la importancia del contrato de trabajo en la forma en que la concebía la contraparte. Su definición del empleado no se valió de esta herramienta legal, sino que recurrió a definiciones provenientes de los tratados de economía y que estaban detrás de las ideas académicas sobre el contrato de trabajo, sin nutrir su argumento con citas de Jurisprudencia que reforzaran la idea del "colaborador". Pero sí utilizó la Jurisprudencia y la Doctrina a la hora de definir el concepto de patrón, construyendo el polo opuesto al que representaba ante los estrados. De esta manera construyó la figura del empleado mediante la red de relaciones que los une: justificando la existencia de un patrón, se justificaba la existencia de empleados que colaboraban para lograr dar mayor utilidad a la empresa. Al haber utilizado los trabajadores -en este caso los vendedores ambulantes- su energía en pos de los beneficios de la empresa, ésta se constituyó en su patrón en la medida en que ejerció y explotó la industria mediante la colaboración de estos trabajadores. El lugar que los vendedores ambulantes ocuparon en la estructura de la empresa, que otorgó a ésta el beneficio del trabajo de dichos vendedores, era lo que reemplazaba a la figura del contrato tradicional entre las dos partes.

En una situación similar se encuentró el abogado del estibador Alfredo Desio quien decidió entablar una demanda por accidente inculpable -es decir ajeno a la responsabilidad del trabajador- en 1949. Este trabajador sufrió un accidente cuando regresaba a su casa después de la jornada laboral. Viajando en el tranvía que lo traía de la zona del puerto hacia el centro de la ciudad se

${ }^{21} \mathrm{DH} 102 / 1$ foja 51 volta y 52 , subrayado y acentuación originales. 
cayó y sufrió una herida desgarrante en el torso del pie. Según la demanda, Alfredo Desio estuvo inactivo por más de tres meses, por lo que reclamó a la empresa Murchison Estibajes el pago de los haberes correspondientes a los meses que estuvo sin poder trabajar ${ }^{22}$. Para poder exigir a la demandada el pago de dichos haberes el actor debía demostrar, según el abogado de la empresa demandada, Jorge Romano Yalour, que efectivamente estuvo vinculado a la empresa. En el escrito de contestación de la demanda el letrado negó que

el actor haya estado vinculado en momento alguno a la demandada, por el contrato de trabajo privado que prevee la Ley 11.729 , sino que por el contrario, las pocas veces que se desempeño para Murchison Estibajes S.R.L. lo hizo siempre en calidad de obrero changuista ${ }^{23}$.

Las características propias del trabajo que desempeñaba Desio, ocupado en la carga y descarga de buques, lo excluía de los beneficios de la ley debido a que su actividad era ocasional y de duración limitada al tiempo que llevaba la tarea. Esto permitió a Romano Yalour sostener que como obrero changuista no generaba en el patrón la obligación de mantener el puesto del trabajador al día siguiente ni de hacerse cargo de las cargas sociales que la ley fijaba. Incluso afirmó que los altos sueldos que se les abonaba a los estibadores se debía a que se les otorgaba, junto con el jornal, un adicional en donde se abonaban aguinaldos, jubilación y demás cargas sociales, pero estas se dejaban en manos de los operarios y no se destinaban a ninguna institución estatal.

Ante estos argumentos el abogado del trabajador, el Dr. Armando Amarilla -funcionario de la Delegación Regional de la Secretaria de Trabajo y Previsión- sostuvo que la relación de empleado de la empresa se desprendía del hecho de que

por el tipo de trabajo existía un compromiso entre el sindicato y las firmas patronales que se dedican al estibaje, carga y descarga de buques, por el cual los obreros que comenzaban a trabajar con un buque no podían cambiar su trabajo por otro buque sino luego de que hubieran terminado su trabajo para la firma patronal para la cual estaban trabajando. En este caso el buque en que trabajaba Desio terminó la firma estibadora sus tareas recién (...) 20 días después del accidente ocurrido a Desio ${ }^{24}$.

\footnotetext{
${ }^{22}$ Los hechos son los narrados en la demanda DH 102/4 Desio Alfredo c/ Murchison Estibajes S.R.L. S/ haberes, Año 1949, Fojas 2 y 3.

23 DH 102/4, foja 30 y sig.

${ }^{24} \mathrm{DH} 102 / 4$, Foja 2 volta.
} 
De esta manera los derechos correspondientes al control y la vigilancia de los obreros era la demostración del vínculo que ligaba ambas partes. El razonamiento utilizado desprendía del derecho de los patrones a fijar condiciones laborales las obligaciones correspondientes, como las dos caras correspondientes al vínculo.

La probatoria de la relación de dependencia entre el patrón y el trabajador era el punto central de estas dos causas. La metodología utilizada por los abogados de los trabajadores escapaba del marco que brindaba la ley -el marco fijado por la relación contractual- y buscaban incluir a diferentes tipos de trabajadores dentro de la categoría más específica de empleado. De esta manera estaban peleando por la ampliación de la definición de empleado.

Las definiciones de los beneficiarios de las políticas estatales bajo el peronismo eran englobados bajo categorías universalizantes (los trabajadores, los niños), pero al momento de aplicar los beneficios se hacía necesaria una definición más precisa. Según Juan Carlos Torre y Elisa Pastoriza el presupuesto era universalista, pero el aprovechamiento de las medidas de carácter universal dependía de la ubicación del grupo o individuo en capacidad de aprovecharlo. Así la política de viviendas benefició a la clase media más que a los obreros, en cambio la expansión de la instrucción pública trajo beneficios a franjas más amplias de la población ${ }^{25}$. Una perspectiva opuesta asumen las investigadoras Adriana Valobra y Karina Ramaccioti ${ }^{26}$. Complejizando la imagen del Estado, que no es ya un Estado con una racionalidad única, sino una sumatoria de proyectos no siempre convergentes, matizan el presupuesto universalista. Analizando los patrones que expresaba la gráfica de la Secretaria de Salud Pública (SSP) bajo la dirección de Carrillo, las autoras afirman, entre otras conclusiones, que tal secretaría no tuvo una acción homologada unívocamente a la que expresaba generalmente otros sectores del Estado nacional. Esto influía en quiénes eran los beneficiarios de la acción de la SSP. La delimitación que implica toda determinación de un universal operaba de

\footnotetext{
25 TORRE Juan Carlos y PASTORIZA Elisa, "La democratización del bienestar" en J.C.TORRE (dir) Los años peronistas (1943-1955). Nueva Historia Argentina. Vol. 8, Sudamericana, Buenos Aires, 2002.

${ }^{26}$ RAMACCIOTTI Karina I. y VALOBRA Adriana M., "Plasmar la raza fuerte..." Relaciones de género en la campaña sanitaria de la Secretaria de Salud Pública de la Argentina (1946-1949)" en RAMACCIOTTI Karina I. y VALOBRA Adriana M. (compiladoras) Generando el Peronismo. Estudios de cultura política y género. Proyecto Editorial, Buenos Aires, 2004.
} 
manera tal que en la práctica de la SSP el universal equivalía al varón en edad productiva y ese era el ideal al que apuntaba las acciones concretas así como la propaganda.

Algo de esta particularización de lo universal parece estar en la preferencia del sindicalismo y del gobierno por "la opción por la negociación contractual en lugar de una legislación garantista de alcance general como mecanismo principal para la regulación de las condiciones de trabajo" 27 . Pero en la disputa de los tribunales las leyes obreras eran concebidas por los trabajadores y sus representantes ante el tribunal como de carácter universal, haciéndose eco de la imagen que el Estado se encargaba de difundir. A pesar de que el contrato adquirió para los jueces importancia capital a la hora de demostrar la relación de dependencia, aun así se permitían incluir otros factores que facilitaba observar "el fondo de la cuestión" y no se limitaba a esta figura al momento de dictar sentencia. Se hace necesario revisar, entonces, de qué manera la legislación, planteada en base a un universal como beneficiario el trabajador- entraba en conflicto con el particular en base a la cual se definía -el empleado en relación de dependencia-.

Esto no significa restarle importancia a la definición del universal, sino justamente tratar de observar de qué manera esta imagen del trabajador como beneficiario de la política gubernamental, en este caso la implementación de tribunales laborales, fue asumida por las partes en litigio y por aquellos encargados de trazar los límites legales de la categoría empleado. En los debates de la ley de creación de los tribunales aparece una imagen consolidada del beneficiario de la medida, y este era el trabajador -al fin y al cabo el "Nuevo Derecho" estaba pensado en base a asumir las desigualdades entre los trabajadores y el patrón-. Pero detrás de esta imagen la que parece subyacer era la del obrero industrial ${ }^{28}$, sin embargo a los tribunales laborales acudieron no solo obreros industriales, sino también empleados de comercio, vendedores ambulantes o, como Alfredo Desio, changarines, que, en su

\footnotetext{
${ }^{27}$ DOYON Louise, Op. Cit., pp. 114.

${ }^{28}$ La imagen del trabajador más común del peronismo era la del "descamisado". Esta imagen ocupaba un lugar central en el ideal de la masa beneficiaria de las obras del gobierno. A pesar de simbolizar mucho más que el obrero industrial (el descamisado representaba a los trabajadores manuales, pero también a los niños, los ancianos, los "pobres de Evita", etc.) la imagen que predominaba en la gráfica de la época era la del varón obrero industrial o rural. GENÉ Marcela, Op. Cit.
} 
contacto con otros trabajadores, con abogados y jueces, y con patrones, pusieron a prueba la elasticidad del universal para poder ser incluidos en él.

Retomando la causa que Desio inició contra la empresa Murchison Estibajes se observó que en el Acuerdo de la causa, el tribunal fundamentó la negativa a aceptar la demanda del actor en los siguientes términos:

Resulta claro, en consecuencia, que al actor no puedo considerarlo unido en una relación de carácter normal y permanente o estable con la razón social demandada, por faltarle la intención de perdurar en la organización de la Empresa, propia de todo "contrato de empleo"29.

A pesar de que dió cuenta de la importancia del "contrato de empleo" este no apareció como una formalidad, sino como un conjunto de características que se debían cumplir para considerar al trabajador como empleado. Como herramienta fundante de la relación de empleo, y que por lo tanto constituía al obrero en sujeto de derechos laborales, el contrato de empleo perdía la rigidez que caracterizaba el contrato bajo el Derecho Civil y fue objeto de definiciones y redefiniciones. Era esta posibilidad la que abrió las puertas a aquellos trabajadores que no estaban insertos en categorías en donde el contrato de empleo estaba más extendido y que por lo tanto no debían lidiar con ser reconocidos como parte en juicio.

En el caso de los vendedores de la compañía Saint Hnos se observó que los actores justamente reconocían la existencia del contrato no como un régimen formal, sino como una serie de características: su trabajo otorgaba beneficio a la demandada, esta proveía los elementos de trabajo -tales como uniformes, carritos, identificación, y lugar de trabajo- y daba las órdenes. Además les pagaba una comisión y retiraban los productos sin abonarlos de dos casas comerciales. Se encontraban ante una situación no contemplada por ninguno de los contratos previstos por la legislación civil, sino en el tipo de contrato que pone a disposición una mercancía que ya no entraba libremente al mercado (el trabajo). Pero a pesar de las definiciones teóricas en torno al contrato de trabajo, a la hora de la sentencia prevaleció la jurisprudencia acumulada durante años de experiencia en el fuero civil, ya que la figura del contrato que predominó fue la del contrato de venta de productos por parte de

${ }^{29} \mathrm{DH} 102 / 4$ Foja 110. 
Saint Hnos. a las dos casas comerciales de La Plata, por un lado al Sr. González y por otro al Sr. Carús.

En este punto el tribunal consideró que el contrato existente entre estas dos partes rompía la cadena lógica utilizada por el abogado Pedro Apaolaza: los vendedores no podían tener relación de dependencia con la demandada si ésta vendía los productos a las firmas comerciales de La Plata. Sin negar la existencia de una relación laboral, esta no podía ser probada entre los vendedores ambulantes y la sociedad que producía las golosinas y los helados, ya que prevalecía la unión de derecho entre la compañía productora y las casas comerciales, formalizadas mediante la existencia de un contrato formal (escrito). A pesar del avance en términos de autonomización del Derecho del Trabajo con respecto a otras ramas del derecho, su existencia subsidiaria con respecto al Código Civil se seguía expresando en los fallos del Tribunal del Trabajo

El intento de los vendedores ambulantes y su representante legal, el Dr. Apaolazza, de construir la figura del "empleado" dependió de los tratados de economía y no descansaba exclusivamente en la autoridad de textos jurídicos. Esta causalidad era producto de la influencia que el avance de la ciencia económica tuvo en esos mismos años sobre el estudio del derecho, ya que la realidad material se impuso como fuente del derecho. Por otra parte la falta de autoridad de los textos jurídicos sobre el contrato de trabajo -que los había y en gran cantidad ya que era el objeto de reflexión por parte de diferentes juristas- respondía a la falta de prestigio que aun arrastraba el Derecho Laboral en el campo jurídico. La sentencia de la causa, con la primacía de la figura contractual de sociedad legislada en el Código Civil, daba cuenta del peso de la tradición civilista en un campo que se presentaba como científicamente autónomo, así como también de las diversas temporalidades del cambio. El peso de la figura contractual del Derecho Civil daba muestras de la larga agonía de la exégesis legal que prevaleció en la enseñanza del derecho durante las primeras décadas del siglo XX. A pesar de los cambios en la enseñanza y la exégesis del derecho desarrollados en los capítulos anteriores, los jueces del Tribunal del Trabajo $\mathrm{N}^{\circ} 1$ aun aplicaban sus conceptos a la hora de definir las causas. 
La ambigüedad y el peso de la tradición civil, y el amplio marco de referencias legales que los jueces tenían a la hora de dictar sentencia quedó en evidencia al contrastar la definición contractualista aplicada al caso de los vendedores ambulantes con la causa que Carlos Mengotti le inició a la "Compañía de Ahorro y Capitalización Sociedad Anónima Argentina". Los representantes legales de Mengotti -Manuel Santos Lavalle y Arsenio Osvaldo Granillo Fernández- se basaron en un decreto del Poder Ejecutivo, por lo tanto una fuente legal reconocida por la jurisprudencia, para sustentar la constitución de su defendido como sujeto de derechos laborales. El decreto 33.302 del año $1945^{30}$ estableció un aumento de emergencia para los obreros y empleados y definía

por empleado u obrero a toda persona que realice tareas en relación de dependencia, para uno o varios empleadores, alternativa, conjunta, o separadamente, en forma permanente, provisoria, transitoria, accidental, o supleatoria. ${ }^{31}$

Este decreto, por lo tanto, definió de forma más bien amplia quien podía acogerse a los beneficios que dictaba. Lo significativo de esta causa es la respuesta que pone por escrito el abogado de la empresa, Manlio Maggi, cuando, en un proceso inverso, intentó poner coto a la expansión de la categoría de empleado y negar así el beneficio a Mengotti. Maggi recuerda al tribunal que el mismo decreto, en su artículo segundo,

exige como condición esencial para que exista una relación de empleo, la situación de dependencia del empleado frente al patrono.

Ello supone subordinación y control permanente sobre la labor del subordinado, jornada máxima y horarios, recepción de órdenes, vigilancia y demás requisitos que configuran una relación de trabajo.-

El concepto es muy claro y ha sido incorporado a la jurisprudencia para que sea necesario abundar en citas. ${ }^{32}$

Es notable la similitud entre las condiciones que establecieron los vendedores de los productos de Saint Hnos., en la primer causa expuesta, para ser considerados empleados de la compañía (sobre todo aquellos referidos a la

\footnotetext{
${ }^{30}$ Este decreto, del 20 de Diciembre de 1945, creaba el Instituto Nacional de Remuneraciones, salario vital mínimo, salario básico, sueldo anual complementario, aumento de emergencia y estabilidad de los trabajadores, fue ratificado por la ley 12.921 de 1946. Todas las Leyes Obreras de la Revolución, Editorial Primicias, Buenos Aires, 1947.

31 102/12 Mengotti Carlos Ricardo c/ Compañía de Ahorro y Capitalización Sociedad Anónima Argentina (en Liquidación), Año1950. Foja 3 y sig.

$32 \mathrm{DH}$ 102/12, foja 12.
} 
vigilancia y recepción de órdenes) y los que aquí utiliza Maggi -basándose en un decreto- para realizar la operación inversa.

Estas causas daban cuenta de las lógicas diferentes utilizadas para definir al empleado -y por lo tanto constituirlos en sujetos de derechos al conformarlos en parte en juicio-. La posición de los jueces en este juego de tire y afloje no dejaba de ser ambigua. En el primer caso la existencia de un contrato comercial impidió pensar que haya existido una relación contractual entre ambas partes. En cambio el caso propuesto contra la firma Murchinson Estibajes se admitió que existía una relación, pero, justamente el incumplimiento por parte de Alfredo Desio -por la naturaleza transitoria del trabajo que realizaban los estibadores- de una de esas características tácitas que tenían los "contratos de empleo", es lo que llevó a los jueces a sostener que no existía una relación de dependencia que sujetase a la empresa a los derechos y las obligaciones establecidas por la ley. Para el caso de Carlos Mengotti la existencia de un decreto en el cual se amparaba -decreto que, tomando en cuenta la resolución positiva que tiene el juicio para el trabajador, se impuso a la jurisprudencia que sostiene el abogado Manlio Maggi- fue suficiente para aceptar la relación de dependencia, sin ahondar el Tribunal en las consideraciones de fondo de la cuestión.

Estas causas pudieron encontrar su razón de ser al tratarse de los primeros años de funcionamiento de la justicia del trabajo y por lo tanto la novedad que implicaban hizo necesario conocer sus límites. Sin embargo la cuestión de la relación de dependencia constituyó un problema importante hasta la caida del peronismo. Catorce de las cuarenta y dos causas que se preservan del Tribunal del Trabajo N¹ para el período 1948-1955 fueron consecuencia de la presentación de trabajadores que buscaban ser reconocidos en su relación de dependencia. La distribución de estas catorce causas en el tiempo es uniforme y no se trata exclusivamente de causas de los primeros años.

El 20 de Septiembre de 1954 Dario Barceló le entabló demanda a Simón Izarovsky para cobrar la indemnización por despido, el preaviso y las diferencias de los jornales. Darío Gregorio Barceló se desempeñó como acompañate de Izarovsky en el camión que este poseía y habían acordado para esa tarea el pago de $\$ 1100$ por mes, pero su patrón solo le pagó durante 
6 meses $\$ 500$ ya que adució dificultades económicas. Ante esta situación el actor decidió enviarle un telegrama colacionado intimandolé al pago de la diferencia. Como el patrón nunca regularizó su situación se consideró despedido y ahí fundó su derecho a los reclamos ${ }^{33}$.

El Dr. Juan Alberto Perez Albizú -abogado del demandado que formaba parte del estudio del Dr. Romano Yalour- previo a la contestación de la demanda interpuso la excepción de incompetencia de jurisdicción sostenida en el hecho de que nunca existió entre las partes un contrato individual del trabajo que lo amparase ante las leyes laborales vigentes. En caso de que hubiese creído que le correspondía alguna acción, el actor, al tratarse de una sociedad y no un contrato de trabajo, debió dirigirse ante la justicia civil y comercial. Por si la acción de todas maneras prosperaba en la defensa en torno a los hechos, en la contestación de la demanda sostuvo que no eran patrón y empleado, sino socios. La relación había nacido en la Dirección Provincial de Vialidad donde ambos habían trabajado y en el mes de Junio de 1953 se volvieron a encontrar. En ese encuentro Simón Izarovsky le propuso ir a la zafra de la caña de azúcar en Tucumán en su camión y que ambos pagarían los gastos y se repartirían, si la suerte los acompañaba, las ganancias en mitades iguales. La empresa no tuvo éxito y las ganancias no parece haber sido el destino de ambos siendo que su incursión en la zafra les terminó ocasionando pérdidas. Además de la insatisfacción económica, Izarovsky "se siente traicionado en su buena fe, ante esta burda ficción"34, ya que si en algún momento había pensado sumarlo como socio esto había sido por la amistad que los unía y porque Barceló le había dicho que se sentía descontento con su trabajo. Para la parte actora, este recurso que interpuso el Dr. Pérez Albizú "se trata de una defensa que tiende a privar de un derecho laboral legítimo otorgado por las leyes al actor"35.

Ante esta situación el tribunal resolvió en el Acuerdo del 28 de Febrero de 1955 sobre el recurso de incompetencia de jurisdicción. Realizado el sorteo de orden fue el doctor De La Vega quien fundamentó el voto, mientras que los otros dos jueces, Cabanillas y Montaña, asumieron como propios lo expresado

\footnotetext{
${ }^{33}$ DH104/5 Barceló Dario Gregorio c/ Izarovsky Simón s/despido, etc., Año 1954.

${ }^{34} \mathrm{DH} 104 / 5$, foja 6.

${ }^{35} \mathrm{DH} 104 / 5$, foja 11.
} 
por De la Vega. Sobre si el recurso que había interpuesto el demandado era válido sostuvo De La Vega:

se trae a estos estrados judiciales, una cuestión sobradamente debatida: pues como se tiene resuelto, la competencia de los tribunales se determina por la naturaleza de las acciones deducidas en la demanda, por lo que si en estas se formulan reclamaciones fundadas en leyes del trabajo, el conocimiento del caso corresponde al fuero laboral, el cual no puede declararse incompetente por estimar que no existiese entre las partes un contrato de trabajo, consideración de fondo que resuelve el pleito y que sólo tiene cabida en la sentencia definitiva ${ }^{36}$.

Con el paso de los años, el funcionamiento de los tribunales ya hizo de este tipo de reclamaciones por parte de los demandados improcedentes. La existencia o no del contrato de trabajo era, en última instancia, la consideración de fondo sobre la que se resolvió el caso. Y este contrato ya no era concebido como la expresión de la voluntad escrita, en la medida en que las partes contratantes no se encontraban en pie de igualdad para declarar su consentimiento de manera autónoma. Lo que se disputaba en la causa era si existió una relación laboral que colocase al trabajador bajo el amparo de las leyes laborales y la legislación social del periodo. Sobre esa cuestión sólo podía resolver el Tribunal del Trabajo y no ninguna otra instancia, en tanto jurisdicción natural de los conflictos laborales.

El Veredicto terminó fallando a favor de Barceló, ya que según los jueces no se pudo probar la existencia de una sociedad entre ambos, y además testigos citados a declarar en la causa sostuvieron que se trataba de patrón y empleado, como fue el caso del mecánico del camión apellidado Bartola. Se trataba, entonces, de una relación laboral y le correspondía a Izarovski los deberes del patrón, entre ellos el pago del salario completo, la indemnización por despido acorde a la antigüedad y el preaviso.

Pero sin embargo el tribunal, si bien aceptó la existencia de un contrato de trabajo ya que la relación era laboral, no adhirió al pedido del trabajador en cuanto a las condiciones de ese contrato y por tanto decidió no otorgarle el diferencial de jornal que pedía (reclamaba un salario de $\$ 1000$ por mes). Si la relación laboral era aceptada debido a las condiciones en las que se establecían los contratos de trabajo -es decir, su aceptación tácita sin conformidad escrita-, el Estado ya había avanzado los suficiente en la

\footnotetext{
${ }^{36} \mathrm{DH} 104 / 5$, foja 13 vuelta.
} 
regulación de las relaciones laborales como para dejar librado al arbitrio cuestiones como el salario. Es en este sentido que el tribunal resolvió aceptar el pedido del trabajador en cuanto al salario no abonado, pero no la suma reclamada, sino el que correspondía a la tarea que desempeñaba acompañante- en el convenio colectivo del sector (Ampliación del Convenio 197/50 del 10 de Marzo de 1952).

Se debe tener en cuenta que la definición de la relación de dependencia fue puesta en tensión ante la gran cantidad de decretos, leyes, reglamentaciones y resoluciones que intentaron regular las relaciones laborales. Las derivaciones doctrinarias de la ley 11.729 , que había modificado los artículos 154 a 160 del Código de Comercio y que trataban los aspectos relacionados a los empleados comerciales, ya no eran las únicas disposiciones que regulaban las relaciones entre el capital y el trabajo en los ámbitos tribunalicios, tal como había sido en los años previos a $1943^{37}$. Esta ley permitió ampliar la categoría de "empleado comercial" y facilitaba el acceso de una proporción mayor de trabajadores a los beneficios establecidos en el Código de Comercio con respecto a la intangibilidad del empleo, la duración de la jornada de trabajo o la posibilidad de pleitear por la indemnización en caso de ser despedido sin justa causa. El proceso legislativo propendía a considerar a los trabajadores que trabajasen a las órdenes de casa comerciales pero que no se desempeñasen como empleados de mostrador de venta al público como "empleados comerciales". La ampliación de la categoría llevó a diferentes debates por definir que era un establecimiento comercial, ya que si se lograba considerar a las industrias como establecimientos comerciales los beneficios del Código Comercial podía ser extendido a los obreros industriales ${ }^{38}$.

Es claro entonces que la pelea por ser declarados sujetos de derechos no era nueva y ya se había esbozado cuando obreros industriales pugnaron por ser considerados "empleados comerciales". Pero la autora también sostiene que esto cambió en 1943 con la profusión de leyes, decretos y reglamentos que la revolución de Junio emitió con respecto a las relaciones laborales.

\footnotetext{
37 Schjolden sostiene que en todo el período previo a 1943, la ley 11.729 de 1934 fue el intento más profundo de regular mediante la justicia las relaciones laborales.

${ }^{38}$ Las consecuencias de la ampliación de la categoría de "empleado comercial", los debates parlamentarios y el rol de los jueces al dictar sentencia en casos claves que sentaron jurisprudencia, pueden observarse en la ya citada tesis de Line Schjolden. SCHJOLDEN, Line, Op. Cit. Pp. 187 y sig.
} 
Sin negar la ampliación de la ciudadanía que significó la posibilidad de disponer de nuevos derechos y hacer uso de ellos como ocurrió con el advenimiento del peronismo, las causas aquí señaladas brindan un panorama diferente, donde la lucha en los tribunales por la ampliación de la categoría empleado aun estaba vigente. Diferente parece haber sido el panorama para el caso de las instituciones que dependían de los poderes ejecutivos, tanto nacional como provinciales o municipales, en la medida en que distintos organismos se fueron configurando en base a universalizar nociones y prácticas de los significados de empleado y de los derechos asociados a esta figura. De todas maneras esta universalización de la categoría empleado en las instancias administrativas estaba atada a identificaciones colectivas más que individuales. Es decir, el empleado lo era en virtud de estar comprendido en algún tipo de asociación colectiva -reconocida por las autoridades- que los incluyese.

Esta universalización colectiva es una de las razones por las cuáles la acción estatal se centraba, por medio de la intervención del Poder Ejecutivo, en la firma de convenios colectivos de trabajo. Estos convenios comenzaron a aplicarse ya en la década del treinta tanto en el ámbito urbano ${ }^{39}$ como en el rural ${ }^{40}$ y tuvieron un alcance limitado al estar atados a la voluntad de las autoridades políticas de los Departamentos Provinciales del Trabajo de aplicarlos.

Tal vez la razón de la vigencia de esta pelea por la ampliación de la categoría de empleado pueda ser encontrada en la afirmación ya citada de Louise Doyon. La opción por la negociación contractual que señala Doyon significó en la práctica que desde la Revolución de Junio se establecieron una multiplicidad de convenios colectivos por rama o sector de la industria. Esta práctica permitió a los gremios mejor organizados y con mayor capacidad de negociación ganar mejores condiciones. La alta tasa de sindicalización y la voluntad política de los líderes sindicales habría logrado, según Doyon, ampliar la cantidad de convenios colectivos firmados ${ }^{41}$.

\footnotetext{
${ }^{39}$ KORZENIEWICZ Patricio, Op. Cit.

${ }^{40}$ ASCOLANI Adrian, Op. Cit., BARANDIARAN Luciano, Op. Cit.

${ }^{41}$ DOYON Louise, Op. Cit.
} 
Este tipo de negociación transformaba a los sindicatos en agentes de control del cumplimiento de las normas establecidas en el convenio. Al no contar todos los sindicatos con la fuerza política para llevar adelante estos cometidos se reprodujeron algunos de los límites del período anterior. Trabajadores que encontraban su oficio en empleos como la venta ambulante, changas, $O$ en pequeños comercios $e$ industrias no parecieron estar tan protegidos como aquellos que trabajaban en los frigoríficos o en la industria metal-mecánica.

En las causas en que se puso en tela de juicio la relación de dependencia de los trabajadores, y por lo tanto su posibilidad de constituirse en sujeto de derecho laborales, asomaba la existencia de diferentes lógicas que buscaron romper la tradición establecida en el Código Civil. La importancia que para los trabajadores tenía ser incluidos dentro de la categoría "obrero u empleado", entendiendo este como en relación de dependencia, necesitaba de una definición específica vinculada a las relaciones que en el mundo del trabajo establecían con sus patrones. La inclusión en esta categoría les permitía escapar de los preceptos que establecía el Código Civil que supone que "la libertad de las partes contratantes (patrón-obrero) se cumplía en realidad, es decir, se encontraban en un perfecto pie de igualdad para manifestar su consentimiento" $^{\prime 42}$. Los tribunales laborales permitieron aprehender una realidad que le era propia al mundo del trabajo, pero para esto había que lograr encasillarse en alguno de los dos polos que suponía la relación laboral. Dentro de la tradición civil esta posibilidad de aprehensión de la realidad laboral era casi nula.

Las luchas por la constitución de los trabajadores como sujetos de derechos específicos tuvieron sin lugar a dudas antecedentes importantes en los espacios institucionales del Poder Ejecutivo. Pero en el espacio judicial, y a pesar del impulso que en algunas provincias argentinas, por medio de sus departamentos del trabajo, se le dio a la iniciación de juicios sobre accidentes de trabajo o cobro de salarios adeudados en el fuero civil, la complejidad del espacio civil redundó en una escasa efectividad de esta vía. No escapa esta

\footnotetext{
42 GARCIA BOSSIO, Horacio: "La fuente Judicial y el mundo del trabajo", en Actas de las Jornadas. La fuente judicial en la construcción de la memoria, Mar del Plata, Junio de 1999, Talleres Gráficos del Poder Judicial de Buenos Aires, La Plata, 1999.
} 
afirmación de lo que ocurrió en el caso brasilero en donde también fue en el ámbito del Poder Ejecutivo donde se desarrollo la justicinha. Pero en el caso de la constitución en cuanto sujetos de derecho en el ámbito judicial su importancia radica en la elevación del empleado, en cuanto individuo, al rango de sujeto de derechos especiales. Ya no dependería de su inclusión dentro de un colectivo normalizado -trabajador de tal o cual rama sujeto a las disposiciones de tal o cual convenio colectivo- sino de su ubicación relativa en el entramado productivo.

Al definirse los Tribunales Laborales como espacio de disputa entre dos polos opuestos -el capital y el trabajo-, se obligaba a pensar la propia concepción de trabajador en relación a otro. Pero esta concepción no podía ser construida sino sobre la reinterpretación y adaptación de las pautas que el Estado, a través de múltiples leyes, decretos y resoluciones, y las mismas relaciones sociales -el lugar en la estructura productiva, por ejemplo-, pusieron a disposición de los actores. La construcción de un nosotros en relación a otro, mediado por los límites impuestos por la institución en la que estaban sumergidos, colocaba sus acciones en una "Iógica compartida, y en ese sentido, pueden pertenecer al menos parcialmente a mundos imaginativos similares" ${ }^{\prime 3}$.

En la ciudad de La Plata los trabajadores ya contaban con los derechos civiles y políticos, y la ampliación de la ciudadanía para incluir los derechos sociales fue un proceso en el cual se cruzaron diferentes proyectos y tradiciones. Estas disputas en torno a quién era sujeto de qué derechos en el seno de la Justicia Laboral puso en juego la manera en que los trabajadores asumieron el discurso oficial de la justicia social. Entendiendo a la ley como arena del conflicto, el uso de la legislación laboral en los tribunales refleja como los significados simbólicos de la noción de justicia se expresaba en un lenguaje de derechos. Concepciones en torno a lo justo, los derechos y la ley se entremezclaban en la búsqueda de estos trabajadores de su reconocimiento como sujetos de derechos laborales.

A pesar de la importancia que el obrero adquiría en la cultura política del peronismo, la definición del universal "trabajador" -en términos de sujeto de

43 GRIMSON, A.; SEMÁN, P.: "Presentación, la cuestión "cultura"”, Etnografías Contemporáneas, № 1 
derechos laborales- escapaba al control del Estado si comprendemos a éste como dotado de una lógica unívoca. Por el contrario fue la interacción entre diferentes sujetos y diferentes caras del Estado las que fueron dotando de contenido al universal y marcando sus límites.

La importancia que tenía para los trabajadores ser reconocidos como "empleados u obreros" en los términos dictados por la ley, aun cuando tuviesen que utilizar argumentos por fuera de la definición legal, no puede ser menospreciada. Ser reconocidos como empleados significó la posibilidad de erigirse como sujetos de derecho y de esta manera lograr, mediante el reclamo soterrado pero permanente, la universalización de los derechos. La construcción del reconocimiento, al igual que la categoría que buscaba fundar, era objeto de múltiples relaciones con otros sujetos que entraban en contacto con los trabajadores y que en la práctica y el roce cotidiano en los tribunales coayudaban, de manera consciente o no, a definir y redefinir el significado de ser obrero.

\section{VI.3 Los patrones ante la impugnación de los Tribunales del Trabajo}

Pensar a los trabajadores en un sistema relacional implica colocarlo en diálogo con el otro -con quien se lucha y se negocia- y que tiene también un importante papel dentro del mundo del trabajo. Es por eso que aquí se plantea indagar a los empresarios, a los patrones y propietarios de los medios de producción, pero no en cuanto a sus estrategias puramente empresariales y en su relación con otros empresarios, sino en una situación de conflicto determinada con sus empleados. El objetivo es, por lo tanto, abordar a los empleadores dentro de una situación relacional de conflicto con sus trabajadores.

Al tratarse de una institución con una clara pretensión pro obrera, la Justicia del Trabajo puso a los empleadores a la defensiva. En sus estrategias se pudo percibir el paternalismo, la indiferencia, la oposición (a los trabajadores o incluso al gobierno) y las pretensiones de mantener el control de su empresa expresado en términos de derechos. Por otro lado el tipo de intervención estatal en estos casos era diferente a las impuestas desde los ámbitos del Poder Ejecutivo. Mientras que aquellas eran por lo general propuestas en términos de industrias -en lo que respecta a las condiciones de trabajo- o de 
regulación del mercado de trabajo -un ejemplo claro es la imposición de salario mínimo-, la intervención judicial significaba una interpelación personal a los dueños de las empresas.

Así la justicia laboral interpelaba al obrero individual en tanto trabajador o empleado y al patrón en tanto empleador. Esta conformación de una justicia desligada de la idea de ciudadanos iguales ante la ley permitió abordar el entramado productivo desde otra óptica. La intervención sobre el problema laboral era presentada como cumpliendo el Estado un rol tutelar y negociador frente a dos partes en pugna. Este tipo de intervención marcó un cambio sustancial con lo establecido para períodos anteriores, en donde la intervención estatal estaba ligada a la represión de los movimientos operarios, aunque ya se vislumbraban algunas intenciones interventoras de otro carácter.

Era en este ambiente institucionalmente hostil donde los patrones debían enfrentar en juicio a sus empleados o ex empleados. Hasta el lugar elegido para albergar a los Tribunales del Trabajo parecía buscar el efecto de lidiar con las diferencias entre los dos polos de la relación al establecer como sede el mismo lugar que las oficinas de la Delegación Regional de la Secretaría de Trabajo y Previsión, en vez de utilizar el edificio de Tribunales ${ }^{44}$.

Es claro que el avance del Estado sobre la esfera productiva produjo una pérdida de poder por parte de los patrones. Los expedientes judiciales exponen muchas veces el choque entre la lógica de un patrón que aun no es del todo consciente de las limitaciones impuestas, y la novedosa legislación. Sería tal vez enriquecedor para casos como el que sigue hacer algún análisis con las ideas que giraban en torno al ser patrón.

Los patrones en cuestión son los hermanos Ayastuy: Armaldo, Omar y el menor Genaro (aparece también bajo el nombre Juan Gerardo). El primero era propietario de la confitería "La Esfera" mientras que Omar lo secundaba en cuanto a la administración del negocio y el más chico se dedicaba a diferentes actividades dentro del establecimiento. En 1946 contrataron como peón confitero a Jorge Nierchi, quien se afilia al Sindicato de Obreros Pasteleros, Confiteros, Pizzeros y Afines. A fines del mes de Agosto de 1949 el trabajador

\footnotetext{
${ }^{44}$ Mientras la Delegación Regional y los Tribunales del Trabajo estaban en la intersección de las avenidas 1 y 60 -en un edificio de reciente construcción-, la sede del Poder Judicial platense está en el Palacio de los Tribunales que ocupa toda la manzana comprendida entre la avenida 13 y las calles 14,47 y 48 , edificio de la época fundacional de la ciudad.
} 
comienza a tener algunos altercados con el menor de los Ayastuy y fue suspendido por diez días al ser considerado culpable de los disturbios. Al consultar con Omar Ayastuy sobre los motivos de su suspensión este le contestó de mala manera, produciéndose agresiones verbales y físicas entre Jorge Nierchi y su patrón, razón por la cual este lo despide. A la hora de presentar la demanda, Nierchi sostiene que la razón por la cual lo despiden fue por los aumentos de sueldo logrados por el gremio debido a los convenios sancionados por la época y que otorgaban un aumento en forma retroactiva. El camino trazado por Jorge Nierchi no es una excepción:

Ante lo burdo de la maniobra patronal concurrió -después de haber recabado ante el Sindicato la asistencia del miembro asesor, señor Pedro Rodríguez-, el día 16 de setiembre, a la Delegación Regional de la Secretaria de Trabajo y Previsión, para dejar constancia del reclamo que formulaba por la actitud patronal $^{45}$

La imposibilidad de resolver el pleito en la instancia propuesta por la Secretaria de Trabajo y Previsión -las audiencias terminaron con los hermanos Ayastuy expulsados del recinto por la violencia con la que se dirigieron a Nierchi-, llevó al trabajador por el camino institucional establecido, es decir la Justicia del Trabajo.

Ante la demanda interpuesta por Jorge Nierchi, la defensa de los hermanos Ayastuy presentó su versión de los hechos, sin desaprovechar la chance de construir la imagen de los patrones buenos frente al trabajador desagradecido. La estrategia buscaba torcer la idea del despido, para esto el abogado de los hermanos propietarios de la confitería adució que fue el joven Nierchi $^{46}$ quien abandonó el trabajo, incumpliendo con sus deberes como obrero. El hecho de ser nominalizado como joven no es casual y busca construir la imagen de un trabajador aun sin disciplina, producto propio de la edad. Al relatar los hechos en la contestación de la demanda, el Dr. Luis Antonio Morzone -patrocinante de los propietarios- comentó que hubo una suspensión producto de la indisciplina del joven Nierchi dentro del establecimiento al entablar una discusión con el hermano menor -Juan Gerardo Ayastuy, que estaba en la fábrica a fin de aprender el oficio-que se

\footnotetext{
${ }^{45}$ DH 102/2 Nierchi Jorge c/ Ayastuy Arnaldo René y Omar s/ indemnización despido, haberes, etc., Año 1949.

${ }^{46}$ Al momento de iniciar las acciones legales Jorge Nierchi contaba con 22 años.
} 
fue de las manos después de haber estado "jugando" ya que eran compañeros de trabajo.

Los patrones, aparecen en el conflicto como verdaderos pater familias:

en nuestro propósito de ser justos y deseosos de mantener la disciplina en nuestra casa, impusimos una sanción al empleado, amparándonos en las normas legales que determinan las leyes 11.729 y 12.991 y prohibimos a nuestro propio hermano que volviera a la fábrica a fin de evitar que con su carácter expansivo y alegre indisciplinara a los obreros ${ }^{47}$

Las referencias a nuestra casa, en el caso de imponer la disciplina al obrero, y la fábrica al momento de referirse al hermano menor son, cuanto menos, llamativas. La construcción del discurso de la fábrica como el hogar se extendía también en la consideración de los obreros. Jorge Nierchi, en su construcción de los hechos, remarcó el perjuicio a su honor en cuanto obrero, y que demostraba el trato "agraviante" hacia su persona, al relatar que con posterioridad a la pelea con Genaro Ayastuy ya no se le servía el desayuno junto con sus compañeros. Ante esta acusación los hermanos Ayastuy declararon que

yendo al fondo del punto que se debate, debemos expresar que la obligación de proporcionar comida a los obreros de la industria del pan no surge de ningún texto legal ni forma parte de ningún convenio colectivo de trabajo. Es más, esta modalidad está expresamente prohibida por el Decreto 29.669 del año 1945.

Solo debido a nuestra costumbre, heredada de nuestros mayores, que consideraban a sus obreros como integrantes de su propia familia, nos ha llevado a continuar una tradición que no se funda en la ley ${ }^{48}$

La buena voluntad patronal estaba fundada en la costumbre. Siguiendo a sus mayores constituyen un relato en donde el patrón era el encargado de velar por su familia ${ }^{49}$. Al ser las relaciones vistas a través de la óptica de la familia la acusación del obrero fue percibida como prácticamente una traición. El reclamo de Nierchi, también fundado en la costumbre, atacó la sensibilidad patronal al poner en disputa o reclamar en base al propio discurso paternalista de los dueños de "La Esfera". Dentro de esta concepción de la disciplina y el manejo del negocio -sobre todo en lo que respecta a la cuestión del manejo de personal-, el Acuerdo del Tribunal del Trabajo $\mathrm{N}^{\circ} 1$ fue como un nocaut. Al justificar las razones que llevó al tribunal a sentenciar a los hermanos Ayastuy

\footnotetext{
${ }^{47} \mathrm{DH} 102 / 2$, foja 15.

${ }^{48} \mathrm{DH} 102 / 2$ foja 17 volta

${ }^{49}$ La imagen del patrón como padre no es inusual y fue estudiada en relación a su lugar en la conformación de villas obreras, sobre todo en la región central de la provincia de Buenos Aires.
} 
a pagar el monto reclamado por Nierchi, el juez Dr. Miguel Ángel Zorraindo argumentaba que

\begin{abstract}
si hemos de atender la consideración patronal, ya anticipé mi disentimiento al respecto por cuanto no solo daban una aparente solución a la rencilla sostenida por su personal, con el sacrificio de un obrero, sino que ello revelaba la elección del camino más difícil para allanar esas dificultades, que pudieron superarse elocuentemente con la palabra oportuna, la digna autoridad de los dueños, ejemplo de elevada dirección, y no como aconteció ya una vez el intento de agresión, imposible a todas luces de excusar.

Es que las facultades de dirigir, ordenar y fiscalizar, reconocidas a favor de todo patrón con el objetos de cumplir los fines de su empresa, motivante del "jus variandi", debe como todo derecho, recibir un límite para su validéz (sic). ${ }^{50}$
\end{abstract}

Este tipo de intervención de un poder estatal sobre el control que un patrón ejercía sobre su empresa debe haber resultado en un golpe a la percepción que con respecto a su función como patrones tenían dentro de su empresa. Este reto, no exento de su propia carga patriarcal y prácticamente sugiriéndole de que manera llevar adelante la disciplina de su establecimiento, también generó resistencias a la intervención de las autoridades estatales sobre las relaciones laborales. El choque de dos lógicas diferentes daba con tierra la forma en que los empleadores tenían de relacionarse con sus trabajadores.

Los patrones quisieron también hacer uso de la Justicia del Trabajo a fin de anticipar cualquier tipo de demanda interpuesta por sus trabajadores. La interposición de una demanda contra sus trabajadores le aseguraba al patrón la posibilidad de poder controlar al menos inicialmente la carátula de la causa, $y$, porqué no, sentar un buen precedente con respecto a la voluntad de los jueces en cuanto a intenciones de solucionar un posible conflicto mediante los canales institucionales. Hay que destacar que los patrones que acudían a los Tribunales Laborales eran los menos, y solo dos causas del universo analizado dan cuenta de esa posibilidad.

En el caso que envolvió a Formenti José e hijos Sociedad Anónima y el menor -bajo tutela estatal- Juan Francisco Fernández ${ }^{51}$, indica algunas de las pautas que seguían los patrones para hacer uso de la estructura institucional dispuesta por el poder judicial. En Junio de 1955 la empresa -propietaria de

\footnotetext{
${ }^{50} \mathrm{DH} 102 / 2$, foja 81 y sig.

${ }^{51} \mathrm{DH}$ 104/7 Formenti José e hijos Sociedad Anónima c/ Fernández Juan Francisco s/ consignación. Año 1955.
} 
comercios de panadería- le inició una causa por consignación de haberes a Juan Francisco Fernández. La consignación constaba en el depósito, en una cuenta especial perteneciente al Tribunal, del monto del salario y la indemnización que la Sociedad Anónima sostuvo le adeudaba al obrero en ocasión de haber abandonado este su trabajo. Al tratarse de un menor la causa era por demás compleja, ya que intervenó también la Dirección General de Protección de Menores (el menor estaba bajo su tutela y el trabajo era consecuencia de un pedido de este organismo a empresas de la región), y actuaba de oficio el defensor de pobres. Al defensor de pobres se sumaban como patrocinantes del obrero los abogados de la Sección Patrocinio Jurídico de la Delegación Regional de la Secretaría de Trabajo y Previsión. Estos abogados tenían una participación activa en la promoción de causas de los obreros por sus fluidos contactos con sindicatos y asociaciones obreras y su rol como funcionarios estatales de la secretaría. El abogado de dicha repartición, Roberto Terrasa, negó por completo los dichos de la demanda.

La firma Formenti e hijos sostenía que la contratación del menor fue a raíz de un pedido de la Dirección General de Protección de Menores y que si bien su primer sueldo correspondió al arreglo que esa institución tuvo con la empresa, al mes de entrar ya estaba enmarcado como planta del establecimiento y cobrando lo estipulado por el Convenio Colectivo correspondiente. Siempre según el patrón, Juan Francisco abandonó su trabajo en Diciembre de 1954 por propia voluntad e inició posteriormente acciones en la Delegación Regional (donde entró en contacto con los funcionarios del área legal), solicitando indemnización por falta de preaviso, diferencia de jornal y sueldo anual complementario. En Enero de 1955 Formenti envió un telegrama solicitándole al trabajador que pasase por la panadería a retirar la suma adeuda y este se negó, por "ello, y a fin de procurar una decisión judicial que ponga fin al diferendo, mi parte se ve precisada a deducir esta demanda" 52

El traslado de la demanda marca a las claras la estrategia del empresario. El abogado Dr. Terrasa otorgó otra versión de los hechos. Sostiene que Juan Francisco ingresó como ayudante de pastelería, y que no

\footnotetext{
${ }^{52} \mathrm{DH} 104 / 7$, foja 7.
} 
se fue por sus propios medios, sino que fue despedido arbitraria e injustificadamente. Por lo tanto lo consignado es muy inferior a lo que en realidad se le adeudaba. Expuso que el actor fue despedido

por haberse enterado (el patrón) de que el mismo había concurrido al sindicato respectivo a enterarse de las condiciones de trabajo que le correspondían, motivando que aquélla (la sociedad anónima) se presentase a la Dirección de Protección de Menores de la cual dependía mi mandante, a que exigiera de este su renuncia al trabajo, todo lo cual está reconocido expresamente por la actora en las actuaciones administrativas producidas. ${ }^{53}$

Ante la complicación de la estrategia legal de prever los movimientos del menor y sus representantes legales, la empresa buscó dirigir la causa hacia la indisciplina y la poca voluntad de trabajar de Juan Francisco. Amparados por el testimonio de su guardadora ${ }^{54}$, buscaron promover la idea de una demanda infundada basada en la exageración de los abogados que defienden al menor y que atentaban contra el normal desarrollo de la actividad productiva de una empresa comprometida con el bienestar de sus trabajadores. Sostuvo que el menor abandonó el trabajo por cuestiones de su propio carácter poco afecto al trabajo.

El veredicto finalmente no terminó siendo favorable a ninguna de las dos partes, ya que el patrón fue obligado a pagar un monto mayor al que había depositado, aunque se reconoce en el mismo que Juan Francisco Fernández abandonó el trabajo, y por lo tanto no correspondía la indemnización por despido que hubiese duplicado la indemnización.

Otro caso en el que se percibió de una estrategia similar por parte de la patronal es el que refiere a la demanda que Ángel Cosimati presenta contra la empresa Prenz y Zanette ${ }^{55}$, fabricante de ladrillos. Aquí fue el obrero quien

\footnotetext{
${ }^{53} \mathrm{DH} 104 / 7$, foja 20. Cursiva agregado mío.

${ }^{54}$ El informe de la inspectora Carolina Luisa Faverio, dice que "pudiendo comprobar por propias manifestaciones del menor causante, corroboradas por su guardadora, de que este es poco afecto al trabajo, es decir que no persevera en el desempeño de sus obligaciones, pues que el mínimo sacrificio, común a todo trabajo, como es levantarse temprano, etc., el menor opta por abandonar su ocupación y dedicar el tiempo libre a sus amigos, poco recomendables por cierto. También manifiesta su guardadora que el poco dinero percibido en lugar de invertirlo en ropas y efectos personales, o bien con este ayudar a solventar los gastos del hogar, lo distrae en pequeñeces y con los amigos, desoyendo los consejos de su guardadora, y más aun la conducta de este menor ha variado notablemente, por lo que llamé seriamente a la reflexión a este menor, quien prometió desde este momento cambiar de conducta.

Destaco que en realidad no es todo imputable al menor, sino que en parte debe culpársele a sus guardadores, personas honorables y de trabajo, pero en razón del acendrado cariño que le profesan, en parte y por ser personas débiles de carácter, no han tenido la energía necesaria para reprimir desde sus comienzos y encauzarlo". DH 104/7, foja 81.

${ }^{55} \mathrm{DH}$ 103/8Cosimati Ángel c/ Prenz y Zanette s/despido, etc. Año 1953.
} 
presentó su segunda demanda contra la empresa (la primera estaba radicada en el Tribunal Laboral $\mathrm{N}^{\circ} 2$ de la misma ciudad de La Plata y era por cobro de salarios por enfermedad inculpable), sobre indemnización por despido en momentos de enfermedad inculpable. El obrero era apilador de ladrillos y sereno en la fábrica mencionada y residía en una vivienda dentro del establecimiento que formaba parte de su salario. Si bien por cuestiones de plazo procesal se cae el derecho a contestar la demanda -se vence el plazo legal- el abogado de la empresa, el Dr. Romano Yalour, interpone un recurso de Litis Pendencia. Este recurso da cuenta de la existencia de una causa judicial previa entre las mismas partes, y de ser aceptado, supone que el juicio en cuestión es declarado nulo en tanto y en cuanto no se resuelva previamente el proceso anterior en marcha.

En el caso en cuestión el juicio previo estaba afincado en el Tribunal Laboral $\mathrm{N}^{\circ} 2$, en la secretaría del Dr. Wamba. El juicio iniciado por la patronal sobre consignación de haberes y desalojo se debía a que el trabajador

fue despedido por sus mandantes, con justa causa por haberse negado a trabajar, sin motivo alguno, negándose también a percibir los haberes que mis representados le adeudaban, como así también a dejar la vivienda que ocupa en el horno propiedad de mis representados que fue en parte del salario que recibía. ${ }^{56}$

Nuevamente se observa a los patrones actuando con anterioridad a la presentación del obrero frente a las autoridades judiciales (las causas tienen 10 días de diferencia) como una manera de controlar el proceso. En este caso las cuestiones de forma a las que eran tan apegados en la institución judicial incluso en el fuero laboral- terminaron por derrumbar el intento del Dr. Jorge Romano Yalour de interponer el pedido de Litis Pendencia, ya que el tribunal consideró que la presentación fue hecha fuera de plazo por lo que no corresponde tenerla en cuenta a la hora de emitir su fallo, que sería contrario a los intereses patronales. Yalour, conocedor de los laberintos legales, presenta un recurso de apelación a la Suprema Corte de Justicia, debido a que considera que el fallo es anticonstitucional por no haber permitido al justa defensa al negarse la aceptación del recurso de Litis Pendencia. De todas maneras tanto el Procurador como la Suprema Corte de la Provincia de Buenos Aires terminaron desestimando el recurso y aceptando la sentencia del tribunal, que de esta manera quedó firme.

\footnotetext{
${ }^{56} \mathrm{DH} 103 / 8$, foja 15.
} 
Lo interesante de estos dos casos es la de encontrar a patrones dispuestos a utilizar un espacio considerado a priori contrario a la patronal como medida de prevención frente a posibles reclamos obreros. De todas maneras no parece que esta estrategia fuese adoptada previo a cualquier reclamo, sino que era más bien una anticipación a los pasos que seguramente seguiría el obrero. De hecho muchas de las causas no comenzaban en las salas de los tribunales, sino en las oficinas de la Delegación Regional de la Secretaría de Trabajo y Previsión, o en los locales de los sindicatos.

Por lo general el recorrido del reclamo obrero partió desde su acercamiento al sindicato, de allí a las oficinas de la Delegación Regional, y si ese recurso no daba los resultados esperados, los Tribunales del Trabajo. En ambos casos hay indicios firmes de que los obreros ya estaban recorriendo ese camino en el reclamo de sus derechos. De esta manera el recurso o estrategia del patrón es la de saltear pasos -una resolución negativa a sus intereses por parte de la autoridad administrativa podía sentar precedentes a la hora del juicio- y buscar controlar el devenir de la causa. El hecho de anticiparse al reclamo pudo influir tanto en la resolución de tribunal como en los montos fijados en caso de perder el juicio. Aun así, según se desprende de estos casos, la estrategia patronal no logró cambiar el sentido pro obrero de los Tribunales Laborales.

La posición de los patrones ante la justicia del trabajo propone también un sistema de colectivización en donde los caminos individuales son desestimados por parte de las autoridades. En la medida en que son capaces de emplear a uno o más trabajadores ya son patrones, sin importar el tamaño del establecimiento o las capacidades económicas que posean. En este sentido la ley con su pretensión universalisante generó disconformidad en los patrones que consideran su particular situación como una variante que debió ser contemplada excepcionalmente. La legislación ampliadora de derechos del peronismo sin dudas beneficiaba al trabajador y predisponía también a la mala voluntad de los patrones. Sin embargo en la medida en que el peronismo buscaba la resolución de los conflictos y la armonía de las clases, el discurso de la humanización del capital implicaba reconocer un lugar especial para los patrones. La idea de la cooperación y del capital puesto a servicio de la economía social implicaba reconocer en ese capital -no ya en el capital 
especulativo y avaro de otrora- un aliado fundamental de los intereses de la Nación. En este sentido la justicia laboral, aun con sus prerrogativas proobreras, respondía a un modelo en lo que debía primar era la justicia social, en donde la contracara de los beneficios para los obreros era la jerarquización del capital puesto al servicio de lo social.

Este discurso no le era ajeno a los propietarios de los establecimientos que no dudaban en colocar a sus trabajadores como saboteadores y promotores de los conflictos que rompian con la armonía que debía regir entre los patrones y sus trabajadores. Tal es el caso del propietario de una grasería en la localidad de Lobos, el Sr. Pedro Yannarella. El 21 de Marzo de 1950 Crescencio Osvaldo Babino le inició una demanda por indemnización de despido, aguinaldo y diferencia de sueldos. Según el escrito de demanda el despido fue producto de que el actor se acercó el 4 de Febrero de 1950 a la delegación local de la Secretaría de Trabajo y Previsión a interiorizarse sobre el salario que le correspondía según el convenio colectivo celebrado por el sindicato de obreros de su profesión. Esta actitud fue mal vista por la parte patronal "la que con un desconocimiento incalificable de los derechos de sus subordinado envía el telegrama $\mathrm{N}^{\circ} 30^{\prime \prime} 57$ de despido.

La versión de la patronal difirió fuertemente de aquella que presentó el trabajador y al contrario de esta construyó una imagen de armonía que se vio interrumpida por la presencia de Babino. La sospecha que quería el actor presentar ante el tribunal quedó a cubierto ante "la solvencia moral y material de la demandada" ${ }^{\prime 58}$. El reforzamiento moral de la imagen del buen patrón como garantía de lo descabellado de la demanda -imagen que por otro lado no era inusual- fue sostenida con la presentación de la contraparte: el trabajador indisciplinado y desordenado que al atentar contra el patrón atentó contra la patria.

Sostiene el escrito de contestación de demanda el despido se debió a que:

el actor como obrero se destacó siempre por su falta de contracción al trabajo y por sus repetidas faltas sin causa justificada, lo que provocaba el reclamo de los demás obreros, ya que a este no se le descontaba el importe de sus sueldo cuando faltaba.

\footnotetext{
${ }^{57}$ DH 102/17 Babino Crescencio Osvaldo c/ Yannarella Pedro A y Cía s/ Despido- aguinaldodiferencia de sueldo, Año 1950. Foja 4 vuelta.

${ }^{58} \mathrm{DH} 102 / 17$, foja 17
} 
El 18 de Octubre de 1949 fue suspendido por diez días por sus faltas reiteradas, incumplimiento horario y trabajo a desgano (...) dos días después y ante la promesa de comportarse correctamente, ésta suspensión le fue levantada y sus sueldos íntegramente pagados.

Las promesas de enmienda del obrero fueron simples palabras; su acción perturbadora llega hasta sus compañeros de trabajo, a quienes pretende llevar a provocar conflictos con sus patrones y los incita a trabajar a desgano, saboteando la producción de la fábrica que está y estará siempre al servicio de los intereses de la patria.

La vida desordenada que lleva este obrero culmina con su detención y procesamiento por la Policía de Lobos, por violación de la Ley de Pesca.(...) Al tenerse conocimiento de estos hechos irregulares en la vida del obrero, se dispuso llamarle seriamente la atención, considerando que el hecho de colocarse al margen de la ley era causal de despido justificado ${ }^{59}$.

El trabajador díscolo era el que rompía con la armonía reinante en el trabajo, su vida desordenada, y su falta de disciplina generaba en el ambiente de trabajo hostilidad, tanto entre sus compañeros como ante con el patrón. En cambio el patrón era el que colocaba su establecimiento al servicio de la patria, dando cuenta de las necesidades de la hora. La decisión patronal en cuanto al despido del trabajador se sustentó, entonces, en el discurso político imperante y fue expresado en un lenguaje de construcción de la estatura moral del patrón, pero en una matriz diferente de los casos anteriores. Efectivamente en muchos casos la patronal, incapaz de percibir los cambios que se gestaron en la relación laboral, construyó su relato desde una matriz del patronazgo, donde la autoridad del patrón equivalía a la del padre de familia. En cambio en esta situación el Sr. Pedro Yannarella dio cuenta de otra matriz discursiva, en la que la autoridad patronal se construye en el respeto a la legislación y a la construcción de un espacio laboral acorde con la propuesta de armonía entre las clases, en la que el capital se ponía a disposición de la patria.

El respeto por el lugar del trabajador en el entramado productivo y la falta de respecto de la contraparte la reforzó el patrón por medio del aval de la representación sindical. El momento del despido marca la materialización del discurso patronal: ante el delegado sindical de la fábrica, el sr. Francisco Calviño, el actor de la causa trató de ladrones a los propietarios, y reclamó por la retención que estos hacían de los aportes jubilatorios. El patrón, así, fue presentado en la acción como el que resguardaba los derechos del trabajador cumpliendo con la ley, mientras que el trabajador reaccionó demostrando su

\footnotetext{
${ }^{59} \mathrm{DH} 102 / 17$, foja 17 vuelta y sig.
} 
indisciplina. Además la presencia del delegado de la parte obrera, avalando con su presencia la acción, daba cuenta del marco de legalidad que cubrió a la acción de la cesantía del trabajador.

La estrategia patronal finalmente no rindió frutos y el Tribunal falló a favor del actor. Sin embargo continuaron asociando al patrón con el buen industrial en el pedido de elevación a la Corte provincial -la instancia de apelación de la justicia del trabajo- en un recurso de inconstitucionalidad e inaplicabilidad de la ley y nulidad del proceso, ya que el fallo del tribunal se basó en la contestación en rebeldía del pliego de posiciones. Efectivamente la parte demandada no contestó el pliego de posiciones a absolver en el tiempo procesal previsto dando por verdaderas las pruebas provistas por el actor ${ }^{60}$. Esta cuestión procesal fue acusada por el nuevo representante legal del demandado, el Dr. Carlos Antonio Rua, quien sostuvo que sus mandantes

han ajustado su conducta al ámbito de sus derechos que solo una negligencia culpable de la persona comisionada para la presentación del escrito de contestación y de la probanza correspondiente ha podido hacer que he escrito no fuera glosado al juicio en su oportunidad ${ }^{61}$.

Esta situación había dejado a la parte patronal verdaderamente indefensos ante la acción intentada por Babino. Ante esta situación los jueces no podían quedar "impasibles en presencia de una sentencia que confiere derechos que no corresponden al actor y que la ley no les concede"62. El recurso legal interpuesto se sustentaba en cuestiones procesales y de derecho, pero también en lo justo:

si legítimos y valederos son los derechos de quienes trabajan, no menos legítimos y justos son los de aquellos que, además de su esfuerzo personal, ponen sus capitales menguados en una industria, la que es de necesidad nacional ${ }^{63}$.

La política asumida por la parte patronal implicaba el reconocimiento explícito de los derechos laborales, al tiempo de resaltar la importancia del capital en el proyecto nacional. Lo justo era fundamental en la definición de la estrategia patronal. La condena económica -que según Carlos Rua era

\footnotetext{
${ }^{60}$ Debido a la inversión de la carga de la prueba que se sostenía como principio en la justicia del trabajo, al no contestar el pliego y no acudir a la audiencia previa al dictado del veredicto la parte demandada avaló que el tribunal considerara demostrados los hechos expuestos en el escrito de la demanda.

${ }^{61} \mathrm{DH} 102 / 17$, Foja 81 vuelta.

${ }^{62}$ Ibídem.

${ }^{63}$ Ibídem.
} 
confiscatorio teniendo en cuenta lo menguado del capital de la empresa- era fundamentalmente una condena moral a quienes habían puesto su conocimiento, su capital y su esfuerzo personal al servicio de la patria.

El recurso sería aceptado por la procuración y elevado, entonces a la Suprema Corte de Justicia de la provincia de Buenos Aires, haciendo lugar exclusivamente al pedido de nulidad e inaplicabilidad de la ley y rechazando el pedido de inconstitucionalidad. Ante esta posibilidad El Dr. Carlos Rua redactó la presentación ante la Corte centrándose en la inaplicabilidad de los Convenios Colectivos N$^{\circ} 73$ del 17 de Mayo de 1948 y el $N^{\circ} 129$ del 22 de Junio de 1949 firmados en la Capital Federal entre el sindicato y la cámara empresarial sobre los que se sustentó la sentencia que obligaba al pago "confiscatorio". Según el abogado de la demandada los convenios sobre los que se obligaba al pago habían sido firmado por los patrones de la Capital Federal y que "esos que aceptaron las clausulas de los convenios, estaban en condiciones económicas para aceptar las pertinentes erogaciones" ${ }^{\prime 64}$. En cambio los pequeños establecimientos como el de sus defendidos carecían de las características de las grandes empresas porteñas, y por lo tanto el pago se tornaba imposible.

El patrón, en estas empresas era un trabajador más y no era justo aplicarles la misma ley que a los grandes capitalistas.

estos pequeños industriales reciben un escaso interés por el capital reducido que inviertes en la empresa y una módica retribución por sus tareas personales, pues trabajan a la par que los mismos obreros del establecimiento y no podrían soportar la carga que les impone esos convenios colectivos ${ }^{65}$.

La diferenciación con respecto a los grandes patrones debía ser parte de las funciones de las autoridades administrativas tal como lo había promovido el decreto 33.302 de 1945 convertido en ley 12.921 que establecía el Instituto Nacional de Remuneraciones acordando que se debía contemplar las diferencias para evitar las injusticias. No había sido este el caso ya que

cuando las autoridades administrativas establecen condiciones de labor, garantías de seguridad y de higiene y demás circunstancias, lo hacen teniendo en cuenta las responsabilidades patronales y las necesidades obreras, conforme al medio en que uno y otro se desenvuelven. Pero medir con el mismo rasero a poderosos capitalistas del gran Buenos Aires y a

\footnotetext{
${ }^{64} \mathrm{DH}$ 102/17, Foja 97.

${ }^{65} \mathrm{DH} 102 / 17$, foja 97 vuelta
} 
pequeños industriales de zonas del interior, importa un atentado contra la misma libertad de trabajo, encerrando un perjuicio, tanto para los obreros que trabajan en las pequeñas industrias, cuanto a quienes son los titulares de estas. ${ }^{66}$

La patronal no se presentó como ajena a la necesidad de la sanción y aplicación de la legislación laboral, sino que reclamaba el uso de la discrecionalidad a fin de separar la paja del trigo. En tanto pequeños industriales del interior de la provincia reclamaban un trato acorde y que no se los equiparase en las obligaciones con los grandes capitalistas del Gran Buenos Aires. Cabe preguntarse cuanto de este relato es exclusivamente estrategia judicial y cuanto responde a la adopción, por parte de Pedro Yannarella, del discurso de armonía de las clases y la promoción de los que trabajan por la patria. La equiparación del patrón al trabajador en la medida en que trabajan a la par da cuenta de una concepción distinta sobre lo que significa ser patrón con respecto a las causas anteriormente expuestas. Pero además el reclamo sobre lo verdaderamente justo interpela a la idea de Justicia Social que promovía el gobierno. ¿Era justo que se lo condenara como a un capitalista cuando daba sobradas pruebas de ser parte del capital humanizado?

Pero si los jueces debían contemplar las situaciones particulares y escapar -cuando era necesario- de la fría letra de la ley, la Suprema Corte provincial conservó para estas causas los lineamientos del poder del que era la cabeza. La resolución de la causa no se basó en si el patrón respondía o no a los lineamientos de política económica que se proponía el gobierno, o si los convenios eran aplicables a pequeños empresarios tanto como a los grandes. La resolución de la Corte fue expresada en el voto del Dr. Moreno Hueyo. Las razones del rechazo de las excepciones planteadas en el recurso estiban en las cuestiones procesales, ya que el rechazo a los convenios no fue realizado ni en la contestación de la demanda ni en la audiencia previa al veredicto de la primera instancia. La Corte no resolvió sobre las cuestiones de fondo, sino que primó el derecho y las razones procesales.

En definitiva la patronal buscó revertir la situación que le planteaba la institucionalización de un derecho que les era contrario a sus intereses. Aun en

\footnotetext{
${ }^{66} \mathrm{DH} 102 / 17$, foja 98.
} 
el caso de los pequeños industriales, que fueron el objetivo del discurso gubernamental después de los trabajadores, la justicia del trabajo era una arena hostil para las pretensiones patronales. Las causas judiciales brindaron una mirada sobre las concepciones que los patrones tenían sobre su rol como tales y la relación con sus trabajadores. Pero fundamentalmente permitieron reconstruir en parte las trayectorias y la experiencia de estos actores centrales en la relación productiva. Al plantear desde la misma institución el reconocimiento de las partes en términos relacionales (hay patrón si y sólo si hay obreros y viceversa) la fuente es solidaria con la perspectiva en la que pretendo fundar la investigación ya que permite no sólo reconstruir la experiencia obrera en relación a sus patrones, sino que da la posibilidad de observar los cambios a los que estaba sujetos los participantes de esa relación.

\section{VI.4 Reflexiones/Conclusiones}

La justicia del trabajo abrió nuevas formas de encauzar el conflicto laboral, que colocaron a los trabajadores y patrones ante nuevas interpelaciones ya que puso en tensión los significados de los dos polos de la relación laboral. En el camino a la justicia del trabajo los trabajadores entraron en contacto con diferentes actores (abogados, funcionarios estatales, delegados sindicales, representantes legales) y los colocó frente a su opuesto que redefinieron el significado de ser trabajador. Estas trayectorias abre el interrogante sobre las pretensiones individualizadoras de la justicia laboral.

¿Cómo asumir la presentación de los trabajadores ante la justicia del trabajo como una forma de acción colectiva y no individual? Aun dando cuenta de los límites de la individualización que como institución imponía el proceso de la justicia laboral, la presencia de trabajadores individuales ante el estrado judicial no puede ser pensado exclusivamente dentro de marcos analíticos individualizantes o centrados en la acción racional de un individuo como ejes explicatorios. Ya sugería Durkheim en su estudio sobre el suicidio en Francia que una acción de índole tan privada y ligada al individuo como la decisión de quitarse la vida no podía explicarse sólo por "constitución orgánico-psiquica de los individuos" ${ }^{67}$ sino que se debe a causas sociales y por este motivo constituir

\footnotetext{
${ }^{67}$ DURKHEIM Emile, El Suicidio, Ediciones del Libertador, Buenos Aires, 2004. Pp.127
} 
un fenómeno colectivo. Entonces ¿qué causas sociales explican la afluencia de los trabajadores a la Justicia del Trabajo?

El tipo de conflicto analizado no reviste las características de un conflicto tendiente al cambio social, entendiendo este como el reemplazo de una sociedad por otra. Sin embargo se trata de una conflictividad permanente que apunta hacia el centro de la disputa entre el capital y el trabajo. La acción judicial asumía que se trataba de resolver las disputas surgidas de una relación social y no ya del simple intercambio de mercaderías sobre la que se sostenía la forma jurídica del fetiche de la mercancía en la tradición civil. Se trata de una forma más del mismo conflicto, en la medida en que las disputas se dan en torno a los derechos surgidos de la relación (de explotación) entre el trabajador y su patrón, y este conflicto sólo puede ser entendido colectivamente.

No es posible, comprendiendo a los conflictos en la justicia del trabajo como conflictos colectivos, construir la explicación de los conflictos a través exclusivamente de las acciones de los individuos. No hay dudas de que los trabajadores que acuden a la justicia del trabajo lo hacen con un previo análisis de sus posibilidades. $Y$ este análisis conlleva la elección de un fin y los medios para llevarlo a cabo. Pero esta elección no es común a todos los individuos envueltos en una relación laboral $e$ incluso no todos tienen las mismas posibilidades a la hora de optar por los medios. Este tipo de conflicto en donde pesan las motivaciones individuales pero sin negar el carácter colectivo del mismo se presentan como una ocasión ideal para repensar el concepto de la agencia histórica de los individuos. La lucha es llevada adelante por un individuo en una institución individualizante como la Justicia del Trabajo bonaerense, pero responde a un conflicto que se desprende no ya de una relación entre individuos privados sino que es consecuencia de la desigualdad en la que se funda dicha relación y que define incluso el carácter de la sociedad misma. La agencia histórica permite abordar a los actores en pugna sin dejar de lado su posición concreta en el entramado social.

Esta posibilidad que abre el concepto de agencia histórica permite reconstruir las trayectorias individuales e interrelacionarlas en configuraciones sociales (¿marco estructural?). Al contemplar la agencia histórica como concepto clave de la explicación se logra romper con una dicotomía entre la explicación basada exclusivamente en el individuo o aquellas que buscan 
hacerlo exclusivamente mediante la estructura. El concepto de agencia, definido como las capacidades estructurales de los individuos ${ }^{66}$, permite desnaturalizar una distinción que las ciencias sociales han tomado ya como real entre el individuo y la estructura. Ya Norbert Elías llamó la atención sobre los problemas que implica en términos del análisis sociohistórico perder de vista en entramado social en el que operan los individuos. Del mismo modo que las acciones individuales no pueden ser explicadas exclusivamente sobre las bases estructurales de una sociedad, la sociedad misma no puede ser explicada sin recurrir a los individuos que la conforman ni mediante la consideración de la suma de los individuos como partes autónomas ${ }^{69}$.

Trasladadas estas reflexiones al caso de la Justicia del Trabajo es evidente, como ya se remarco, el impulso individual de los trabajadores a acudir a la justicia. Pero esta posibilidad es producto de una mejora en las capacidades estructurales de los trabajadores. La creación de una institución directamente ligada a resolver cuestiones tan sensibles al colectivo del trabajo, como las formas y el valor en las que se intercambian el trabajo, no podía sino interpelar a toda la comunidad laboral. Retomando la cuestión de los límites, la interpelación misma que el Derecho del Trabajo realiza sobre los sujetos los cataloga dentro de un colectivo que posee características distintivas según el polo de la relación que encarnen. En el caso de los trabajadores los interpela justamente como trabajadores y no ya sólo como ciudadanos dotados de los mismos derechos y obligaciones. Esta interpelación, aun pensada como ampliación de los derechos de ciudadanía, es una ampliación ligada a la existencia de una comunidad determinada, es decir que se identifican como parte de un colectivo.

Esta identificación permite pensar a los trabajadores que acuden a la Justicia del Trabajo como parte de una misma comunidad. Según Hobsbawm a la clase obrera "su experiencia de las cosas laborales les demuestra todos los días que han de obrar colectivamente. Pero aun su labor colectiva requiere, para ser efectiva, estructuración y dirección"70. La referencia es clara y alude a los Sindicatos u organizaciones de carácter clasista que buscasen activamente

\footnotetext{
${ }^{68}$ CALLINICOS Alex, Op. Cit.

${ }_{70}^{69}$ ELÍAS Norbert, Op. Cit.

70 HOBSBAWM Eric, Marxismo e Historia Social, Universidad Autónoma de Puebla, México, 1983. Pp. 73.
} 
la promoción y defensa de los trabajadores como colectividad. La existencia de este tipo de organizaciones formales garantiza la permanencia de las formas duraderas de acción colectiva. Pero aunque los sindicatos sin dudas se encuentran en la trayectoria del trabajador en la procura de sus derechos (muchas causas judiciales eran promovidas por los abogados provistos por los sindicatos o era en el local sindical donde el trabajador recurría en primer término para buscar resarcimiento) y a pesar de contar con personería jurídica $^{71}$ su presencia como parte en juicio era explícitamente excluida por la Ley 5178 de la provincia de Buenos Aires.

Si bien la acción colectiva, en su definición minimalista, implica ciertamente la existencia de la voluntad de individuos -ya definidos como agentes- de coordinar sus acciones en búsqueda de un fin, la presencia de una organización formal le otorga permanencia en el tiempo. Pero excluidos los sindicatos el trabajo de pensar la acción judicial como acción colectiva requiere una explicación en donde el concepto mismo de agente sea central.

Definida la agencia como el ejercicio de la capacidad estructural de los individuos se puede sostener que la voluntad (individual) de presentarse como parte de un conflicto implica el análisis de la situación y la elección del medio para logar el fin deseado. En este camino la Justicia del Trabajo, ¿implica una transformación de dichas capacidades estructurales? ¿su estructura organizativa puede ser pensada como una organización formal que promueva la acción colectiva? La primera pregunta no parece encontrar demasiadas complicaciones. No hay dudas de que la creación de un canal más para llevar adelante el conflicto, aun cuando se trate de una institución estatal, cambia las condiciones estructurales sobre las cuales sostener y promover el conflicto, aun cuando se trate de un cambio que promueve no ya un nivel de aspiración de cambio social profundo, sino a la satisfacción de demandas inmediatas concretas.

En lo que respecta al tipo de organización la respuesta implica desandar algunos lugares comunes sobre el lugar del Estado en el conflicto. Una idea

\footnotetext{
${ }^{71}$ El Código Civil otorga derechos y obligaciones a personas físicas. La figura de persona jurídica avala que actores colectivos bajo ciertas premisas adquieran la potestad de presentarse como poseedores de derechos y obligaciones.
} 
común sobre el Estado y el conflicto de clases lo expresa historiográficamente Eric Hobsbawm

el conflicto de clase puede ser regulado mediante una especie de válvula de seguridad, como en tantas revueltas de plebeyos urbanos en las ciudades preindustriales, o institucionalizado como "rituales de la rebelíon" (para emplear la frase iluminadora de Max Gluckman) o de otras formas; pero a veces no puede serlo. El Estado normalmente legitimará el orden social mediante el control del conflicto de clases dentro de un sistema estable de instituciones y valores, permanenciendo ostensiblemente por encima y fuera de ellos (el rey remoto como "fuente de justicia"), y al hacer esto perpetuará una sociedad que de otra forma se vería desgarrada por sus tensiones internas ${ }^{72}$

Esta premisa implica aceptar que el conflicto de clases funciona como una olla donde se va acumulando presión hasta estallar e implica creer que esta presión puede ser liberada en dosis tales de no desestabilizar el sistema en su totalidad. Asumir esto es herir de muerte la creencia el concepto de agencia histórica. Ya no se trata del ejercicio de los poderes estructurales históricamente limitados o potenciados, sino la existencia de umbrales de aceptación o rechazo de la explotación que pueden ser definidos de antemano por los sectores dominantes. La Justicia del trabajo podría ser catalogada como un ritual de la rebelión en tanto institución estatal que se coloca discursivamente ostensiblemente por encima y fuera del conflicto. Pero la existencia de una institución ligada y nacida bajo la intención de evitar los desgarros sociales no se puede sostener que fuese una válvula de escape a las tensiones entre el capital y el trabajo. En tanto institución basada en domesticar mediante la individualización un conflicto colectivo que tiene potencialmente la salida de llevar a un cambio social, otorga al mismo tiempo la posibilidad concreta de ser reconocida como un posibilidad más del mismo conflicto, potencialmente ampliando las capacidades estructurales de una clase por sobre la otra.

\footnotetext{
72 Ibídem. Pp.96.
} 


\section{TERCERA PARTE: \\ LA JUSTICIA DEL TRABAJO \\ ANTE EL ORDEN POST- PERONISTA}




\section{CAPÍTULO VII \\ LA JUSTICIA LABORAL POSTPERONISTA. REORGANIZACIÓN Y REVANCHA}

\section{Introducción}

En Septiembre de 1955 Argentina entraba en una nueva etapa de su historia al caer el gobierno de Juan Domingo Perón dando paso a un período de inestabilidad política que marcaría todo el proceso político posterior. La autoproclamada Revolución Libertadora que destituyó el gobierno se propuso como su objetivo el regreso de la Argentina a las senda de la tradición repúblicana, liberal y democrática que según sus ejecutores marcaban el desarrollo político previo al peronismo -lo que se dio a conocer como la desperonización-. La proyección de los gobiernos peronistas como versión local de los totalitarismos europeos, operación que había comenzado incluso en el período previo a la elección de Febrero de 1946 en la que fue elegido Perón como presidente, otorgaba a la Revolución Libertadora y sus adherentes más radicales el derecho de su revolución a imponer la justicia de su causa ética ${ }^{1}$.

Si bien esta imagen del peronismo como mala copia del nazi fascismo no era compartida por el conglomerado de fuerzas antiperonistas que vieron con buenos ojos el derrocamiento de Perón, su definición por la negativa llevó a todos los actores antiperonistas inmersos en la vida política y social posterior a 1955 a responder a la pregunta sobre qué hacer con el peronismo de la misma manera. La desperonización aparecía como un objetivo imprescindible para garantizar la estabilidad política. Los alcances y límites del proceso de desperonización pretendidos variaron según la pertenencia ideológica de quienes sostenían la necesidad del proceso y de la resistencia que los actores implicados pudiesen oponer al mismo.

En el caso del Poder Judicial bonaerense la desperonización fue objeto de disputas entre diferentes actores que incluyó desde ya a los actores implicados directamente en la tarea de administrar justicia (jueces, abogados, secretarios, peritos, empleados administrativos), como así también a los

1 SPINELLI María Estela, Los vencedores vencidos. El antiperonismo y la "Revolución Libertadora", Biblos, Buenos Aires, 2005. 
actores que se disputaban el proyecto político estatal. Como institución creada por el peronismo, los Tribunales del Trabajo fueron objeto de un proceso de depuración de sus funcionarios, pero sin embargo continuaron regidos por la ley 5178 y sus modificatorias hasta la década de 1970. La desperonización encontró en las instituciones de la Justicia Social un escollo. Mientras que en el interregno del general Lonardi la defensa de estas instituciones fueron parte del proyecto político ${ }^{2}$, con el ascenso de las facciones más antiperonistas de la coalición (con el General Aramburu y el Comandante Rojas a la cabeza), el sostenimiento de estas instituciones pasó por la imposibilidad concreta de desandar el camino que había recorrido el peronismo.

El desgaste en su lucha contra el peronismo -con flagrantes violaciones a las disposiciones legales- y el fracaso por lograr una fuerza política capaz de vencer en elecciones fueron alguna de las razones que llevaron a los militares de la Libertadora a buscar una salida por medio de las urnas. Pero los ensayos electorales -las elecciones para la Constituyente de 1957- sólo demostraron la necesidad de las fuerzas del arco político de buscar una salida para la cuestión del peronismo que pudiese mantener la proscripción pero al mismo tiempo garantizar cierta representatividad electoral para los grandes contingentes electorales peronistas. Opciones neoperonistas -con fuerzas provinciales localmente fuertes- fueron una de las formas de lograr encauzar el voto peronista. Partidos como la UCR sufrieron una ruptura interna -ruptura que se venía prefigurando desde los tiempos del peronismo- por la respuesta a la "cuestión peronista". El contexto de las elecciones de 1957 dejaron en evidencia la necesidad de contar con algún acuerdo con Perón y los peronistas a fin de lograr la mayoría. Al mismo tiempo el gobierno militar vio ante sus ojos como sus estrategias fracasaron y no pudieron sostener la alianza con partidos y figuras que inicialmente apoyaron el golpe de Septiembre de 1955, pero que ahora se encontraban en la oposición al gobierno militar. El abandono de la Convención Constituyente por la Intransigencia del Partido Radical marcó el quiebre definitivo entre esa fuerza política -comandada por Arturo Frondizi y Oscar Alende entre otros- y el gobierno militar. Esto facilito el acercamiento al

\footnotetext{
${ }^{2}$ Lonardi recibió a dirigentes de la CGT y les garantizó la continuidad de las medidas de Justicia Social, en una demostración de que no habría "vencedores ni vencidos". Este intento de acercamiento de Lonardi con el movimiento obrero organizado se tradujo en la designación de Luis Benito Cerruti Costa como Ministro de Trabajo y Previsión. JAMES Daniel, Op. Cit.
} 
peronismo, incluyendo un pacto entre Perón y Rogelio Frigerio, que fue denunciado posteriormente por el propio Perón, que permitió a la UCRI ganar las elecciones presidenciales iniciando su mandato Arturo Frondizi en 1958.

La línea política de Frondizi implicó en sus primeros meses un acercamiento con objeto de seducir a los sindicalistas obreros a fin de que integrasen su proyecto político. Construyó un acercamiento a los sindicalistas peronistas en base a la proyección de su propia figura como una oposición al gobierno de la Libertadora y promotor de la ruptura del consenso antiperonista. Además esta seducción se sostuvo sobre la prédica de una estructura discursiva afín al peronismo (con énfasis en la Soberanía Nacional y la Justicia Social) ${ }^{3}$. Esto le permitió gozar de una tregua durante los primeros meses de su gobierno ${ }^{4}$ hasta que su plan económico dejó en evidencia el camino económico del desarrollismo con su énfasis en la productividad ${ }^{5}$.

Es en este contexto en el que se intenta recorrer el camino de la conflictividad judicial para percibir el impacto en el fuero de la revancha de los patrones. Sin embargo la hipótesis de trabajo es que el fuero laboral, como institución judicial, sostuvo una temporalidad que le era propia. Ajena en parte a los cambios -sobre todo en lo que respecta a sus formas procesales e instancias de resolución- enfrento el cambiante contexto en el que se iniciaban sus demandas con una serie de instrumentos que resguardaban su marca de origen. Indagar en los aspectos sobre los que la justicia laboral mantuvo su carácter proobrero en un momento de declinación o pérdida de capacidad de otras instituciones estatales encargadas de lidiar con el conflicto laboral.

El presente capítulo cierra circa 1960. La elección de la fecha no coincide con cortes institucionales ni responde a una razón interna del Tribunal del Trabajo $\mathrm{N}^{\circ} 1$ al que responden las fuentes fundamentales del capítulo. La razón debe encontrarse en los cambios en la conflictividad laboral que impiden extender las hipótesis aquí expuestas más allá del año 1960. De todas maneras cabe aclarar que la fecha 1960 en el caso de los expedientes

\footnotetext{
${ }^{3}$ MELON PIRRO Julio César, EI Peronismo.... Op. Cit.

${ }^{4}$ SCHNEIDER Alejandro, Los compañeros. Trabajadores, izquierda y peronismo (1955-1973). Imago Mundi, Buenos Aires, 2005.

${ }^{5}$ Sobre el viraje del discurso de la cuestión social en el desarrollismo y como este terminó imprimiendo un nuevo marco al debate de la cuestión social con énfasis en la idea de desarrollo como abarcadora de la cuestión social por medio de la superación del subdesarrollo veáse LAGUADO DUCA Arturo, La construcción de la cuestión social. El desarrollismo postperonista, Espacio Editorial, Buenos Aires, 2011.
} 
judiciales responde al inicio de las causas, ya que, de la misma manera como pudieron los tribunales laborales mantener una temporalidad propia de una institución de otro tiempo en el contexto postperonista, los juicios laborales demandaban un tiempo en su resolución que hace difícil trazar un corte definitivo. Sin embargo el contexto incide mucho más en las razones que llevan a iniciar una causa y el análisis de las opciones de ese momento realizadas por el trabajador y sus abogados patrocinantes, que en el momento del cierre de la causa.

Desde dos perspectivas diferentes se asume el bienio 1959-1960 como un año decisivo en la conflictividad obrero patronal. Daniel James y Alejandro Schneider reseñan el auge y decadencia de la movilización obrera del bienio 1959/60, aunque extraen diferentes conclusiones.

Para Daniel James el período 1955-1960 cierra con la desmoralización y el aislamiento de los trabajadores palpables en la desmovilización de los años 1960-1962 después de una intensa movilización de base que incluso -en los primeros momentos de negociación entre la CGT y el gobierno de la libertadora- había impedido a los dirigentes sindicales actuar por sobre su voluntad $^{6}$. Así, después de la incertidumbre de los primeros meses posteriores al golpe en el que las dirigencias sindicales buscaron aproximarse a las nuevas autoridades, la clase obrera no estuvo dispuesta a asumir el derrotismo de Perón y los dirigentes sindicales. De ahí que comenzaran acciones de resistencia en los lugares de trabajo y que los colocó en posición de impugnar los acuerdos entre esta clase dirigente y las nuevas autoridades. Los líderes sindicales que surgieron de estos momentos de resistencia, a pesar de no poder controlar el proceso, lograron asentarse en sus sindicatos generando una verdadera renovación de los cuadros sindicales. Su conformación como dirigentes logró superar la oposición de los militares quienes hicieron lo posible por lograr que dirigentes no peronistas ganasen la dirección de los sindicatos más importantes, pero al desplazar a la pasiva dirigencia del final del peronismo sólo abrieron el camino para el surgimiento de esta nueva dirigencia más combativa ${ }^{7}$.

\footnotetext{
${ }^{6}$ Ibídem.

7 JAMES Daniel, Op. Cit. Especialmente el capítulo 3.
} 
El análisis de Schneider, aunque coincidente sobre los primeros momentos y la conformación de una nueva dirigencia gremial, sostiene por el contrario que la amplia movilización de 1959 fue consecuencia de movimientos defensivos de la clase obrera organizada cuyos dirigentes ya habían logrado restablecerse después de los conflictos de 1956-58 y no por el optimismo de la base como sostiene James. Por lo tanto el retroceso en la actividad huelguística del año 1960 se debió a una combinación de elementos: el establecimiento definitivo de una nueva dirigencia sindical no dispuesta a perder lo ganado -encuentra en esta oposición la pervivencia de una conciencia de clase que choca contra el papel asumido durante el peronismo por la dirigencia cuyos "intereses no se correspondían con la clase trabajadora que decían representar" ${ }^{\prime 3}$ es decir que ya habían satisfecho sus demandas orgánicas- y el cambio general en cuanto al empleo que ya tendía hacia un proceso de menor creación de puestos de trabajo. Además se suma el compromiso que asumieron los metalúrgicos en el convenio colectivo que regulaba las relaciones laborales y facilitaba el reordenamiento industrial en búsqueda de una mayor productividad.

Ambos autores además coinciden en un punto central que define el fin del idilio del gobierno de Frondizi con la clase obrera organizada que es la instauración del plan CONINTES (Conmoción Interna del Estado) ${ }^{9}$ que demostró el límite concreto a la movilización obrera de 1959 al oponer a la movilización obrera $-y$ social- el empleo de las fuerzas de seguridad ${ }^{10}$. La represión progresiva y planificada (con detenciones de obreros y dirigentes sindicales, procesamientos por la jurisdicción militar, la intervención de sindicatos, etc.) colocó a los trabajadores en una situación desventajosa para rechazar el plan de estabilización económica implementado a partir de 1958 y los planes de racionalización industrial acordes con el proceso de cambio de la

\footnotetext{
${ }^{8}$ SCHNEIDER, Op. Cit. Pp. 77 y sig.

${ }^{9}$ El 14 de noviembre, por decreto secreto 9880, Frondizi creó el Plan de Conmoción Interna del Estado.

${ }^{10}$ DAMIN Nicolás, Plan CONINTES y Resistencia Peronista, 1955-1973, Instituto Nacional Juan Domingo Perón, Buenos Aires, 2010.
} 
industria argentina y el avance de las industrias dinámicas por sobre las tradicionales $^{11}$.

\section{VII.1 La Desperonización del Poder Judicial bonaerense}

\section{VII.1.1 Panorama de la Justicia a la caída de Perón}

Los miembros de la Revolución Libertadora, más que hacer hincapié en la peronización, resaltaban su opuesto, la desperonización, de esta manera se puede inferir que a todo aquello a lo que apuntaba a corregir la desperonización podría ser considerada peronización. La peronización también fue común en la década del sesenta y setenta, aunque en ese caso da cuenta del acercamiento de sectores de la izquierda a organizaciones peronistas y a sus bases, cuando no la aceptación de algunos de sus postulados. La peronización, en tanto categoría nativa de los gobiernos antiperonistas post 1955, daba cuenta de la avanzada totalitaria que en todos los aspectos de la vida que había significado el régimen del tirano prófugo ${ }^{12}$. Por lo general peronización englobaba diferentes fenómenos, que al ser presentados mediante su adjetivación, encontraban su origen en el régimen peronista, cuando no directamente en su líder. Así, la peronización encerraba la malversación de fondos públicos, la inmoralidad en el manejo de la cosa pública -expresión de la inmoralidad propia de Perón y sus hombres más cercanos $^{13}$-, la ausencia de ética, el desprecio por el estado de derecho, en fin, todos los vicios que sostenían la consagración de los gobiernos peronistas como la Segunda Tiranía ${ }^{14}$.

\footnotetext{
${ }^{11}$ Las industrias vegetativas eran las industrias tradicionales vinculadas a la demanda del mercado interno o a la elaboración básica de los productos primarios. Sobre el avance de los sectores dinámicos veáse SCHVARZER Jorge, Op. Cit, especialmente el capítulo 7.

${ }^{12}$ En su afán por detener las múltiples formas que adquirió la resistencia peronista, el gobierno de Aramburu -el segundo gobierno de la autoproclamada revolución Libertadora- prohibió la utilización de cualquier símbolo peronista incluido el nombre de Juan Domingo Perón. Tirano prófugo fue el apodo elegido sobre todo por los medios liberales para dar cuenta de Perón según se desprende de los titulares de los matutinos más importantes de la época.

${ }^{13}$ Es interesante percibir el impacto que en los medios gráficos tuvo la aparición de una menor de edad en los meses posteriores al golpe de Septiembre de 1955 que aducía tener una relación con el mandatario. A partir de la existencia de dos cartas firmadas por Perón en su estancia en la cañonera Paraguay y de la posesión por parte de la menos de joyas pertenecientes a Evita y autos y motos del general Perón, los medios construyeron una historia de perversión destinada a conformar un contra mito.

${ }_{14}$ Claramente para los sectores liberales la Primera Tiranía fue la de Juan Manuel de Rosas. Esto le spermitía ubicarse como los continuadores de los ideales de Caseros.
} 
Sin las cuestiones morales y éticas, aunque aun preservando parte de la carga política peyorativa, la peronización tal como la presenta Luis Alberto Romero ${ }^{15}$ es definida como el avance del gobierno peronista sobre la sociedad. El particular gobierno de la democracia de masas, en su voluntad por absorber en su plan a todas las esferas de actuación de la sociedad civil, avasalló la autonomía de diferentes organizaciones y llevó a una participación organizada desde arriba de las masas ${ }^{16}$. La peronización, es descrita entonces como el adoctrinamiento de la sociedad y del Estado. La burocracia estatal es obligada a afiliarse masivamente al partido gobernante -exigencia para la permanencia en los cargos-, y el ascenso y las promociones ya no fueron por medio de méritos, sino por la adhesión al ideario justicialista.

Romero sostiene su análisis en la elevación de la Doctrina Peronista como Doctrina Nacional en la Constitución de 1949 y su énfasis en la Comunidad Organizada como horizonte político para la conformación del Estado, objetivo sin dudas promovido por Perón. Efectivamente la Constitución de 1949 es un hito en la construcción del entramado institucional justicialista, y sus objetivos -expresados tanto en el preámbulo como en el capítulo IVguarda consonancia con dos pilares de la concepción ideológica del peronismo: la Justicia Social y la Tercera Posición ${ }^{17}$. Desde la promulgación de la Constitución de 1949 se atiende, entonces, a una real peronización, en la medida en que la Carta Magna, en tanto acción y aspiración de una nación expresión de la hegemonía que en ese momento ejercía el peronismo en tanto fuerza política- anteponía el logro del justicialismo como derecho fundamental de la nación.

El impacto que sobre el tejido social tuvo la peronización no significó, tal como se desprende de la lógica de Romero, una pérdida de autonomía de las asociaciones de la sociedad civil ni significó el fin del asociacionismo

\footnotetext{
${ }^{15}$ ROMERO Luis Alberto, Breve Historia Contemporánea de la Argentina, FCE, Buenos Aires, 1994.

${ }^{16}$ En otro trabajo Romero enfatiza la vigorosidad de las asociaciones de la sociedad civil previo al surgimiento del peronismo.

17 La constitución de 1949 fue abordada desde distintas perspectivas por investigadores sociales de diferentes disciplinas y afinidad ideológica. El tratamiento que aquí se hace se desprende de la ponencia presentada por Santiago Regolo al Primer Congreso del Peronismo REGOLO Santiago, Op. Cit.
} 
democratizador como práctica ${ }^{18}$. En el ámbito estatal y sobre todo en algunas de sus instituciones el peronismo sí implicó un profundo cambio que puede ser presentado como la voluntad de materializar hacia el interior del entramado burocrático un proyecto político en términos de Oszlak.

La Nueva Argentina ya no podía contar con funcionarios que no comprendiesen el sentido del justicialismo y sus máximas. Se trató de imprimir una nueva lógica burocrática al entramado estatal. La creación del la Justicia del Trabajo, las modificaciones en la Secretaría de Trabajo y Previsión, el pedido de afiliación, etc. fueron medidas tendientes a garantizar la aplicación de los dos pilares del justicialismo. En el caso de la provincia de Buenos Aires la separación entre los jueces y la doctrina justicialista promovió que el Poder Ejecutivo Nacional, interviniese el Poder Judicial bonaerense en 1952. La intervención quedó a cargo del doctor Raúl J. Rodríguez de Felipe, amigo personal del ministro de Asuntos Políticos, Román Subiza. En términos de la Comisión Nacional de Investigaciones "removió a los antiguos magistrados y los reemplazó por otros totalmente adictos"19. El sometimiento de los jueces por parte del Poder Ejecutivo se basaba en las renuncias que sin fecha debieron presentar los jueces nombrados por la intervención al gobernador Carlos Aloé. Muchas de ellas hacían referencia a su adhesión a los postulados de la Doctrina Justicialista, al partido peronista o expresaban su lealtad personal a Perón ${ }^{20}$. Los textos de las renuncias se le solicitaban a prácticamente todos los escalafones del Poder Judicial. Estas renuncias fueron el puntapié para la acusación de peronización de la justicia que hiciese la Comisión Nacional Investigadora. Al romper con la tradición judicial de inamovilidad de los jueces mediante el pedido de renuncia firmado previo a su aceptación al cargo, se suponía que los jueces no tendrían muchas posibilidades de fallar en contra de los intereses del gobierno, ya que hacerlo hubiese significado perder su puesto. Aun así la misma comisión sostuvo que no todos los magistrados fallaron según se les solicitaba, aunque algunos casos resonantes -como la

${ }^{18}$ ACHA Omar, "Sociedad Civil y Sociedad Política durante el primer peronismo", Desarrollo Económico, Vol. 44, №174 (Jul-Sept, 2004), pp. 199-230.

${ }^{19}$ Comisión Nacional Investigadora, Libro negro de la Segunda Tiranía, Comisión de la afirmación de la Revolución Libertadora, Buenos Aires, 1987, Pp. 119.

20 Texto de estas renuncias sin fechas pueden consultarse en Comisión Nacional de Investigaciones, Vicepresidencia de la Nación, Documentación, autores y cómplices de las irregularidades cometidas durante la Segunda Tiranía, Tomo I, Buenos Aires, 1958. Comisión $N^{\circ} 15$, Román A. Subiza. 
expropiación del grupo Bemberg y la situación del Departamento Judicial San Nicolás ${ }^{21}$ - eran lo suficientemente claros para demostrar las complicidades de los magistrados peronistas en el sostenimiento del aparato totalitario con el que se acusaba al peronismo.

En definitiva la peronización de la justicia -entendida como el ajuste de la estructura del Poder Judicial a los pilares ideológicos del Justicialismo- implicó una restructuración profunda del mapa judicial, con la creación de un nuevo fuero -el laboral-, la cesantía y designación de nuevos magistrados por medio de la intervención, y la búsqueda de vinculaciones de los magistrados con las ideas justicialistas, expresadas en la caída de la torre de marfil y la vinculación de los magistrados con los problemas sociales. Sin lugar a dudas este proceso puede ser entendido como un proceso de subordinación y pérdida de independencia con respecto a las autoridades del Poder Ejecutivo ${ }^{22}$, tanto nacional como provincial.

\section{VII.1.2 Desperonización del Poder Judicial}

El proceso iniciado por la Revolución Libertadora supuso en un primer momento que no habría vencedores ni vencidos. Sin embargo arremetió fuertemente en un proceso desperonizador de la sociedad que tenía como objetivo extirpar el problema de raíz. Su alcance intentó tener el mismo alcance capilar al que supuestamente había tenido el proceso de peronización. El devenir histórico terminó demostrando la imposibilidad de semejante plan y la capacidad de resistencia de los peronistas.

Se trataba de extirpar la "enfermedad totalitaria" de una sociedad que era presentada como esencialmente liberal, republicana y democrática. El retorno a los carriles tradicionales de la democracia no podía concebirse mientras el peronismo estuviese presente, y aunque la solución pudiese presentar matices entre las fuerzas antiperonistas, el proceso desperonizador alcanzaba a todos

\footnotetext{
${ }^{21}$ El ministro Subiza provenía de la ciudad de San Nicolás y allí tenía su estudio jurídico. Según las acusaciones de la Comisión Nacional Investigadora el Departamento Judicial San Nicolás fue en donde la injerencia de la intervención fue mayor, y muchos de los magistrados nombrados en ese y otros departamentos -en reemplazo de los cesantes- provenían de dicha ciudad y habían tenido vínculos con el ministro y el interventor, por lo que la trama de sometimiento adquiría mayor profundidad.

${ }^{22}$ MARCILESE José, EI Poder Judicial bonaerense... Op. Cit.
} 
los actores sociales triunfantes en las jornadas de Septiembre de $1955^{23}$. La avanzada desperonizadora, que incluyó la supresión del nombre de Juan Domingo Perón y su esposa Eva, la proscripción de las tres ramas del movimiento Peronista, la prohibición de utilizar los símbolos partidarios, alcanzó a todas las instituciones estatales. La sangre ${ }^{24}$ que se había derramado en post de la liberación y el fin de la dictadura justificaba en el discurso oficial las medidas de excepción a las que se debía someter a la sociedad y el Estado argentino. La expresión más clara de los excesos cometidos por "el tirano y sus adalides" se publico en 1958 como el Libro Negro de la Segunda Tiranía, pero incluso antes de la publicación, cada paso de la Comisión Nacional Investigadora era publicitada por los diarios de la época y durante los primeros meses de la Libertadora se presenció una verdadera campaña de difamación ${ }^{25}$ tendiente a la construcción del contra mito.

El primer impacto de la Revolución Libertadora sobre el Poder Judicial fue su interrupción real. Aunque se buscó que el Golpe de Estado no generase mayores contratiempos en la vida cotidiana, los sucesivos asuetos sobre la actividad del foro bonaerense mantuvieron a este inactivo prácticamente hasta fin de año, recién llegando a la normalización después de la feria del año 1956. El Poder Judicial no fue la única institución que permaneció aletargada en su actuación cotidiana, ya que los bancos -aunque por su función en este caso fue menor- la universidad y otras instituciones y servicios tuvieron gran cantidad de asuetos que, si por un lado ocasionaron la inactividad, también permitieron una mayor intervención desperonizadora. A fin de no ocasionar mayores trastornos, en el caso de los tribunales, el asueto también contemplaba la suspensión de los términos procesales.

\footnotetext{
${ }^{23}$ SPINELLI, Op. Cit.

24 Después de las jornadas de Septiembre de 1955 los diarios daban cuenta de manera cotidiana de los diferentes homenajes a los caídos en el bando libertador así como a los héroes que resistieron a la dictadura (entre estos héroes se contaba a los ejecutores del bombardeo de la Plaza de Mayo el 16 de Junio de 1955 que dejó centenares de víctimas). También se sucedían los mensajes de agradecimiento hacia los medios uruguayos. Diario El Día, varias ediciones de Octubre y Noviembre de 1955.

${ }^{25}$ Por ejemplo en el diario El Día es notorio el cambio en sus notas entre los días de Septiembre de 1955 a los días en que Perón ya se encontraba refugiado en la cañonera Paraguay.
} 
Al igual que en el gobierno de Perón, el derecho y la justicia tenían un lugar central en el discurso de las autoridades. Ni bien el proceso golpista logró controlar la situación militar -después de días que incluyeron enfrentamientos armados y escaramuzas-, el General Lonardi, expuso los motivos del golpe y su proyecto. "La revolución no se hace en provecho de partidos, clases o tendencias, sino para restablecer el imperio del derecho" ${ }^{26}$, sostuvo la proclama leída por el General Lonardi. Resumió en esa frase las aspiraciones de su grupo dentro de la Libertadora. Asumiendo como cierto el carácter dictatorial del gobierno de Perón, Lonardi se propuso restablecer el imperio del derecho y lo que esto significaba en términos de división de poderes $\mathrm{y}$, en el caso del Poder Judicial, independencia de los poderes.

Las primeras medidas apuntaron a desplazar a las cúpulas de los poderes judiciales nacional y provinciales. Así el 23 de Septiembre de 1955, Rodolfo Valenzuela, Felipe Pérez, Atilio Pessagno y Luis Longhi presentaron la renuncia como miembros de la Corte Suprema de Justicia de la Nación, permaneciendo en su puesto, y sólo para realizar diligencias, el Dr. Tomás Casares, único miembro en ejercicio de la Corte preperonista. A la renuncia de cuatro de los cinco miembros de la Corte Suprema de la Nación, le siguió, el 24 de Septiembre, la renuncia del presidente de la Suprema Corte de Justicia de la provincia de Buenos Aires, el Dr. Eduardo Servini. Para el 5 de Octubre, juraron ante el interventor federal de la provincia de Buenos Aires, el coronel Ossorio Arana, los nuevos miembros de la Corte provincial. El 6 de Octubre se dejaba sin efecto las renuncias ya que se removían por decreto 415 a los miembros de la Corte Suprema de Justicia de la Nación.

En su discurso Ossorio Arana se refirió varias veces a la importancia de haber dado la sangre por la libertad y la Constitución -comparándolo con la epopeya independentista ${ }^{27}$ - para justificar el acto de nombramiento de jueces de la corte, acto reservado para autoridades de derecho. Justificar el acto reñido contra el propio discurso de lo que significaba un gobierno legítimo, fue el objetivo de este y varios discursos de las autoridades de la Revolución Libertadora que se encontraban en la disyuntiva de presentarse como

26 "'La revolución no se hace en provecho de partidos, clases o tendencias, sino para restablecer el imperio del derecho" Dice la proclama de la Libertad que se leyó al comenzar el movimiento", Diario El Día 22/9/1955, Pp. 2.

27 "Juraron los miembros de la Suprema Corte", diario El Día, 6/10/1955, Pp. 4. 
restauradores de una sociedad argentina esencialmente democrática y al mismo tiempo encarar un proceso de exclusión de antiguos actores políticos y desperonización, en el marco de un gobierno de facto. De todas maneras en un momento de ánimos triunfalistas -que rayaban el revanchismo- las bases legitimadoras de las nuevas autoridades no eran profundamente discutidas a pesar de que las mismas autoridades buscasen adecuar su discurso a la situación de excepción que vivía la república.

El desplazamiento no se detuvo en las autoridades de la jerarquía del Poder Judicial. Las cesantías de jueces fueron una constante en los primeros meses. Aquellos jueces que habían sido nombrados por la intervención federal de 1952 fueron los primeros en ser desplazados. A estos los siguieron significativamente los jueces del trabajo de la mayoría de los tribunales de la provincia de Buenos Aires. Interesante fue el hecho de que la misma Justicia del Trabajo haya sobrevivido, ya que dio cuenta del arraigo que evidentemente había logrado a lo largo de esos 7 años de funcionamiento y las imposibilidades de volver atrás medidas de carácter social.

Los desplazamientos tuvieron lugar a pesar de que los jueces laborales fueron nombrados antes de la intervención federal a medida en que se abrían las vacantes al conformarse los tribunales. En esos casos la cesantía fue justificada por las autoridades ya "que por ser una creación del gobierno depuesto y por lo tanto, tamizados sus hombres en identificación con el régimen peronista, no era necesario su ajuste, como se hizo dentro de los otros fueros del Poder Judicial"28 por parte de la intervención del Dr. Rodríguez de Felipe. Su peronización, para los desperonizadores, había sido previa, la misma designación por el gobierno depuesto justificaba su remoción.

De esta manera, la Justicia del Trabajo, y principalmente sus funcionarios, pasaron a estar bajo la sospecha de las autoridades interventoras. A pesar de que se puede trazar la voluntad del gobierno peronista de que los jueces del trabajo fuesen hombres comprometidos con lo social, la designación de los jueces laborales se realizó bajos los parámetros estipulados por la ley, con acuerdo de ambas cámaras legislativas. El mantenimiento de las formas en sus

${ }^{28}$ Documentación Autores y Cómplices de las Irregularidades Cometidas durante la Segunda Tiranía, Comisión Nacional de Investigaciones Vicepresidencia de laNación, Tomo 1 , año 1958, Pp. 938. 
designaciones hicieron llamativas sus destituciones por la desperonización. A pesar de que algunos Colegios de Abogados pusieron reparos en su momento a las designaciones, estas fueron finalmente desechadas al considerar que la ausencia de tradición del fuero justificaba la designación de jueces sin carreras judiciales prolongadas.

Las designaciones de jueces y otros funcionarios se sucedieron entre los meses de Septiembre y Diciembre de 1955. En principio se trató de desplazar a todos los funcionarios nombrados por la intervención, aunque

los magistrados, funcionarios y empleados que conservaron sus cargos después de estas purgas -se refiere a las llevadas adelante por la intervención-, están bajo un interrogante y será preciso que tomen a su cargo la demostración desvirtuadora de lo que hace presumir su permanencia durante el período intervencionista; pues es indispensable averiguar si esa permanencia no responde a fidelidad al régimen depuesto o sumisión incondicional. En efecto es peligroso y gravísimo que perduren sumisiones de esa especie, cuando la independencia de los tres poderes del Estado, manteniendo cada cual en su órbita propia, constituye una de las más seguras garantías del patrimonio y de los derechos de cada uno en la sociedad $^{29}$.

Así, la simple actuación durante los años peronistas colocaba un manto de duda sobre los funcionarios judiciales que tenían que probar que su adhesión había sido circunstancial. Esto fue significativo en el caso de los puestos menores, ya que los jueces y funcionarios más destacados no contaron con esa oportunidad y fueron desplazados de sus cargos. Es significativo que durante esos meses aparecieran en las páginas del diario El Día la mención a los funcionarios judiciales que se mantenían en sus cargos, siendo en su mayoría oficiales de notificaciones. El proceso desperonizador llevó a los desplazados por la intervención a realizar una campaña a fin de entrevistarse con el interventor y reclamar el retorno a sus cargos ${ }^{30}$, aunque el resultado de tales requerimientos permanece incierto.

Estos actos de las nuevas autoridades se enmarcaban dentro de los límites borrosos de la legitimidad. Como ya se mencionó las autoridades surgidas del golpe de estado se preocuparon por buscar legitimarse a fin de asumir potestades que les correspondían a autoridades de derecho. La construcción del peronismo como mala copia del nazi fascismo justificaba ideológicamente la actuación de los miembros de la autoproclamada

\footnotetext{
${ }^{29}$ Ibídem, Pp. 937.

30 "Ex empleados del Poder Judicial piden retornar a sus cargos", El Día, 29/9/1955.
} 
Libertadora $^{31}$, pero la justificación legal no tenía la misma firmeza. Ante tal situación se vieron obligados a confirmar algunas de sus medidas. El 8 de Octubre de 1955 mediante un decreto del interventor de la provincia se declaraba la inamovilidad de los jueces nombrados por dicho gobierno provisional con posterioridad al decreto 41 del 30 de Septiembre que había declarado previamente en comisión a todos los funcionarios del Poder Judicial.

Esto implicaba que el gobierno provisional se adjudicaba la potestad de nombrar los jueces y que futuros gobiernos constitucionales debieron respetar dichos mandatos. La voluntad detrás de este decreto era la de evitar que el peronismo, en tanto fuerza política, fuese capaz de impugnar las designaciones, o, en el peor de los casos que en un futuro algún gobierno constitucional olvidase las razones que habían llevado a la actuación de las fuerzas armadas. La inamovilidad de los jueces es uno de los fundamentos de la democracia liberal, es la herramienta que en última instancia garantiza la independencia del Poder Judicial de los otros dos poderes estatales. Sin embargo, en el caso de un gobierno de facto esto generaba ciertas contradicciones tanto en la legitimación de ese gobierno presentado como provisional, como en las posibilidades de gobiernos constitucionales futuros. El texto del decreto rezaba

que el mantenimiento de una justicia independiente del poder que la nombró, es la base fundamental de una auténtica democracia y respaldo necesario de las garantías ciudadanas ${ }^{32}$

Y por ese motivo era fundamental la inamovilidad de los jueces. Ya que esto garantizaría una justicia independiente. Ahora, en un proceso de desperonización, con el quiebre de carreras judiciales de por medio, y con el impacto que un proceso semejante tuvo sobre las estructuras del Poder Judicial, la inamovilidad de los jueces apareció como una marca inicial anti peronista que dejó su huella en los sucesivos gobiernos constitucionales. Por otro lado la voluntad del gobierno provisional al constituir una justicia con esas características es central para comprender el desarrollo de las instituciones ya que justamente será el Poder Judicial el encargado de velar, ni más ni menos, que por la legalidad de las acciones de los otros dos poderes de allí en

\footnotetext{
${ }^{31}$ SPINELLI, Op. Cit.

32 "Se conoce el texto de los tres decretos firmados en la primera reunión del gabinete bonaerense", El Día, 9/10/1955 Pp.3.
} 
adelante. Los ideales de la Revolución Libertadora se perpetuaron en la marca de origen del Poder del Estado que justamente está excluido de los avatares coyunturales de la política.

Para resguardar de algún modo las formas, las autoridades interventoras otorgaron, a partir del 17 de Octubre, amplias potestades a la Corte provincial nombrada y puesta en funciones por el interventor Ossorio Arana- para la reorganización del Poder Judicial. Esta actividad fue encarada por la Corte, cuyo vocero declaró el 22 de Octubre de ese mismo año que las actividades de reorganización ya estaban concluidas y que aún faltaban cuestiones referidas a los nombramientos del personal ${ }^{33}$. De todas maneras para el 24 de Octubre estaban en condiciones de jurar los magistrados correspondientes al departamento Judicial Capital -con sede en la ciudad de la Plata- y los componentes de los Tribunales del Trabajo de La Plata, Avellaneda, San Martín, Quilmes, Lanús, Lomas de Zamora y Morón. El acto que se llevó a cabo en la sala de audiencias de la corte provincial patentaba

el hondo interés que había suscitado el anuncio de la designación de los magistrados, para lo cual han vuelto a tenerse en cuenta únicamente condiciones de idoneidad y de decoro, con absoluta exclusión de banderías políticas o intereses sectarios. ${ }^{34}$

La desperonización no solo fue por medio de cambios a nivel institucional. Adquirió rasgos de revancha en algunos actores que se habían visto perjudicados por algunas de las medidas adoptadas por el peronismo. En el caso de los abogados platenses las expresiones de revancha fueron puestas en evidencia por el proceso de recuperación de la sede destinada para su caja de jubilación y del local con que la asociación contaba en el interior del palacio de justicia. Estos actos precedieron a la reorganización del Poder Judicial y pueden dar cuenta en parte del ánimo que regía a muchos de estos actores en las jornadas de Septiembre y Octubre de 1955. Al grito de "Viva la Libertad", abogados platenses recorrieron los pasillos del Palacio de Justicia mientras

\footnotetext{
33 "Ha sido ampliamente reorganizado el Poder Judicial de la provincia", El Día, 23/10/1955, Pp. 3 y sig.

34 "Normalizase la situación del Poder Judicial: jurarán hoy los nuevos magistrados de La Plata", EL Día, 24/10/1955.
} 
eran retiradas y destrozadas las efigies que, por doquier, simbolizaban el sojuzgamiento del pueblo, aun en el sagrado recinto donde se consagra el más fundamental de los derechos ${ }^{35}$

Luego de recorrer los pasillos del Palacio de Justicia los allí presentes se dirigieron a un antiguo salón dentro del Palacio que había estado destinado al Colegio de Abogados y retomaron el control del mismo, luego de que este había pasados a manos de una asociación de abogados que supuestamente respondía al partido justicialista, y por lo tanto, no expresaba la voluntad de los abogados. No contentos con esta demostración se dirigieron al solar donde actualmente se levanta el edificio del Colegio de Abogados de la ciudad de La Plata y pintaron frente a la obra "este edificio confiscado por el régimen es de los abogados libres"36. El edificio en cuestión había comenzado a ser construido como sede de la Caja de Previsión del Colegio de Abogados platense, pero durante el gobierno peronista había pasados a manos del Instituto de Previsión Social. Aun sin tener una definición concreta del destino que se le daría al inmueble en manos del estado provincial, interesa resaltar la reapropiación que estos actores hicieron del mismo. En este acto simbolizaro en parte cuáles eran sus inmediatos intereses y daban cuenta de qué era lo que entendían como desperonización. La expulsión y desalojo del que habían sido objetos por el ex interventor ${ }^{37}$ avalaban sus expresiones de jubilosa revancha y marcaban para las autoridades el rumbo a seguir en el proceso desperonizador.

\section{VII.2 Continuidades y cambios en la administración de la justicia laboral}

La desperonización implicó al igual que para el Poder Judicial, la suspensión de las actividades del Tribunal del Trabajo $\mathrm{N}^{\circ} 1$ y su intervención los jueces actuantes hasta Septiembre de 1955 fueron desplazados de sus cargos y se nombró en su lugar a los Dres. Alberto Lecot -reemplazado al poco tiempo por el Dr. Federico Isla-, Leopoldo Russo y Julio Ves Losada. En el Tribunal

35 "En emotiva ceremonia, restituyose un local al Colegio de Abogados", EL Día, 23/9/1955, Pp2. ${ }^{36}$ Ibid.

${ }^{37}$ En una nota posterior se reproduce algunas de las pruebas de que los Colegios de Abogados habían sido desalojados por el ex interventor en razón de ser estos opositores al gobierno peronista. Este desalojo se habría realizada aun en desmedro de la ley 5177, dictada por el gobierno de Mercante, que establecía la personería jurídica para los Colegios de Abogados y les otorgaba un lugar físico en cada cabecera departamental. 
N² fueron nombrados Rodolfo Nápoli, Horacio Wamba -único que tenía carrera en el fuero antes de 1955 ya que era secretario del mismo tribunal, por lo que 1955 significó no solo la continuidad de su carrera sino un ascenso- y Enrique Weisberg. A diferencia de lo que ocurrió con los jueces nombrados en el período anterior, los que fueron puestos en funciones por la Libertadora contaban ya con años de experiencia. Julio Ves Losada se recibió en 1933, en 1935 se recibió Rodolfo Napoli doctorandosé en $1945^{38}$, 1942 fue el año de recibida de Alberto Lecott y Horacio Wamba, en 1946 Enrque Weisberg y un año después Leopoldo Russo ${ }^{39}$.

Como consecuencia de la suspensión de las actividades en los tribunales se demoró la resolución dos de las causas preservadas para el período 19481955. Se tratan de las demandas que, por un lado, Ricardo Lejarza le inicia al Instituto de Previsión y Ahorro para Edificación S.A., y por el otro el ya citado caso de José Formenti e hijos contra Juan Francisco Férnadez ${ }^{40}$. La causa contra el Instituto de Previsión y Ahorro finalmente fue abandonada y quedó sin resolución por la muerte de Lejarza en el transcurso del proceso y a pesar de que su viuda e hijo solicitaron la continuidad del mismo. Las excepciones de jurisdicción interpuesta por la demandada parece haber sido la causa principal de la demora, ya que obligó a la actuación de la Corte Suprema de Justicia de la Nación y eso prolongó las actuaciones. En el caso de la sociedad Formenti e hijos estos iniciaron la causa el 6 de Junio de 1955 y el proceso sí se vio demorado por la remoción de los jueces. La vista de causa terminó estando a cargo de Ves Losada, Ruso y Lecot, que fueron los encargados de dictar el veredito y la sentencia -desfavorable para el trabajador-. Pero incluso a pesar de esta interrupción el tiempo procesal de la Justicia del Trabajo siguió manteniendo su estrechez y la resolución del pleito fue posible el 22 de Febrero de 1956, un poco más de siete meses después de iniciada la causa (30 de Junio de 1955).

Aunque las condiciones de preservación de las fuentes judiciales descritas en la introducción hace difícil un análisis cuantitativo concluyente en

\footnotetext{
${ }^{38}$ Rodolfo Nápoli fue designado ministro de la Suprema Corte en 1958 y permaneció en dicho puesto hasta 1973.

${ }^{39}$ Nómina de egresados, 1905-1951, Op. Cit.

${ }^{40}$ DH 104/1 Lejarza Ricardo c/ Instituto de Previsión y ahorro para edificación SA s/ haberes, Año 1954 y DH 104/7 Formenti José e hijos Sociedad Anónima c/ Fernández Juan Francisco s/ consignación, Año 1955.
} 
base a los expedientes, un panorama comparativo de los dos periodos aquí contemplados dan una imagen de cierta continuidad en los procesos (Cuadro $\left.N^{\circ} 1\right)$.

Hay en el período 1955-60 incluso una profundización de las resoluciones pro obreras (Gráfico $\mathrm{N}^{\circ} 1$ ) en la medida en que los trabajadores duplican el porcentaje de las causas que ganan. Sin embargo es necesario contemplar en forma binaria las cifras incluyendo la conciliación y el desestimiento de las causas. Así, para el período 1948-55 las causas ganadas por el trabajador o en las que este consiguió un resarcimiento por parte de sus patrones suman un $55 \%$ del total, mientras que los trabajadores desisten de la demanda o estas son ganadas por los patrones en el $38 \%$ de los casos. En la serie 2 que contempla las causas iniciadas entre 1956-60 los trabajadores logran ganar o arribar a una conciliación en el $68 \%$ de los casos, mientras que el patrón logra triunfar o el trabajador desiste de la demanda sólo el 16\% de los casos.

En el plano hipotético la disminución de la tasa de conciliación puede ser considerado como indicativa una profundización del conflicto. En el imaginario peronista la lucha de clases fue desestimada por la construcción discursiva con un mayor énfasis en la conciliación y cooperación. ¿Puede la tasa de conciliación mayor durante el peronismo demostrar el impacto de esta construcción discursiva? Sin dudas las limitaciones expuestas impiden sostener una propuesta de este tenor, pero el dato no deja de ser significativo. De todas maneras hay que contemplar también el significado de la conciliación, ya que en algunos casos puede indicar o ser percibido por el trabajador como un éxito, mientras que en otros casos la conciliación es el reconocimiento de la incapacidad de logar el objetivo propuesto a la hora de entablar una demanda. Una variable importante a tener en cuenta con respecto al significado de la conciliación era el tiempo que demandaba la causa en arribar a una resolución.

El Cuadro $\mathrm{N}^{\circ} 1$ da cuenta también de un cambio institucional de cierta trascendencia, pero que por tratarse de un cambio en la materia abordada cuestiones de orden exclusivamente rural, no ya laboral- no son abordados en esta tesis. Por el Decreto Ley N 868 de 1957 se creó para la provincia de Buenos Aires el fuero rural. Al año siguiente el Decreto Ley $\mathrm{N}^{\circ} 3739$ el fuero rural pasó a depender de la órbita del fuero laboral. Así los Tribunales del Trabajo quedaron habilitados para actuar en instancia de apelación sobre las 
resoluciones de las Cámaras Arbitrales de Arrendamiento. Por ese motivo para el período 1956-1960 se contabilizan 4 causas de desalojo rurales. De todas maneras estas cuatro causas no fueron contempladas a la hora de construir los índices de resolución de las causas volcadas en el Grafico N² 2 .

\section{Cuadro $\mathrm{N}^{\circ} 1$}

Cuadro resumen análisis de causas según periodos:

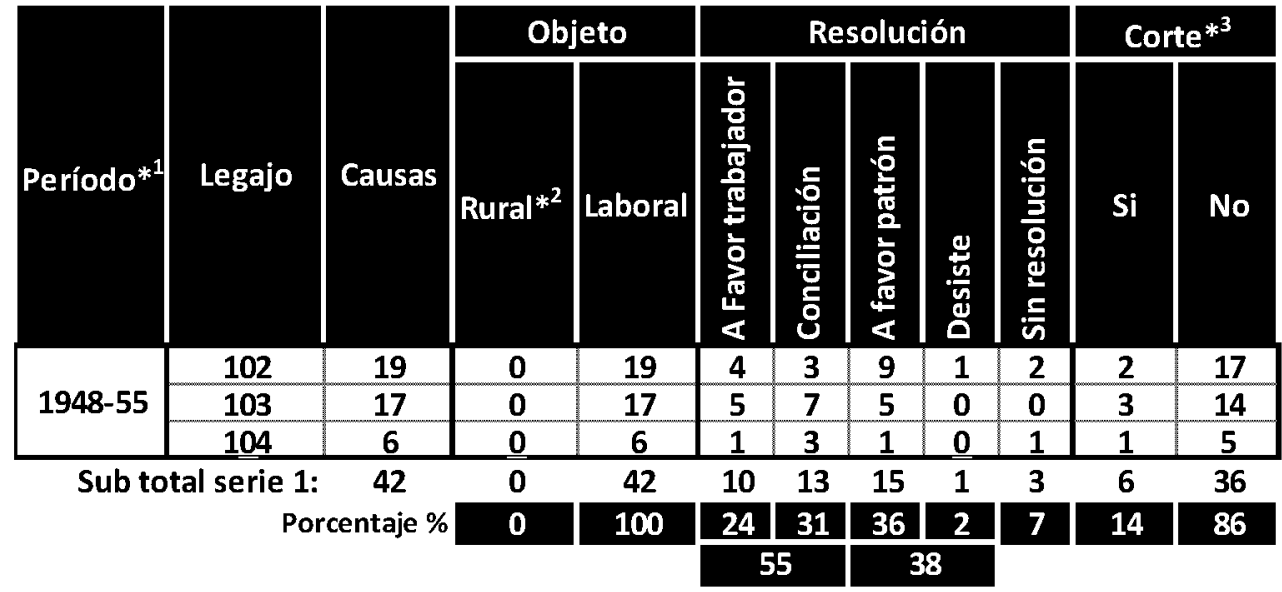

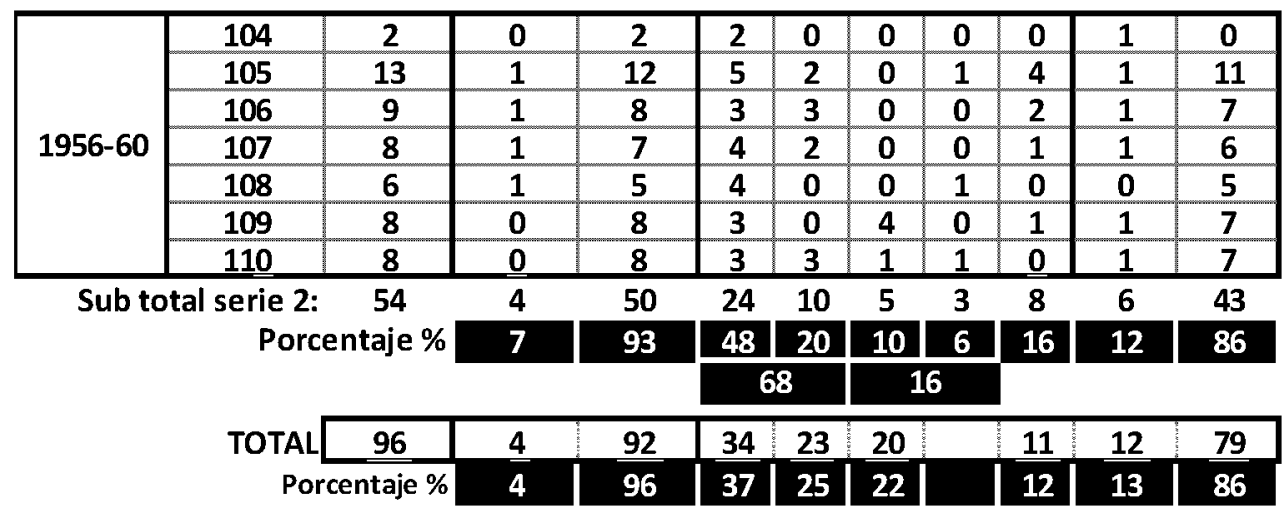

${ }^{* 1}$ Se toma como referencia el año de inicio de la causa.

*2 Las causas rurales no fueron consideradas para la elaboración de los índices de resolución.

*3 Refiere tanto a la Corte Suprema de la Nación como a la Suprema Corte de la Provincia.

\section{Gráfico N¹}

\section{Resolución según periodo}

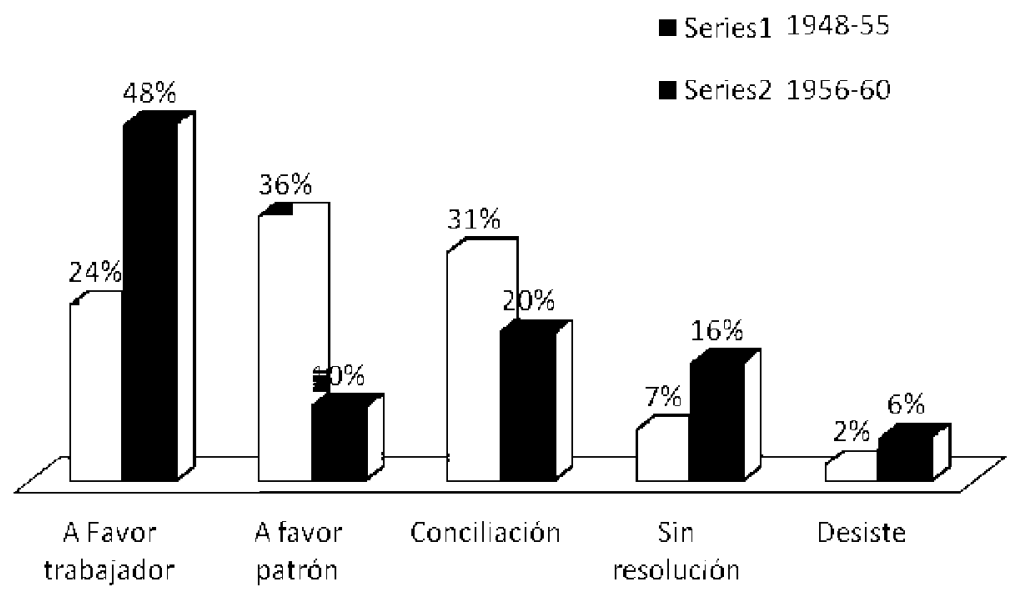


VII.2.1 Los tiempos procesales cortos, garantía de justicia

Aunque algunas causas encontraron un largo proceso por delante, la premura de la Tribunales del Trabajo siguió siendo una característica también en este período. Es importante resaltar la importancia para los trabajadores de contar con un proceso corto ya que esto garantizaba la consecución de la justicia. Para los trabajadores el mantenimiento de un largo pleito, incluso cuando era gratuito, significó un esfuerzo que no valía la pena sobrellevar de manera individual, o cuando la resolución finalmente llegaba no encontraba en ella el objetivo perseguido en primera instancia. Tres excepciones sobre la rapidez procesal que primaba en los tribunales del trabajo apoyan estas hipótesis.

Nieves López le entabló demanda a Américo Cederna por indemnización de despido, vacaciones, aguinaldo y haberes ${ }^{41}$. El trabajador, obrero de la construcción, realizó trabajos en la Estación Dock Central del Ferrocarril Roca en el puerto de Ensenada durante cuatro meses y medio hasta que la patronal se negó a darle trabajo. La demanda fue entablada pocos días después del despido, el 25 de Septiembre -el despido databa del 2 del mismo mes- de 1958. Problemas en los traslados y notificaciones de demanda, al ser el demandado de Temperley, generó una situación excepcional: la contestación de la demanda -cuyo plazo legal venció 10 días después de notificada, se realizó el 16 de Abril de 1963, y la ratificación de la demanda el 31 de julio de 1965. La conclusión de la causa da cuenta del desinterés por parte del trabajador y sus representantes de continuar con la causa. La Audiencia del 3 de Noviembre de 1967 en la que se debía realizar la vista de la causa previo al veredicto se suspende porque ninguna de las partes acude a los Tribunales. El trabajador, en búsqueda de su resarcimiento, precisaba el proceso rápido que garantizase la satisfacción de sus demandas inmediatas de justicia.

La prolongación como estrategia patronal fue utilizada como método de desmoralización con respecto a los justo del reclamo. Los trabajadores de la tradicional confitería "La Paris" sintieron en carne propia las consecuencias de la lentitud procesal ${ }^{42}$. Fueron despedidos el 31 de Agosto de 1960 por cambio

\footnotetext{
${ }^{41} \mathrm{DH}$ 105/13 López Nieves c/Cederna Américo s/haberes, Año 1958.

${ }^{42} \mathrm{DH} 110 / 7$ Orellano Juan Facundo y otros c/ confitería Paris ex y actuales propietarios s/indemnización, despido, etc., Año 1960.
} 
de propietarios del comercio y se les abonó la indemnización que consideró la patronal que les correspondía. Insatisfechos con la suma acudieron a la justicia laboral. En primera instancia debieron afrontar las dificultades para determinar a quien correspondía responder a la demanda. A pesar de que esta se dirigió a ambas firmas comerciales (la vendedora y la compradora) adujeron que las notificaciones habían sido mal hechas y por tanto se debía recomenzar los plazos procesales anulándose lo actuado. Estos trámites prolongaron 8 meses el pleito hasta que finalmente fue aceptada la demanda por la firma Lafuente, Juria y Cía, propietaria de la confitería cuando los trabajadores estaban en ejercicio. El siguiente paso fue la persecución que se estableció a los libros contables del comercio, fundamentales para determinar los montos que correspondían a cada ex empleado. Recién en 1965 pudo el Contador Alfredo Carrere llegar a una conclusión en su pericia ${ }^{43}$, que fue impugnada por los trabajadores. Finalmente ambas partes llegaron a un acuerdo ante los jueces Oscar Berodino ${ }^{44}$, Federico Isla y Carlos Renom en la audiencia del 22 de Septiembre de 1965. Teniendo en cuenta la importancia de la pericia -por inversión de la prueba era obligación de la patronal demostrar que lo solicitado no se ajustaba a derecho- y las dificultades expresadas por el contador, en el terreno contrafáctico, se podía preveer una resolución favorable a los trabajadores. Sin embargo a pesar de estas ventajas procesales terminaron arreglando con sus antiguos patrones por una suma mayor que la reclamada originalmente, pero cinco años después. Sin dudas el tiempo transcurrido entre el inicio de la demanda y la audiencia inclinó a los trabajadores a aceptar el arreglo con la patronal. Considerando que la ley 5178 habilitaba a suspender el proceso en cualquier instancia del proceso para llegar a una resolución amistosa llama la atención que siendo finalmente la resolución adoptada esta haya tardado tanto tiempo. Las improbabilidades de resolver el diferendo en un tiempo considerado prudencia por los trabajadores tal vez fue el impulso necesario para arribar a una conciliación.

\footnotetext{
${ }^{43}$ Al defender su actuación sostuvo el Contador Carrere: "agote las gestiones para obtener todos los elementos conducentes a la elaboración de una pericia completa. Dicho esfuerzo desgraciadamente no está cristalizado en un trabajo que pudiera ser todo lo ilustrativo y eficaza como era mi deseo, pero si no lo logré fue por causas agenas (sic) a mí". Agregó que fue 8 a 10 veces al estudio del abogado de la patronal, recurrió a otros peritos que realizaron pericias en juicios contra la demandada, se apersonó en el establecimiento, etc. DH 110/7, foja 77 y sig. ${ }^{44} \mathrm{Se}$ debe recordar que desde el inicio de la causa en 1960 pasaron 5 años. El ingreso de Berodino como juez se dio en algún momento entre 1962 y 1965.
} 
El otro problema era que el prolongamiento del proceso podía generar un sentimiento de insatisfacción, aun cuando el trabajador ganaba el caso. Esto fue especialmente importante para César González. Despedido, según su descripción de los hechos en la demanda, por el encono que el reclamo por el cumplimiento del pago de haberes en otra causa que se le resolvió favorablemente en el mismo tribunal y por el pedido del cumplimiento del convenio colectivo de los trabajadores de entidades deportivas para sus compañeros de dotarlos de botas de goma en caso de tener que trabajar en zonas pantanosas ${ }^{45}$-González era capataz y delegado gremial-, reclamaba

se declare ilegitima la ruptura del contrato de empleo por parte de la patronal, ordenando se reintegre a sus funciones a mi mandante, previo pago de los meses de inactividad por culpa de la patronal. ${ }^{46}$

Solo en caso de que la demandada sostuviese el despido se solicitaba la indemnización. Los poco más de tres años transcurridos entre la instauración de la demanda, desde Marzo de 1960 a Abril de 1963 -unos meses más si computamos el paso del trabajador por la Delegación Regional que databa de Noviembre de 1959-, llevaron a los jueces a definir como improcedente el pedido de reincoporación, otorgando en cambio la indemnización. Teniendo en cuenta que el trabajador vivía en las instalaciones del club y que fue solicitado su desalojo por sus patrones en un juicio en el Tribunal del Trabajo $\mathrm{N}^{\circ} 2$ que se encontraba -por recurso de litis pendencia- a la espera de la resolución de esta causa, lo justo para el trabajador era la permanencia en su puesto laboral. Sin embargo lo prolongado del juicio con un considerable retraso en la contestación de la demanda ${ }^{47}$, hacían improcedente el retorno del trabajador a su puesto de trabajo. Por tanto González recibió la indemnización que le correspondía por derecho, pero lejos de la justicia que esperaba al sufrir el desalojo de su hogar y la pérdida de su trabajo y sus relaciones de amistad allí establecidas.

\footnotetext{
${ }^{45} \mathrm{DH} 110 / 8$ González César M. c/ Club Hípico de City Bell s/despido, Año 1960.

${ }^{46} \mathrm{DH} 110 / 8$ Foja 11 vuelta.

${ }^{47}$ En la contestación del traslado de la demanda el abogado del trabajador, el Dr. Horacio Alberto Colombo, sostuvo que la demandad no podía argumentar que la demora en la contestación de la demanda se debió a una desprolijidad en la notificación ya que en el juicio de desalojo que le interpuso al actor en el Tribunal del Trabajo $\mathrm{N}^{\circ} 2$, Secretaría $\mathrm{N}^{\circ} 3$, se le interpuso un recurso de litis pendencia que fue aceptado por el tribunal. Sin embargo la contestación de la demanda fue demorada un año e interpuso pedido de nulidad del proceso de notificación. A pesar de que el tribunal no aceptó el pedido de nulidad permitió a la demandada continuar con su defensa.
} 
VII.2.2 Pavimentando el camino

El camino a la justicia del trabajo descripto en el capítulo anterior siguió estando vigente. El trabajador acudía en principio al sindicato, acto seguido a la Delegación Regional del Ministerio de Trabajo y Previsión y a partir de allí a los tribunales del trabajo. Resulta interesante, sin embargo, percibir una mayor presencia en los juicios de los sindicatos. La asesoría en las instancias administrativas -donde la presencia de los representantes era parte misma del entramado institucional dispuesto para la solución del conflicto- parece haber formado parte del cotidiano de los representantes sindicales.

Carlos Gosella y Carlos Martinez, colaboradores de la intervención del sindicato Unión Obrera Metalúrgica, acompañaron a Delfina Magnapane cuando reclamo a la dueña del establecimiento metalúrgico "TRIUNFO" de City Bell diferencias de salarios y aguinaldo ante las autoridades de la Delegación Regional del Ministerio de Trabajo. Además en su paso por la Delegación regional obtuvo la asesoría legal de los miembros de la oficina de Asesoría Jurídica, los Dres Jorge César Felices, Jorge Bravo, Guillermo Arturo Cueto y Abel Larrain ${ }^{48}$. Raul Mario Pereyra, interventor de la UOCRA, fue quien se presentó ante la Secretaría de Conciliación $N^{\circ} 5$ de la Delegación regional en representación de Alberto Palleiro, Maximiliano Zenon Piñeiro, Félix Ibañez, César Mascciochi, Vicente Durante, Domingo Marinkovich, Miguel Rosica, Jorge Arrascanta, José Pedon, Eusebio Jacinto Sandoval y Manuel Álvarez todos ex empleados de Raul San Román, un empresario de la construcción que los suspendió por 60 días coincidentemente cuando se dio publicidad al aumento establecido por el Laudo del Tribunal Arbitral dictado en Octubre de $1956^{49}$. En las oficinas del Departamento Provincial del Trabajo ${ }^{50}$ comparecieron Segundo Palma, secretario general de la UOCRA La Plata, y su

\footnotetext{
${ }^{48}$ DH 105/4 Magnapane Delfina c/Hiriart María Nicanosa s/cobro ejecutivo, Año 1957.

49 La causa administrativa da origen a dos causas judiciales diferentes, ambas bajo la representación de los mismos abogados (Carlos Brusa y Emilio Trabuco, quienes representaron a trabajadores en diversas causas durante el período) $\mathrm{DH}$ 105/2 Rosica Miguel y otros c/Raul San Román e hijos s /preaviso y antigüedad, Año 1957 y DH105/3 Durante Vicente y otros c/Raul San Román e hijos s/ preaviso, antigüedad y otros, Año 1957.

${ }^{50}$ Bajo la gobernación de Oscar Alende (1958-1962) de la Unión Cívica Radical Intransigente, este departamento asumió las funciones de la Delegación Regional del Ministerio de Trabajo y Previsión bajo la órbita provincial, aunque fue necesario esperar hasta sanción de la Ley 6014 publicada en el Boletin Oficial el 27 de Febrero de 1959 y su reglamentación por el Decreto 3910/61que le otorgó la estructura orgánica para que este Departamento fuera redefinido y dotado de una estructutra legal. La ley también resolvió su relocalización en el Ministerio de Acción Social -otra creación de Alende- como Subsecretaría de Trabajo.
} 
adjunto, el Sr. Roberto Oscar Saavedra, que junto con el delegado de la obra que en Destilería La Plata ejecutaba el Sr. Cuchiarelli representaron a los trabajadores en la instancia administraticva en su conflicto con su patrón ${ }^{51}$. También fue acompañado, ya normalizados los sindicatos, por el Secretario Glaremial de la Union Obrero Gastronómica -Francisco Figliese- el lavacopas Francisco Berenguer, despedido de la confitería "El Rayo" que estaba frente a la estación de ferrocarriles ${ }^{52}$. La presencia de los secretarios generales de la seccional no era infrecuente y permite al menos espiar en las acciones cotidianas de estos dirigentes gremiales cuando no estaban pensando $u$ organizando la próxima medida de fuerza.

El despido de delegados obreros implicó necesariamente a los sindicatos en los conflictos judiciales. Las prerrogativas otorgadas por ley a la representación sindical -principalmente la estabilidad laboral mientras duraba su mandato- no fue respetado por los patrones. Aunque en estos casos el interés de los sindicatos apuntaba a la defensa de intereses corporativos.

\section{VII.2.3 Continuidad doctrinaria, ¿ruptura política?}

En rigor a pesar de los cambios de jueces los Tribunales del Trabajo siguieron aplicando las mismas leyes del período peronista. Incluso muchos de los decretos y resoluciones continuaron vigentes a pesar de declarar la invalidez de la Constitución Justicialista de 1949 y el retorno a la Constitución de 1853 con el agregado del artículo 14 bis por la fallida constituyente de 1957. El derecho laboral y su doctrina siguieron vigentes y la casuística continuó privilegiando la defensa del más débil en la relación laboral. Incluso ante patrones tan poderosos como los frigoríficos los trabajadores continuaron con chances de obtener resarcimiento por parte de sus patrones.

El caso de los frigoríficos fue paradigmático ya que por la importancia en el empleo de la región sus vaivenes tenían inmediata repercusión pública. El periplo de las Catedrales del Corned Beef desde la caída del peronismo fueron marcados por cambios en el sistema productivo de la industria -con pérdida de importancia de los grandes establecimientos ante la descentralización de la producción-, la conflictividad presente en tanto los empresarios buscaron

\footnotetext{
${ }^{51} \mathrm{DH}$ 108/5 Villafañe Nicolás y otros c/ Cuchiarelli Florentino s/despido y haberes, Año 1959.

${ }^{52}$ DH110/2 Berenguer Francisco c/Fidalgo y Cía s/despido, Año 1960.
} 
reeducar a los trabajadores reafirmando su autoridad dentro de la planta y los cambios en los ritmos productivos. Esto redundó en una mayor circulación de trabajadores -es decir un aumento en el trabajo eventual- y en el desconocimiento por parte de los dueños de las plantas de la legislación protectora del trabajo ${ }^{53}$. Estos conflictos quedaron reflejados en las causas judiciales que envolvieron a los trabajadores de la industria de los frigoríficos esos años. Lo interesante fue percibir que a pesar de la importancia política y la repercusión pública que rodeaba a los conflictos los jueces del Tribunal del Trabajo $\mathrm{N}^{\circ} 1$ lograron sostener posiciones proobreras al avalar los reclamos de los trabajadores en el estrado judicial.

La disminución de la faena y la crisis que atravesó el sector fueron las razones principales que esgrimieron los abogados de las empresas cárnicas a la hora de justificar los despidos. Los Dres. José Forners Rogers y Edmundo Spencer Talbois representaron al Armour, mientras que la defensa de la compañía Swift la asumió el Dr. Manuel Pérez de Vargas quien buscó, en las causas que se conservan, acudir a las instancias de apelación como ya había hecho en las causas del período anterior.

Cinco son las causas que enfrentan a los trabajadores ${ }^{54}$ de la carne con sus patrones. Sólo una de ellas fue iniciada antes de los aumentos convenidos

\footnotetext{
${ }^{53}$ LOBATO Mirta, La vida en las fábricas... Op. Cit. Especialmente el capítulo IX.

${ }^{54} \mathrm{DH}$ 105/12 Palacios Suárez José Alejandro y otros c/Frig. Armour La Plata s/despido, Año 1958; DH 106/2 Alarcón Julio César y otros c/Frigorífico Armour de La Plata s/despido, Año 1959; DH 107/7 Fernández Henry Napoleón c/ Cía Swift de La Plata S.A. s /despido y haberes, Año1959; DH 109/6 García pablo y otros c/Cía Swift de La Plata s/indem, despido, etc., Año 1960; y DH110/3 D'uva Tomás D y otros c /Cía Swift de La Plata S. A. Frig. s/despido, etc., Año 1960. Los actores de las diferentes causas eran por causa: DH 105/12: José Alejandro Palacios Suarez, Armando Arturo Duarte, Cornelio Enrique, Vicente Smijosky, Juan Roldán, Emeterio Grosso, Héctor Reinaldo Zapata, Rodolfo Domingo Miserere, Félix Gallardo, Modesto Maceira, Manuel Alberto Guzmán, Transito Lorenzo Apacama; DH 106/2:Julio César Alarcón, Juan Carlos Zabala, Germán Buich, Enrique Moriones, Pedro Favetti, Hugo Oscar Martínez, Aniceto Misael Acosta, Norma Ángela Bialoglovich, Olga Rosa Herrera de Corvalán, Elma Oviedo de Caride, Ana María Armendi de Sierto, Josefina de Lezcano, Juan Lezcano, Manuel Teodosio Carreño Viru, Verónica Kapala, Héctor Normando Defelipe, Ramón Dalmiro Aguirre, Francisco Luján Munar, Celso Rubén Stock, Eduardo Rubén Lazaro, Honorio Roberto Plaza, Antonio Chamorro, Ireneo Juan Coronel, Evaristo Pregot, Héctor Oscar Lafalce, Lionel Chaparro, Marcelino Ibarra, Panfilio Retamozo, Irene Roldán, Manuel Mansore, Armenia Paula Meyer de Gómez, Abel Florentino Honorio Casal, Germán Lorea, Félix Gagliardo, Pablo Fabián Vincent, Tomás Silvano Rodríguez, Pio Guillermo Roldán, Miguel Euclides López, Elvira del Luján Sosa de Robledo, Antonio Valenzuela, Juana Wilczynski, Nélida Emma Nevietti de Scotella, Juana Magdalena Stapic de Viskovic, Irma Elena Sueldo, Ángela Zulema Martínez de Navarro, Josefa Fenoy, Manuel Alberto del Valle, Roque Osmar González, Antonio Edgar Barros, José Ignacio Rojas, Elías Rodríguez, Faustino Ríos, Abraham Jaiten, José Arturo Zuda, Manuel Adrian Fernández, Ángel Raúl Andrada, Francisco Anselmo Freyte, Juan Iriquin, Esteban Pintos, José Euclides Retamozo, Luis Nuñez, Romuldo Alberto Islas, Albino Rosendo
} 
para la industria que entró en vigencia el $1^{\circ}$ de enero de 1959. El dato debe ser tenido en cuenta en la medida en que los montos reclamados dependieron de la aceptación por parte de la patronal de dicha fecha, ya que en las liquidaciones pagadas a los obreros al momento de su despido se computó que el mencionado aumento se hizo efectivo a partir del 19 de Febrero de ese año, mientras que la mayoría de los despidos fueron previos a esa fecha.

Con la excepción de la demanda instaurada por Henry Napoleón Fernández ${ }^{55}$ a la compañía Swift, el resto son causas que se catalogan como colectivas ya que la cantidad de obreros demandantes superan en todos los casos los tres obreros, llegando a demandas de 77 obreros, como en el caso de la causa DH 106/2 Alarcón Julio César y otros c/Frigorífico Armour de La Plata s/despido. Las causas que aparecen en la jurisprudencia o en los antecedentes tanto de la demanda como de las contestaciones patronales citada también son causas con múltiples obreros. Esto daba cuenta de un verdadero aluvión de causas ${ }^{56}$ destinados a sostener las fuentes de trabajo si se considera que se solía reclamar el reintegro o, en caso de persistir en la actitud de despido, la indemnización correspondiente a derecho.

Los conflictos entre estos trabajadores y la patronal se iniciaron con los despidos de los trabajadores. Estos fueron realizados, y así quedó comprobado en las pericias, según la antigüedad tal como definía el Convenio Colectivo del sector. Sin embargo, aduciendo las faltas de stock ganadero, la consecuente disminución de la faena y las malas políticas estatales que sin dudas no ayudaban a la recuperación de la industria ${ }^{57}$, las empresas no pagaron la doble

Correa, Juan Omar Sánchez, Oscar Osvaldo Frencesena, Guillermo Porter; DH 107/7: Henry Napoleón Fernández; DH 109/6: Pablo García, Gilberto Omar Kalinoff, Salvador Rivero; DH110/3: Tomás Domingo D’Uva, Carlos Jorge González, Domingo Benito Nuñez, Patrocinio Cejas, José Amado Terceros, Pedro Pablo Espinillo, Juan Ramón Rozas, Enrique Oviedo, Juan Falladjian. Elías Avelino Álvarez, Fernando Oscar Zaniratto, Agustín Valente, Nelly Perreri, Héctor Hipólito Vera Fourcade, Tomás Crespo, Luis María Sosa, Juan Benito Ermilli, Juan Lubenoff, Juan Noel Halty, Juan Garibaldi.

${ }^{55} \mathrm{DH}$ 107/7. Esta causa será analizada en detalles al indagar sobre la revancha de los patrones, ya que Henry napoleón Fernández aduce ser representante gremial. La inclusión en este apartado es porque la contestación de la demanda sostuvo que el despido se debió a la falta de trabajo.

${ }^{56}$ De la presentación a la Corte Suprema realizada por el abogado de los trabajadores, Eduardo Etcheverry, Armour despide 3348 personas y Swift 2640 desde julio de 1958 a febrero de 1959.DH 110/3, Foja 179

${ }^{57}$ Entre las razones que aducían las empresas especial énfasis se hacía en lo errónea de la política del Estado nacional concerniente al sector. Las medidas adoptadas por el gobierno nacional para aumentar el stock de cabezas de ganado sumado a los topes impuestos a los precios de venta de la carne hacían inviable la continuidad de la producción ya que se debía 
indemnización ya que no eran causantes de la situación de falta de trabajo. Esto ocasionó que los trabajadores acudiesen a la justicia laboral. Las resoluciones de las causas encuentran cauces parecidos -con la consabida excepción del caso de Henry Napoleón Fernández que desiste del juicio-, aunque en una de las causas, a pesar de reconocer los hechos, el reclamo se cayó por haber prescripto la acción.

Este es el caso de la causa 6 del Legajo 109 que enfrentó a Pablo García, Gilberto Omar Kalinoff y Salvador Rivero con la Compañía Swift. Los tres trabajadores cumplieron con su trabajo en distintas áreas del frigorífico, pero las fechas de despido llaman la atención ya que mientras que García y Kalinoff fueron despedidos el 15 de Enero de 1959, Salvador Rivero fue despedido más de una año después, el 30 de Abril de 1960. Las carta poder a favor del abogado actuante también datan de fechas distintas a lo largo de ese año. La demanda apunta a las irregularidades de los despidos masivos de Enero y Marzo de 1960 que configuran un despido injusto y arbitrario a pesar de la merma de trabajo aducida. Reclamaba entonces las compensaciones legales y para el caso de Rivero solicitó por el reintegro ya que "a los pocos días de los despidos "por falta de trabajo", la firma empleadora, incorpora personal nuevo a su establecimiento" 58 .

La respuesta de la demandada adujo las cuestiones de merma de trabajo y sobre el caso de Rivero sostuvo que en primer lugar es absurdo pensar que la compañía no contratase personal en los momentos en que la merma de trabajo no era tal, y además que esas contrataciones fueron en tripería y playa donde Rivero nunca se desempeño. Es interesante remarcar el pedido de reincorporación de Rivero en el marco de inestabilidad que volvió a predominar a fines de la década del cincuenta en el trabajo en las plantas. Además Pérez de Vargas sostuvo que la demanda era improcedente porque estos reclamos no fueron antepuestos ante la comisión paritaria al momento de los despidos, y los obreros firmaron su conformidad con la liquidación efectuada al momento de la cesantía.

pagar altos precios por el animal vivo, mientras que dicho aumento no podía trasladarse a los consumidores.

${ }^{58} \mathrm{DH} 109 / 6$, foja 4 vuelta. 
El veredicto firmado por los jueces Dres. Renom, Isla, y el agente fiscal Marcelo Arteaga ${ }^{59}$ el 23 de Mayo de 1961, determinó que la demanda era procedente ya que no se había respetado el orden de antigüedad en los despidos ni tampoco se justificaba la merma de trabajo. Por tanto se sentenciaba, más de un año después de conocido el veredicto ${ }^{60}$, a la Compañía Swift al pago de sumas de entre $\$ 4100$ y $\$ 4300$ (habían recibido en el momento de despido unos $\$ 3000$ cada uno), aunque algunos ítems de la demanda eran rechazados, como las vacaciones de Rivero y algunos aumentos por convenio.

La fundamentación del fallo tuvo que dar cuenta del recurso de excepción planteado en la contestación de demanda y reafirmar la jurisdicción del fuero laboral. Decía el Acuerdo "las comisiones paritarias en su acción ante conflictos individuales actúan solo por opción sin excluir la competencia judicial (Ley 14.250)" ${ }^{\text {,61 }}$. La cuestión de la jurisdicción no era una problemática nueva para los Tribunales Laborales, pero en este caso resalta que la opción de la demandada era la comisión paritaria, un órgano donde también compartía con los trabajadores el espacio. Sin dudas el cambio en el contexto político post1955 volvió menos intimidantes a estas comisiones para la patronal. Sin embargo los Tribunales del Trabajo aun seguían siendo un ambiente hostil para el patrón. Los jueces seguían siendo celosos defensores de los principios del derecho de trabajo y a pesar del nuevo auge liberal concebían las relaciones como fundamentalmente desiguales y al Derecho Laboral como protector de la parte más débil de dicha relación.

Esta protección quedó en evidencia en la forma en la que el Tribunal resolvió la cuestión de la firma, por parte de los trabajadores, de la conformidad con la liquidación de los rubros que ahora estaban reclamando judicialmente. Los pagos realizados con la conformidad de los actores tenía, para Pérez de Vargas -el abogado de Swift- los efectos liberatorios establecidos en el artículo 505 del Código Civil, por lo tanto la demanda era improcedente. Sin embargo el

\footnotetext{
${ }^{59}$ A fin de conformar el Tribunal no era infrecuente encontrar que ante la ausencia de uno de los jueces titulares se convocara o a otros jueces del mismo fuero o, como en este caso, al agente fiscal.

60 El Acuerdo y la Sentencia son del 5 de Julio de 1962.

${ }^{61} \mathrm{DH} 109 / 6$ foja 75 vuelta.
} 
doctor Isla -el juez que fundamentó el fallo- sostuvo sobre el renunciamiento que habrían dado los actores al firmar recibos indemnizatorios simples ${ }^{62}$

La irrenunciabilidad para ambas partes que supone esta disposición, la sindica como de orden público. En este sentido, y para alejar toda duda, cabe recordar que tales indemnizaciones (la de antigüedad por lo menos) fueron modificadas por el art.67 Dec 33.302/45, Ley 12921, el cual, expresamente, ha sido catalogado de orden público (...) La norma del art.158 del Cod. Com. También es aplicable al pago y en este sentido se ha expedido la S.C.J.B.A. en su actual integración (...) ello es lógico si se piensa que todo derecho laboral se basa en la iderogabilidad e irrenunciabilidad de ciertas normas mínimas, por lo cual darle prevalencia al principio de la autonomía de la voluntad del obrero en la percepción de un pago (que es el modo usual de extinción de obligaciones, art 724 del Cod. Civil), importa abrir una ancha puerta para la modificación de la obligación en sí, dando por tierra con toda la legislación laboral. El obrero percibe por la misma necesidad por la que suscribe un contrato ilegal. Y esa percepción, al igual que todas las conformidades que preste no garantizadas por un mismo plano de igualdad, no tiene efecto liberatorio, en cuanto no se ajusta a las prescripciones de la ley. De otro modo el derecho laboral es letra muerta ${ }^{63}$

En la casuística aun encontraban los jueces resistencias del derecho laboral. El trato desigual que proponía a los participantes de la relación laboral el Nuevo Derecho -ya no tan nuevo- era aun resistido. La primacía de la especificidad de la esfera laboral dentro del campo jurídico, el espacio de acción propio del juez, garantizaba en cierto punto el sostenimiento de las mismas cualidades que la justicia del trabajo poseyó desde su conformación institucional. A pesar del contexto regresivo que encontraban los trabajadores en otros espacios, con una retracción de su poder real, en la justicia del trabajo aun conservaban las prerrogativas dictadas por la doctrina y la jurisprudencia.

Manuel Pérez de Vargas disintió con respecto a la resolución adoptada por el tribunal -los otros dos jueces adhirieron al voto del Dr. Isla- y solicitó la elevación de las actuaciones a la Corte Suprema de Justicia de la Nación en tanto el fallo violaba la Constitución Nacional y permitía el planteo de la cuestión federal, ya que consideraba que violaba un derecho patrimonial adquirido. El Dictamen del Procurador General de la Nación, Ramón Lascano, desestimó el pedido aduciendo que la Corte

tiene reiteradamente declarado que, en materia laboral, no rige la doctrina referente al efecto liberatorio del pago cuando la demandada y sus actos preparatorios por cobro de diferencias de indemnizaciones se promuevan en un plazo razonablemente breve posterior al pago.

\footnotetext{
${ }^{62}$ Los actores reclamaban la indemnización doble por considerar injustificado el despido.

${ }^{63} \mathrm{DH} 109 / 6$ foja 76 vuelta y sig.
} 
En consecuencia la Corte falló el 10 de Octubre de 1962 tal como se desprendía del dictamen del procurador. Esto implicaba desconocer la validez de los recibos firmados por los trabajadores, pero al mismo tiempo desestimaba la demanda de dos de los actores -Kalinoff y García- ya que la jurisprudencia que avalaba el desconocimineto de la firma en conformidad en la relación laboral también sostenía que el plazo para instaurar el reclamo era de 4 meses. En última instancia fue un inconveniente de carácter procesal el que terminó dando por tierra con las pretensiones de dos de los trabajadores. Lo mismo ocurrió con los trabajadores de la causa DH 110/3 que si bien en primera instancia lograron una sentencia favorable, el tiempor transcurrido entre la firma de los recibos y la demanda hizo caer su derecho a reclamar.

Esto no limita el carácter pro obrero que seguían sosteniendo los Tribunales del Trabajo en el período en base a la doctrina, pero para el caso de los trabajadores de los frigoríficos había que tener presente que la inestabilidad laboral jugaba un rol importante en la definición de sus estrategias ante la patronal. Aunque en el plano hipotético se podría pensar que el plazo razonable de los cuatro meses atentaba contra dicha estrategia. En la medida en que el trabajador contaba con la posibilidad de volver a la planta, la interposición de la demanda podía ser percibida como un antecedente negativo por la parte patronal. Si pasado el tiempo no se lo volvía a contratar la opción del resarcimiento por medio de la acción judicial era percibida positivamente.

Justamente la cuestión de la puerta giratoria de los frigoríficos queda en evidencia en las siguientes causas. La inestabilidad laboral, que implicaba también la intercalación de períodos de actividad con períodos de paro, fue utilizada por parte de los jueces del Tribunal para deshacer el argumento patronal de la falta o merma de trabajo. Pero al mismo tiempo la recurrencia de períodos de empleo y paro obligó a los trabajadores a cambiar de estrategia frente a la situación de inestabilidad que enfrentaban. En la causa que 77 trabajadores le inician al frigorífico Armour $^{64}$ el 14 de Abril de 1959, 21 de ellos terminaran desistiendo de la acción en diferentes instancias del pleito. Lo mismo ocurre con 5 de los 20 obreros que le inciaron acciones al frigorífico

${ }^{64} 106 / 2$. 
Swift $^{65}$. Las razones las brinda el abogado de estos trabajadores, el Dr. Eduardo Etcheverry, al presentar su escrito ante la Corte Suprema de Justicia ${ }^{66}$

la Suprema Corte debe saber y valorar que todos los desestimientos que figuran en autos, de muchos actores se debe a reingresos de los mismos a la firma accionada (...) estos desestimientos que se advierten en autos y que obedecen a la causa señalada, se advierten igualmente en cualquier expediente colectivo o con varios actores que accionan contra el frigorífico. La población obrera de los frigoríficos de Berisso, no acierta a comprender como se los despide por falta de trabajo, con pago de media indemnización y a los quince o veinte días se los llama a trabajar de nuevo. ${ }^{67}$

La solución residía en poner fin a esta práctica patronal y retornar al camino de la estabilidad laboral. Por este motivo las demandas solían reclamar el cumplimiento de la garantía horaria que a su entender garantizaría trabajo para todos los trabajadores, al menos así sea unas horas al mes. Pero por otro lado el desestimiento indicaba también lo frágil de las estrategias de los trabajadores, demostraba lo limitado de su capacidad autónoma de elegirla en la medida en que los limitantes estructurales constreñían su acción.

Esta continuidad doctrinaria de la justicia del trabajo con su insistencia en la protección del más débil de la relación laboral produjo, en el caso de las causas de los frigoríficos, la adopción por parte del tribunal de una postura política con respecto al lugar que las empresas cárnicas debían ocupar en la sociedad. Las potestades que las empresas recuperaron en relación a sus trabajadores eran abandonadas en las puertas de los tribunales. El voto del Dr. Renom en el Veredicto de la causa DH 106/2 del 3 de Abril de 1961 indica una pauta en este sentido. Ante la justificación de la patronal del pago de la indemnización simple a los trabajadores despedidos por tratarse de una reducción de trabajo que lo amparaba en los lineamientos de la Dirección Nacional del Trabajo del 30 de Noviembre de 1949 que permitía tal medida, contrargumentó el Dr. Renom

no pueda cuestionarse que ante situaciones de crisis que amenazan con conducir a la muerte de la empresa, deben adoptarse todas las medidas por drásticas que sean para evitar el quebranto definitivo, pero si se admitiera que la fluctuación, previsible técnicamente, o la oscilación normal de los negocios fuera factor determinante de aplicación lisa y llana del concepto de falta o disminución de trabajo, se aniquilará el principio de estabilidad y

\footnotetext{
$65110 / 3$.

${ }^{66}$ Es de recordar que Manuel Pérez de Vargas, ell abogado del Swift, interponía siempre recursos legales a fin de obtener instancias de apelación de la sentencia de los tribunales del trabajo.

${ }^{67} \mathrm{DH} 110 / 3$ foja 179 vuelta y sig.
} 
propiedad del empleo (Ac. Y Sent. IV 277 S.C.J.B.A.) ya que técnicamente "toda empresa mercantil está inexorablemente sujeta a fluctuaciones de su dinámica económica"68

Después de presentar los resultados de la pericia contable que daban cuenta de la relación entre disminución de matanza y expulsión de personal ${ }^{69}$, al tiempo que certificaba la continuación de los giros a la casa matriz y la obtención de significativas utilidades, terminaba concluyendo que lo que había que referise era al monto de la indemnización porque la responsabilidad patronal en el despido estaba comprobada que no se fundó en causa legal. Así continuaba Renom

creo, que vale la pena insistir algo más sobre el tema. Aunque poco adicto a la casuística, quiero imaginar una situación en que la penuria del proceso inflacionario no recaiga sobre el trabajador sino que incida sobre la patronal. Desde luego, hablo de situación imaginada, puesto que no dudo de las previsiones que empresas tan importantes, como la demandada, adoptan en sus relaciones contractuales. Así reflexionemos sobre la hipótesis de que la empresa Armour, arrastrara desde 1934, en que los precios de los productos ganaderos se hallaban estabilizados y aun con tendencia a decrecer, el cumplimiento de un contrato de provisión de grandes cantidades de carnes, por ejemplo, al Ejército Argentino, en el que el precio de la mercadería estuviera establecido de acuerdo con un promedio determinado por el precio de los últimos cinco años, $y$, que, incluso, se hubiera fijado convencionalmente un tope máximo del costo. Incluyamos ahora, en la misma hipótesis, el hecho de que en 1945, Armour hubiese obtenido la duplicación de este tope máximo de precio. Y bien: aun con esa duplicación es de preguntar ¿Armour, en la actualidad, aun con la duplicación, se sentiría pagado como en 1945? ¿Y qué diría Armour, si se le discutiera, por razones más o menos atendibles, que no debe cobrar la duplicación sino el anterior tope de 1945 ?

No cabe consideración posible para tales interrogantes, porque la respuesta está en lo absurdo de la situación planteada -como lo es también la de la ley 11.729- y en último análisis, porque la doctrina ha elaborado, a pesar de los vetusto de las normas civiles, remedios apropiados para que no pueda llegarse, cuando por motivos ajenos a los contratantes se quebrantara ínsitamente, el equilibrio económico de los contratos, a la ejecución de prestaciones que constituyen no otra cosa que verdaderas exacciones (...) quien exige el cumplimiento de un contrato no obstante la mutación

\footnotetext{
${ }^{68} \mathrm{DH} 110 / 3$, Foja 267.

${ }^{69}$ Esta situación propuesta por la patronal terminó siendo invertida en la fundamentación del mismo Renom, y con argumentos similares se refirió a la cuestión el Dr Ves Losada en la causa $\mathrm{DH}$ 105/12. La contrargumentación de Renom se baso en la pregunta sobre el huevo y la gallina, sembrando la duda si los despidos eran consecuencia de la disminución de la matanza o la disminución de la matanza era consecuencia de la menor cantidad de personal. El Dr. Ves Losada realiza la misma pregunta, aunque sin la referencia al huevo o a la gallina. Sin embargo dos párrafos después utiliza la metáfora del agujero del queso para referirse a algo que se ve pero es la nada misma, refiriéndose a la resistida doble indemnización. Ambas metáforas dan cuenta del lenguaje sencillo que aun predominaba en los Tribunales del Trabajo. Sin dudas esta sencillez lingüística acercaba al trabajador a la justicia.
} 
fundamental de las circunstancias que determinaron su ajuste, abusa de su derecho y no puede hallar amparo en la justicia. ${ }^{70}$

El rechazo de la empresa a pagar la doble indemnización dejaba a los trabajadores desarmados ante la carestía de los productos indispensables. La sorna e ironía detrás de la argumentación de Renom dejaba traslucir el descontento con el que los encargados de administrar justicia en el foro veían la forma en que la empresa manejaba sus relaciones con sus trabajadores, olvidando sus obligaciones sociales. Al mismo tiempo remarcaba que la desprotección en la que se encontraba el trabajador-desprotección que la empresa con su capacidad previsora podía evadir- no podía ser refrendada por los tribunales. Así hacerlo sería escapar de lo justo ya que implicaba el beneficio a la parte más fuerte en la relación laboral y la Justicia del Trabajo debía cumplir con su papel doctinario de salvaguarda de la parte más débil del contrato.

La función de los tribunales del Trabajo al evitar los despidos baratos incluso era pensado por los jueces prácticamente como medidas anticíclicas que aleccionaba a los empresarios sobre las consecuencias de seguir con sus acciones. Decía Renom

no puede dudarse, creo, que si el sector de la industria manufacturera, y aun el Estado como patrono, hubiese reaccionado en igual forma que la industria frigorífica frente al "impacto" producido por el plan económico del gobierno nacional, esto es, acudiendo a la simple fórmula de efectivizar despidos en masa, el aumento desmedido y sin control de la desocupación habría traído imprevisibles penurias para todo el país, sino conmociones sociales de resultados insospechables.

Ellos así, aun cuando sólo fuera con criterio aleccionador estimo no debe ser admitido el "despido barato" que implica la posición de la demandada al acogerse, indebidamente, a la excepción del art. 67 del Dec. 33.302.

Los motivos que llevaban a los jueces del Tribunal a actuar de esta manera tenía sus raíces en la importancia que la justicia del trabajo otorgaba a las consideraciones de las condiciones reales en las que se establecía el conflicto y no solamente en la aplicación del derecho. Sin embargo también recordaba que era desde el derecho mismo que se les obligaba a los profesionales a llevar adelante su misión, definida en términos de justicia. Decía Renom

\footnotetext{
${ }^{70} \mathrm{DH} 110 / 3$, Foja 270 y sig.
} 
las precedentes reflexiones no pretenden plantear un mero problema de "sensibilidad". Se trata, en realidad, que la disciplina del derecho impide permanecer impasible ante el problema humano.(...) No cabe en el jurista ese pensamiento abstracto que conduce a la despersonalización en las relaciones humanas. El jurista que cumple con su misión de tal, no puede, en pseudo actitud científica, considerar al hombre como un organismo animal o un compuesto de electrones y protones. El jurista se mueve en una atmosfera impregnada de respeto por la persona humana. ${ }^{71}$

Por momentos la descripción del jurista promovida por el Dr. Renom se acercaba al juez que se alejaba de la fría letra de la ley para dar respuesta a las problemáticas sociales, el modelo de juez que había propiciado discursivamente el primer peronismo.

Esta cuestión de los juristas habilita la pregunta sobre los límites de la desperonización. En tanto fuero creado bajo el peronismo la permanencia de algunas características -no necesariamente peronistas- pro obreras marcaron una frontera para los procesos desperonizadores. De todas maneras el nuevo contexto sobre el que actuó la justicia laboral ya no era el de la promoción de la cooperación de las clases bajo el justicialismo. Los patrones presionaron sobre los trabajadores a fin de retomar el control de los establecimientos y del proceso productivo. Sin importar demasiado el tipo de actividad que desarrollase, el patrón busco retomar esa imagen del patrón que chocó contra la lógica pro obrera de los Tribunales del Trabajo durante el peronismo.

\section{VII.3 La revancha de los patrones y sus límites}

En las causas del período se percibió el ánimo revanchista de los patrones y la voluntad de retomar el control del proceso del trabajo que el peronismo había puesto en duda y del que dan cuenta distintas perspectivas historiográficas. La intención revanchista se percibe en los juicios que promueven delegados gremiales despedidos, casos inéditos para el período previo.

Henry Napoleón Fernández se desempeñaba como delegado gremial en la planta frigorífica que la empresa Swift poseía en la ciudad de Berisso ${ }^{72}$. El 11 de Abril de 1959 fue despedido junto con otros 21 trabajadores, alegando la empresa falta de trabajo. En el texto de la demanda los abogados de

\footnotetext{
${ }_{71}^{71} \mathrm{DH}$ 110/3 Foja 274 vuelta y sig.

${ }^{72} \mathrm{DH} 107 / 7$.
} 
Fernández sostienen que la empresa actuó en "ostensible práctica desleal, violando la garantía de INAMOVILIDAD que estatuye la ley de ASOCIACIONES PROFESIONALES $n^{\circ} 14.455^{\prime 73}$ y se preguntan

qué ocurriría si todas las empresas patronales adoptaran la desleal actitud de la demandada? Evidentemente que la ley 14.455 quedaría destruida y desvirtuadas las asociaciones profesionales que coadyuvan a mantener el equilibrio económico y la paz social.

La sanción de la ley 14.455 -en el caso que nos ocupa- el art. 41 de la misma, había traído la tranquilidad a los hombres dedicados a la lucha gremial posibilitando su acción sin riesgos para su seguridad. Pero lamentablemente y no obstante las prescripciones de la ley nuestro representado se ve despedido por la arbitrariedad patronal ${ }^{14}$

La sanción de la referida ley bajo el gobierno de Frondizi buscó relanzar la alianza entre el gobierno y la clase obrera sindicalizada, aunque con dispar éxito, y evitar una práctica común a los años de la Libertadora que era la cesantía de los delegados gremiales con el objetivo de deteriorar el poder de las comisiones internas de fábrica. Sin embargo la mera sanción de la ley no impidió el despido de Fernández. La parte patronal se sustentó en una triple estrategia: la falta de trabajo y la caída en la faena de animales, desconocimiento del carácter de delegado gremial y la falta de jurisdicción del tribunal para actuar sobre el tema, "demasiadas "gangas" no fáciles de ocultar"75 a su criterio que hacian a la demanda improcedente. El Tribunal resolvió las cuestiones referidas a la falta de jurisdicción, no llegando a resolver las cuestiones de fondo porque el actor desistió del juicio.

En la resolución de la cuestión de excepción, el Dr. Isla -uno de los jueces del tribunal- sostiene

al votar la causa BOERO c. ARMOUR $(2119, \mathrm{Sec}$. 1), similar en un todo a la presente, sostuve la competencia del Tribunal.

Argumenté en aquella oportunidad que la acción tenía su origen en un conflicto individual del trabajo, en los términos del art. $6^{\circ}$, ley 5178 , t.o., ya que se invocaba un contrato de trabajo y un despido y se reclamaba una indemnización por dicho despido. $Y$ en cuanto a la existencia de un procedimiento previo y necesario para la apertura de la vía judicial; expresé que la "práctica desleal" y la "estabilidad" del dirigente gremial son dos institutos diferenciados de la ley, en cuanto protegen intereses distintos, el colectivo y el individual. Que la previa clasificación por el Consejo de Relaciones Profesionales no está impuesta por ley, mucho

\footnotetext{
${ }^{73} \mathrm{DH} 107 / 7$ Foja 3 Mayúsculas en el original.

${ }_{75}^{74} \mathrm{DH} 107 / 7$, foja 3 vuelta y sig.

${ }^{75} \mathrm{DH} 107 / 7$, foja 19
} 
menos si la estabilidad del dirigente gremial tiene hoy jerarquía de garantía constitucional. ${ }^{76}$

La distinción que traza entre los dos institutos de la ley da cuenta de la tradición privada en el caso de los orígenes del Derecho del Trabajo como prolongación de la tradición civil y sujeta a la jurisdicción de los tribunales, mientras que el carácter colectivo -la práctica desleal- sí podía quedar en manos de las autoridades del Poder Ejecutivo.

En otro caso, el 14 de marzo de 1960 César González, a través de su abogado patrocinante Horacio Colombo, inicia demanda contra el Club Hípico de City Bell, localidad cercana a La Plata ${ }^{77}$. Fue despedido el 9 de Noviembre de 1959 al reclamar enfáticamente al representante patronal, el señor Felipe Traynor, el cumplimiento del convenio colectivo vigente y que proveyese a los peones de botas de goma ya que debian realizar tareas en una zona pantanosa.

indudablemente, esta reclamación perturbó la tranquilidad del Señor "delegado interno", quien en alta voz recriminó a González que no tenía derecho a intervenir porque él no lo reconocía como capataz, ni como delegado gremial. Así se originó una discusión. ${ }^{78}$

La Discusión concluyó con una denuncia penal en la comisaría local y en la justicia criminal en la que el actor fue acusado de amenazar al Sr. Traynor con un arma de fuego, denuncia que fue desestimada por la justicia y sobreseído el actor. Todo el incidente del 9 de Noviembre fueron

con el único objeto de tratar de justificar el despido de González, cuya persona parece serles no grata, desde el momento en que tuvo que reclamar judicialmente las mejoras y derechos que le acuerdan las leyes. ${ }^{79}$

Finalmente el tribunal fallará a favor del despedido González el 18 de Abril de 1963. En esa instancia se rechaza el pedido de reincorporación al cargo por improcedente.

Es curioso que delegados gremiales acudiesen a la institución judicial teniendo la posibilidad de recurrir, a través del sindicato, al Poder Ejecutivo. Solo puedo aquí aventurar una respuesta al interrogante. Teniendo en cuenta el recorrido que la mayoría de los trabajadores realizaba en la procura de sus

\footnotetext{
${ }^{76} \mathrm{DH} 107 / 7$, foja 42 y sig.

${ }^{77} \mathrm{DH}$ 110/8 González César M c/ Club Hípico de City Bell s/despido, Año 1960.

${ }_{78}^{78} \mathrm{DH} 110 / 8$, foja 9.

${ }^{79} \mathrm{DH} 110 / 8$, foja10 vuelta.
} 
derechos - sindicato, autoridad administrativa, tribunales- el porqué de acudir a los tribunales se puede encontrar en el fracaso de las instancias previas. El caso del delegado de obra Mario Benítez puede servir como el contrapunto. Se trata de un delegado gremial que logró su estabilidad laboral mediante la intervención del sindicato y la instancia administrativa en la relación con su patrón, el constructor Florentino Cuchiarelli. En efecto, en la causa que iniciaran Gancho Dilchoff, Nicolás Villafañe, Manuel José Helguera, Omar David Barrios, Alberto Ubaldo Guerrero y Ángel Negronida a Florentino Cuchiarelli el 28 de Diciembre de $1959^{80}$ por despidos y diferencial de haberes no se incluye la presencia del delegado y compañero en la obra de los actores, Mario Benítez. La causa, rápidamente resuelta por los jueces de forma favorable a los actores a diez meses de iniciado el juicio, fue motivada por el continuo atraso en el pago de las quincenas, suspensiones arbitrarias de las tareas e irregularidades varias que habían llevado a los trabajadores a realizar más de una medida de fuerza contra su patrón.

En las actuaciones judiciales se suman como pruebas los expedientes llevados adelante por el Departamento Provincial del Trabajo, en los que se puede rastrear la suerte de Mario Benítez. En el caso de estos expedientes el promotor no es un sujeto individual, sino que es el sindicato quien se presenta como parte en el conflicto. La Unión Obrera de la Construcción de la República Argentina (Uocra), en la persona de su secretario general Segundo Palma, da inicio al expediente 3850/58 en Mayo del año 1958 en la Secretaría de Conciliación $\mathrm{N}^{\circ} 3$. De las actuaciones se desprende que el día anterior Mario Benítez recibió el telegrama colacionado que decía "por inconducta en el trabajo y falta de capacidad queda ud. Despedido a partir del día 27 del corriente" ${ }^{\prime \prime 1}$. La parte obrera rechazó los términos de dicho telegrama "por improcedentes, entendiendo que dicha medida es una represalia por la acción gremial que dicho obrero desarrolla en la obra" ${ }^{22}$, por lo cual el patrón estaba encuadrado en "práctica desleal".

El personal de la obra paralizó las tareas ese día en solidaridad con su delegado hasta la normalización de la situación. La respuesta patronal no se

\footnotetext{
${ }^{80} \mathrm{DH}$ 108/5 Villafañe Nicolás y otros c/ Cuchiarelli Florentino s/despido y haberes, Año 1959.

${ }^{81}$ 108/5, foja 6 de expediente agregado a cuerda floja.

82 108/5, foja 6 de expediente agregado a cuerda floja.
} 
hizo esperar y al día siguiente de iniciado el paro se presentó el patrón en las oficinas del DPT a realizar su descargo. En esa ocasión el Sr Cuchiarelli admitió el retraso en el pago de las quincenas y haber despedido a Benítez. Ante el reclamo del sindicato de la restitución del delegado gremial este responde que

\begin{abstract}
con respecto a la reincorporación del Delgado (sic) Obrero MARIO BENITEZ, pedida por los representantes obreros, el declarante no puede hacer lugar en virtud que dicho obrero ha sido despedido con causa grave. Que esa causa es ajena a la acción gremial de dicho delegado. Que una reincorporación de dicho obrero, después de lo sucedido significaría un resquebrajamiento de la disciplina en las relaciones obrero-patronales que el declarante entiende de su derecho tutelar. Que no existe de parte del declarante animosidad alguna hacia el Sindicato Obrero, y tanto es así que desde ya admite cualquier otro delegado en su reemplazo, pero el señor BENITEZ, no. ${ }^{83}$
\end{abstract}

Se permitió también recomendar a los delegados obreros que le hiciesen saber a los trabajadores que "este asunto no debiera ser motivo para decretar paros o actos de fuerza ya que en tal caso el declarante consideraría a esos obreros incursos en abandono de trabajo" ${ }^{\prime 4}$. A pesar de la amenaza patronal los obreros no volvieron al trabajo y prolongaron la medida de fuerza mientras en el DPT en nueva audiencia los sindicalistas sostenían que de ninguna manera la reincorporación del delegado obrero resquebrajaría la disciplina en las relaciones obreras-patronales "puesto que parte sindical entiende que las faltas de disciplina si así se les puede llamar a las reacciones lógicas de los obreros que en defensa de sus intereses" eran provocadas por la posición patronal y agravado por "el carácter violento del señor capataz" ${ }^{85}$. En este contexto de desavenencias fue que se dio el atraso para efectuar el pago de los jornales y que ante el reclamo de los obreros por esto "puso en práctica otra de sus medidas arbitrarias a las que los tiene acostumbrado, negándoles trabajo a sus obreros" ${ }^{\prime 6}$. El reclamo por parte de Benítez es lo que desencadena

la reacción del patrono, que acostumbrado anteriormente a actuar según su libre albedrio, llegada la oportunidad de que un representante obrero le exije (sic) el cumplimiento del convenio y de las leyes laborales es natural que dicho señor se sienta perjudicado en sus intereses y entonces

\footnotetext{
${ }^{83} \mathrm{DH} 108 / 5$, foja 9 expediente agregado a cuerda floja. Mayúsculas en el original.

${ }^{84} \mathrm{DH} 108 / 5$, foja 9 vuelta expediente agregado a cuerda floja.

$85 \mathrm{DH} 108 / 5$, foja 10 expediente agregado en cuerda floja.

${ }^{86} \mathrm{DH} 108 / 5$, foja 10 vuelta expediente agregado a cuerda floja.
} 
resuelva librarse del mismo por cualquier medio y de ahí que invente la "falta grave", para justificar el despido. ${ }^{87}$

Finalmente el Laudo Arbitral del DPT termina fallando por la reincorporación de Benítez y el pago de los jornales adeudados más la mitad de los días en los que los trabajadores realizaron paro. El Laudo de la institución administrativa, además, daba cuenta de la necesidad de conciliar dos de los tópicos más importantes de la esfera laboral en los años finales del peronismo y el post peronismo. Al cerrar sus actuaciones la Secretaria de Conciliación $\mathrm{N}^{\circ} 3$ recomendaba al

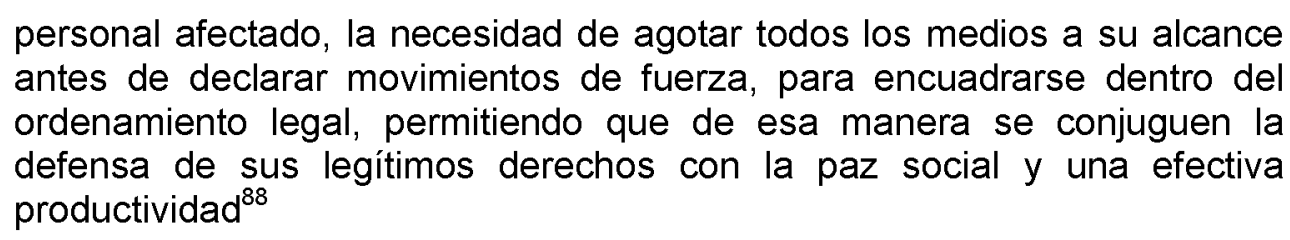

El sostenimiento de la productividad, eje de los conflictos desde los primeros años de la década del cincuenta, irrumpía en las instituciones laborales que se habían sostenido siempre sobre el ideal de la paz social y la armonía entre las clases.

El recorrido de Benítez es iluminador con respecto a los casos anteriores y el porqué de la actuación judicial de los delegados despedidos. El caso de Mario Benítez no llegó a la instancia judicial -de hecho su participación en el juicio es como testigo de los atropellos patronales- porque su situación fue solucionada mediante la intervención de las instancias administrativas previas. El funcionamiento o no de estas instancias eran las que promovía a la justicia del trabajo a resolver conflictos que antes les eran ajenos.

Sin duda la fortaleza de la organización sindical de los trabajadores de la construcción impactó en el desarrollo de la causa de Mario Benítez, pero no es suficiente para sostener que la resolución de su conflicto sea sólo consecuencia de esta variable. El caso del delegado gremial del Club Hípico de City Bell podría abonar esta hipótesis en la medida en que el sindicato al que representaba no era un sindicato fuerte y bien organizado como sí lo era la Uocra, pero no se sostiene ante la situación de Henry Napoleón Fernández.

\footnotetext{
${ }^{87} \mathrm{DH} 108 / 5$, foja 10 vuelta expediente agregado a cuerda floja.

${ }^{88} \mathrm{DH} 108 / 5$, foja 34 de expediente agregado a cuerda floja.
} 
Este delegado sindical pertenecía al poderoso gremio de Trabajadores de la Carne.

El contexto político, con trabas a la acción sindical e impedimentos en la acción mediadora de las instituciones administrativas dedicadas a regular la relación laboral, era desfavorable para las acciones de los trabajadores. Es en ese contexto que la Justicia del Trabajo apareció como un escenario más favorable en la medida en que, en tanto institución con relativa autonomía de los vaivenes políticos del Poder Ejecutivo y con características institucionales pro obreras, fue percibida como arena de disputas que antes eran sostenidas en las instancias administrativas.

\section{VII.3.1 Las revanchas de los patrones ¿antiperonistas?}

Significativas son también las causas que dan cuenta de trabajadores despedidos por adherir a medidas de fuerza. En el contexto represivo sobre la actividad del movimiento obrero la huelga brindaba a los patrones una oportunidad para deshacerse de trabajadores considerados "revoltosos". Una serie de causas que envuelven a trabajadores de la Sociedad Cooperativa de Tamberos la Plata Ltd. comienza con la adhesión de estos al paro general de 48 horas convocado por las 62 Organizaciones ${ }^{89}$ para el 22 de Octubre de $1957^{90}$. Desgraciadamente no se cuenta con las resoluciones adoptadas por el Tribunal en estos casos ya que por cuestiones de economía procesal se decidió, al tratarse de un mismo patrón denunciado por la misma causa, resolver el pleito en una causa y hacer extensible al resto de las causas las medidas allí adoptadas. Así el 22 de diciembre de 1958 en los autos "Orellano Facundo Martín c/Sociedad cooperativa de Tamberos La Plata Ltda s/haberes"

\footnotetext{
${ }^{89}$ Las 62 Organizaciones constituía la agrupación de los gremios cuyos líderes respondían al peronismo y al comunismo -aunque estos últimos abandonarían Las 62 meses después-, frente a los 32 Organizaciones que nucleaba a los sindicatos no peronistas. Ambos agrupamientos surgieron de la división producida en el Congreso Normalizador del la CGT de Agosto de 1957. ${ }^{90}$ DH 105/8 Nieto Emilio y otro c/Sociedad cooperativa de tamberos La Plata Ltd s/despido y haberes, Año 1958; DH 105/9 Quiroga de Hrvatin María Clara c/Sociedad Cooperativa de tamberos La Plata Limitada s/despido y haberes, Año 1958; DH 106/5 Orellano Juan Bautista c/ Sociedad Cooperativa de Tamberos "La Plata" Ltda s/haberes, Año 1958. Hay otra causa contra la misma compañía de Junio de 1960 pero el motivo de despido no es este paro, sino la intervención por parte de las autoridades del Poder Ejecutivo provincial, esa causa -DH 111/1 Gabino Waldi Elías c/Sociedad cooperativa de tamberos La Plata Ltd s/despido y haberes, Año 1960- concluyó con un acuerdo entre las partes.
} 
se jugó la suerte de estos trabajadores ${ }^{91}$. Dicha causa no sobrevivió al paso del tiempo por lo que es casi imposible conocer el resultado de la táctica obrera ${ }^{92}$.

Sin embargo a pesar de estas limitaciones importa destacar el hecho de que estos trabajadores fueron despedidos por haber adherido a un paro convocado por una organización gremial que respondía ideológicamente a los postulados del peronismo. Las demandas, presentadas entre el $1^{\circ} \mathrm{y}$ el 21 de Julio de 1958, están redactas en términos prácticamente idénticos producto de que los representantes legales ${ }^{93}$ y los hechos sobre los que se funda el reclamo son los mismos. En ellas se describe que el 22 y 23 de Octubre el

Movimiento Obrero Argentino dispuso la realización de un paro de 48 horas a efecto de la concreción de 5 puntos a la que se plegó la CGT local y $\mathrm{ATIL}^{94}$ Seccional La Plata a la que pertenencen los accionantes. ${ }^{95}$

El día 23 de Octubre, aun durante el paro, fueron suspendidos por 30 días. Las sanciones de los trabajadores motivaron que la CGT local los respaldara en la promoción de las actuaciones administrativas bajo el $N^{\circ} 96.012 / 57$.

En la instancia administrativa las sanciones fueron rechazadas "por arbitraria, por cuanto importa conforme a la legislación vigente una práctica desleal ya que el acto constituyó una represalia por motivos estrictamente gremiales" $"$. La rápida decisión de la autoridad administrativa no encontró la respuesta deseada de la patronal que ante el revés administrativo despidió a los trabajadores. Sin embargo hasta aquí la situación de plegarse a un paro que fue declarado ilegal por las autoridades- no resultaba suficiente para sostener que la patronal haya aprovechado para deshacerse de trabajadores

\footnotetext{
${ }^{91}$ Por referencias en los autos de las causas consultadas se infiere que la cantidad de trabajadores implicados era mayor. Aquí se detallan sólo aquellos que aparecen en las causas como actores: DH 105/8:Emilio Nieto y Ángel Luján Espósito; DH 105/9: Quiroga de Hrvatin María Clara; DH106/5: Orellano Juan Bautista; DH 106/6 Washington González.

${ }_{92}$ A pesar de varios pedidos me fue imposible acceder a los libros de sentencia del Tribunal del Trabajo $\mathrm{N}^{\circ} 1$ que aun se encuentra en poder del tribunal.

${ }^{93}$ Los abogados son Carlos Alberto Brusa, Pedro Emilio Michelini, Carlos Antonio Pons, Ezequiel Zuloaga, Adolfo Carlos González Etcheverry, Antonio Carlos Casco y Roberto Guaresti. En las causas DH 105/8 el abogado actuante fue Zuloaga, y en la DH 106/6 Brusa, mientras que en las otras dos actúan indistintamente. De todas maneras lo más probable es que compartieran el mismo estudio, ya que estos abogados aparecen asociados en diferentes causas. De este grupo de abogados el más destacado por su función política fue Pedro Michelini, quien fue el representante de Perón para la zona de La Plata, Berisso y Ensenada. Además actuó como asesor letrado de la CGT local.

${ }_{94}$ Asociación Trabajadores de la Industria Lechera de la República Argentina.

${ }^{95} \mathrm{DH} 105 / 8$ foja 3 vuelta.

${ }^{96} \mathrm{DH} 105 / 8$ foja 3 vuelta.
} 
que consideraba poco dóciles. Pero en la demanda también se sostuvo, a fin de justificar los arbitrario de la medida tomada contra estos trabajadores que "obreros despedidos en las mismas circunstancias que sus representantes, fueron reintegrados a sus empleos, situación que evidencia el trato desigual"97

El abogado Carlos César Tejo, apoderado de la Sociedad Cooperativa, reconoció la existencia de la relación laboral que se invocaba, pero sostuvo que fueron despedidos con causa. Aduce que además de realizar tareas remuneradas eran socios cooperativistas de la sociedad.

el ingreso de ambos como socios se produjo el día 24 de enero de 1957 con motivo del convenio celebrado con los empleados y obreros de la sociedad, para su incorporación como socios, habiendo quedado obligados los mismos desde esa fecha a comportarse y asumir actitudes que en manera alguna, como es lógico, podían estar en pugna o reñidas con los intereses de la sociedad de la que forman parte.

Pero los accionantes no lo entendieron así y colocándose al margen de las obligaciones que tenían para con la misma y demostrando una falta absoluta de conciencia societaria, a la vez que asumían toda clase de actitudes contrarias a la sociedad, prestaron toda su adhesión a un paro de trabajo que tuvo lugar los días 22 y 23 de Octubre ppdo que por lo inconsulto y fuera de lugar fue declarado ilegal por las autoridades correspondientes. ${ }^{98}$

Esto se sumaba a varias actitudes contrarias a la cooperativa que dio justo motivo para que ésta los expulsara como socios y como empleados de la misma, pues si la conducta de estos como componentes de la sociedad fue intolerable, como empleados fue injuriosa y por ende pasible de la sanción de que fueron objeto. ${ }^{99}$

La argumentación de la demandada de que eran socios de la cooperativa encontró en la identificación de estos actores como trabajadores un impedimento para lograr que adoptasen la conducta esperada de un socio cooperativista. El cambio en la denominación legal no fue suficiente y la consideración de la Cooperativa como el patrón -y que al fin y al cabo se asumía como tal al despedirlos- forzaba su autorrepresentación como trabajadores al encontrar al otro de la relación. Estas medidas, para los abogados de los trabajadores, tuvo como objetivo incumplir con los derechos laborales. La patronal, además de ser efectivamente el patrón y no el socio, era

\footnotetext{
${ }^{97} \mathrm{DH}$ 105/8 Foja 4. Los despedidos y posteriormente reincorporados fueron -según los hechos de la causa DH 106/6- Luis Minaudo, Carlos Adolfo Bigal, Walter González, Juan Arias y Rodolfo Sempé.

${ }_{98}^{\mathrm{DH}}$ 105/8, Foja 8 vuelta.

${ }^{99} \mathrm{DH} 105 / 8$, Foja 9.
} 
también arbitraria "por cuanto reintegró a personal huelguista despedido, estableciendo distinciones que repugnan al derecho"100.

Las acciones de la empresa tendientes a desplazar a los trabajadores activistas se refuerza con los hechos que envuelven a Juan Bautista Orellano $^{101}$ y a Washington González ${ }^{102}$. A las generales descritas de la causa DH 105/8 se suma el hecho de que Orellano y González eran subdelegados de fábrica de ATIL elegidos en Junio de 1956. Siempre según la demanda ambos fueron suspendidos al igual que sus compañeros huelguistas el 23 de Octubre de 1957 y junto con 4 dirigentes gremiales más. Ante la medida disciplinaria arbitraria y la práctica desleal la instancia administrativa intimó a la empresa a levantar suspensiones y cesantías, bajo apercibimiento de de aplicar las sanciones de ley. Al igual que las otras causas la resolución del conflicto se encuentra en los autos "Orellano Facundo Martín c/Sociedad cooperativa de Tamberos La Plata Ltda s/haberes"

\section{VII.3.2 El Peronismo y el Antiperonismo en las causas judiciales}

Los enfrentamientos entre peronistas y antiperonistas tuvieron su expresión en las causas judiciales. El peronismo y antiperonismo adquiere relevancia en la explicación de tres causas judiciales debido a la empresa patronal de los trabajadores envueltos en ellas. La importancia política y estratégica de la destilería de YPF de la ciudad la convirtió en un campo de batalla entre peronistas y antiperonistas. La importancia de YPF en los planes estratégicos de cualquier fuerza que aspirase a construir un proyecto de Nación avalaba la protección de la empresa petrolera estatal ante los embates de fuerzas contrarias a las que regían el destino del país. La estrecha vinculación entre YPF y Nación constituyó un límite a la acción de los trabajadores de la destilería. Incluso en una institución pro obrera como los Tribunales del Trabajo, la empresa se veía resguardada en tanto expresaba un interés superior a los de los trabajadores: el interés nacional.

\footnotetext{
${ }_{100}^{100} \mathrm{DH} 105 / 8$, Foja 16

101 Actor en la causa DH 106/5.

102 Actor en la causa DH 106/6.
} 
En el Acuerdo de la causa que 38 trabajadores le iniciaron a la empresa por el despido ${ }^{103}$-también producto de un paro- el Juez Ves Losada fue el encargado de fundamentar el fallo que dio lugar a la cuestión de competencia. A diferencia de otras causas donde se estable un recurso de inaplicabilidad de la jurisdicción, el tribunal no opuso reparos a perder la jurisdicción sobre los pleitos entablados entre YPF y sus trabajadores. Sostuvo en su voto el Juez Ves Losada:

Todo ello pone de manifiesto que la Nación y Yacimientos Petrolíferos Fiscales, están compenetrados de los mismos intereses económicos y políticos, cuya efectividad solamente puede alcanzarse satisfactoriamente, mediante la dependencia jurídica establecida en los recordados textos legales. Toda interferencia de una jurisdicción extraña, podría, sino llegar a frustrar, por lo menos perturbar el desenvolvimiento de la empresa, y a través de ella, los más importantes intereses de la Nación. ${ }^{104}$

Por este motivo la responsabilidad ejercida por el Tribunal le impidió actuar en una causa que podía perturbar el desarrollo nacional. En el caso del enfrentamiento entre el peronismo y sus detractores, primero, y la autoproclamada Revolución Libertadora y el peronismo, después, una forma de eliminar el riesgo que implicaba tener trabajadores contrarios en la destilería fue por medio del despido o las cesantías ${ }^{105}$.

Entre los años 1950 y 1952 Pedro Erramouspe, Adán Broglio, Félix Héctor Buiani, Albertto Della Pietra y Oscár Aniceto Amieva fueron cesanteados, según la demanda redactada por el abogado Pedro Michelini, sin seguir los preceptos establecidos en el estatuto de la empresa que garantizaba la legítima defensa, ya que no se les inició el sumario correspondiente. Sin embargo la resolución del 7 de Abril 1956 del expediente 97.724/56 dice que

Razones de buen servicio hacen aconsejable continuar contando con el concurso de los agentes que por razones ajenas a su capacidad $y$ contracción al trabaio fueron separados de la empresa. ${ }^{106}$

\footnotetext{
${ }^{103}$ DH106/9 Busto Acosta c/YPF s/ Haberes, Año 1958.

${ }_{104} \mathrm{DH}$ 106/9 Foja 170.

105 En prácticamente todos los conflictos entre peronistas y antiperonistas ambos bandos amenazaban con volar la destilería. En las jornadas de Septiembre de 1955 el Almirante Rojas estacionó parte de la flota de mar en la rada de Punta Lara y bombardeó barrios obreros de Ensenada, amenazando con destruir la destilería, esto produjo la presurosa salida de la región hacia el interior de la provincia de habitantes de La Plata, Berisso y Ensenada, ente ellos la familia de mi madre. La destilería era objeto de continuas amenazas y siempre existía el riesgo del sabotaje que mantenía en vilo a las autoridades.

${ }_{106}$ DH 107/8 Erramouspe Pedro y otros c/ Y.P.F. s/ haberes, Año 1959. Foja 11vuelta. Subrayado original.
} 
En la contestación de la demanda, previo recurso de incompetencia de jurisdicción, el abogado de la empresa Manuel Antueno deja en claro los motivos de la cesantía

significa que los motivos de la separación eran justos en su momento y hechos posteriores les hicieron perder significación o que una suerte de amnistía vino a purgar los motivos o causas anteriormente tenidos en cuenta. $^{107}$

Fueron razones de seguridad lo que motivó la cesantía de diversos empleados. Las razones de la amnistía fue el cambio en la orientación política del gobierno nacional, cuyos intereses, como ya quedó dicho, estaban profundamente imbricados con los objetivos de YPF.

El caso inverso se dio en las razones de la cesantía de Juan Rosales, Celestino Contreras, Elio Víctor Mendez, Orestes Pedro Piboul ${ }^{108}$, Salvador Leonardo Agasi, Albano Luis Buratini, Pedro Caram, Edelmiro Pinelli, Juan Raffetto, Teodoro Walter Wichcabbich, Enrique Andrés Barragán y Juan Antonio Gómez. Todos ellos fueron cesanteados en razón de considerar las autoridades de la destilería que habían puesto en riesgo el funcionamiento de la planta. En el caso de Edelmiro Pinelli se sumaba que estaba inhabilitado de trabajar en la destilería en razón de la aplicación del decreto ley $4258^{109}$. La justificación de las formas en las que se dieron los despidos y posterior reincoporaciones, que justificaba según la demanda el reclamo de los haberes no cobrados durante su cesantía, se encontraba en las razones de seguridad y los momentos convulsionados que atravesó la planta. Entre las pruebas

\footnotetext{
${ }^{107}$ DH 107/8, Foja 24.

${ }^{108}$ Estos trabajadores eran los actores en la causa DH 109/3 Rosales Juan y otros c/YPF s/haberes, mientras que los siguientes llevaron adelante la demanda en la causa DH 109/4 Agasi Salvador L. y otros C/ Y.P.F. s/ haberes, Año 1959.

${ }^{109}$ En los considerandos del Decreto Ley $N^{\circ} 4258$ del 6 de marzo de 1956 se exponían las razones por las cuales se promulgaba el decreto:
}

\section{CONSIDERANDO:}

Que de las características predominantes del régimen depuesto por la Revolución Libertadora, es la subversión total de los valores éticos con el consiguiente caos institucional, jurídico y económico que padece la República:

Que esta labor destructiva de la nacionalidad, no hubiera alcanzado la magnitud que los hechos evidencian, sin la complicidad, intervención o beneplácito de los funcionarios que prestaron activa o pasivamente su colaboración.

Que igual culpa recae sobre el disuelto Partido Peronista y sobre sus autoridades, en sus dos ramas, que sirvieron incondicionalmente a los fines de la dictadura.

Que es imprescindible adoptar medidas moralizadoras que impidan la repetición de hechos semejantes, por los cuales la vida, el honor y el patrimonio de los argentinos queden a merced de un tirano. 
solicitadas por el abogado Manuel Antueno, en caso que no prosperara el recurso de incompetencia de jurisdicción hecho que no sucedió, pedía

$1^{\circ}$ Se libre oficio al Juzgado federal $\mathrm{N}^{\circ} 3$ de esta ciudad a cargo del Doctor Alejandro Elguera, Secretaría $n^{\circ} 8$ para que remita la causa $N^{\circ} 804$ y sus conexas, iniciada por conspiración para cometer rebelión

$2^{\circ}$ Se libre oficio a la Policía de esta Provincia (División Judicial) para que remita copia del informe elevado el 10 de enero de 1956 por el Comisario Instructor Osvaldo Pérez Castro, en las actuaciones iniciadas con motivo de los hechos ocurridos en la Destilería La Plata los días $1^{\circ}$ y 2 de Noviembre de 1955; para que remita asimismo el sumario instruído por el Comisario Inspector Amilcar $O$ Tarragona, por infracción al decreto-ley $n^{\circ} 4161$, elevado a la división Judicial el 2 de Mayo de 1956, del que resultan acusados Celestino Contreras y otros. ${ }^{110}$

La filiación de estos trabajadores con el peronismo los convertía en una variable inestable dentro de la planta. La situación política justificaba su cesantía y, aun incluso cuando posteriormente fueron reincorporados, el acto en el que se habían visto envueltos y la excepcionalidad que vivía el país impidió que la justicia del trabajo, a pesar de su pro obrerismo, fallase en contra de los intereses de la Nación. YPF, como patrón, no podía ser considerado en las generales de la ley, su estrecha vinculación con los intereses nacionales suspendía también los derechos de sus trabajadores y dejaba expuesto los límites de la justicia del trabajo con respecto a las políticas estatales.

\section{VII.4 Conclusiones}

El proceso abierto en Septiembre de 1955 implicó nuevos desafíos para la justicia del trabajo y los actores en ella envueltos. En tanto institución creada bajo el peronismo los tribunales laborales fueron objeto de los intentos desperonizadores llevados adelante por la autoproclamada Revolución Libertadora, cuya idiosincrasia se construyó en torno al regreso al imperio del derecho y a la senda tradicional -liberal y republicana- argentina. Los sentidos de la desperonización portados por las diferentes fuerzas políticas que convergieron en el golpe de estado de Septiembre de 1955 no eran coincidentes y, aunque antiperonistas, muchos adherentes de los principios del

\footnotetext{
${ }^{110}$ DH 109/4 Agasi Salvador L. y otros c/ Y.P.F. s/ haberes, Año 1959, foja 21. El paro al que hace referencia fue el primero que llevaron adelante sectores del sindicalismo que respondían al peronismo de la conducción de la CGT aunque según Daniel James no pudo ser conducido por esta y terminó en manos de la base ya que el paro del 3 de noviembre fue detenido por la CGT. Veáse JAMES Daniel, Op. Cit. Pp 73 y sig.
} 
la Libertadora no consideraban posible desandar el camino que el peronismo había recorrido en la promoción de los derechos de los trabajadores.

De hecho figuras antiperonistas como el general Lonardi, o políticos como Frondizi buscaron resaltar la continuidad -e incluso proclamar la profundización- de los derechos sociales a fin de lograr capturar la voluntad de los peronistas para sus propios proyectos políticos. Pero el ánimo triunfalista reinante no pareció ir en esos primeros meses de incertidumbre por el mismo camino. A tal punto se instaló la idea de una revancha entre algunos actores de la vida política y social argentina que las autoridades tuvieron que reclamar el cumplimiento de las leyes laborales vigentes. El mismo día en que se publicaba la proclama de Lonardi sobre los objetivos de la Revolución Libertadora, una nota en la misma página del matutino El Día hacía referencia a que "la revolución no es para los patrones" y advertía que "toda cesantía debe ser comunicada inmediatamente a las autoridades" ${ }^{111}$. La reprimenda no parece haber surtido el efecto esperado y sólo días más tarde el Ministro de Trabajo envió a los medios el siguiente comunicado:

Habiendo llegando a conocimiento del ministerio de Trabajo y Previsión que algunos empleadores han dispuesto contra trabajadores, medidas disciplinarias que configuran práctica desleal, violatorias de las normas éticas en las relaciones del trabajo, dicho Ministerio hace saber a los empleadores en general, que tales hechos han de ser reprimidos con el máximo de la pena prevista en las disposiciones legales vigentes. ${ }^{112}$

Fue en este contexto desfavorable para los trabajadores en el que la Justicia del Trabajo debió encontrar su lugar en el entramado institucional tendiente a lidiar con el conflicto entre el capital y el trabajo. Esos primeros meses de incertidumbre favorecieron el retorno a prácticas anteriores al establecimiento de la justicia laboral atentando contra el mismo derecho que regía la relación entre trabajadores y patrones.

La justicia del Trabajo no se vio exenta de las pretensiones desperonizadoras que impulsaran los seguidores de la Libertadora. Tal es así que en la procura de retornar a la senda liberal que según los golpistas de 1955 constituía la identidad política tradicional de la Argentina las autoridades militares dispusieron la remoción de los que consideraban los jueces y

\footnotetext{
111 "Los despidos serán considerados como actos de Sabotaje", Diario El Día, edición del 22/9/1955, Pp. 2.

112 "Formulan una advertencia a empleadores", Diario El Día, edición del 28/9/1955, Pp. 3.
} 
funcionarios adictos al "tirano prófugo". En esa purga fueron destituidos los jueces de los tribunales del trabajo de la provincia de Buenos Aires por la identificación que dicho fuero tenía con el peronismo. La acción del gobierno de facto de la provincia de Buenos Aires, bajo el dominio del general Osorio Arana, sobre el Poder Judicial fue incluso más profundo que el llevado adelante por las autoridades interventoras nacionales de 1952. Si en la práctica la intervención de 1952 significó una peronización de la justicia como poder estatal, esta fue llevada adelante con la anuencia de las cámaras legislativas y el aval del entonces gobernador Carlos Alóe. Sin embargo en el caso del paso a disponibilidad y expulsión de los magistrados y secretarios llevado a delante por las autoridades de facto, estas medidas no contaron con el resguardo del imperio del derecho y sólo mostró el imperio de la fuerza, aunque, para el caso de sus ejecutores, justificada por la situación traumática que vivía la república.

El impacto de la desperonización fue en primer término la suspensión de las actividades del Poder Judicial y el desplazamiento de varios de sus jueces. La normalización llevó más de seis meses y aun después de la feria judicial del año 1956 el Boletín Judicial dejaba en evidencia, con sus espacios en blanco en la nómina del Poder Judicial de la provincia, que la mayoría de los juzgados y tribunales no habían sido regularizados. Esta interrupción institucional cortó con las carreras judiciales -con la excepción del secretario del Tribunal del Trabajo $N^{\circ} 2$ de la ciudad de La Plata, el Dr. Wamba que fue promovido a juez en ese mismo tribunal- y produjo una situación excepcional: las nuevas autoridades del Poder Judicial nombradas por un poder de facto fueron ratificadas en sus puestos -mediante la afirmación de la inamovilidad de los jueces- por esas mismas autoridades que se arrogaron una prerrogativa constitucional, dejando una pesada herencia para las autoridades constitucionales posteriores.

Sin embargo el nombramiento de nuevos jueces no atentó contra algunas características de la justicia laboral. Los límites doctrinarios del derecho laboral impedía que los Tribunales del Trabajo siguieran la senda del contexto político en donde era evidente la revancha de los patrones ante el crecimiento del poder que habían experimentado los trabajadores bajo el peronismo. La propia razón de ser de los Tribunales del Trabajo se hallaba en la igualación que mediante la desigualdad jurídica se planteaba el derecho laboral. Por más que 
los jueces hubiesen querido dar cuenta de los cambios a nivel político y avalar la revancha patronal en el ámbito judicial no podrían haberlo hecho sin antes cuestionar su propia función judicial.

De esta manera los Tribunales del Trabajo siguieron contando con una actitud pro obrera que en un contexto como el descripto potenció su función como escenario de conflicto. Las causas judiciales analizadas así parecen confirmar al dar cuenta de los conflictos que en ellas se narran. Despidos por falta de trabajo, despidos por acciones gremiales o de trabajadores revoltosos encontraron en la justicia laboral un freno. Con una menor predisposición de las autoridades del Poder Ejecutivo a atender a los reclamos obreros, la institución judicial, con sus propios tiempos y tradiciones, se volvió un lugar central en los trabajadores que procuraban sus derechos. 


\section{REFLEXIONES FINALES}

¿Cuál fue la importancia del los Tribunales del Trabajo? Aunque la respuesta parezca obvia la importancia de los Tribunales del Trabajo fue la de garantizar al trabajador el acceso a la justicia. Los datos actuales de la Suprema Corte de Justicia de la provincia de Buenos Aires arrojan como resultado que el fuero laboral mantiene un crecimiento continuo de sus causas. En los últimos diez años prácticamente se duplicó la cantidad de trabajadores que acudieron a los distintos tribunales del trabajo de la provincia y su lugar en la estructura judicial aparece hoy incuestionada ${ }^{1}$. Sin dudas los Tribunales del Trabajo han sido incorporados por los trabajadores dentro del repertorio de lucha como un mecanismo más para garantizar la concreción y ampliación de sus derechos.

Esta imagen de trabajadores acudiendo al Poder Judicial por propia voluntad y movilizados por la idea de que sus derechos han sido vulnerados contrasta con el sentido común que enfrenta a los trabajadores $-y$ a los sectores subalternos en general- con la justicia. Las visiones más tradicionales del conflicto conciben esta relación como básicamente represiva. La Judicialización de la protesta es abordada generalmente, entonces, como la imposición de un orden represivo tendiente a sostener las desigualdades fundantes de la sociedad. De esta manera la relación de los trabajadores con el Poder Judicial es a través del fuero penal encargado de punir las desviaciones de lo normal.

En el campo historiográfico, sin embargo, esta visión tradicional amparada en el sentido común- comenzó a ser desandada desde los estudios de la relación entre la legislación -incluso la legislación criminal- y los sectores subalternos que daban cuenta de la utilización por parte de estos actores de las leyes. Pionero en este campo, el trabajo de Edward Thompson sobre la Ley

\footnotetext{
${ }^{1}$ Las causas del fuero laboral pasaron de 32.964 en el año 2000 a 57.307 en el año 2010 . Fuente http://www.scba.gov.ar/planificacion/tribunales\%20de\%20trabajo.pdf consultado 18 de octubre de 2012. Las conclusiones sobre el lugar relativo de la justicia laboral con respecto a otros fueros es en base a la consulta de las estadísticas de los otros fueros en la página de la Suprema Corte: http://www.scba.gov.ar/informacion/estadisticas.asp
} 
Negra en la Inglaterra ${ }^{2}$, abrió todo un abanico de posibilidades del estudio de la relación entre los sectores subalternos y la ley. La idea de campesinos y cazadores utilizando a su favor una ley pensada para reprimir sus costumbres de utilización de los bosques cuando estos se vieron amenazados por la vorágine del avance de la propiedad privada le permitió a Thompson brindar una imagen distinta de la relación de la ley con estos sujetos. La obligación impuesta por la Black Act sobre los bosques pensada para reprimir la caza furtiva y la utilización de los recursos forestales fue dotada de nuevos sentidos años después y reveló en que medida lo justo y la justicia, ideales fundamentales de cualquier sociedad, son compartidos por distintos actores de la sociedad aun cuando se las dote de significados diferentes. La idea misma de un imperio de la ley, aun cuando esta falle en dotar de sentido pleno a la idea de igualdad, es un bien fundamental también para estos sujetos a los que la ley busca reprimir. De otra manera la ley y el derecho lejos estarían de cumplir con su función ideológica

El impacto de las propuestas de Thompson se sumaron a la renovación del campo historiográfico sobre todo a partir de la influencia de los trabajos de Michel Foucault y Clifford Geertz. De todas maneras esta renovación en el estudio de la relación entre las clases subalternas y la justicia siguió predominando, aun cuando fuese posible obligar a otros actores sociales a cumplir con la ley, la idea de actores que compulsivamente son puestos bajo el peso de la ley, pero a pesar de ellos logran -utilizando esas mismas leyes que los oprimen- escapar en parte al castigo o incluso volverlas a su favor. Sin embargo el caso de la Justicia del Trabajo presenta a simple vista la imagen inversa. El actor que acude a los Tribunales del Trabajo no lo hace compulsivamente, sino de manera voluntaria. Si los estudios del sistema penal y criminal apuntan a buscar las formas en que los sectores subalternos intentan subvertir el sentido represivo de las leyes, en el caso de la justicia laboral la ley y el derecho buscan explícitamente beneficiar al trabajador.

\section{$\star \star *$}

\footnotetext{
${ }^{2}$ THOMPSON Edward Palmer, Los orígenes de la Ley... Op. Cit.
} 
El sentido, así, de la ley y el derecho es diametralmente opuesto al carácter represivo que prima en las relaciones entre los subalternos y la justicia. Esto genera nuevos desafíos porque no se trata ya de encontrar los resquicios en los que los estos actores sociales generalmente desatendidos encuentran la posibilidad de subvertir el sentido opresor en un espacio construido con la intención de reprimir sus acciones. La ley, en el caso de las leyes laborales, es pensada en tanto mecanismo de reconocimiento de las desigualdades a las que están sometidos los trabajadores. Incluso a pesar de la intención manifiesta de sus promotores de creer que con la ley se podía evitar que los conflictos de la cuestión social finalmente rompieran la cohesión de la sociedad, la génesis misma del derecho laboral fue construyendo un sujeto de derechos diferenciado -el trabajador- que debía ser protegido ante la desigualdad que limitaba su autonomía en la relación laboral.

Entonces cabe preguntarse cuál es la función ideológica de una Ley que limita su propia concepción universalista. El fundamento ideológico de la ley en el caso del derecho laboral no reside en la consideración de que la ley es igual para todos. Tal vez allí reside su fuerza ideológica. El arraigo de la idea de la ley desigual expresada en la jerga popular como una tela araña donde los chicos quedan atrapados y los grandes pasan no puede pasar desapercibido. Es en este punto importante retomar el análisis de Daniel James ${ }^{3}$ sobre el éxito del peronismo -y de Perón- en constituir una alternativa al liberalismo que contemplase este sentido común como lógica política. La reformulación de la ciudadanía en un molde social implicaba necesariamente rechazar la noción individualista de la ciudadanía. El escepticismo con que los trabajadores recibían los símbolos formales del liberalismo da cuenta de la existencia de un sentido común arraigado contrario a la igualdad de la ley.

La fuerza de la legislación laboral y la posibilidad de que estas se aplicasen residió en la aceptación explícita de que la sociedad estaba dividida al menos- en dos. La desigualdad jurídica propuesta por la legislación laboral sobre todo a partir de la sanción de Accidentes del Trabajo de 1915- era más acorde con la forma en que la justicia era percibida por los trabajadores. Al menos esta concepción partía de una instancia relacional en el que los

\footnotetext{
${ }^{3}$ JAMES Daniel, Op. Cit. Pp. 29 y sig.
} 
trabajadores -changarines, obreros industriales, empleados comerciales 0 vendedores ambulantes- se reconocían como parte de un mismo colectivo separado y opuesto a los patrones. No fue sino hasta la constitución de los Juzgados del Trabajo en la Capital Federal y los Tribunales del Trabajo en el caso de la provincia de Buenos Aires, que esa concepción de la justicia encontró su forma institucional.

\section{$\star \star \star$}

El reconocimiento como sujetos de derechos especiales en tanto obreros estuvo ligado a la forma que la respuesta a la cuestión social encontró desde principios del siglo XX. Las respuestas a la cuestión social también fueron de la mano de la diferenciación entre los sujetos que conformaban la sociedad. En sus dos caras -la faceta represiva y la faceta integradora- estas respuestas apuntaron a identificar al sujeto sobre el que se debía llevar a cabo la acción. La cuestión social como universal encontraba la cuestión obrera como su singular y centro de su propia definición.

La cuestión social como problema a ser resueltos por la elite fue contemporánea a la institucionalización del Estado y las problemáticas allí planteadas llevaron a amplios sectores de las elites vernáculas a plantear modificaciones o nuevas propuestas para el creciente entramado estatal. El proceso de modernización de la estructura productiva del país, la cuestión social a esta asociada y los problemas políticos derivados de la federalización de la ciudad de Buenos Aires encontraron en la ciudad de La Plata un ejemplo de resolución que intentaba ser total sobre estos problemas. Ciudad planeada desde sus fundamentos y creada para ser la capital del mayor estado de la federación, su planeamiento estuvo cruzado por la cuestión social e intentó ser una respuesta a esta.

No solo desde el plano higiénico fue la ciudad una búsqueda de solucionar una de las aristas más visibles de la cuestión social. La forma en la que se distribuyeron los espacios de la ciudad dieron cuenta de las dos caras de las respuestas estatales. Los trabajadores quedaron relegados a las zonas periféricas de la ciudad mientras que el centro se reservo a los poderes estatales y, a partir de 1905 -significativamente catalogado como la segunda 
fundación-, la Universidad. De este modo la ciudad pensada al calor de la cuestión social se percibió como un refugio de la razón, donde la elite argentina podría formarse e incluso estudiar la cuestión social sin tenerla en las puertas de sus facultades.

\section{$* * *$}

La Cuestión Social no fue un problema exclusivamente local, ni siquiera regional. El problema obrero era un problema internacional y así quedo en evidencia a la hora de resolver por medio de la diplomacia los problemas expuestos o abiertos por la Primera Guerra Mundial. Los tratados de paz que se sucedieron a finalizar el conflicto bélico intentaron fundar un nuevo orden para la resolución de los conflictos entre las naciones -se creó la Sociedad de Naciones- al tiempo que también buscaron dar cuenta de otros conflictos que, si bien no alcanzaban los rasgos sangrientos del enfrentamiento en las trincheras, era un núcleo central de las preocupaciones gubernamentales. Así nació la Organización Internacional del Trabajo en el seno de la Sociedad de las Naciones. Su prédica y su capacidad para, entre otras cosas, homogeneizar la problemática a nivel mundial hiceron de la OIT una institución exitosa que sobrevivió incluso a la desaparición de su institución marco, la Sociedad de Naciones.

La OIT fue fundamental para impulsar el estudio del derecho laboral en todo el mundo y la Argentina no fue la excepción. El derecho laboral, fuertemente ligado también a un proceso de renovación en los estudios del derecho con fuerte base en el derecho comparativo, se vio beneficiado por el empuje que a la materia otorgó la OIT. Las conferencias internacionales organizadas en forma anual y la divulgación del material tanto por los participantes locales en dichas conferencias, como por la propia OIT, fueron un espacio atractivo para jóvenes abogados que vieron en el naciente Nuevo Derecho la posibilidad de ganar mayor notoriedad.

El Nuevo Derecho encontró en el ámbito local dos instituciones claves para su promoción: el Departamento nacional del Trabajo y el sistema universitario. Ambas compartían múltiples lazos que también las unía al desarrollo internacional de la materia y a la OIT -principalmente los actores 
eran los mismos, tal el caso de Alejandro Unsain tal vez como el ejemplo más claro-. En búsqueda de respuestas a la cuestión social y al problema obrero, tanto el DNT como el sistema universitario buscaron comprender por medio de herramientas científicas la problemática. En este sistema universitario la Universidad de La Plata adquirió un lugar cada vez más preponderante. En el caso de la cuestión obrera la Facultad de Ciencias Jurídicas y Sociales fue central ya que fue la primera facultad en contar con una cátedra específica sobre legislación social con especialistas del tema y dentro de una carrera de ciencias jurídicas.

\section{$* * *$}

El crecimiento institucional del Nuevo Derecho repercutió en una mayor especialización que permitieron fundar una base doctrinaria más sólida. Pero paradójicamente este avance en términos doctrinarios tuvo como consecuencia una ralentización de la producción de legislación del trabajo en las cámaras del Congreso de la Nación. Al tratarse de un derecho nuevo y no ya atado a la tradición civil -que reglamentaba la forma en la que se relacionaban legalmente los ciudadanos-, la legislación laboral no era materia de competencia del Congreso de la Nación. En tanto la Constitución Nacional no habilitaba al Congreso a legislar sobre cuestiones nuevas su poder quedaba reducido a ser legislatura para los territorios bajo dominio federal, estos era la ciudad de Buenos Aires y los territorios nacionales. Así la fundamentación de la legislación laboral como un derecho nuevo implicaba dejar en manos de las legislaturas provinciales la promulgación y reglamentación de leyes del trabajo. Las provincias argentinas que vieron avanzar los poderes federales sobre las autonomías provinciales, eran reacios a entregar nuevas potestades al gobierno federal. Así las posibilidades de una legislación laboral homogénea perdió terreno -evidente en el caso de los fracasos legislativos de los proyectos de Códigos del Trabajo-.

De todas maneras las reglas mismas de funcionamiento del Congreso Nacional y su sistema de conformación -con una Cámara alta poco dispuesta a llevar adelante medidas pro obreras y sin representación, a diferencia de lo que ocurría en Diputados, de partidos que reconocían en el polo trabajo parte 
fundante de su propio proyecto político- hicieron del Congreso de la Nación un espacio estéril en cuanto a legislación laboral se refiere. Así los sucesivos proyectos de Código del Trabajo encontraron poco eco en los ámbitos legislativos y el país se vio privado de una obra homogénea en torno a la materia. Pero también es necesario remarcar que esta negativa a contar con un código no fue exclusivamente producto de la conformación política e institucional del Congreso de la Nación o de las Legislaturas provinciales. La misma cultura jurídica ya había destronado a los Códigos de su lugar central. Pero fundamentalmente las oposiciones estuvieron expuestas por aquellos a quienes los proyectos intentaba regular: los patrones y los trabajadores.

Las oposiciones patronales siguieron un patrón constante de rechazo a las intervenciones en general y no sólo a la legislación del trabajo. La legislación laboral fue socavando la autoridad patronal y por ese motivo era rechazada por las asociaciones patronales más representativas. Sin embargo algunas medidas -como la obligatoriedad de contratación de seguros para accidentes en las plantas- fueron aceptadas aunque siempre en carácter provisional. Distinto fue el caso de los trabajadores. Desde las distintas organizaciones obreras que se disputaron la conducción del movimiento obrero se concibió la relación con el Estado de forma diferente. Del rechazo plano de las conducciones anarquistas a la aceptación tácita por parte de los sindicalistas, las organizaciones obreras tuvieron una relación contradictoria con la legislación laboral y el lugar del Estado en la relación laboral. La evidencia de la doble cara de la moneda en la respuesta estatal a la cuestión social obligó a los sindicatos y organizaciones obreras a estar atentos a las medidas represivas que en mayor o menos medida contenían los códigos, sobre todo aquellas que atentaban contra la organización sindical o que criminalizaban al promotor sindical.

\section{$* * *$}

La organización de diferentes instituciones dedicadas a conciliar o arbitrar entre el capital y el trabajo estuvo generalmente ligada a la esfera del Poder Ejecutivo. Desde el reconocimiento de la cuestión social como un problema a ser resuelto el Estado buscó, por medio de estas instituciones, establecer 
instancias de negociación que adoptaron por lo general la representación corporativa de los contendientes, tanto patronales como obreros. Esto así porque los conflictos que fundamentalmente buscaba evitar o controlar el Estado eran aquellos que envolvían a las organizaciones obreras -únicos actores capaces de llevar adelante la organización y los costos de las medidas de fuerza-. Por tanto el Estado a través de sus funcionarios e instituciones específicas otorgó cierto reconocimiento a unas organizaciones por sobre otras en su necesidad de clasificar a los contendientes y dotarlos de representación a fin de hacer de sus medidas de conciliación y arbitraje una herramienta útil en la resolución de los conflictos.

Esta pretensión estatal de dotar de representatividad a ciertos sindicatos en desmedro de otros -generalmente elegidos por su orientación políticoideoógica- fue interpretada muchas veces como el ascenso de un entramado corporativo. Sin embargo el carácter corporativo estaba dado por el tipo de conflicto al que se debía dar respuesta y no tanto por, o al menos no exclusivamente, una pretensión de imposición de políticas corporativas tendientes a reemplazar al liberalismo político como base de las relaciones sociales. Pesa aquí muchas veces las proyecciones ideológicas de los propios investigadores. En un afán por determinar el carácter corporativo de una sociedad buscaron en estos mecanismos la demostración empírica de sus hipótesis políticas -esto fue particularmente claro para el caso del Departamento Provincial del Trabajo bajo el gobierno de Manuel Fresco-. Sin ir en desmedro de estas interpretaciones -el gobierno de Fresco por caso buscaba conscientemente orientarse hacia la representación coorporativaestos casos de las diferentes instancias de Conciliación y Arbitraje debe ser analizadas a partir del objetivo que se propone que es el de mediar en conflictos colectivos. El tipo de respuesta esperada no puede más que conformar espacios corporativos, pero esto no indica que puedan ser la base empírica para sostener el corporativismo de tal o cual gobierno, sino baste recordar que proyectos de instituciones de este tipo se presentaron en gobiernos que son catalogados de liberales tanto a nivel provincial como nacional y que muchas veces seguían como modelo a instituciones análogas de países como Nueva Zelanda, que lejos estaba de la Italia fascista. 
La instauración de estas formas de conciliación y arbitraje en términos corporativos estaba, entonces, vinculada al tipo de conflicto que debía afrontar. Pero con el aumento lento pero sostenido de la legislación laboral fue cada vez más necesaria la constitución de una institución capaz de responder, mediar y resolver las disputas que surgían de una enfrentamiento relacional colectivo entre el capital y el trabajo pero expresado en términos individuales concretos, es decir entre tal trabajador y tal patrón.

\section{$* * *$}

Con su carga individualizante el Poder Judicial parecía a priori un lugar más receptivo para la conformación de una institución de este tipo. Sin embargo dentro del poder encargado de una función tan importante para el Estado como la de administrar la justicia, se había conformado un campo jurídico, en términos bourdieanos, en el que el centro de la definición ideológica era la creencia absoluta en la igualdad de los sujetos. De esta manera en el propio seno del Poder Judicial y la estructuración del campo jurídico se hallaban barreras que impedían el reconocimiento de la desigualdad fundante de la relación laboral- eje del derecho laboral-.

Estas resistencias encontraron defensores al interior del campo del derecho laboral y uno de sus mayores promotores -tanto por su propia formación y dedicación como por los espacios institucionales que logró acceder y desde los que promovió al derecho del trabajo, fue el Dr. Leónidas Anastasi. Pero el horizonte cambió con la llegada de una nueva fuerza política. El ascenso del peronismo, en el contexto de un gobierno de facto y de un proceso de rechazo hacia el liberalismo, fue fundamental para la conformación de un esquema dispuesto a dar cuenta de los conflictos laborales en el seno del Poder Judicial. No sin contramarchas y enfrentamientos -como aquél que opuso al propio Perón con la jerarquía del Poder Judicial de la nación, la Corte Suprema- el peronismo logró establecer Juzgados del Trabajo para la ciudad de Buenos Aires.

Este antecedente fue fundamental en el debate y conformación de los Tribunales del Trabajo en la provincia de Bueno Aires. La primacía de la autonomía de las provincias en cuanto a la potestad para construir su propio 
armazón institucional hizo posible que los Tribunales del Trabajo bonaerense contaran con características propias que los diferenciaban de sus pares de la ciudad de Buenos Aires. Estas características fueron otorgadas tanto por el contexto espacial específico de la discusión como por las propias características que poseía el gobierno de Domingo Mercante -el corazón de Perón- que otorgaron un marco distinto aquél presentado por la historiografía para el caso del gobierno federal. La disposición al debate parlamentario producto de su propia debilidad electoral inicial, el carácter proactivo de la legislatura y una predisposición mayor a sostener la tradición liberal de la separación de los poderes hicieron posible la forma institucional que finalmente adoptó el sistema de la justicia laboral en el territorio bonaerense.

Volviendo al peronismo como fenómeno político se debe remarcar que la pretendida refundación propuesta desde dicha fuerza política aunó fuerzas con los pedidos existentes dentro del campo jurídico por la conformación de un fuero especializado. Sin dudas el discurso conciliador que en cuanto al conflicto entre el capital y el trabajo expresaba el peronismo fue fundamental para relanzar la propuesta de contar con una instancia de resolución de los conflictos pacífica que brindase el espectáculo de la cooperación y el acatamiento pasivo de los contendientes ante la voluntad nacional y que sirviese como herramienta para presentar otras formas de conflicto como expresivas de una realidad ajena a la Argentina. ¿Puede entonces pensarse a la constitución de la justicia del trabajo en términos individualizantes como la expresión institucional del fin de la lucha de clases que pregonaba el peronismo? Al fin y al cabo al no haber más lucha de clases se negaba la existencia misma de las clases y la justicia del trabajo lo que debía hacer era actuar en los diferendos que surgieran entre dos sujetos de derechos -como lo hacía la justicia civil- que se veían envueltos en una relación laboral. Pero sin embargo esta misma relación constituía a los sujetos de derechos en dos categorías bien diferenciadas -trabajadores y patrones- que respondían a colectivos -clases- enfrentadas en razón de su propia relación. La acción individualizante tenía un límite expresado en la propia posición que cada uno de los contendientes asumía en el conflicto y que los colocaba en relación a otros sujetos y actores en forma antagónica. Lejos de expresar el fin del conflicto lo potenciaba. 
La constitución de los Tribunales del Trabajo conformó un espacio de interacción social entre distintos actores. En tanto era el lugar en el que recurrían trabajadores y empresarios o patrones, se constituyó en un espacio de conflicto más en la disputa que enfrentaba a ambos polos de la relación laboral. Pero como arena de disputas la justicia del trabajo contaba con reglas propias, relativamente autónomas, establecidas por aquellos capaces de dominar las herramientas necesarias para llevar la disputa a buen término en los parámetros que la misma institución establecía. Así, la justicia laboral estableció una diferenciación entre los expertos y los profanos, que, aunque menor que en otros fueros, obligó a los contendientes fundamentales de la disputa a recurrir a aquellos sujetos y actores capaces de entablar el conflicto con las reglas establecidas del campo, es decir por medio del saber profesional.
\end{abstract}

Estos actores eran portadores de proyectos propios que también entraban en la consideración de las disputas en la medida en que no convergían con los otros actores profesionales. La disputa en el campo jurídico laboral -o en el subcampo en términos más precisos- no era simplemente el correlato del enfrentamiento entre dos partes sobre cuál de las dos gozaría del monopolio de dictar el derecho, sino que implicaba también el enfrentamiento de lógicas y proyectos políticos distintos. Esto quedó en evidencia en la conformación de especializaciones dentro de los profesionales encargados de defender a las partes en disputa. Los abogados laboralistas fueron cada vez más los portadores de una misión en tanto poseedores de un saber especializados que los impulsaba a tomar parte por el más débil en la relación laboral. Esta misión no era, evidentemente, compartida por los abogados de la parte patronal, pero tampoco, me animo a decir, por aquellos que sólo veían en el juicio laboral la posibilidad de ejercer la profesión sin reparo de si los interese a representar fueron unos u otros. En algún punto la creencia en el cumplimiento de esta misión alejaba a estos abogados del ideario profesionalista y respondía en parte a los cambios mismos que la enseñanza jurídica había atravesado en los 
años previos al surgimiento del fuero y del que la Universidad de la Plata y la Facultad de Ciencias jurídicas y Sociales tuvieron un lugar destacado.

Fueron estos profesionales -abogados, jueces y peritos- los que a la hora de dotar de contenido a la institución judicial laboral logaron llevar el reclamo expresado en derechos a los términos de la ley.

\section{$* * *$}

La Justicia del Trabajo no estuvo exenta de los avatares que sacudieron a la política y la sociedad argentina tanto durante los años del peronismo como durante el quinquenio que separa la caída del gobierno de Perón por el golpe militar de Septiembre de 1955 y el comienzo de la década del sesenta. Sin embargo es necesario indicar algunas cuestiones que invitan a pensar en una relativa autonomía para la institución judicial.

Su preeminencia pro obrera fue un rasgo sobresaliente para todo el período investigado. Aun en contextos adversos como la revancha patronal posterior a la caída del gobierno peronista, o ante cuestiones tan sensibles a los años de la mitad de la década del cincuenta del siglo pasado como lo fue la productividad, los Tribunales del Trabajo mantuvieron una tendencia a beneficiar a los trabajadores. No solo cuando los jueces fallaron a favor del trabajador se puede observar estas características: las férreas defensas de la jurisdicción y competencias de los tribunales, el sostenimiento de los tiempos procesales cortos y las propias aplicaciones doctrinarias del derecho laboral como la inversión de la carga de la prueba dan cuenta de una predisposición institucional a amparar al más débil de la relación laboral.

Esta marca de origen tuvo también limitaciones en sus comienzos cuando la definición de quiénes serían los sujetos de derechos que se debía amparar no estaba aun del todo resuelta. La negativa a considerar a algunos trabajadores como obreros o empleados en los primeros años del funcionamiento de los Tribunales del Trabajo también dan cuenta de cierta autonomía. A pesar de la fuerte insistencia del gobierno peronista en la construcción del trabajador como la razón de ser de sus acciones, los Tribunales tuvieron un significativo trabajo al abordar de forma singular al 
sujeto universal portador de los derechos. En un contexto de profusión de normas relativas a los derechos de los trabajadores -entendidos estos en forma genérica y universal. Los tribunales se sostuvieron a sus propias formas y reglas del campo a la hora de constituir al sujeto de derechos. Sin embargo al mismo tiempo dejaron en evidencia las dificultades de aislarse totalmente de dicho contexto y el campo mostró su permeabilidad al adoptar muchas veces medidas contradictorias, algunas veces basadas en el derecho, otras en la economía y otras tantas en una construcción jurisprudencial un tanto endeble.

Pero si las estructuras y formas de la institución judicial garantizaban cierta autonomía del contexto, este dotaría a la institución de significaciones diferentes según el momento. Así, si durante el peronismo las causas ventiladas en la justicia del trabajo expresaban conflictos cargados de cierta trivialidad -aunque no por cierto para los actores envueltos en él- o el pedido por la ampliación de derechos, en el post peronismo la justicia laboral será el escenario de los reclamos ante lo que es percibido como una avasallamiento de derechos ya consagrados. En algún punto el quinquenio posterior a 1955 da cuenta de la Justicia del Trabajo como un espacio de conflictos de resistencia ante el avance patronal. Espacio que por sus características ofrecía mejores posibilidades al éxito que otras formas de conflicto. 


\section{BIBLIOGRAFÍA Y FUENTES}

\section{Bibliografía}

Bibliografía y Fuentes

\section{Bibliografía}

ACHA Omar, "Sociedad Civil y Sociedad Política durante el primer peronismo", Desarrollo Económico, Vol. 44, N¹74 (Jul-Sept, 2004), pp. 199-230.

ACHA Omar y QUIROGA Nicolás, "Presentación" en Prohistoria N9, Número Monográfico La Trayectoria de la cultura política peronista, 1943-2003, Rosario, 2005.

, "Pliegues de la normalización de los estudios sobre el primer peronismo: complementos y aclaraciones" en REIN Raanan, BARRY Carolina, ACHA Omar, QUIROGA Nicolás, Los Estudios sobre el primer peronismo. Aproximaciones desde el siglo XXI, Instituto Cultural de la Provincia de Buenos Aires, La Plata, 2009.

ADORNO Sergio, Os Aprendices do poder. O bacharelismo liberal na politica brasileira.Paz e Terra, Río de Janeiro, 1988.

AELO Oscar H., El peronismo en la provincia de Buenos Aires.1946-1955, Eduntref, Caseros, 2012.

"La Legislatura de Buenos Aires y la administración Mercante. ¿Subordinación o cooperación?" en PANELLA Claudio (compilador), El gobierno de Domingo A. Mercante en Buenos Aires (1946-1952). Un caso de peronismo provincial. Tomo II, Instituto Cultural de la Provincia de Buenos Aires, La Plata, 2006

AGUIRRE Carlos y SALVATORE Ricardo, "Writing the History of Law, Crime and Punishment in Latin America" en en R. SALVATORE, C. AGUIRRE, G.M JOSEPH, Crime and punishment in Latin America. Duke University Press. London, 2001.

AGULLA Juan Carlos, "Crisis en la Facultad de Derecho de la Universidad de Buenos Aires (una huelga estudiantil a principios de siglo)" en Revista del Instituto de Historia del Derecho "Ricardo Levene", № 31, Buenos Aires.

ARMUS Diego, "Consenso, conflicto y liderazgo en la lucha contra la tuberculosis. Buenos Aires 1870-1950" en SURIANO Juan (comp), La Cuestión Social en Argentina, 1870-1943, La Colmena, Buenos Aires, 2000. 
ASCOLANI Adrián. El sindicalismo rural en la Argentina. De la resistencia clasista a la comunidad organizada (1928 - 1952). Universidad Nacional de Quilmes, Bernal, 2009.

ASPELL DE YANZI FERREIRA, Marcela, "Los proyectos de Código de Trabajo presentados a las cámaras del Congreso Nacional, 1904-1974" en Cuadernos de Historia $\mathrm{N}^{\circ} 3$, Academia Nacional de Derecho y Ciencias Sociales de Córdoba, Córdoba, 1993.

"Expulsión de extranjeros. La ley 4144 "de Residencia" y la jurisprudencia de la Suprema Corte de Justicia de la Nación " en Revista de Historia del Derecho, N 15, IIIHD, Buenos Aires, 1987.

"Los precedentes legislativos del primer proyecto de Ley nacional del Trabajo (1880-1904)", Revista de Historia del Derecho, $N^{\circ} 8$, Instituto de investigaciones de Historia del Derecho, Buenos Aires, 1980.

AUZA Néstor Tomás, "El rostro del dolor en el trabajo industrial. La legislación protectora de accidentes y enfermedades del trabajo" en Revista de Historia del Derecho, $\mathbf{N}^{\circ} 19$, Instituto de Investigaciones de Historia del Derecho, Buenos Aires, 1991.

"La legislación laboral y la complejidad del mundo del trabajo. El Departamento Nacional del Trabajo, 1913-1925" en Revista de Historia del Derecho, $\mathrm{N}^{\circ}$ 17, Instituto de Investigaciones de Historia del Derecho, Buenos Aires, 1989.

"La política del Estado en la cuestión obrera al comenzar el siglo XX. El Departamento Nacional del Trabajo, 1907-1912" en Revista de Historia del Derecho, $\mathrm{N}^{\circ}$ 15, Instituto de Investigaciones de Historia del Derecho, Buenos Aires, 1987.

AZEVEDO Elciene: "En las trincheras de la justicia. Abogados y esclavos en el movimiento abolicionista en San Pablo" en LARA, Silva $H$. e NUNES DE MENDOCA (orgs), Direitos e Justicas no Brasil. Ensaios de História Social. Editora da Unicamp, Campinas, 2005.

BAILEY Joanne, "Voices in Court: lawyers or litigants" Historical Research, Vol. 74, No 186 (November 2001), Blackwell Publishers, Oxford, 2001, pp. 392-408.

BARANDIARÁN Luciano, "El rol de los tribunales en los accidentes de trabajo rurales fatales, Azul (1930-1945)", XXII Jornadas de Historia Económica, Rio Cuarto, 2010.

Estado y trabajo. Las políticas públicas y los trabajadores rurales pampeanos en los inicios del estado "interventor" (19251950), Tesis doctoral inédita, Universidad Nacional del Centro de la Provincia de Buenos Aires, Tandil, 2008. 
BARBA Fernando Enrique, "Manuel Fresco y el Departamento de Trabajo. Un intento de regular los conflictos sociales" en REITANO Emir (comp.), El gobierno de Manuel Fresco en la provincia de Buenos Aires (1936-1940), Instituto Cultural de la Provincia de Buenos Aires, La Plata, 2010

La Plata orígenes y fundación: La cuestión capital de la República y la fundación de la capital de la provincia de Buenos Aires, La Plata, 1995.

BARRENECHE Osvaldo, "¿Lega o letrada? Discusiones sobre la participación ciudadana en la justicia de la ciudad de Buenos Aires durante las primeras décadas de independencia y experiencia republicana" en PALACIO Juan Manuel y CANDIOTI Magdalena (comp.), Justicia, política y derechos en América Latina, Prometeo, Buenos Aires, 2007.

Dentro de la ley, TODO. La justicia criminal de Buenos Aires en la etapa formativa del sistema penal moderno de la Argentina. Ediciones Al Margen, La Plata, 2001.

BÉJAR María Dolores, "La política laboral del gobierno de Manuel Fresco" en PANETTIERI José (comp.), Argentina: trabajadores entre dos guerras, Eudeba, Buenos Aires, 2000.

BERROTARRÁN Patricia M., "Educar al funcionario: "de la frialdad de las leyes a las innovaciones doctrinarias" (Argentina 1946-1952). », Nuevo Mundo Mundos Nuevos, Debates, 2008, [En línea], Puesto en línea el 16 juin 2008. URL : http://nuevomundo.revues.org//index36602.html. Consultado el 23 juin 2008

BERTOLO Maricel, Una propuesta alternativa: el sindicalismo revolucionario (1904-1916), CEAL, Buenos Aires, 1993.

BOBBIO Norberto, Estado, gobierno y sociedad. Por una teoría general de la política, FCE, México D.F., 1994.

BOHOSLAVSKY, Ernesto, "Sobre los límites del control social. Estado, historia y política en la periferia argentina, 1890-1930" en DI LISCIA María Silvia y BOHOSLAVSKY Ernesto (editores), Instituciones y formas de control social en América Latina, 1840-1940. Una revisión, Buenos Aires, Prometeo, 2006.

BOHOSLAVSKY Ernesto y SOPRANO Germán (eds.), Un Estado con rostro humano. Funcionarios e instituciones estatales en la Argentina (1880 a la actualidad). Universidad Nacional de General Sarmiento, 2009.

BOTANA Natalio, El Orden conservador: la política argentina entre 1880 y 1916, Ed. Hyspamerica, Buenos Aires, 1985.

BOURDIEU Pierre, Razones prácticas. Sobre la teoría de la acción. Barcelona, Anagrama, 1997. 
"La forcé du Droit" en Actes de la Recherche en Sciences Sociales, Volume 64, Numéro 1, 1986.Pags. 3 - 19.

Grijalbo, 1995

Respuestas por una antropología reflexiva, México,

BUCHBINDER, Pablo, Historia de las Universidades Argentinas. Sudamericana, Buenos Aires, 2005.

CAIMARI, Lila, "Presentación" en CAIMARI, Lila, (comp.) La Ley de los profanos. Delito, justicia y cultura en Buenos Aires (1870-1940), FCEUniversidad de San Andrés, Buenos Aires, 2007.

Apenas un delincuente. Crimen, castigo y cultura en la Argentina, 1880-1955, Siglo XXI Editores, Buenos Aires, 2004.

CALLINICOS Alex, Making History. Agency, Structure and Change in Social History, Brill, London-Leiden, 2004.

CAMPIONE Daniel, Orígenes estatales del Peronismo, Miño y Dávila, Buenos Aires, 2007.

CANTÓN Dario, El Parlamento Argentino en épocas de cambio, 1890, 1916 y 1946. Ed del Instituto, Buenos Aires, 1966.

CAPARRÓS Martín y ANGUITA Eduardo, La Voluntad. Una historia de la militancia revolucionaria en la. Argentina 1973-1976, Tomo II, Norma, Buenos Aires, 1998.

CARUSO Laura, "Estado, armadores y clase obrera en la Argentina de entreguerras: la Segunda Conferencia de la OIT sobre trabajo marítimo (1920)", Anuario IEHS, $\mathrm{N}^{\circ} 26$, Tandil, en prensa.

"La política laboral argentina en la inmediata posguerra: una perspectiva internacional, 1907-1925", Relaciones. Estudios de Historia y Sociedad, Michoacán, en prensa

CASAGRANDE Agustín, Los vagabundos y la justicia de Buenos Aires durante el período tardo colonial (1785-1810), INHIDE, Buenos Aires, 2012.

CASTEL Robert, Las Metamorfosis de la cuestión social. Una crónica del salariado, Paidós, Buenos Aires, 2009.

CLARKE Guillermo A.; GHISIGLIERI Juan A.; SARNO Alicia, "La gobernación Mercante. Construcción Histórica con documentos orales" en PANELLA, Claudio (compilador), El gobierno de Domingo A. Mercante en Buenos Aires (1946-1952). Un caso de Peronismo provincial., Tomo I, Instituto Cultural de la Provincia de Buenos Aires, La Plata, 2006. 
COCA Joaquín, Derecho burgués y Derecho obrero, CEAL, Buenos Aires, 1985.

CORRÊA Larissa Rosa, A tessitura dos direitos. Patrões e empregados na Justiçã do Trabalho, 1953-1964, São Paulo, FAPESP-LTr75, 2011.

DAMIN Nicolás, Plan CONINTES y Resistencia Peronista, 1955-1973, Instituto Nacional Juan Domingo Perón, Buenos Aires, 2010.

DA ORDEN María Liliana, "Socialismo y Peronismo en la Provincia de Buenos Aires: discurso y práctica legislativa durante el gobierno de Mercante, 19481952" en MELON PIRRO Julio César y QUIROGA Nicolás, El Peronismo bonaerense. Partido y prácticas políticas, 1946-1955, Ediciones Suárez, Mar del Plata, 2006.

DE IPOLA Emilio, "Ruptura y continuidad. Claves parciales para un balance de las interpretaciones del peronismo" en Desarrollo Económico, Vol. 29, No. 115 (Oct-Dic, 1989), pp. 331-359.

, "Respuesta a comentario: "reflexiones sobre un balance de las interpretaciones del peronismo"', en Desarrollo Económico, Vol 30 No. 118, pp. 284-288.

DEL CAMPO Hugo, Sindicalismo y peronismo. Los comienzos de un vínculo perdurable, FLACSO, Buenos Aires, 1983.

DE MORAES Evaristo, Apontamentos de Direito Operário. Ltr Editôra, San Pablo, 1971 (1905).

DIAZ DE GUIJARRO Enrique, Abogados y Jueces. Buenos Aires, 1959.

DIEZ, María Angélica: "Las fuentes judiciales en los estudios socio-históricos: problemas, enfoques y métodos desde la experiencia en historia regional" en La fuente judicial en la construcción de la memoria, Talleres Gráficos del Poder judicial de la Provincia de Buenos Aires, La Plata, 1999.

DI LISCIA Maria Silvia y BOHOSLAVSKY Ernesto (editores), Instituciones y formas de control social en América Latina, 1840-1940. Prometeo, Buenos Aires, 2005

DOMINGO Pilar, "La judicialización de la política: el nuevo perfil de la Suprema Corte en el sistema político de México" en PALACIO Juan Manuel y CANDIOTI Magdalena (comp.), Justicia, política y derechos en América Latina, Prometeo, Buenos Aires, 2007.

DOYON Louise M., Perón y los trabajadores. los orígenes del sindicalismo peronista, 1943-1955, Siglo Veintiuno Editora Iberoamericana, Buenos Aires, 2006. 
DURAN Claudia L., "Apuntes sobre la fuente judicial como recurso para la investigación social" Sociohistórica. Cuadernos del C/SH, No 6, Segundo Semestre de 1999, Ediciones Al Margen, La Plata, 1999

DURKHEIM Emile, El Suicidio, Ediciones del Libertador, Buenos Aires, 2004.

ELÍAS Norbert, La Sociedad de los individuos, Península, Barcelona, 1990.

ERBETTA Cecilia, "La impronta de la justicia social durante el primer peronismo en Santiago del Estero. (1943-1955)." Ponencia presentada al Primer Congreso de Estudios Sobre el Peronismo: la primera década, Mar del Plata, Noviembre de 2008, Mimeo

FALCÓN Ricardo, El mundo del trabajo urbano (1890-1914), CEAL, Buenos Aires, 1986

FERRER, Aldo, "Factores condicionantes y expansión agropecuaria", en La economía argentina. Desde sus orígenes hasta principios del siglo XXI, FCE, Buenos Aires, 2004.

FORTES Alexandre et al. Na luta por direitos. Estudos recentes em história social do trabalho., Editora da Unicamp, Campinas, 1999.

FREDERIC Sabina, GRACIANO Osvaldo y SOPRANO Germán (coords.), EI Estado y las profesiones liberales, académicas y armadas, Prohistoria, Rosario, 2010.

FRENCH John, Afogados em leis. A CLT e a cultura jurídica dos trabalhadores. Editora Fundação Perseu Abramo, Saõ Paulo, 2001.

FRYDENBERG Julio y RUFFO Miguel, La semana Roja de 1909, Buenos Aires, Centro Editor de América Latina, 1992.

GARCÍA BOSSIO Horacio, "La Fuente Judicial y el mundo del trabajo", en Actas de las Jornadas La Fuente judicial en la construcción de la memoria, Talleres Gráficos del Poder Judicial de la Provincia de Buenos Aires, La Plata, 1999.

GARGUÍN Enrique, "Relaciones entre estado y sindicatos durante los gobiernos radicales, 1916-1930" en PANETTIERI José (comp.), Argentina: trabajadores entre dos guerras, Eudeba, Buenos Aires, 2000.

GASPARRI Mario R, "Mercante y los ferroviarios. Una relación trascendente y necesaria para la consolidación de la gestión de Perón al frente de la Secretaria de Trabajo y Previsión" en PANELLA, Claudio (compilador), El gobierno de Domingo A. Mercante en Buenos Aires (1946-1952). Un caso de peronismo provincial. Tomo I, Instituto Cultural de la Provincia de Buenos Aires, La Plata, 2005 
GAUDIO Ricardo y PILONE Jorge, "Estado y relaciones laborales en el período previo al surgimiento del peronismo, 1935-1943", Desarrollo Económico, Vol. 24, № 94, Buenos Aires, 1984.

GAYOL Sandra y KESSLER Gabriel (compiladores), Violencias, justicias y delitos en la Argentina. Ediciones Manantial y Universidad Nacional de General Sarmiento, Buenos Aires, 2002.

GEERTZ Clifford, Conocimiento local. Ensayos sobre la interpretación de las culturas. Paidos, Barcelona, 1994.

GENÉ Marcela, Un mundo feliz. Imágenes de los trabajadores en el primer peronismo, 1946-1955, FCE-Universidad de San Andrés, Buenos Aires, 2008.

"Los rostros del General: Perón, del retrato protocolar a la caricatura", Prohistoria $N^{\circ}$ 9, número monográfico. La trayectoria de la cultura política peronista, 1943-2003, Prohistoria Ediciones, Rosario, Primavera de 2005.

GERMANI G.; S.S. de YUJNOVSKY, "El surgimiento del peronismo: el rol de los obreros y de los migrantes internos", en Desarrollo Económico, № 51 , IDES, Buenos Aires, 1973.

GOMES Angela de Castro, Cidadania e Direitos do Trabalho, Jorge Zahar Editor, Rio de Janeiro, 2002.

de Janeiro, 1988.

A invenção do Trabalhismo, IUPERJ/VERTICE, Río

Burguesia e trabalho. Politica e Legislação social no Brasil 1917-1937. Campus, Río de Janeiro, 1979.

GONZÁLEZ LEANDRI Ricardo, "Notas acerca de la profesionalización médica en Bueno Aires durante la segunda mitad del siglo XIX" en SURIANO Juan (comp), La Cuestión Social en Argentina, 1870-1943, La Colmena, Buenos Aires, 2000.

GRACIANO, Osvaldo, Entre la torre de marfil y el compromiso político. Intelectuales de izquierda en la Argentina, 1918-1955. Editorial de la Universidad Nacional de Quilmes, Bernal, 2008.

GRAMSCI Antonio, Los intelectuales y la organización de la cultura, Ediciones Nueva Visión, Buenos Aires, 1984.

GRIMSON, A.; SEMÁN, P.: "Presentación, la cuestión "cultura"”, Etnografías Contemporáneas, № 1 .

GUTIERREZ Leandro y ROMERO Luis Alberto, Sectores populares, cultura y política. Buenos Aires en entreguerra, Sudamericana, Buenos Aires, 1995. 
HALPERIN DONGHI Tulio, La república imposible, Ariel, Buenos Aires, 2004.

HOBSBAWM Eric, Historia del Siglo XX, Crítica, Buenos Aires, 1998.

El mundo del trabajo. Estudios históricos sobre la formación y evolución de la clase obrera, Crítica, Barcelona, 1987.

HOBSBAWM Eric, Marxismo e Historia Social, Universidad Autónoma de Puebla, México,1983.

HOROWITZ, Los sindicatos, el Estado y el surgimiento del peronismo, 1930/1946. Eduntref, Buenos Aires 2004

IÑIGO CARRERA Nicolás, "La historia de los trabajadores" en GELMAN Jorge (comp.), La Historia económica argentina en la encrucijada. Balances y perspectivas, Prometeo Libros, Buenos Aires, 2006.

La estrategia de la clase obrera. 1936. Ediciones Madres de Plaza de Mayo, Buenos Aires, 2004.

"La huelga general de masas de 1936: un hecho borrado de la historia de la clase obrera argentina", Anuario IEHS, $\mathrm{N}^{\circ} 9$, Tandil, UNCPBA, pp. 289-315.

JAMES Daniel, Resistencia e Integración. El Peronismo y la clase trabajadora argentina, 1946-1976. Siglo XXI, Buenos Aires, 2005.

JORRAT, Jorge Raúl, "Reflexiones sobre un balance de las interpretaciones del peronismo" en Desarrollo Económico, Vol. 30, No. 118. (Jul-Sep 1990), pp. 277-283.

KORZENIEWICZ Roberto P., "Las vísperas del peronismo. Los conflictos laborales entre 1930 y 1943", Desarrollo Económico, Vol. 33, № 131 (OctubreDiciembre 1993), IDES, Buenos Aires, 1993

LACLAU Ernesto, La razón populista, FCE, Buenos Aires, 2008.

LOBATO Mirta Zaida, La vida en las fábricas. Trabajo, protesta y política en una comunidad obrera, Berisso (1904-1970), Prometeo, Buenos Aires, 2004.

"Los trabajadores en la era del progreso", en El progreso, la modernización y sus límites t. $\mathrm{V}$ de la Nueva Historia Argentina, Buenos Aires, Sudamericana, 2000 pp. 467-505

"Entre la protección y la exclusión: discurso maternal y protección de la mujer obrera, argentina 1890-1934" en SURIANO Juan (comp), La Cuestión Social en Argentina, 1870-1943, La Colmena, Buenos Aires, 2000 
, "Una visión del mundo del trabajo. Obreros inmigrantes en la industria frigorífica, 1900-1930" en DEVOTO Fernando y MIGUEZ Eduardo (comp.), Asociacionismo, trabajo e identidad étnica, CEMLA-CSERIEHS, Buenos Aires, 1992.

MACKINNON Moira, Los Años formativos del partido peronista, Siglo XXI, Buenos Aires, 2002.

MACOR Darío y TCACH César (comp.), La invención del peronismo en el interior del país, Ediciones Universidad Nacional del Litoral, Santa Fe, 2003.

MARCILESE José, "El Poder Judicial bonaerense durante el Primer Peronismo: de la autonomía a la dependencia", EIAL, 2007. Consultado en www1.tau.ac.il/eial. Generado el 14 de Junio de 2008

"La justicia bonaerense durante la gobernación de Domingo A. Mercante" en PANELLA Claudio (comp.), El gobierno de Domingo A. Mercante en Buenos Aires (1946-1952). Un caso de peronismo provincial. Tomo III., Instituto Cultural de la Provincia de Buenos Aires, La Plata, 2007.

MAROTTA Sebastían, El movimiento sindical argentino, su origen y desarrollo, Buenos Aires, 1960.

MARSHALL Thomas H, Ciudadanía y Clase social; Alianza, Madrid, 1998.

MARTINEZ Josefina, "La guerra de las fotocopias. Escritura y poder en las prácticas judiciales" en PALACIO Juan Manuel y CANDIOTI Magdalena (compiladores), Justicia, política y derecho en América Latina, Prometeo, Buenos Aires, 2007.

MARX Karl, El Capital. El Proceso de producción del capital, Tomo I, Siglo XXI Editores, Buenos Aires,2002.

MAYO Carlos, "En torno al valor de la fuente judicial" en AAV La Fuente judicial en la Construcción de la Memoria. Jornadas, Suprema Corte de Justicia provincia de Buenos Aires, La Plata, 1999.

MELON PIRRO Julio César y QUIROGA Nicolás, "introducción" en MELON PIRRO Julio César y QUIROGA Nicolás (comp.), El peronismo bonaerense. Partido y prácticas políticas, 1946-1955, Edición Suárez, Mar del Plata, 2006.

MELON PIRRO Julio César, El Peronismo después del Peronismo. Resistencia, sindicalismo y política luego del 55, Siglo XXI, Buenos Aires, 2009.

MUNAKATA Kazumi, A legislação Trabalhista no Brasil, Ed. Brasiliense, Saõ Paulo 1982.

MURILO DE CARVALHO, José, Desenvolvimiento de la ciudadanía en Brasil, Colegio de México/FCE, México, 1995. 
NEGRO Antonio Luigi, "O que a Justica do Trabalho não queimou: novas fontes para o estudo do trabalho no século XX", en Politeia. Historia e Sociedade, Vitória da Conquista, Vol. 6, No. 1, 2006.

NIETO Agustín, "Conflictividad obrera en el terreno de la justicia laboral. La experiencia de las obreras/os del pescado, 1950-1955", en Segundo Congreso de Estudios sobre el Peronismo (1943-1976), Caseros, 2010.

OZLAK Oscar, La formación del Estado Argentino. Orden y progreso y organización nacional, Buenos Aires, Ariel, 1997.

"Notas críticas para una teoría de la burocracia estatal", en Desarrollo Económico, Num. 74, Vol. 19. IDES, Buenos Aires 1979.

PALACIO, Juan Manuel y CANDIOTI, Magdalena, "Justicia, política y derechos en América Latina. Apuntes para un debate interdisciplinario" en Juan Manuel Palacio, Magdalena Candioti (comp.), Justicia, política y derechos en América Latina, Prometeo, Buenos Aires, 2007.

PALACIO Juan Manuel, "De la paz a la discordia: El peronismo y la experiencia del Estado en la provincia de Buenos Aires (1943-1955)". Desarrollo Económico. Revista de Ciencias Sociales. Vol. 49 N 194 . Buenos Aires. IDES. 2009. Pp. 221-246.

La Paz del trigo, Edhasa, Buenos Aires, 2004.

"Judges, lawyers and the circulation of the law" en SALVATORE, R; AGUIRRE, C; JOSEPH, G.M.: Crime and punishment in Latin America. Duke University Press. London 2001.

PANELLA Claudio (Comp.), El gobierno de Domingo A. Mercante en Buenos Aires (1946-1952). Un caso de peronismo provincial, Instituto Cultural de la provincia de Buenos Aires, La Plata, 2005, 5 volúmenes.

PANETTIERI José, Las Primeras leyes obreras; CEAL, Buenos Aires, 1985. Los trabajadores, Jorge Álvarez, Buenos Aires, 1967.

PERKIN Harold, The rise of professional society. England since 1880. London \& New York. Routledge, 2002.

PLOTKIN Mariano Ben y ZIMMERMANN Eduardo (comp.), Los Saberes del Estado, Edhasa, Buenos Aires, 2012. , Las prácticas del Estado. Política, sociedad y elites estatales en la Argentina del siglo XX, Edhasa, Buenos Aires, 2012.

PORTELLI María Belén, "Saberes modernos para políticas eficaces. El Derecho Laboral y el estudio del mundo del trabajo. Córdoba, 1906-1930" 
Población \& Sociedad [en línea], Vol. 18, N² 2, 2011, pp. 145-185. Puesto en línea en diciembre de $2011 . \quad$ URL: http://www.poblacionysociedad.org.ar/archivos/18/P\&S V18-N2-Portelli.pdf

RAFART, Gabriel, Tiempo de violencia en la patagonia. Bandidos, policías y jueces, 1890-1940, Buenos Aires, Prometeo, 2008.

RAMACCIOTTI Karina Inés, "De la culpa al seguro. La Ley de Accidentes del Trabajo, Argentina (1915-1955)" en Mundos do Trabalho, Vol 3, N 5, janeirojunho de 2011, p266-284.Publicación electrónica del GT Mundos do Trabalho, Sp, Brasil.

RAMACCIOTTI Karina I. y VALOBRA Adriana M., "'Plasmar la raza fuerte..." Relaciones de género en la campaña sanitaria de la Secretaria de Salud Pública de la Argentina (1946-1949)" en RAMACCIOTTI Karina I. y VALOBRA Adriana M. (compiladoras) Generando el Peronismo. Estudios de cultura política y género. Proyecto Editorial, Buenos Aires, 2004.

REGOLO Santiago, "La Constitución Social de 1949. Hacia una democracia de masas", ponencia presentada en el Primer Congreso de estudios sobre el Peronismo: la primera década, Mar del Plata, Noviembre de 2008. Disponible en la web: http://redesperonismo.com.ar/archivos/CD1/SC/regolo.pdf

REIN Raanan, "De los grandes relatos a los estudios de "pequeña escala": algunas notas acerca de la hisotriografía del primer peronismo" en REIN Raanan, BARRY Carolina, ACHA Omar, QUIROGA Nicolás, Los Estudios sobre el primer peronismo. Aproximaciones desde el siglo XXI, Instituto Cultural de la Provincia de Buenos Aires, La Plata, 2009.

Peronismo, populismo y política. Argentina 1943-1955. Editorial de Belgrano, Buenos Aires, 1998.

REITANO Emir (comp.), El gobierno de Manuel Fresco en la provincia de Buenos Aires (1936-1940), Instituto Cultural de la Provincia de Buenos Aires, La Plata, 2010.

Manuel Fresco. Entre la renovación y el fraude. Archivo Histórico de la Provincia de Buenos Aires, La Plata, 2005.

REVEL Jacques, "Microanálise e construçao do social", en REVEL, Jacques (org.), Jogos de escala. A experiencia da microanálise. Fundaçao. Getulio Vargas Editora, Rio de Janeiro, 1998.

ROCCHI Fernando, "Un largo camino a casa: empresarios, trabajadores e identidad industrial en Argentina, 1880-1930" en SURIANO Juan (comp), La Cuestión Social en Argentina, 1870-1943, La Colmena, Buenos Aires, 2000.

ROMERO Luis Alberto, "Los sectores populares en las ciudades latinoamericanas del siglo XIX: la cuestión de la identidad" en GUTIERREZ 
Leandro y ROMERO Luis Alberto, Sectores populares, cultura y política. Buenos Aires en entreguerra, Sudamericana, Buenos Aires, 1995

$\overline{\text { Buenos Aires, } 1994 .}$

Breve Historia Contemporánea de la Argentina, FCE,

SABATO Hilda, "La formación del mercado de trabajo en Buenos Aires, 18501880" en Desarrollo Económico, Vol. 24, N 96, enero-marzo, Buenos Aires, 1985.

SABATO Hilda y ROMERO Luis Alberto, "Artesanos, oficiales, operarios, trabajo calificado en Buenos Aires (1854-1887)" en Anuario Escuela de Historia, N 12 1986-1987, Publicaciones UNR, Rosario, 1987.

SALVATORE Ricardo, Subalternos, derechos y Justicia Penal. Ensayos de Historia Social y Cultural Argentina, 1829-1940. Gedisa, Buenos Aires, 2010.

Wandering Paysanos. State Order and Subaltern Experience in Buenos Aires during the Rosas Era. Duke University Press, Durham and London, 2003.

"Criminología positivista, reforma de prisiones y lla cuestión social/obrera en Argentina" en SURIANO Juan (comp.), La Cuestión Social en Argentina, 1870-1943, La Colmena, Buenos Aires, 2000.

SARDEGNA, Miguel Ángel, "Historia de la cátedra de Derecho del Trabajo y de la Seguridad Social en la Facultad de Derecho y Ciencias Sociales de la Universidad de Buenos Aires", Revista de Historia del Derecho "Ricardo Levene", № 33, Buenos Aires, 1997.

SARTELLI Eduardo, "Mecanización y conflicto social en la llanura pampeana: Santa Fe y la huelga de braceros de 1928" en ANSALDI Waldo (comp.) Conflictos obrero-rurales pampeanos/3 (1900 - 1937). CEAL. Buenos. Aires, 1993.

"Rehacer todo lo destruido. Los conflictos obrero-rurales en la década 1927-1937" en ANSALDI Waldo (comp.) Conflictos obrero-rurales pampeanos/3 (1900 - 1937). CEAL. Buenos Aires, 1993.

SAYÂO ROMITA Arion, "A Justiçã do Trabalho: produto do Estado Novo" en PANDOLFI Dulce (org.), Repensando o Estado Novo, Ed. Fundação Getulio Vargas, Rio de Janeiro, 1999.

SCHJOLDEN, Line, Suing for Justice: Labor and the Courts in Argentina, 19001943. Berkeley, Tesis de Doctorado, Universidad de California, 2002.

SCHNEIDER Alejandro, Los compañeros. Trabajadores, izquierda y peronismo (1955-1973). Imago Mundi, Buenos Aires, 2005. 
SCHVARZER Jorge, La industria que supimos conseguir. Una historia políticosocial de la industria argentina, Planeta, Buenos Aires, 1996.

SCOTT, James C., Los dominados y el arte de la resistencia. Discursos ocultos. Ediciones Era, México D.F. 2000.

SKOCPOL Theda "Bringing the state back in: strategies of analysis in current research," in P. EVANS, D. RUESCHEMEYER and T. SKOCPOL (eds.), Bringing the State Back In, Cambridge University Press, London, 1985.

SOPRANO Germán, "Haciendo inspección. Un análisis del diseño y aplicación de la inspección laboral por los funcionarios del Departamento Nacional del Trabajo entre 1907 y 1914". En: BOHOSLAVSKY Ernesto y SOPRANO Germán (eds.). Un Estado con rostro humano. Funcionarios e instituciones estatales en la Argentina (1880 a la actualidad). Prometeo, Buenos Aires, 2010.

"Del Estado en singular al Estado en plural. Contribución para una historia social de las agencias estatales en la Argentina" en Cuestiones de Sociología $N^{\circ} 4$, Departamento de Sociología, Facultad de Humanidades y Ciencias de la Educación, Universidad Nacional de La Plata. La Plata, 2007.

"El Departamento Nacional del Trabajo y su proyecto de regulación estatal de las relaciones Capital-Trabajo en Argentina. 1907-1943". En: José Panettieri (comp.) Argentina: Trabajadores entre dos guerras, Eudeba, Buenos Aires, 2000.

SPINELLI María Estela, Los vencedores vencidos. El antiperonismo y la "Revolución Libertadora", Biblos, Buenos Aires, 2005.

STAGNARO Andrés, "Vocación de poder. Los abogados porteños a través de las colaciones de grado. 1884-1919", Revista Temas de Historia Argentina y Americana, UCALP, en prensa.

"Los Abogados laboralistas de la Delegación Regional de la Secretaría de Trabajo y Previsión de La Plata, 1948-1955" en en S. FREDERIC, O. GRACIANO y G. SOPRANO (comp.), Profesión, Estado y Política. Prohistoria, Buenos Aires, 2010.

"Un Nuevo Derecho. Notas sobre la materialización del derecho laboral en Argentina y Brasil durante la primera mitad del siglo XX" en BARRENECHE Osvaldo y BISSO Andrés, Ayer, hoy y mañana son contemporáneos. Tradiciones, leyes y proyectos en América Latina. EDULP, La Plata, 2010.

SUPIOT Alain, Homo Juridicus. La Función antropológica del Derecho. Buenos Aires, Siglo XXI, 2007. 
SURIANO Juan, "EI Departamento Nacional del Trabajo y la política laboral durante el primer gobierno de Hipólito Yrigoyen" en PLOTKIN Mariano Ben y ZIMMERMAN Eduardo (comp.), Los Saberes del Estado, Edhasa, Buenos Aires, 2012.

, "Los dilemas actuales de la historia de los trabajadores" en GELMAN Juan (comp.), La Historia económica argentina en la encrucijada. Balances y perspectivas, Prometeo Libros, Buenos Aires, 2006.

Anarquistas. Cultura y política Libertarias en Buenos Aires. 1890-1910, Manantial, Buenos Aires, 2001

"Introducción: Una aproximación a la definición de la cuestión social en Argentina" en SURIANO Juan (comp.), La Cuestión Social en Argentina, 1870-1943, La Colmena, Buenos Aires, 2000,

"La oposición anarquista a la intervención estatal en las relaciones laborales" en SURIANO Juan (comp), La Cuestión Social en Argentina, 1870-1943, La Colmena, Buenos Aires, 2000.

TARRUELA Ramón, Mitos y Leyendas de La Plata, La Comuna, La Plata, 2006.

TAU ANZOÁTEGUI, Víctor, "Pensamiento Jurídico y acción legislativa" en Nueva Historia de la Nación Argentina. Academia Nacional de la Historia, Planeta, Buenos Aires, 2001.

TEIXEIRA DA SILVA Fernando, "Nem Crematório de Fontes Nem Museu de Curiosidades: por que Preservar os Documentos da Justiça do Trabalho" en BIAVASCHI Magda Barros et al (orgs), Memória e preservação de documentos: direitos do cidadão, San Pablo, LTr, 2007.

apontamientos comparativos", Mimeo.

"Justiça do Trabalho e Magistratura del Lavoro:

TILLY, Charles, “¿De dónde vienen los derechos?”, Sociológica, № 55, México, 2004.

Grandes estructuras, procesos amplios, comparaciones enormes, Alianza, Madrid, 1984.

THOMPSON Edward Palmer, La Formación de la clase obrera en Inglaterra, Ed. Capitan Swing, Madrid, 2012.

Los origenes de la ley negra. Un episodio de la historia criminal inglesa, Siglo XXI, Buenos Aires, 2010.

1995.

Costumbres en común, Ed. Crítica, Barcelona, 
TORRE Juan Carlos y PASTORIZA Elisa, "La democratización del bienestar" en J.C.TORRE (dir) Los años peronistas (1943-1955). Nueva Historia Argentina. Vol. 8, Sudamericana, Buenos Aires, 2002

TORRE Juan Carlos, "Acerca de los estudios sobre la historia de los trabajadores en Argentina", Anuario IEHS, N ${ }^{\circ} \mathrm{V}$, Tandil, 1990.

La vieja guardia sindical y Perón. Sobre los orígenes del peronismo. Eudeba, Buenos Aires, 1983

UNAMUNO Miguel y CORBIERE Emilio J., "Joaquín Coca: peronismo y socialismo en la Argentina" en COCA Joaquín, Derecho burgués y Derecho obrero, CEAL, Buenos Aires, 1985.

UPRIMNY YEPES Rodrigo, "La judicialización de la política en Colombia: casos, potencialidades y riesgos" en PALACIO Juan Manuel y CANDIOTI Magdalena (comp.), Justicia, política y derechos en América Latina, Prometeo, Buenos Aires, 2007.

VALLEJO Gustavo, Escenarios de la cultura científica argentina. Ciudad y Universidad (1882-1955), Consejo Superior de Investigaciones Científicas, Madrid, 2007.

VARUSSA, Rinaldo J., Trabalho e legislação: experiências de trabalhadores na Justiça do Trabalho (Jundiaí - SP, décadas de 40 a 60). Tese (Doutorado), Pontifícia Universidade Católica/SP, 2002.

VECCHIOLI Virginia, A luta pelo direito: engajamento militante e profissionalizaçao dos adrogados nas caussas pelos direitos humanos na Argentina, Rio de Janeiro, Tesis de Doctorado PPGAS/UFRJ, 2006.

WERNECK VIANNA, Luis, Liberalismo e sindicato no Brasil. Paz e Terra, Rio de Janeiro, 1978.

ZIMMERMAN Eduardo, "La enseñanza jurídica y la conformación del derecho administrativo como "saber de estado" en la Argentina 1900-1930", Mimeo (2009) disponible para su consulta en http://www.saberesdeestado.com.ar/wpcontent/uploads/2009/11/eduardo_zimmermann.pdf

Los liberales reformistas. La cuestión social en la Argentina, Buenos Aires, Sudamericana-Universidad de San Andrés, 1995.

"Los intelectuales, las ciencias sociales y el reformismo liberal: Argentina, 1890-1916", Desarrollo Económico, vol. 31, No124 (Ene-Mar, 1992), Pp. 545-564. 


\section{Fuentes}

\section{a) Inéditas}

Expedientes de causas laborales iniciadas ante los Tribunales del Trabajo $\mathrm{N}^{\circ} 1$ de la ciudad de La Plata. Años de referencia: 1948-1960.

Discursos de Juan Domingo Perón, Varias Carpetas, Biblioteca del Congreso de la Nación, Fondo reservado Juan Domingo Perón.

\section{b)Editadas}

Artículos de la época

BERRO Luis María, "Prólogo" en La Plata a su fundador, Ediciones de la Municipalidad, La Plata, 1939.

DE MORAES Evaristo, Apontamentos de Direito Operário. Ltr Editôra, San Pablo, 1971 (1905).

DESMARÁS Carlos R., "Noticia Biográfica. Leónidas Anastasi", Anales de la Facultad de Ciencias Jurídicas y Sociales de la Universidad Nacional de La Plata, Tomo XII, $2^{\circ}$ Parte, Talleres Gráficos Olivieri \& Domínguez La Plata, 1941.

DEVEALI Mario, Lineamientos del Derecho del Trabajo, Tipografía Editora Argentina, Buenos Aires, 1953

FIGUEROA FEDERICO, "La Jurisprudencia nacional sobre accidentes del trabajo" en Boletín del Departamento Nacional del Trabajo, No. 20, Julio de 1912.

FRESCO Manuel, Cómo encaré la cuestión obrera durante mi gobierno. La Plata 1940

GENOUD Héctor, "La competencia de los tribunales del trabajo en la legislación provincial", Gaceta del Trabajo, Tomo IX, Abril a Junio de 1949, Editorial Bibliográfica Argentina, Buenos Aires, 1949.

GENOUD, Héctor, "Los órganos de la Justicia del Trabajo en la legislación provincial", Gaceta del Trabajo, Tomo X Julio a Septiembre de 1949, Editorial Bibliográfica Argentina, Buenos Aires, 1949.

GONZÁLEZ Joaquín V., "Proyecto de Ley Nacional del Trabajo", Obras Completas, Volumen VI, Universidad Nacional de La Plata, Buenos Aires, 1935

LASCANO, David; RIVAROLA, Enrique; DONATO DEL CARRIL, Emilio; RAMÍREZ GRONDA, Juan D.; SALAS, Acdeel Ernesto, "Proyecto de la Comisión Especial del Centro de Estudios Jurídicos de La Plata", Jurisprudencia Argentina 1946, Tomo IV, sección Doctrina. La Ley, 1947. 
MATIENZO José Nicolás, "Plan de Trabajo" en Boletín del Departamento Nacional del Trabajo, №1 Junio 30 de 1907, Departamento Nacional del Trabajo, Buenos Aires, 1907.

PEREZ Benito, "Los fueros del trabajo" en Anales de la Facultad de Ciencias Jurídicas y Sociales de la Universidad de La Plata, Tomo XII (1 ra Parte), 1941.

PÉREZ Benito, "El derecho del trabajo y la reforma del código civil", Anales de la Facultad de Ciencias Jurídicas y Sociales de la Universidad de La Plata. Tomo XI, 1940, La Plata.

PINTO Manuel "El Derecho del Trabajo" en Anales de Ciencias Jurídicas y Sociales de la universidad de La Plata, Tomo VII año 1934 Imprenta de la Universidad, Buenos Aires, 1935.

PINTO Manuel, "El Contrato de Trabajo", Anales de Ciencias Jurídicas y Sociales, Tomo 2, Oliveri y Domínguez Editores, la Plata, 1927

QUESADA Ernesto, "La cuestión obrera y su estudio universitario", Boletín del Departamento Nacional del Trabajo, №1 Junio 30 de 1907, DNT, Buenos Aires, 1907.

RUZO Alejandro, "Fundamentos jurídicos del riesgo profesional" en Boletín de la Dirección General del Trabajo, N20 Julio 31 de 1912, Dirección General del Trabajo, Buenos Aires, 1912.

SANCHEZ REULET Aníbal, "Historia y presentación de la ciudad" en La Plata a su fundador, Ediciones de la Municipalidad, La Plata, 1939.

SASOT BETES Miguel Angel, Código Civil Argentino. Concordado y anotado con la jurisprudencia, Ed Economía Argentina, Buenos Aires, 1932.

\section{Por organismos Oficiales}

Acuerdos y Sentencias dictados por la Suprema Corte de Justicia de la provincia de Buenos Aires, Tomo V, Imprenta de la Dirección General de Rentas, La Plata, 1951.

Argentina. Ayer, hoy y mañana, Subsecretaría de informaciones y prensa, Buenos Aires, 1950.

Boletín del Departamento Nacional del Trabajo, Varios tomos.

Boletín Judicial de la provincia de Buenos Aires. Diario de Jurisprudencia. Varios Tomos.

Diario de Sesiones. Cámara de Diputados de la Provincia de Buenos Aires. Varios Tomos, 
Diario de Sesiones. Cámara de Senadores de la Provincia de Buenos Aires. Varios Tomos

Diario de Sesiones. Honorable Congreso de la Nación. cámara de Diputados. Varios Tomos.

Diario de Sesiones. Honorable Congreso de la Nación. Cámara de Senadores. Varios Tomos

Comisión Nacional de Investigaciones, Vicepresidencia de la Nación, Documentación, autores y cómplices de las irregularidades cometidas durante la Segunda Tiranía, Tomo I, Buenos Aires, 1958. Comisión N¹5, Román A. Subiza

Justicia del Trabajo. Organización, competencia y procedimiento, Imprenta del Congreso Nacional, Buenos Aires, 1944.

La Plata a su fundador, Edición de la Municipalidad, La Plata, 1939.

MINISTERIO DE EDUCACIÓN DE LA NACIÓN, Nómina de Egresados, Facultad de Ciencias Jurídicas y Sociales, 1905-1951. Universidad Nacional ciudad Eva Perón, Ministerio de educación, 1951.

"Proyecto de Código del Trabajo", Boletín del Departamento Nacional del Trabajo, N48, Noviembre de 1921, DNT, Buenos Aires, 1921.

\section{Otras}

Anales de la Facultad de Ciencias Jurídicas y Sociales de la Universidad Nacional de La Plata. Varios tomos.

Anales de Legislación Argentina, Editorial La Ley. Varios Tomos.

Comisión Nacional Investigadora, Libro negro de la Segunda Tiranía, Comisión de la afirmación de la Revolución Libertadora, Buenos Aires, 1987

Diario El Día, varios ejemplares. Años de referencia: 1945-1960.

Facultad de Ciencias Jurídicas y Sociales de la Universidad Nacional de La Plata, Programas, La Plata, 1926 a 1952.

Organización Internacional del Trabajo, Claúsulas de los Tratados de Paz relativas al Trabajo, Oficina Internacional del Trabajo, Ginebra, 1929.

Todas las leyes obreras de la Revolución, Editorial Primicias, Buenos Aires, c 1948

Universidad Nacional de La Plata, "Instituto de Altos Estudios Jurídicos y Sociales; Seminario de Investigación y adaptación profesional; Museo Vucetich y Laboratorio de Identificación", La Plata, 1929. 


\section{c) Páginas web}

http://www.laboralistasplatenses.org/

http://www.scba.gov.ar/planificacion/tribunales\%20de\%20trabajo.pdf http://www.ilo.org/ilolex/spanish/mstatess.htm 